UNIVERSIDADE DE SÃO PAULO

INSTITUTO DE FÍSICA

\title{
Estudos da interação do peptídeo antimicrobiano KHya1 com membranas modelo
}

\section{Thais Azevedo Enoki}

Orientadora: Profa. Dra. M. Teresa M. Lamy

Co-orientadora: Profa. Dra. Karin A. Riske

Tese de doutorado
apresentada ao Instituto de Física
da Universidade de São Paulo
para obtenção do título de Doutor
em ciências.

Banca examinadora:

Profa. Dra. Maria Teresa Lamy (IF-USP)

Profa. Dr. Amando S. Ito (FFCLRP-USP)

Profa. Dra. Elisabeth A. de Oliveira (IF-USP)

Prof. Dr. João Ruggiero Neto (IBILCE-UNESP)

Profa. Dra. Vera B. Henriques (IF-USP)

São Paulo, SP 



\section{Dedicatória}

\section{Dedicado aos meus pais}

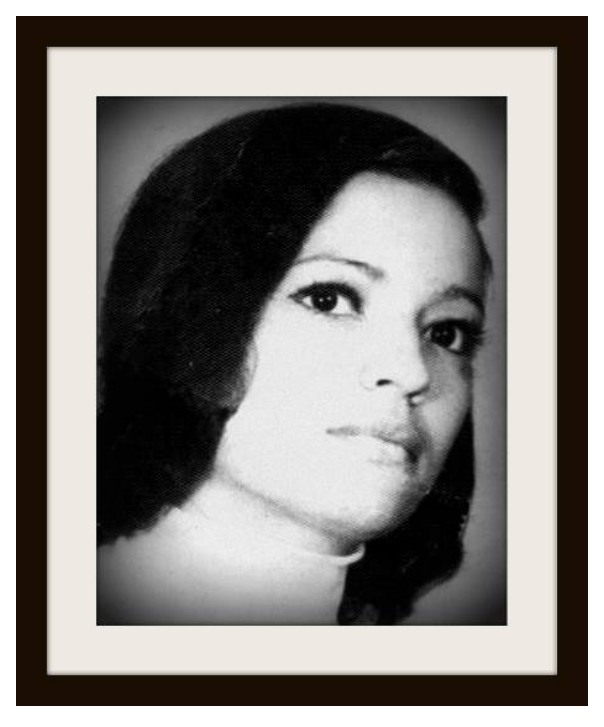

Maria José Azevedo Enoki

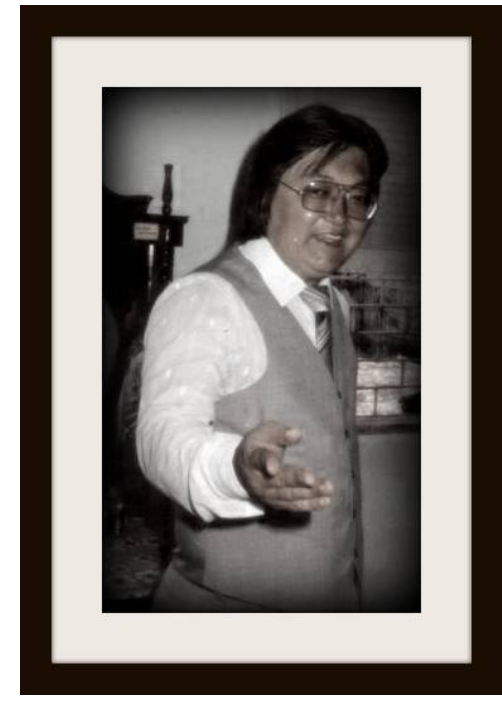

Tosio Enoki 

"Não façam nada por ambição egoísta ou vaidade, mas humildemente considere os outros superiores a si mesmo." Filipenses 2:3 



\section{Prefácio}

Para melhor entendimento desta tese, dedico aqui uma seção para explicar a organização desse trabalho. O tema principal deste trabalho está no estudo do peptídeo antimicrobiano KHya1 com membranas modelo. Entretanto, outros estudos também participaram da minha formação acadêmica ao longo deste período de doutorado. De forma geral, e talvez sucinta, os demais estudos relacionados, e não tão relacionados com o tema principal, também compõem essa tese.

Em relação à escrita, optei muitas vezes em utilizar a terceira pessoa do plural, para enfatizar a minha visão, ou a contribuição desse trabalho. Além disso, a notação numérica adotada ao longo de toda tese é composta por numerais escritos, por exemplo, na forma 7.0 em vez de 7,0. Como todos os programas que fazem a aquisição de dados são americanos e trabalham com pontos em vez de vírgulas, como descrito no exemplo acima, por conveniência, os números foram citados no texto da forma que aparecem nos gráficos. Dado a quantidade de gráficos aqui apresentados, fazer cada gráfico em duplicata, ou seja, na forma americana para publicação e em português para essa tese, expenderia um tempo excessivo o qual poderia ser investido em mais experimentos, por exemplo.

Essa tese foi dividida em vários capítulos a fim de facilitar a compreensão. No capítulo 1, Introdução, apresento a motivação principal da tese, uma breve descrição do objeto de estudo e dos objetivos desse trabalho. A interação do peptídeo antimicrobiano KHya1 com membranas modelo foi estudada com o uso de diversas técnicas experimentais. Portanto, no capítulo 2, Técnica experimentais, há um resumo da teoria das técnicas experimentais aqui estudadas. Como as técnicas experimentais são ferramentas que podem ser utilizadas em diversos objetos de estudo, optei pela descrição dirigida para os propósitos desse trabalho.

No capítulo 3, apresento os modelos experimentais utilizados ao longo desse estudo, os quais referem-se a como o objeto de estudo foi mimetizado in vitro. Neste capítulo, apresento as razões principais da escolha dos modelos e suas limitações. Resultados experimentais, muitas vezes, 
devem ser acompanhados de controles, experimentos independentes que auxiliam a validação dos dados, ou experimentos testes que buscam as melhores condições experimentais de trabalho. Logo, neste capítulo, Modelos e Controles, também estão resumidos os principais controles. Os capítulos seguintes 4, 5 e 6 apresentam o estudo da interação do peptídeo antimicrobiano KHya1 com membranas modelos. Esses capítulos se diferenciam em relação às diversas técnicas experimentais ou a aspectos específicos da interação peptídeo-lipídio. Por fim, o capítulo 7 descreve uma conclusão geral, integrando as conclusões parciais obtidas em cada capítulo.

Adicionalmente, essa tese contém estudos, apêndices B e C, que embora não façam parte do corpo da tese e não dividem o mesmo tema principal, são estudos importantes e de grande interesse contemporâneos. Esses estudos foram realizados em Cornell University, sob a supervisão do Prof. Gerald W.Feigenson. No apêndice B é apresentado um estudo de uma proteína modelo, peptídeo transmembranar GWALP23, com membranas modelo com coexistência de fases; fase líquida ordenada (Lo) e líquida desordenada (Ld). Embora esse peptídeo não tenha propriedades antimicrobianas, e o modelo de membrana do estudo apresenta maior complexidade, esse estudo também trata da interação de um peptídeo com a membrana. Esse apêndice traz uma breve descrição da investigação do coeficiente de partição de proteínas modelo entre as fases Lo e Ld, para sistemas que apresentam macro e nanodominios.

Além disso, o apêndice $\mathrm{C}$ traz uma breve descrição de modelos de membranas assimétricas, onde a composição lipídica da camada interna difere da composição lipídica da camada externa. Recentemente, grandes esforços têm sido feitos para tornar as membranas modelo que conhecemos hoje mais parecidas com as membranas naturais. O estudo apresentado neste apêndice é parte, talvez hoje, uma pequena parte, desses esforços.

Por fim, e de modo não convencional, os agradecimentos foram relocados para o final da tese, pois gostaria de fechar esse trabalho de uma forma calorosa e trazendo os momentos mais bonitos e importantes dessa difícil tarefa, as relações humanas; que fique aqui a recordação dos bons momentos.

Particularmente, eu aprendi muito com o desenvolvimento deste trabalho, e, sei que ainda tenho muito a aprender.

"I am not young enough to know everything"

Oscar Wilde. 


\section{Resumo}

Peptídeos antimicrobianos (PAMs) fazem parte do sistema de defesa de muitas plantas e animais, e apresentam potente ação contra micro-organismos parasitas e patógenos, sem causar danos às células do organismo hospedeiro. A seletividade dos peptídeos antimicrobianos por tais micro-organismos ocorre por diversos fatores, dentre eles a composição lipídica diferenciada de organismos procariotos e eucariotos. A camada externa da membrana celular de animais procariotos é composta, em parte, por lipídios negativos, diferindo da camada externa de organismos eucariotos, neutra. Logo, os peptídeos antimicrobianos, catiônicos, apresentam seletiva atração pela membrana de animais procariotos, como bactérias e fungos, devido à interação eletrostática. Deste modo, a interação do peptídeo com a membrana de organismos procariotos e eucariotos ocorre de modo diferenciado, levando a diferentes mecanismos de ação e efeitos.

Para melhor compreensão da atividade de peptídeos antimicrobianos, este trabalho apresenta um estudo da interação do peptídeo antimicrobiano KHya1 com membranas modelo, que são sistemas miméticos de membranas celulares formados por lipossomos de composição lipídica controlada. O peptídeo KHya1 apresenta sequência (Ile - Phe - Gly - Ala - Ile - Leu - Phe Leu - Ala - Leu - Gly - Ala - Leu - Lys - Ans - Leu - Ile - Lys - $\mathrm{NH}_{2}$ ) com 4 cargas positivas. Sua sequência primária provém de uma modificação com relação à sequência do peptídeo Hylina1, originalmente encontrado na secreção da pele do sapo, Hipsiboas albopunctatus. Ambos os peptídeos apresentam comprovada ação anti- bacteriana e anti- fúngica.

Neste trabalho, a interação do peptídeo KHya1 com membranas modelo de composição lipídica neutra (DPPC, dipalmitoil fosfatidil colina), aniônica (DPPG, dipalmitoil fosfatidil glicerol) e mista (DPPC:DPPG, 1:1) foi estudada por meio de diversas técnicas experimentais: calorimetria diferencial de varredura (DSC), fluorescência estática e temporal, utilizando a sonda natural do peptídeo (Trp, Triptofano) e sonda extrínseca de bicamada (Laurdan), experimentos de vazamento de sonda fluorescente encapsulada, espalhamento de luz dinâmico (DLS), microscopia óptica, ressonância paramagnética eletrônica (ESR) e espalhamento de 
raios-X a baixo ângulo (SAXS).

Esses estudos reportam que o peptídeo antimicrobiano KHya1 pode apresentar diferentes mecanismos em membranas neutras e aniônicas/ mistas, que estão relacionados a diferentes posições do peptídeo na bicamada, levando a modificações estruturais distintas nas membranas, dependendo de sua composição lipídica.

Os resultados sugerem que o peptídeo KHya1 interage preferencialmente com a superfície da membrana neutra, causando uma perturbação média nos lipídios. Também foi observado neste caso, maior partição do peptídeo em solução aquosa, comparada à partição observada em dispersões lipídicas aniônicas. Por outro lado, o peptídeo KHya1 pode estar ancorado transversamente em membranas compostas por lipídios negativos. Resultados de SAXS sugerem que o peptídeo causa estreitamento da espessura da bicamada, tanto na fase gel quanto na fase fluida. Para os sistemas modelo compostos pela mistura de lipídios, foi observado que o peptídeo interage preferencialmente com os lipídios aniônicos, e as perturbações que o peptídeo causa em DPPC:DPPG são maiores do que as observadas para os sistemas neutro e aniônico. Esse efeito pode ser consequência da maior razão molar peptídeo-PG em vesiculas mistas, e/ou o peptídeo pode causar defeitos entres lipídios neutros e aniônicos, modificando a permeabilidade da membrana. Embora também seja observado vazamento em vesículas neutras, a microscopia óptica e medidas de vazamento de sonda fluorescente encapsulada mostraram diferentes mecanismos de vazamento de membranas neutras e aniônicas. Para altas concentrações de peptídeo grandes poros são formados levando ao colapso de vesículas compostas por lipídios aniônicos.

Os diferentes efeitos do peptídeo antimicrobiano KHya1 em membranas neutra e aniônica, aqui observados, podem ter relevante importância para entender a ação eficaz de peptídeos antimicrobianos contra organismos procariotos, como bactérias e fungos, e ação reduzida em células eucariotas. 


\section{Abstract}

Antimicrobial peptides are part of the innate defense immunity system of several plants and animals. In general, they exhibit strong activity against pathogen microorganisms, without affecting the host cells. The antimicrobial peptides selectivity against specific target pathogens is due to several factors, including the different lipid composition of prokaryotic and eukaryotic membranes: for instance, they can be distinguished by the presence or absence of negatively charged lipids at the cell surface, respectively. Therefore, the electrostatic interaction between cationic antimicrobial peptides and anionic membranes can play an important role in the selectivity and activity of these peptides.

Here, we present a study of the antimicrobial peptide KHya1 with model membranes: liposomes prepared with controlled lipid composition that mimic the membrane outer leaflet of bacterial and eukaryotic cells. Peptide KHya1 (Ile - Phe - Gly - Ala - Ile - Leu - Phe - Leu Ala - Leu - Gly - Ala - Leu - Lys - Ans - Leu - Ile - Lys - $\mathrm{NH}_{2}$ ) has a net charge of +4 . KHya1 primary sequence originates from a modification of the sequence of Hylina1, a peptide isolated from the secretion of the skin of the frog Hipsiboas albopunctatus. Both peptides are known to exhibit effective action against bacteria and fungi.

The interaction of peptide KHya1 with model membranes composed by neutral (DPPC, dipalmitoyl phosphatidyl choline), anionic (DPPG, dipalmitoyl phosphatidyl glycerol) and a mixture of both lipids (DPPC:DPPG, 1:1) was studied by the use of several different experimental techniques: differential scanning calorimetry (DSC), static and time-resolved fluorescence, using the peptide natural probe (Trp, Tryptophan) and an extrinsic bilayer probe (Laurdan), experiments of leakage of an entrapped fluorescent dye, dynamical light scattering (DLS), optical microscopy, electron spin resonance (ESR) and small-angle x-ray scattering (SAXS).

The peptide KHya1 was found to interact differently with neutral and anionic membranes, located at different positions in the bilayer, and causing distinct membrane structural modifications. KHya1 preferentially interacts at the surface of neutral membranes, causing an average 
perturbation in the lipids. With DPPC, we also observed a larger partition of the peptide in aqueous solution, compared to the peptide aqueous partition in anionic lipid dispersions. In membranes composed of negatively charged lipids, the peptide KHya1 seems to be strongly anchored in a transmembrane position. SAXS results suggest that the peptide insertion causes membrane thinning, in both gel and fluid phases. For model systems composed by the mixture of neutral and anionic lipids, we observed that the peptide preferentially interacts with anionic lipids, and the changes the peptide causes in DPPC:DPPG vesicles are larger than those observed with pure anionic systems. This effect may be due to the larger peptide/PG molar ratio in DPPC:DPPG vesicles, and/or to lipid segregation caused by the peptide, and the consequent structural defects at the borders of neutral and anionic domains. Although KHya1 increases the permeability of neutral bilayers, optical microscopy and experiments of leakage of entrapped fluorescent dyes showed different mechanism of leakage for neutral and negatively charged bilayers. For high peptide concentrations, large pores are formed in anionic vesicles, leading to vesicle collapse.

The new insights shown here about the different structural modifications caused by the antimicrobial peptide KHya1 in neutral and anionic vesicles can possibly explain the efficient action of this peptide against bacteria and its reduced effect in eukaryotic cells. 


\section{Sumário}

1 Introdução 1

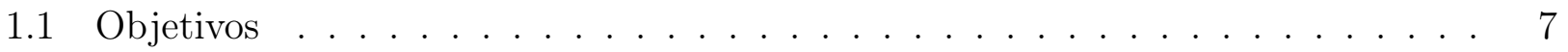

1.2 Sumário dos capítulos seguintes . . . . . . . . . . . . . . . . 8

2 Técnicas experimentais $\quad 11$

2.1 Calorimetria Diferencial de Varredura

em sistemas lipídicos . . . . . . . . . . . . . . . . . . . . . . 11

2.1.1 A transição gel-fluido . . . . . . . . . . . . . . . . . 11

2.1.2 A medida do calor específico . . . . . . . . . . . . . 13

2.2 Absorção óptica . . . . . . . . . . . . . . . . . . . . . . . . 16

2.3 Fluorescência . . . . . . . . . . . . . . . . . . . . . 19

2.3.1 O rendimento quântico . . . . . . . . . . . . . . 20

2.3.2 Deslocamento de Stokes ....................... 21

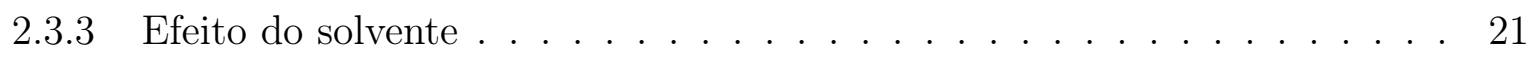

2.3.4 Anisotropia de fluorescência . . . . . . . . . . . . . . . 22

2.4 Fluorescência com Resolução Temporal . . . . . . . . . . . . . . . . . . . 23

2.5 Deconvolução da lâmpada . . . . . . . . . . . . . . . . . . 25

2.6 Análise do decaimento fluorescente . . . . . . . . . . . . . . . . . 26

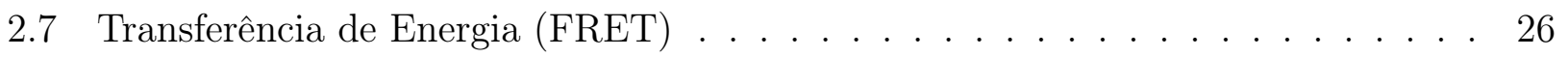

2.8 Distribuição de Distâncias . . . . . . . . . . . . . . . . . . . . . . . . . . . . . 29

2.8.1 CONTIN - Programa de Ajuste . . . . . . . . . . . . 31

2.9 Espalhamento de luz dinâmico . . . . . . . . . . . . . . . . . . 31

2.9.1 Função de auto-correlação . . . . . . . . . . . . . . . . 32

2.9.2 Como a medida é realizada no correlator . . . . . . . . . . . . 34

2.9.3 Análises na função de correlação do campo elétrico . . . . . . . . . . . 35 
2.10 Ressonância paramagnética eletrônica . . . . . . . . . . . . . . . . . 36

2.10.1 Hamiltonia de Spin . . . . . . . . . . . . . . . . . . . . 37

2.10.2 Análises dos sinais paramagnéticos aplicadas ao estudo de membranas . . 41

2.11 Espalhamento de raios-X a baixo ângulo . . . . . . . . . . . . . . . . . . 45

2.11.1 GIFT (Generalized indirect Fourier transform) . . . . . . . . . . . . 46

3 Modelos e Controles $\quad 49$

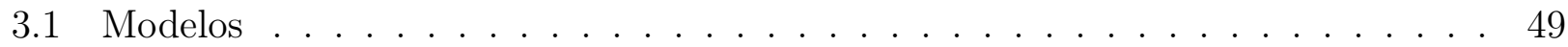

3.1.1 Estudo sob o ponto de vista da membrana . . . . . . . . . . . . 49

3.1.2 Membranas Modelo ..................... 50

3.1 .3 Força iônica . . . . . . . . . . . . . . . . . 52

3.1.4 Sistemas multilamelares versus unilamelares. . . . . . . . . . . . . . 53

3.1.5 A mistura de lipídios neutros e aniônicos . . . . . . . . . . . . . 56

3.1.6 Membranas modelo adotadas para o estudo por Microscopia óptica. . . . 56

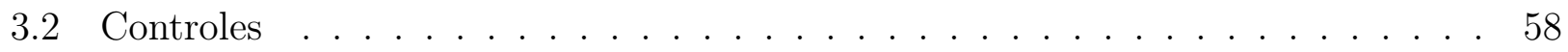

3.2.1 Determinação precisa da concentração de peptídeo e lipídio. . . . . . . . 58

3.2.2 A peculiaridade do comportamento calorimétrico da mistura de DPPC:DDPG com a temperatura inicial da medida . . . . . . . . . . . . . . . . 61

3.2.3 O vazamento espontâneo dos lipossomos . . . . . . . . . . . . . . 62

3.2.4 A transferência de energia (FRET) entre Trp e Laurdan. . . . . . . . . . 64

3.2.5 Tamanho dos lipossomos na ausência de peptídeo: condição inicial . . . . 66

3.2.6 A quantidade certa de marcador paramagnético . . . . . . . . . . 66

3.2.7 O controle de temperatura no ESR . . . . . . . . . . . . . . 68

\section{Interações distintas entre o peptídeo KHya1 e membranas aniônicas e neu-} $\begin{array}{ll}\text { tras } & 71\end{array}$

4.1 Motivação . . . . . . . . . . . . . . . . . . . . . . 71

4.2 Materiais e Métodos . . . . . . . . . . . . . . . . . 71

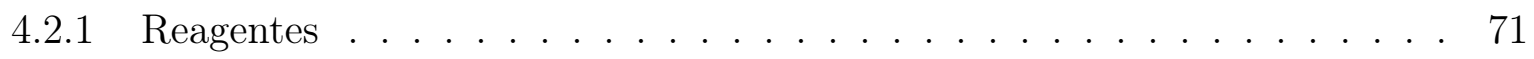

4.2 .2 Preparações das dispersões lipídicas . . . . . . . . . . . . . . . . 72

4.2 .3 Vesículas extrusadas . . . . . . . . . . . . . . . . 72

4.2.4 Experimentos de vazamento de sonda encapsulada no interior de lipossomos 72

4.2.5 Razão molar do peptídeo . . . . . . . . . . . . . . . . . . 73

4.2.6 Calorimetria diferencial de varredura $(\mathrm{DSC}) \ldots \ldots . \ldots . \ldots$ 
4.2.7 Absorção óptica do Trp . . . . . . . . . . . . . . . . . . . . . . . . 73

4.2 .8 Fluorescência do $\operatorname{Trp} \ldots \ldots$. . . . . . . . . . . . . . . . 75

4.2 .9 Espalhamento de luz dinâmico . . . . . . . . . . . . . . . . . 77

4.2.10 Experimentos de vazamento de sonda fluorescente encapsulada . . . . . . 78

4.2 .11 Microscopia óptica . . . . . . . . . . . . . . . . . . . . 78

4.2.12 Reprodutibilidade dos resultados . . . . . . . . . . . . . 79

4.3 Resultados . . . . . . . . . . . . . . . . . . . . . . . . . . 80

4.3.1 Calorimetria Diferencial de Varredura (DSC) . . . . . . . . . . . . 80

4.3 .2 Absorção do $\operatorname{Trp} \ldots \ldots$. . . . . . . . . . . . . . . . . . . . . 81

4.3 .3 Emissão fluorescente do Trp. . . . . . . . . . . . . . . . . . . . . . 83

4.3.4 Espalhamento de luz dinâmico . . . . . . . . . . . . . . . . . . . . 86

4.3.5 Vazamento de sonda fluorescente encapsulada por lipossomos . . . . . . . 88

4.3 .6 Microscopia óptica . . . . . . . . . . . . . . . . . . . . . . . . . 93

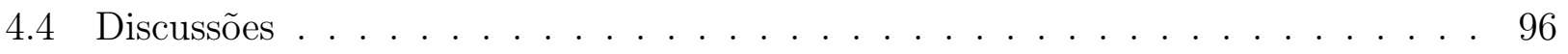

4.5 Conclusões . . . . . . . . . . . . . . . . . . . . . . . . . . . . 103

5 Interação do peptídeo KHya1 com membranas aniônicas: um estudo da flu$\begin{array}{ll}\text { orescência do Trp e da sonda exógena Laurdan } & 105\end{array}$

5.1 Motivação . . . . . . . . . . . . . . . . . . . . . . . . . . . . 105

5.2 Materiais e Métodos . . . . . . . . . . . . . . . . . . 106

5.2 .1 Reagentes . . . . . . . . . . . . . . . . . . . 106

5.2 .2 Preparações das dispersões lipídicas . . . . . . . . . . . . . . . . . 107

5.2 .3 Vesículas extrusadas . . . . . . . . . . . . . . . . . . 107

5.2.4 Razão molar do peptídeo . . . . . . . . . . . . . . . . . . . . . . . 107

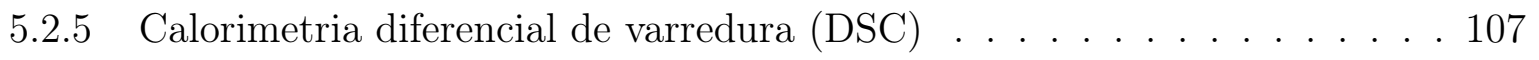

5.2 .6 Absorção óptica do Trp e do Laurdan . . . . . . . . . . . . . . . . . . 108

5.2.7 Fluorescência estática do Trp e do Laurdan . . . . . . . . . . . . . . 109

5.2 .8 Análise do espectro de emissão do Laurdan . . . . . . . . . . . . . . . . 110

5.2 .9 Cálculo do rendimento quântico para o Trp . . . . . . . . . . . . . . 112

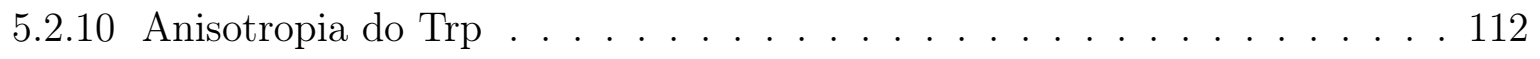

5.2 .11 Fluorescência temporal do Trp e do Laurdan . . . . . . . . . . . . . . . 113

5.2.12 Análise dos decaimentos fluorescentes: Análise global . . . . . . . . . 113

5.2.13 Espectros de emissão associados aos decaimentos (DAS) . . . . . . . 114 
5.2 .14 Transferência de energia (FRET) . . . . . . . . . . . . . 115

5.2 .15 Cálculo da distância de Förster . . . . . . . . . . . . . . . . 115

5.2 .16 Cálculo da eficiência do FRET entre Trp e Laurdan . . . . . . . . . . . 116

5.2 .17 Reprodutibilidade dos resultados . . . . . . . . . . . . . . . 117

5.3 Resultados e discussões . . . . . . . . . . . . . . . . . . . . . . . . . . . . 117

5.3 .1 Calorimetria diferencial de varredura $(\mathrm{DSC}) \ldots \ldots . \ldots 117$

5.3 .2 Absorção óptica . . . . . . . . . . . . . . . . . . . . . . . . 118

5.3 .3 Fluorescência estática do $\operatorname{Trp} \ldots \ldots$. . . . . . . . . . . 118

5.3 .4 Cálculo do Rendimento quântico do Trp . . . . . . . . . . . . . . . 124

5.3.5 Fluorescência temporal do $\operatorname{Trp} \ldots \ldots$. . . . . . . . . . . . . . . . 125

5.3.6 Espectros associados aos decaimentos (DAS) para o Trp . . . . . . . 129

5.3 .7 Fluorescência estática do Laurdan . . . . . . . . . . . . . . . . . . . 131

5.3.8 Espectros associados aos decaimentos (DAS) para Laurdan . . . . . . . 136

5.3 .9 Transferência de Energia . . . . . . . . . . . . . . . . . . . . 137

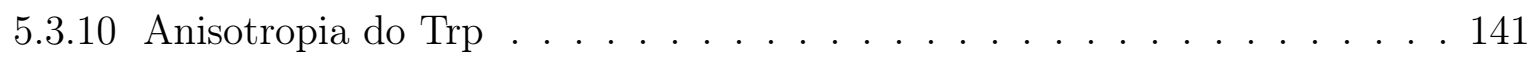

5.4 Conclusão . . . . . . . . . . . . . . . . . . . . . . . . . . . 146

\section{Posições diferentes do peptídeo antimicrobiano KHya1 em membranas neu-} tras e aniônicas são a causa de efeitos distintos nas membranas 149

6.1 Motivação . . . . . . . . . . . . . . . . . . . . . . . . . . . . . . . . . . . . . . 149

6.2 Materiais e Métodos . . . . . . . . . . . . . . . . . . 150

6.2 .1 Reagentes . . . . . . . . . . . . . . . . . . . . . 150

6.2 .2 Preparações das dispersões lipídicas . . . . . . . . . . . . . . . 150

6.2 .3 Vesículas não extrusadas . . . . . . . . . . . . . . . . . . . . . . . . 150

6.2 .4 Vesículas extrusadas . . . . . . . . . . . . . . . . . . . 151

6.2 .5 Razão molar do peptídeo . . . . . . . . . . . . . . . . . . . . . . . . . 151

6.2.6 Ressonância Paramagnética Eletrônica (ESR) . . . . . . . . . . . . 151

6.2 .7 Análises dos espectros de ESR . . . . . . . . . . . . . . . . . . . 152

6.2.8 Espalhamento de Raio-X a baixo ângulo (SAXS) . . . . . . . . . 153

6.2 .9 Analise das curvas de SAXS . . . . . . . . . . . . . . . . 154

6.3 Resultados e discussões . . . . . . . . . . . . . . . . . . . . . . 155

6.3 .1 Fase gel . . . . . . . . . . . . . . . . . . . 155

$6.3 .2 \quad$ Fase fluida . . . . . . . . . . . . . . . . . . . . . 160 


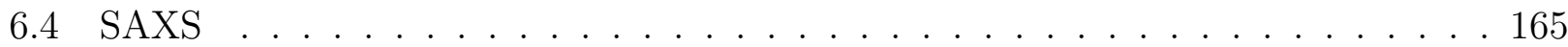

6.4.1 Sistemas multilamelares e unilamelares em ausência de peptídeo . . . . . 165

6.4.2 Vesículas extrusadas em presença de peptídeo . . . . . . . . . . . . 168

6.4.3 Vesículas não extrusadas em presença de peptídeo . . . . . . . . . . . . . 174

6.4.4 Análises preliminares das curvas de SAXS . . . . . . . . . . . . . 176

6.5 Considerações gerais . . . . . . . . . . . . . . . . . . . . . . . . 182

6.6 Conclusões . . . . . . . . . . . . . . . . . . . . . . . . . . . . 183

7 Conclusões $\quad 185$

A Distribuição de distâncias entre Trp e Laurdan 189

A.1 Distâncias entre Trp e Laurdan . . . . . . . . . . . . . . . . . . . . . . . . . 189

B Partição do peptídeo transmembranar GWALP23 entre as fases liquido ordenada (Lo) e liquido desordenada (Ld) para sistemas com macro e nanodomínios.

B.1 Introdução . . . . . . . . . . . . . . . . . . . . . . . . . 193

B.1.1 Diagramas de fase . . . . . . . . . . . . . . . . . . . . . . . 194

B.2 Apresentação da parte teórica . . . . . . . . . . . . . . . . . . . 195

B.3 Materiais e Métodos . . . . . . . . . . . . . . . . . . . . . . 197

B.4 Preparação das amostras para FRET - trajetórias de FRET . . . . . . . . . . 198

B.5 Resultados e Discussões . . . . . . . . . . . . . . . . . . . . . . . 198

B.6 Modelagem do coeficiente de partição . . . . . . . . . . . . . . . . . . . . . . 201

B.6.1 macro domínios . . . . . . . . . . . . . . . . . . . . . . 201

B.6.2 nano domínios . . . . . . . . . . . . . . . . . . . . . 202

C Estudo de vesículas assimétricas em sistemas ternários: bSM ou DSPC / DOPC / Chol. 205

C.1 Introdução . . . . . . . . . . . . . . . . . . . . . . . 205

C.2 Materiais e métodos . . . . . . . . . . . . . . 206

C.3 Resultados . . . . . . . . . . . . . . . . . . . . . 206

D Partição do peptídeo antimicrobiano KHya1 entre as fases liquido ordenada (Lo) e liquido desordenada (Ld) para sistemas com macro e nano-domínios.211 D.1 Introdução . . . . . . . . . . . . . . . . . . . . . . . . 211 
D.2 Materiais e métodos . . . . . . . . . . . . . . . . . . . . 212

D.3 Resultados e Discussões . . . . . . . . . . . . . . . . . . . . . . . . . . . . . . . 212

$\begin{array}{ll}\text { Referências Bibliográficas } & 217\end{array}$

Acknowledgment 


\section{Lista de Figuras}

1.1 Esquema ilustrativo de modelos típicos do mecanismo de ação dos peptídeos antimicrobianos. Figura extraída de (Park, 2011). (A) poro do tipo barril, (B) poro toroidal e $(\mathrm{C})$ modelo carpete. . . . . . . . . . . . . . . . . . . . . . . . .

1.2 Modelo sugerido para o peptídeo antimicrobiano transportan 10, atravessando a bicamada lipidica e passando a ocupar a camada interna da membrana. Figura extraída de (Yanked et al., 2007) e adaptada. . . . . . . . . . . . . . . . . . . .

1.3 Esquema ilustrativo de membranas modelos. Na formação de uma bicamada lipídica os agregados recebem o nome de vesículas unilamelares e, na formação de multicamadas, têm-se vesículas multilamelares. Figura adaptada de Biljana Kaurinovic and Mira Popovic (2012) . . . . . . . . . . . . . . . . . . . . . . . .

1.4 Sapo Hipsiboas albopunctatus. Figura extraída da enciclopédia livre Wikipedia. . . . .

1.5 Estruturas da sequência de amino ácidos do peptídeo KHy1 desenhadas com o uso do programa PepDraw, disponível online. Os resíduos polares estão destacados em vermelho e os resíduos apolar estão destacados em azul. A distribuição de cargas positivas também é representada pelo sinal $(+)$. Os dois sinais consecutivos no primeiro painel referem-se as cargas do N-terminal e da Lys+. O C-terminal do peptídeo é amidado e não apresenta carga negativa. O Trp, fluorescente também esta destacado com uma estrela. . . . . . . . . . . . . . . . . . . . . . .

2.1 Ilustração da transição ordem-desordem de sistemas lipídicos. O sistema ordenado caracteriza a fase gel, enquanto o sistema desordenado caracteriza a fase fluida. Figura extraída de (Heimburg, 2007). . . . . . . . . . . . . . . . .

2.2 Curvas calorimétricas obtidas para o DMPC, lipídio saturado com 14 em suas cadeias (preta) e para o DPPC lipídio saturado com 16 em suas cadeias (vermelha). . . . . . . 
2.3 Temperaturas de transição de fase (gel-fluida) para diferentes lipídios, variando o tamanho das cadeias hidrocarbônicas e a cabeça polar. Informações extraídas do site da avanti polar lipids inc, ilustrando as transições de fase em alta força iônica. . . . . . . . 13

2.4 lustração da quantidade de calor absorvida pela referência e pela amostra, para levar o sistema ao mesmo incremento de temperatura $\Delta T$, na transição de fase $\Delta Q^{\prime}>>\Delta Q$, pois parte do calor absorvido é destinado a excitar novos graus de liberdade do sistema.

2.5 Figura ilustrativa das curvas de potencial para uma molécula diatômica ilustrando uma transição vertical, segundo o princípio de Frank-Condon. Figura baseada nos textos Takara, 2006 e Vequi-Suplyci, 2010 . . . . . . . . . . . . . . . . . . 17

2.6 Ilustração da atenuação do feixe de luz incidente, na Absorção Óptica. . . . . . . . 18

2.7 Diagrama de Perrin-Jablonski, esquematizando as transições entre o estado fundamental e o estado excitado, onde IC (Internal Conversion) significa conversão interna e ISC (InterSystem Crossing) significa cruzamento entre sistemas. Figura baseada no texto Vequi-Suplicy, 2010 (original de Valeur, 2001) ～. . . . . . . . . . . . . . . 20

2.8 Esquema ilustrativo do modelo de Lippert, onde $\mu \mathrm{G}$ corresponde ao momento de dipolo no estado fundamental e $\mu \mathrm{E}$ no estado excitado. Figura extraída da tese de doutorado de Vequi-Suplicy, 2010 (original de Lakowicz, 2006) (modificada) . . . . . . . . . . . . 22

2.9 Exemplo da configuração operacional para medidas de anisotropia de fluorescência. Figura extraída de (Valeur, 2001) (adaptada) . . . . . . . . . . . . . . . 23

2.10 Exemplo esquemático da contagem de fótons. . . . . . . . . . . . . . . . . . . . 24

2.11 Exemplo do decaimento fluorescente obtido para o Trp, pepteideo HKya1, em $\mathrm{T}=25^{\circ} \mathrm{C}$ $\lambda_{e x}=280 \mathrm{~nm}$ e $\lambda_{\text {em }}=325 \mathrm{~nm} \ldots \ldots \ldots \ldots \ldots$

2.12 Ilustração da região de sobreposição entre o espectro de emissão do doador e o espectro de absorção do aceitador. . . . . . . . . . . . . . . . . . . . . . . 27

2.13 Orientação dos momentos de dipolo do doador e do aceitador. Figura extraída de Lakowicz, 2006. . . . . . . . . . . . . . . . . . . . . . . . . . . . . . . . . . 28

2.14 Dependência da eficiência do FRET em função da distância entre o par doador-aceitador. Figura extraída de Lakowicz, 2006. . . . . . . . . . . . . . . . . . . . . 29

2.15 Flutuações da intensidade da luz espalhada no tempo, causada pelo movimento das moléculas no fluído. Figura extraída de Berne e Pecora, 2000 (modificada). . . . . . . 33

2.16 Sequência de pulsos processados por um correlator. Figura extraída de Rodembusch, 2001 (adaptada). . . . . . . . . . . . . . . . . . . . 34 
2.17 Ilustração dos auto-valores da hamiltoniana de spin. Figura obtida das notas de aula da Prof. Teresa Lamy. . . . . . . . . . . . . . . . . . . . . . . . . . 38

2.18 Ilustração da medida de ESR, variando o campo magnético. Figura obtida das notas de aula da Prof. Teresa Lamy. . . . . . . . . . . . . . . . . . . . . . . . 38

2.19 Radical nitróxido e espectros de ESR em diferentes condições, onde o campo magnético esta alinhado paralelamente ao eixo-x (a), eixo-y (b) e eixo-z (3). Sinal paramagnético em solução congelada (d) e em solução de baixa viscosidade (e). Figura baseada nos textos Riske, 2001 e Oliveira, 2008, original de Marsh, 1981 (modificada). . . . . . . . 40

2.20 Sinais de EPR da sonda paramagnética, Tempol, em soluções de viscosidades crescentes. Figura baseada nos textos Riske, 2001 e Oliveira, 2008, original de . . . . . . . . 41

2.21 Exemplo de como medir a altura das linhas do sinal de ESR para o marcador 16PCSL. 42

2.22 Figura ilustrativa da restrição de movimento do marcador paramagnético ligado a cadeia hidrocarbônica. Figura obtida das notas de aula da Profa. Teresa Lamy. . . . . .

2.23 Exemplo de como medir os parâmetros $2 A_{\max }$ e $A_{\min }$ diretamente do sinal de ESR, para o marcador 5PCSL, na fase fluida do lipídio . . . . . . . . . . . . . . . . 44

2.24 Exemplo de como medir o parâmetro $2 A_{\max }$ e $\Delta H_{0}$ diretamente do sinal de ESR, para o marcador 5PCSL (esquerda) e 16PCSL (direita) na fase gel do lipídio. . . . . . . .

2.25 Esquema ilustrativo da medida de SAXS. Figura extraída do livro "Proteins in solution and in the interfaces: Methods and Applications in biotechnology and materials science". Editado por Ruso e Pineiro, 2013; capítulo 3, Barbosa et al, 2013. . . . . . .

2.26 Exemplo da p(r) obtida por um conjunto de splines e do ajuste do dado experimental. Neste exemplo, para uma geometria cilíndrica. Figura extraída de (Dahlgren 2002). .

3.1 Perfis calorimétricos obtidos por DSC para lipídios aniônicos com grupo polar, PG, em baixa força iônica. O calor específico à pressão constante é analisado em função de $T-T_{m}[K]$, onde $T$ corresponde à temperatura (variável independente da medida) e $T_{m}$ à temperatura de transição principal. Os termogramas abaixo do DPPG mostram os perfis calorimétricos obtidos para lipídios com 15, 14 e 13 carbonos em suas cadeias laterais. Figura extraída de Heimburg (2007) e adaptada. . . . . . . . . . . . . . . . 51

3.2 Perfis calorimétricos obtidos por DSC para o DPPG $(1.0 \mathrm{mM})$ em solução tampão HEPES $(10.0 \mathrm{mM})$ com EDTA $(1.0 \mathrm{mM})$ e variando a concentração de sal, $\mathrm{NaCl}$,

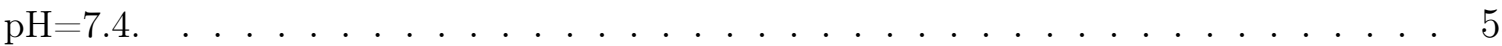


3.3 Condutividade elétrica das soluções tampão utilizadas nos experimentos de DSC variando a concentração salina, em $T=26^{\circ} C$. A condutividade elétrica é diretamente proporcional à concentração de eletrólitos em solução. . . . . . . . . . . . . . . . 53

3.4 Representação esquemática de vesículas multilamelares - MLVs (A) e unilamelares ULVs (B). Os graficos representam os padrões de difração característicos obtidos por SAXS para MLVs e LUVs. Os picos de repetição observados no primeiro painel referemse à estrutura de repetição das lamelas, conforme esquematizado em (A). Medidas realizadas no LNLS, conforme descrito no capítulo $6 . \quad \ldots . . . . . .54$

3.5 Perfis calorimétricos obtidos por DSC comparando sistemas lipídicos extrusados (vermelho) e não extrusados (preto) compostos por: DPPC, DPPG e DPPC:DPPG (ordenados de cima para baixo). . . . . . . . . . . . . . . . . . . 55

3.6 Representação esquemática para ilustrar a relação entre o efeito cooperativo na transição de fase e o raio de curvatura do lipossomo, onde a ilustração à esquerda representa uma bicamada com pequeno raio de curvatura, e à direita uma bicamada com grande raio de curvatura. Figura extraída de Heimburg (2007) e adaptada. . . . . . . . . . . 56

3.7 Perfil calorimétrico obtido por DSC para a mistura DPPC:DPPG (1:1) (vermelho) comparado ao perfil calorimétrico obtido pela soma dos termogramas medidos individualmente para o DPPC e o DPPG, onde cada curva somada contribui com metade da entalpia total de transição (preto). . . . . . . . . . . . . . . . . 57

3.8 Exemplo do espectro de absorção do Trp, resíduo na posição 7 do peptídeo KHya1. O valor da absorbância em $\lambda=280 \mathrm{~nm}$ é utilizado para o cálculo da concentração de peptídeo de acordo com a Lei de Lambert-Beer. A linearidade da Lei de Lambert-Beer é representada pelos valores da Absorbância em $\lambda=280 \mathrm{~nm}$ em função da concentração

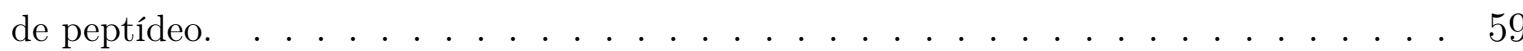

3.9 Exemplo da determinação da concentração de fósforo inorgânico, Pi, de amostras submetidas à dosagem de fosfato. A linha tracejada ilustra a curva de calibração e os pontos são exemplos de triplicas de amostras. . . . . . . . . . . . . . . . . . . . 61

3.10 Curvas calorimétricas para as dispersões lipídicas mistas de DPPC:DPPG (1:1) (1.0 $m M)$ não extrusadas (A) e extrusadas (B). As medidas foram realizadas com o aumento da temperatura, partindo de diferentes temperaturas iniciais: $T=15,10$ e $5^{\circ} \mathrm{C}$ representadas nas Varreduras de $\mathrm{N}^{o} 1,2$ e 3, respectivamente. . . . . . . . . . . . 62

3.11 Exemplo do vazamento espontâneo de lipossomos compostos por DPPC, DPPG e

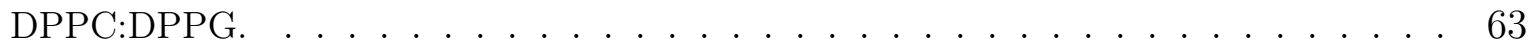


3.12 Decaimento Fluorescente do doador, Trp, em ausência e presença do aceitador, Laurdan e em função do aumento da concentração do aceitador $\left(\lambda_{e x c}=280 \mathrm{~nm}, \lambda_{e m s}=325 \mathrm{~nm}\right)$. 65

3.13 A diminuição do tempo de vida do doador na presença do aceitador é representada pela razão $\tau_{d a} / \tau_{d}$ em função do aumento da concentração de aceitador, em $T=50^{\circ} \mathrm{C}$.

3.14 Sinais de ESR para dispersões lipídicas de DPPC:DPPG (1:1) em função do aumento da razão molar de marcador paramagnético 16-PCSL, 0.2, 0.3, 0.4, 0.5 e 1.0 mol\%. Fase gel, $T=25^{\circ} \mathrm{C}$ e fase fluida, $T=45^{\circ} \mathrm{C} \ldots \ldots \ldots$

3.15 Comparação das razões molares de sonda paramagnética 16-PCSL utilizada nas medidas de ESR para a mistura DPPC:DPPG, fase fluida. A menor razão molar $0.2 \mathrm{~mol} \%$ é comparada com as demais. . . . . . . . . . . . . . . . . . .

3.16 Curva de calibração do sistema de controle de temperatura do equipamento de ressonância paramagnética eletrônica. . . . . . . . . . . . . . . . .

4.1 Espectro de absorção do Trp, resíduo na posição 7 do peptídeo. A figura ilustra que a adição de peptídeo leva ao aumento do espalhamento da dispersão, além do esperado aumento de suas bandas de absorção. As setas apontam a excitação (1) e a região de emissão do Trp (2), onde na região de emissão do Trp ainda há grande espalhamento (alta turbidez). . . . . . . . . . . . . . . . . . . .

4.2 Tratamento do espectro de absorção referente à subtração da linha de base, para monitoramento da banda de absorção em $\lambda=280 \mathrm{~nm}$. (A) Exemplo de uma medida experimental coletada para a mistura DPPC:DPPG a $T=50^{\circ} C$. (B) Subtração de uma linha de base para cada espectro. (C) Banda de absorção em $\sim 280 \mathrm{~nm}$ após a subtração da linha de base. . . . . . . . . . . . . . . . . . . . . 75

4.3 Perfis calorimétricos das dispersões lipídicas DPPC, DPPG e DPPC:DPPG na ausência e presença do peptídeo antimicrobiano KHya1. Os termogramas estão deslocados verticalmente para melhor visualização. As curvas superiores mostram as dispersões na ausência de peptídeo, as inferiores mostram as dispersões lipídicas com o aumento da concentração de peptídeo de acordo com a legenda. . . . . . . . . . . . . . . 80

4.4 Valores da absorbância medidos a $400 \mathrm{~nm}$. A figura ilustra como o peptídeo KHya1 afeta a turbidez das dispersões lipídicas na fase gel e fluida dos lipídios. . . . . . . . .

4.5 Variação linear da absorção do Trp, em $\lambda=280 \mathrm{~nm}$ com a concentração de peptídeo, exemplo obtido a $T=25^{\circ} \mathrm{C} \ldots \ldots \ldots \ldots$ 
4.6 Espectro de emissão fluorescente do Trp, resíduo na posição 7 do peptídeo, em solução aquosa tampão HEPES; e dispersão lipídica, DPPC, DPPG e DPPC:DPPG, para $T=$ $50^{\circ} \mathrm{C}$. Os gráficos inseridos nos painéis à direita mostram os espectros normalizados. . 84

4.7 Resumo das intensidades integradas de fluorescência (área sob o espectro de emissão) e posições espectrais medidas no máximo da emissão fluorescente, para os espectros de emissão do Trp do peptídeo em tampão HEPES, e em dispersões lipídicas de DPPC, DPPG e DPPC:DPPG, nas temperaturas $T=25^{\circ}$ e $50^{\circ} C$, fases gel e fluida dos lipídios,

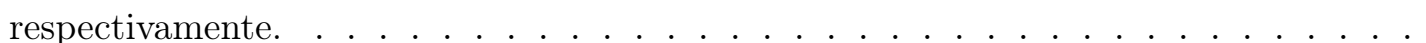

4.8 Raio efetivo, Ref, dos lipossomos compostos DPPC, DPPG e DPPC:DPPG em ausência de peptídeo, indicado por $[\mathrm{P}] /[\mathrm{L}]=0.00$, seguido do raio efetivo dos lipossomos com o aumento da concentração de peptídeo, para as razões molares $[\mathrm{P}] /[\mathrm{L}]=0.01,0.02,0.03$, 0.04, 0.05, 0.06 e 0.07 (A). Aumento do Ref aparente comparado ao raio dos lipossomos em ausência de peptídeo (B). . . . . . . . . . . . . . . . 87

4.9 Cinéticas de vazamento obtidas para os lipossomos compostos por DPPC, DPPG e DPPC:DPPG sob a ação do peptídeo antimicrobiano KHya1, $T=25^{\circ} C$. . . . . . . . 89

4.10 Exemplo dos ajustes das cinéticas de vazamento com o uso da equação 4.6. As cinéticas exemplificam perfis com diferentes formatos e tais curvas foram escolhidas de modo a obter a melhor representação para cada formato incluindo um bom ajuste. Da esquerda para a direita são representados DPPC, $[\mathrm{P}] /[\mathrm{L}]=0.285, R^{2}=0.997, \mathrm{DPPG},[\mathrm{P}] /[\mathrm{L}]=$

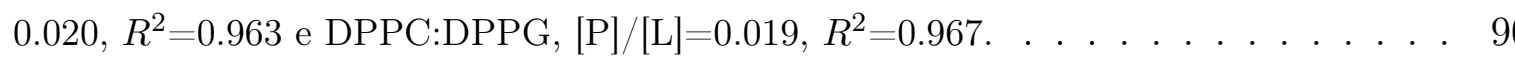

4.11 Tempos associados às taxas de vazamento, obtidos pelo ajuste da equação (4.6), para as cinéticas de vazamento dos lipossomos compostos por DPPC, DPPG e DPPC:DPPG sob a ação do peptídeo antimicrobiano KHya1. Os parâmetros resumidos nesta figura foram obtidos a partir dos ajustes com $R^{2} \leq 0.96$. Duplicata de amostras são representadas por símbolos abertos e fechados. . . . . . . . . . . . . . . . . 9

4.12 Fração relativa dos tempos associados às taxas de vazamento, obtidos pelo ajuste da equação (4.6), onde $A_{1}$ e $A_{2}$ correspondem aos fatores pré-exponenciais dos processos relacionados a $t_{1}$ e $t_{2}$, respectivamente. Os parâmetros resumidos nesta figura foram obtidos a partir dos ajustes com $R^{2} \leq 0.96$. Duplicata de amostras são representadas por símbolos abertos e fechados. . . . . . . . . . . . . . . . . . . . . 92 
4.13 Porcentagem de vazamento final medida em $\mathrm{t}=1800 \mathrm{~s}$ obtida pelas cinéticas de vazamento dos compostos por DPPC, DPPG e DPPC:DPPG e sob a ação do peptídeo antimicrobiano KHya1. O painel à direita amplia a região de $[\mathrm{P}] /[\mathrm{L}]=0.0$ a 0.08 . Duplicata de amostras são representadas por símbolos abertos e fechados. . . . . . . . . 93

4.14 Vesículas gigantes, GUVs, sob o efeito do peptídeo antimicrobiano KHya1 observadas por microscopia óptica de contraste de fase. GUVs compostas por DPPC (A), POPC (B) e POPC:POPG (C) e após a adição de $2 \mu M$ de peptídeo KHya1. As barras na

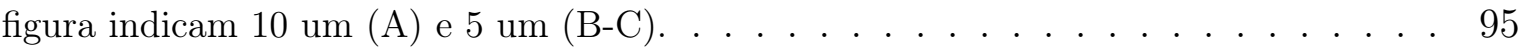

4.15 Figura esquemática e obtida da referência Vostrikov et. al. 2010 (adaptada) para ilustrar os possíveis arranjos do peptídeo na bicamada e o modo que um amino ácido positivo pode afetar a interação peptídeo - lipídio. (A) O peptídeo pode causar o estreitamento da bicamada na tentativa de seu resíduo positivo buscar a superfície ("snorkeling"). (B) A carga positiva pode desestabilizar a posição do peptídeo na membrana em diferentes situações: o amino ácido buscando a superfície pelo N-terminal, ou pelo C-terminal, ou ainda o peptídeo na superfície da bicamada. . . . . . . . . . 100

4.16 Figura esquemática sugerindo um modelo para a interação do peptídeo antimicrobiano KHya1 em membranas aniônicas, compostas por PG e em membranas neutras compostas por PC. Os amino ácidos positivos do peptídeo estão representados em vermelho e o $\operatorname{Trp}$ em verde. . . . . . . . . . . . . . . . . . . 101

5.1 Estrutura química da molécula Laurdan. . . . . . . . . . . . . . . . . . . 107

5.2 Exemplo dos espectros de absorção do Trp e Laurdan em bicamada de DPPG. Amostras contendo apenas o peptídeo apresentam um espectro de absorção semelhante ao observado com a curva preta. Para amostras com peptídeo e marcador fluorescente de membrana, Laurdan, o espectro de absorção mostra as bandas de absorção do Trp e Laurdan. A diferença entre curva vermelha e preta (curvas do gráfico à esquerda) leva ao espectro de absorção do Laurdan, curva azul (curva à direita). Neste exemplo as amostras contêm 2 mol\% de peptídeo (curvas preta e vermelha) e 1 mol\% de Laurdan (apenas curva vermelha). . . . . . . . . . . . . . . . . . . 108

5.3 Espectro de absorção do Trp, para $T=25^{\circ} C$, com o aumento da concentração de peptídeo. A curva pontilhada representa o DPPG na ausência de peptídeo. . . . . . . 109

5.4 Exemplo do espectro de emissão do Laurdan $\lambda_{\text {exc }}=340 \mathrm{~nm}$, para $T=25^{\circ} \mathrm{C}$ com emissão máxima em $\lambda=440 \mathrm{~nm}$ e para $T=50^{\circ} \mathrm{C}$ com emissão em $\lambda=490 \mathrm{~nm}$. . . 111 
5.5 Exemplo dos decaimentos fluorescentes do Trp obtidos para $\lambda_{\text {exc }}=280 \mathrm{~nm}, \lambda_{\text {em }}=315$, 325 e $335 n m, T=50^{\circ} \mathrm{C} \ldots \ldots \ldots$. . . . . . . . . . . . . . 114

5.6 Emissão fluorescente do Trp (doador), resíduo 7 do peptídeo KHya1, em ausência de Laurdan (aceitador) curva preta e em presença de aceitador, curva vermelha. A eficiência do FRET foi calculada de acordo com as áreas dos espectros, segundo a equação (5.12) (ver também Lakowicz, 2006). . . . . . . . . . . . . . . . . . . . 116

5.7 Perfis de calorimetria diferencial de varredura (DSC) para lipossomos compostos por DPPG (preto) e com o aumento da concentração de peptídeo. Resultado semelhante foi apresentado no capítulo $4 . \ldots \ldots \ldots$. . . . . . . . . . . 117

5.8 Valores da absorbância medidos em $\lambda=280 \mathrm{~nm}$, após subtração da linha de base conforme descrito na seção 5.2.6 e em função da concentração de peptídeo, e para as temperaturas $T=25,30,35,40,45$ e $50^{\circ} \mathrm{C} \ldots \ldots \ldots \ldots$

5.9 Espectros da emissão fluorescente do Trp, resíduo 7 do peptídeo KHya1 $(70 \mu M)$, em solução aquosa, tampão HEPES . (A) Emissão do Trp em diferentes temperaturas $T=25,30,35,40,45$ e $50^{\circ} \mathrm{C}$. (B) Os espectros do painel (A) foram normalizados pela intensidade máxima. . . . . . . . . . . . . . . . . . . . . . 119

5.10 Espectros da emissão fluorescente do Trp, resíduo 7 do peptídeo KHya1, em membranas lipídicas de DPPG em diferentes temperaturas $T=25,30,35,40,45$ e $50^{\circ} \mathrm{C}$ e para diferentes razões molares $[\mathrm{P}] /[\mathrm{L}]$ conforme indicado nos painéis.

5.11 Razões entre as áreas dos espectros $A_{T} / A_{\left(T=25^{\circ} \mathrm{C}\right)}$, onde $T=25,30,35,40,45$ e $50^{\circ} \mathrm{C}$ para o peptídeo em solução aquosa, e em diferentes concentrações na bicamada lipídica,

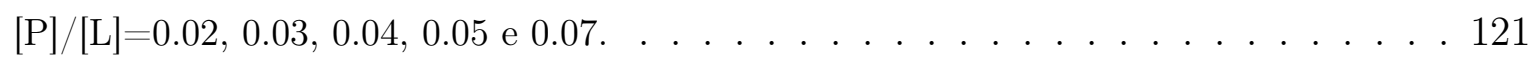

5.12 Espectros da emissão fluorescente do Trp da Figura 5.10 normalizados pela intensidade máxima. . . . . . . . . . . . . . . . . . . . . 122

5.13 Comparação entre a posição espectral do peptídeo em solução aquosa (preto) e o peptídeo em bicamada lipídica de DPPG (vermelho) . . . . . . . . . . . . . . . . . 123

5.14 Intensidade integrada ou área sob o espectro de emissão em função da concentração de peptídeo. As diferentes retas representam as diferentes temperaturas conforme legenda. Os números indicados no gráfico representam a razão molar, $[\mathrm{P}] /[\mathrm{L}]$. . . . . . . . . . 124

5.15 Tempos de vida do Trp em solução aquosa e em bicamadas lipídicas de DPPG em função da temperatura, mostrando a diminuição dos tempos de vida com o aumento da temperatura, $\lambda_{\text {exc }}=280 \mathrm{~nm}$, análise global $\lambda_{\text {em }}=315,325$ e $335 \mathrm{~nm}$. . . . . 126 
5.16 Tempos de vida do Trp em solução aquosa (linhas contínuas) e em bicamadas lipídicas de DPPG em função da concentração de peptídeo, para cada temperatura estudada $T=25,30,35,40,45,50^{\circ} \mathrm{C}, \lambda_{\text {exc }}=280 \mathrm{~nm}$, análise global $\lambda_{e m}=315,325$ e $335 \mathrm{~nm}$.

5.17 Tempos de vida médios em função da concentração de peptídeo em membranas de DPPG, e para as temperaturas , $T=25,30,35,40,45$ e $50^{\circ} \mathrm{C}, \lambda=280 \mathrm{~nm}$ e $\lambda=325 \mathrm{~nm} .128$

5.18 Contribuições fracionais dos tempos de vida com o aumento da concentração de peptídeo e para as temperaturas, $T=25,30,35,40,45$ e $50^{\circ} C, \lambda_{e x c}=280 \mathrm{~nm}$, análise global $\lambda_{e m}=315,325$ e 335 nm.. . . . . . . . . . . . . . . . . . 129

5.19 Tempos de vida do Trp associados ao seu espectro de emissão (DAS), $\lambda_{\text {exc }}=280 \mathrm{~nm}$,

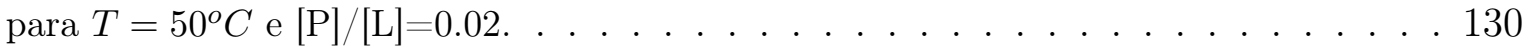

5.20 Espectros de emissão fluorescente do Laurdan $\lambda_{\text {exc }}=340 \mathrm{~nm}$ em membranas de DPPG em ausência de peptídeo e com o aumento da concentração de peptídeo, $[\mathrm{P}] /[\mathrm{L}]=0.02$, $0.03,0.04,0.05$ e $0.07 \ldots \ldots \ldots \ldots$

5.21 Parâmetro GP calculado para os espectros da Figura 5.20 de acordo com a equação (5.2).132

5.22 Exemplos da decomposição do espectro de emissão do Laurdan em bicamadas de DPPG para diferentes temperaturas, e diferentes fases da membrana. . . . . . . . . . . . 134

5.23 Comparação das bandas de emissão do Laurdan utilizando a razão entre a área da banda 1 e o espectro de emissão total, $A_{1} / A_{T}$, em função da temperatura, e para as diferentes concentrações de peptídeo, $[\mathrm{P}] /[\mathrm{L}]=0.00,0.02,0.03,0.04,0.05$ e 0.07 . . . 134

5.24 Posição espectral das bandas de emissão fluorescente obtidas a partir da decomposição espectral. O perfil das bandas na fase gel dos lipídios é representado em baixas temperaturas, assim como um perfil da fase fluida é representado em altas temperaturas, para facilitar a compreensão. . . . . . . . . . . . . . . . . . 135

5.25 Tempos de vida do Laurdan associados ao seu espectro de emissão (DAS), $\lambda_{\text {exc }}=$ $340 \mathrm{~nm}$, para $T=50^{\circ} \mathrm{C} \ldots \ldots \ldots \ldots \ldots \ldots \ldots$

5.26 Sobreposição dos espectros de absorção do Laurdan e de emissão do Trp, onde a área de intersecção representa $J$, é utilizada para o cálculo de $R_{0}(\operatorname{Trp}$ - Laurdan). . . 138

5.27 Razões entre os tempos de vida do Trp na presença do aceitador, $\tau_{d a}$, e ausência do aceitador $\tau_{d} \ldots \ldots \ldots \ldots \ldots \ldots \ldots \ldots \ldots$

5.28 Eficiência da transferência de energia entre Trp e Laurdan. A eficiência do FRET foi calculada de acordo com a equação $5.12 \ldots$. . . . . . . . . . . . . . . . . . . 140

5.29 Sobreposição dos espectros de absorção do Trp e de emissão do Trp, onde a área de intersecção representa, $J$, e é utilizada para o cálculo de $R_{0}(\operatorname{Trp}$ - Trp). . . . . . . . 141 
5.30 Anisotropia de fluorescência do Trp do peptídeo KHya1 em bicamadas de DDPG com o aumento da concentração de peptídeo e para as temperaturas $\mathrm{T}=25,30,35,40,45$ e $50^{\circ} \mathrm{C}$. As medidas de anisotropia foram realizadas utilizando $\lambda_{e x c}=280 \mathrm{~nm}$ e $\lambda_{e m}=330$ $n m$ (gráfico superior). Valores da absorbância das amostras medidos em $\lambda=450 \mathrm{~nm}$, para monitoramento do espalhamento da dispersão (gráfico inferior). . . . . . . . . . 142

5.31 Anisotropia de fluorescência do amino ácido Trp em solução aquosa com o aumento da concentração de nano esferas de poliestireno em $\mathrm{T}=25^{\circ} \mathrm{C}$. As medidas de anisotropia foram realizadas utilizando $\lambda_{e x c}=280 \mathrm{~nm}$ e $\lambda_{e m}=350 \mathrm{~nm}$ (gráfico superior). Valores da absorbância das amostras medidos em $\lambda=450 \mathrm{~nm}$, para monitoramento do espalhamento da solução (gráfico inferior) . . . . . . . . . . . . . . . . . . . . . . 143

5.32 Posição da intensidade máxima do espectro de emissão fluorescente do amino ácido Trp em função do aumento da concentração de nano esferas de poliestireno. Os símbolos pretos mostram os valores da posição espectral sem a correção de filtro interno e em vermelho após a correção. . . . . . . . . . . . . . . . . . . . . . . 144

6.1 Estrutura química das moléculas 5PCSL e 16PCSL. . . . . . . . . . . . . . . 150

6.2 Fotografia do "repeating dispenser" da Hamilton. . . . . . . . . . . . . . . . . . . . . 151

6.3 Exemplo de como medir os parâmetros $2 A_{\max }$ e $A_{\min }$ diretamente do sinal de ESR, para o marcador 5PCSL, na fase fluida do lipídio . . . . . . . . . . . 153

6.4 Exemplo do perfil de densidade eletrônica obtido para bicamadas lipídicas. . . . . . 154

6.5 Sinais paramagnéticos da sonda 16PCSL incorporada em membranas de DPPC na ausência e com o aumento da concentração de peptídeo, $[\mathrm{P}] /[\mathrm{L}]=0.00,0.02,0.03,0.04$ e 0.05 , nas temperaturas $T=15,20$ e $25^{\circ} \mathrm{C}$, fase gel do lipídio. . . . . . . . . . . 155

6.6 Sinais paramagnéticos da sonda 16PCSL incorporada em membranas de DPPG na ausência e com o aumento da concentração de peptídeo, $[\mathrm{P}] /[\mathrm{L}]=0.00,0.02,0.03,0.04$ e 0.05 , nas temperaturas $T=15,20$ e $25^{\circ} C$, fase gel do lipídio. . . . . . . . . . 156

6.7 Sinais paramagnéticos da sonda 16PCSL incorporada em membranas de DPPC:DPPG na ausência e com o aumento da concentração de peptídeo, $[\mathrm{P}] /[\mathrm{L}]=0.00,0.02,0.03$, 0.04 e 0.05 , nas temperaturas $T=15,20$ e $25{ }^{\circ} C$, fase gel da mistura. . . . . . . . 157 
6.8 Resumo dos valores medidos para $2 A_{\max }$, com o marcador 16PCSL, para as dispersões lipídicas (DPPC, DPPG e DPPC:DPPG), na ausência e com o aumento da concentração de peptídeo, na fase gel dos lipídios e para diferentes temperaturas. Os painéis inferiores mostram as relações de aumento/diminuição dos parâmetros $2 A_{\max }$ em função da concentração de peptídeo, comparados aos obtidos em dispersões lipídicas em ausência de peptídeo. . . . . . . . . . . . . . . . . . . . 157

6.9 Resumo dos valores medidos para $\Delta H_{0}$, com o marcador 16PCSL, para as dispersões lipídicas (DPPC, DPPG e DPPC:DPPG), na ausência e com o aumento da concentração de peptídeo, na fase gel dos lipídios e para diferentes temperaturas. Os painéis inferiores mostram as relações de aumento/diminuição dos parâmetros $\Delta H_{0}$ em função da concentração de peptídeo, comparados aos obtidos em dispersões lipídicas em ausência de peptídeo. . . . . . . . . . . . . . . . . . . 158

6.10 Sinais paramagnéticos da sonda 5PCSL incorporada em membranas de DPPC na ausência e com o aumento da concentração de peptídeo, $[\mathrm{P}] /[\mathrm{L}]=0.00,0.02,0.03,0.04$ e 0.05, nas temperaturas $T=15,20$ e $25{ }^{\circ} C$, fase gel do lipídio. . . . . . . . . . 159

6.11 Sinais paramagnéticos da sonda 5PCSL incorporada em membranas de DPPG na ausência e com o aumento da concentração de peptídeo, $[\mathrm{P}] /[\mathrm{L}]=0.00,0.02,0.03,0.04$ e 0.05, nas temperaturas $T=15,20$ e $25^{\circ} C$, fase gel do lipídio. . . . . . . . . . 159

6.12 Sinais paramagnéticos da sonda 5PCSL incorporada em membranas de DPPC:DPPG na presença e com o aumento da concentração de peptídeo, $[\mathrm{P}] /[\mathrm{L}]=0.00,0.02,0.03$, 0.04 e 0.05 , nas temperaturas $T=15,20$ e $25{ }^{\circ} C$, fase gel da mistura. . . . . . . . . 160

6.13 Resumo dos valores medidos para $2 A_{\max }$, com o marcador 5PCSL, para as dispersões lipídicas (DPPC, DPPG e DPPC:DPPG), na ausência e com o aumento da concentração de peptídeo, na fase gel dos lipídios e para diferentes temperaturas. Os painéis inferiores mostram as relações de aumento/diminuição dos parâmetros $2 A_{\max }$ em função da concentração de peptídeo, comparados aos obtidos em dispersões lipídicas em ausência de peptídeo.

6.14 Sinais paramagnéticos da sonda 16PCSL incorporada em membranas de DPPC, DPPG, e DPPC:DPPG na ausência e com o aumento da concentração de peptídeo, $[\mathrm{P}] /[\mathrm{L}]=0.00$, 0.02, 0.03, 0.04 e 0.05 , exemplo obtido na temperatura $T=50^{\circ} C$, fase gel do lipídio. $\quad$. 161 
6.15 Resumo dos valores medidos para $h_{-1} / h_{0}$, com o marcador 16PCSL, para as dispersões lipídicas (DPPC, DPPG e DPPC:DPPG) na ausência e com o aumento da concentração de peptídeo, na fase fluida dos lipídios e para diferentes temperaturas. Os painéis inferiores mostram as relações de aumento/diminuição dos parâmetros $h_{-1} / h_{0}$ em função da concentração de peptídeo, comparado às dispersões lipídicas em ausência de peptídeo. . . . . . . . . . . . . . . . . . . . 162

6.16 Sinais paramagnéticos da sonda 5PCSL incorporada em membranas de DPPC, DPPG, e DPPC:DPPG na ausência e com o aumento da concentração de peptídeo, $[\mathrm{P}] /[\mathrm{L}]=0.00$, 0.02, 0.03, 0.04 e 0.05 , exemplo obtido na temperatura $T=50^{\circ} \mathrm{C}$, fase gel do lipídio. $\quad 163$

6.17 Resumo dos valores calculados para $S_{e f}$, com o marcador 5PCSL na fase fluida dos lipídios, para as dispersões lipídicas (DPPC, DPPG e DPPC:DPPG) na ausência e com o aumento da concentração de peptídeo. Os painéis inferiores mostram as relações de aumento/diminuição dos parâmetros $S_{e f}$ em função da concentração de peptídeo, comparado às dispersões lipídicas em ausência de peptídeo. . . . . . . . . . . . . 163

6.18 Curvas de SAXS obtidas para dispersões lipídicas de DPPC. Dispersões não extrusadas formando vesícula multilamelares, MLVs: (A) fase gel do lipídio, $T=30^{\circ} \mathrm{C}$. fase fluida, $T=50^{\circ} \mathrm{C}$. Dispersões extrusadas formando majoritariamente vesículas unilamelares, LUVs: (C) fase gel do lipídio, $T=30^{\circ} \mathrm{C}$. (D) fase fluida, $T=50^{\circ} \mathrm{C}$. Em (D) mostramos um ajuste obtido com $20 \%$ de MLVs e $80 \%$ de LUVs. . . . . . . . . . 166

6.19 Curvas de SAXS obtidas para dispersões lipídicas de DPPG (preto) e DPPC:DPPG (vermelho). Dispersões não extrusadas formando vesículas unilamelares, LUVs: (A) fase gel do lipídio, $T=30^{\circ} \mathrm{C}$. (B) fase fluida, $T=50^{\circ} \mathrm{C}$. Dispersões extrusadas formando vesículas unilamelares, LUVs: (C) fase gel do lipídio, $T=30^{\circ} \mathrm{C}$. (D) fase fluida,$T=50^{\circ} C \ldots \ldots \ldots \ldots$. . . . . . . . . . . . . . . . . . . . . . . . .

6.20 Curvas de SAXS obtidas para dispersões lipídicas extrusadas de DPPC em ausência e com o aumento da concentração de peptídeo, $[\mathrm{P}] /[\mathrm{L}]=0.00,0.02,0.03,0.04,0.05,0.06$ e 0.07 , e para diferentes temperaturas, $T=25,30,35,40,45$ e $50^{\circ} C$. . . . . . 168

6.21 Curvas de SAXS obtidas para dispersões lipídicas extrusadas de DPPG em ausência e com o aumento da concentração de peptídeo, $[\mathrm{P}] /[\mathrm{L}]=0.00,0.02,0.03,0.04,0.05,0.06$ e 0.07, e para diferentes temperaturas, $T=25,30,35,40,45$ e $50^{\circ} \mathrm{C}$. . . . . . . 170

6.22 Curvas de SAXS obtidas para dispersões lipídicas extrusadas de DPPC:DPPG em ausência e com o aumento da concentração de peptídeo, $[\mathrm{P}] /[\mathrm{L}]=0.00,0.02,0.03,0.04$, 0.05, 0.06 e 0.07 , e para diferentes temperaturas, $T=25,30,35,40,45$ e $50^{\circ} \mathrm{C}$. . . 171 
6.23 Curvas de espalhamento para as vesículas de DPPC, DPPG e DPPC:DPPG em $\mathrm{T}=30^{\circ} C$, mostrando uma ampliação da região próxima ao mínimo do fator de forma (indicado pela linha vertical das figuras anteriores). . . . . . . . . . . . . . . . . . 172

6.24 Comparação entre a curva de SAXS obtida para o DPPG em ausência de peptídeo exibindo um perfil de vesículas unilamelares e a curva obtida para o DPPC com razão molar $[\mathrm{P}] /[\mathrm{L}]=0.07$. As curvas são representadas em escala log-log e as setas apontam possível evidencia de uma estrutura de repetição. . . . . . . . . . . . . . . . . . . 173

6.25 Intensidade de espalhamento dividida pelo fator de forma (curva aproximada à curva de DPPC com $[\mathrm{P}] /[\mathrm{L}]=0.02) \ldots \ldots \ldots \ldots \ldots \ldots$

6.26 Curvas de SAXS obtidas para dispersões lipídicas não extrusadas de DPPC, DPPG, e DPPC:DPPG em ausência e com o aumento da concentração de peptídeo, $[\mathrm{P}] /[\mathrm{L}]=0.00$, 0.02 e 0.05 , e para diferentes temperaturas, $T=30$ e $50^{\circ} C \ldots \ldots \ldots$

6.27 Exemplos dos ajustes para as curvas de SAXS obtidas para o DPPC em presença de peptídeo, nas razões molares $[\mathrm{P}] /[\mathrm{L}]=0.02,0.03,0.05,0.06$ e 0.07 para $\mathrm{T}=30^{\circ} C$, fase gel do lipídio. O primeiro painel ilustra a curva de espalhamento do DPPC em ausência de peptídeo, que além do fator de forma apresenta também um fator de estrutura. . . 176

6.28 Exemplos dos ajustes para as curvas de SAXS obtidas para o DPPC em presença de peptídeo, nas razões molares $[\mathrm{P}] /[\mathrm{L}]=0.02$ e 0.03 para $\mathrm{T}=45^{\circ} C$, fase gel do lipídio. $\mathrm{O}$ primeiro painel ilustra a curva de espalhamento do DPPC em ausência de peptídeo, que além do fator de forma apresenta fator de estrutura. O ajuste dessa curva foi previamente apresentado na Figura 6.20 (D). . . . . . . . . . . . . . . . 177

6.29 Exemplos dos ajustes para as curvas de SAXS obtidas para o DPPG em ausência e presença de peptídeo, nas razões molares $[\mathrm{P}] /[\mathrm{L}]=0.02,0.03,0.04,0.05$ e 0.07 para $\mathrm{T}=30^{\circ} C$, fase gel do lipídio. . . . . . . . . . . . . . . . . . 178

6.30 Exemplos dos ajustes para as curvas de SAXS obtidas para o DPPG em ausência e presença de peptídeo, nas razões molares $[\mathrm{P}] /[\mathrm{L}]=0.02,0.03,0.05,0.06$ e 0.07 para $\mathrm{T}=45^{\circ} \mathrm{C}$, fase fluida do lipídio. . . . . . . . . . . . . . . . . 179

6.31 Exemplos dos perfis de densidade eletrônica obtidos a partir dos ajustes mostrados na Figura, para o DPPC e DPPG em ausência e presença de peptídeo, para $\mathrm{T}=30^{\circ} C$, fase gel do lipídio. . . . . . . . . . . . . . . . . . . . . . . . . 179

6.32 Diminuição da espessura da bicamada em presença de peptídeo. . . . . . . . . . . . . 180 
6.33 Figura esquemática e obtida da referência Vostrikov et. al. 2010 (adaptada) para ilustrar que o peptídeo pode causar o estreitamento da bicamada na tentativa de seu resíduo positivo buscar a superfície ("snorkeling"). . . . . . . . . . . . . . . . 183

7.1 Modelo para interação do peptídeo antimicrobiano com membranas neutras de DPPC. 186

7.2 Modelo para interação do peptídeo antimicrobiano com membranas neutras de DPPG. 188

A.1 Distribuição de distâncias entre doador e aceitador obtidas a partir dos decaimentos fluorescentes para peptídeo $[\mathrm{P}] /[\mathrm{L}]=0.03$ e 0.04 e para as temperaturas $T=30$ e $45^{\circ} C$, caracterizando a fase gel e fluida dos lipídios, respectivamente. . . . . . . . . . . . 190

B.1 Diagramas de fases para os sistemas DSPC/DOPC/Chol (A), and DSPC/POPC/Chol (B), Konyakhina et al., 2013. Trajetória ao longo da linha de coexistência de fases em vermelho. . . . . . . . . . . . . . . . . . . . . . 194

B.2 Sinal de FRET de acordo com a Eq. (1). Sondas particionando na mesma fase, Ld (A), Sondas particionando na mesma fase, Lo (B). Sondas particionando em diferentes

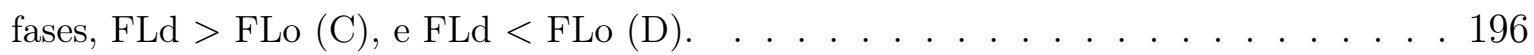

B.3 Comparação da solução teórica, equação (B.1) e simulação numérica, no regime macroscopico. . . . . . . . . . . . . . . . . . . . . . 197

B.4 Sinal de FRET usando os pares Trp-oe (doador) e DHE (aceitador), em preto, e Trp -GWALP23 (doador) e DHE (aceitador), em azul (A). Sinal de FRET usando os pares DHE (doador) e Bodipy (aceitador) (em preto, em presença de Trp-oe) e (em azul, em presença de GWALP23) (B). Sistema macroscópico DSPC/DOPC/Chol. ..... . 199

B.5 Contornos de fase para DSPC/DOPC/Chol + GWALP23 são determinados pelo encontro das retas traçadas em (Ld ou Lo) e a região de coexistência $(\mathrm{Lo}+\mathrm{Ld})$. Os gráficos tem a mesma legenda do anterior. . . . . . . . . . . . . . . . . 200

B.6 Sinal de FRET usando os pares Trp-oe (doador) e DHE (aceitador), em azul, e TrpGWALP23 (doador) e DHE (aceitador), em verde (A). Sinal de FRET usando os pares DHE (doador) e Bodipy (aceitador) (em azul, em presença de Trp-oe) e (em verde, em presença de GWALP23) (B). Sistema macroscópico DSPC/POPC/Chol. . . . . . . . 200

B.7 Mapeamento dos coeficientes de partição do peptídeo GWALP23 e da sonda Boidipy em DSPC/DOPC/Chol. . . . . . . . . . . . . . . . . . . . 201

B.8 Ajustes obtidos das análises para o sistema DSPC/DOPC/Chol, para diferentes pares de FRET, GWALP23-DHE, DHE-Bodipy e GWALP23-Bodipy. . . . . . . . . . . . . 202 
B.9 Mapeamento dos coeficientes de partição do peptídeo GWALP23 e da sonda Boidipy, e do tamanho dos dominios, em DSPC/POPC/Chol. . . . . . . . . . . . . . 202

B.10 Ajustes obtidos das análises para o sistema DSPC/POPC/Chol, para diferentes pares de FRET, GWALP23-DHE, DHE-Bodipy e GWALP23-Bodipy. . . . . . . . . . . 203

C.1 GUV simétricas com coexitência de fase líquida, $\mathrm{Ld}+\mathrm{Lo}, \mathrm{bSM} / \mathrm{DOPC} / \mathrm{Chol}=0.3 / 0.3 / 0.4$.

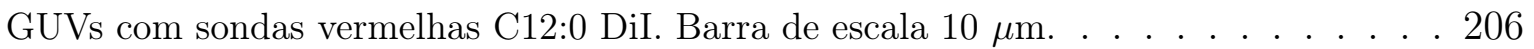

C.2 Diagrama de fases bSM/DOPC/Chol adaptado de Petruzielo et al., 2013. O diagrama de fase mostra a composição inicial das GUVs (quadrado). Assim que a camada externa é substituída por DOPC, e a fração de Chol não muda, a composição da monocamada externa se altera na direção da seta. . . . . . . . . . . . . . . . . . . . 207

C.3 GUVS assimétricas. A sonda verde marca os lipídios que foram substituídos na camada externa, e a sonda vermelha marca principalmente a camada interna. (A) Canais vermelho e verde do microcópio combinados. (B) Canal verde. (C) Canal vermelho.

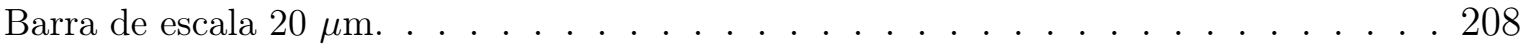

C.4 GUVS assimétricas. A sonda verde marca os lipídios que foram substituídos na camada externa, e a sonda vermelha marca principalmente a camada interna. (A) Canais vermelho e verde do microcópio combinados. (B) Canal verde. (C) Canal vermelho.

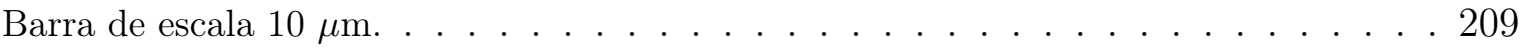

D.1 Sinal de FRET usando os pares TRP-KHya1 (doador) e DHE (aceitador), DSPC/DOPC/Chol + KHya1 (A) e DSPC/POPC/Chol + KHya1 (B). As setas indicam os contornos de fases. . . . . . . . . . . . . . . . . . . . . . . . 212

D.2 Esquema ilustrando a transição entre sistemas macorscópicos para nanoscópicos passando por fases moduladas. . . . . . . . . . . . . . . . . . . . 213

D.3 Esquema ilustrando a conexão entre tensão linear e tensão de curvatura, adaptado de Amazon et. al. 2014. . . . . . . . . . . . . . . . . . . . . . . 213

D.4 Janela onde ocorre as fases moduladas muda em presença de KHya1 $0.5 \mathrm{~mol} \% \mathrm{bSM} /$ $(\mathrm{DOPC}+\mathrm{SOPC}) / \mathrm{Chol}=0.39 / 0.39 / 0.22 \ldots \ldots \ldots \ldots . \ldots \ldots$

D.5 Morfologia dos domínios ao longo da linha de coexistência de fase para DSPC/DOPC/Chol. Em ausência de peptídeo (A, B, C, D, E, e F). Em presença de 0.5 mol\% de KHya1

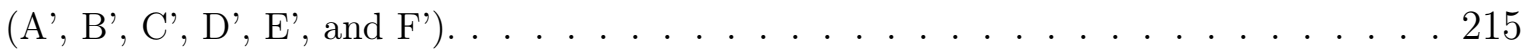





\section{Lista de Tabelas}

2.1 Valores principais dos tensores g e A. . . . . . . . . . . . . . . . . 39

3.1 Diâmetro efetivo obtido por DLS para diversas medidas dos lipossomos compostos por DPPC, DPPG e DPPC:DPPG. . . . . . . . . . . . . 66

4.1 Temperaturas de transição de fase dos sistemas lipídicos compostos por DPPC, DPPG e DPPC:DPPG. O número entre parênteses indica o número de amostras analisadas. .

4.2 Entalpias dos picos calorimétricos calculadas para cada razão molar peptídeo/ lipídio dos sistemas lipídicos compostos por DPPC, DPPG e DPPC:DPPG. Os números entre parênteses indicam o intervalo de temperaturas utilizado no cálculo da entalpia. . . . . 82

5.1 Rendimento quântico do Trp no peptídeo KHya1. O rendimento quântico do peptídeo foi calculado de acordo com a equação (5.5). . . . . . . . . . . . . . . . . 125

5.2 Distância estimada entre peptídeos considerando uma distribuição homogênea de peptídeos pela membrana. . . . . . . . . . . . . . . . . . . 146

6.1 Espessura das bicamadas em presença e com o aumento da concentração de peptídeo KHya1, para $\mathrm{T}=30^{\circ} \mathrm{C}$ e $\mathrm{T}=50^{\circ} \mathrm{C}$. Valores obtidos da literatura ( ${ }^{a}$ Nagle e Nalge, 2003, Leekumjorn e Sum 2007) e $\left({ }^{b}\right.$ Heftberger et al. 2014) . . . . . . . . . . . . . . . . . 180 



\section{Lista de abreviações}

$\mathrm{HClO}_{4}$ ácido perclórico

16PCSL 1-palmitoil-2-stearoyl- (16-doxyl) -sn-glicero-3-fosfocolina

5PCSL -palmitoil-2-stearoyl- (5-doxyl) -sn-glicero-3-fosfocolina

CD Dicroísmo Circular

CF carboxifluoreceína

DLS Dynamic Light Scattering - Espalhamento de luz dinâmico

DMPG dimiristoil fosfatidilglicerol

DPPC dipalmitoil fosfatidilcolina

DPPG dipalmitoil fosfatidilglicerol

DSC Calorimetria diferencial de varredura - Differencial scanning calorimetry

EDTA Ethylenediamine tetraacetic acid - ácido etilenodiamino tetra-acético

ESR Electron spin resonance - Ressonância paramagnôtica eletrônica

FRET Förster Resonance Energy Transfer - Transferência da energia

GUVs Giant Unilamellar Vesicles - Vesículas gigantes

HEPES N-[2-hidroxietil]piperazina-N'-[2-etanosulfônico ácido]

LNLS Laboratório Nacional Luz Sincrotron

LUVs Large Unilamellar Vesicles - Vesículas unilamelares

MLVs Multilamellar Vesicles - Vesículas multilamelares 
$\mathrm{NaCl}$ cloreto de sódio

PAMs Peptídeos antimicrobianos

POPC palmitoil oleoil fosfatidilcolina

POPG palmitoil oleoil fosfatidilglicerol

SAXS Small angle X-Ray scattering - Espalhamento de raios-X a baixo ângulo 


\section{Capítulo 1}

\section{Introdução}

A resistência de micro-organismos patógenos a antibióticos tem sido alarmante nas últimas décadas. Por outro lado, diversos estudos têm apontado os peptídeos antimicrobianos (PAMs) como uma alternativa para o combate de agentes patógenos. Desde então, diversos peptídeos antimicrobianos vêm sendo testados contra bactérias, fungos e células animais (Zasloff, 2002; Yeaman e Yount, 2003). Além disso, para a melhor compreensão da ação desses peptídeos em membranas celulares, estudos com membranas modelo têm sido amplamente realizados para mimetizar os sistemas naturais.

Peptídeos antimicrobianos (PAMs) fazem parte do sistema imunológico de muitas plantas e animais. Seu modo de ação envolve a desestruturação da membrana celular levando ao rompimento da célula por meio de um mecanismo que ainda não é completamente compreendido. Algumas características principais dos PAMs são: o comprimento variando entre 10 e 40 resíduos de aminoácidos e a presença de resíduos catiônicos e hidrofóbicos (Zasloff, 2002; Power e Hancock, 2003; Sato e B.Feix, 2006). Estudos de dicroísmo circular mostram que vários peptídeos antimicrobianos só adquirem uma estrutura secundária em presença de uma interface anfifílica, sugerindo que a estrutura conformacional está ligada a sua atividade (Yeaman e Yount, 2003).

Surpreendentemente, alguns peptídeos isolados de alguns tecidos de animal, às vezes, apresentam pequena ou irrelevante ação antimicrobiana nas células de seu animal de origem, e potente ação contra células microbianas. Uma importante consideração na ação dos peptídeos antimicrobianos refere-se à capacidade de distinguir as células microbianas das células de seus portadores, com relação à toxicidade. Como os peptídeos antimicrobianos podem fazer tal distinção? 
A seletividade dos PAMs consiste em explorar as diferenças fundamentais entre células patógenas (em geral, procarióticas) das células de seus portadores (em geral, eucarióticas). Essas diferenças foram selecionadas ao longo do processo evolutivo e servem de sinalizadores para a seletividade dos peptídeos antimicrobianos. As características de significante distinção são: composição e arquitetura das membranas; fatores energéticos, como potencial transmembranar e polarização, e fatores estruturais, como esteróis e lipossacarídeos. A seletividade e ação tóxica dos peptídeos em diferentes células dependerão de como esses fatores irão interferir na interação entre o peptídeo e a membrana.

A composição da membrana lipídica é um fator de importante contribuição na seletividade dos peptídeos antimicrobianos. A monocamada externa da membrana celular de organismos procariotos apresenta considerável fração de lipídios negativos, como PG (fosfatidilglicerol) e PS (fosfatidilserina). Por outro lado, a camada externa da membrana celular de mamíferos e organismos eucariotos em geral, é composta por lipídios neutros (zwitteriônicos), rica em PC (fosfatidilcolina) e colesterol. Como os peptídeos antimicrobianos são catiônicos, a seletividade pelas membranas negativamente carregadas é maior devido à interação eletrostática.

Deste modo, as interações eletrostáticas podem exercer importante contribuição na seleção dos peptídeos antimicrobianos por membranas de bactérias. Entretanto, há outras interações que também contribuem para a afinidade do peptídeo por membranas em geral, como por exemplo, muitos peptídeos possuem resíduos hidrofóbicos que também vão influenciar na interação peptídeo-lipídio. O fato dos peptídeos antimicrobianos terem como alvo a membrana lipídica torna-se uma vantagem para sua aplicação farmacológica, pois os peptídeos não atuam por vias especificas que poderiam levar à seleção de organismos mais resistentes (Epand, Schmitt, Gellman, e Epand, 1999; Yeaman e Yount, 2003; Zasloff, 2002).

Entretanto, alguns peptídeos antimicrobianos possuem também atividade hemolítica. Grande esforço tem sido dirigido objetivando o desenvolvimento de análogos sintéticos com potente especificidade contra patógenos, e, com reduzidos efeitos citotóxicos para células eucarióticas (Power e Hancock, 2003; Yeaman e Yount, 2003).

\section{Mecanismo de Ação}

Existem alguns modelos para descrever os mecanismos de ação dos PAMs, dentre eles, podemos citar a formação de poros toroidais, ou do tipo barril, e o modelo carpete. Esses modelos foram os primeiros a serem investigados e propostos como mecanismo de ação dos 
PAMs. Comum a esses mecanismos, os peptídeos são, inicialmente, atraídos eletrostaticamente pela superfície da membrana de microrganismos, rica em fosfolipídios aniônicos (Brogden, 2005). Então, supõe-se que uma concentração limiar de peptídeo ligados à bicamada é alcançada, desencadeando diferentes mecanismos de acordo com a especificidade de cada peptídeo.

Os peptídeos que atuam por meio do modelo conhecido como poro toroidal, em geral são absorvidos pela membrana até uma concentração crítica, e a partir desta, o peptídeo imprime à membrana uma curvatura positiva dando origem a um poro, onde o contorno do poro também contém lipídios que se organizam em uma estrutura similar à forma geométrica de um toroide. No modelo, conhecido por poro do tipo barril o poro é estabilizado pelo peptídeo, onde sua face apolar se alinha as cadeias hidrocarbônicas dos lipídios e sua face polar volta-se para o solvente, conforme ilustra a Figura 1.1 extraída de (Park, Park, e Hahm, 2011).

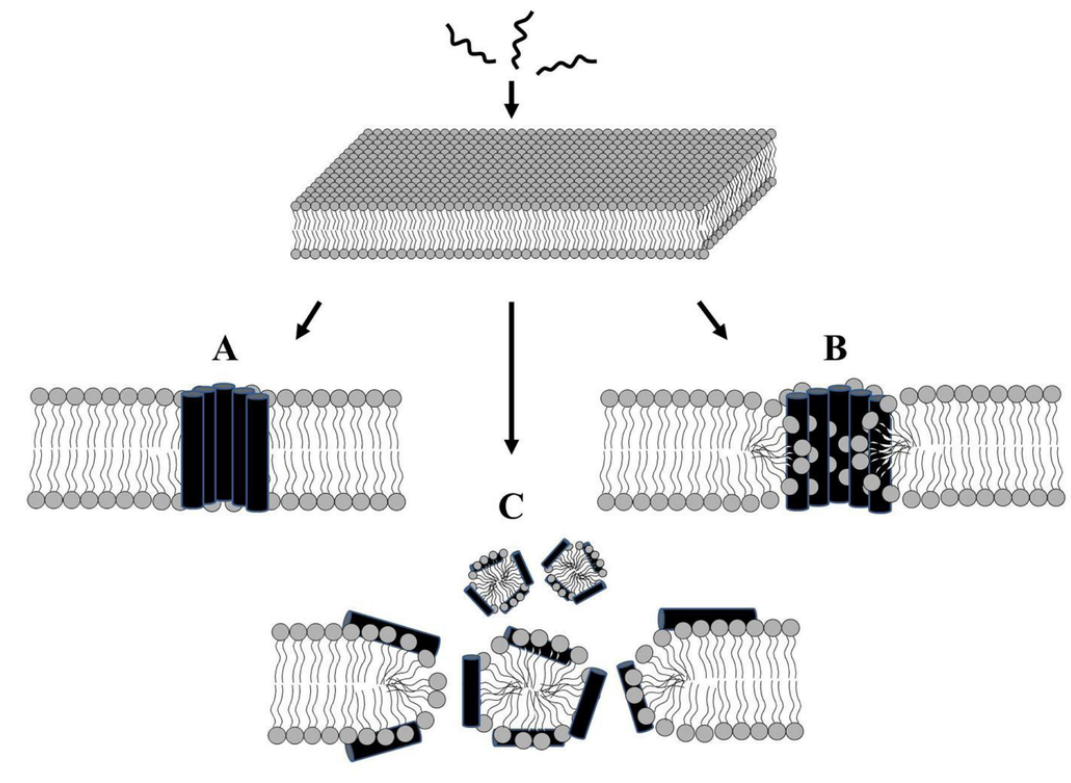

Figura 1.1: Esquema ilustrativo de modelos típicos do mecanismo de ação dos peptídeos antimicrobianos. Figura extraída de (Park, 2011). (A) poro do tipo barril, (B) poro toroidal e (C) modelo carpete.

Por fim, no mecanismo de ação conhecido por modelo carpete, os PAMs revestem a superfície da membrana que se rompe subitamente, desintegrando-se. Esse tipo de ação também é conhecido por modo de ação do tipo detergente, pois podem levar à formação de agregados micelares (Brogden, 2005), Figura 1.1.

Yanked e colaboradores (Yandek et al., 2007) também sugerem que a inserção do peptídeo na membrana pode causar mudanças de curvatura de bicamada, pois a membrana se adapta para acomodar o agente exógeno. Tal mudança de curvatura pode facilitar a translocação do 
peptídeo para a monocamada interna de modo a regular a pressão lateral que o peptídeo causa nos lipídios devido à sua inserção.
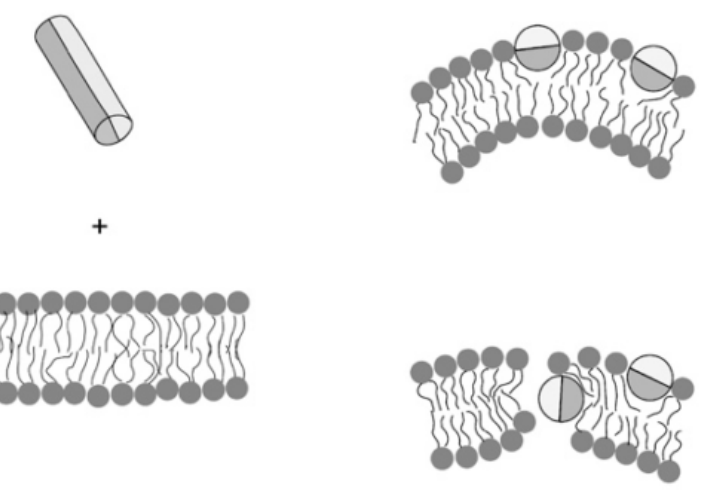

Peptídeo antimicrobiano atravessando a membrana

Figura 1.2: Modelo sugerido para o peptídeo antimicrobiano transportan 10, atravessando a bicamada lipidica e passando a ocupar a camada interna da membrana. Figura extraída de (Yanked et al., 2007) e adaptada.

Mais recentemente, novos mecanismos de ação de peptídeos antimicrobianos vêm sendo propostos na literatura. Por exemplo, Epand e Epand sugerem que moléculas catiônicas, interagindo com membranas compostas por lipídios aniônicos e neutros, podem causar a segregação de lipídios aniônicos, intervindo, portanto, na permeabilidade da membrana (Epand e Epand, 2009a, 2009b). Outros autores (Guo, Smith-Dupont, e Gai, 2011) reportam a formação de diferentes domínios lipídicos formados por aglomerados e peptídeos e lipídios, onde possíveis defeitos no contorno desses domínios poderiam ser um fator de alta toxicidade para as células.

\section{Membranas Modelos}

A membrana celular é um sistema de grande complexidade, que contém uma variedade de lipídios, proteínas e receptores de membranas. Como o principal mecanismo de ação de PAMs em membranas celulares envolve interações com a matriz lipídica da membrana, optamos por estudar a interação de PAMs com sistemas miméticos de membrana, mais especificamente, bicamadas lipídicas de composição conhecida, formando vesículas (lipossomos), Figura 1.3.

Em solução aquosa os lipídios se organizam em uma bicamada lipídica devido à interação 

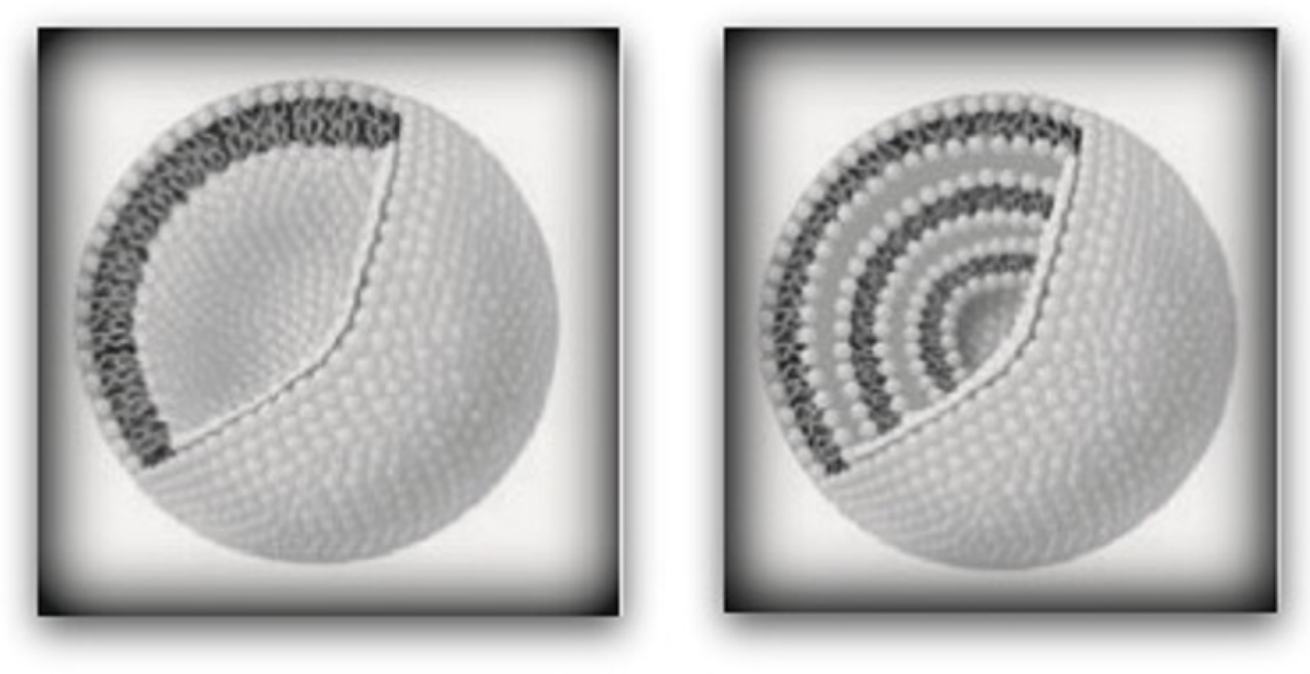

Figura 1.3: Esquema ilustrativo de membranas modelos. Na formação de uma bicamada lipídica os agregados recebem o nome de vesículas unilamelares e, na formação de multicamadas, têm-se vesículas multilamelares. Figura adaptada de Biljana Kaurinovic and Mira Popovic (2012).

hidrofóbica. Essa estrutura tende a se fechar em um agregado esférico para minimizar energia. As vesículas ou lipossomos são caracterizados pelo aprisionamento de volume interno de solução, e podem ser encontrados na forma de estrutura unilamelares, ou multilamelares. Para maiores detalhes, ver capítulo 3, Modelos e Controles.

\section{Peptídeos antimicrobianos}

O peptídeo Hylina1 (Hya1) foi isolado da secreção da pele do sapo Hipsiboas albopunctatus, Figura 1.4, e apresenta comprovada atividade antibacteriana e antifúngica.

O peptídeo Hya1 contém 18 resíduos de amino ácidos (Ile - Phe - Gly - Ala - Ile - Leu - Phe - Leu - Ala - Leu - Gly - Ala - Leu - Lys - Ans - Leu - Ile - Lys - $\mathrm{NH}_{2}$ ) e com o C-terminal amidado, apresenta 3 cargas positivas em excesso. Estudos de Dicroísmo Circular (CD) , juntamente com uma predição teórica, indicaram cerca de $80 \%$ de alpha hélice em sua estrutura secundária em meio anfipático (Castro et al., 2009). Entretanto, em solução aquosa não se define uma estrutura secundária.

Com a finalidade de aumentar o efeito antimicrobiano, foram sintetizados análogos, (Crusca et al., 2011). O análogo aqui estudado teve a Leucina da posição 6 substituída por um Triptofano. Além disso, foi inserido um amino ácido carregado antes da Isoleucina, na primeira posição. Então o peptídeo modificado KHya1 tem sequência dada por (Lys - Ile - Phe - Gly - 


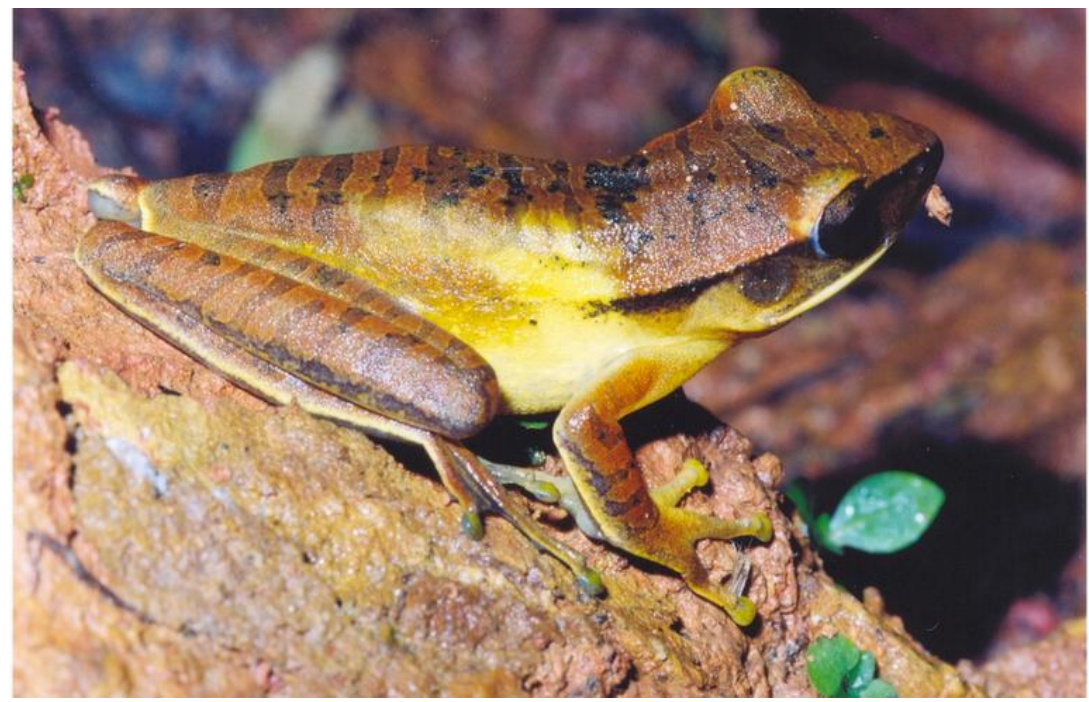

Figura 1.4: Sapo Hipsiboas albopunctatus. Figura extraída da enciclopédia livre Wikipedia.

Ala - Ile - Trp - Phe - Leu - Ala - Leu - Gly - Ala - Leu - Lys - Ans - Leu - Ile - Lys - $N H_{2}$ ) e apresenta carga igual a +4 , conforme ilustra a Figura 1.5. Este análogo também apresenta e atividade antimicrobiana e antifúngica comprovada, e um espectro de CD característico de alpha-hélice, onde a predição teórica das análises de CD estimam cercar de 50\% em hélice (Crusca et al., 2011).

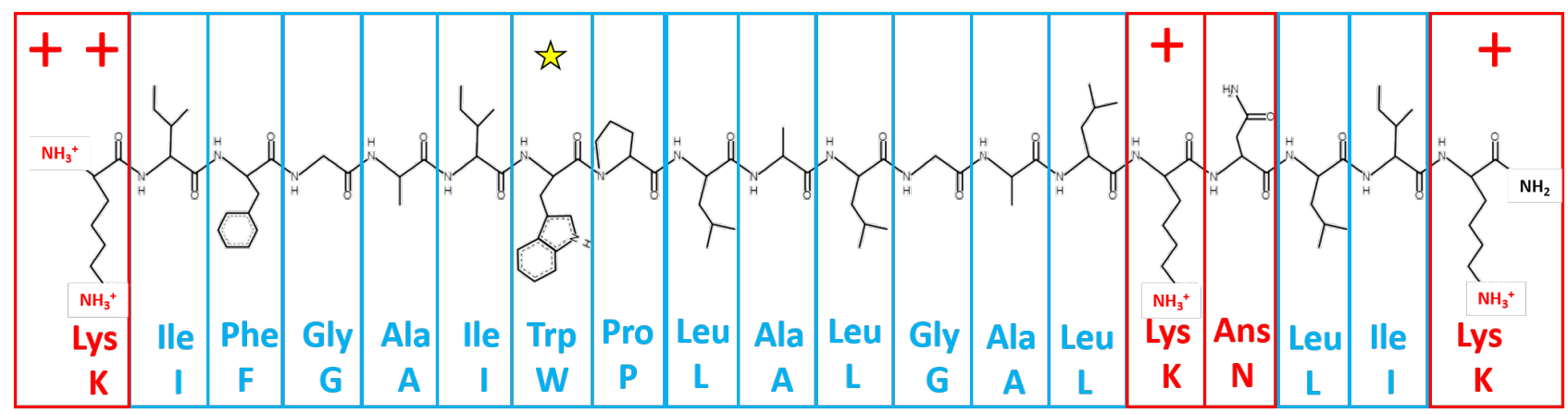

Figura 1.5: Estruturas da sequência de amino ácidos do peptídeo KHy1 desenhadas com o uso do programa PepDraw, disponível online. Os resíduos polares estão destacados em vermelho e os resíduos apolar estão destacados em azul. A distribuição de cargas positivas também é representada pelo sinal $(+)$. Os dois sinais consecutivos no primeiro painel referem-se as cargas do N-terminal e da Lys + . O C-terminal do peptídeo é amidado e não apresenta carga negativa. O Trp, fluorescente também esta destacado com uma estrela. 


\section{Caracterização estrutural da membrana lipídica}

Em nossa proposta de estudo, trabalhamos bastante em caracterizações estruturais da membrana lipídica afetada pela ação do peptídeo antimicrobiano. Deste modo, além do grande interesse do efeito antimicrobiano deste trabalho, as propriedades físico-químicas de membranas lipídicas também podem ser exploradas por esses estudos. Sobre uma visão geral de membranas lipídicas, agentes externos de qualquer natureza: peptídeos, fármacos, entre outros, que se ligam à membrana, consequentemente afetam suas propriedades estruturais. Mais interessante ainda, a deformação criada por um componente externo ligado/inserido na bicamada lipídica obedece a regras extremamente complexas. Os autores (Yolcu, Haussman, e Deserno, 2014) discutem que agentes externos incorporados a membranas, não somente criam perturbações às propriedades elásticas e de curvatura da membrana, como também, respondem pelo efeito de tê-las criado.

Então, sob um ponto de vista mais fundamental, é interessante buscar compreender como os lipídios passam a se organizar para poder acomodar/expulsar um agente externo. Por exemplo, os autores, Koller e Lohner, descrevem a membrana lipídica como um sistema de molas acopladas, onde a inserção de um componente externo causa um desequilíbrio da tensão da bicamada, podendo levar ao seu rompimento. Neste modelo, é interessante observar que, dependendo da posição espacial do agente externo na bicamada, ou dependendo de como este modifica as propriedades elásticas e de curvatura da membrana, são desencadeados efeitos diferentes na

membrana. Por exemplo, o peptídeo inserido na superfície da bicamada pode promover uma assimetria na pressão lateral dos lipídios da camada externa com relação à camada interna (Koller e Lohner, 2014). Por outro lado, um peptídeo atravessando a membrana pode, por exemplo, levar ao estreitamento ou estiramento da bicamada (Gleason et al., 2012), criando tensões diferentes nas regiões onde ocorrem ou não esse efeito.

\subsection{Objetivos}

O objetivo deste trabalho é estudar a interação do peptídeo antimicrobiano KHya1 com membranas modelo, que são sistemas miméticos de membranas celulares, formados por lipossomos de composição lipídica controlada.

Neste trabalho buscamos investigar as modificações estruturais que o peptídeo KHya1 causa em membranas compostas por lipídios neutros (mimetizando a membrana celular de eucariotos) 
e aniônicos / mistos (mimetizando a membrana celular de eucariotos), investigando também a posição e ambiente do peptídeo na membrana.

\subsection{Sumário dos capítulos seguintes}

O estudo da interação de peptídeos antimicrobianos com membranas modelo foi abordado com uma ampla variedade de técnicas experimentais. O capítulo seguinte, resume brevemente a teoria das principais técnicas experimentais utilizadas ao longo da tese.

No capítulo 3, Modelos e Controles, descrevemos o sistema modelo adotado, suas peculiaridades e as justificativas da escolha por tais modelos. Além disso, mostramos alguns experimentos controle importantes para a caracterização correta de nossos resultados experimentais.

O estudo da interação do peptídeo KHya1 com membranas modelo foi divido nos capítulos 4, 5 e 6 . No capítulo 4 discutimos diferentes efeitos que o peptídeo causa em membranas neutras e em membranas compostas por lipídios negativamente carregados. Essas diferenças foram evidenciadas com o uso de diversas técnicas experimentais: Calorimetria Diferencial de Varredura (DSC), fluorescência estática do Trp, espalhamento de luz dinâmico, experimentos de vazamento de sonda fluorescente encapsulada pelos lipossomos e microscopia óptica. Neste capítulo discutimos os possíveis modelos que podem levar aos distintos efeitos observados em membranas neutras e aniônicas, como por exemplo o peptídeo se ligando a diferentes posições na membrana dependendo de densidade de carga.

No capítulo 5 realizamos um estudo com a técnica de fluorescência: estática e resolvida no tempo. Esse estudo tem como foco principal a interação do peptídeo antimicrobiano KHya1 com membranas compostas por DPPG, pois foi observado que o peptídeo causa um efeito peculiar em membranas aniônicas, levando a coexistência de dois diferentes regimes em membranas negativamente carregadas. Neste capítulo, monitoramos a fluorescência (estática e temporal) da sonda natural Trp do peptídeo e da sonda exógena, Laurdan, incorporada na bicamada. Além disso, caracterizamos o par Trp-Laurdan como doador-aceitador no processo de transferência de energia (FRET), onde a monitoração da eficiência do FRET também pode sugerir a formação de poros em membranas compostas por lipídios aniônicos. Além disso, a possível interação entre resíduos de Trp (Homo-FRET) sugere uma distribuição não homogênea de peptídeos na membrana.

Por fim, no capítulo 6 estudamos a interação do peptídeo KHya1 com membranas modelo neutras e compostas por lipídios aniônicos com o uso da técnicas experimentais: ressonância pa- 
ramagnética eletrônica (ESR) e espalhamento de raios-X a baixo ângulo (SAXS). Os resultados confirmam que o peptídeo antimicrobiano KHya1 liga-se em diferentes posições em membranas neutras e membranas aniônicas. Embora essa hipótese tenha sido discutida ao longo dos capítulos 4 e 5, neste trazemos outras fortes evidencias experimentais de que o peptídeo pode ocupar diferentes posições na membrana dependendo da composição lipídica. Deste modo, as perturbações que o peptídeo causa à membrana estão fortemente correlacionadas a sua posição na bicamada.

O peptídeo KHay1 também foi testado em modelos de membrana com coexistência de fases (liquida ordernada, (Lo) + liquida desordenada, $(\mathrm{Ld})$ ) e resultados preliminares podem ser encontrados no apêndice D. 



\section{Capítulo 2}

\section{Técnicas experimentais}

Este capítulo apresenta a teoria das técnicas experimentais utilizadas ao longo dos trabalhos apresentados nos capítulos 4, 5 e 6. Devido à variedade de técnicas experimentais estudas, essas estão aqui apresentadas de forma sucinta e dirigida para nosso objeto de estudo, a interação do peptídeo antimicrobiano KHya1 com membranas modelo.

\subsection{Calorimetria Diferencial de Varredura em sistemas lipídicos}

\subsubsection{A transição gel-fluido}

Em sistemas lipídicos, do ponto de vista microscópico, moléculas com o mesmo tipo de agregação e/ou que apresentam propriedades físico-químicas semelhantes, em um sistema homogêneo, compõem uma fase. Podemos caracterizar diferentes estados de agregação em sistemas lipídicos, ou diferentes propriedades que são distintas nas diferentes fases lipídicas. Por exemplo, a fase gel é caracterizada por alta ordem e baixo coeficiente de difusão lateral dos lipídios, enquanto a fase fluida apresenta baixa ordem e alta difusão. Também, devido à menor ordem das cadeias lipídicas, um lipídio na fase fluida tem maior área ocupada que na fase gel.

Portanto, a transição gel - fluida pode ser caracterizada por uma transição ordem - desordem. Na fase gel, os lipídios apresentam um determinado empacotamento; onde seus grupos polares estão arranjados em uma rede triangular (Janiak e Shipley, 1979), e suas cadeias laterais assumem conformações estendidas e altamente ordenadas. Por outro lado, na fase fluida, os grupos polares já não compõem uma rede ordenada e suas cadeias hidrofóbicas apresentam configurações aleatórias, conforme ilustra a Figura 2.1. A entropia do sistema ordenado difere muito da entropia do sistema desordenado. Essa diferença brusca de entropia, em geral, 
caracteriza uma transição de fase, para sistemas lipídicos.

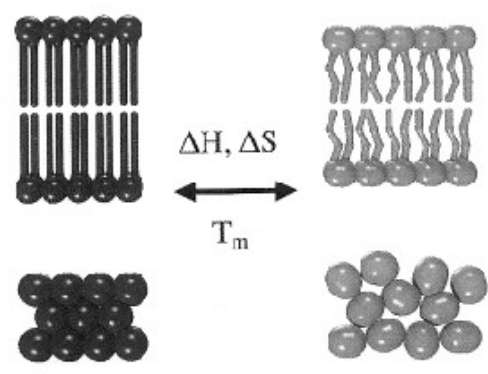

Figura 2.1: Ilustração da transição ordem-desordem de sistemas lipídicos. O sistema ordenado caracteriza a fase gel, enquanto o sistema desordenado caracteriza a fase fluida. Figura extraída de (Heimburg, 2007).

Os diferentes fosfolipídios presentes na natureza diversificam-se com relação à temperatura de transição de fase. Para lipídios saturados, o comprimento da cadeia carbônica exerce grande influência na temperatura de transição principal, $T_{m}$ (temperatura de transição da fase gel para a fase fluida). A Figura 2.2 mostra o perfil calorimétrico do i) DMPC, lipídio que apresenta cadeias saturadas compostas por 14 carbonos e $T_{m}=23^{\circ} C$, e ii) DPPC; lipídio de cadeias saturadas compostas por 16 carbonos e $T_{m}=41^{\circ} \mathrm{C}$. Portanto, quanto maior o comprimento das cadeias, maior a temperatura de transição de fase. Portanto, em uma mesma temperatura, esses lipídios usados como exemplos, podem ser encontrados em diferentes fases. Por exemplo, na temperatura $\mathrm{T}=30^{\circ} \mathrm{C}$ o DMPC se encontra na fase fluida, enquanto que o DPPC está na fase gel.

O gráfico da Figura 2.3 mostra como varia a temperatura de transição de fase, $T_{m}$, para sistemas lipídicos saturados em relação ao aumento das cadeias laterais e o grupo polar. É interessante notar que os grupos polares PC e PG apresentam temperaturas de transição semelhantes, para um mesmo comprimento de cadeia hidrocarbônica.

Em geral, sistemas lipídicos com ligações insaturadas (presença de dupla ligação na cadeia carbônica) apresentam temperatura de transição inferior a sistemas saturados. Curiosamente, o número de insaturações e o comprimento da cadeia não seguem uma regra clara, como para os sistemas saturados, o que torna esses sistemas ainda mais complexos.

Tendo visto algumas propriedades da transição de fases de lipídios saturados, podemos então, introduzir como a medida da temperatura de transição fases é realizada. 


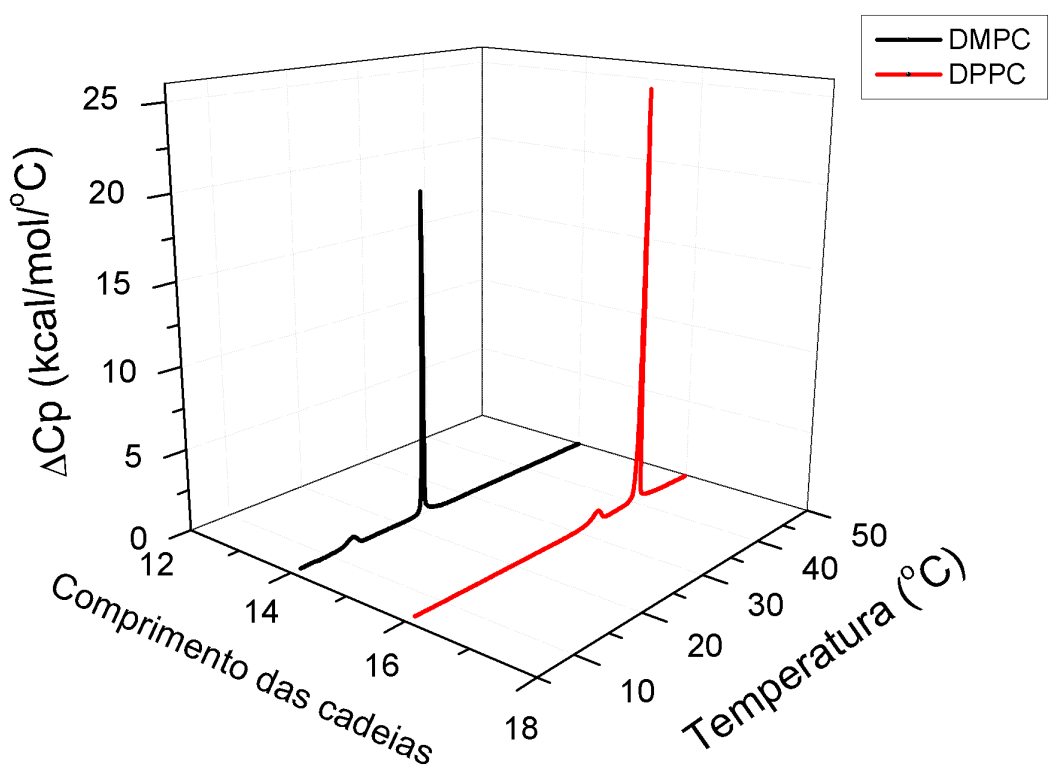

Figura 2.2: Curvas calorimétricas obtidas para o DMPC, lipídio saturado com 14 em suas cadeias (preta) e para o DPPC lipídio saturado com 16 em suas cadeias (vermelha).

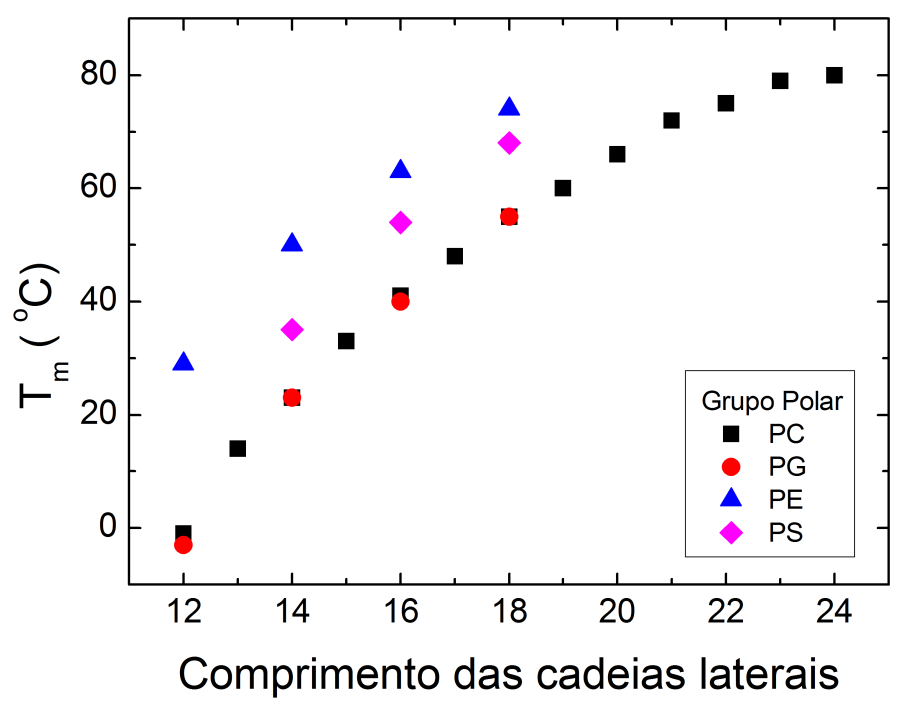

Figura 2.3: Temperaturas de transição de fase (gel-fluida) para diferentes lipídios, variando o tamanho das cadeias hidrocarbônicas e a cabeça polar. Informações extraídas do site da avanti polar lipids inc, ilustrando as transições de fase em alta força iônica.

\subsubsection{A medida do calor específico}

A capacidade térmica é a razão entre a quantidade de calor fornecida a um sistema fechado e a consequente variação na temperatura, devido a essa quantidade de calor fornecida (Salinas, 
2008). No caso em que esta medida é feita, a uma pressão constante, pode-se escrever

$$
C_{p}=\left.\lim _{\Delta T \rightarrow 0}\left(\frac{\Delta Q}{\Delta T}\right)\right|_{p, N}
$$

Do ponto de vista da interpretação física, a grandeza mais fundamental é o calor específico molar, que reflete a estrutura molecular da matéria e pode indicar variações abruptas na energia de interação molecular em certas regiões de temperatura. Ele é dado por

$$
c_{p}=\left.\lim _{\Delta T \rightarrow 0} \frac{1}{N}\left(\frac{\Delta Q}{\Delta T}\right)\right|_{p, N}=\frac{1}{N} C p
$$

sendo $N$ o número de mols do sistema.

A capacidade térmica, ou o calor específico, também podem ser escrita em termos da entropia do sistema, de acordo com a equação

$$
C_{p}=\left.\lim _{\Delta T \rightarrow 0} T\left(\frac{\Delta S}{\Delta T}\right)\right|_{p, N}=\left.T \frac{\partial S}{\partial T}\right|_{p, N} .
$$

O Calorímetro Diferencial de Varredura (DSC) mede a capacidade térmica $\left(C_{p}\right)$ ou o calor específico $\left(c_{p}\right)$, de um sistema fechado à pressão constante. O equipamento utiliza um sistema de referência para medir o saldo de calor fornecido ao sistema de interesse. Deste modo, o equipamento é composto por duas celas. Em uma das celas, chamada de cela de referência, coloca-se uma solução à qual será usada como referência para a medida, como, por exemplo, água (ou a solução tampão). Na outra cela, descriminada por amostra, coloca-se a solução cujo calor específico deseja-se conhecer. A medida é feita de modo comparativo ao sistema de referência, medindo indiretamente a quantidade de calor necessária para produzir o mesmo incremento de temperatura $\Delta T$, tanto no sistema da referência como na cela da amostra (solução tampão + lipossomos).

A potência dos aquecedores de ambas as celas (amostra e referência) é ajustada de modo que a taxa de variação de temperatura por unidade de tempo, $\left({ }^{\circ} \mathrm{C} / \mathrm{s}\right)$, denominada "scan rate" seja preservada constante ao longo da medida. Além disso, as duas celas são mantidas sempre à mesma temperatura (Heimburg, 2007).

Quando o sistema passa por uma transição de fase, é necessário fornecer mais calor à cela da amostra, para que ambas apresentem o mesmo incremento de temperatura, Figura 2.4. Deste modo, a potência na cela da amostra será maior que na cela da referência. A diferença de potência, dada em $(\mathrm{Cal} / \mathrm{s})$, entre os aquecedores das celas de referência e de amostra, é registrada ao longo da temperatura. Essa potência é, então, normalizada pelo "scan rate", para depois obter a variação do calor específico em função da temperatura $\left(\Delta C a l /{ }^{\circ} C\right)$. Nesse 
trabalho, utilizaremos a unidade $\left(\Delta \mathrm{kcal} / \mathrm{mol} /{ }^{\circ} \mathrm{C}\right)$, a qual se refere à quantidade de calor por mol de moléculas e por grau Celsius.

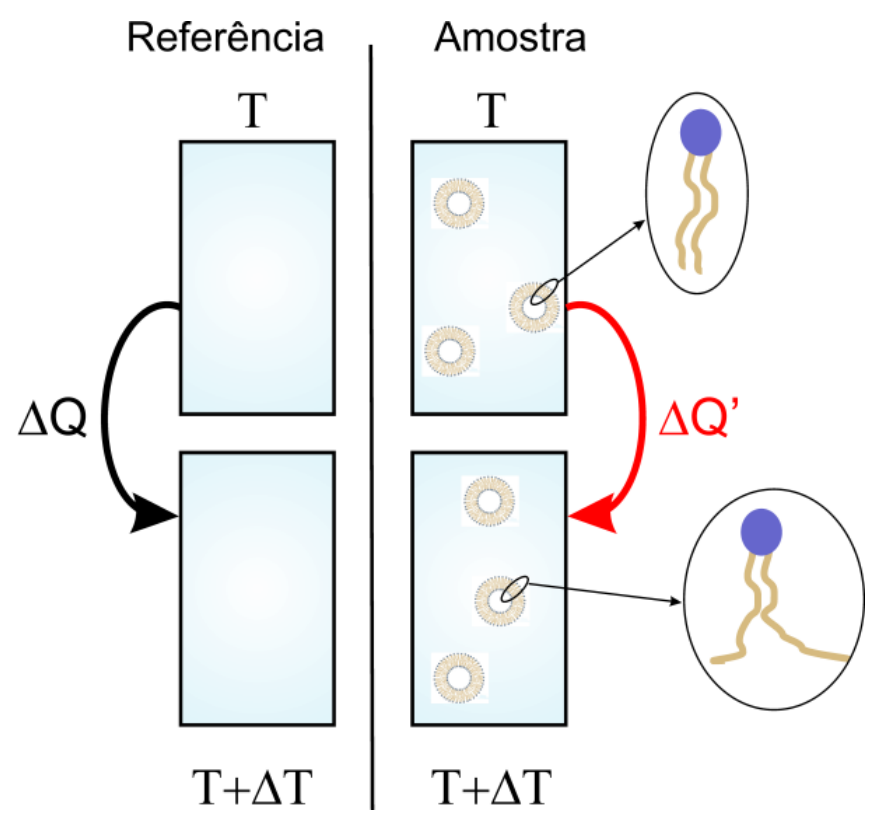

Figura 2.4: lustração da quantidade de calor absorvida pela referência e pela amostra, para levar o sistema ao mesmo incremento de temperatura $\Delta T$, na transição de fase $\Delta Q^{\prime}>>\Delta Q$, pois parte do calor absorvido é destinado a excitar novos graus de liberdade do sistema.

Os dados obtidos por DSC permitem obter também outras grandezas termodinâmicas para o sistema de interesse, como, por exemplo, a entalpia.

Utilizando a Primeira Lei da Termodinâmica e uma transformação de Legendre, podemos relacionar o calor específico com a entalpia. A energia interna de um sistema fechado varia em função do calor que recebe e do trabalho que realiza:

$$
d U=d Q_{\text {recebido pelo sistema }}+d W_{\text {realizado pelo sistema }}
$$

Escrevendo calor e trabalho em termos dos campos e densidades termodinâmicas, temos

$$
d U(S, V)=T d S-p d V
$$

Através de uma transformada de Legendre para a energia $U(S, V, N)$ em relação ao volume,

$$
H(S, p)=U+p V
$$

obtemos uma nova função, $H(S, p)$ que denominamos entalpia. Então,

$$
d H=d U+p d V+V d p
$$


Substituindo a equação (2.5) na equação (2.7), temos:

$$
d H=T d S+V d p
$$

Dado que a pressão é mantida constante, $d H=T d S$, e portanto de acordo com a equação (2.3) temos

$$
c_{p}=\left.\left(\frac{\partial H}{\partial T}\right)\right|_{p, N}
$$

onde $c_{p}=C_{p} / N$, equação $(2.2)$.

Portanto, a integral sob a curva de $c_{p}$, ou seja $C_{p}$ normalizada pelo número de mols, em função da temperatura corresponde à variação de entalpia envolvida na transição de fase. ${ }^{1}$

$$
\Delta H(T, p)=\int_{T_{0}}^{T} c_{p} d T
$$

\subsection{Absorção óptica}

No processo de interação da radiação com a matéria pode ocorrer a absorção de energia. A energia absorvida depende da frequência da radiação $\nu$,

$$
E=h \nu
$$

onde $h$ corresponde a constate de Planck. A equação (2.11), primeiramente postulada por Planck em 1900 para explicar a radiação espectral de um corpo negro, introduziu à Física conceitos importantes, pois a princípio identificou falhas na física clássica e foi uma das bases para a mecânica quântica moderna (Eisberg e Resnick, 1979). O postulado de Planck traz como implicação a quantização da energia e o caráter corpuscular da luz, que posteriormente, seria esclarecido com o efeito fotoelétrico (Eisberg e Resnick, 1979).

Para os fins dessa tese, não vamos nos ater a deduções quânticas dos níveis de energia, então podemos recorrer a um modelo simplificado para compreender a absorção óptica, sob um ponto de vista qualitativo. A Figura 2.5 mostra uma molécula diatômica, onde para um dado estado, a energia potencial depende da distância entre os núcleos. Cada estado eletrônico, curvas mostradas na Figura 2.5, apresenta um dado conjunto de níveis vibracionais e rotacionais. Logo, as transições entre os níveis de energia podem ocorrer em níveis eletrônicos, vibracionais e rotacionais da molécula.

\footnotetext{
${ }^{1} \mathrm{O}$ texto da seção 2.1 foi utilizado como material suplementar ao minicurso: (Transições de fase em membranas lipídicas - modelos, experimento e simulações (2014)), lecionado pela Profa. Dra. Vera B. Henriques, no programa de pós-graduação do IFUSP, segundo semestre de 2014.
} 


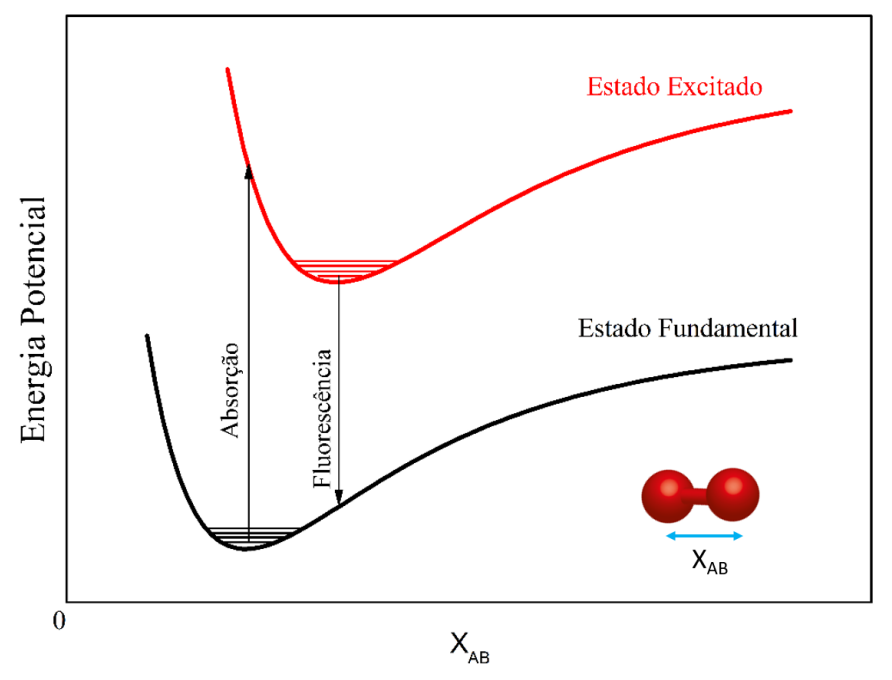

Figura 2.5: Figura ilustrativa das curvas de potencial para uma molécula diatômica ilustrando uma transição vertical, segundo o princípio de Frank-Condon. Figura baseada nos textos Takara, 2006 e Vequi-Suplyci, 2010.

A absorção de energias com frequência na faixa das micro-ondas leva a transições que envolvem essencialmente os níveis rotacionais, enquanto a faixa espectral do infravermelho promove transições entre estados vibracionais. As transições eletrônicas abrangem a absorção de energia com frequências na faixa do UV (ultravioleta) e visível; então conhecida por absorção óptica.

A transição eletrônica ocorre quando um elétron que ocupa o estado fundamental no orbital de mais alta energia (HOMO Highest Occupied Molecular Orbital) é promovido ao estado excitado no orbital desocupado de mais baixa energia (LUMO Lowest Unoccupied Molecular Orbital). Como a absorção de luz ocorre na escala de tempo de $\approx 10^{-15} s$, e vibrações moleculares são da ordem de $\left(10^{-10}-10^{-12} s\right)$, a transição eletrônica ocorre sem a variação na posição molecular, por isso na Figura 2.5 essa transição é representada por uma linha vertical. Esse princípio é conhecido com princípio de Frank-Codon [Franck, 1926; Condon, 1928].

A absorção óptica pode ser detectada pela atenuação do feixe incidente em um certo material absorvedor. Lambert observou empiricamente que a atenuação de um feixe monocromático incidente em um certo material não depende da magnitude do feixe incidente, e sim do caminho óptico percorrido pelo feixe. Além disso, Beer observou que a atenuação de um feixe incidente sobre um certo material depende da concentração de centros absorvedores. A partir das observações fenomenológicas de Lambert e Beer (Beer, 1852), pode-se deduzir uma equação para a grandeza denominada absorbância, ou a Lei de Lambert-Beer. 
A dedução da Lei de Lambert-Beer pode ser feita com o auxílio do seguinte modelo. Considere um feixe de luz que transporta energia e tem intensidade $I_{0}$, conforme a Figura 2.6.

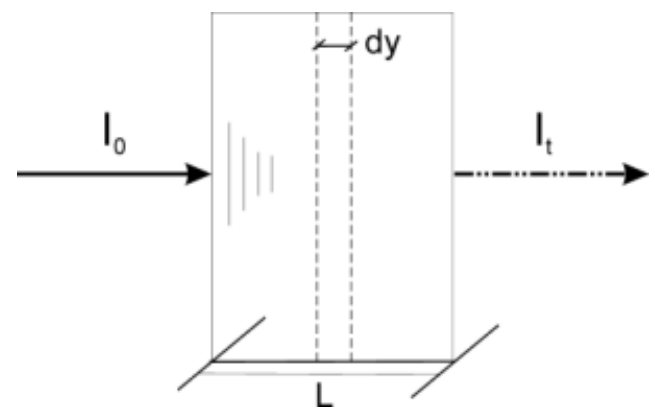

Figura 2.6: Ilustração da atenuação do feixe de luz incidente, na Absorção Óptica.

O feixe incide em uma amostra contida em um recipiente de caminho óptico, $L$. O diferencial de intensidade, $d I$, ao longo do caminho percorrido pela luz, pode ser escrito do seguinte modo,

$$
d I(y)=-\epsilon C I(y) d y
$$

onde $\epsilon$ corresponde a uma constante que se refere a características intrínsecas da molécula absorvedora, e $C$ refere-se à concentração de centros absorvedores. Portanto assume-se que a intensidade da luz absorvida é proporcional a $C$ e $d y$.

Integrando a equação (2.12), nos limites de intensidade $I_{t}$ e $I_{0}$, visto que $I_{t} \leq I_{0}$, e no caminho percorrido pela luz, temos,

$$
\ln \left(\frac{I_{0}}{I_{t}}\right)=\epsilon^{\prime} C L
$$

Define-se, portanto, a absorbância, A,

$$
A \equiv \log \left(\frac{I_{0}}{I_{t}}\right)
$$

Fazendo uma mudança na base logarítmica da equação (2.13), temos:

$$
A=\frac{\epsilon^{\prime}}{\log 10} C L
$$

logo, a lei de Lambert-Beer pode ser escrita sob a forma,

$$
A=\epsilon C L
$$

onde $\epsilon$ é conhecido como coeficiente de extinção molar, e $C$ é dado em (mol/L) (Beer, 1852). 


\subsection{Fluorescência}

Na absorção, a energia absorvida promove transições eletrônicas do estado fundamental para níveis de maior energia (estados excitados). Os elétrons, que passam a popular estados excitados, relaxam para o primeiro estado excitado (singleto ou tripleto) e, a partir deste, decaem ao estado fundamental. O decaimento ao estado fundamental pode ser ou não um processo radioativo. Quando esse decaimento ocorre com a emissão de fótons temos o fenômeno conhecido por luminescência.

Existem dois tipos de luminescência: a fluorescência e fosforescência, esse fenômeno depende da natureza do estado excitado. Tanto a fluorescência como a fosforescência são processos radioativos.

Na fluorescência o estado excitado é singleto; o elétron excitado está com spin oposto a um segundo elétron que está no estado fundamental, em geral também singleto. Consequentemente, o decaimento ao estado fundamental é rápido e as taxas de emissão da fluorescência são da ordem de $10^{9} \mathrm{~s}^{-1}$. O tempo que o elétron permanece no estado excitado é caracterizado com tempo de vida do estado excitado, e na fluorescência, esse tempo é da ordem de $10^{-9} s$.

A Fosforescência é a emissão de luz do estado excitado tripleto, no qual o elétron excitado tem a mesma orientação de spin que o elétron do estado fundamental. As transições para o estado fundamental são proibidas em primeira ordem, e as taxas de emissão são muito lentas (em torno de $10^{3}$ até $1 \mathrm{~s}^{-1}$ ), então o tempo de vida da fosforescência é da ordem de milissegundos a segundos.

O diagrama de Perrin-Jablonski, Figura 2.7, é uma maneira de visualizar os processos radioativos e não radioativos que podem ocorrer desde a absorção ao decaimento para o estado fundamental. Os estados eletrônicos singletos são chamados de $S_{0}$ (estado fundamental), $S_{1}$, $S_{2}$ e assim por diante; os estados tripletos são chamados de $T_{1}, T_{2}$, e os níveis vibracionais, associados a cada estado eletrônico, são representados pelas linhas mais finas. As relaxações dos níveis vibracionais são processos não radioativos. O decaimento de estados excitados de ordens maiores para o primeiro estado excitado é conhecido como conversão interna (IC) e, em geral, também é um processo não radioativo. O cruzamento entre sistemas (ISC) ocorre quando o elétron passa de um estado singleto para um estado excitado tripleto, de forma não radioativa (Valeur e Berberan-Santos, 2012).

É importante observar que o decaimento do primeiro estado excitado singleto ou tripleto pode também ocorrer de forma não radioativa, porém quando há emissão de fótons, esses 
processos são caracterizados como fluorescência e fosforescência, respectivamente.

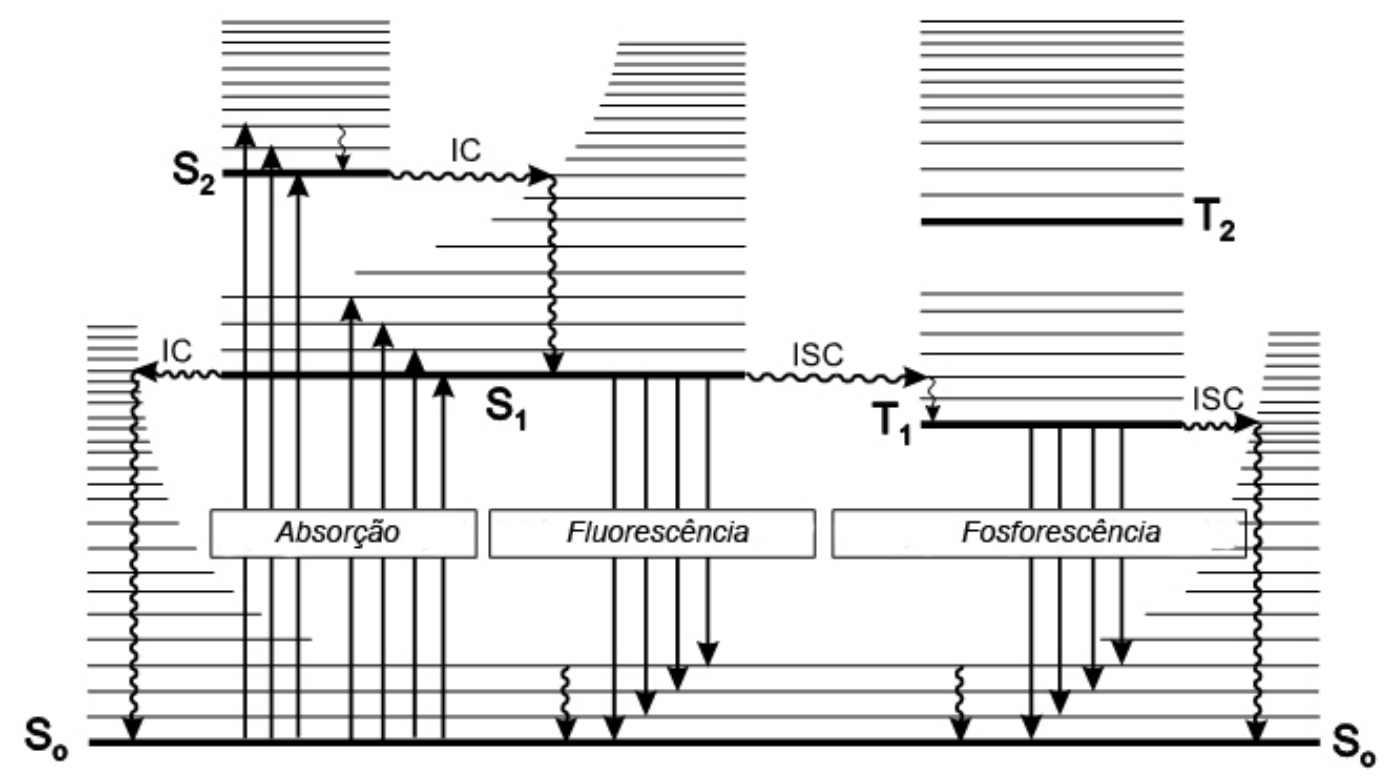

Figura 2.7: Diagrama de Perrin-Jablonski, esquematizando as transições entre o estado fundamental e o estado excitado, onde IC (Internal Conversion) significa conversão interna e ISC (InterSystem Crossing) significa cruzamento entre sistemas. Figura baseada no texto Vequi-Suplicy, 2010 (original de Valeur, 2001) .

\subsubsection{O rendimento quântico}

O rendimento quântico corresponde à razão entre a taxa de emissão fluorescente e as taxas radioativas e não radioativas, conforme a equação

$$
Q=\frac{\Gamma}{\left(\Gamma+k_{n r}\right)}
$$

onde $\Gamma$ corresponde à taxa de emissão fluorescente e $k_{n r}$ à taxa de emissão não radioativa.

Moléculas com alto rendimento quântico como, por exemplo, a Rodamina, apresentam altas taxas de emissão fluorescente. Neste exemplo, a Rodamina apresenta $Q \approx 0.94$ e praticamente toda sua energia absorvida é liberada na forma radioativa (Karstens e Kobs, 1980; Lakowicz, 2006).

O rendimento quântico de um fluoróforo pode ser calculado de forma comparativa ao rendimento de alguma molécula conhecida, com o uso da equação

$$
Q=Q_{r} \frac{I}{I_{r}} \cdot \frac{A b s_{r}}{A b s} \cdot \frac{n^{2}}{n_{r}^{2}},
$$


onde $Q_{r}$ equivale ao rendimento quântico de uma substância padrão (referência), assim como $I_{r}$ e $A b s_{r}$ referem-se a área sob os espectros de emissão e absorção da referência. Para a molécula de estudo, a qual se investiga o rendimento quântico, $I$ e Abs correspondem às áreas dos espectros de emissão e absorção, respectivamente. O fator $n^{2} / n_{r}^{2}$ vem de uma evidência experimental que uma fonte de luz em um meio de índice de refração $n_{r}$ coletada por um detector em um meio de índice de refração $n_{0}$, deve ser corrigida pelo fator $n^{2} / n_{0}^{2}$ (Crosby e Demas, 1971).

\subsubsection{Deslocamento de Stokes}

Em solução, Stokes observou um fenômeno que ficou conhecido na literatura por deslocamento de Stokes (Stokes, 1852). Considerando a absorção de um único fóton, o espectro de emissão fluorescente está sempre em comprimentos de onda maiores do que a absorção eletrônica. Esse deslocamento ocorre porque a molécula sempre perde energia no estado excitado devido às relaxações vibracionais. O efeito do solvente pode intensificar/ modificar o deslocamento de Stokes.

\subsubsection{Efeito do solvente}

Quando o tempo de relaxação da sonda com o meio é menor que o tempo de vida do estado excitado, as moléculas do meio podem se reorganizar atingindo uma nova posição de equilíbrio, e depois desse rearranjo molecular pode ocorrer a emissão fluorescente. Deste modo, dependendo do meio, no qual a sonda se encontra, essa relaxação do meio com a sonda pode dar-se de diferentes maneiras. Este modelo é conhecido modelo de Lippert, como ilustra a Figura 2.8.

Observe, no esquema, que a molécula no estado fundamental apresenta momento de dipolo dado por $\mu G$. Quando esta molécula absorve um fóton e muda para o estado excitado, seu momento de dipolo passa a ser $\mu E$. Há, então, um rearranjo eletrônico, muito rápido da ordem

de $10^{-15} \mathrm{~s}$, assim como um rearranjo molecular do solvente com o fluoróforo no estado excitado, da ordem de $10^{-9} s$. Esse rearranjo tem um custo energético não radioativo, por isso a relaxação com o solvente diminui a energia do fóton emitido. Após a emissão fluorescente, o momento de dipolo da molécula volta à $\mu G$ e há um novo rearranjo molecular do solvente até a molécula voltar completamente ao estado fundamental.

O modelo de Lippert é muito útil para entender deslocamentos nos espectros de emissão fluorescente. Pois quanto maior a relaxação da sonda com o meio, menor a energia do fóton emitido e consequentemente o espectro de emissão será observado em altos comprimentos de 


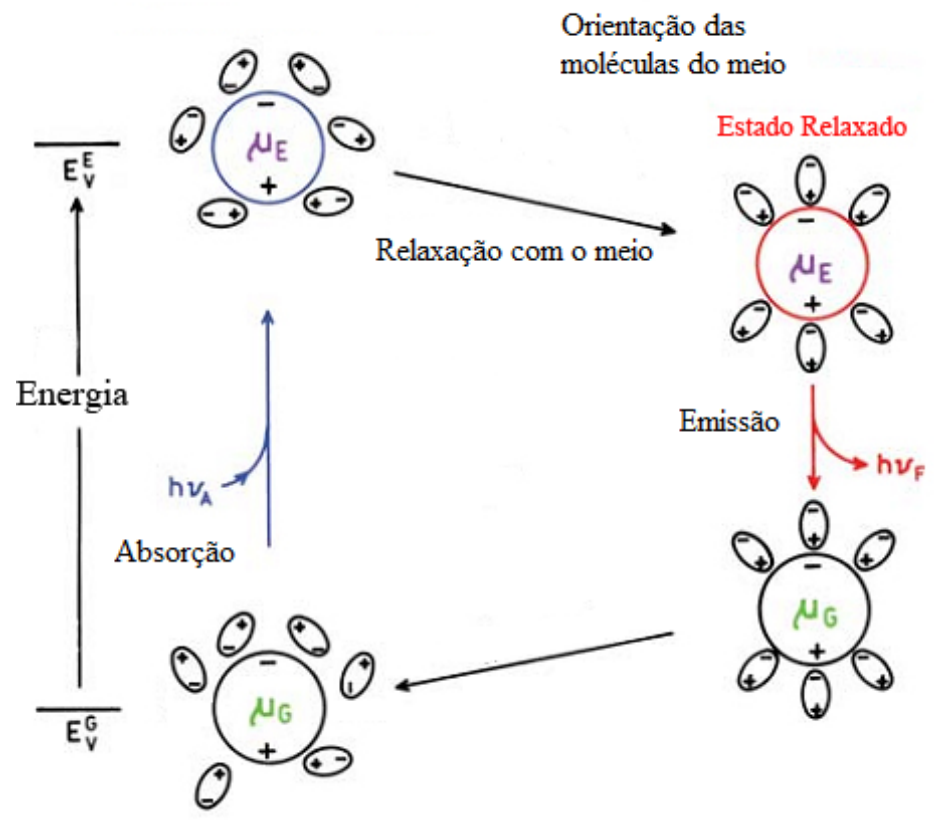

Figura 2.8: Esquema ilustrativo do modelo de Lippert, onde $\mu \mathrm{G}$ corresponde ao momento de dipolo no estado fundamental e $\mu \mathrm{E}$ no estado excitado. Figura extraída da tese de doutorado de Vequi-Suplicy, 2010 (original de Lakowicz, 2006) (modificada).

onda. Por outro lado, menores relaxações da sonda com o meio, levam a diferenças de energias entre o estado excitado e o estado fundamental maiores, ou seja, os fótons emitidos têm maiores energias, então o espectro de emissão será observado em baixos comprimentos de onda.

\subsubsection{Anisotropia de fluorescência}

O grau de polarização é descrito em termos da grandeza conhecida por anisotropia, $r$. As medidas de anisotropia revelam uma média do movimento angular da sonda durante o tempo de vida do estado excitado. A difusão rotacional das sondas também depende da viscosidade do solvente e de propriedades intrínsecas da molécula como tamanho e forma. Para sondas pequenas em solução de baixa viscosidade, a taxa de difusão rotacional é mais rápida que a taxa de emissão fluorescente, de modo que $r \rightarrow 0$.

A medida experimental da anisotropia estática é ilustrada na Figura 2.9. A amostra é excitada por um feixe de luz verticalmente polarizado (paralelo ao eixo z). Então, são registrados, a intensidade de emissão fluorescente com orientação paralela ao feixe incidente, $I_{/ / /}$, e a intensidade de emissão com orientação perpendicular ao feixe incidente, $I_{\perp}$. As medidas são realizadas com o um de um polarizador acoplado antes da detecção. Por fim, a anisotropia é 
calculada com o uso da equação 2.19,

$$
r=\frac{I_{/ /}-G I_{\perp}}{I_{/ /}+2 G I_{\perp}}
$$

onde $G$, é conhecido como fator $G$. Esse parâmetro leva em conta o rendimento quântico da sonda fluorescente e fatores instrumentais. O valor calculado na equação 2.19 é adimensional e independente da intensidade total da amostra

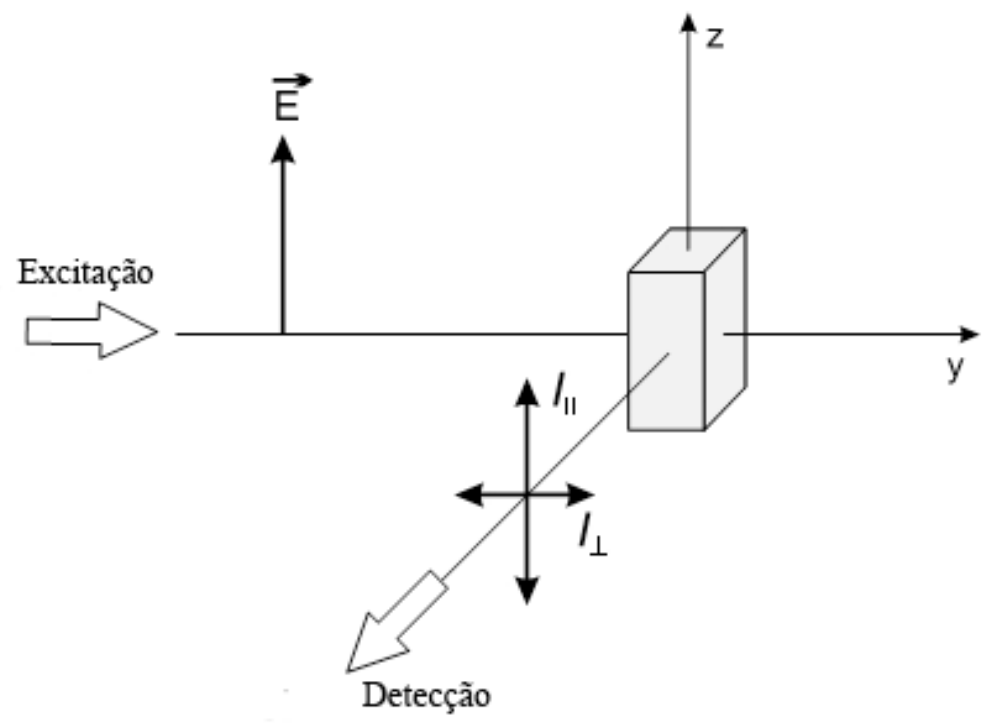

Figura 2.9: Exemplo da configuração operacional para medidas de anisotropia de fluorescência. Figura extraída de (Valeur, 2001) (adaptada).

\subsection{Fluorescência com Resolução Temporal}

A fluorescência com resolução temporal mede um valor médio do tempo que a molécula permanece no estado excitado. Medidas do tempo de vida são sensíveis à taxa de reação e de transferência de energia, como por exemplo, as que ocorrem no estado excitado.

Como o tempo de vida do estado excitado ocorre na faixa do nano segundo, os equipamentos que realizam esta medida são extremamente delicados e precisos. Neste trabalho, utilizamos o método por pulsos. A amostra é excitada por um breve pulso de luz, e, são medidos os intervalos de tempo decorridos entre absorção e a emissão dos fótons. Em geral os tempos de vida do estado excitado de moléculas em solução são da ordem de nano segundos, $10^{-9} s$, e por sua vez, estes estão relacionados ao inverso da soma de todas as taxas, radioativas e não 
radioativas,

$$
\tau=\frac{1}{\Gamma+k_{n r}} .
$$

Após a absorção, que ocorre em escala de tempos de $10^{-15} \mathrm{~s}$, os elétrons começam a depopular o estado excitado com ou sem a emissão de fótons ao retomarem ao estado fundamental. Esse decaimento ocorre com uma certa taxa, a qual está associada a uma probabilidade de transição, e o tempo de vida corresponde a um intervalo de tempo médio para os elétrons que ocupavam o estado excitado voltarem ao estado fundamental. A depopulação do estado excitado não ocorre de modo instantâneo no tempo de vida igual a $\tau$, mas, em geral, obedece a uma lei exponencial. Para decaimentos monoexponenciais a intensidade de fluorescência pode ser escrita por

$$
I(t)=I_{0} \exp (-t / \tau)
$$

onde, $37 \%$ (1/e) dos elétrons do estado excitado decaem em tempos inferiores a $\tau$. Portanto para medirmos o tempo de vida do estado excitado, obtemos uma espécie de histograma, onde contamos o número de fótons que atingiu o detector nos diferentes intervalos de tempos após a absorção, conforme ilustra a Figura 2.10.

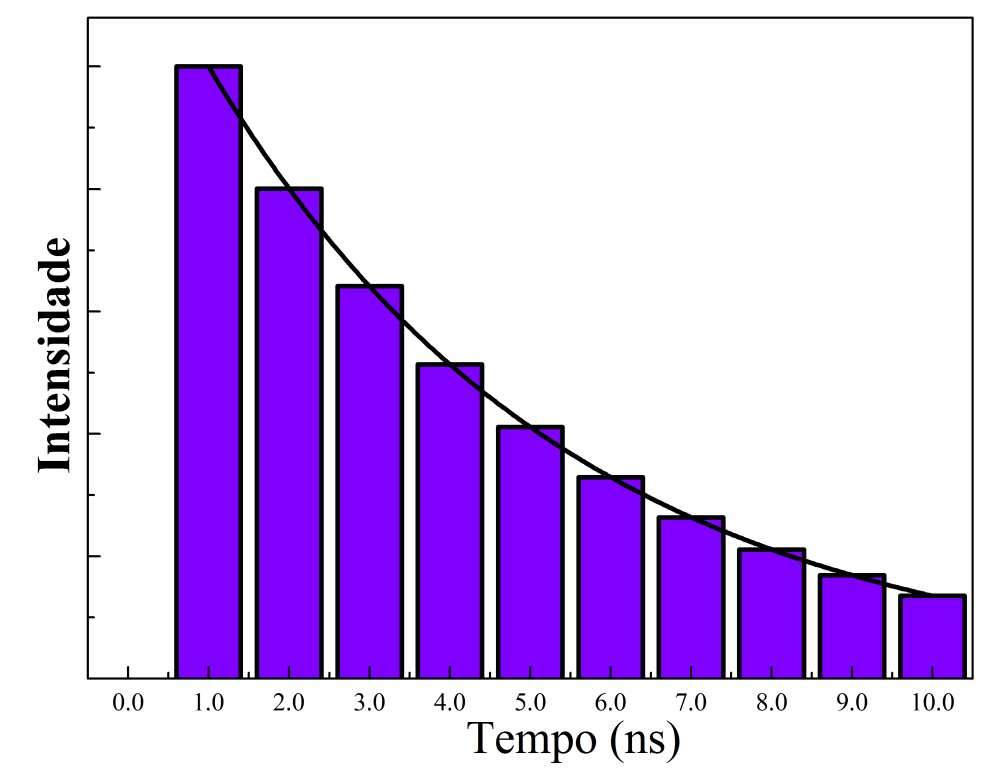

Figura 2.10: Exemplo esquemático da contagem de fótons.

Entretanto, para que essa contagem seja realizada de forma correta e eficiente foi utilizado o método de contagem de fótons únicos. Isto é, para um dado evento fluorescente, somente um fóton é detectado, e, mede-se o intervalo de tempo entre um pulso de excitação na amostra e a 
detecção do fóton emitido por esta. A Figura 2.11 mostra um exemplo da medida experimental.

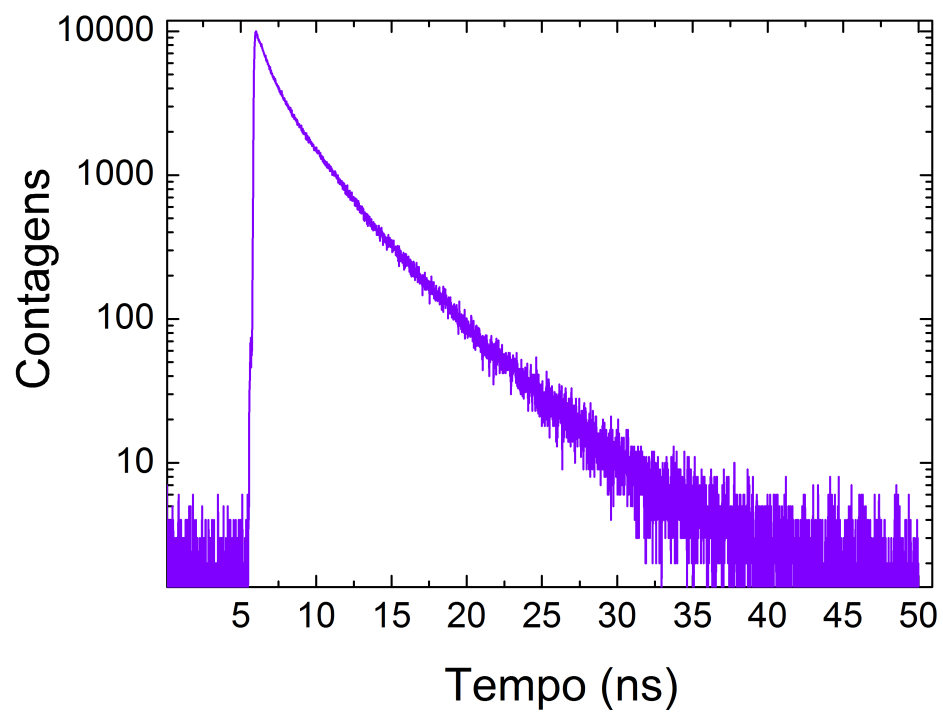

Figura 2.11: Exemplo do decaimento fluorescente obtido para o Trp, pepteideo HKya1, em $\mathrm{T}=25^{\circ} \mathrm{C}$ $\lambda_{e x}=280 \mathrm{~nm}$ e $\lambda_{e m}=325 \mathrm{~nm}$.

\subsection{Deconvolução da lâmpada}

Contudo o sinal coletado na detecção, também conhecido por IFR (instrument response function), também contém o pulso da excitação. O pulso da lâmpada responsável pela excitação não é infinitamente estreito e sua largura é comparável aos tempos de vida do estado excitado.

Uma vez que o pulso de excitação tem largura considerável, as moléculas fluorescentes não são excitadas no mesmo instante de tempo. Logo, a interferência da lâmpada deve ser descontada.

Para o tratamento da intensidade coletada no detector, consideramos que a lâmpada pode ser aproximada a um conjunto de pulso estreitos de largura $\Delta t$ onde $(\Delta t<<\tau)$ e onde a soma sobre todos os intervalos corresponde à largura da lâmpada. Cada um desses pulsos será emitido em tempo $t_{i}$, gerando uma resposta, $R_{i}(t)$, em tempo $t$.

$$
R_{i}(t)=L\left(t_{i}\right) \Delta F(t-t i), \quad\left(t>t_{i}\right)
$$

Logo, a resposta total corresponde à soma de todos os pulsos

$$
R(t)=\sum_{t=0}^{t=t_{i}} L(t-\gamma) F(\gamma) \Delta \gamma
$$


onde $\gamma=t-t_{i}$. A equação (2.23) pode ser escrita como uma integral assumindo $(\Delta t \rightarrow 0)$ :

$$
R(t)=\int_{0}^{t} L(t-\gamma) F(\gamma) \Delta \gamma
$$

Deste modo, o sinal da lâmpada deve ser deconvoluido do sinal coletado no detector, obtendo-se, portanto o decaimento fluorescente da molécula de interesse, $F(\gamma)$.

\subsection{Análise do decaimento fluorescente}

O decaimento fluorescente é então tratado como um decaimento mono ou multiexponencial, de acordo com a equação (2.25),

$$
F(t)=\sum_{i} a_{i} \exp \left(-t / \tau_{i}\right)
$$

onde $\tau_{i}$ é o tempo de vida da componente $i$ do decaimento e $a_{i}$ o correspondente fator préexponencial.

Na natureza, muitas moléculas fluorescentes apresentam decaimentos multiexponenciais, como é o caso do Trp em peptídeos e proteínas, por exemplo, que apresenta três diferentes tempos de vida. Para decaimentos multiexponenciais, também podemos analizar o tempo de vida médio, dado por:

$$
\langle\tau\rangle=\sum_{i} \alpha_{i} \cdot \tau_{i}
$$

onde $\alpha_{i}$ corresponde a contribuição de cada tempo de vida $\tau_{i}$.

\subsection{Transferência de Energia (FRET)}

Na Transferência de Energia, também conhecida por FRET , abreviação do inglês ("Förster Resonance Energy Transfer"), temos uma molécula fluorescente chamada de doador (D), que absorve a radiação e transfere a energia absorvida, sem emissão de fótons, para outra molécula chamada de aceitador (A). O aceitador pode ou não ser fluorescente, pois a transferência de energia pode ser caracterizada pela mudança no tempo de vida do doador.

A transferência de energia ocorre devido à interação entre momentos de dipolos transientes dos grupos: aceitador e doador. Em geral, quanto há transferência de energia, ocorre uma sobreposição do espectro de fluorescência do doador e a absorção do aceitador, conforme ilustra a Figura 2.12. 


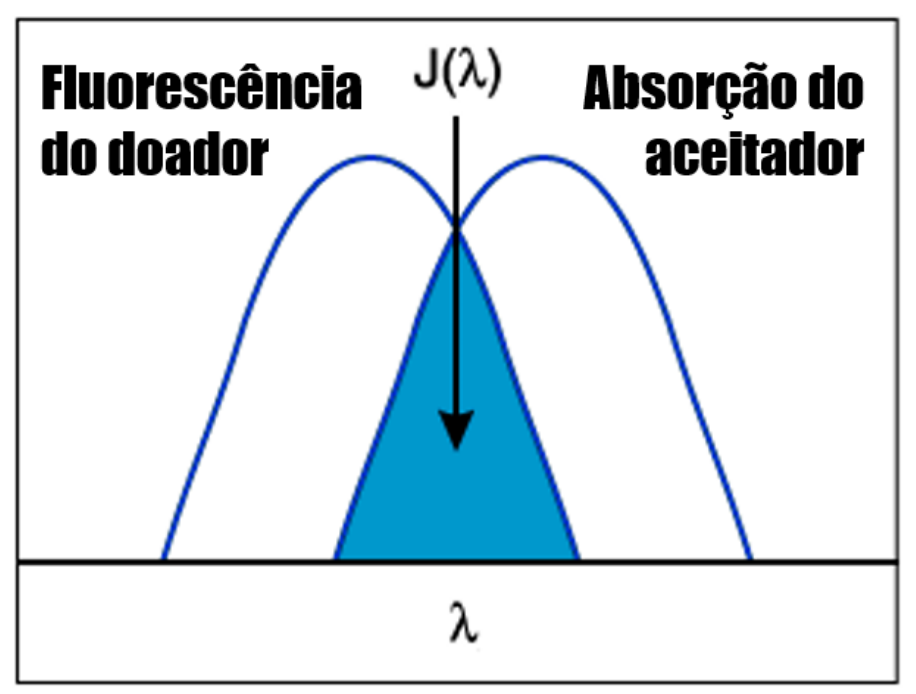

Figura 2.12: Ilustração da região de sobreposição entre o espectro de emissão do doador e o espectro de absorção do aceitador.

A sobreposição entre as bandas espectrais do par doador/aceitador, $J$, representa a intensidade da ressonância entre o estado excitado do doador e o estado fundamental do aceitador. Essa grandeza pode ser descrita pela equação (2.27)

$$
J=\int_{0}^{\infty} F_{d}(\lambda) \epsilon_{a}(\lambda) \lambda^{4} d \lambda
$$

onde $F_{d}(\lambda)$ é o espectro de emissão do doador normalizado, e $\epsilon_{a}(\lambda)$ é o coeficiente de extinção molar do aceitador, ou seja, o espectro de absorção normalizado pela concentração do aceitador e pelo caminho óptico.

A taxa de transferência de energia para uma distância $r$, fixa, é dada por

$$
k_{T}=\frac{1}{\tau_{d} r^{6}} \frac{9000(\ln 10) \kappa^{2} \Phi_{d}}{128 \pi^{5} n^{4} N_{A}} J(\lambda)
$$

onde $\Phi_{d}$ e $\tau_{d}$ são, respectivamente, o rendimento quântico e o tempo de vida do doador na ausência do aceitador; n é o índice de refração do meio e $N_{A}$ é o número de Avogadro. Essa taxa é dada em $s^{-1}$. A dependência das orientações dos momentos de dipolo do doador e aceitador é dada por $\kappa^{2}$, grandeza conhecida por fator orientacional

$$
\kappa^{2}=\left(\cos \theta_{d a}-3 \cos \theta_{d} \cos \theta_{a}\right)^{2}
$$

onde $\theta_{d a}$ é o ângulo entre os dipolos de emissão do doador e de absorção do aceitador; $\theta_{d}$ e $\theta_{a}$ são os ângulos entre o vetor $\vec{r}$ e os respectivos momentos de dipolo, conforme ilustrado na Figura 2.13. O modulo do vetor $r$, corresponde à distância entre as moléculas. 


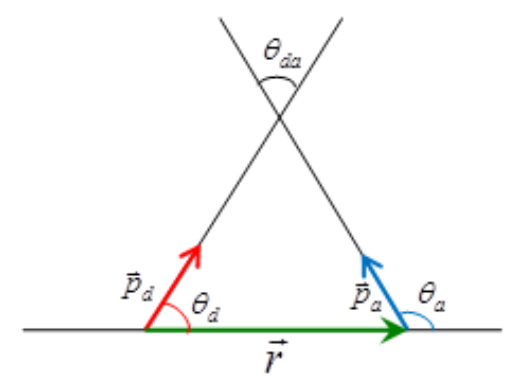

Figura 2.13: Orientação dos momentos de dipolo do doador e do aceitador. Figura extraída de Lakowicz, 2006.

Assumindo que os momentos de dipolo do doador e aceitador podem girar livremente, temos que o valor médio de $\kappa^{2}$ equivale a $2 / 3$. Essa dedução pode ser encontrada em (Lakowicz, 2006)

A distância de Förster é definida por

$$
R_{0}^{6}=8.810^{-25}\left(\kappa^{2} n^{-4} \Phi_{d} J\right)
$$

A taxa de transferência de energia, equação 2.28, pode ser escrita em função da distância de Förster, segundo a forma

$$
k_{T}=\frac{1}{\tau_{d}}\left(\frac{R_{0}}{r}\right)^{6}
$$

Deste modo, quando a distância entre os momentos de dipolos do doador e aceitador corresponde à distância de Förster, temos que a taxa de decaimento por transferência de energia é igual à taxa de decaimento do doador.

Da equação 2.31, podemos observar que para $r>R_{0}$, a taxa para transferência de energia será muito menor que a taxa de decaimento do doador e, portanto, a maioria dos doadores decairá por fluorescência ou outros processos não radioativos, enquanto que para $r<<R_{0}$ a maioria dos doadores decairá por transferência de energia.

A eficiência da transferência de energia é definida por

$$
E=\frac{k_{T}}{\Gamma+k_{T}+k_{n r}}
$$

onde $k_{T}, \Gamma, k_{n} r$ são as taxas de decaimento por FRET, fluorescência e processos não radioativos, respectivamente.

A razão dos rendimentos quânticos do doador na presença do aceitador, e do doador na ausência de aceitador é dada por

$$
\frac{\phi_{d a}}{\phi_{d}}=\frac{\Gamma}{\Gamma+k_{T}+k_{n r}}
$$


Deste modo, podemos reescrever a eficiência da transferência de energia como

$$
E=1-\frac{\phi_{d a}}{\phi_{d}}
$$

ou ainda com o uso da equação (2.31), temos

$$
E=\frac{R_{0}^{6}}{R_{0}^{6}+r^{6}} .
$$

A equação 2.34 também pode ser escrita em termos da intensidade integrada (áreas sob o espectro de emissão) de acordo com a equação 2.36:

$$
E=1-\frac{I_{d a}}{I_{d}}
$$

onde $I_{d a}$ e $I_{d}$ são as intensidades integradas do doador na presença e ausência do aceitador.

Da equação (2.35) podemos observar que, quando a distância entre doador e aceitador equivale a $R_{0}, r=R_{0}$, temos a eficiência do FRET corresponde a 50\%. A Figura 2.14 ilustra como a eficiência do FRET varia com a distância entre o par doador e aceitador. Podemos observar que para $r=2 R_{0}$ a eficiência do FRET é praticamente nula.

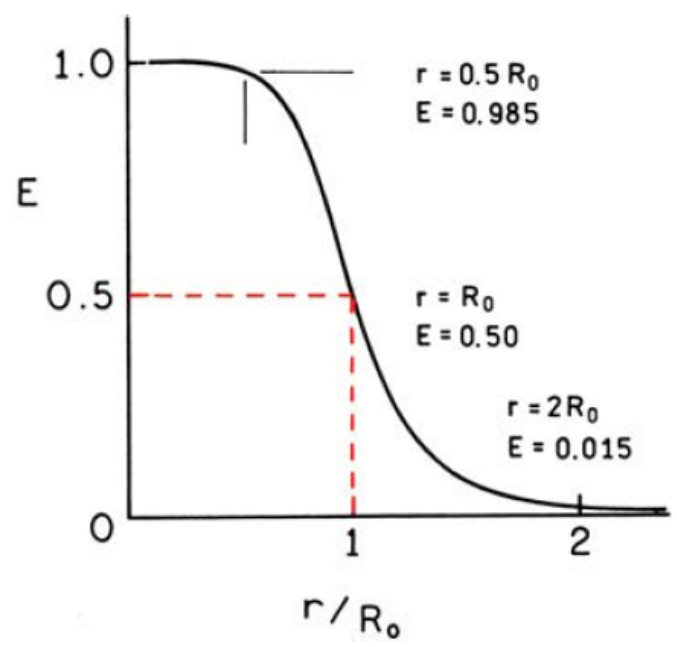

Figura 2.14: Dependência da eficiência do FRET em função da distância entre o par doador-aceitador. Figura extraída de Lakowicz, 2006.

\subsection{Distribuição de Distâncias}

Visto que a transferência de energia depende da distância do doador ao aceitador, $r$, e em solução, essa distância entre as moléculas não é fixa, tem-se, portanto, uma distribuição de distâncias entre doadores e aceitadores. 
Por simplicidade, considere que a intensidade de fluorescência do doador na presença do aceitador seja mono exponencial de acordo com a equação (2.37)

$$
I(t)=I_{0} \exp \left(-t / \tau_{d a}\right)
$$

onde a taxa do doador na presença do aceitador será dada pela taxa de transferência de energia e pela taxa de fluorescência doador isolado,

$$
\frac{1}{\tau_{d a}}=k_{T}+\frac{1}{\tau_{d}}
$$

Escrevendo a taxa de transferência de energia em termos de $R_{0}$, com o uso da equação (2.31), temos:

$$
\frac{1}{\tau_{d a}}=k_{T}+\frac{R_{0}^{6}}{\tau_{d} r^{6}}
$$

e se tomarmos $r$ constante, temos que a taxa de transferência de energia continua sendo uma constante.

Deste modo, a intensidade da $I(t)$ do decaimento monoexponencial que sugerimos a princípio, equação (2.37), e considerando $r$ constante, será dada por

$$
I(t)=I_{0} \exp \left[\left(-\frac{1}{\tau_{d}}-\frac{R_{0}^{6}}{\tau_{d} r^{6}}\right) t\right]
$$

Note que o decaimento do doador na presença do aceitador continua sendo monoexponencial, uma vez que o decaimento do doador isolado é monoexponencial.

Entretanto, os pares de doador e aceitador distribuem-se aleatoriamente e a distância entre eles pode ser descrita por $r_{i}$, onde o índice $i$ discrimina um dado par. Deste modo, há uma distribuição de distâncias que contabiliza as possíveis distâncias entre as moléculas, e a equação (2.40) pode ser reescrita, agora levando em conta cada distância assumida entre pares, conforme a equação (2.41)

$$
I(t)=I_{0} \sum_{i} f\left(r_{i}\right) \exp \left[\left(-\frac{1}{\tau_{d}}-\frac{R_{0}^{6}}{\tau_{d} r^{6}}\right) t\right]
$$

onde $f\left(r_{i}\right)$ corresponde à frequência com que cada distância aparece.

Por fim, podemos generalizar a equação (2.41) para uma distribuição contínua de distâncias e decaimentos multiexponenciais, logo

$$
I(t)=\sum_{i} a_{i} I_{0} \int_{0}^{\infty} f\left(r_{i}\right) \exp \left[\left(-\frac{1}{\tau_{d i}}-\frac{R_{0}^{6}}{\tau_{d i} r_{i}^{6}}\right) t\right]
$$

onde $a_{i}$ é a amplitude do decaimento com o tempo de vida $\tau_{d_{i}}$. 


\subsubsection{CONTIN - Programa de Ajuste}

O programa CONTIN, utilizado no apêndice A e desenvolvido por Provencher, 1953, calcula as distribuições de distâncias $f\left(r_{i}\right)$ fazendo uso da equação (2.43)

$$
I\left(t_{k}\right)=\int_{a}^{b} F\left(r, t_{k}\right) f(r) d r+\sum_{j=1}^{N_{L}} L_{k j} \beta_{i}, \quad k=1, \ldots, N_{y} .
$$

onde $I\left(t_{k}\right)$ corresponde à intensidade obtida experimentalmente. A função $F\left(r, t_{k}\right)$ é dada por

$$
F(r, t)=\sum_{i} \alpha_{i} \int_{0}^{\infty} f\left(r_{i}\right) L\left(t-t^{\prime}\right) \exp \left[\left(-\frac{1}{\tau_{d i}}-\frac{R_{0}^{6}}{\tau_{d i} r_{i}^{6}}\right) t^{\prime}\right] d t^{\prime}
$$

e $a_{i}$ e $\tau_{d_{i}}$ são os fatores pré-exponenciais e os tempos de vida do doador na ausência do aceitador, respectivamente. $L\left(t-t^{\prime}\right)$ é o perfil da lâmpada, inserido no programa, para fazer a deconvolução da lâmpada conforme descrito na seção 2.5 Essa modificação foi e previamente publicada em (Souza, Hirata, Juliano, e Ito, 2000).

Esse programa calcula a transformada de Laplace inversa dos decaimentos para obter $f\left(r_{i}\right)$, conforme discutido no capítulo 5.

Adicionalmente, o segundo termo do lado direito da equação (2.43) pode ser tomado como uma constante, fazendo $N_{L}=1$ e $L_{k 1}=1$. Neste caso, esse termo corresponde a um fundo (background) do decaimento. Além disso, esse termo também pode ser considerado como um decaimento, por exemplo, como uma impureza, artefato devido a algum ruído proveniente de espalhamento, ou a um tempo de vida que não participa do FRET. Deste modo, o termo $L_{k j}$ é descrito por:

$$
L_{k j}=\exp \left(-t_{k} / \tau_{j}\right)
$$

onde $\tau_{j}$ é o tempo de vida correspondente a tal decaimento.

\subsection{Espalhamento de luz dinâmico}

A técnica de Espalhamento de Luz Dinâmico (DLS - Dynamic Light Scattering), ou também conhecida como Espectroscopia de Correlação de Fótons, PCS ( Photon Correlation Spectroscopy), tem sido amplamente utilizada em vários ramos da ciência e indústria. Polímeros, proteínas, dispersões lipídicas, carregadores de drogas ("drug deliveres"), são exemplos de objetos de estudo, os quais tem sido vastamente explorados pela ciência e indústria. Muitas vezes, na caracterização desses sistemas, é imprescindível conhecer o tamanho do objeto em estudo. 
A ordem de grandeza dos objetos citados corresponde a $10^{-9} \mathrm{~m}(\mathrm{~nm})$. Entretanto, o limite de resolução óptica do microscópio comum é da ordem de $10^{-6} \mathrm{~m}(\mu \mathrm{m})$. Então, podemos questionar, "Como medir tamanhos abaixo da resolução óptica?"

A técnica de espalhamento de luz dinâmico é uma técnica que permite inferir o tamanho médio de partículas em solução em escala nanoscópica. De um modo geral, partículas grandes se difundem lentamente enquanto as pequenas podem se difundir rapidamente, e medindo o coeficiente de difusão das partículas podemos inferir suas dimensões.

\subsubsection{Função de auto-correlação}

O Espalhamento de luz dinâmico mede a intensidade da luz espalhada ao longo tempo e calcula a função de correlação de intensidades.

A intensidade da luz espalhada é função da variável estocástica, $r$, grandeza a qual refere-se à distância dada entre a posição do centro espalhador no instante de tempo $t$ e a posição em um dado instante de tempo seguinte $t+\tau$. O valor esperado da intensidade, considerando um ensemble de configurações que depende da variável estocástica $r$ é representado na forma $\langle I\rangle$. Para sistemas ergódicos, onde a média no ensemble de configurações equivale a média temporal, denotada por $I$, então, podemos escrever a equação

$$
\langle I\rangle=\bar{I} \equiv \frac{1}{T} \int_{0}^{2 T} I(t) d t
$$

onde a média temporal deve ser realizada em um período muito maior que o período de flutuação das intensidades medidas, assumindo $T \rightarrow \infty$, (Berne, 2000).

Deste modo, a função de correlação das intensidades será dada por

$$
G^{(2)}(\tau)=\lim _{2 T \rightarrow \infty} \frac{1}{2 T} \int_{0}^{2 T} I(t) I(t+\tau) d t .
$$

Novamente para sistemas ergódicos, temos a equivalência entre as médias temporal e a média obtida sobre as configurações, tal que

$$
\begin{aligned}
G^{(2)}(\tau) & =\langle I(t) I(t+\tau)\rangle=\lim _{2 T \rightarrow \infty} \frac{1}{2 T} \int_{0}^{2 T} I(t) I(t+\tau) d t \\
& =\langle I(0) I(\tau)\rangle,
\end{aligned}
$$

onde $\langle\cdots\rangle$ denota uma média no ensemble de configurações.

Quando $I(t)$ e $I(t+\tau)$ referem-se à mesma partícula, a função de correlação é conhecida como função de auto-correlação, no entanto, quando referem-se a partículas diferentes chamamos de 
função de correlação cruzada. Para sistemas diluídos a correlação cruzada é nula e, portanto, a função de correlação medida experimentalmente refere-se apenas à auto-correlação.

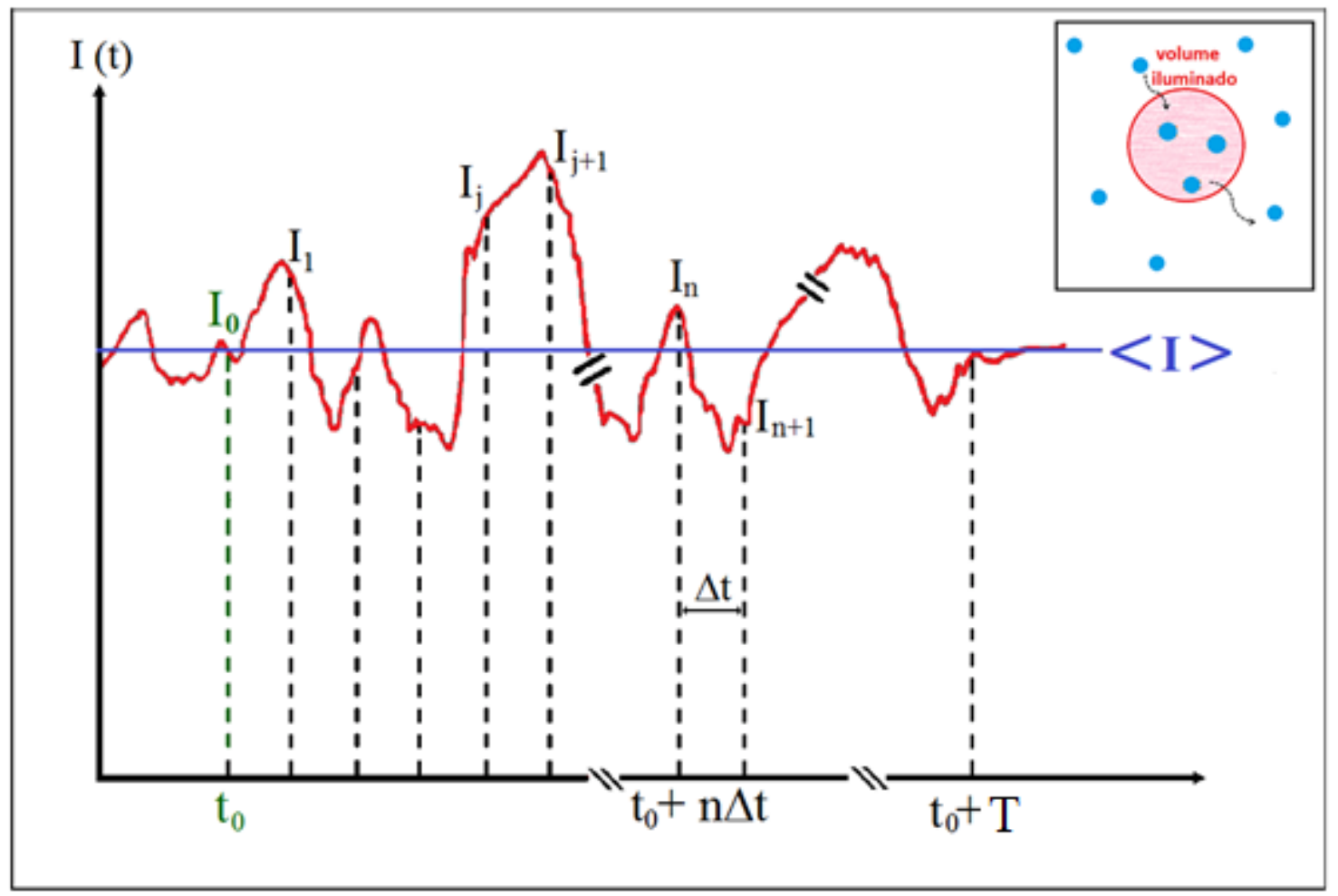

Figura 2.15: Flutuações da intensidade da luz espalhada no tempo, causada pelo movimento das moléculas no fluído. Figura extraída de Berne e Pecora, 2000 (modificada).

A Figura $2.15^{2}$ ilustra um exemplo da flutuação da intensidade da luz espalhada. A partir deste exemplo podemos calcular o valor esperado intensidade e para a função de auto-correlação de intensidades. Considerando a intensidade da luz espalhada em intervalos discretos de largura, $\Delta t$, onde por exemplo, $I_{n}$ equivalente à medida da intensidade no tempo $t_{n}$. em que, $t_{n}=$ $t_{0}+n \Delta t$, onde $n \Delta t=\tau$, e $\tau$ é a variável independente conhecida como tempo de correlação (Berne, 2000).

Deste modo, o valor esperado para intensidade, e para a função de auto-correlação das intensidades é dado por

$$
\langle I\rangle=\lim _{N \rightarrow \infty} \frac{1}{N} \sum_{j}^{N} I_{j}
$$

$\mathrm{e}$

$$
g^{(2)}(\tau)=\langle I(0) I(\tau)\rangle=\lim _{N \rightarrow \infty} \frac{1}{N} \sum_{j}^{N} I_{j} I_{j+n}
$$

\footnotetext{
${ }^{2}$ Figura utilizada na apostila para a Escola de Coloides e Superfícies, IQ-USP, fevereiro de 2014
} 
onde $I_{j}$ é a medida da intensidade no instante $t_{j}$, e $I_{j+n}$ é a medida da intensidade no instante $t_{j+n \Delta t}$, onde $n \Delta t=\tau$ e o tempo da medida equivale a $N \Delta t$.

\subsubsection{Como a medida é realizada no correlator}

Os fótons provenientes das flutuações de intensidades atingem o detector, e são convertidos em sinais elétricos. O correlator registra os pulsos elétricos coletados em intervalos de tempo discretos $\Delta t$, como podemos observar na ilustração da Figura 2.16, (Rodembusch, 2001). Por exemplo, no canal $C_{1}$ foi registrado um pulso e no canal $C_{2}$ foram registrados três pulsos.

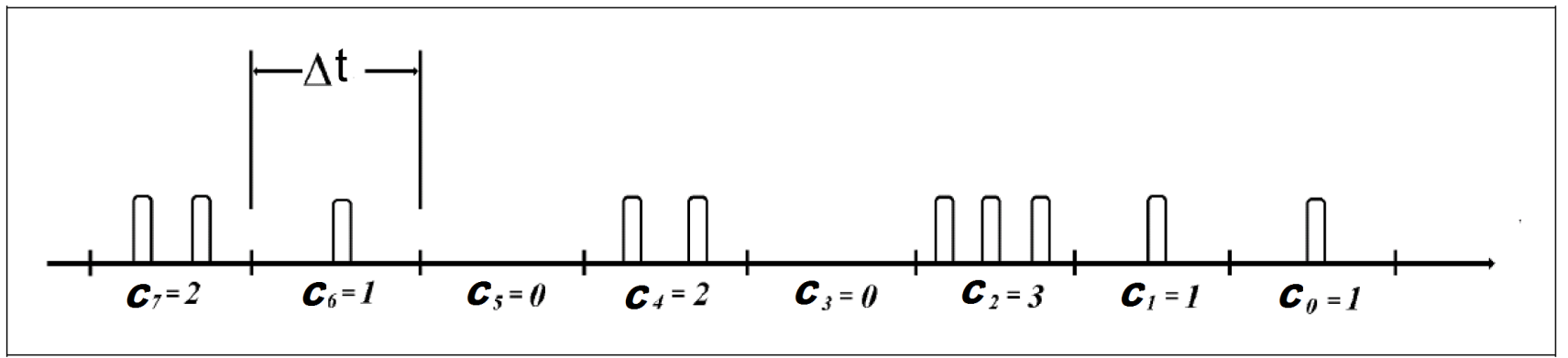

Figura 2.16: Sequência de pulsos processados por um correlator. Figura extraída de Rodembusch, 2001 (adaptada).

O correlator possui um gerenciador de somas, que acumula a soma das correlações. Isto é, o correlator soma os produtos de pulsos elétricos obtidos do instante de tempo $t$ e de outros instantes de tempo $t+\tau$, onde $\tau$ assume os valores $n \Delta t$.

Por exemplo, a soma das correlações estabelecidas para $n=1, \tau=\Delta t$, será dada por:

$$
C_{0} \cdot C_{1}+C_{1} \cdot C_{2}+C_{2} \cdot C_{3}+C_{3} \cdot C_{4}+\ldots
$$

Portanto, o gerenciado de somas acumula todas as correlações possíveis, dos dados que foram registrados. Então uma expressão geral para representar a soma de todas as correlações é dada por

$$
\begin{aligned}
C\left(\tau_{j}\right) & =\lim _{N \rightarrow \infty} \frac{1}{N} C_{0} \cdot C_{n}+C_{1} \cdot C_{n}+\ldots \\
& =\lim _{N \rightarrow \infty} \frac{1}{N} \sum_{i}^{N} C_{i} \cdot C_{i+n},
\end{aligned}
$$

onde $n=1,2,3, \ldots$, e esta, consiste em uma boa aproximação para a função de correlação, como vimos na equação (2.50), (Rodembusch, 2001). 


\subsubsection{Análises na função de correlação do campo elétrico}

A função de correlação do campo elétrico, $g^{(1)}(\tau)$, pode ser obtida a partir da função de auto-correlação de intensidades normalizada $g^{(2)}(\tau)=G^{(2)}(\tau) /<I>^{2}$ segundo a equação de Siegert, para sistemas diluídos, (Brown, 1993)

$$
g^{(2)}(\tau)=\beta\left(1+\left|g^{(1)}(\tau)\right|^{2}\right)
$$

onde $\beta$ depende de condições instrumentais e a normalização de $g^{(1)}(\tau)$.

A função de correlação $g^{(1)}(\tau)$ pode ser relacionada a um decaimento exponencial, quando o sistema é monodisperso

$$
g^{(1)}(\tau) \sim \exp (-\Gamma \tau)
$$

onde $\Gamma$ é a taxa de decaimento da função e está relacionada a uma frequência de relaxação do movimento da partícula, e $\tau$ corresponde ao intervalo de tempo em que as correlações são estabelecidas.

A frequência de relaxação do movimento da partícula, $\Gamma$, para movimento Browniano, pode ser relacionada ao coeficiente de difusão translacional, $D_{T}$, dos centros espalhadores segundo a equação 2.55:

$$
\Gamma=D_{T} q^{2}
$$

onde $q$ corresponde ao vetor de espalhamento, conforme a expressão

$$
q=\frac{4 \pi n_{0}}{\lambda} \operatorname{sen}(\theta / 2)
$$

onde $n_{0}$ corresponde ao índice de refração do meio, $\lambda$ ao comprimento de onda do laser, e $\theta$ ao ângulo de espalhamento.

No entanto, para sistemas polidispersos a função de auto-correlação contém a informação de diversos decaimentos, referentes aos tamanhos variados da dispersão. Para separar os diferentes decaimentos são necessários programas e métodos adequados.

Há diversos métodos de ajuste para função de correlação, $g^{(1)}(\tau)$. Entre eles, um dos mais utilizados é o método dos cumulantes, (Koppel, 1972), segundo o qual

$$
g^{(1)}(\tau)=A \exp \left\{-\left(<\Gamma>\tau+\frac{\mu_{2}}{2 !} \tau^{2}-\frac{\mu_{3}}{3 !} \tau^{3}+\cdots\right)\right\}
$$

onde $\mu_{n}$ corresponde aos momentos, ou cumulantes, da expansão ${ }^{3}$.

\footnotetext{
${ }^{3}$ A dedução desta equação pode ser encontrada em Enoki, 2008.
} 
O primeiro momento desta expansão em cumulantes fornece um valor esperado para a taxa de decaimento, $\langle\Gamma>$, enquanto o segundo momento da expansão está relacionado com a variância da distribuição (índice de polidispersão).

Nos resultados experimentais apresentados no capítulo 4, utilizamos a equação 2.57 para ajustar os dados experimentais. Deste modo, foi obtida uma a taxa de relaxação média dos centro espalhadores, $\langle\Gamma>$, que por sua vez com o uso da equação 2.55 foi utilizada para o cálculo do coeficiente de difusão.

Também deve ser observado que a medida do coeficiente de difusão pode ser influenciada pelas interações envolvidas no sistema. Logo, o coeficiente de difusão deve ser medido em um regime de diluição infinita, (Berne, 2000; Brown, 1993).

Uma vez obtido o coeficiente de difusão translacional dos centros espalhadores, livre de interações com relação aos demais centros (regime de diluição infinita) é possível determinar o diâmetro hidrodinâmico das partículas, $d_{e f}$ assumidas esferas, de acordo com a equação de Stokes-Einstein,

$$
D_{0}=\frac{k_{B} T}{3 \pi \eta d_{e f}},
$$

onde $k_{B}$ é a constante de Boltzmann e $\eta$ a viscosidade do solvente.

O diâmetro efetivo obtido por DLS, nas análises que apresentamos acima, fornecem valores médios. É importante observar que as partículas grandes podem influenciar grandemente nessas medidas pois sua contribuição no espalhamento é muito maior.

\subsection{Ressonância paramagnética eletrônica}

Na natureza, alguns materiais apresentam propriedades paramagnéticas, tais com alguns metais e radicais livres. Moléculas paramagnéticas possuem elétrons desemparelhados, resultando em um momento de dipolo magnético permanente.

A técnica de Ressonância paramagnética eletrônica, (ESR - Electron spin resonance) faz uso das propriedades paramagnéticas dessas moléculas. A aplicação de um campo magnético a moléculas paramagnéticas levanta a degenerescência dos auto-estados do momento angular do spin eletrônico, efeito o qual é conhecido com efeito Zeeman. Além disso, a interação entre o spin eletrônico e o spin nuclear, interação hiperfina, leva a um desdobramento espectral em novos níveis de energia. A condição de ressonância é atingida quando a absorção da radiação eletromagnética promove transições entre os níveis energéticos permitidos segundo regras de seleção. 
Em sistemas biológicos, moléculas paramagnéticas são raramente encontradas e em geral não são estáveis. As metaloproteínas são uns dos poucos exemplos de radicais livres naturais e estáveis. Em nosso estudo com membranas modelo, utilizamos sonda paramagnética (marcadores de spin) que são incorporadas à membrana lipídica. As sondas utilizadas neste trabalho apresentam um radical nitróxido, com o elétron desemparelhado principalmente localizado no orbital p do nitrogênio. Este radical, considerado bem estável, pode ser inserido em diferentes posições da cadeia hidrocarbônica de uma molécula anfifílica.

\subsubsection{Hamiltonia de Spin}

A hamiltoniana de spin que descreve o efeito Zeeman e a interação hiperfina pode ser escrita de acordo com a equação

$$
H=\beta \mathbf{H} . \mathbf{g} . \mathbf{S}+\mathbf{I} . \mathbf{A} . \mathbf{S}
$$

onde $\beta$ é o magneton de Bohr, $\mathbf{H}$ é o campo magnético estático aplicado, $\mathbf{S}$ e $\mathbf{I}$ são os operadores momento angular de spin do centro paramagnético e do núcleo, respectivamente, e g e $\mathbf{A}$ são tensores de $2^{a}$ ordem, relacionados ao efeito Zeeman e à interação hiperfina, respectivamente. Os eixos de simetria do radical nitróxido (Fig. II.2) geralmente coincidem com os eixos principais dos tensores $\mathbf{g}$ e $\mathbf{A}$.

Considerando o campo magnético, $H$, paralelo ao eixo z do radical nitróxido, temos

$$
H=g_{z} \beta H m_{s}+A_{z} m_{I} m_{S}
$$

O elétron desemparelhado do grupo nitróxido possui $S=1 / 2$, caracterizando um sistema de dois níveis $\left(m_{s}=+1 / 2,-1 / 2\right)$, além disso o momento angular do spin nuclear do nitrogênio possui $I=1$, levando ao desdobramento de cada nível em outros três níveis com números quânticos $m_{I}=+1,0,-1$. Portanto os autovalores da Hamiltoniana de spin serão dados pela equação 2.60, onde $m_{s}=+1 / 2,-1 / 2$ e $m_{I}=+1,0,-1$, conforme ilustra a Figura 2.17 .

Segundo as regras de seleção, serão observadas as transições cujos valores correspondem a $\Delta m_{S}= \pm 1$ e $\Delta m_{I}=0$. Deste modo a frequência de microonda absorvida será dada por $h \nu=g \beta H+A m_{I}$. Entretanto, experimentalmente, é mais fácil variar o campo magnético em vez da frequência da microonda, para encontrar a condição de ressonância. O diagrama da Figura 2.18 ilustra como a medida é realizada experimentalmente.

As curvas desenhadas nas Figuras 2.17 e2.18 indicam os espectros de absorção da microonda. Para o campo alinhado com o eixo z da molécula observamos três espectros de absorção 


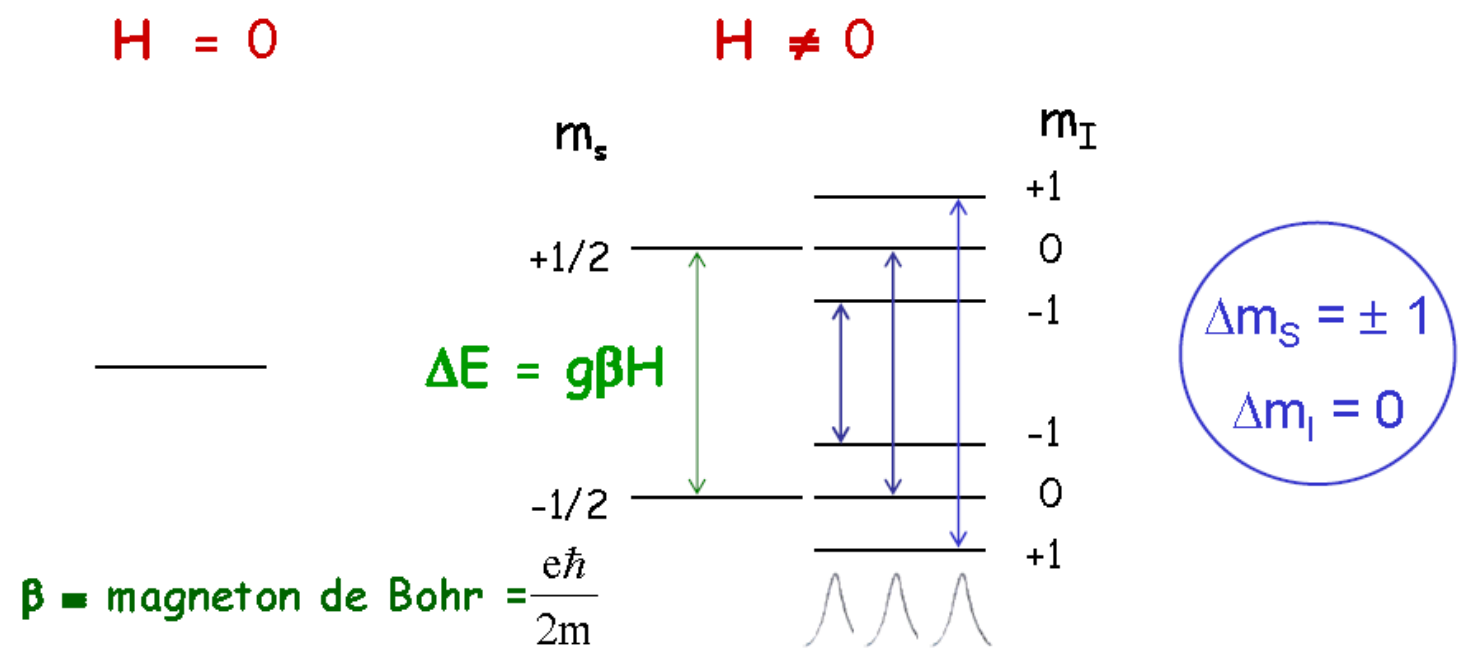

Figura 2.17: Ilustração dos auto-valores da hamiltoniana de spin. Figura obtida das notas de aula da Prof. Teresa Lamy.

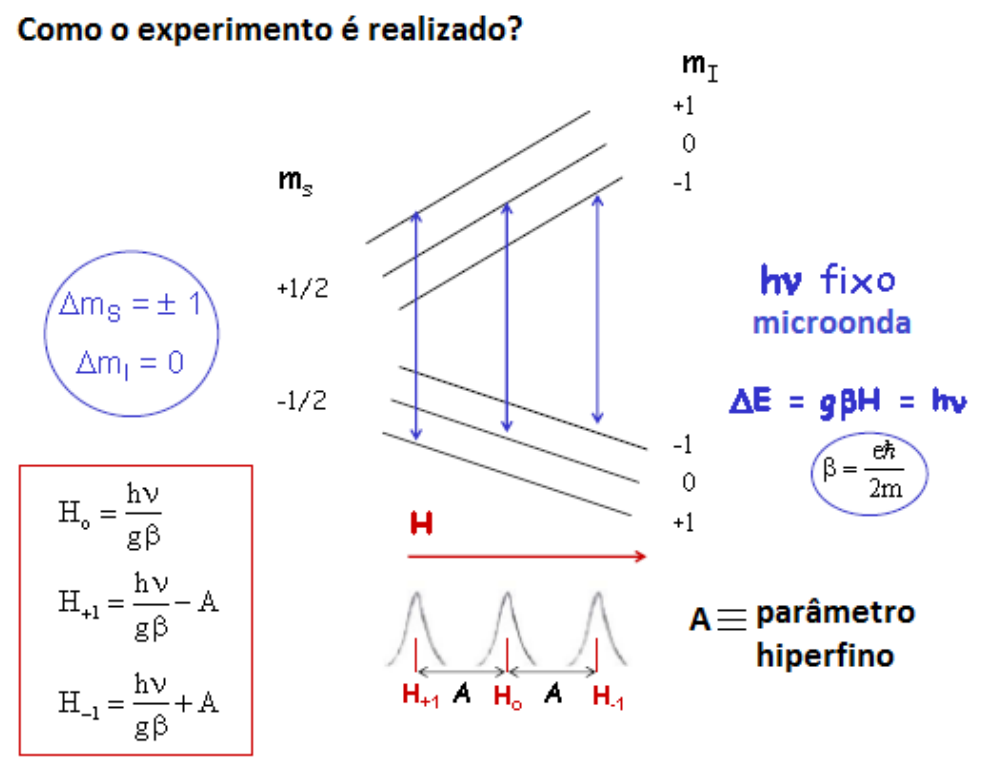

Figura 2.18: Ilustração da medida de ESR, variando o campo magnético. Figura obtida das notas de aula da Prof. Teresa Lamy.

semelhantes quanto a forma. Em geral as análises de ESR são realizadas na primeira derivada do espectro de absorção.

Caso o campo magnético não esteja alinhado com um dois eixos da molécula, os espectros de absorção podem diferir quanto a forma, largura e altura, mas a área sob cada curva permanece a mesma, pois todas as transições são igualmente prováveis.

A seguir podemos observar os efeitos dos diferentes alinhamentos da molécula paramagnética com o campo magnético. O radical nitróxido apresenta uma simetria axial, pois seu elétron 
desemparelhado encontra-se no eixo z do orbital pp do nitrogênio, Figura 2.19. Essa sonda paramagnética como uma impureza em cristal e na presença de um campo magnético alinhado paralelamente ao seu eixo de simetria x, ou y apresenta um sinal de EPR dado pela Figura 2.19 (a) e (b), respectivamente. Quando o campo está alinhado ao exio z da molécula temos o sinal observado em (c). A partir desse alinhamento com os eixos de simetria do radical é possível obter as componentes principais dos tensores g e A (Griffith e Jost, 1976; Riske, 2012), conforme apresentado na Tabela 2.1.

\section{Tensores}

\begin{tabular}{ccccccc}
\hline & $g_{x x}$ & $g_{y y}$ & $g_{z z}$ & $A_{x x}$ & $A_{y y}$ & $A_{z z}$ \\
\hline \hline $\begin{array}{c}\text { Doxil cadeias alifática } \\
\text { (PCSL) }\end{array}$ & 2.0088 & 2.0058 & 2.0022 & 5.9 & 5.4 & 32.9 \\
\hline \hline
\end{tabular}

Tabela 2.1: Valores principais dos tensores g e A.

Considerando agora duas situações extremas: uma de movimento muito lento e outra de movimento rápido temos os espectros apresentados na Figura 2.19 em (d) e (e), respectivamente (Marsh, 1981; Marsh et al., 1982) (também baseado nos textos (Riske, 2001; Oliveira, 2008)).

No movimento muito lento (d), também conhecido por espectro de pó, o espectro resultante observado corresponde à soma dos espectros do radical nitróxido alinhado em todas as direções possíveis, ou seja, todas as orientações são somadas. Já no caso de movimento rápido (e), todas as orientações das sondas em relação ao campo magnético são visitadas com a mesma probabilidade, e, portanto, o espectro resultante é caracterizado pela média das orientações da sonda em solução. Neste caso, os tensores g e A, podem ser escritas como um escalar, dado por $g_{0}=\left(g_{x x}+g_{y y}+g_{z z}\right) / 3$, e $A_{0}=\left(A_{x x}+A_{y y}+A_{z z}\right) / 3$ (Griffith e Jost, 1976).

Logo, a anisotropia da molécula paramagnética, com relação a seus eixos de simetria, e a dependência orientacional dos tensores $\mathbf{g}$ e $\mathbf{A}$, tornam a técnica de ESR sensível ao movimento da sonda. A Figura 2.20 mostra exemplos dos sinais de ESR obtidos para o marcador paramagnético (Tempol) em soluções de diferentes viscosidades. Utilizando o modelo de Stokes-Einstein para esses sistemas, é possível relacionar o tempo de correlação rotacional, $\tau_{r}$ da sonda com a viscosidade de meio $\eta$, segundo a equação

$$
\tau_{r}=4 \pi \eta r^{3} / 3 k_{B} T
$$

onde $k_{B}$ é a constante de Boltzmann e $T$ a temperatura e $r$ é o raio da molécula, Tempol. 

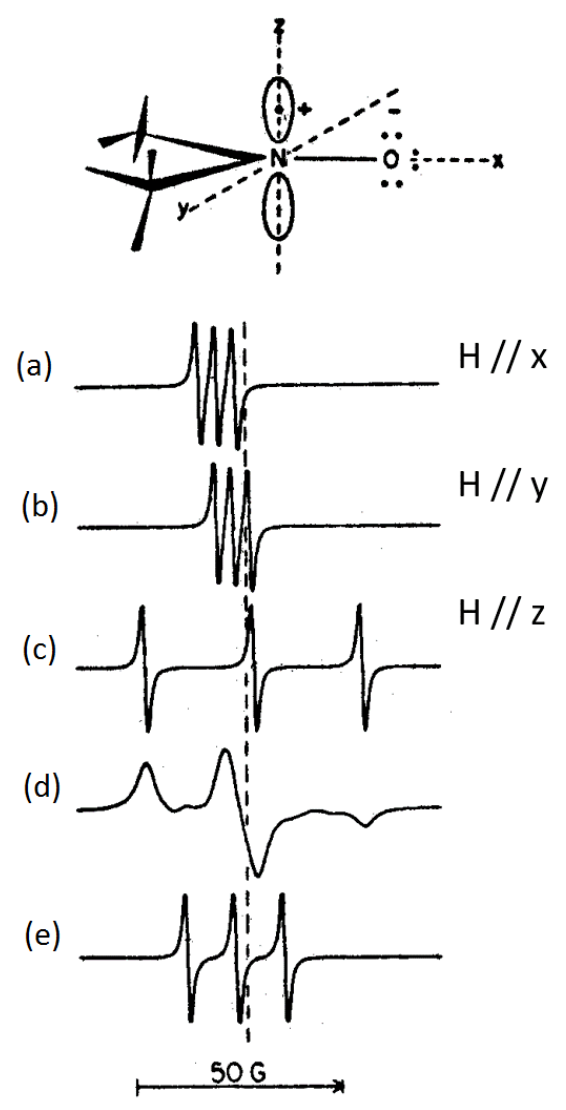

Figura 2.19: Radical nitróxido e espectros de ESR em diferentes condições, onde o campo magnético esta alinhado paralelamente ao eixo-x (a), eixo-y (b) e eixo-z (3). Sinal paramagnético em solução congelada (d) e em solução de baixa viscosidade (e). Figura baseada nos textos Riske, 2001 e Oliveira, 2008, original de Marsh, 1981 (modificada).

Devido à complexidade e as peculiaridades dos sinais de ESR para cada tempo de correlação rotacional, torna-se difícil o uso de um modelo geral para descrever o comportamento das linhas, referente à primeira derivada da absorção da microonda. Deste modo, através desses estudos do radical em solução, e utilizando banda $\mathrm{X}\left(\nu \approx 9.10^{-} 9 \mathrm{~Hz}\right)$, os perfis dos espectros foram divididos em grupos de acordo com o tempo de correlação, conforme listado a seguir:

- $\tau_{r}<10^{-11} s$ - Movimento isotrópico. Neste caso o sinal de ESR é representado por três linhas de igual intensidade, Figura 2.19 (e). Esses sinais podem ser encontrados com o marcador livre em solução aquosa, por exemplo, e é possível medir $a_{0}$ e $g_{0}$.

- $10^{-11} s<\tau_{r}<3 \cdot 10^{-9} s-$ Motional narrowing. Nesse caso, as linhas referentes às transições eletrônicas $h_{+1}, h_{0}$ e $h_{-1}$ apresentam diferentes alargamentos, similar ao sinal observado na Figura 2.20 (I). Esses sinais podem ser encontrados, por exemplo, na fase 


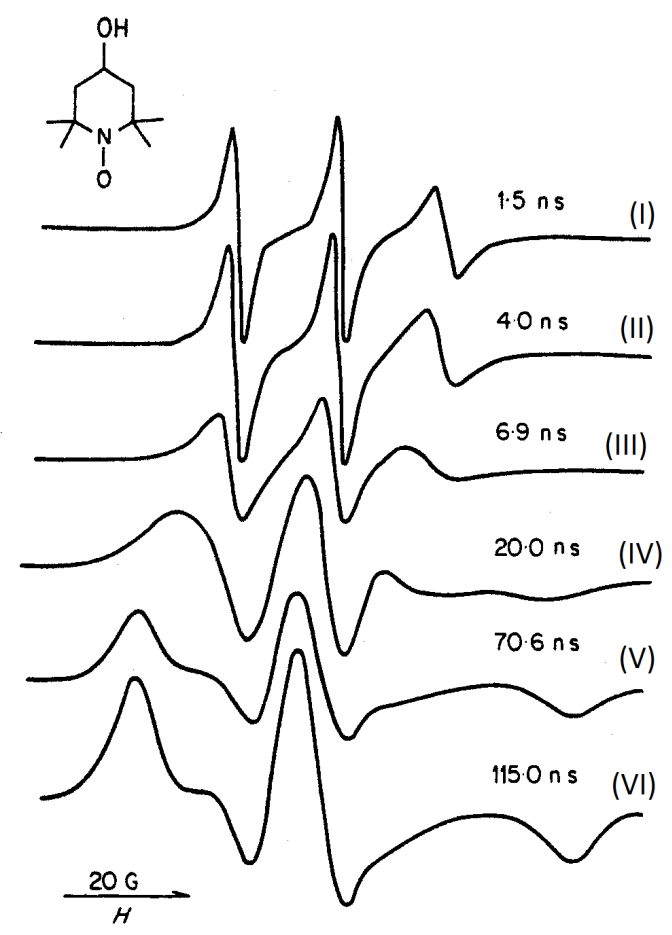

Figura 2.20: Sinais de EPR da sonda paramagnética, Tempol, em soluções de viscosidades crescentes. Figura baseada nos textos Riske, 2001 e Oliveira, 2008, original de

fluida de sistemas lipídicos.

- $3.10^{-9} s<\tau_{r}<10^{-7} s-$ Movimento lento. Neste caso, as linhas se alargam e também mudam de posição, similares aos perfis observados na Figura 2.20 (III-VI). Esses sinais podem ser encontrados, por exemplo, na fase gel de sistemas lipídicos.

- $\tau_{r}>10^{-7} s$ - Espectro de pó. Neste caso, o sinal de ESR é dado pela soma de todos os sinais do marcador em todas as direções relativas ao campo externo, como representado na Figura $2.19(\mathrm{~d})$.

\subsubsection{Análises dos sinais paramagnéticos aplicadas ao estudo de mem- branas}

Uma primeira e simplificada análise dos sinais paramagnéticos consiste em obter parâmetros fenomenológicos do próprio espectro. Em geral, esses parâmetros são sensíveis à mobilidade da bicamada e polaridade do meio, inclusive alguns desses parâmetros podem apontar transições de fase da membrana. Como relatado anteriormente, analisamos a primeira derivada do espectro de absorção ressonante, as Figuras 2.21, 2.22 e 2.24 ilustram alguns dos parâmetros que podem 
ser estudados dos espectros medidos.

Por exemplo, a Figura 2.21 mostra as alturas das linhas denominas $h_{+1}, h_{0}$ e $h_{-1}$, de sinais no regime Motional narrowing, onde a comparação das razões $h_{+1} / h_{0}$ e $h_{-1} / h_{0}$ pode indicar mudanças na mobilidade e rigidez da bicamada.

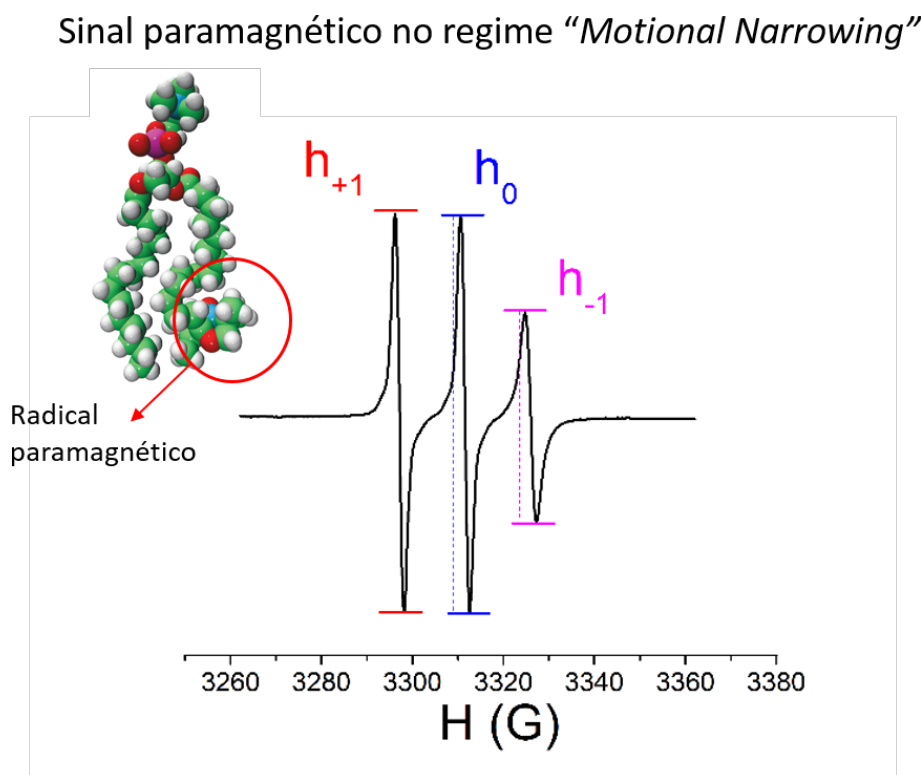

Figura 2.21: Exemplo de como medir a altura das linhas do sinal de ESR para o marcador 16PCSL.

Além disso, para sistemas mais ordenados que o observado na Figura 2.21 é possível calcular um parâmetro de ordem efetivo, $S_{e f}$ diretamente dos parâmetros dos sinais paramagnéticos. O parâmetro de ordem depende das componentes do tensor A (McConnell e Hubbell, 1971), conforme descrito na equação 2.62 ,

$$
S_{e f}=\frac{A_{/ /}-A_{\perp}}{A_{z z}-(1 / 2)\left(A_{x x}+A_{y y}\right)} \cdot \frac{A_{0}^{\prime}}{A_{0}}
$$

onde

$$
\begin{aligned}
A_{0}^{\prime} & =\frac{1}{3}\left(A_{x x}+A_{y y}+A_{z z}\right) \\
A_{0} & =\frac{1}{3}\left(A_{/ /}+A_{-} \perp\right)
\end{aligned}
$$

e os valores $A_{x x}, A_{y y}, A_{z z}$ para o radical nitróxido estão descritos na Tabela 2.1.

Da Figura 2.22, podemos observar que a bicamada lipídica impõe restrições ao movimento da sonda paramagnética. O radical livre ligado a um dos carbonos da cadeia hidrocarbônica pode apenas girar em torno do eixo indicado por $A_{/ /}$e mover-se ao longo do ângulo $\beta$.

Deste modo, o parâmetro de ordem pode ser interpretado como uma distribuição angular média do eixo principal da molécula paramagnética com relação aa normal da bicamada. Em 


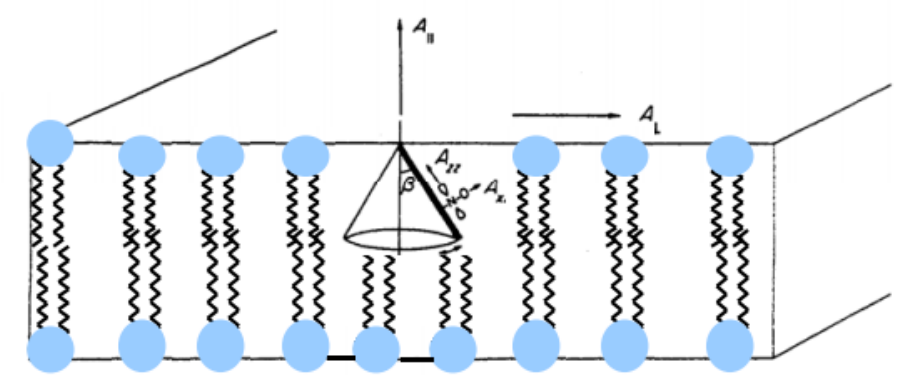

Figura 2.22: Figura ilustrativa da restrição de movimento do marcador paramagnético ligado a cadeia hidrocarbônica. Figura obtida das notas de aula da Profa. Teresa Lamy.

sistemas cristalinos, a anisotropia máxima da sonda é dada por $\left(A_{x x}+A_{y y}+A_{z z}\right)$, enquanto que $A_{/ /}-A_{\perp}$ reflete a anisotropia do sistema. Deste modo, o parâmetro de ordem é uma grandeza que varia de 0 a 1.

O valor de $A_{/ /}$será muito semelhante ao desdobramento hiperfino máximo, $A_{\max }$. A Figura 2.23 ilustra um exemplo da medida de $2 A_{\max }$, a partir do sinal paramagnético. Entretanto, $A_{\perp}$ é elaborado a partir de uma correção empírica, equação 2.64, como reportado em (McConnell e Hubbell, 1971),

$$
A_{\perp}=A_{\text {min }}+1.4\left[1-\frac{A_{\max }-A_{\min }}{A_{z z}-(1 / 2)\left(A_{x x}+A_{y y}\right)}\right]
$$

Para regimes de movimento mais lento, o parâmetro $2 A_{\max }$ também pode ser utilizado para acessar as mudanças estruturais com relação ao empacotamento da bicamada, nesse regime, os espectros são semelhantes aos exemplos da Figura 2.24. Quando o marcador paramagnético possui baixa mobilidade (por exemplo como observado na Figura 2.19 (e) ) maior o valor esperado para o parâmetro $2 A_{\max }$. 


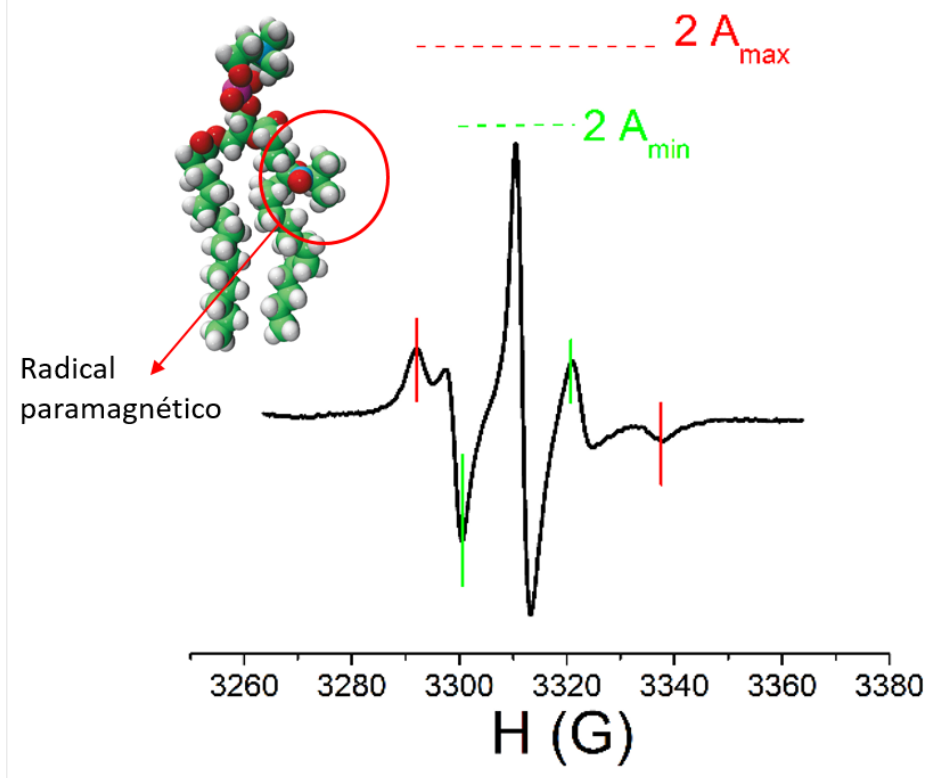

Figura 2.23: Exemplo de como medir os parâmetros $2 A_{\max }$ e $A_{\min }$ diretamente do sinal de ESR, para o marcador 5PCSL, na fase fluida do lipídio

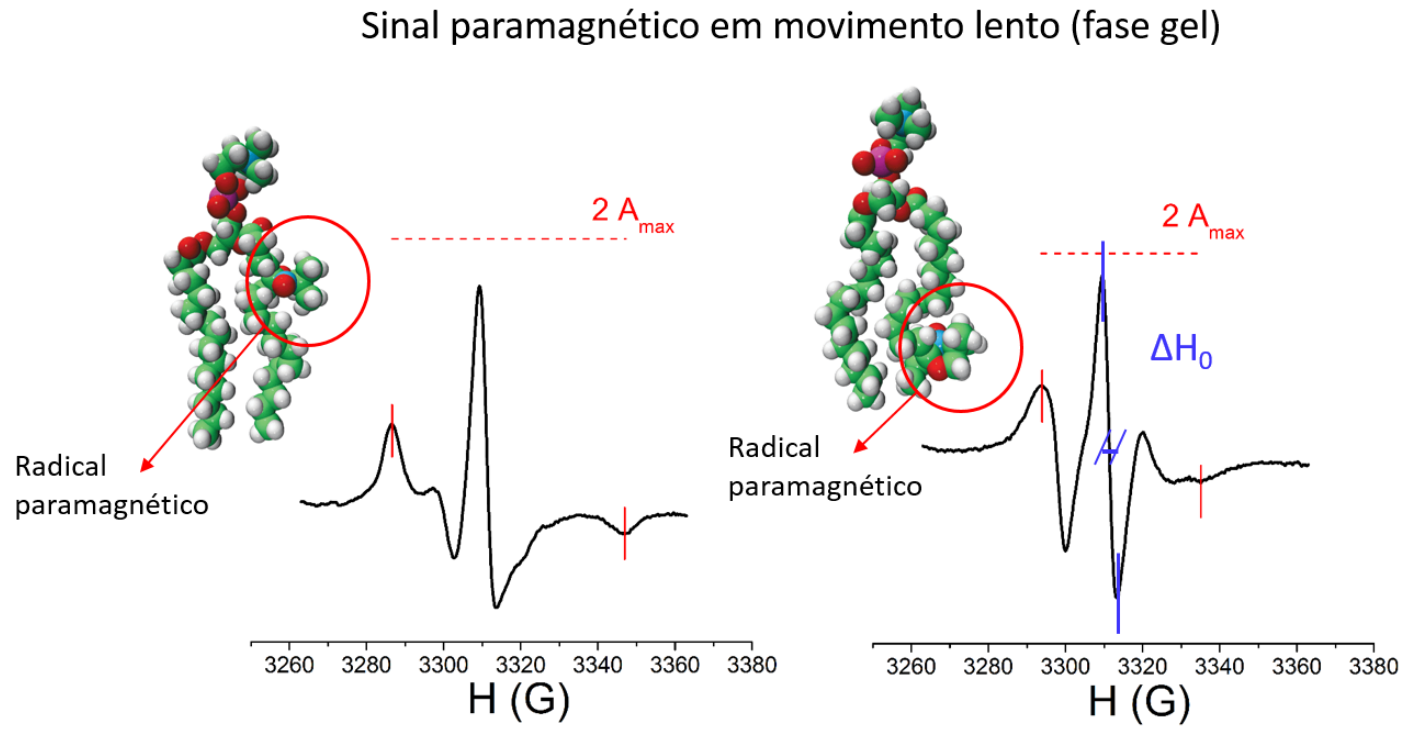

Figura 2.24: Exemplo de como medir o parâmetro $2 A_{\max }$ e $\Delta H_{0}$ diretamente do sinal de ESR, para o marcador 5PCSL (esquerda) e 16PCSL (direita) na fase gel do lipídio.

Visto que o parâmetro $2 A_{\max }$ para o marcador paramagnético $16 \mathrm{PCSL}$ pode ser difícil de ser analisado, monitoramos também o parâmetro $\Delta H_{0}$, o qual corresponde ao alargamento do pico central, Figura 2.24. Novamente, quando o marcador paramagnético possui baixa mobilidade maior o valor esperado para o parâmetro $\Delta H_{0}$. 


\subsection{Espalhamento de raios-X a baixo ângulo}

A técnica de espalhamento de raios-X a baixo ângulo (SAXS) (Small angle X-Ray scattering) tem sido amplamente utilizada para estudos estruturais de macromoléculas de interesse biológico. Neste trabalho, os resultados de SAXS foram obtidos no Laboratório Nacional Luz Sincrotron (LNLS), Campinas.

Nos experimentos de SAXS a radicao incidente, raios-X, tem comprimento de onda da ordem de $\sim 0.1 \mathrm{~nm}$ e a radiação espalhada é coletada em baixo ângulo da ordem de 0.1 a $10^{\circ}$. Em resumo, um feixe de raios-X policromático que sai do anel Sincrotron atravessa um monocromador, que seleciona uma pequena janele de comprimentos de ondas. Então, o feixe monocromático passa por um colimador e atinge a amostra, com vetor de onda $\vec{K}$. O feixe diretamente transmitido atinge um aparato de metal, em geral, chamado de "beam stopper". Por outro lado, o feixe refletido pela amostra atinge o detector com ângulo de espalhamento $2 \theta$ e tem vetor de espalhamento dado por $\overrightarrow{k^{\prime}}$, conforme ilustra a Figura 2.25.

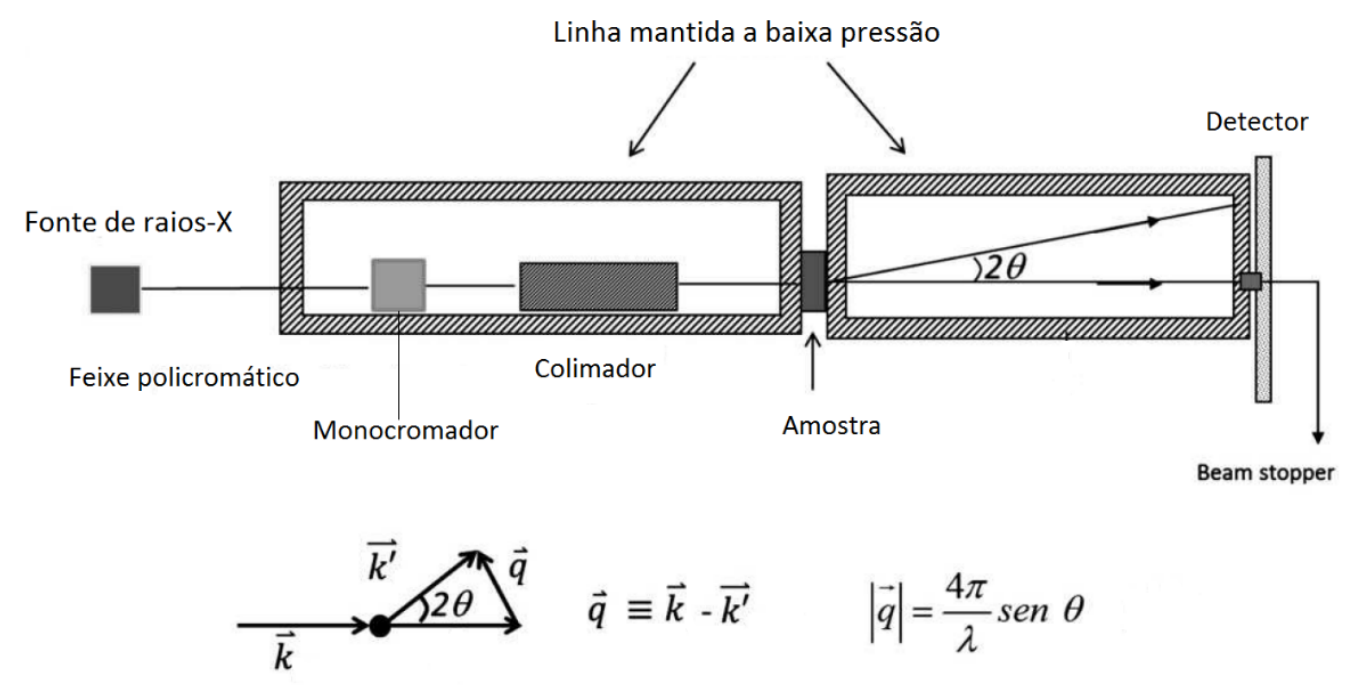

Figura 2.25: Esquema ilustrativo da medida de SAXS. Figura extraída do livro "Proteins in solution and in the interfaces: Methods and Applications in biotechnology and materials science". Editado por Ruso e Pineiro, 2013; capítulo 3, Barbosa et al, 2013.

O espalhamento de raios-X a baixo ângulo é considerado um espalhamento elástico pois $|\vec{k}| \approx \overrightarrow{k^{\prime}}$ e o modulo do vetor de espalhamento pe dado por

$$
q=\frac{4 \pi}{\lambda} \operatorname{sen} o(\theta)
$$

A intensidade da radiação espalhada, para um sistema de partículas em solução pode ser 
escrita pela equação

$$
I(q)=N\langle P(q)\rangle \cdot\langle S(q)\rangle
$$

onde $N$ corresponde ao número de centros espalhadores, e $P(q)$ e $S(q)$ são os fatores de forma e estrutura, respectivamente. Os símbolos $\langle\ldots\rangle$ indicam as medias sob as orientações das partículas, e ensembles de configurações.

O fator de forma contém informações sobre a forma, dimensões, anisotropia e contrastes de densidade eletrônicas dos centros espalhadores, enquanto o fator de estrutura está relacionado a interações entre partículas, estrutura de rede, agregação, por exemplo.

Para sistemas não interagentes, compostos apenas pelo fator de forma, podemos assumir $I(q) \sim P(q)$, onde $S(q) \rightarrow 1$. Deste modo, podemos definir a função $p(r)$, também conhecida como função de distribuição de pares, como a transformada de Fourier da intensidade de espalhamento

$$
\begin{array}{r}
I(q) \sim N\langle P(q)\rangle=N I_{1}(q) \\
I_{1}(q)=4 \pi \int_{0}^{\infty} p(r) \frac{\operatorname{sen}(q r)}{q r} d r \\
p(r)=\frac{r^{2}}{2 \pi^{2}} \int_{0}^{\infty} q^{2} I_{1}(q) \frac{\operatorname{sen}(q r)}{q r} d q
\end{array}
$$

Portanto, a $p(r)$ tem significa físico de uma distribuição de distancias no interior da partícula.

\subsubsection{GIFT (Generalized indirect Fourier transform)}

Esse programa utiliza a soma de curvas cubicas, $\phi_{\nu}$ ("cubic- $\beta$ splines") para criar uma função $p(r)$. A partir do modelo da $p(r)$, o qual é previamente escolhido de acordo com a geometria do sistema, o programa calcula a transformada de Fourier desse conjunto de curvas, criando uma função de Intensidade de espalhamento a qual é ajustada aos dados experimentais. Deste modo, a intensidade da radiação espalhada teórica, $I_{T}$, será dada pela equação

$$
I_{T}(q)=\sum_{\nu=1}^{N_{s}} c_{\nu} \Phi_{\nu}(q)
$$

onde $\Phi_{\nu}$ corresponde a transformada de Fourier de uma dada curva cúbica, $\phi_{\nu}$, e $N_{s}$ o número de curvas. A soma desse conjunto de funções com seus respectivos coeficientes, $c_{\nu}$, leva a $p(r)$, segundo a equação

$$
p(r)=\sum_{\nu=1}^{N_{s}} c_{\nu} \phi_{\nu}(q)
$$



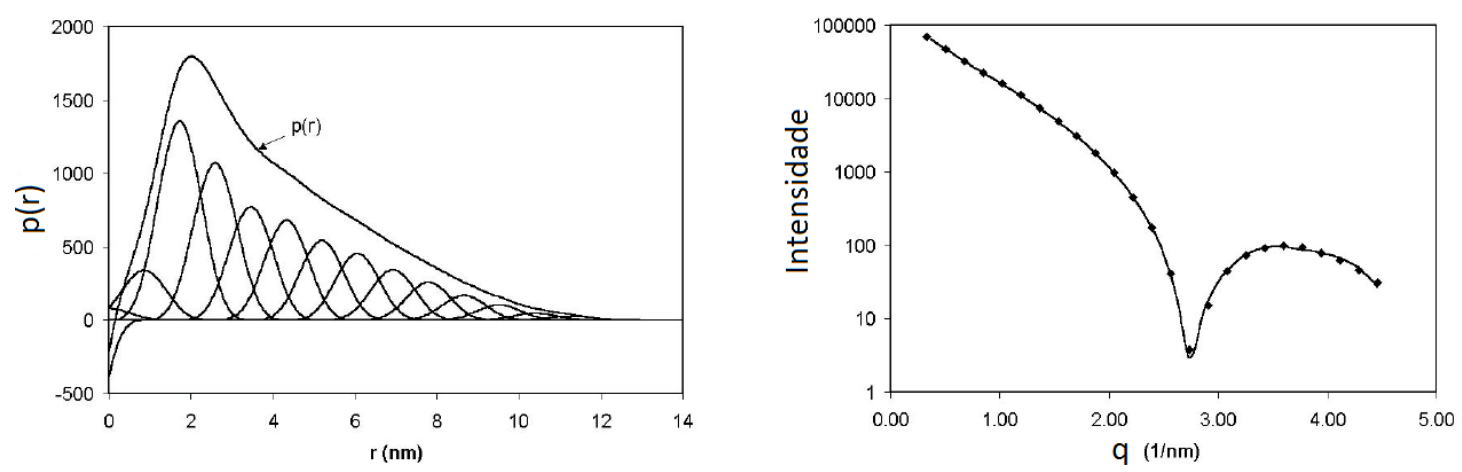

Figura 2.26: Exemplo da p(r) obtida por um conjunto de splines e do ajuste do dado experimental. Neste exemplo, para uma geometria cilíndrica. Figura extraída de (Dahlgren 2002).

A determinação dos coeficientes de cada curva é dada pela minimização da equação 2.71, dentro de uma dada variância, $\sigma(q)$

$$
L=\sum_{\nu=1}^{M}\left[I_{\text {exp }}\left(q_{i}\right)-\sum_{\nu=1}^{N_{s}} c_{\nu} \Phi_{\nu}\left(q_{i}\right)\right] / \sigma^{2}\left(q_{i}\right)=\min
$$

onde $M$ corresponde ao número de pontos experimentais. Desde modo, a minimização de $L$ leva a curva teórica que mais se assemelha a curva experimental $I_{\text {exp }}(q)$.

Entretanto, o aumento de $N$ pode levar a soluções não estáveis, e um vínculo é introduzido para otimizar os cálculos a encontrar uma solução estável, onde a condição da equação 2.72 também deve ser satisfeita.

$$
N c^{\prime}=\sum_{\nu=1}^{N_{s}}\left(c_{\nu+1}-c_{\nu}\right)^{2}
$$

Desde modo, para satisfazer condições de estabilidade da solução analítica tem-se que

$$
L+\lambda \cdot N c^{\prime}=\min
$$

onde $\lambda$ corresponde a um multiplicador de Lagrange.

A Figura 2.26 ilustra um exemplo das curvas splines gerando uma $p(r)$, e a Transformada de Fourier desse conjunto de curvas corresponde ao ajuste melhor ajuste dos dados experimentais (Dahlgren 2002).

Por fim, o programa DECON obtém a função de densidade eletrônica calculado a deconvolução da p(r). 



\section{Capítulo 3}

\section{Modelos e Controles}

\subsection{Modelos}

Definimos como modelos os sistemas miméticos de membranas biológicas que serão a base de nosso estudo. Os sistemas modelo discutidos nesta seção serão abordados nos capítulos 4, 5 e 6 . Essa seção é dedicada a discutir as características principais dos sistemas modelo, incluindo as razões principais de tê-los adotados. Este plano envolve desde a escolha apropriada dos lipídios à escolha da força iônica do sistema, incluindo algumas características gerais dos agregados lipídicos.

\subsubsection{Estudo sob o ponto de vista da membrana}

De um modo geral, o estudo de peptídeos antimicrobianos em células ou sistemas modelo tem sido amplamente explorado nas últimas décadas, devido à necessidade de desenvolver novos fármacos com eficaz ação antimicrobiana. Um grande número desses estudos tem como foco principal o peptídeo e possíveis modificações em sua estrutura primária. Muitos trabalhos se baseiam na comparação dos efeitos causados por esses diferentes peptídeos análogos, buscando explorar a formulação de maior dano às células ou às membranas modelo. Todavia, as modificações estruturais que os peptídeos causam em membranas lipídicas, por vezes, não são muito detalhadas. Portanto, nosso estudo busca compreender o efeito de peptídeos antimicrobianos em membranas modelo, sob o ponto de vista da membrana, e, incluindo algumas de suas complexidades como, por exemplo, a transição de fase dos lipídios. 


\subsubsection{Membranas Modelo}

Membranas modelo são sistemas que mimetizam a membrana celular, mas são estruturas simples, compostas apenas por lipídios. Logo, utilizaremos como modelo, lipossomos (vesículas) como ilustrado na Figura 3.4, para modelar a membrana celular. Esses modelos simplificam a grande complexidade da membrana das células, como por exemplo, composição lipídica variada, assimetria da composição lipídica nas camadas interna e externa da membrana, a presença de açúcares e receptores de membranas, além de simplificar a interpretação dos resultados experimentais. Os lipídios são a fração relevante da membrana celular, por isso convém modelar esse sistema apenas com lipídios. Nos lipossomos, os lipídios se organizam em uma bicamada lipídica, de modo que o agregado lipídico apresenta volume interno preenchido pelo solvente, Figura 3.4 .

Os sistemas lipídicos podem ser encontrados em diferentes fases: gel, fluida, hexagonal, hexagonal invertida, cúbica, etc. Nos estudos apresentados nos capítulos 4, 5 e 6 estaremos particularmente interessados nas fases lamelares gel e fluida. A transição de fase gel-fluida depende das interações entre lipídios e, portanto, de suas características, como por exemplo, a cabeça polar ou o comprimento das cadeias apolares. Para lipídios saturados, a temperatura de transição de fase aumenta com o comprimento das cadeias carbônicas. Como a interação lipídio - lipídio pode competir com a interação peptídeo - lipídio, propomos estudar a interação entre peptídeos e lipídios com membranas modelo em diferentes fases lipídicas: gel e fluida, e, quando possível, ao longo da transição de fase.

Deste modo, convém trabalharmos com lipídios que apresentam $T_{m}$ entre 15 e $50^{\circ} \mathrm{C}$, pois neste intervalo de temperaturas podemos monitorar as fases lipídicas de interesse, sem grandes complicações no arranjo experimental. Dentre os lipídios que apresentam $T_{m}$ neste intervalo de temperaturas podemos citar os lipídios com 13 a 16 carbonos em suas cadeias hidrofóbicas. Entretanto, alguns dos lipídios aniônicos com essas características exibem uma transição de fase muito peculiar em baixa força iônica. A Figura 3.1, extraída do livro "Thermal biophysics of membranes" (Heimburg, 2007), mostra os perfis de calor específico para esses lipídios. Nesta figura, o eixo horizontal está representado em Kelvin e descreve a largura da região de transição de fase, onde foi tomado como referência o DPPG, lipídio com 16 carbonos em suas cadeias, o qual exibe temperatura de transição, $T_{m}=41^{\circ} \mathrm{C}$.

É interessante notar que quanto menor o comprimento das cadeias carbônicas, maior a largura da região de transição. Tais lipídios com extensa região de transição são sistemas 


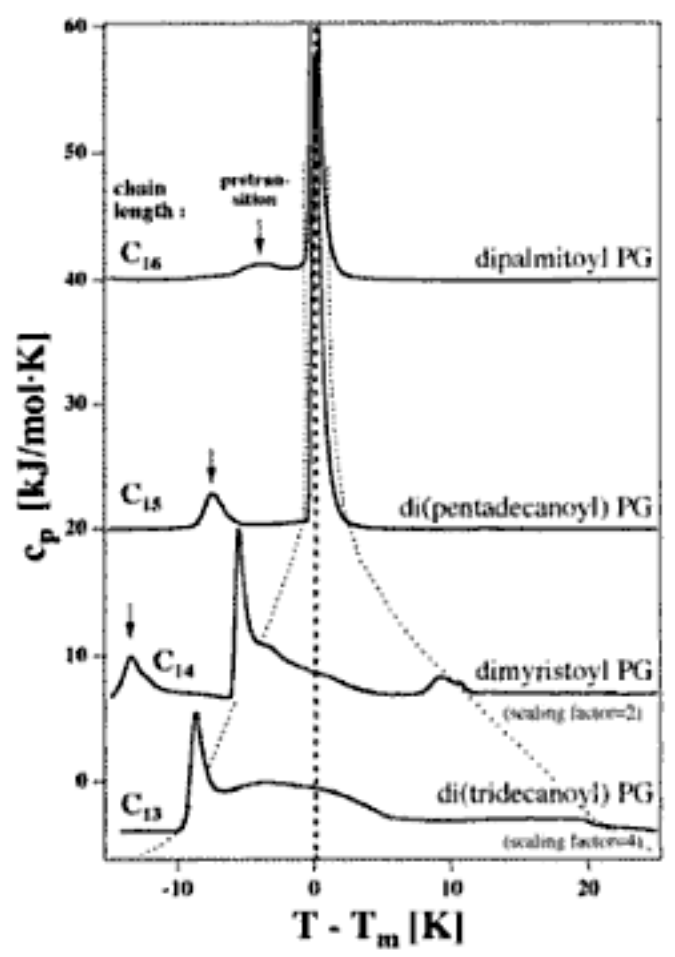

Figura 3.1: Perfis calorimétricos obtidos por DSC para lipídios aniônicos com grupo polar, PG, em baixa força iônica. O calor específico à pressão constante é analisado em função de $T-T_{m}[K]$, onde $T$ corresponde à temperatura (variável independente da medida) e $T_{m}$ à temperatura de transição principal. Os termogramas abaixo do DPPG mostram os perfis calorimétricos obtidos para lipídios com 15, 14 e 13 carbonos em suas cadeias laterais. Figura extraída de Heimburg (2007) e adaptada.

complexos e pouco compreendidos. Todavia, é de nosso conhecimento que na região de transição desses lipídios ocorrem fenômenos surpreendentes como, por exemplo, para o dimiristoil fosfatidilglicerol (DMPG) há um aumento da condutividade elétrica, da viscosidade e do tamanho do agregado, acompanhado por grande diminuição da turbidez (ver por exemplo (Enoki, Henriques, e Lamy, 2012) e referências).

Portanto, a fim de obter um bom controle dos experimentos no quesito de separar as peculiaridades do sistema lipídico e efeito causado pelos peptídeos antimicrobianos em sistemas carregados, escolhemos como modelo o lipídio aniônico que exibe menor alargamento no pico calorimétrico referente à transição de fase, em baixa força iônica, dipalmitoil fosfatidilglicerol (DPPG). 


\subsubsection{Força iônica}

De fato, essas peculiaridades para lipídios aniônicos são observadas em sistemas com baixa força iônica, isto é, baixas concentrações de sal. Em sistemas modelo torna-se conveniente trabalhar em baixa força iônica, pois o efeito da blindagem eletrostática é reduzido, e a ligação do peptídeo na bicamada é favorecida. Como estamos interessados no efeito do peptídeo nas membranas, convém que o peptídeo se ligue a membrana.

A interação eletrostática entre o peptídeo e o lipídio pode ter grande contribuição no mecanismo de ação dos peptídeos antimicrobianos. Então, optamos trabalhar com sistemas modelos em baixa força iônica, pelos seguintes motivos: (i) amplificarmos a contribuição da interação eletrostática, buscando compreender em que aspecto a interação eletrostática poderia ser um diferencial no mecanismo de ação dos peptídeos; (ii) favorecer a ligação peptídeo-lipídio e acessar os efeitos causados à membrana que talvez só fossem possíveis com altas concentrações de peptídeo em alta força iônica, o que implicaria um alto custo da produção de peptídeo.

Testamos algumas concentrações de sal no sistema modelo composto por lipídios aniônicos. A força iônica reduz a largura da região de transição dos lipídios aniônicos, como mencionado anteriormente. A Figura 3.2 mostra as curvas do calor especifico para dispersões lipídicas de DPPG contendo $0,3,5,15$ e $50 \mathrm{mM}$ de cloreto de sódio $(\mathrm{NaCl})$ e ácido etilenodiamino tetraacético (EDTA) $(1.0 \mathrm{mM})$. O tampão utilizado para suspender a dispersão lipídica também teve sua condutividade elétrica medida. A condutividade elétrica é diretamente proporcional à concentração de eletrólitos, conforme mostra a Figura 3.3.

O aumento da força iônica leva a um pequeno deslocamento do pico calorimétrico de 39.5 a $40.5^{\circ} \mathrm{C}$, também acompanhado de leve estreitamento do pico. Avaliamos que $3 m M$ de $\mathrm{NaCl}$ corresponde à concentração de sal apropriada para os experimentos. Observamos que tal concentração salina resulta em estreitamento do pico calorimétrico, e similar ao efeito observado para $5 m M$ de $\mathrm{NaCl}$.

Portanto, escolhemos os lipídios saturados com 16 carbonos em suas cadeias laterais, DPPG, e seu análogo zwiterionico, dipalmitoil fosfatidilcolina (DPPC), para comporem os lipossomos modelo. As dispersões lipídicas do sistema modelo foram então preparadas em tampão HEPES $10 \mathrm{mM}$ e concentração salina de $3.0 \mathrm{mM}$ de $\mathrm{NaCl}$, contendo $1.0 \mathrm{mM}$ de EDTA, um quelante para íons de cálcio e $\mathrm{pH}$ fisiológico, $\mathrm{pH}=7.4$. Maiores detalhes sobre a pregação das amostras serão apresentados na seção de Materiais e Métodos de cada capítulo. 


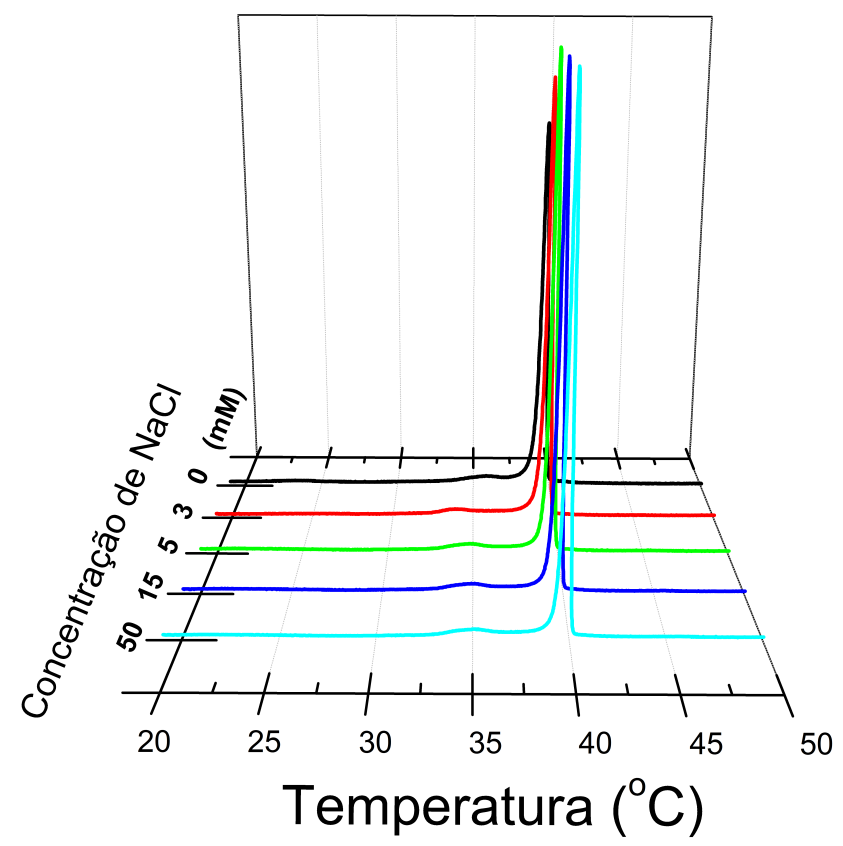

Figura 3.2: Perfis calorimétricos obtidos por DSC para o DPPG (1.0 $m M$ ) em solução tampão HEPES $(10.0 \mathrm{mM})$ com EDTA $(1.0 \mathrm{mM})$ e variando a concentração de sal, $\mathrm{NaCl}, \mathrm{pH}=7.4$.

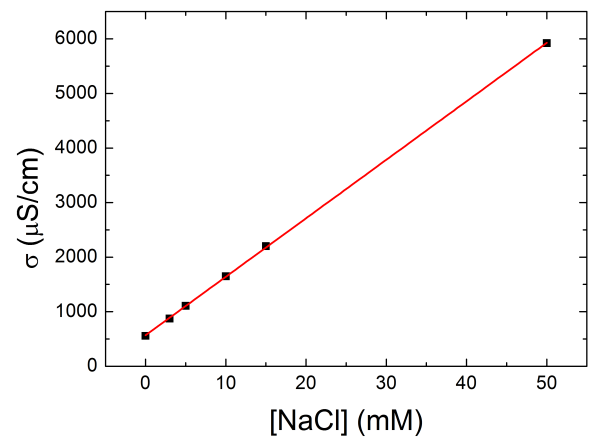

Figura 3.3: Condutividade elétrica das soluções tampão utilizadas nos experimentos de DSC variando a concentração salina, em $T=26^{\circ} C$. A condutividade elétrica é diretamente proporcional à concentração de eletrólitos em solução.

\subsubsection{Sistemas multilamelares versus unilamelares.}

Em geral, os lipossomos aniônicos são unilamelares (LUVs), como o caso de vesículas formadas por DPPG puro, por exemplo. Entretanto, vesículas compostas por lipídios neutros tendem a se organizar em multilamelas (multi-bicamadas) (MLVs). A Figura 3.4 ilustra a representação esquemática dos sistemas multi e unilamelar acompanhados por padrões de di- 
fração obtidos por SAXS. Os múltiplos picos observados na Figura 3.4 estão relacionados à estrutura de repetição das diversas camadas.
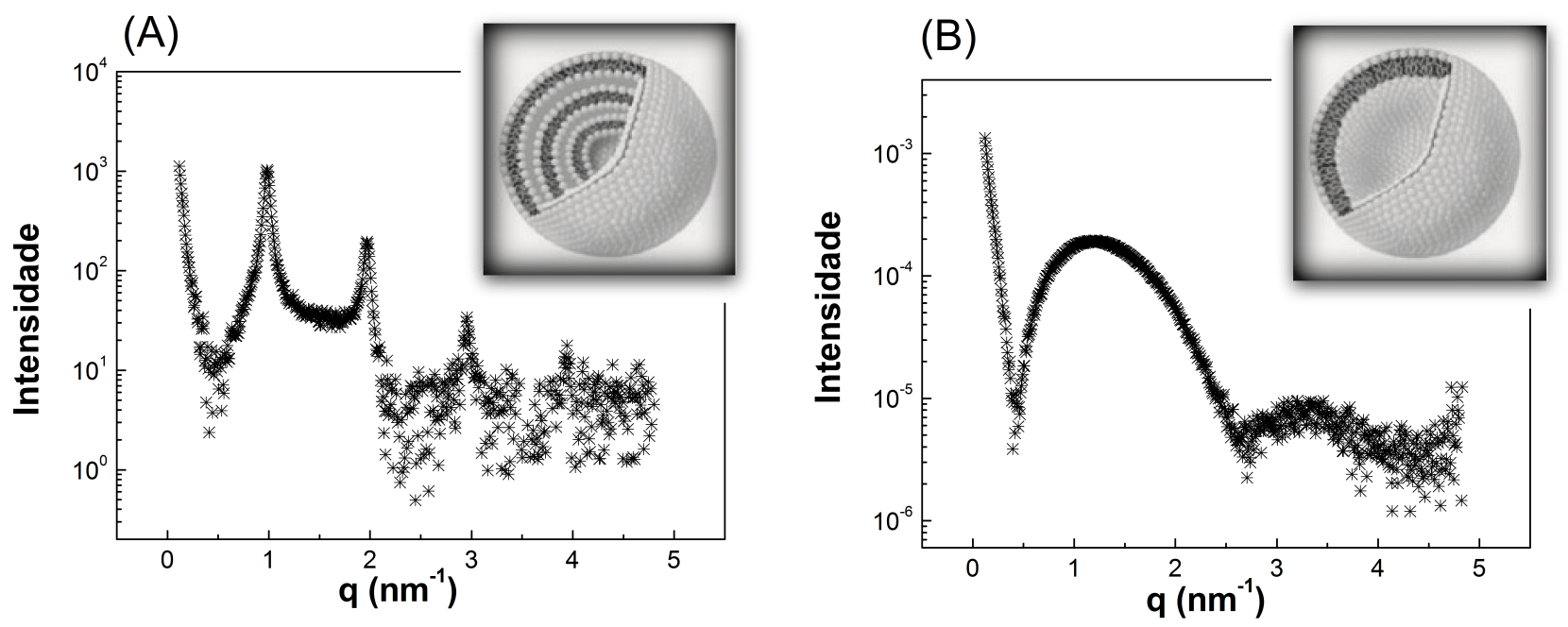

Figura 3.4: Representação esquemática de vesículas multilamelares - MLVs (A) e unilamelares - ULVs (B). Os graficos representam os padrões de difração característicos obtidos por SAXS para MLVs e LUVs. Os picos de repetição observados no primeiro painel referem-se à estrutura de repetição das lamelas, conforme esquematizado em (A). Medidas realizadas no LNLS, conforme descrito no capítulo 6.

Padronizamos condições iniciais semelhantes, e então, optamos em trabalhar com dispersões lipídicas extrusadas. As vesículas extrusadas passam por uma membrana de policarbonato com tamanho de poros bem definidos, em geral da ordem de nanômetros, resultando em vesículas unilamelares com diâmetro similar ao poro da membrana ${ }^{1}$.

Os lipossomos, que naturalmente se organizam em multicamadas, podem atingir tamanhos da ordem do micrometro, e, portanto, esses agregados apresentam pequeno raio de curvatura. Quando extrusados, o tamanho dessas estruturas pode ser reduzido em 3 ordens de grandeza, e, consequentemente, seu raio de curvatura aumenta ${ }^{2}$. Não há problema em trabalharmos com lipossomos de raio de curvatura maior, desde que possamos caracterizar o nosso sistema modelo apropriadamente.

A Figura 3.5 compara os perfis de calor específico para as dispersões lipídicas compostas por DPPC e DPPG, extrusadas e não extrusadas. A transição de fase para vesículas de DPPC organizadas em multicamadas apresenta um pico calorimétrico abrupto e estreito. Esta transição de

\footnotetext{
${ }^{1}$ Maiores detalhes sobre a pregação das amostras serão apresentados na seção de Materiais e Métodos de cada capítulo.

${ }^{2} \mathrm{O}$ raio de curvatura apresenta proporcionalidade inversa ao raio do objeto, Heimburg (2007).
} 
fase é caracterizada como altamente cooperativa. Visto que as estruturas multilamelares apresentam pequeno raio de curvatura, podemos aproximar a geometria da bicamada como plana, de acordo com a Figura 3.6. Nesta geometria, todos os lipídios ocupam a mesma área por lipídio e têm igual probabilidade de transição. Deste modo, quando um lipídio ganha mais graus de liberdade com o aumento da temperatura, passando da fase gel para a fluida, este imediatamente perturba toda a sua vizinhança, favorecendo, portanto, a transição ordem-desordem. Esse fenômeno recebe o nome de efeito cooperativo.

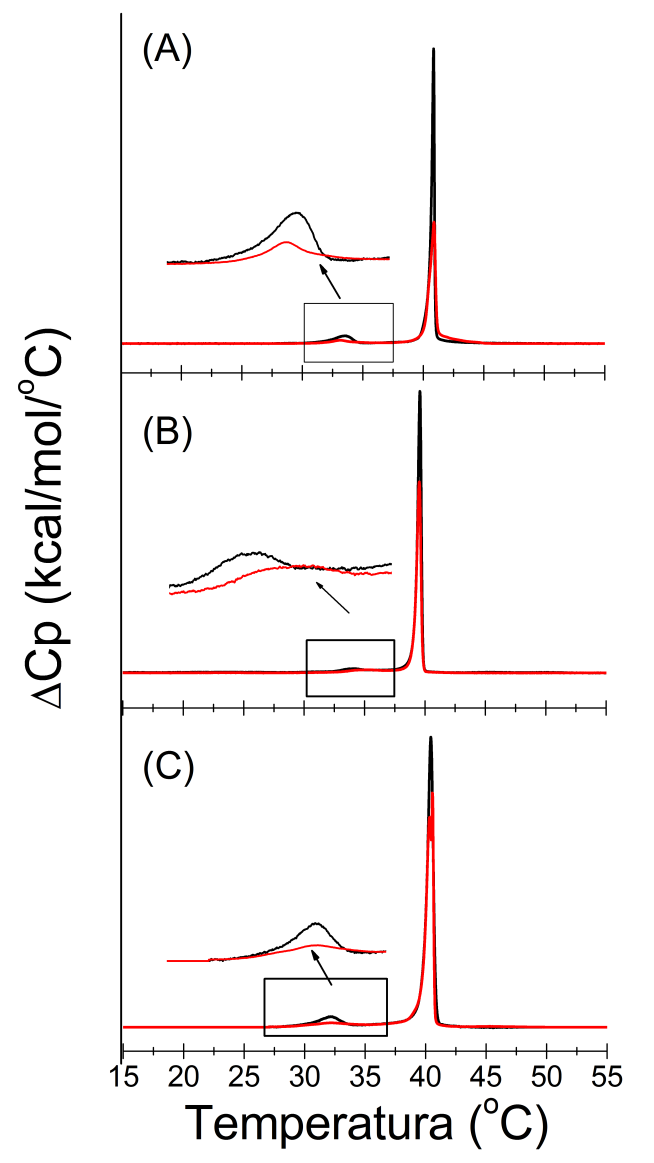

Figura 3.5: Perfis calorimétricos obtidos por DSC comparando sistemas lipídicos extrusados (vermelho) e não extrusados (preto) compostos por: DPPC, DPPG e DPPC:DPPG (ordenados de cima para baixo).

Entretanto, em estruturas com grandes raios de curvatura, como ilustra a Figura 3.6, a própria geometria do sistema imprime diferentes probabilidades de transição do sistema ordenado para o desordenado. Os lipídios que ocupam a camada externa naturalmente apresentam maior área por cabeça polar e estão mais propícios à transição. Deste modo, o sistema passa a ser menos cooperativo na transição de fase, resultando em um pequeno alargamento do pico calorimétrico, como pode ser observado principalmente para o DPPC, extrusado e não extrusado. 

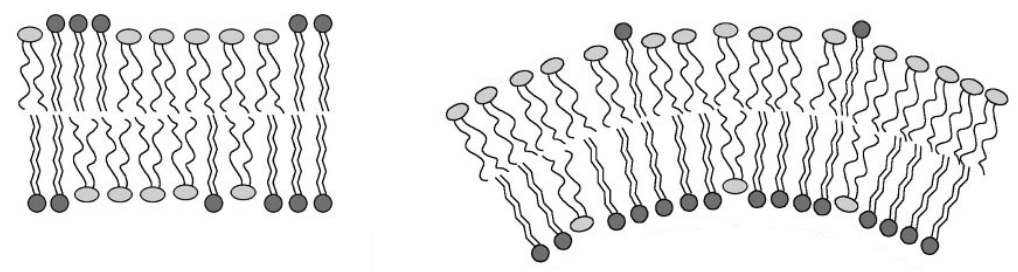

Figura 3.6: Representação esquemática para ilustrar a relação entre o efeito cooperativo na transição de fase e o raio de curvatura do lipossomo, onde a ilustração à esquerda representa uma bicamada com pequeno raio de curvatura, e à direita uma bicamada com grande raio de curvatura. Figura extraída de Heimburg (2007) e adaptada.

\subsubsection{A mistura de lipídios neutros e aniônicos}

Embora dispersões lipídicas extrusadas e não extrusadas apresentem diferentes efeitos cooperativos, a temperatura de transição não apresenta mudanças. A transição gel-fluida do DPPC é observada em $T_{m}=41^{\circ} \mathrm{C}$ (independente da força iônica), enquanto para o DPPG em baixa força iônica, a transição principal apresenta um pequeno deslocamento para $T_{m}=39.5^{\circ} C$, conforme relatado anteriormente em (Riske, Germano et al. 2009). A temperatura de transição da mistura DPPC:DPPG foi observada entre os picos citados do DPPC e DPPG em $T_{m}=40.5^{\circ} C$.

Podemos comparar o termograma obtido pela mistura com um termograma fictício montado a partir da composição entre os perfis calorimétricos do DPPC e do DPPG. A Figura 3.7 mostra um exemplo da soma dos termogramas DPPC e DPPG, onde cada perfil contribui com 50\% da entalpia total (preto), e compara esta soma com a medida experimental obtida para mistura, DPPC:DPPG (1:1) (vermelho). Esse resultado, indica que na mistura de DPPC:DPPG os lipídios neutros e aniônicos estão misturados e não existe a segregação de grandes domínios de PC e PG de modo a coexistirem diferentes picos nas curvas calorimétricas.

Além disso, a mistura também é um sistema unilamelar. Os resultados de SAXS, detalhados no capítulo 6, mostram os perfis de espalhamento obtidos para dispersões lipídicas de DPPC:DPPG (não extrusado), indicando lipossomos compostos por uma única bicamada lipídica.

\subsubsection{Membranas modelo adotadas para o estudo por Microscopia óptica.}

A visualização de vesículas com o uso de um microscópio óptico exige a formação de vesículas gigantes, conforme descrito na seção 4.2.11. As vesículas gigantes possuem tamanhos 


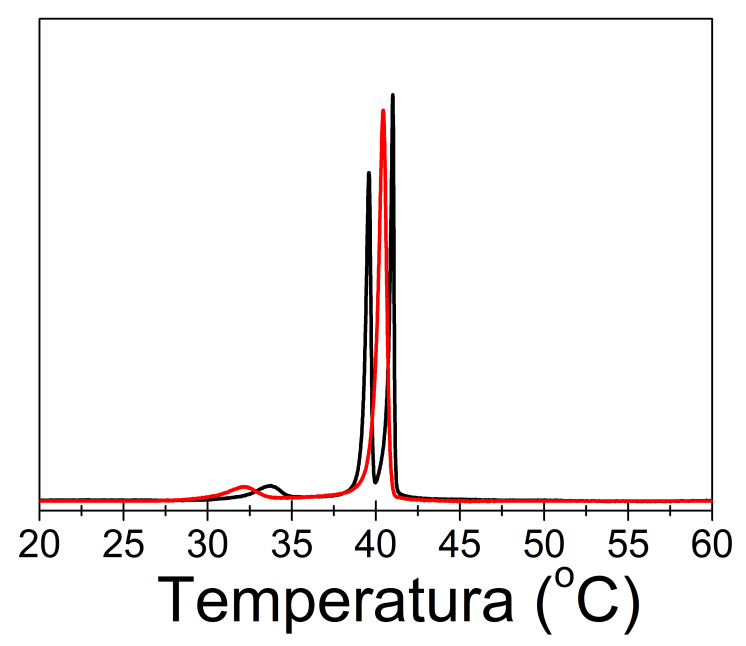

Figura 3.7: Perfil calorimétrico obtido por DSC para a mistura DPPC:DPPG (1:1) (vermelho) comparado ao perfil calorimétrico obtido pela soma dos termogramas medidos individualmente para o DPPC e o DPPG, onde cada curva somada contribui com metade da entalpia total de transição (preto).

da ordem de dezenas ou centenas de micrometros e, portanto, podem ser visualizadas com uso de um microscópio óptico. Em geral, quando as vesículas gigantes organizam-se em estruturas multilamelares podemos observar uma vesícula dentro da outra, ou um contorno espesso delimitando a sua borda. O protocolo experimental para a formação de vesículas gigantes, eletroformação, ( ver seção 4.2.11), difere do protocolo para lipossomos unilamelares (ver seção 4.2.2, por exemplo). No processo de eletroformação, muitas vezes, torna-se difícil produzir vesículas gigantes puramente aniônicas, devido à grande densidade de carga.

Além disso, os lipídios DPPC e DPPG apresentam alta temperatura de transição de fase, aproximadamente em $40^{\circ} \mathrm{C}$. Portanto, para observamos esses lipossomos na fase fluida, precisamos trabalhar em torno de $45-50^{\circ} \mathrm{C}$, o que torna o arranjo experimental mais complicado.

Logo, para os experimentos de microscopia, adotamos o uso de lipídios que apresentam uma insaturação em uma de suas cadeias laterais, e são comumente utilizados para esses estudos. O palmitoil oleoil fosfatidilcolina (POPC), ou palmitoil oleoil fosfatidilglicerol (POPG), apresentam cadeias assimétricas, uma delas contém 16 carbonos e não há insaturações, e outra contém 18 carbonos com uma insaturação no carbono 9. Essas características podem ser apresentadas da seguinte forma (16:0/18:1). Esses lipídios apresentam temperatura de transição de fase em torno de $-2^{\circ} C$, e, portanto, em temperatura ambiente eles estão na fase fluida.

Em resumo, o conhecimento e a caracterização dos sistemas modelo é de fundamental im- 
portância para a compreensão e distinção do efeito de peptídeos antimicrobianos sobre esses sistemas. Na seção seguinte apresentaremos alguns controles específicos do nosso trabalho para os sistemas modelo adotados.

\subsection{Controles}

Definimos como controles experimentos independentes, os quais auxiliam na caracterização correta dos dados experimentais. Nesta seção abordaremos os controles utilizados ao longo dos capítulos 4, 5 e 6, os quais caracterizam a interação do peptídeo antimicrobiano KHya1 com membrana modelos. Deste modo, os resultados aqui apresentados estão diretamente conectados aos resultados que serão discutidos nos capítulos adiante. Em alguns casos, os controles são experimentos testes, utilizados para elaborar o melhor arranjo experimental na coleta dos dados. Optamos em separar os controles dos resultados experimentais de cada capítulo, a fim de obter uma seção experimental mais fácil de ser compreendida.

\subsubsection{Determinação precisa da concentração de peptídeo e lipídio.}

\section{A concentração do estoque de peptídeo}

Embora o peptídeo KHya1, sintetizado no laboratório do Prof. Eduardo Cili (UNESP Araraquara), tenha alto grau de pureza, 99\%, assim como identificado pela espectroscopia de massa, realizada no laboratório do Prof. Cili, a concentração de peptídeo do estoque é sempre determinada pela absorção do Trp, resíduo na posição 7 do peptídeo. Sabendo que o coeficiente

de extinção molar do Trp é $\epsilon=5500(\mathrm{~cm} \mathrm{M})^{-1}$, (Lakowicz, 2006), utilizamos a Lei de LambertBeer para determinar a concentração do estoque, equação 1.2.

Além disso, é importante ressaltar que o peptídeo não se encontra agregado nas concentrações estocadas. Possíveis agregações do peptídeo em solução aquosa poderiam levar a uma leitura equivocada de sua concentração. A Figura 3.8 ilustra um exemplo da leitura da absorbância do peptídeo em água, após a subtração do espectro de absorção do tampão (branco), e a absorbância em $\lambda=280 \mathrm{~nm}$ em função da concentração de peptídeo reproduzindo o comportamento linear da Lei de Lambert-Beer. O gráfico inserido na Figura 3.8(B) foi obtido através de diluições sucessivas, e as concentrações foram calculadas considerando a conservação do número de moles ao longo da diluição ${ }^{3}$. Logo, as concentrações obtidas levam a valores de

\footnotetext{
${ }^{3} C_{1} \cdot V_{1}=C_{2} \cdot V_{2}$
} 
absorbância que decrescem linearmente com a concentração, indicando que o centro absorvedor não apresenta modificações em suas propriedades ópticas, como poderia apresentar se estivesse agregado. Resultados semelhantes serão retomados nos capítulos 4 e 5 para ilustrar que não há agregação lateral do peptídeo.

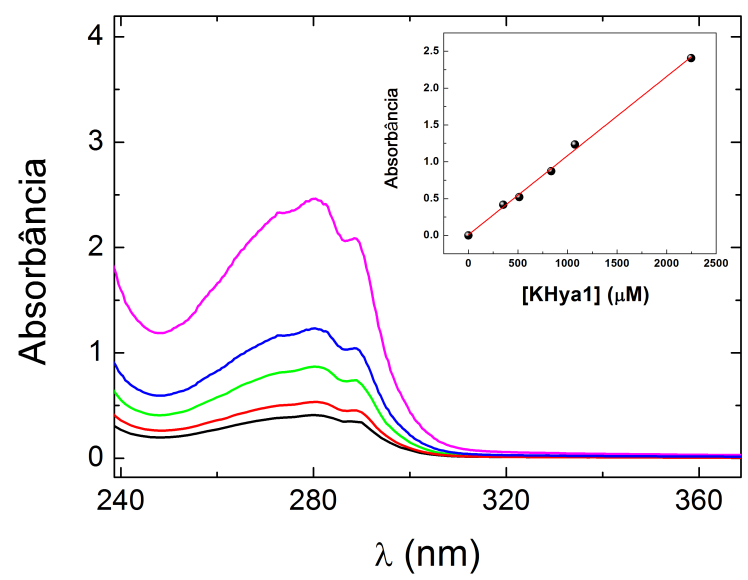

Figura 3.8: Exemplo do espectro de absorção do Trp, resíduo na posição 7 do peptídeo KHya1. O valor da absorbância em $\lambda=280 \mathrm{~nm}$ é utilizado para o cálculo da concentração de peptídeo de acordo com a Lei de Lambert-Beer. A linearidade da Lei de Lambert-Beer é representada pelos valores da Absorbância em $\lambda=280 \mathrm{~nm}$ em função da concentração de peptídeo.

\section{Dosagem de fosfato}

As dosagens de fosfato das amostras que estudamos são experimentos importantes para determinar a concentração exata dos lipídios. O protocolo utilizado para dosar a quantidade de fosfato das amostras, pode ser encontrado em (Rousser et al, 1970) e está resumido a seguir.

1. Separamos alíquotas de $10 \mu L$ das soluções que desejamos determinar a concentração. Esses volumes são dispostos em um tubo de ensaio de $5.0 \mathrm{~mL}$.

2. Estabelecemos uma curva de calibração a partir de 5 referências ( 5 tubos) com uma solução tampão fosfato de concentração $1.0 \mathrm{mM}$. No exemplo que iremos descrever a seguir, cada tubo contém 10; 30; 50; 70 e $90 \mu L$ de tampão. Para a concentração de tampão fosfato que utilizamos, essas quantias correspondem a 10; 30; 50; 70 e 90 n moles de fosfato (n moles Pi), onde Pi é a sigla adotada para fosfato inorgânico. 
A solução que se deseja determinar a concentração deve conter uma quantidade molar dentro do intervalo descrito pela curva de calibração. Neste exemplo, de 10 a 90 n moles de $\mathrm{Pi}$.

3. Então, deixamos as amostras em uma estufa a $120^{\circ} \mathrm{C}$, para secar o conteúdo dos tubos.

4. A partir desse passo, inclui-se uma referência que não contém fosfato, que servirá de branco nas leituras do espectrofotômetro.

5. Adicionamos $0.4 \mathrm{~mL}$ de ácido perclórico, $\mathrm{HClO}_{4}$, concentrado, 70\%, e colocamos os tubos em um bloco quente a $180^{\circ} \mathrm{C}$. Os tubos são vedados com bolinhas de gude para minimizar efeitos da evaporação. Essa condição deve ser mantida por 1 hora.

6. Após esfriar, adicionamos $1.0 \mathrm{~mL}$ de água destilada, e a solução é imediatamente agitada em vórtex.

7. Adicionamos $0.4 \mathrm{~mL}$ de molibidato de amônio $25 \%(\mathrm{p} / \mathrm{v})$, e novamente agitamos em vórtex.

8. Em seguida, são adicionados $0.4 \mathrm{~mL}$ de ácido ascórbico $3 \%(\mathrm{p} / \mathrm{v})$, e a mistura é agitada.

9. Os tubos são então deixados em banho térmico com agua fervente, por cerca de 10 minutos, para a formação do composto que absorve luz em $\lambda=797 \mathrm{~nm}$.

10. Após as amostras esfriarem, e com o uso de um espectrofotômetro, medimos a absorbância em $\lambda=797 \mathrm{~nm}$ após a subtração do branco.

As leituras das referências nos fornecem a curva de calibração, e as leituras das amostras que desejamos determinar a concentração são comparadas com os valores obtidos na curva de calibração. Assim podemos determinar o número de moles que a alíquota inicial continha.

A Figura 3.9 mostra alguns exemplos da dosagem de fosfato para amostras de DPPG. Os pontos em azul correspondem às soluções padrão de fosfato, ou seja, à curva de calibração, onde tomamos a média de duplicatas de amostras. Os pontos em pretos correspondem às alíquotas das dispersões lipídicas medidas, onde calculamos a média de 3 amostras independentes (triplicatas). A linha tracejada mostra um exemplo de uma determinada alíquota de $10 \mu L$, que contém 35.8 n moles, e portanto concentração $3.58 \mathrm{~m} M$. A concentração, $C$, é dada por $C=n / V$, onde $n$ é o número de moles e $V$ o volume. 


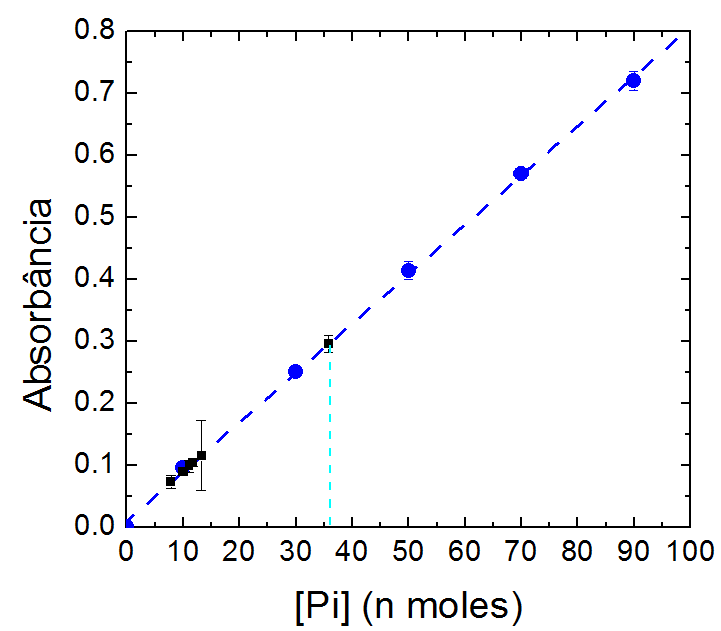

Figura 3.9: Exemplo da determinação da concentração de fósforo inorgânico, Pi, de amostras submetidas à dosagem de fosfato. A linha tracejada ilustra a curva de calibração e os pontos são exemplos de triplicas de amostras.

\subsubsection{A peculiaridade do comportamento calorimétrico da mistura de DPPC:DDPG com a temperatura inicial da medida}

Eperimentos com essa mistura de lipídios, utilizando DSC, revelaram um evento térmico que ocorre abaixo da pré-transição, em $23^{\circ} \mathrm{C}$, o qual apresenta uma dependência com a temperatura inicial da medida. Esse evento térmico pode ser observado para amostras extrusadas e não extrusadas, sendo mais intenso em amostras não extrusadas.

A Figura 3.10 mostra diferentes medidas da mesma amostra, onde os perfis calorimétricos foram obtidos com os mesmos parâmetros de varredura e para diferentes temperaturas iniciais $\left(T=5,10,15^{\circ} C\right)$. Na medida identificada por (Varredura de $\left.\mathrm{N}^{o} 1\right)$, a varredura iniciou-se de $T=15^{\circ} \mathrm{C}$, e o pico calorimétrico em $T=23^{\circ} \mathrm{C}$ não foi constatado. A medida realizada em (Varredura de $\mathrm{N}^{o}$ 2) foi iniciada em $T=10^{\circ} \mathrm{C}$, e já houve pequeno pronunciamento deste evento térmico. E por fim a (Varredura de $\mathrm{N}^{o} 3$ ), com temperatura inicial $T=5^{\circ} \mathrm{C}$ o pico em $T=23^{\circ} \mathrm{C}$ apresentou entalpia superior à pré-transição, e equivalente a $\Delta \mathrm{H}=(4,1 \pm 0,5)$ kcal/mol, para o caso não extrusado. Logo, a temperatura inicial da medida está relacionada à existência deste evento térmico. Além disso, a ordem que os experimentos são reproduzidos não altera o resultado. A existência desse evento térmico depende apenas da temperatura inicial.

Alguns trabalhos na Literatura reportam que alguns sistemas lipídicos apresentam sub fases, as quais são dependentes da termalização e do histórico da amostra. O DPPC, por exemplo, quando encubado em baixas temperaturas pode apresentar uma fase caracterizada 
(A)

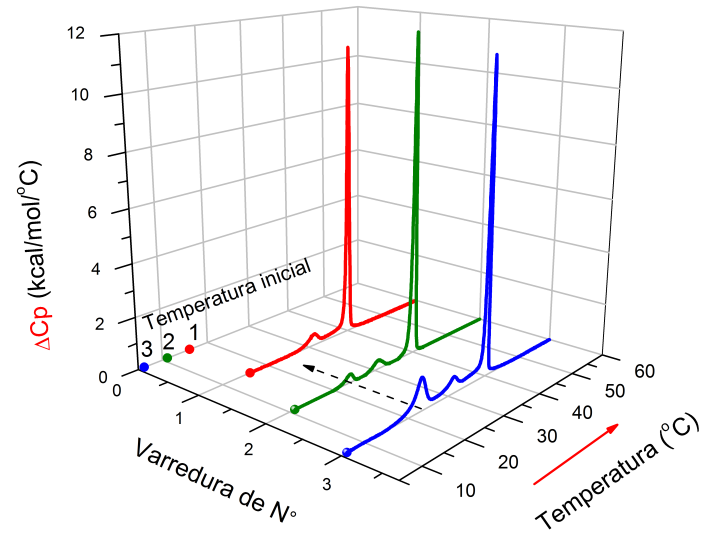

(B)

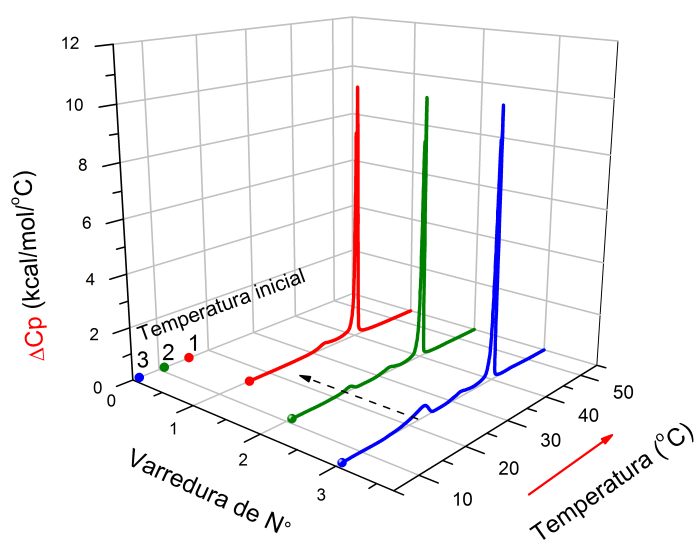

Figura 3.10: Curvas calorimétricas para as dispersões lipídicas mistas de DPPC:DPPG (1:1) (1.0 mM) não extrusadas (A) e extrusadas (B). As medidas foram realizadas com o aumento da temperatura, partindo de diferentes temperaturas iniciais: $T=15,10 e 5^{\circ} C$ representadas nas Varreduras de $\mathrm{N}^{o} 1$, 2 e 3 , respectivamente.

por fase sub-gel ((Tristram-Nagle e Nagle, 2004)), onde os autores sugerem que o estoque em baixas temperaturas leva a uma estrutura mais similar à estrutura de um cristal.

Neste trabalho, não nos preocupamos com a caracterização estrutural da bicamada que origina este evento térmico, a $23^{\circ} \mathrm{C}$. Optamos por começar todas as medidas experimentais em temperaturas igual ou superior a $15^{\circ} \mathrm{C}$, a fim de evitar qualquer que seja o arranjo estrutural dos lipídios a baixas temperaturas. Supomos que ao iniciar as medidas da mistura a $15^{\circ} \mathrm{C}$, obtemos uma fase gel abaixo da temperatura de transição principal, a qual se assemelha às demais fases gel observadas para o DPPC e DPPG. Diversos parâmetros experimentais obtidos para a mistura de lipídios, DPPC:DPPG, entre $15^{\circ} \mathrm{C}$ e a transição de fase principal são compatíveis com os mesmos parâmetros observados para os lipossomos puros compostos por DPPC ou DPPG, sugerindo que a fase gel da mistura é similar à fase gel dos compostos puros.

\subsubsection{O vazamento espontâneo dos lipossomos}

O resultado apresentado a seguir está diretamente relacionado aos resultados experimentais apresentados no capítulo 4, seção 4.3.5. A referida seção apresenta cinéticas de vazamento de uma sonda fluorescente encapsula no volume interno dos lipossomos (detalhes sobre o procedimento experimental podem ser encontrados na seção 4.2.10). A ação do peptídeo antimicrobiano sobre os lipossomos leva ao vazamento do conteúdo interno das membranas modelo, 
onde o vazamento da sonda fluorescente é monitorado através da fluorescência da sonda. No capítulo 4 comparamos o efeito do peptídeo em diferentes bicamadas lipídicas: DPPC, DPPG e DPPC:DPPG. Logo, um controle indispensável para esse experimento é diferenciar o vazamento espontâneo dos lipossomos do vazamento causado pelo peptídeo.

A Figura 3.11 mostra a porcentagem de vazamento dos lipossomos compostos por DPPC, DPPG e DPPC:DPPG, na fase gel dos lipídios $\left(T=25^{\circ} C\right.$ ) e em função do tempo (curvas em preto). No instante de tempo $t=2000 \mathrm{~s}$ a porcentagem de vazamento equivalente a $100 \%$ foi obtida através do rompimento de todos os lipossomos com o uso de um detergente, de acordo com a seção experimental 4.2.10. A porcentagem de vazamento foi calculada de acordo com a equação (4.5), capítulo 4 .

Portanto, podemos observar que o vazamento espontâneo dos lipossomos na fase gel, no tempo da coleta de dados, equivale a menos de $1 \%$ do vazamento total, de modo que esse pode ser desprezado nas cinéticas analisadas na Figura 4.9.
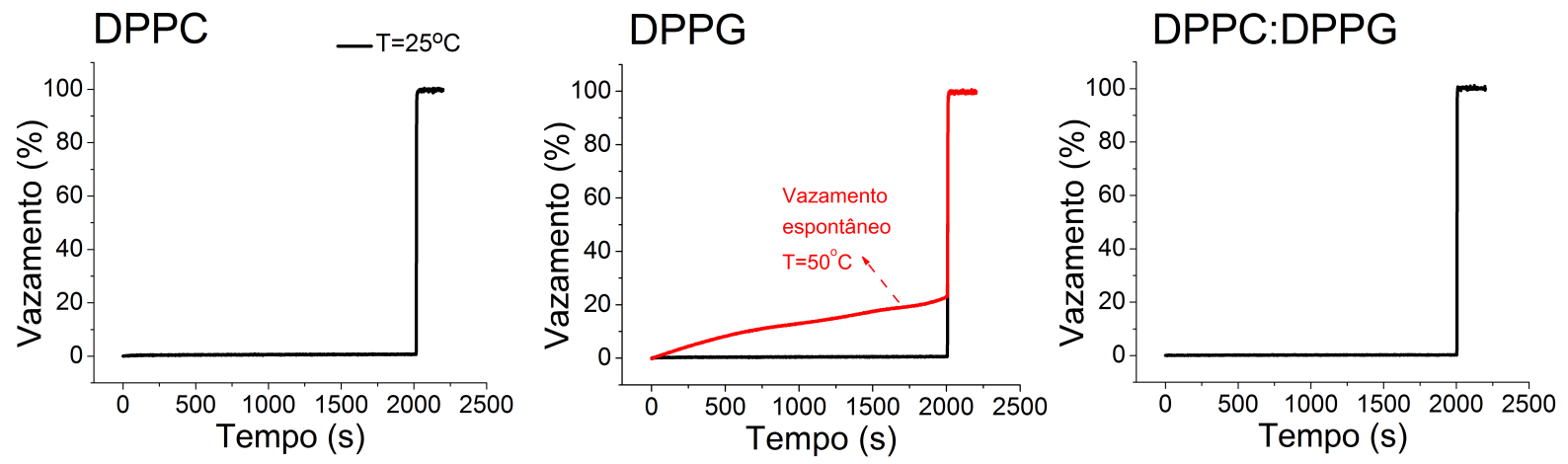

Figura 3.11: Exemplo do vazamento espontâneo de lipossomos compostos por DPPC, DPPG e DPPC:DPPG.

Entretanto os lipossomos compostos por DPPG na fase fluida $\left(T=50^{\circ} \mathrm{C}\right)$ apresentam considerável vazamento espontâneo. A Figura 3.11 ilustra a porcentagem de vazamento de lipossomos de DPPG em $T=50^{\circ} \mathrm{C}$ em função do tempo (segundo painel - curva vermelha). Embora os lipossomos negativamente carregados sejam naturalmente mais permeáveis na fase fluida (Barroso, et. al. 2012), supomos que o aumento da energia cinética das moléculas devido à agitação térmica, também favoreça o aumento da permeabilidade da membrana. Neste caso, o estudo do vazamento da sonda fluorescente encapsulada no volume interno do lipossomo, e sob o efeito do peptídeo antimicrobiano, pode ser comprometido, pois torna-se difícil diferenciar o vazamento espontâneo do lipossomo, uma vez que esse evolui com o tempo, do efeito causado pelo peptídeo. Portanto, não foram realizados experimentos de vazamento na fase fluida 
das dispersões lipídicas compostas por DPPC, DPPG e DPPC:DPPG, conforme discutido no capítulo 4 .

\subsubsection{A transferência de energia (FRET) entre Trp e Laurdan.}

Os resultados experimentais apresentados a seguir estão diretamente relacionados com os resultados do capítulo 5. Neste capítulo, caracterizamos a transferência de energia entre o Trp, uma sonda intrínseca do peptídeo, e o Laurdan, sonda extrínseca incorporada à membrana lipídica. Em resumo, a transferência de energia (FRET-Förster energy transfer) corresponde a uma supressão de fluorescência de um fluoróforo, denominado doador, na presença de uma molécula denominada de aceitador. A transferência de energia também é caracterizada pela sobreposição dos espectros de emissão do doador e de absorção do aceitador. Neste caso o Trp corresponde ao doador e o Laudan ao aceitador. A Figura 5.26, capítulo 5, mostra a sobreposição das bandas de emissão do Trp e absorção do Laurdan.

Além da sobreposição dos espectros, o tempo de vida do doador diminui em função do aumento da concentração do aceitador. Logo, testamos como o tempo de vida do Trp (doador) é alterado com o aumento da concentração de aceitador. Preparamos, portanto, dispersões lipídicas de DPPG com uma concentração fixa de peptídeo, 2 mol\% (2\% de peptídeo por lipídio, razão em mol) e diferentes concentrações de Laurdan: 1, 2 e 3 mol\% (1, 2 e 3 mol\% de Laurdan por mol de lipídio). As amostras que contém Laurdan são preparadas a partir de diferentes filmes lipídicos, com suas respectivas concentrações de marcador, conforme descrito em materiais e métodos, capítulo 5 .

A Figura 3.12 mostra os decaimentos de fluorescência do Trp, em $\lambda_{e m s}=325 \mathrm{~nm}$. As medidas foram realizadas na fase fluida do lipídio, $T=50^{\circ} \mathrm{C}$. As mudanças observadas nos decaimentos indicam que os tempos de vida do Trp estão diminuindo com o aumento da concentração de Laurdan (aceitador). O Trp apresenta 3 diferentes tempos de vida, conforme discutido no capítulo 5 .

A Figura 3.13 compara os tempos de vida do Trp (doador) na ausência de aceitador, $\tau_{d}$;

com os tempos de vida do doador em presença de aceitador, $\tau_{d a}$. Logo, razões $\tau_{d a} / \tau_{d}<1$ indicam que $\tau_{d a}<\tau_{d}$ confirmando que os tempos de vida do Trp diminuem com o aumento da concentração de Laurdan.

Esses experimentos auxiliam na validação do FRET entre o Trp e o Laurdan. Contudo, o principal foco desse estudo refere-se ao efeito do peptídeo KHya1 em membranas lipídicas, e 


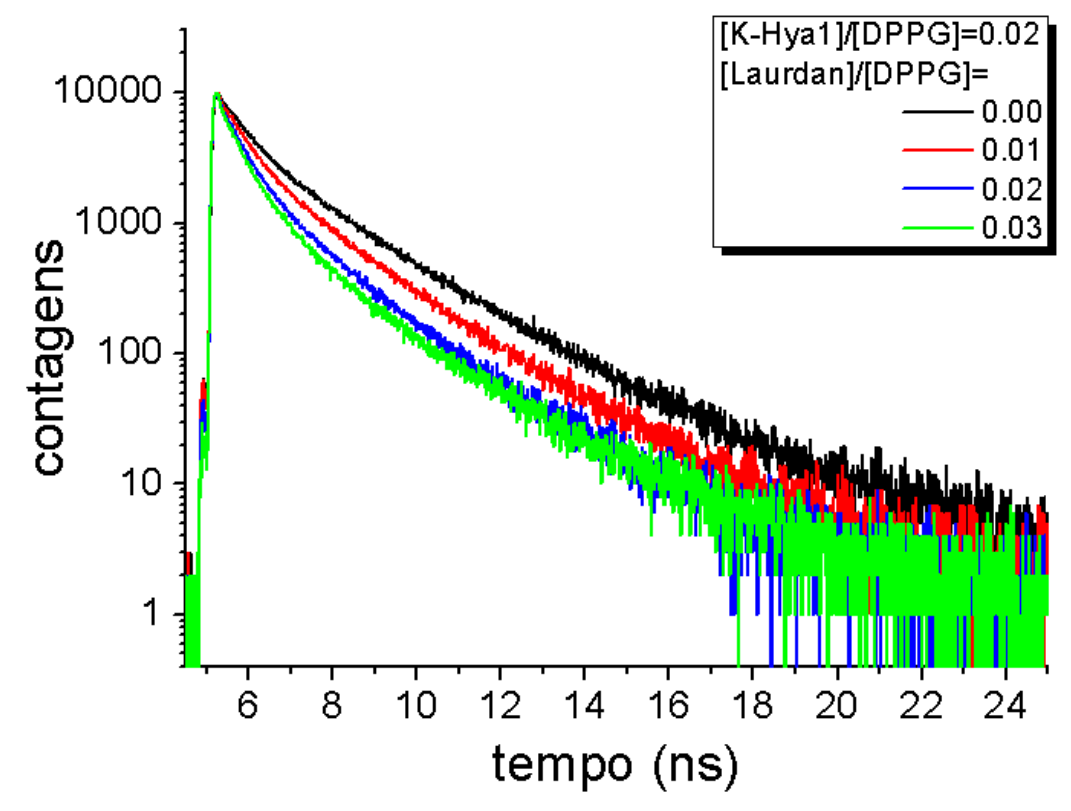

Figura 3.12: Decaimento Fluorescente do doador, Trp, em ausência e presença do aceitador, Laurdan e em função do aumento da concentração do aceitador $\left(\lambda_{e x c}=280 \mathrm{~nm}, \lambda_{\text {ems }}=325 \mathrm{~nm}\right)$.

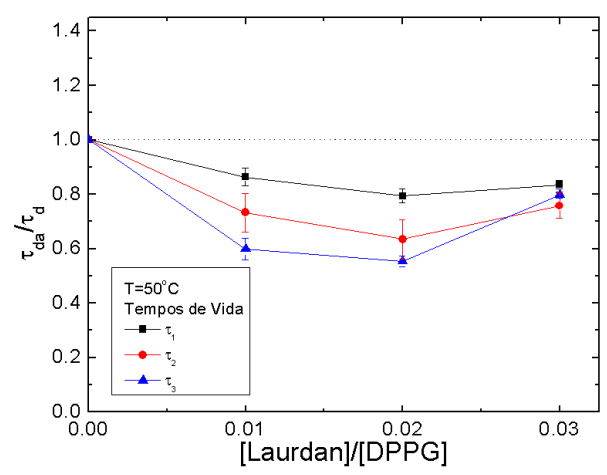

Figura 3.13: A diminuição do tempo de vida do doador na presença do aceitador é representada pela razão $\tau_{d a} / \tau_{d}$ em função do aumento da concentração de aceitador, em $T=50^{\circ} \mathrm{C}$.

convém estudarmos o aumento da concentração de peptídeo, em vez do aumento da concentração de Laurdan. No capítulo 5, discutimos o efeito do aumento da concentração de peptídeo em membranas de DPPG, com análises baseadas na transferência de energia entre a sonda natural do peptídeo e a sonda inserida na bicamada, Laurdan. 


\subsubsection{Tamanho dos lipossomos na ausência de peptídeo: condição inicial}

Como mencionado no item 3.1.4, optamos em trabalhar com lipossomos extrusados. No processo de extrusão adotado ao longo dos capítulos 4, 5 e 6, os lipossomos passam por uma membrana de policarbonato com tamanho de $100 \mathrm{~nm}$, resultando em lipossomos com tamanhos similares a este poro. Em geral, medimos o raio efetivo dos lipossomos antes de iniciarmos os estudos experimentais.

A Tabela 3.1 mostra o diâmetro efetivo obtido para diversas medidas coletadas ao longo de todos os resultados experimentais. Portanto, em geral, partimos de uma condição inicial de lipossomos compostos por DPPC ou DPPG ou DPPC:DPPG que possuem diâmetro efetivo próximo a $100 \mathrm{~nm}$.

\begin{tabular}{ccc}
\multicolumn{3}{c}{ Diâmetro efetivo $(\mathrm{nm})$} \\
\hline DPPC & DPPG & DPPC:DPPG \\
\hline \hline $114 \pm 10$ & $102 \pm 7$ & $105 \pm 8$ \\
\hline \hline
\end{tabular}

Tabela 3.1: Diâmetro efetivo obtido por DLS para diversas medidas dos lipossomos compostos por DPPC, DPPG e DPPC:DPPG.

Curiosamente, as dispersões lipídicas de DPPC apresentam um diâmetro efetivo e um desvio maior. Como mencionado anteriormente, as vesículas de DPPC podem formar grandes estruturas multilamelares e consequentemente seu processo de extrusão é mais difícil. Logo, conforme indica a Tabela 3.1 ainda há alguma porcentagem de agregados um pouco maiores que $100 \mathrm{~nm}$ nas dispersões de DPPC.

\subsubsection{A quantidade certa de marcador paramagnético}

Para trabalhar com ESR, precisamos inserir sondas paramagnéticas em nosso sistema de estudo. Em geral, sondas paramagnéticas, ou mesmo sondas fluorescentes, devem ser adicionadas em baixas quantidades para não interferir ou modificar as propriedades do sistema modelo. Contudo, estamos trabalhando com concentrações lipídicas baixas, da ordem de 1 - $3 m M$, e, dependendo da quantidade de sonda que iremos utilizar, podemos afetar nosso sistema, ou não ter uma leitura apropriada do sinal paramagnético.

Deste modo, testamos algumas razões molares de sonda paramagnética para obter uma boa relação entre o sinal e ruído da medida experimental (sinal/ruído), e sem a interferência entre 
sondas, pois quando a concentração de sondas paramagnéticas é alta, as sondas começam a interagir entre si, apresentando um sinal de ESR alargado.

Os gráficos da Figura 3.14 mostram algumas razões molares de 16-PCSL em dispersões lipídicas mistas (DPPC:DPPG), na fase gel e na fase fluida. Podemos observar que a fração de 0.2 mol\% deixa o sinal de ESR bem ruidoso, principalmente na fase gel. À medida que aumentamos a fração de sonda, a relação sinal/ruído melhora, mas o sinal passa a ser comprometido pela interação spin-spin, principalmente observado na fase fluida.

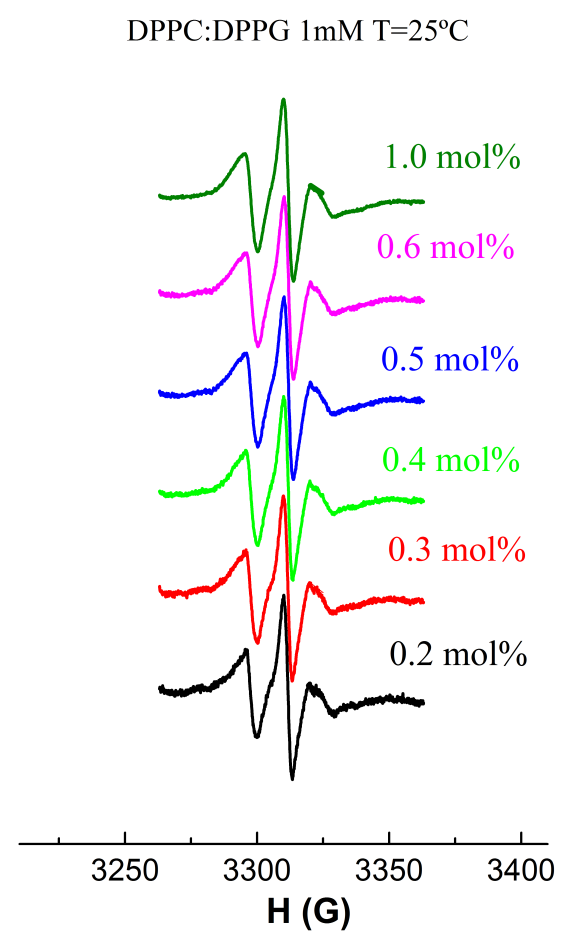

DPPC:DPPG $1 \mathrm{mM} \mathrm{T}=45^{\circ} \mathrm{C}$

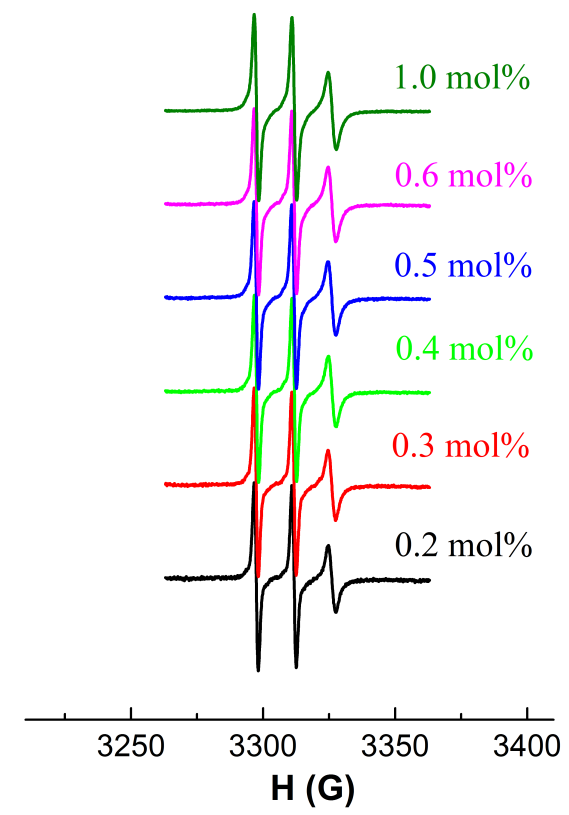

Figura 3.14: Sinais de ESR para dispersões lipídicas de DPPC:DPPG (1:1) em função do aumento da razão molar de marcador paramagnético 16-PCSL, 0.2, 0.3, 0.4, 0.5 e $1.0 \mathrm{~mol} \%$. Fase gel, $T=25^{\circ} \mathrm{C}$ e fase fluida, $T=45^{\circ} \mathrm{C}$.

Portanto, na Figura 3.15 comparamos a menor razão molar de sonda paramagnética utilizada com as demais. Observamos que para $0.6 \mathrm{~mol} \%$ de marcador 16-SLPC há um nítido alargamento do sinal paramagnético, enquanto $0.5 \mathrm{~mol} \%$ apresenta um pequeno alargamento. Logo, concluímos que a fração de 0.4 mol\%, corresponde à razão ideal para ser utilizada na coleta de dados, pois relação a sinal/ruído já apresenta melhora, sem o comprometimento da interação entre as sondas. 

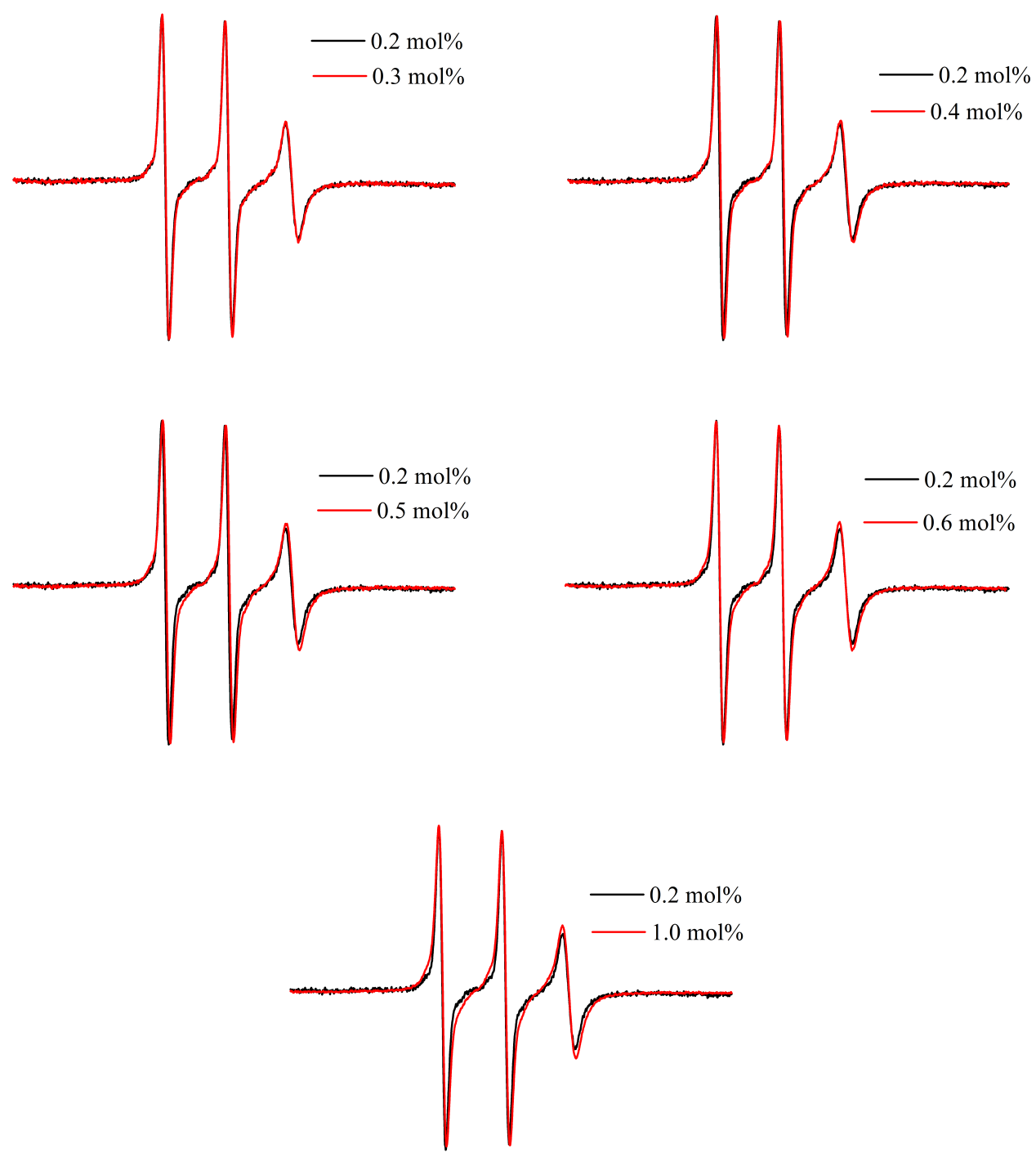

Figura 3.15: Comparação das razões molares de sonda paramagnética 16-PCSL utilizada nas medidas de ESR para a mistura DPPC:DPPG, fase fluida. A menor razão molar 0.2 mol\% é comparada com as demais.

\subsubsection{O controle de temperatura no ESR}

O controle de temperaturas do ESR é realizado através do módulo controlador de temperaturas da Bruker (Eurothem), e é realizado com o auxilio de um fluxo de nitrogênio, o qual envolve a amostra que está contida em um fino capilar de quartzo. Entretanto, esse sistema de controle de temperaturas apresenta desvios, onde a temperatura acertada na interface de aquisição de dados difere ligeiramente da temperatura real na amostra. Esses desvios não são apenas devido a perdas de calor para o meio, pois para algumas temperaturas, a temperatura na amostra é maior que a temperatura ajustada no programa de controle. 
Deste modo, o grupo de Biofísica desenvolveu uma curva de calibração que leva a temperatura ajustada no programa de aquisição à temperatura real na amostra. Essa curva de calibração foi obtida através de várias medidas de temperaturas com o uso de um termopar colocado no interior de uma solução aquosa. Tal controle foi realizado diversas vezes e por diferentes operadores, resultando em uma curva de calibração bem reprodutível com ilustra a Figura 3.16.

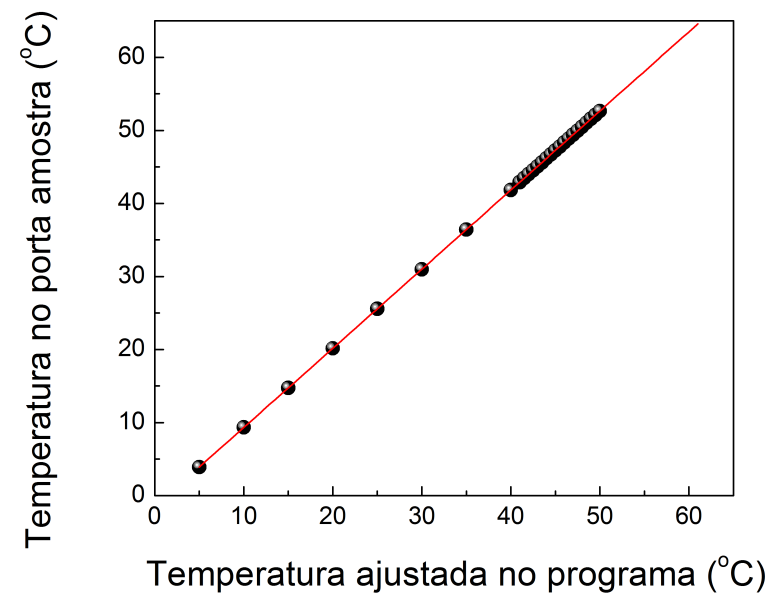

Figura 3.16: Curva de calibração do sistema de controle de temperatura do equipamento de ressonância paramagnética eletrônica.

Portanto, as temperaturas das curvas de ESR discutidas no capítulo 6 foram corrigidas conforme a equação (3.1)

$$
T_{\text {amostra }}\left({ }^{\circ} C\right)=-1.51869+1.08369 \cdot T_{\text {programa }}\left({ }^{o} C\right)
$$

que ajusta os pontos experimentais apresentados no gráfico da Figura 3.16.

Por fim, os controles são experimentos independentes e muitas vezes são laboriosos, mas também são importantes quer sejam como testes preliminares ou como experimentos complementares. 



\section{Capítulo 4}

\section{Interações distintas entre o peptídeo KHya1 e membranas aniônicas e neutras}

\subsection{Motivação}

Neste trabalho buscamos investigar o efeito do peptídeo antimicrobiano KHya1 em membranas modelo compostas por DPPC, DPPG e a mistura DPPC:DPPG com as técnicas experimentais: DSC, fluorescência estática do Trp, DLS, e experimentos de vazamento de sonda encapsulada no interior de lipossomos, LUVs. Observamos que o peptídeo KHya1 apresenta diferentes interações com lipossomos neutros e aniônicos. Essas diferenças podem ser atribuídas a diferentes posições do peptídeo na bicamada lipídica, e a localização espacial do peptídeo na membrana é mediada pela interação peptídeo - lipídio, onde a interação eletrostática tem importante contribuição para definir as diferenças observadas. Além disso, experimentos complementares com o uso da microscopia óptica em vesículas gigantes compostas por POPC e POPC: POPG, claramente mostram a diferença na ação do peptídeo KHyal em vesículas neutras e aniônicas, corroborando o fato de que a interação eletrostática entre o peptídeo catiônico e o grupo PG é importante para levar a efeitos distintos do observado no sistema neutro.

\subsection{Materiais e Métodos}

\subsubsection{Reagentes}

Lipídios: dipalmitoil fosfatidilcolina (DPPC), dipalmitoil fosfatidilglicerol (DPPG), (Avanti Polar Lipids, Inc.). Peptídeo: K-Hya1 sintetizado no laboratório do Prof. Eduardo Cilli, 
(UNESP). Tampão: (N-[2-hidroxietil]piperazina-N'-[2-etanosulfônico ácido]) (HEPES) - (Sigma Chemical, Co.), sal: Cloreto de sódio (NaCl) - (Sigma Chemical, Co.).

\subsubsection{Preparações das dispersões lipídicas}

Para preparação de vesículas os lipídios são diluídos em clorofórmio e depois submetidos a um fluxo de nitrogênio, $N_{2}$, levando à formação de um filme na parede do tudo de ensaio. Então, esse filme é submetido à baixa pressão por três horas para remover resquícios do solvente orgânico. As dispersões lipídicas são suspendidas com a adição de tampão HEPES 10 mM em pH=7.4 com $1.0 \mathrm{mM}$ de EDTA e $3.0 \mathrm{mM}$ de $\mathrm{NaCl}$ aos filmes lipídicos e sob agitação (vórtex) durante aproximadamente 2 minutos, na temperatura $T=45^{\circ} \mathrm{C}$.

\subsubsection{Vesículas extrusadas}

Com o uso de um extrusor (Avanti Polar Lipids, Inc.), as vesículas passam por um filtro de policarbonato (Nuclepore) de $19 \mathrm{~mm}$ de diâmetro com poros de diâmetro de $100 \mathrm{~nm}$. Esse processo é repetido 31 vezes para formar vesículas unilamelares (LUVs) de tamanhos aproximados ao diâmetro dos poros do filtro.

\subsubsection{Experimentos de vazamento de sonda encapsulada no interior de lipossomos}

Para as medidas de vazamento de sonda fluorescente, os filmes lipídicos são hidratados com tampão que contém $50 m M$ de carboxifluoreceína, CF $(10 m M$ de HEPES com $1 m M$ de EDTA, $3 m M$ de $\mathrm{NaCl}$ e $50 m M$ de $\mathrm{CF}$, pH =7.4). A alta concentração de sonda fluorescente foi utilizada para suprimir o sinal de fluorescência da sonda encapsulada. Então, a dispersão lipídica foi extrusada como descrito no item 4.2.3. Finalmente, a sonda fluorescente não encapsulada foi removida passando a dispersão lipídica por uma coluna de separação, coluna Sephadex-G25. A eluição foi realizada com um tampão que contém $150 \mathrm{mM}$ de glicose (10 $m M$ de HEPES com $1 m M$ de EDTA, $3 m M$ de $\mathrm{NaCl}$ e $150 m M$ de glicose, $\mathrm{pH}=7.4)$. Essa quantidade de açúcar é necessária para acertar a osmolaridade do meio externo e interno do lipossomo. Após esse processo de exclusão por tamanhos, a concentração final da dispersão lipídica coletada é determinada por dosagem de fosfato com o protocolo descrito no capítulo 3 , seção 3.2.1. 


\subsubsection{Razão molar do peptídeo}

A razão molar peptídeo/lipídio, $[\mathrm{P}] /[\mathrm{L}]$, corresponde à razão entre a concentração de peptídeo [P] e a concentração de lipídio [L], onde L pode ser DPPC, DPPG ou a mistura DPPC:DPPG (1:1). Para os estudos de absorção óptica, fluorescência do Trp e espalhamento de luz dinâmico, alíquotas da solução estoque de peptídeo foram adicionadas à dispersão lipídica após a extrusão, levando ao aumento de das razões $[\mathrm{P}] /[\mathrm{L}]$. A solução estoque de peptídeo foi preparada com o mesmo tampão descrito no item 4.2.2 e a concentração de peptídeo foi medida

pela absorção do $\operatorname{Trp}$ em $\lambda=280 \mathrm{~nm}$, utilizando $\epsilon=5500(\mathrm{M} . \mathrm{cm})^{-1} \mathrm{~s}$, conforme descrito em Modelo e Controles, capítulo 3. Mesmo que o volume de peptídeo adicionado seja pequeno, o volume total da amostra foi corrigido pelos incrementos de volumes adicionados e a correta razão molar $[\mathrm{P}] /[\mathrm{L}]$ foi calculada. Por outro lado, cada amostra com diferente razão molar, dos experimentos de calorimetria diferencial de varredura, vazamento da sonda fluorescente encapsulada e microscopia óptica, foi preparada individualmente.

\subsubsection{Calorimetria diferencial de varredura (DSC)}

Experimentos de calorimetria (DSC) foram realizados em um microcalorímetro (Microcal VP-DSC, Northampton, MA, USA). Os perfis calorimétricos foram obtidos em uma taxa de $20^{\circ} \mathrm{C} / \mathrm{h}$ (scan rate). A cela da amostra, de volume de aproximadamente $500 \mu L$, foi preenchida com 3.0 mM de dispersão lipídica e com a desejada concentração de peptídeo. A cela da referência foi preenchida com tampão HEPES, conforme descrito na seção 4.2.5. Maiores informações sobre a técnica podem ser encontradas no capítulo 2.

As análises de DSC, como subtração da linha de base, cálculo da entalpia foram desenvolvidos no programa Origin, o qual possui um módulo adicional desenvolvido pela própria Microcal para esse tratamento. As análises dos perfis calorimétricos já foram bem reportadas pelo grupo de acordo com (Riske et al. 2009). Os perfis calorimétricos mostrados ao longo desse capítulo representam curvas típicas obtidas por réplicas de amostras; pelo menos duas réplicas são realizadas para cada medida experimental.

\subsubsection{Absorção óptica do Trp}

A absorção do resíduo Trp foi monitorada com o uso de um espectrofotômetro (Varian Cary, Santa Clara, CA). As amostras contendo $500 \mu L$ de dispersão lipídica são colocadas em uma cubeta de quartzo $(0.2 \times 1.0 \mathrm{~cm})$ com caminho ótico de $1.0 \mathrm{~cm}$. As medidas do 
peptídeo em dispersões lipídicas foram realizadas em $T=25$ e $45^{\circ} C$, onde a temperatura foi controlada ao longo dos experimentos com o uso de um controlador de temperaturas Carry Peltier thermostatted system.

Visto que a adição do peptídeo leva ao aumento dos valores da absorbância, especialmente no intervalo 270-350 $\mathrm{nm}$, então a fluorescência do Trp deve ser corrigida pelo efeito de filtro interno ("Inner filter effect") (Tucker, Amszi, e Acree, 1992).

A Figura 4.1 mostra um exemplo do espectro de absorção, onde o pico de absorção do Trp pode ser observado em cima de uma curva característica de espalhamento, a qual aumenta à medida que a concentração de peptídeo aumenta. As setas apontadas no gráfico da Figura 4.1 ilustram os valores a serem considerados na correção de filtro interno para a espectroscopia de fluorescência $\lambda_{e x c}=280 \mathrm{~nm}$ e $\lambda_{e m}=290-400 \mathrm{~nm}$, como será discutido adiante.

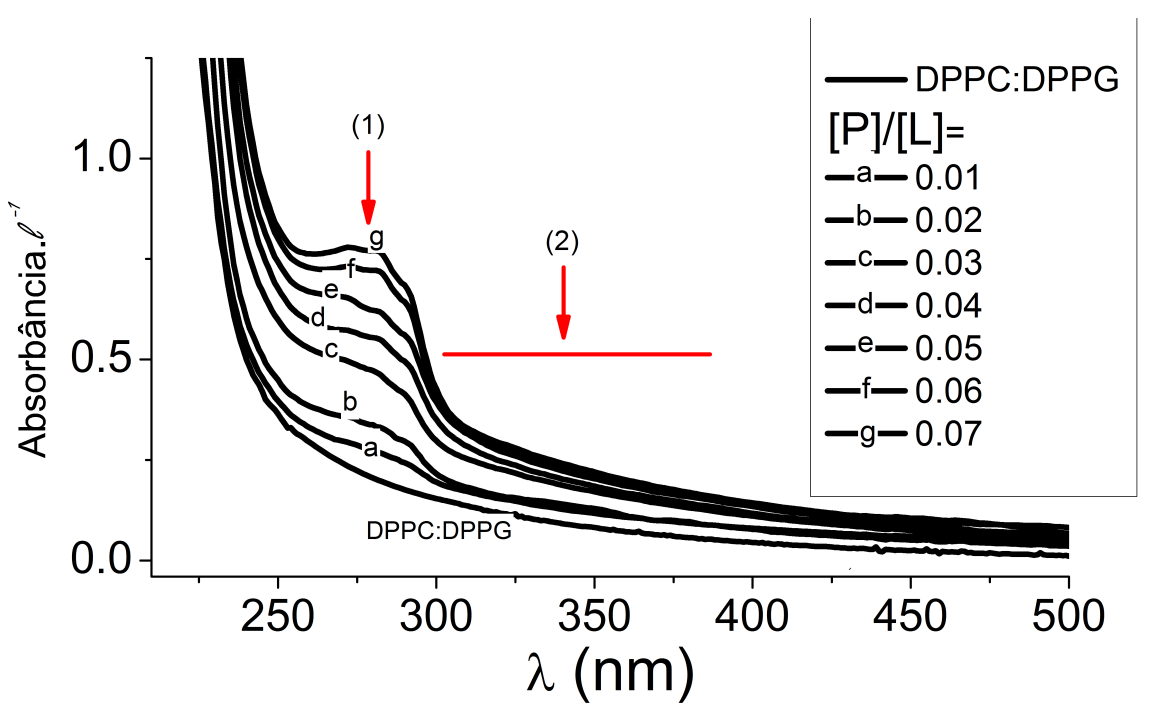

Figura 4.1: Espectro de absorção do Trp, resíduo na posição 7 do peptídeo. A figura ilustra que a adição de peptídeo leva ao aumento do espalhamento da dispersão, além do esperado aumento de suas bandas de absorção. As setas apontam a excitação (1) e a região de emissão do Trp (2), onde na região de emissão do Trp ainda há grande espalhamento (alta turbidez).

Além disso, monitoramos o valor da absorção do Trp em $\lambda=280 \mathrm{~nm}$ A Figura mostra um exemplo do tratamento aplicado aos espectros de absorção, onde foi subtraída uma linha de base de cada perfil, onde nesta linha de base estão incluídas o espalhamento de luz e bandas de maiores energias. Esse tratamento matemático foi realizado no Origin 8.0 para monitoração isolada da banda de menor energia. 

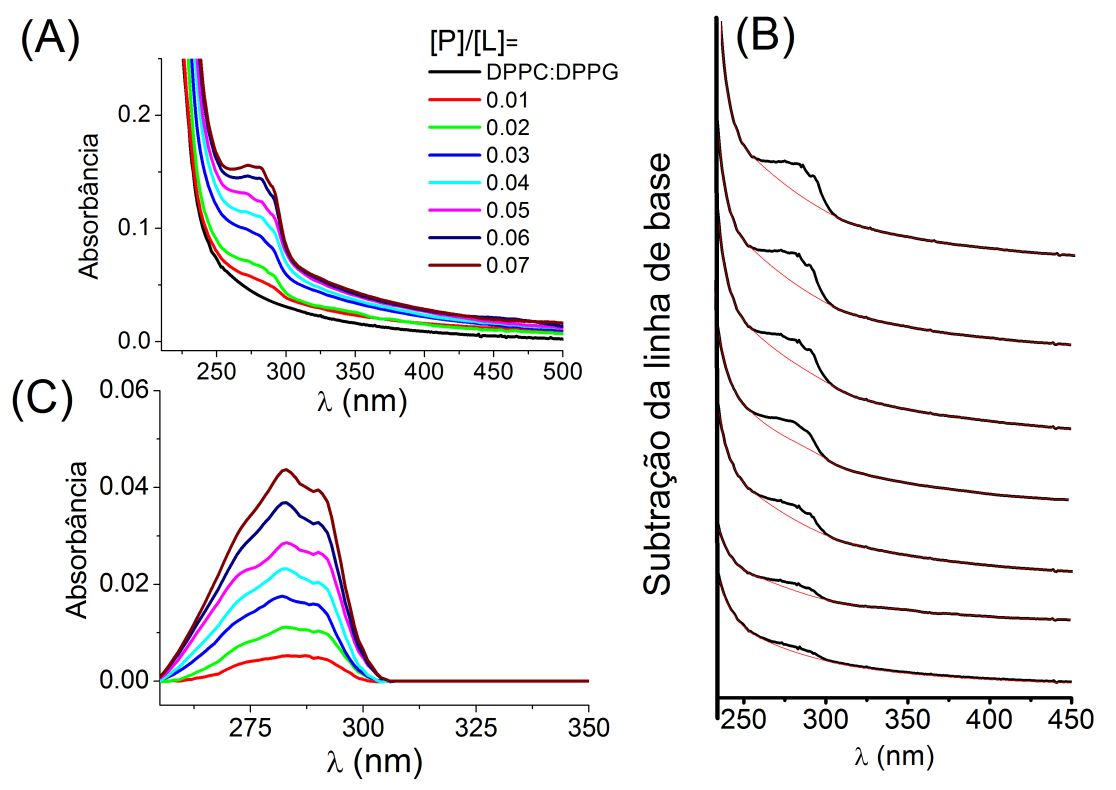

Figura 4.2: Tratamento do espectro de absorção referente à subtração da linha de base, para monitoramento da banda de absorção em $\lambda=280 \mathrm{~nm}$. (A) Exemplo de uma medida experimental coletada para a mistura DPPC:DPPG a $T=50^{\circ} C$. (B) Subtração de uma linha de base para cada espectro. (C) Banda de absorção em $~ 280 \mathrm{~nm}$ após a subtração da linha de base.

\subsubsection{Fluorescência do Trp}

Espectros de emissão fluorescente do $\operatorname{Trp}\left(\lambda_{\text {exc }}=280 \mathrm{~nm}\right)$ foram obtidos no espectrofotômetro de fluorescência (Varian Cary Eclipse, Santa Clara, CA). Amostras contendo $500 \mu L$ de dispersão lipídica são colocadas em cubetas de quartzo $(0.2 \times 1.0 \mathrm{~cm})$ e o porta-amostra contém um controlador de temperatura do tipo (Carry Peltier thermostatted). Alíquotas de peptídeo são adicionadas à dispersão lipídica para aumentar as razões molares de peptídeo [P]/[L], conforme descrito na seção 4.2.5. A coleta de dados foi realizada em aproximadamente 25 minutes após a adição de peptídeo. Os espectros de emissão fluorescente foram corrigidos devido aos efeitos de filtros internos ("Inner filter efects").

A seguir descreveremos brevemente as correções de filtro interno aplicadas aos espectros de emissão, a fim de obter valores mais precisos para a intensidade de fluorescência e a posição espectral. Conforme reportado em (Tucker et al., 1992), uma atenção especial deve ser dada ao efeito de filtro interno, uma vez que este passa a ser mais relevante em menores comprimentos de onda, visto que, a adição de peptídeo leva ao aumento do espalhamento Rayleight, e esse é naturalmente maior em menores comprimentos de onda, onde ocorre a absorção do Trp (ver Figura 4.2).

Por exemplo, caso o espalhamento seja dado pelo espalhamento Rayleigh, onde os tamanhos 
dos centros espalhadores são muito menores do que o comprimento de onda da luz, então este sabidamente apresenta uma dependência com $\left(\lambda^{-4}\right)$, e portanto, menores comprimentos de onda apresentam maiores valores da intensidade da luz espalhada. O aumento da concentração de centro absorvedores e/ou mudanças nas propriedades estruturais desses pode levar ao aumento do espalhamento, ou aumento da turbidez. Em bicamadas lipídicas, uma modificação estrutural comumente observada, e que leva ao aumento da turbidez da amostra, refere-se ao aumento do empacotamento da membrana, o qual aumenta a diferença entre os índices de refração da bicamada e do solvente (Disalvo, 1991; Viera, Senisterra, e Disalvo, 1996). Logo, o aumento do valor da absorbância por conta de qualquer um desses efeitos, pode agir como um filtro na intensidade de fluorescência emitida.

Visto que os espectros de absorção foram medidos, podemos corrigir esse efeito causado na emissão fluorescente. A equação (4.1) descreve como a correção de filtro interno pode ser aplicada:

$$
F=F_{0} \cdot 10^{\left(A_{e x} \cdot x\right)} \cdot 10^{\left(A_{e m} \cdot x^{\prime}\right)},
$$

onde $F_{0}$ e $F$ são as intensidades de fluorescência medida e corrigida, respectivamente. Uma vez que a equação (4.1) não considera a dimensão da região excitada, esta assume que todas as sondas fluorescentes emitem aproximadamente a mesma radiação que aquelas localizadas no centro da cubeta. Mendonça e colaboradores (Mendonça, Rocha, Duarte, e Santos, 2013) mostraram que essa equação (4.1) apresenta resultados satisfatórios, mesmo desprezando a dimensão da região excitada.

Note que a correção primária de filtro interno considera a atenuação na excitação ao longo da incidência da luz, caminho óptico (neste trabalho, $x=0.1 \mathrm{~cm}$ ), e a correção secundária de filtro interno, a atenuação na emissão e, portanto, caminho óptico (neste trabalho, $x^{\prime}=0.5 \mathrm{~cm}$ ). Deste modo, $A_{e x}$ e $A_{e m}$ são os valores de absorbância por unidade de caminho óptico nos comprimentos de onda da excitação e emissão, respectivamente.

Nos resultados de emissão fluorescente do Trp, seção 4.3.3, optamos em mostrar a área sob o espectro de emissão fluorescente em vez da intensidade máxima da emissão, pois, especialmente os espectros obtidos para o DPPC, foi observado um deslocamento espectral com o aumento da concentração de peptídeo em direção do vermelho. 


\subsubsection{Espalhamento de luz dinâmico}

Medidas de espalhamento de luz dinâmico foram realizadas no equipamento Zetasizer Malvern (Nano ZS, Worcestershire, $U K)$, onde $1.0 \mathrm{~mL}$ de dispersão lipídica $(0.1 \mathrm{mM})$, na ausência ou presença do peptídeo antimicrobiano KHya1, foram colocadas em uma cubeta de plástico desenhada para esse equipamento. As medidas foram realizadas a um ângulo fixo, 90 . A função de auto-correlação da intensidade da luz espalhada $g^{(2)}(\tau)$ foi diretamente coletada pelo correlator da Malvern.

A função de auto-correlação do campo elétrico $g^{(1)}(\tau)$ foi analisada com o método dos cumulantes de segunda ordem (Koppel, 1972), equação (4.2)

$$
g^{(1)}(\tau)=A \exp \left\{-\langle\Gamma\rangle \tau+\frac{\mu_{2}}{2 !} \tau^{2}-\frac{\mu_{3}}{3 !} \tau^{3}+\cdots\right\}
$$

onde $\mu_{2}$ corresponde ao segundo momento da expansão e $\Gamma$ a taxa média de decaimento da função de auto-correlação, $g^{(1)}(\tau)$, ou também conhecida por frequência de relaxação média. Neste trabalho não nos preocupamos em monitorar o índice de polidispersão, ao qual está relacionado a $\mu_{2}$.

O coeficiente de difusão translacional, $D_{T}$, foi obtido pelo programa de aquisição, com o uso da equação (4.3)

$$
\langle\Gamma\rangle=D_{T}\left(\frac{4 \pi n_{0} \sin (\theta / 2)}{\lambda_{0}}\right)^{2}
$$

onde $\theta$ é do ângulo de espalhamento e $\lambda_{0}$ e $n_{0}$ correspondem ao comprimento de onda do laser e o índice de refração da solução, respectivamente.

A baixa concentração lipídica $(0.1 \mathrm{mM}-0.07 \mathrm{mg} / \mathrm{mL})$ desses experimentos foram sabidamente escolhida no regime onde $D_{T} \rightarrow D_{0}$, como previamente reportado em (Enoki et al., 2012).

Por fim, a dimensão dos centros espalhadores pode ser então obtida em termos de um raio efetivo, segundo a relação de Stokes-Einstein, equação (4.4)

$$
D_{0}=\frac{k_{B} T}{3 \pi \eta d_{e f}}
$$

onde $k_{B}$ é a constante de Boltzmann, $T$ a temperatura e $\eta$ a viscosidade do solvente.

É importante ressaltar que as medidas de DLS podem ser influenciadas por interações entre partículas e anisotropia dos centros espalhadores. Para vesículas em ausência de peptídeo, 
podemos assegura a medida de um coeficiente de difusão puramente translacional, como reportado em Modelos e Controles, capítulo 3. Para as medidas dos raios efetivos em presença de peptídeo, a medida pode conter contribuições das interações causada pelo peptídeo.

\subsubsection{Experimentos de vazamento de sonda fluorescente encapsulada}

Os lipossomos preparados com uma sonda fluorescente encapsulada, seção 4.2.3, foram utilizados para estudar o vazamento do conteúdo interno devido à ação do peptídeo KHya1. As dispersões lipídicas foram adicionadas a uma cubeta de quartzo $(1.0 \times 1.0 \mathrm{~cm})$ e a fluorescência da CF foi monitorada com o uso de um espectrofotômetro (Varian Cary Eclipse, Santa Clara, CA). De modo análogo ao reportado nas seções 4.2.7 e 4.2.8, a temperatura foi controlada com o uso do controlador de temperatura do próprio equipamento.

A fluorescência da CF está auto suprimida na concentração de sonda utilizada (50 mM). À medida que a sonda passa a ser liberada para a solução devido à permeabilização da membrana, causada pela ação do peptídeo ou pela adição de detergente, a intensidade de fluorescência da CF, agora diluída, aumenta. Portanto, a emissão fluorescente da CF foi registrada continuamente ao longo do tempo (uma medida por segundo) a $T=25^{\circ} \mathrm{C}$ e $\lambda_{\text {exc }}=490 \mathrm{~nm}$ e $\lambda_{\text {em }}=512$ nm. A intensidade de fluorescência zero $\left(I_{0}\right)$ foi obtida a partir dos lipossomos com CF encapsulada e sem a adição de peptídeo. Em seguida, a desejada concentração de peptídeo foi adicionada aos lipossomos (seta 1 da Figura 4.9) e o sinal de fluorescência foi monitorado por 2000 s. O vazamento total da sonda, ou a intensidade total, $I_{\text {total }}$, foi obtida pela adição de 25 $\mu L$ de $10 \%(\mathrm{w} / \mathrm{v})$ de Triton-X100 (seta 2 da Figura 4.9).

A porcentagem de vazamento, vazamento (\%), da CF foi calculada de acordo com a equação $(4.5)$

$$
\text { Vazamento }(\%)=\left[\left(I(t)-I_{0}\right) /\left(I_{\text {Total }}-I_{0}\right)\right] .100
$$

onde $I_{t}$ é a intensidade de fluorescência no instante $t .^{1}$

\subsubsection{Microscopia óptica}

Vesículas unilamelares gigantes (GUVs) foram preparadas pelo método de eletroformação (Angelova e Dimitrov, 1986). Neste método, lipídios dissolvidos em clorofórmio são espalhados em lâminas de vidro para microscópio. Essas lâminas são especiais, pois são revestidas por FTO (óxido de estanho dopado com flúor). Utilizamos cerca de $8 \mu L$ do lipídio desejado para

\footnotetext{
${ }^{1}$ Esses experimentos tiveram a co-orientação à distância da Profa. Dra. Katia R. Perez
} 
formar um filme lipídico sobre tais lâminas. As lâminas são então secas com um fluxo de $N_{2}$, similarmente ao procedimento para formação de filmes lipídicos nas paredes do tubo de ensaio, seção 4.2.2. Utilizando duas lâminas cobertas com o filme lipídio e uma peça de Teflon $(2 \mathrm{~mm}$ de espessura) que serve como um espaçador, montamos uma cela a qual é preenchida com uma solução de sacarose $(200 \mathrm{mM})$. Cada lâmina pode então ser conectada a um gerador de funções, no modo: corrente alternada (AC), voltagem $1.0 \mathrm{~V}$ e frequência $10 \mathrm{~Hz}$ por $1 \mathrm{~h}$. Em seguida, as dispersões de vesículas gigantes foram diluídas em uma solução de glicose $(200 \mathrm{mM})$.

Então, alíquotas da dispersão de GUVs preparadas em sacarose são adicionadas a uma solução de glicose de mesma osmolaridade e que contém o peptídeo antimicrobiano KHya1 em concentrações que variam entre 1 e $10 \mu M$. As molaridades das soluções de açúcar foram medidas com um osmômetro (Osmomat Gonotec, Berlin, Germany). A diferença no índice de refração do açúcar no interior da GUV (sacarose) com relação ao açúcar do lado externo (glicose) auxiliam a visualização por contraste de fase.

A observação de GUVs, por contraste de fase, foi realizada em um microscópio invertido (Zeiss Axiovert 200, Jena, Germany) equipado com uma objetiva de 63x e uma câmera digital (Zeiss AxioCam HSm, Jena, Germany). Na coleta de dados, um porta-amostra construído no laboratório da Profa. Karin Riske foi preenchido com $95 \mu L$ da solução de glicose contendo a concentração desejada de peptídeo. O porta-amostra aberto foi colocado no microscópio e o plano focal foi ajustado aproximadamente no centro da amostra. Em seguida, $5 \mu L$ da suspensão de GUVs foram adicionados ao porta-amostra que já continha o peptídeo, e, uma lamínula para microscópio foi utilizada para selar o porta-amostra. Então, o foco foi imediatamente ajustado em uma GUV aleatoriamente escolhida, seguido pela a observação do efeito do peptídeo. ${ }^{2}$

\subsubsection{Reprodutibilidade dos resultados}

Todas as medidas discutidas neste trabalho foram realizadas em duplicatas de amostras ou reproduzidas mais de 2 vezes. Em resultados, apresentamos os valores médios, onde o erro experimental foi estimado de acordo com o desvio padrão das amostras réplicas.

\footnotetext{
${ }^{2}$ Esses experimentos foram realizados no laboratório da Profa. Dra. Karin A. Riske e foram presencialmente assistidos por ela.
} 


\subsection{Resultados}

As interações do peptídeo antimicrobiano KHya1 com membranas modelo neutras, aniônicas ou mistas foram estudadas com diversas técnicas experimentais: DSC, fluorescência estática do Trp, DLS, vazamento de sonda fluorescente encapsulada e microscopia óptica..

\subsubsection{Calorimetria Diferencial de Varredura (DSC)}

A transição de fase de sistemas lipídicos pode ser afetada devido à presença de um componente externo. A presença de um agente externo na bicamada lipídica pode perturbar a ordem das cadeias laterais assim como o arranjo das cabeças polares dos lipídios. Portanto, a investigação de como o peptídeo perturba a organização dos lipídios pode trazer informações relevantes com relação a seu mecanismo de ação.

A Figura 4.3 mostra curvas de DSC para dispersões lipídicas puras (preto) DPPC, DPPG e DPPC:DPPG, e com o aumento da fração molar de peptídeo, $[\mathrm{P}] /[\mathrm{L}]$. As temperaturas de transição para os sistemas extrusados são semelhantes àquelas para os sistemas não extrusados, como discutido no capítulo 3. A Tabela 4.1 resume as temperaturas de transição de fase: pré-transição $T_{p}$ e a transição principal $T_{m}$, dos sistemas lipídios apresentados na Figura 4.3.
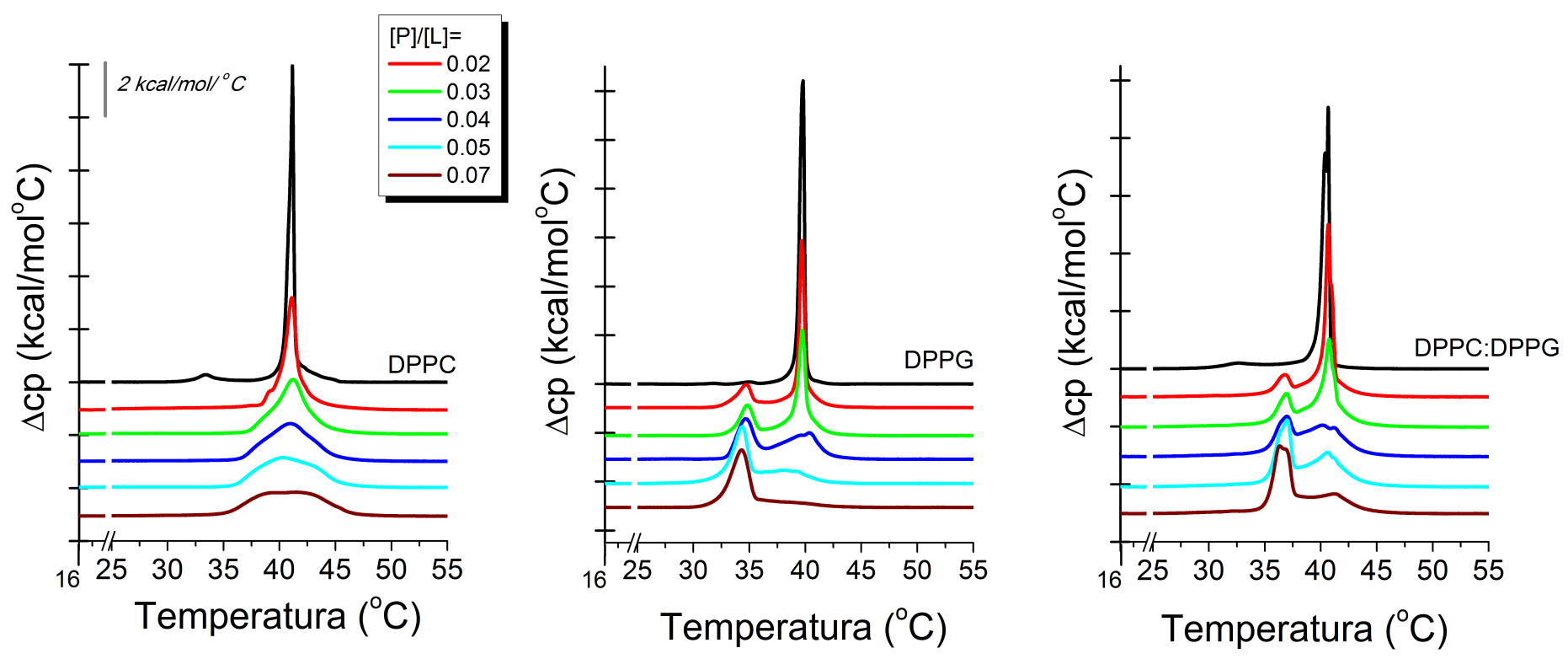

Figura 4.3: Perfis calorimétricos das dispersões lipídicas DPPC, DPPG e DPPC:DPPG na ausência e presença do peptídeo antimicrobiano KHya1. Os termogramas estão deslocados verticalmente para melhor visualização. As curvas superiores mostram as dispersões na ausência de peptídeo, as inferiores mostram as dispersões lipídicas com o aumento da concentração de peptídeo de acordo com a legenda. 
Temperaturas de transição de fase dos lipídios

\begin{tabular}{cccc}
\hline & DPPC & DPPG & DPPC:DPPG \\
\hline \hline$T_{p}$ & $33.5 \pm 0.1(2)$ & $34.8 \pm 1.2(4)$ & $32.4 \pm 0.4(3)$ \\
$T_{m}$ & $41.1 \pm 0.1(2)$ & $39.5 \pm 0.1(4)$ & $40.3 \pm 0.4(3)$ \\
\hline \hline
\end{tabular}

Tabela 4.1: Temperaturas de transição de fase dos sistemas lipídicos compostos por DPPC, DPPG e DPPC:DPPG. O número entre parênteses indica o número de amostras analisadas.

O aumento da concentração de peptídeo em vesículas neutras, compostas por DPPC, leva ao alargamento progressivo do pico calorimétrico da transição principal, diminuindo, portanto, o caráter cooperativo da transição. Logo, os resultados sugerem que o peptídeo causa uma perturbação média na bicamada.

Por outro lado, as curvas calorimétricas obtidas para o DPPG e a mistura DPPC:DPPG apresentam um resultado peculiar e interessante. O aumento da concentração do peptídeo leva ao aumento gradual do evento térmico que surge nas temperaturas $T=34$ e $36.5^{\circ} \mathrm{C}$ para o DPPG e a mistura, respectivamente. Para baixas razões molares de peptídeo, $[\mathrm{P}] /[\mathrm{L}]=0.02$ e 0.03, a transição de fase principal do lipídio, transição gel-fluida, coexiste com esse novo pico calorimétrico observado. Para essas razões, portanto, é possível observar dois regimes na bicamada: um perturbado pelo peptídeo e outro onde a bicamada é pouco afetada pela ação do peptídeo.

A Tabela 4.2 resume as entalpias dos picos calorimétricos calculadas para cada razão molar peptídeo/ lipídio. É interessante observar que as entalpias encontradas são similares àquelas encontradas para sistemas lipídicos na ausência de peptídeo, e permanecem praticamente constantes com o aumento da concentração de peptídeo. Os valores entre parênteses correspondem ao intervalo de temperaturas utilizado na integral sob a curva calorimétrica, os intervalos são levemente diferentes pois os picos calorimétricos alargam com o aumento da concentração de peptídeo.

\subsubsection{Absorção do Trp}

A Figura 4.4, mostra a variação do espalhamento de luz com o aumento da concentração de peptídeo, como mencionado na seção 4.2.7, onde monitoramos a turbidez da amostra, ou neste caso, o valor da absorbância em 400 nm (ver Figura 4.1). Os valores da absorbância em $400 \mathrm{~nm}$ mostram que a razão molar $[\mathrm{P}] /[\mathrm{L}]=0.08$ apresenta grande aumento da turbidez para a 
Entalpias de transição $\Delta \mathrm{H}\left(\mathrm{kcal} / \mathrm{mol} /{ }^{\circ} \mathrm{C}\right)$

\begin{tabular}{c|ccc}
\hline$[\mathrm{P}] /[\mathrm{L}]$ & DPPC & DPPG & DPPC:DPPG \\
\hline \hline 0.00 & $8.1 \pm 0.1\left(39-43^{\circ} C\right)$ & $8.4 \pm 0.3\left(37-42^{\circ} C\right)$ & $7.9 \pm 0.1\left(37-42^{\circ} C\right)$ \\
0.02 & $8.1 \pm 0.1\left(37-45^{\circ} C\right)$ & $7.7 \pm 0.2\left(32-45^{\circ} C\right)$ & $8.0 \pm 0.1\left(34-45^{\circ} C\right)$ \\
0.03 & $7.7 \pm 0.3\left(35-46^{\circ} C\right)$ & $7.8 \pm 0.1\left(32-45^{\circ} C\right)$ & $8.0 \pm 0.1\left(34-45^{\circ} C\right)$ \\
0.04 & $7.8 \pm 0.3\left(35-46^{\circ} C\right)$ & $7.6 \pm 0.5\left(32-45^{\circ} C\right)$ & $7.98 \pm 0.04\left(33-46^{\circ} C\right)$ \\
0.05 & $7.6 \pm 0.5\left(35-46^{\circ} C\right)$ & $7.3 \pm 0.1\left(32-45^{\circ} C\right)$ & $8.3 \pm 0.3\left(33-46^{\circ} C\right)$ \\
0.07 & $7.6 \pm 0.4\left(35-46^{\circ} C\right)$ & $6.3 \pm 0.5\left(30-45^{\circ} C\right)$ & $8.0 \pm 0.2\left(33-46^{\circ} C\right)$ \\
\hline \hline
\end{tabular}

Tabela 4.2: Entalpias dos picos calorimétricos calculadas para cada razão molar peptídeo/ lipídio dos sistemas lipídicos compostos por DPPC, DPPG e DPPC:DPPG. Os números entre parênteses indicam o intervalo de temperaturas utilizado no cálculo da entalpia.

mistura, DPPC:DPPG, na fase gel, sugerindo possível agregação dos lipossomos. Deste modo, optamos em ater nossos estudos com LUVs em concentrações inferiores a esta.

Das Figuras 4.1 e 4.4, ressaltamos a importância de trabalhar com os espectros de absorção e emissão de cada amostra conjuntamente, pois a correção devido ao filtro interno depende da concentração de peptídeo e da temperatura.

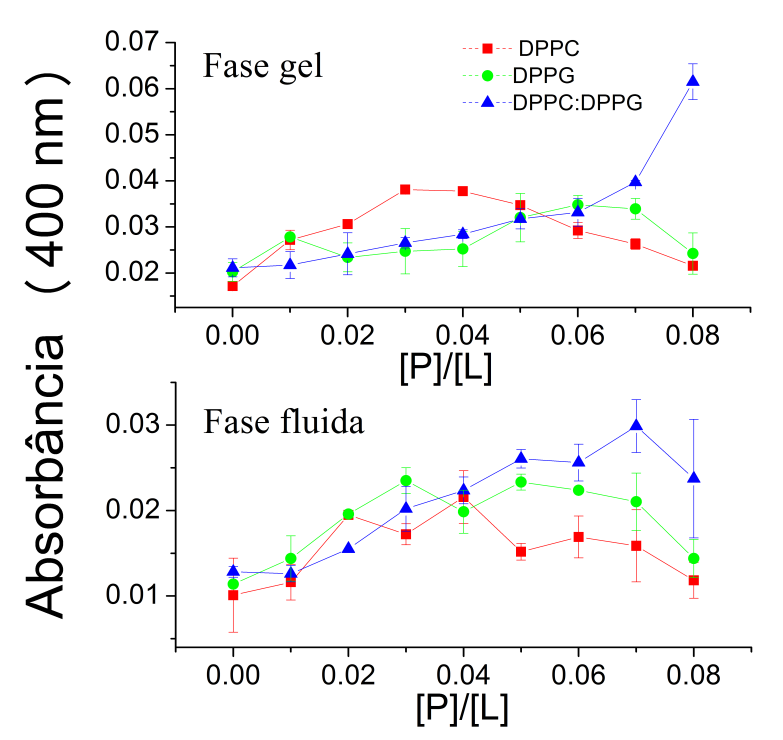

Figura 4.4: Valores da absorbância medidos a $400 \mathrm{~nm}$. A figura ilustra como o peptídeo KHya1 afeta a turbidez das dispersões lipídicas na fase gel e fluida dos lipídios.

A Figura 4.5 mostra o valor da absorção do $\operatorname{Trp}$ em $\lambda=280 \mathrm{~nm}$, após as correções descritas na seção 4.2.7, e em função da concentração de peptídeo. A legenda relaciona a concentração 
de peptídeo com a razão molar $[\mathrm{P}] /[\mathrm{L}]$. Essa relação, entre $[\mathrm{P}]$ e $[\mathrm{P}] /[\mathrm{L}]$, não é linear devido às correções de volume, conforme descrito no item 4.2.5.

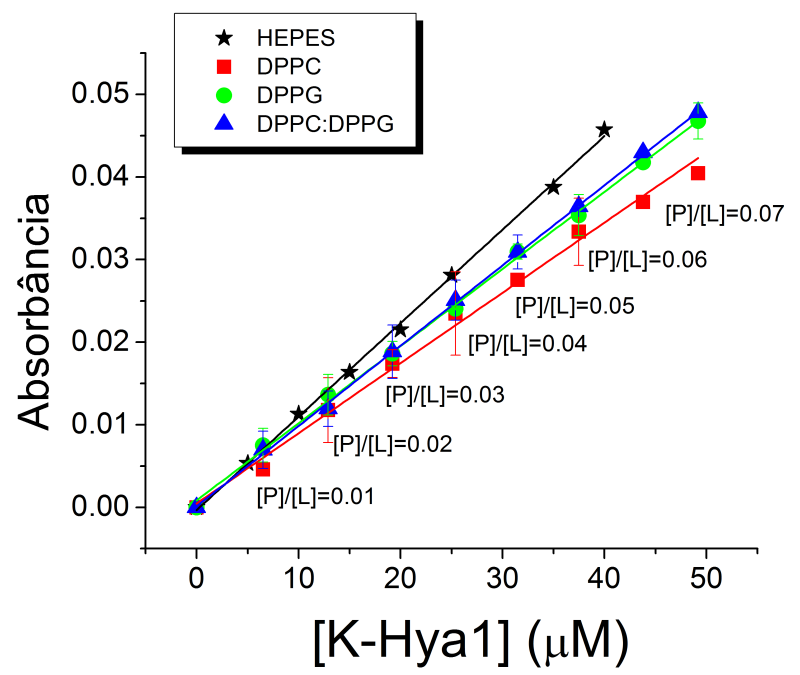

Figura 4.5: Variação linear da absorção do Trp, em $\lambda=280 \mathrm{~nm}$ com a concentração de peptídeo, exemplo obtido a $T=25^{\circ} \mathrm{C}$.

A relação linear entre a absorção e a concentração de peptídeo sugere que não há agregação lateral do peptídeo (contato Trp-Trp) em solução aquosa, e em bicamadas de DPPC, DPPG e DPPC:DPPG, de modo a alterar as propriedades ópticas de absorção do Trp, para as concentrações aqui estudadas.

\subsubsection{Emissão fluorescente do Trp.}

O ambiente do peptídeo foi investigado monitorando o sinal de fluorescência de sua sonda intrínseca, Trp, resíduo na posição 7 do peptídeo. Espectros de emissão fluorescente foram obtidos nas fases: gel $\left(T=25^{\circ} C\right)$ e fluida $\left(T=50^{\circ} C\right)$ dos lipídios. A Figura 4.6 mostra um exemplo dos espectros de emissão do Trp corrigidos conforme descrito na seção 4.2.8, em $T=50^{\circ} \mathrm{C}$. Os gráficos inseridos no lado direito da figura mostram os espectros normalizados, indicando que não há mudanças com relação à forma do espectro e ilustram o deslocamento espectral observado para vesículas neutras, DPPC. A Figura 4.7 resume a posição espectral e as intensidades para cada dispersão lipídica, com o aumento da concentração de peptídeo para as temperaturas, $\mathrm{T}=50^{\circ} \mathrm{C}$.

A emissão fluorescente do Trp do peptídeo KHya1 em membranas neutras (DPPC) revela um deslocamento espectral do pico de fluorescência para menores comprimentos de onda com relação ao espectro do peptídeo em solução aquosa, que é particularmente maior na fase fluida. 

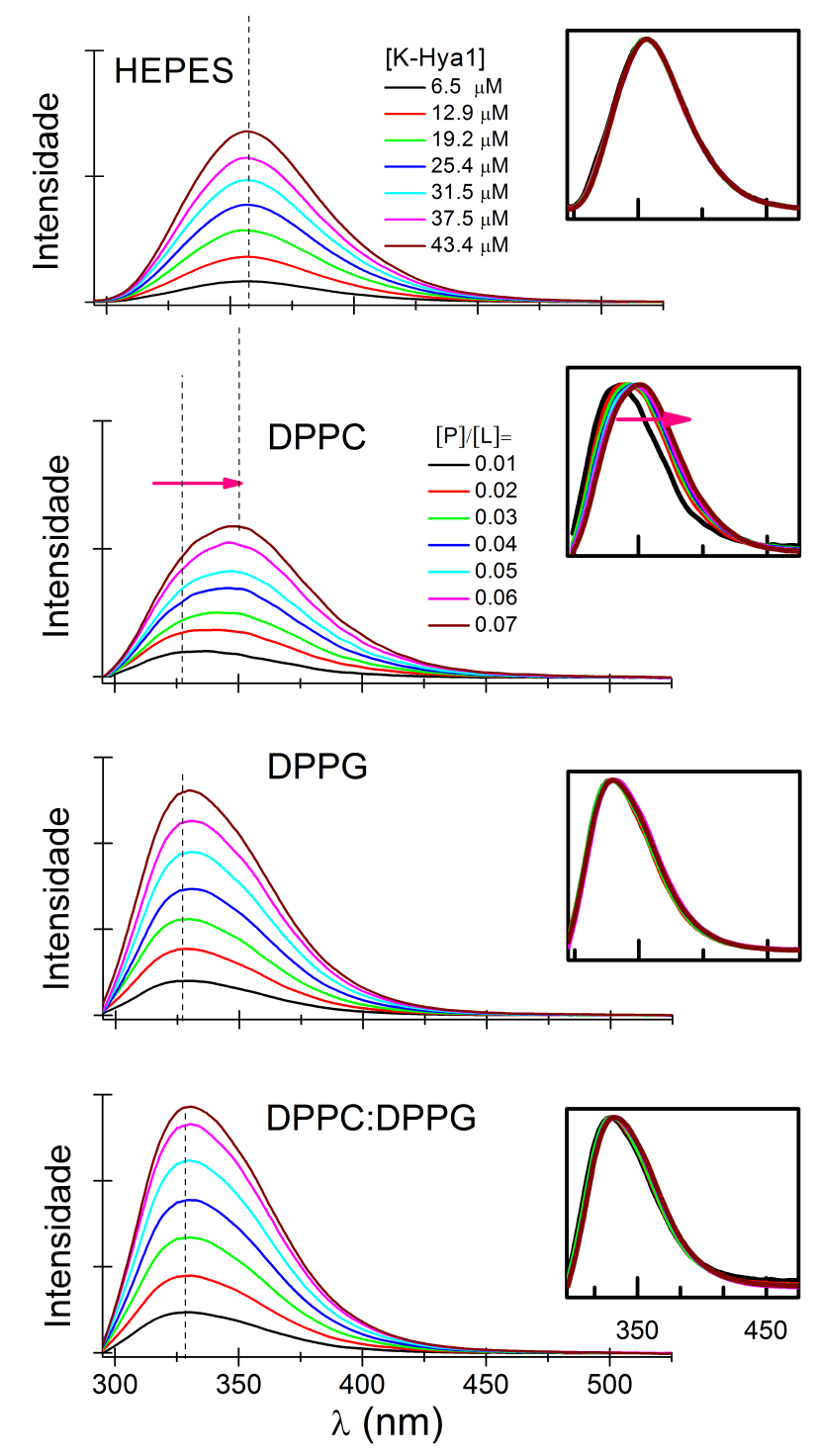

Figura 4.6: Espectro de emissão fluorescente do Trp, resíduo na posição 7 do peptídeo, em solução aquosa tampão HEPES; e dispersão lipídica, DPPC, DPPG e DPPC:DPPG, para $T=50^{\circ} C$. Os gráficos inseridos nos painéis à direita mostram os espectros normalizados.

Para $[\mathrm{P}] /[\mathrm{L}]=0.01$, observamos um deslocamento espectral de aproximadamente $5 \mathrm{~nm}$ na fase gel, a partir de $355 \mathrm{~nm}$ em solução aquosa para $350 \mathrm{~nm}$, e cerca de $20 \mathrm{~nm}$ na fase fluida. A posição do espectro indica que o peptídeo se ligou à bicamada em ambas as fases. Entretanto, a interação peptídeo-membrana depende das propriedades físicas da bicamada, ou da interação lipídio-lipídio.

Além disso, para a fase gel e para a fase fluida do DPPC, a posição do espectro de emissão muda com o aumento da concentração de peptídeo, movendo-se na direção de altos comprimentos de onda ("red shift"). Esse deslocamento espectral em função da concentração de peptídeo pode indicar que o peptídeo está se ligando cada vez menos na membrana. Entretanto, também 

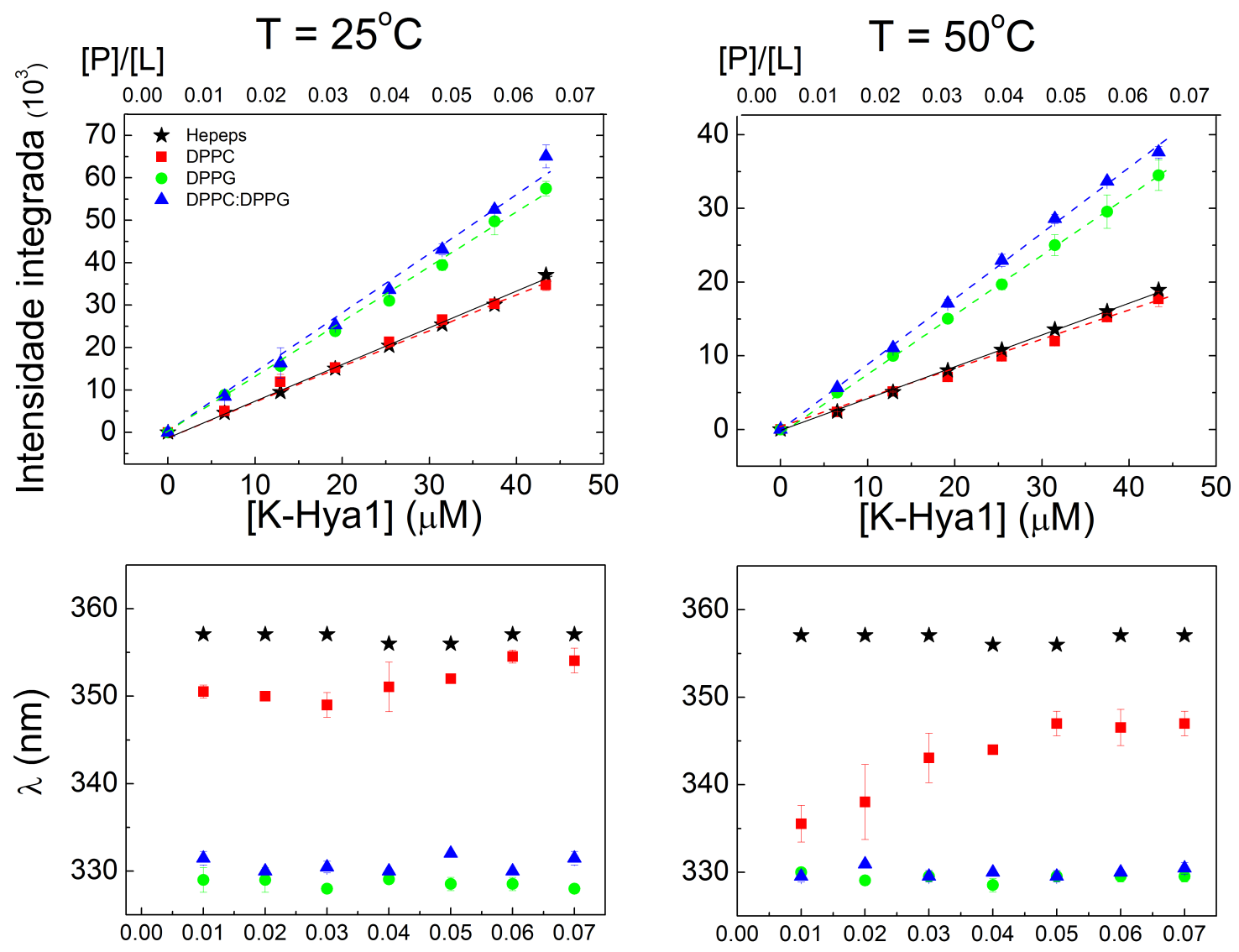

$[\mathrm{P}] /[\mathrm{L}]$

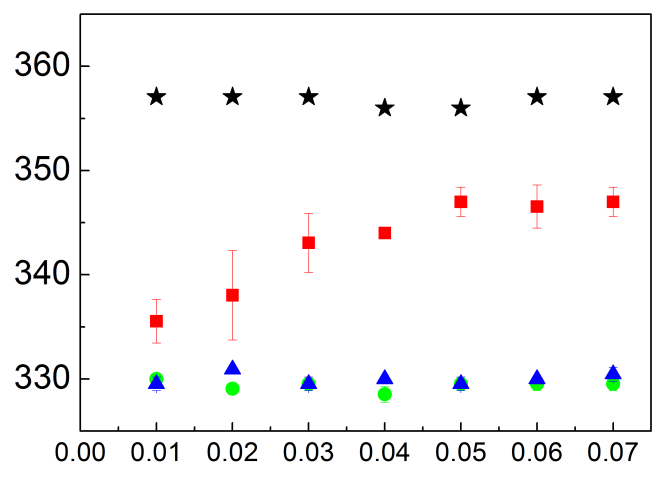

$[\mathrm{P}] /[\mathrm{L}]$

Figura 4.7: Resumo das intensidades integradas de fluorescência (área sob o espectro de emissão) e posições espectrais medidas no máximo da emissão fluorescente, para os espectros de emissão do Trp do peptídeo em tampão HEPES, e em dispersões lipídicas de DPPC, DPPG e DPPC:DPPG, nas temperaturas $T=25^{\circ}$ e $50^{\circ} \mathrm{C}$, fases gel e fluida dos lipídios, respectivamente.

é possível que o peptídeo mude de posição na bicamada com o aumento de sua concentração, mas esse efeito seria mascarado pelo aumento da partição do peptídeo para solução aquosa.

Também podemos comparar os espectros de emissão na fase gel e fluida do DPPC. Para $[\mathrm{P}] /[\mathrm{L}]=0.01$, por exemplo, o deslocamento espectral observado de 5 e $20 \mathrm{~nm}$, para a fase gel e fluida, respectivamente, (partindo do espectro em solução aquosa para o espectro em bicamada) pode indicar que o peptídeo apresenta diferentes partições entre a solução aquosa e a membrana ${ }^{3}$, e/ ou o peptídeo pode estar localizado em diferentes posições na bicamada.

Ainda que a posição do espectro seja diferente na fase gel e fluida do DPPC, as áreas sob o espectro de emissão permanecem similares às áreas observadas para o peptídeo em solução aquosa, indicando que o Trp se encontra em um ambiente menos apolar que o observado para

\footnotetext{
${ }^{3}$ Como o espectro de emissão do Trp em bicamada lipídica é largo, este pôde ser reproduzido com a composição de espectros em solução aquosa e dispersão lipídica, assumindo frações fictícias de cada um deles.
} 
membranas negativas, conforme discutido abaixo.

A emissão fluorescente do Trp do peptídeo KHya1 em membranas negativamente carregadas (DPPG e DPPC:DPPG) exibe um significativo deslocamento espectral para o azul, de 27 nm, com relação ao espectro do peptídeo em solução aquosa. A banda fluorescente do Trp, antes vista em $355 \mathrm{~nm}$ em solução aquosa, passa a ser observada em $328 \mathrm{~nm}$ em dispersões lipídicas aniônicas. A mesma posição do espectro de emissão é encontrada na fase gel e fluida desses sistemas lipídicos, não se alterando com o aumento da concentração de peptídeo. Esse resultado sugere que não é possível detectar um aumento da partição do peptídeo em solução aquosa, mesmo para as mais altas razões molares, $[\mathrm{P}] /[\mathrm{L}]$. Além do deslocamento espectral, a intensidade de fluorescência máxima aumenta, confirmando que o Trp está ambientado em uma região bastante apolar.

O aumento linear da intensidade integrada (área sob o espectro de emissão) indica que a emissão aumenta proporcionalmente ao número de centros fluorescentes, sugerindo que não há agregação lateral do peptídeo de modo a alterar suas propriedades ópticas (contato Trp-Trp), assim como observado com a absorção, seção 4.3.2. Entretanto, a fluorescência mostrou um pequeno desvio da relação linear entre a emissão e a concentração de peptídeo para $[\mathrm{P}] /[\mathrm{L}]=0.07$ para DPPC:DPPG na fase gel. Esse desvio também pode ser efeito do aumento do espalhamento da dispersão lipídica, onde a correção de filtro interno atinge seu limite de funcionalidade. Convém notar que para esta concentração de peptídeo, na mistura, também foi observado grande aumento da turbidez, Figura 4.4.

\subsubsection{Espalhamento de luz dinâmico}

A Figura 4.8 mostra o raio efetivo dos lipossomos compostos por DPPC, DPPG e a mistura DPPC:DPPG em ausência de peptídeo, $[\mathrm{P}] /[\mathrm{L}]=0.00$ e com o aumento da concentração de peptídeo, $[\mathrm{P}] /[\mathrm{L}]=0.01,0.02,0.03,0.04,0.05,0.06$ e 0.07 , para $T=25^{\circ} C$. Em geral, os lipossomos de DPPC apresentaram um raio efetivo levemente maior. Deste modo a Figura 4.8 (B) mostra do aumento raio efetivo relativo ao lipossomo puro.

Em geral observamos um aumento gradual do raio efetivo com o aumento da concentração de peptídeo. Este aumento pode estar relacionado à inserção do peptídeo na bicamada, e também devido a uma pequena porcentagem de agregação dos lipossomos. O aumento do raio efetivo de aproximadamente $30 \%$ para o DPPC e o DPPG até a razão molar $[\mathrm{P}] /[\mathrm{L}]=0.07$, implica em um aumento da área superficial de aproximadamente 70\%, deste modo, possivelmente além 


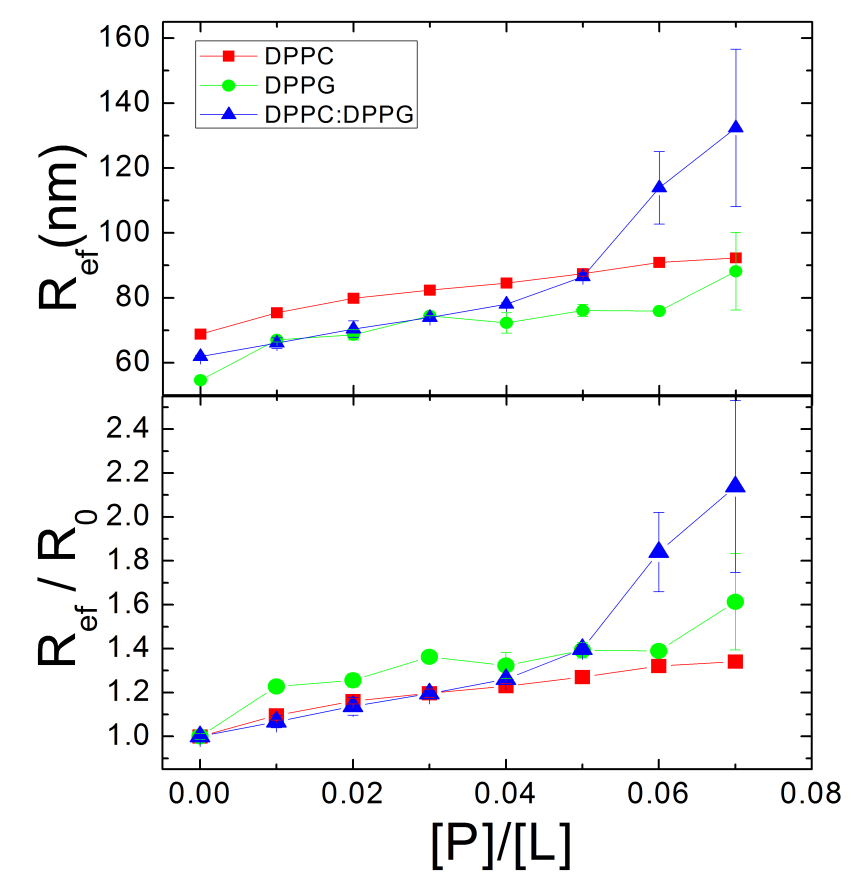

Figura 4.8: Raio efetivo, Ref, dos lipossomos compostos DPPC, DPPG e DPPC:DPPG em ausência de peptídeo, indicado por $[\mathrm{P}] /[\mathrm{L}]=0.00$, seguido do raio efetivo dos lipossomos com o aumento da concentração de peptídeo, para as razões molares $[\mathrm{P}] /[\mathrm{L}]=0.01,0.02,0.03,0.04,0.05,0.06$ e 0.07 (A). Aumento do Ref aparente comparado ao raio dos lipossomos em ausência de peptídeo (B).

do aumento causado pela inserção do peptídeo na bicamada, a interação do peptídeo com as bicamadas pode levar à agregação entre vesículas. A agregação de vesículas é um fenômeno comumente reportado na literatura como efeito da ação de peptídeos antimicrobianos (Cabrera et al., 2011; Domingues, Riske, e Miranda, 2010). Esse resultado concorda com o resultado previamente apresentado da turbidez da dispersão lipídica com o aumento da concentração de peptídeo.

Além disso, para DPPC:DPPG observamos um aumento do raio efetivo dos lipossomos para $[\mathrm{P}] /[\mathrm{L}]=0.07$ superior aos demais, em acordo com os valores da absorbância da Figura 4.4, indicando grande efeito do peptídeo KHya1 na mistura.

É importante ressaltar que não foi detectado agregação a olho nu, assim como não houve decantação de partículas. 


\subsubsection{Vazamento de sonda fluorescente encapsulada por lipossomos}

Sabe-se que peptídeos antimicrobianos alteram a permeabilidade da membrana celular de microrganismos através de mecanismos de ação diversificados. Logo, os experimentos de vazamento da sonda fluorescente, CF, encapsulada por lipossomos, foram realizados para correlacionar as modificações estruturais, aqui estudadas, com os efeitos tóxicos que o peptídeo antimicrobiano KHya1 pode causar em organismos naturais (Castro et al., 2009; Crusca et al., 2011; Silva et al., 2013).

A Figura 4.9 ilustra as cinéticas de vazamento da CF normalizadas, onde as porcentagens de sonda fluorescente liberada pelas vesículas de DPPC, DPPG e DPPC:DPPG são mostradas em função do tempo, para $T=25^{\circ} C$. As medidas foram realizadas na fase gel dos lipídios (ver Figura 4.3.1), pois a taxa de vazamento da sonda encapsulada depende da temperatura do sistema, e para altas temperaturas, há um aumento do vazamento espontâneo das vesículas, tornando difícil a interpretação dos resultados, conforme discutido em Modelo e Controles, capítulo 3, seção 3.2.3.

O vazamento espontâneo das vesículas para cada sistema lipídico, DPPC, DPPG e DPPC:DPPG a $T=25^{\circ} C$, corresponde a um vazamento de menos de $1 \%$ do total, e durante o tempo de observação das medidas, 2000 segundos ( $\approx 30$ min). Esse controle está ilustrado na Figura 4.9 e refere-se à linha preta dos gráficos. Os 100 primeiros segundos de medida são tomados para verificar a estabilidade dos lipossomos, reproduzindo novamente o pequeno vazamento espontâneo das vesículas. Após a injeção do peptídeo nas dispersões lipídicas, observa-se um aumento da porcentagem de vazamento devido à ação do peptídeo na bicamada.

Os diferentes perfis de vazamento devem estar correlacionados aos diferentes mecanismos de ação do peptídeo em bicamadas neutras e aniônicas. As cinéticas de vazamento do DPPC mostram um perfil de vazamento com um formato mais arredondado, onde a porcentagem de vazamento aumenta continuamente mesmo para tempos longos. Por outro lado, o perfil das cinéticas de vazamento, de vesícula puramente aniônicas (DPPG), em geral apresenta um formato mais retangular, onde há um vazamento abrupto nos primeiros segundos de observação e, em seguida, a porcentagem de vazamento é mantida praticamente constante, ou aumenta bem lentamente com o tempo. Por fim, a mistura apresenta uma combinação complexa de ambos as formas, onde para altas concentrações de peptídeo as cinéticas tornam-se mais semelhantes as cinéticas observadas para o DPPC.

Esse comportamento das cinéticas de vazamento pode ser modelado por dois processos, os 

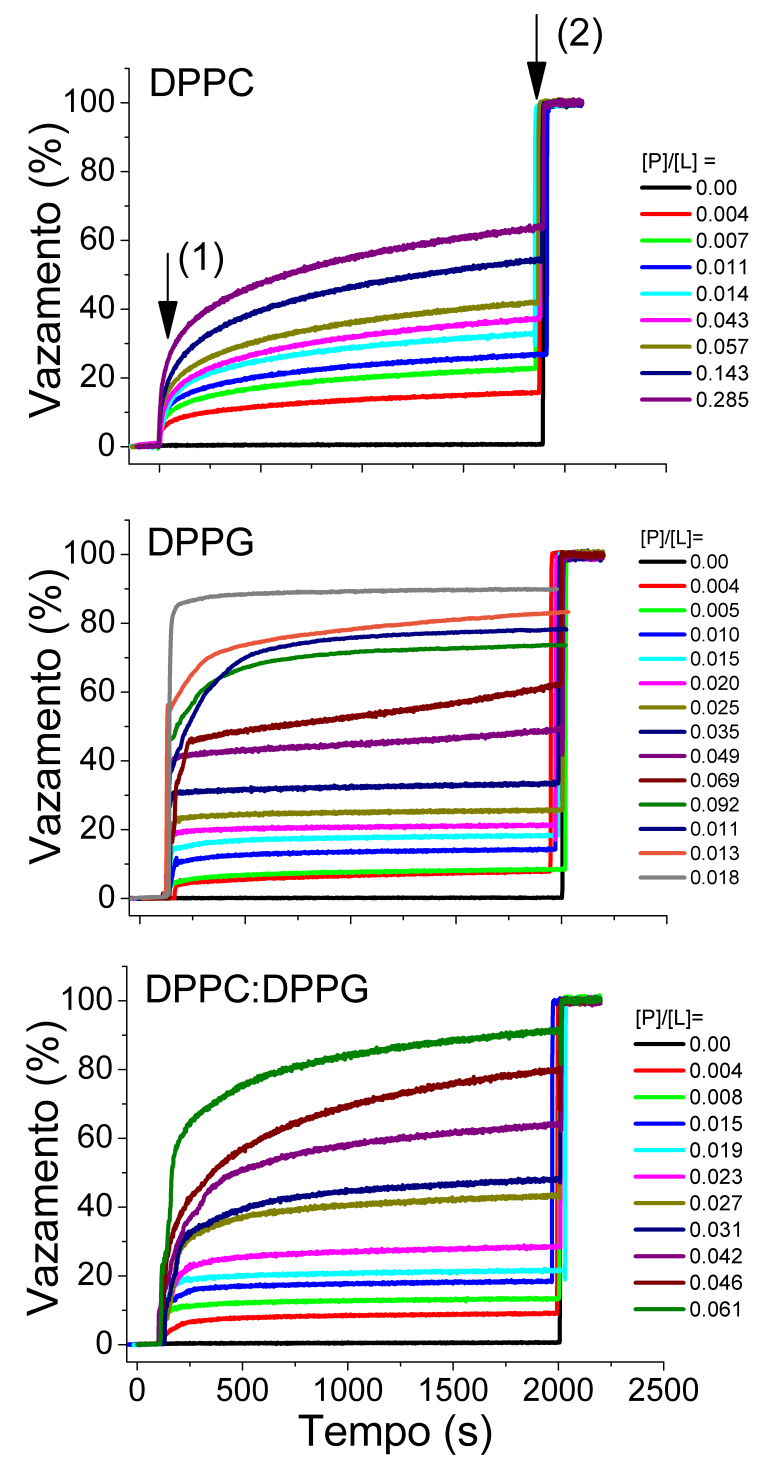

Figura 4.9: Cinéticas de vazamento obtidas para os lipossomos compostos por DPPC, DPPG e DPPC:DPPG sob a ação do peptídeo antimicrobiano KHya1, $T=25^{\circ} C$.

quais são caracterizados por diferentes taxas $\left(1 / t_{1}\right.$ e $\left.1 / t_{2}, t_{1}<<t_{2}\right)$ de acordo com a equação (4.6), onde $A_{1}$ e $A_{2}$ são as frações de vazamento relacionadas aos processos designados por $t_{1}$ e $t_{2}$, respectivamente, e a soma das frações corresponde ao vazamento total, $A_{T}=A_{1}+A_{2}$.

$$
\text { Vazamento }(\%)=A_{1}\left(1-\exp \left(-t / t_{1}\right)\right)+A_{2}\left(1-\exp \left(-t / t_{2}\right)\right)
$$

Então, os perfis de vazamento foram ajustados com o uso a equação (4.6). A Figura 4.10 ilustra exemplos do ajuste para o DPPC, DPPG e a mistura DPPC:DPPG, onde a contribuição de cada processo discriminado pelos índices 1 e 2 , segundo a equação, também é representada na figura de acordo com o índice. Os gráficos inseridos na Figura, para cada sistema lipídico, detalham os primeiros instantes da cinética de vazamento. Selecionamos os ajustes com $R^{2}>$ 
0.96 para analisar os parâmetros ilustrados nas Figuras 4.11 e 4.12.

As cinéticas de vazamento representadas na Figura 4.9 foram obtidas a partir de 2 amostras independentes. Entretanto, as duplicatas de amostras não apresentam mesmas razões molares pois as dispersões lipídicas, provenientes da coluna de separação por pesos moleculares, apresentam pequenas diferenças nas concentrações lipídicas. Após a dosagem de fosfato a relação [P]/[L] foi calculada corretamente, portanto, nesta seção optamos em mostrar cada conjunto de amostras individualmente, em vez da média e desvio das duplicatas. Deste modo, nas Figuras 4.11, 4.12 e 4.13 estão representados os dois conjuntos de amostras independentes discriminados por símbolos abertos e fechados.
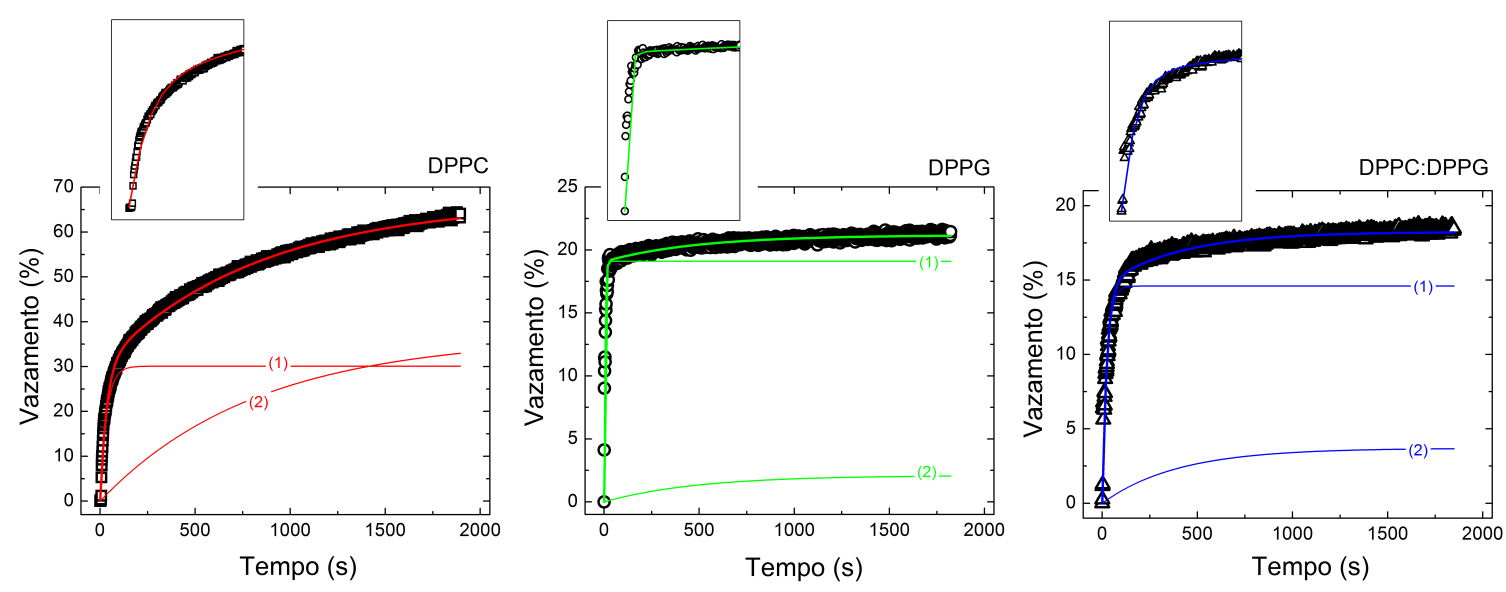

Figura 4.10: Exemplo dos ajustes das cinéticas de vazamento com o uso da equação 4.6. As cinéticas exemplificam perfis com diferentes formatos e tais curvas foram escolhidas de modo a obter a melhor representação para cada formato incluindo um bom ajuste. Da esquerda para a direita são representados DPPC, $[\mathrm{P}] /[\mathrm{L}]=0.285, R^{2}=0.997, D P P G,[\mathrm{P}] /[\mathrm{L}]=0.020, R^{2}=0.963$ e DPPC:DPPG, $[\mathrm{P}] /[\mathrm{L}]=0.019$, $R^{2}=0.967$.

A Figura 4.11 mostra os tempos $t_{1}$ e $t_{2}$ obtidos pelo ajuste da equação (4.6). O tempo curto, neste caso $t_{1}$, implica em um decaimento exponencial rápido, que de acordo com a equação (4.6), o primeiro termo $A_{1}\left(1-\exp \left(-t / t_{1}\right)\right)$ imprime um formato mais retangular da curva. Por outro lado, o tempo longo $t_{2}$ reproduz uma exponencial de decaimento suave, onde o segundo termo da equação (4.6) desenha um perfil mais arredondado. Neste modelo assumimos que os dois processos coexistem ao longo do tempo, mas o primeiro é mais relevante no início da curva, pois para $t$ até $\approx 5 t_{1}$, temos

$$
A_{1}\left(1-1 / e^{5}\right) \approx 0.99 A_{1}
$$

Logo, o segundo processo passa a ser predominante para tempos maiores. As cinéticas de vazamento para vesículas neutras, DPPC, apresentam tempos mais longos, caracterizando uma 
passagem mais lenta da sonda para o meio externo. Os valores encontrados para a mistura (DPPC:DPPG) flutuam entre os valores obtidos para o DPPC e o DPPG, evidenciando um comportamento intermediário.

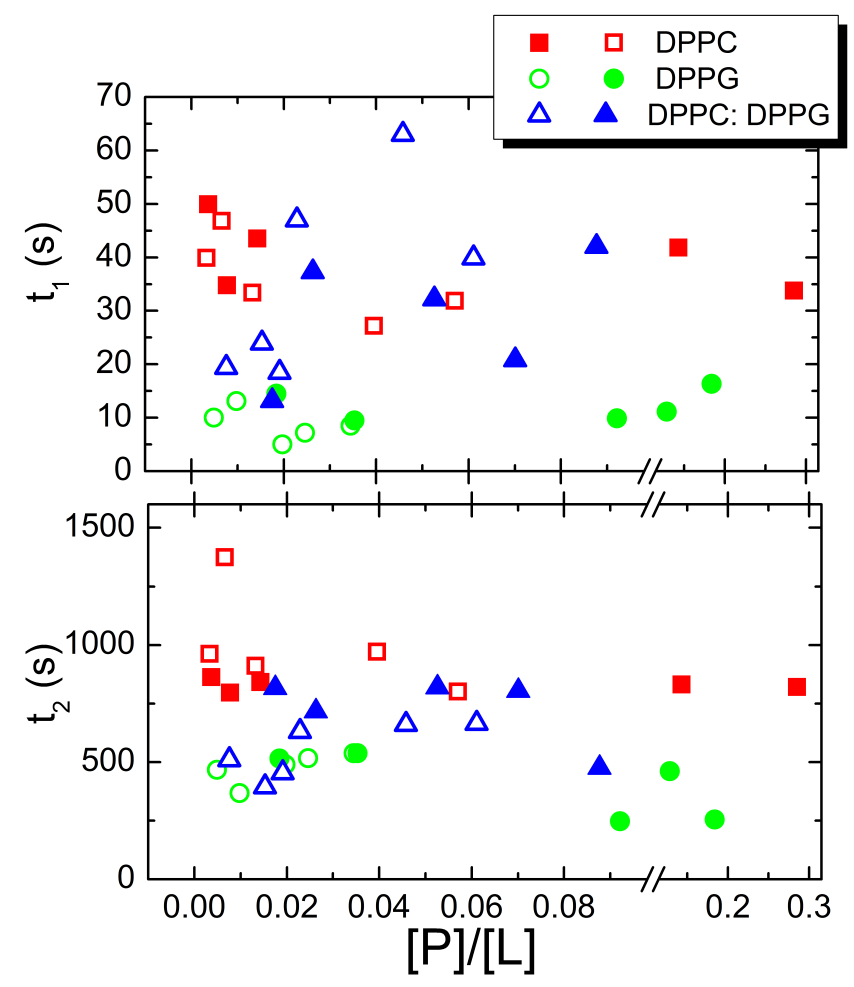

Figura 4.11: Tempos associados às taxas de vazamento, obtidos pelo ajuste da equação (4.6), para as cinéticas de vazamento dos lipossomos compostos por DPPC, DPPG e DPPC:DPPG sob a ação do peptídeo antimicrobiano KHya1. Os parâmetros resumidos nesta figura foram obtidos a partir dos ajustes com $R^{2} \leq 0.96$. Duplicata de amostras são representadas por símbolos abertos e fechados.

O formato das cinéticas de vazamento também depende da contribuição de cada processo de vazamento da sonda para o meio externo. A Figura 4.12 mostra a fração relativa de vazamento para cada processo. É interessante notar que para o DPPC o processo descrito por $t_{1}$ contribui com uma fração de $40 \%\left(A_{1} / A_{T}\right)$ em cada cinética de vazamento, e ainda há um desvio bem pequeno deste valor para as concentrações de peptídeo aqui estudadas. Deste modo, a maior contribuição no vazamento das vesículas neutras, os $60 \%$ restante, são liberados apenas em tempos mais longos, e devido essa alta contribuição em tempos longos as curvas ganham esse perfil mais arredondado.

Entretanto, para as vesículas que contêm lipídios aniônicos, observamos o inverso, pois cerca de $60 \%\left(A_{1} / A_{T}\right)$ ou uma fração superior a esta é liberada nos primeiros instantes da cinética. Também é interessante notar que os ajustes para o DPPG apresentam um tempo 
t1 distintamente mais curto e a contribuição majoritária do vazamento ocorre nos primeiros segundos da cinética indicando um comportamento bem abrupto no início do vazamento.

Portanto, os perfis da cinética de vazamento também evidenciam diferenças na interação do peptídeo KHya1 com membranas neutras ou aniônicas.

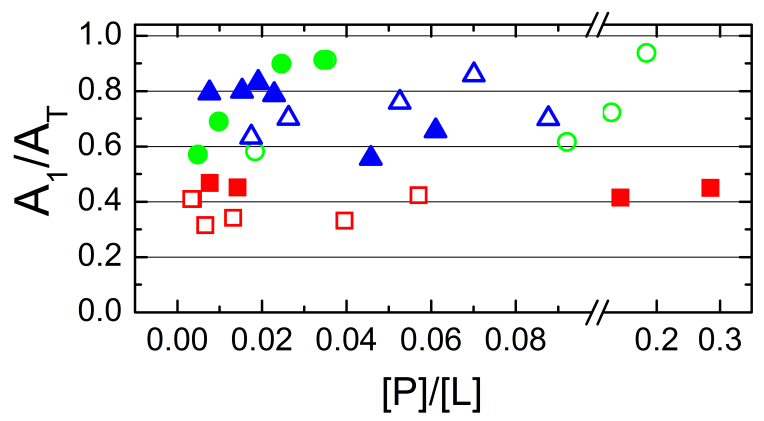

Figura 4.12: Fração relativa dos tempos associados às taxas de vazamento, obtidos pelo ajuste da equação (4.6), onde $A_{1}$ e $A_{2}$ correspondem aos fatores pré-exponenciais dos processos relacionados a $t_{1}$ e $t_{2}$, respectivamente. Os parâmetros resumidos nesta figura foram obtidos a partir dos ajustes com $R^{2} \leq 0.96$. Duplicata de amostras são representadas por símbolos abertos e fechados.

A Figura 4.13 ilustra a porcentagem de vazamento após 1800s (30 min), imediatamente antes da solubilização das vesículas com detergente (Trinton X-100). Essa porcentagem final de vazamento pode ser relacionada com as medidas apresentadas anteriormente (DSC, fluorescência e DLS), que foram realizadas em condições semelhantes do peptídeo com a dispersão lipídica, após encubação aproximada de 30 min.

Para baixas concentrações de peptídeo, a interação do peptídeo e membranas neutras promove uma porcentagem de vazamento similar à observada em vesículas negativamente carregadas. Por exemplo, para $[\mathrm{P}] /[\mathrm{L}]=0.02$ as dispersões de DPPC, DPPG e DPPC:DPPG apresentam porcentagem final de vazamento similares, apesar da distinta interação do peptídeo para lipossomos neutros ou aniônicos, como atestado por DSC, fluorescência e as cinéticas de vazamento. Além disso, os resultados de vazamento corroboram os resultados de DSC, onde foi observado que o peptídeo também interage e modifica a estrutura de bicamada neutras, sugerindo que, além da interação eletrostática, há outras contribuições energéticas que favorecem a ligação do peptídeo com a membrana.

Além disso, para vesículas neutras, observamos que a porcentagem de vazamento passa a crescer mais lentamente com a concentração de peptídeo, quando comparada aos sistemas carregados. Para $[\mathrm{P}] /[\mathrm{L}]=0.06$ e 0.07 a porcentagem de vazamento é praticamente a mesma e 

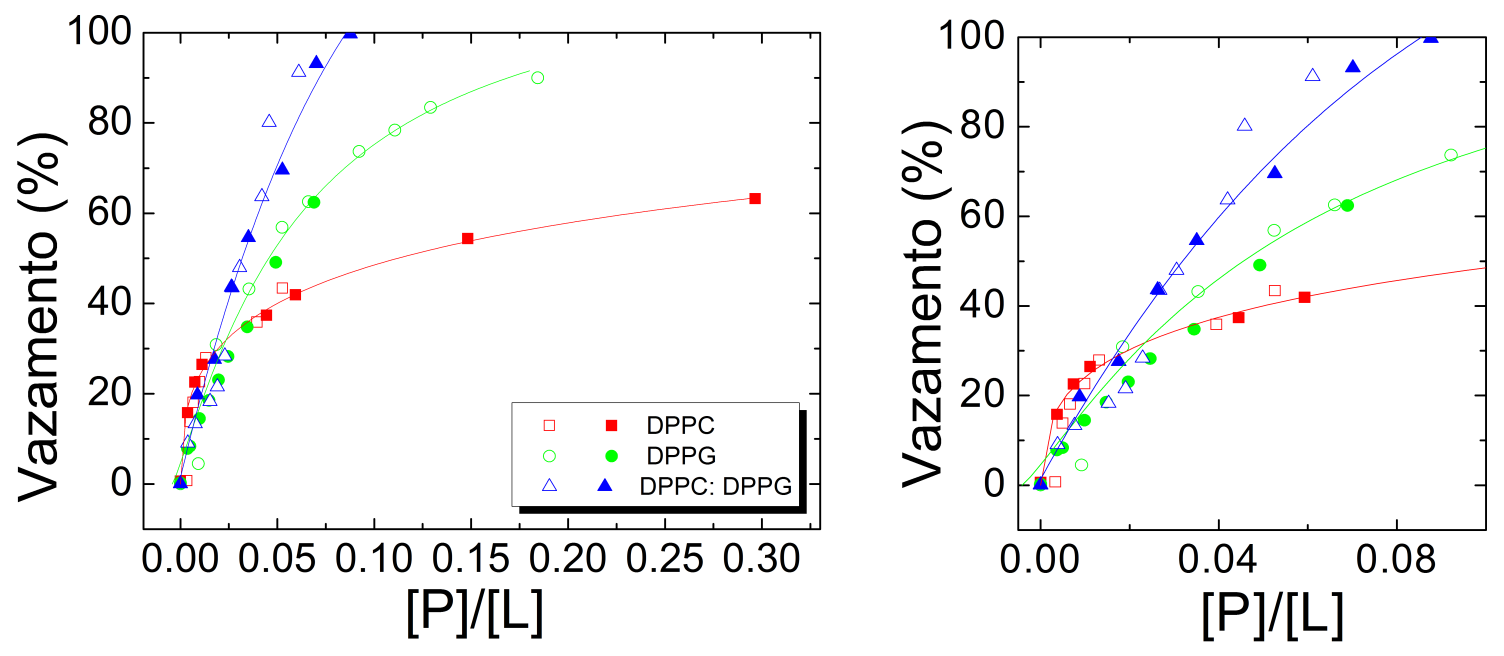

Figura 4.13: Porcentagem de vazamento final medida em $\mathrm{t}=1800 \mathrm{~s}$ obtida pelas cinéticas de vazamento dos compostos por DPPC, DPPG e DPPC:DPPG e sob a ação do peptídeo antimicrobiano KHya1. O painel à direita amplia a região de $[\mathrm{P}] /[\mathrm{L}]=0.0$ a 0.08 . Duplicata de amostras são representadas por símbolos abertos e fechados.

equivalente a 40\%, sugerindo portanto, uma saturação da ligação do peptídeo na bicamada. De modo análogo, a posição espectral do Trp na fase gel, também sugere um aumento da partição do peptídeo em solução aquosa para as maiores concentrações de peptídeo, corroborando a saturação da ligação do peptídeo na bicamada.

Por fim, a porcentagem de vazamento final torna-se claramente distinta para os diversos sistemas lipídicos a partir de $[\mathrm{P}] /[\mathrm{L}] \approx 0.04$, e apresenta a ordem crescente $\mathrm{DPPC}<\mathrm{DPPG}$ < DPPC:DPPG. Curiosamente, observamos maior efeito do peptídeo KHya1 em modificar a permeabilidade de membranas mistas, DPPC:DPPG. Essa discussão será retomada na seção 4.4 .

\subsubsection{Microscopia óptica}

A microscopia óptica permite a observação direta dos efeitos do peptídeo em vesículas gigantes (GUVs) . Entretanto, GUVs compostas por DPPG, DPPC:DPPG e POPG são difíceis de serem produzidas com o método de eletroformação (Angelova e Dimitrov, 1986), por causa da alta densidade de carga negativa. Para lipídios saturados há outro fator que dificulta o arranjo experimental, pois em temperatura ambiente esses lipídios estão abaixo da temperatura de transição de fase. Além disso, observações da fase fluida, em $T=50^{\circ} \mathrm{C}$ também são complicadas, por causa da evaporação das amostras. Portanto, os experimentos de microscopia 
foram realizados com os lipídios insaturados POPC e POPC:POPG em temperatura ambiente onde esses sistemas lipídicos estão na fase fluida, e com o DPPC, também em temperatura ambiente, e fase gel do lipídio.

A Figura 4.14 ilustra exemplos de GUVs de DPPC, POPC e POPC:POPG em presença de $2 \mu M$ de KHya1 na temperatura ambiente. Os efeitos observados dependem da composição da membrana, e, mais especificamente, da presença de lipídios aniônicos. Como as vesículas gigantes são adicionadas a uma solução que contém o peptídeo, não pudemos observar as vesículas na ausência de peptídeo. O contraste observado nos primeiros instantes de observação deve-se a diferença dos índices de refração da sacarose (meio interno da GUV) e da glicose (meio externo da GUV). O principal efeito observado em vesículas neutras foi a perda de contraste, sugerindo que a membrana se tornou mais permeável à passagem do açúcar.

A maior parte das vesículas gigantes de DPPC (fase gel) perde contraste logo após o contato com o peptídeo, como mostra a Figura 4.14A. Também podemos observar nesta figura que uma vesícula encapsulada tem o contraste óptico preservado em $270 \mathrm{~s}$ e, eventualmente, perde o contraste depois de $384 \mathrm{~s}$ (6.4 min), evidenciando que o peptídeo pode atravessar a membrana, sem causar seu rompimento. A Figura 4.14B mostra um exemplo para GUV de POPC perdendo o contraste óptico. A perda de contraste foi observada para a maior parte das GUVs compostas por PC, desde a mais baixa concentração de peptídeo $1 \mu M$ até a mais alta $10 \mu M$. Além disso, a ação de KHya1 em POPC leva ao surgimento de regiões densas na superfície da bicamada, que seriam os pontos escuros ilustrados nos painéis indicados por 48 e 127 s, Figura 4.14B. Esse fenômeno tem sido observado com outros peptídeos antimicrobianos, como por exemplo a Gomesina (Domingues et al., 2010), Mastoparanos (Cabrera et al., 2011) e BP100 (Manzini et al., 2014); e este efeito foi atribuído à habilidade do peptídeo em fazer a membrana lipídica dobrar-se sobre si mesma. É interessante notar que tal efeito não ocorre em vesículas de DPPC, as quais em temperatura ambiente estão na fase gel e, portanto são mais rígidas.

O efeito do peptídeo KHya1 em vesículas gigantes de POPC:POPG é mais extenso e complexo, como mostra a Figura 4.14C. De modo análogo ao observado com as vesículas neutras, inicialmente as GUVs perdem o contraste óptico, como ilustra o exemplo do painel identificado por 58 s. Então, as vesículas apresentam um significativo aumento de área, e grandes flutuações na membrana passam a ser observadas, como por exemplo entre 84 e 130 s. Em seguida, regiões densas começam a se formar na membrana crescendo continuamente até o colapso da vesícula. Portanto, podemos descrever o efeito do peptídeo nas vesículas de POPC:POPG em três estágios consecutivos: (i) aumento da permeabilidade da membrana, (ii) expansão da área da 

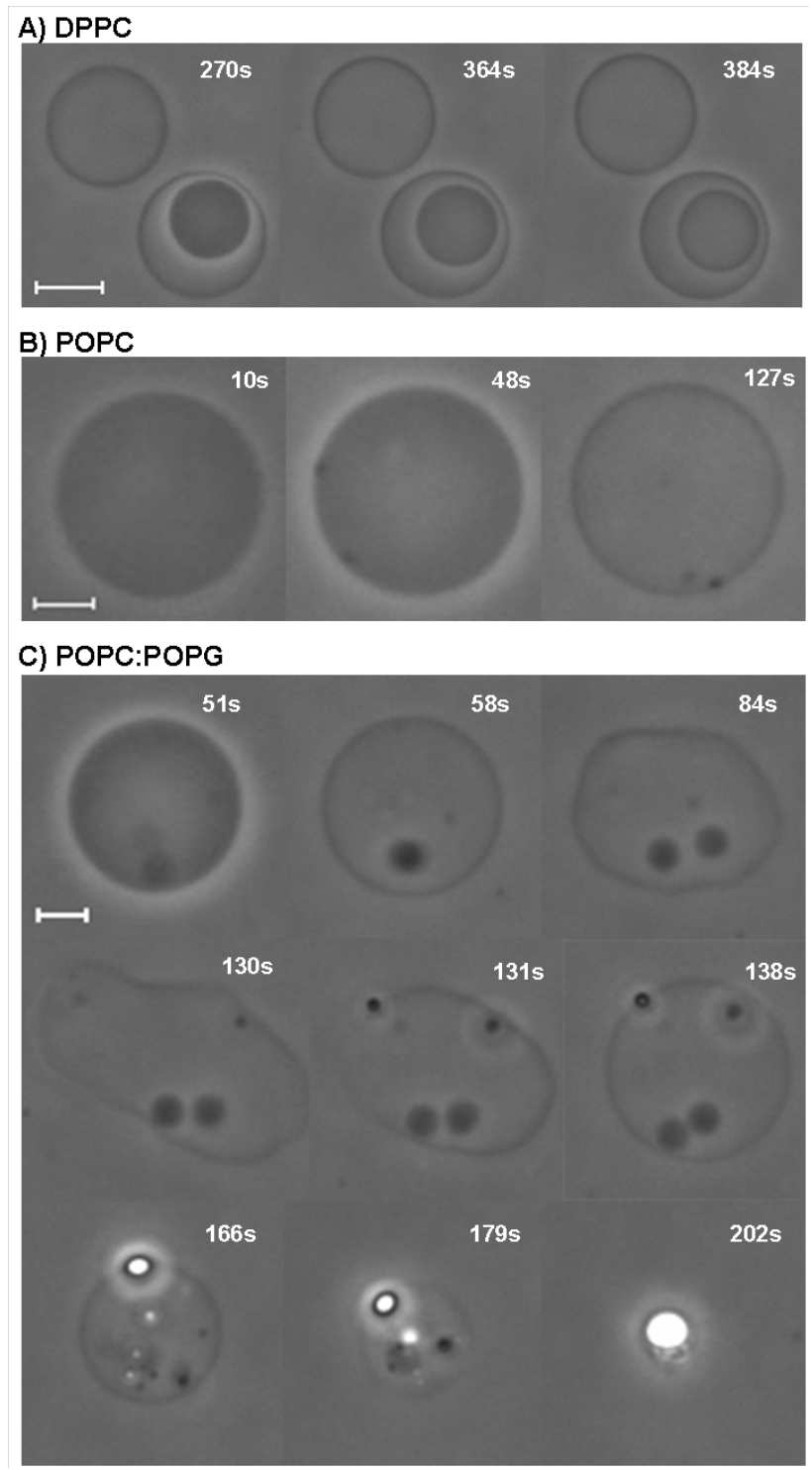

Figura 4.14: Vesículas gigantes, GUVs, sob o efeito do peptídeo antimicrobiano KHya1 observadas por microscopia óptica de contraste de fase. GUVs compostas por DPPC (A), POPC (B) e POPC:POPG (C) e após a adição de $2 \mu M$ de peptídeo KHya1. As barras na figura indicam 10 um (A) e 5 um (B-C).

vesícula e (iii) formações de regiões densas até o colapso da vesícula. Também observamos que a concentração de peptídeo determina o estágio final deste processo. Para uma concentração de $0.5 \mu M$, observamos apenas o aumento da permeabilidade da vesícula. Com aumento da concentração de peptídeo para $1 \mu M$ além da perda de contraste, observamos o aumento da área de muitas vesículas. Para $2 \mu M$ de peptídeo todas as etapas são alcançadas, como descrito anteriormente. E para concentrações maiores a estas encontramos apenas aglomerados de lipídios, semelhante ao ilustrado na Figura 4.14C, no último painel, indicando que as vesículas já passaram por todas essas etapas. 
Possivelmente as concentrações de peptídeo estudadas por microscopia não sejam atingidas nos experimentos com lipossomos, LVUs. Também foram testadas concentrações muito mais baixas de peptídeo, onde não foi possível identificar efeitos nas GUVs. Visto que a concentração das dispersões lipídicas GUVs são muito diluídas, há um grande volume de solução aquosa que pode conter peptídeo o qual encontra-se fora do alcance de interação com a membrana.

Mesmo conhecendo as diferenças estabelecidas entre os dois sistemas modelo: (i) GUVs versus LUVs, (ii) lipídios insaturados versus lipídios saturados e (iii) diferentes [P]/[L]. A microscopia óptica claramente evidencia a diferença nos mecanismos de ação do peptídeo KHya1 em membranas neutras e carregadas. Visto que, a principal semelhança dos sistemas modelo utilizados neste estudo é dada pelo grupo polar PC e PG, integramos esse estudo por microscopia com estudos obtidos pelas demais técnicas experimentais, para reforçar o argumento de que a interação do peptídeo com a cabeça polar do lipídio tem grande contribuição em definir o efeito do peptídeo KHya1 em membranas modelo.

É importante observar que para as demais técnicas estudadas, mesmo para os resultados discutidos nos capítulos seguintes, não foram observadas evidências referentes ao colapso de vesículas como mostrado pela microscopia. Com base na não estabilidade das vesículas gigantes após a abertura de grandes poros e colapso em densos agregados de lipídios, supomos que esta é uma condição de alta concentração de peptídeo por vesícula. Além disso, resultados de ESR (capítulo 6) mostram claramente sinais paramagnéticos característicos da fase gel e fluida até a razão molar $[\mathrm{P}] /[\mathrm{L}]=0.05$ comprovando a existência de bicamadas lipídicas (vesículas LUVs).

\subsection{Discussões}

A seleção que peptídeos antimicrobianos fazem, ao distinguir membranas neutras de membranas aniônicas, é um ponto relevante para sua possível aplicação como um substituto de antibióticos convencionais, (Yeaman e Yount, 2003). Neste trabalho, mostramos que o peptídeo antimicrobiano KHya1 apresenta interações distintas com membranas modelo neutras e aniônicas. As diferentes interações do peptídeo, quando em presença ou ausência de lipídios negativamente carregados, foram evidenciadas com o uso de diversas técnicas experimentais.

Resultados de DSC em membranas neutras, DPPC, mostram que o peptídeo causa uma perturbação média nos lipídios, pois o efeito cooperativo da transição de fase diminui gradativamente com o aumento da concentração de peptídeo. Neste caso, não há nenhuma evidência de uma região da bicamada preservada da ação do peptídeo KHya1. 
Analogamente, Ito e colaboradores (Ito et al., 1993) estudaram o efeito do peptídeo $\alpha$-MSH ( $\alpha$-Melanocyte) em membranas modelos de POPS. O peptídeo $\alpha$-MSH é um peptídeo pequeno, com 13 resíduos ${ }^{4}$ e carga total positiva, +1 . Os autores observaram que deslocamento do espectro de emissão do Trp partindo do espectro em solução aquosa para o espectro em bicada lipídica não muda na fase gel e desloca $5 \mathrm{~nm}$ em direção ao azul na fase fluida.

Posteriormente, Contreras e colaboradores (Contreras, Almeida, Villalaín, Fedorov, e Prieto, 2001) também obtiveram resultado similar em membranas compostas por DMPC:DMPG em alta forca iônica. Os autores reportam que o espectro de emissão fluorescente desloca de 349 nm em solução aquosa para $346 \mathrm{~nm}$ em dispersão lipídica, fase fluida. Além disso, resultados de DSC mostram que o peptídeo causa apenas o alargamento da transição principal do lipídio, neste caso da mistura DMPC:DMPG. Portanto, os autores sugerem que o peptídeo interage preferencialmente com as cabeças polares dos lipídios.

Peptídeos análogos ao $\alpha$ - MSH, conhecidos por MSH-I e MSH-II (Ito et al., 1993) apresentaram deslocamento espectral (da solução aquosa para membrana lipídica) maiores, de 4 e $9 \mathrm{~nm}$ para a fase gel e 7 e $13 \mathrm{~nm}$ na fase fluida, em direção ao azul, novamente sugerindo que a interação do peptídeo $\alpha$-MSH e de seus análogos com a membrana pode ser influenciada pela estrutura da membrana. Os autores sugerem que tais peptídeos penetram mais na fase fluida do lipídio, mas permanecem próximo à superfície das mesmas.

Os resultados de fluorescência obtidos para o KHya1 também indicaram diferentes deslocamentos espectrais (da solução aquosa para membrana lipídica) para a fase gel e fluida do DPPC, sugerindo que a interação peptídeo - lipídio depende da interação entre lipídios. Neste lipídio neutro, para a menor concentração de peptídeo estudada, $[\mathrm{P}] /[\mathrm{L}]=0.01$, onde supõe-se maior fração de peptídeo ligado, foi observado deslocamento espectral de $5 \mathrm{~nm}$ para a fase gel e $20 \mathrm{~nm}$ para a fase fluida, respectivamente. Essa diferença entre os deslocamentos espectrais pode ser consequência do peptídeo se ligar a diferentes posições na bicamada, e/ou apresentar diferentes partições entre a membrana e a solução aquosa.

Os resultados de DSC sugerem que o peptídeo se difunde pela membrana neutra, causando uma perturbação média nos lipídios, e, consequentemente, provocando o alargamento do pico calorimétrico da transição de fase. Deste modo, baseado nos resultados de DSC, convém supor que o peptídeo situa-se na superfície da membrana, pois esta distribuição espacial não causa restrições em sua difusão lateral. Essa hipótese também concorda com a posição do espectro do Trp para a fase gel, assumindo que o peptídeo ocupe uma região mais superficial na membrana.

\footnotetext{
${ }^{4}$ Ac-Ser-Tyr-Ser-Met-Glu-His-Phe-Arg-Trp-Gly- Lys-Pro-Val-NH2
} 
Todavia, na fase fluida do DPPC, a interação e a posição do peptídeo na bicamada podem ser diferentes, e uma vez que todos os lipídios estão fluidos o DSC não traz nenhuma informação adicional sobre suas interações. Possivelmente, o peptídeo pode penetrar mais a membrana na fase fluida do lipídio, de modo análogo ao sugerido por Ito e colaboradores (Ito et al., 1993).

Resultados de ESR, discutidos em detalhes no capítulo 6, monitorando o carbono 16 do DPPC, mostraram que o peptídeo causa pequenas perturbações nessa região da bicamada, na fase fluida do lipídio. Deste modo, mesmo que o peptídeo penetre mais a fase fluida do lipídio, esse não alcança uma posição estável na bicamada de modo a causar grandes perturbações na região central da membrana.

Por outro lado, os resultados de DSC para membranas compostas por lipídios aniônicos, DPPG e DPPC: DPPG, diferem dos resultados anteriormente discutidos para membranas neutras. Os termogramas para membranas negativamente carregadas, em baixas concentrações de peptídeo, $[\mathrm{P}] /[\mathrm{L}]=0.02$ e 0.03, revelam um pico calorimétrico causado pela perturbação do peptídeo na bicamada, coexistindo com o pico calorimétrico da transição gel-fluida dos lipídios. A existência de uma região não perturbada pela presença do peptídeo ("bulk bilayer") sugere que o peptídeo não esteja hábil a se difundir livremente, podendo, por exemplo, estar ancorado a uma certa região da membrana.

Resultados da fluorescência do Trp, resíduo na posição 7 do peptídeo KHya1, mostram que o Trp encontra-se em um ambiente bastante hidrofóbico, pois foi observado um deslocamento espectral de $27 \mathrm{~nm}$ para baixos comprimentos de onda, com relação ao espetro de emissão em água, para bicamadas de DPPG ou DPPC:DPPG. Além disso, a posição do espectro de emissão não depende da concentração de peptídeo, sugerindo que a partição do peptídeo em solução aquosa seja desprezível nas concentrações estudadas. Portanto, a posição do espectro de emissão do Trp, em membranas aniônicas, está essencialmente relacionada à posição do peptídeo na bicamada. Esse resultado também concorda com a hipótese de o peptídeo estar fortemente ligado às membranas negativamente carregadas. O deslocamento espectral mencionado, em direção ao azul cerca de $27 \mathrm{~nm}$, compara-se a deslocamentos espectrais observados para peptídeo transmembranares, como peptídeo da família WALP (Gleason et al., 2012) e a Gramicidina (Kim et al., 2012), por exemplo.

Considerando a hipótese de o peptídeo estar atravessando as membranas aniônicas, podemos supor que a posição transversal seja estabilizada pela forte interação eletrostática próxima aos terminais do peptídeo (C e N terminal), que são positivamente carregados (ver Figura 1.2), com o grupo polar aniônico, PG. Esse modelo concorda com os resultados de DSC, pois o 
peptídeo teria uma difusão dificultada na membrana. Logo, se o peptídeo se difunde muito lentamente pela membrana, em baixas concentrações de peptídeo podem coexistir domínios perturbados e não perturbados ("bulk bilayer") por sua presença. Além disso, o peptídeo na posição transversal perturba diretamente as cadeias hidrocarbônicas dos lipídios, facilitando a transição ordem-desordem de sua vizinhança.

Os peptídeos da família WALP têm sido amplamente estudados por diferentes grupos e pesquisadores sob o ponto de vista teórico e experimental (Gleason et al., 2012; Jong, Lopez, e Marrink, 2013; Killian, 2003), e é possível estabelecermos uma breve comparação entre o peptídeo KHya1 e esses peptídeos, sabidamente transmembranares.

A família WALP é formada por peptídeos estruturados em $\alpha$ - hélice que mimetizam proteínas de membrana, e sua sequência primária é composta basicamente por resíduos hidrofóbicos de Ala e Leu alternados ${ }^{5}$. Em geral, esses peptídeos também apresentam resíduos que auxiliam seu alinhamento na posição vertical. De Planque e colaboradores sintetizaram uma série de diferentes sequências análogas e discutiram a importância de resíduos aromáticos, Trp, Tyr e Phe ou resíduos carregados Lys, Arg, His nas extremidades da sequência primária do peptídeo, para estabilizá-lo na posição transversal (De Planque et al., 2002). Esses resíduos normalmente são colocados na posição 3 ou 5 e $N-3$ ou $N-5$ do peptídeo, onde $N$ é o número total de resíduos. Segundo os autores, esses resíduos preferem a interface entre as cabeças polares e as cadeias hidrofóbicas, onde ainda há certa hidratação das cabeças polares, o que difere da região mais apolar das cadeias. Diversos autores estudaram alguns peptídeos da família WALP, e mediram o ângulo de inclinação dos peptídeos com relação à normal da bicamada (Gleason et al., 2012; De Planque et al., 2002; Vostrikov, Hall, Greathouse, Koeppe, e Sansom, 2010). Deste modo, eles observaram que a disposição ou a combinação desses resíduos podem estabilizar ou não o peptídeo.

Vostrikov e colaboradores também estudaram o peptídeo GWALP23 (Vostrikov et al., 2010) com 23 resíduos de amino ácidos e dois Trp localizados na posição 5 e 19, e de dois outros peptídeos com sequências análogas à original, em membranas de DPPC. Na primeira sequência, apenas a Ala na posição 14 foi substituída por resíduo Arg (positivamente carregado). Na segunda, apenas a Ala, na posição 12, foi substituída por uma Arg. Resultados teóricos (simulação computacional) e experimentais (ressonância magnética nuclear) mostraram que, no primeiro caso, o peptídeo deixa de ser ancorado pelo resíduo 19 (Trp) e passa a ser ancorada pela Arg, na posição 14, causando o estreitamento da bicamada, na região em que o peptídeo está

\footnotetext{
${ }^{5}$ GWALP23: GGALW5LALALALALALALWLAGA, por exemplo
} 
inserido, Figura 4.15 (A). Note que, nesse caso, o peptídeo passa a ser alinhado verticalmente pelos resíduos 5 e 14, espaçados por apenas 9 resíduos hidrofóbicos entre eles. Já no segundo caso (substituição de Ala12 por Arg12), os resultados mostraram que a Arg inserida desestabiliza completamente o alinhamento do peptídeo, que agora também pode ser encontrado paralelo à bicamada.

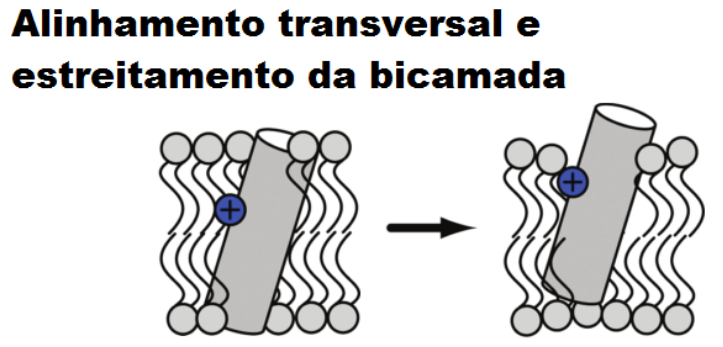

\section{Resíduo positivo buscando a superfície da bicamada}

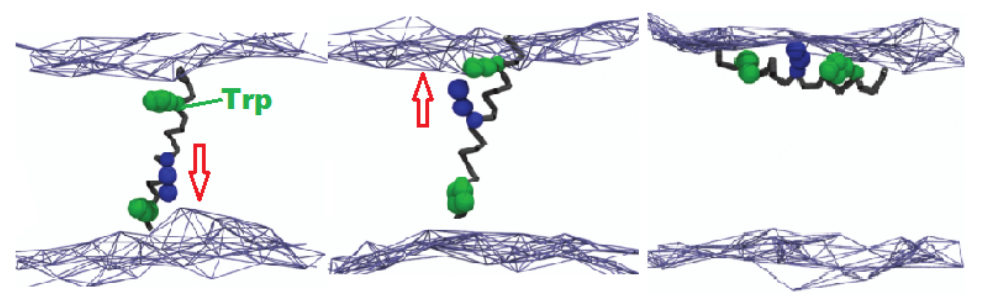

Figura 4.15: Figura esquemática e obtida da referência Vostrikov et. al. 2010 (adaptada) para ilustrar os possíveis arranjos do peptídeo na bicamada e o modo que um amino ácido positivo pode afetar a interação peptídeo - lipídio. (A) O peptídeo pode causar o estreitamento da bicamada na tentativa de seu resíduo positivo buscar a superfície ("snorkeling"). (B) A carga positiva pode desestabilizar a posição do peptídeo na membrana em diferentes situações: o amino ácido buscando a superfície pelo N-terminal, ou pelo C-terminal, ou ainda o peptídeo na superfície da bicamada.

De modo análogo, o peptídeo $\mathrm{KHya1}^{6}$ possui um resíduo aromático, Trp, na posição 7 e um resíduo catiônico, Lys, na posição $15(N-4)$ com 8 resíduos hidrofóbicos entre eles. Logo, podemos supor que tais resíduos (Trp7 e Lys15) auxiliam no alinhamento do peptídeo KHya1 na posição transversal, a mais da interação eletrostática entre as Lys1 e Lys19, (primeiro e último resíduos) com os lipídios aniônicos (DPPG e DPPC:DPPG), fortalecendo portanto, o ancoramento do peptídeo na vertical, Figura 4.16.

A extensão de 19 (KHya1) ou 23 (GWALP23R14) resíduos de aminoácidos em $\alpha$-hélice tem dimensão de 29 e $33 \AA$. A espessura da bicamada desses estudos, distância medida entre as cabeças polares, corresponde a $38 \AA$ (Heftberger et al., 2014). Portanto, para esses pep-

\footnotetext{
${ }^{6}$ Lys-Ile-Phe-Gly-Ala-Ile-Trp-Pro-Leu-Ala-Leu-Gly-Ala-Leu-Lys-Ans-Leu-Ileu-Lys-NH2
} 
tídeos se organizarem transversalmente na membrana, estabelecendo contato com as cadeias apolares, a bicamada deve se estreitar. De fato, Vostrikov e colaboradores (Vostrikov et al., 2010) observaram que o peptídeo transmembranar (GWALP23R14) causa o estreitamento da bicamada. Assim como também foi observado para o peptídeo KHya1 em vesículas aniônicas, com os resultados de SAXS, capítulo 6.

O peptídeo KHya1 possui uma estrutura secundária que pode ser aproximada a $50 \%$ em $\alpha$ - hélice (Crusca et al., 2011), de modo que sua extensão pode ser maior que a extensão de um peptídeo de mesmo número de resíduos e inteiramente estruturado em $\alpha$ - hélice. ${ }^{7}$

Por outro lado, é possível que o excesso de cargas positivas, $(+4)$ do peptídeo KHya1, prefira se expor ao solvente a interagir com a bicamada neutra de DPPC, Figura 4.16. Também é possível que o peptídeo não se encontre em uma posição estável na membrana neutra, semelhantemente ao segundo caso da analogia estabelecida com o peptídeo transmembranar (GWALP23R12), exemplo ilustrado na Figura 4.15 (B), onde ora o peptídeo tenta atravessar a membrana e ora ele busca a superfície. Essa hipótese poderia explicar, por exemplo, o deslocamento espectral observado na fase fluida do DPPC.

No capítulo 6, os resultados de SAXS mostraram que o peptídeo KHya1 causa o estreitamento de membranas lipídicas compostas por PG, onde para a mais alta concentração de peptídeo foi observado um estreitamento médio de aproximadamente $10 \AA$, corroborando o modelo proposto. Além disso, o modelo proposto para o DPPC também concorda com os resultados de SAXS e ESR apresentados no capítulo 6.
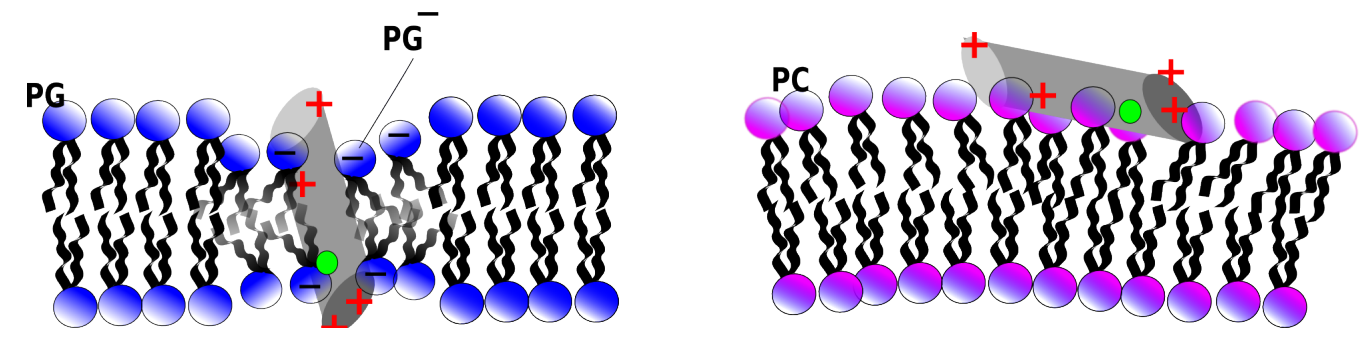

Figura 4.16: Figura esquemática sugerindo um modelo para a interação do peptídeo antimicrobiano KHya1 em membranas aniônicas, compostas por PG e em membranas neutras compostas por PC. Os amino ácidos positivos do peptídeo estão representados em vermelho e o Trp em verde.

Os resultados de DLS trazem informações sobre alterações na estrutura macroscópica dos

\footnotetext{
${ }^{7}$ Para essa comparação utilizamos que cada volta de hélice é composta por 3.6 resíduos com um passo de 5.4 Åcom relação a seu eixo. O valor da espessura da bicamada utilizado para essa comparação foi obtido para o DPPC na fase gel. Utilizamos essa referência por ser uma referência recente, e a espessura de bicamadas de DPPG não difere muito desta
} 
lipossomos causados pelo peptídeo antimicrobiano KHya1. O tamanho aparente dos agregados lipídicos compostos por DPPC, DPPG e DPPC:DPPG aumenta gradualmente com o aumento da concentração de peptídeo. Esse aumento indica a formação de estruturas maiores que também podem estar relacionadas com a agregação dos lipossomos. Entretanto, tais efeitos de agregação não podem ser detectados a olho nu e não há formação de material depositado no fundo do tubo. Os resultados de DLS são importantes para ressaltar que não há evidência de total destruição dos lipossomos, formando vesículas colapsadas como mostrou a microscopia óptica.

As cinéticas de vazamento para lipossomos neutros, ou compostos por lipídios negativamente carregados, também apresentam diferenças que podem estar diretamente relacionadas a diferentes mecanismos de ação. Como mencionado na apresentação dos resultados para lipídios puramente aniônicos, o vazamento da sonda encapsulada é abrupto nos primeiros segundos da cinética. Esse resultado pode ser uma indicação de que a ação do peptídeo em membranas negativamente carregadas tem uma resposta rápida, enquanto para membranas neutras de DPPC seu efeito evolui lentamente com o tempo. A evolução do vazamento com tempo pode ser dividida em dois processos, um caracterizado por um tempo de resposta rápido e outro mais lento. O perfil da cinética de vazamento depende da magnitude desses tempos, assim como da fração que cada processo contribui para o vazamento total. Desta análise, observamos que o vazamento em lipossomos aniônicos tem maior contribuição do processo definido pelo tempo curto, enquanto em lipossomos neutros a maior contribuição no vazamento é proveniente de uma resposta mais lenta.

Curiosamente, o vazamento causado pelo peptídeo KHya1 em membranas mistas, DPPC:DPPG mostrou-se maior que o vazamento observado em DPPC e DPPG. A semelhança dos resultados obtidos por DSC e fluorescência do Trp para membranas puramente aniônicas e mistas sugere que o peptídeo interage preferencialmente com o grupo polar negativo, PG. Logo, o maior vazamento da sonda encapsulada pode ser consequência da maior relação peptídeo/ PG encontrada na mistura. Além disso, a preferência do peptídeo por grupos PG pode gerar a segregação de lipídios aniônicos, trazendo-os para perto do peptídeo, inclusive para auxiliar a estabilizar o peptídeo na posição transversal. Como sugerido por Epand e Epand a segregação de lipídios pode causar mudanças de permeabilidade na membrana (Epand e Epand, 2009a, 2009b). Além disso, possíveis domínios de lipídios segregados podem apresentar defeitos em suas interfaces, onde pode ocorrer maior vazamento.

Considerando a hipótese da segregação de lipídios, convém supor que o aumento da concen- 
tração de peptídeo resultará em um excesso de DPPC segregado e excluído. Como o peptídeo também interage com DPPC, diferentes tipos de interação peptídeo-lipídio podem coexistir em membranas mistas, resultando em uma ação mais eficiente. Essa discussão será retomada no capítulo 6, com os resultados de SAXS.

Por fim, os resultados de microscopia óptica sugerem a abertura de poros em membranas compostas por lipídios aniônicos. A formação de poros também está em acordo com os resultados de DSC. Os resultados de DSC para vesículas compostas de PG mostraram a coexistência de dois eventos térmicos relacionados a uma região perturbada pelo peptídeo, que pode ser atribuída, por exemplo, ao contorno dos poros e/ou regiões próximas ao poro, que apresenta transição de fase em temperatura inferior a $T_{m}$. O aumento da concentração de peptídeo pode levar ao aumento do número de poros, ou o aumento do tamanho dos poros, como observado pela microscopia ótica. Deste modo, a região perturbada pelo peptídeo também aumenta levando ao aumento da entalpia do evento térmico que ocorrer em $\mathrm{T}=34 \mathrm{e} 36.5^{\circ} \mathrm{C}$ para o $\mathrm{DPPG}$ e DPPC:DPPG, respectivamente.

Para vesículas neutras, compostas por PC, a microscopia ótica não evidenciou a formação de poros como em presença de lipídios aniônicos. Além disso, os resultados de DSC sugerem uma perturbação media do peptídeo na membrana, onde o peptídeo pode se difundir livremente. Portanto, podemos supor que o peptídeo causa pequenos defeitos em membranas neutras, devido a sua inserção e difusão, levando ao aumento a sua permeabilidade.

\subsection{Conclusões}

Esse trabalho mostra diferentes interações entre o peptídeo antimicrobiano KHya1 em membranas neutras, e em membranas negativamente carregadas. Observamos que em membranas neutras o peptídeo KHya1 causa uma perturbação média nos lipídios, diminuindo a cooperatividade dos lipídios ao longo da transição de fase, de modo a sugerir que o peptídeo pode se difundir na membrana, ocupando, portanto, uma posição mais próxima à superfície.

Por outro lado, em membranas compostas por lipídios aniônicos, os resultados sugerem que a bicamada pode ser composta por duas regiões distintas, uma perturbada pelo peptídeo e outra isenta de sua ação (bulk bilayer). A difusão lenta do peptídeo, de modo a manter duas regiões distintas na membrana, sugere que o peptídeo pode estar ancorado na bicamada. Em acordo com os resultados de fluorescência e similaridades com peptídeos transmembranares, sugerimos que o peptídeo pode estar em uma posição transmembranar, onde o Trp (resíduo na 
posição 7) encontra-se em um ambiente bastante apolar.

Além disso, as cinéticas de vazamento também distinguiram distintos tempos de respostas dos dois diferentes mecanismos, onde a resposta do vazamento em vesículas compostas por PGs é mais rápida. Por fim, a microscopia mostrou que em presença de PG o peptídeo KHya1 pode formar poros na membrana, diferente do observado para membranas neutras. 


\section{Capítulo 5}

\section{Interação do peptídeo KHya1 com}

\section{membranas aniônicas: um estudo da}

\section{fluorescência do Trp e da sonda exógena}

\section{Laurdan}

\subsection{Motivação}

A interação do peptídeo antimicrobiano KHya1 e membranas negativamente carregadas compostas por DPPG mostrou um peculiar e intrigante efeito, conforme apontado por resultados de Calorimetria Diferencial de Varredura (DSC). O aumento da concentração de peptídeo leva ao surgimento de um evento térmico que ocorre a uma temperatura inferior à temperatura de transição do lipídio puro. Para baixas concentrações de peptídeo, esse evento térmico coexiste com a transição principal do lipídio, Tm, e é relativamente pequeno comparado à transição do lipídio. O aumento da concentração de peptídeo leva ao aumento da entalpia desse evento térmico, até o desaparecimento da transição do lipídio puro, indicando que a perturbação que o peptídeo causa na membrana aumenta e atinge praticamente toda a extensão da bicamada.

A existência de uma região não perturbada pela ação do peptídeo ("bulk bilayer"), em baixas concentrações de peptídeo, nos levou a questionar possíveis organizações do peptídeo na bicamada lipídica. Poderia uma distribuição randômica de peptídeo na membrana causar perturbações à bicamada de modo a produzir tal evento térmico? Ou seriam regiões com diferentes densidades de peptídeo? Poderia ser a evidencia de poros? 
O peptídeo antimicrobiano KHya1 apresenta carga positiva +4 , portanto, o que poderíamos supor que a inserção do peptídeo na bicamada torne essa região da bicamada mais eletropositiva, e consequentemente, menos atrativa para a inserção de um segundo peptídeo. Esse simples raciocínio nos levaria a supor uma distribuição homogênea de peptídeos na bicamada. Entretanto, além do potencial eletrostático, há outras interações que podem dirigir a distribuição dos peptídeos nas membranas.

Neste trabalho, estudamos os tempos de vida do estado excitado do Trp, resíduo na posição 7 do peptídeo KHya1, e, através de reações que podem ocorrer no tempo de vida do estado excitado, entre resíduos de Trp (Homo-FRET), inferimos um intervalo de distâncias entre peptídeos. Esse resultado sugere uma distribuição de peptídeos pela bicamada não homogênea. A região rica em peptídeos pode ser explicada apenas pelo fato do peptídeo deformar a membrana favorecendo a ligação de novos peptídeos em regiões já deformadas.

Também caracterizamos o Trp e o Laurdan como um par doador-aceitador no processo de transferência de energia, FRET, e, estudamos as alterações do tempo de vida do Trp em presença do aceitador. A monitoração da eficiência do FRET também sugere o mecanismo por formação de poros, onde a diminuição da eficiência do FRET pode estar associada ao aumento da distância média entre os pares doador-aceitador devido ao aumento da área da vesícula.

Além disso, estudamos a fluorescência estática do Trp e Laurdan. Embora alguns resultados da absorção e fluorescência estática do Trp tenham sido apresentados no capítulo 4, novos experimentos e incluindo um detalhe maior em novas temperaturas foram realizados neste trabalho. A fluorescência estática do Laurdan também identificou mudanças da bicamada de DPPG causada pelo peptídeo. ${ }^{1}$

\subsection{Materiais e Métodos}

\subsubsection{Reagentes}

Reagentes da seção 4.2.1. Neste trabalho utilizamos a mais a sonda fluorescente incorporada à membrana, Laurdan, Figura 5.1.

\footnotetext{
${ }^{1}$ Esse trabalho foi realizado em colaboração com a Dra. Cintia C. Vequi-Suplicy (IF-USP), Profa. Casssia Marquezin (UFG) e o Prof. Eduardo Souza (UFG)
} 


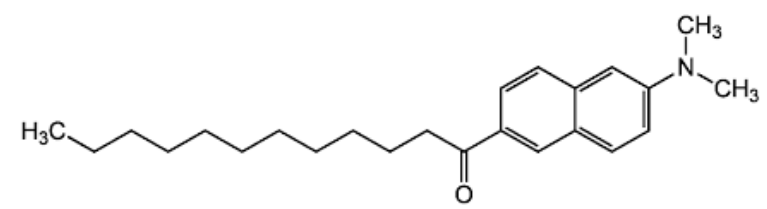

Figura 5.1: Estrutura química da molécula Laurdan.

\subsubsection{Preparações das dispersões lipídicas}

Neste trabalho, os lipossomos foram preparados com e sem a adição de marcador fluorescente, Laurdan. Para preparação de lipossomos, os lipídios $(3 \mathrm{mM})^{2}$, e quando necessário o marcador fluorescente, são diluídos em clorofórmio e depois submetidos a um fluxo de nitrogênio, $N_{2}$, levando à formação de um filme na parede do tudo de ensaio. O filme é então submetido à baixa pressão por três horas para remover resquícios do solvente orgânico. As dispersões lipídicas são suspendidas com a adição de tampão HEPES 10 mM em pH=7.4 com 1.0 mM de EDTA e $3.0 \mathrm{mM}$ de $\mathrm{NaCl}$ aos filmes lipídicos e sob agitação (vórtex) durante aproximadamente 2 minutos, na temperatura $T=45^{\circ} C$, conforme descrito anteriormente. Utilizamos a fração de 1\% em mol de Laurdan, para as vesículas marcadas com sonda fluorescente.

\subsubsection{Vesículas extrusadas}

Após a suspensão da dispersão lipídica com o tampão descrito no item 5.2.2, as vesículas foram extrusadas conforme reportado na seção 4.2.3.

\subsubsection{Razão molar do peptídeo}

Como no capítulo anterior, a razão molar peptídeo/lipídio, $[\mathrm{P}] /[\mathrm{L}]$, corresponde à razão entre a concentração de peptídeo [P] e a concentração de lipídio [L], neste caso DPPG. A razão molar, $[\mathrm{P}] /[\mathrm{L}]$ foi variada através de adições consecutivas de peptídeo, de modo análogo ao descrito na seção 4.2.5.

\subsubsection{Calorimetria diferencial de varredura (DSC)}

Retomamos, neste capítulo, os resultados experimentais de DSC apresentados no capítulo 4, para o DPPG. Portanto, o protocolo experimental corresponde ao previamente apresentado na seção 4.2.6.

\footnotetext{
${ }^{2}$ e não $1.0 \mathrm{mM}$ como utilizado no capítulo 4
} 


\subsubsection{Absorção óptica do Trp e do Laurdan}

As absorções do resíduo Trp e do Laurdan foram monitoradas com o uso de um espectrofotômetro (Varian Cary, Santa Clara, CA). As amostras contendo $500 \mu L$ de dispersão lipídica são colocadas em uma cubeta de quartzo $(0.2 \times 1.0 \mathrm{~cm})$ com caminho ótico de $1.0 \mathrm{~cm}$. As medidas do peptídeo em solução aquosa ou em dispersões lipídicas foram realizadas em $T=25$, $30,35,40,45$ e $50^{\circ} \mathrm{C}$, onde a temperatura foi controlada ao longo dos experimentos com o uso de um controlador de temperaturas Carry Peltier thermostatted system.

A Figura 5.2 mostra os espectros de absorção do Trp e Laurdan, em amostras que contêm apenas o peptídeo (curva preta), e o peptídeo e o Laurdan (curva vermelha). Neste trabalho monitoramos a absorção do Laurdan apenas para controle, pois a razão molar de Laurdan é mantida constante, então os valores da absorbância do Laurdan em todas as medidas, aqui realizadas, são iguais. Em amostras que contêm peptídeo e Laurdan podemos subtrair o espectro de amostras equivalentes que contém apenas peptídeo para obter a banda de absorção do Laurdan.

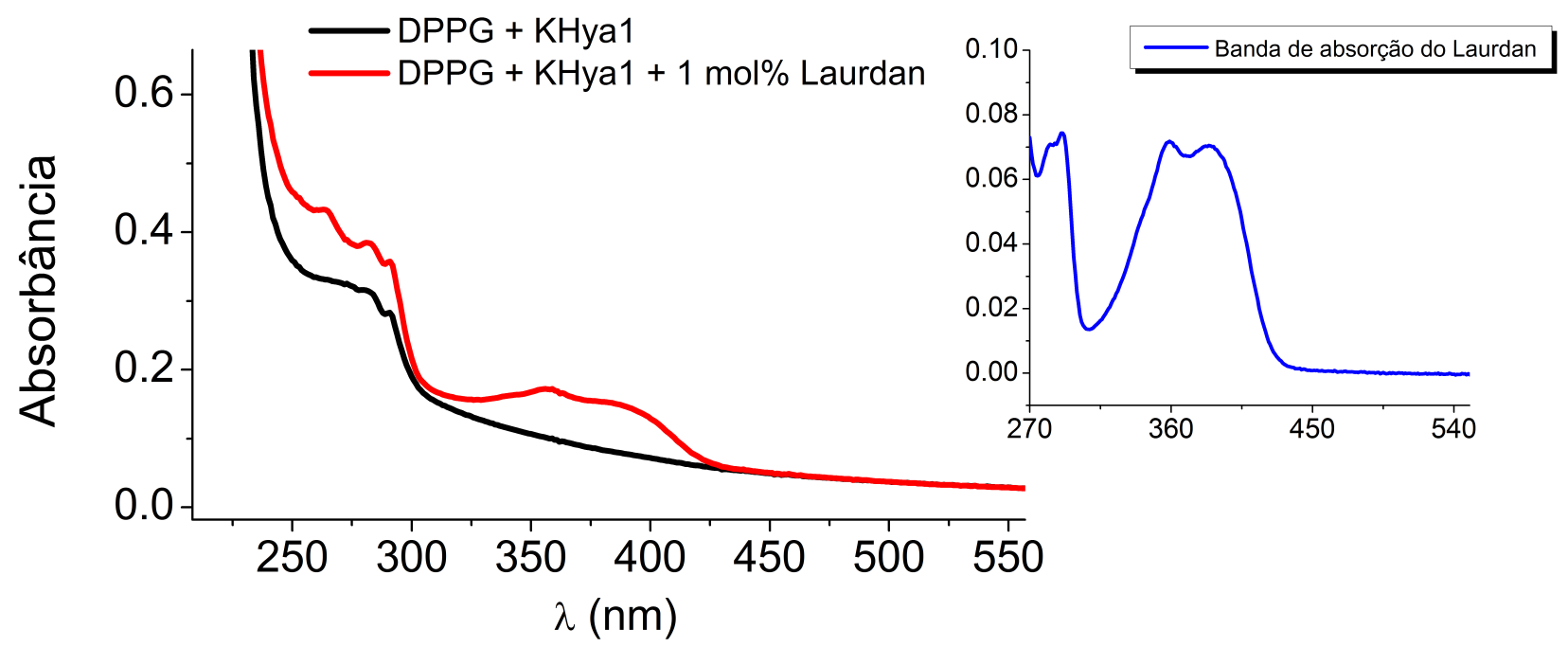

Figura 5.2: Exemplo dos espectros de absorção do Trp e Laurdan em bicamada de DPPG. Amostras contendo apenas o peptídeo apresentam um espectro de absorção semelhante ao observado com a curva preta. Para amostras com peptídeo e marcador fluorescente de membrana, Laurdan, o espectro de absorção mostra as bandas de absorção do Trp e Laurdan. A diferença entre curva vermelha e preta (curvas do gráfico à esquerda) leva ao espectro de absorção do Laurdan, curva azul (curva à direita). Neste exemplo as amostras contêm 2 mol\% de peptídeo (curvas preta e vermelha) e 1 mol\% de Laurdan (apenas curva vermelha). 
Conforme já observado no capítulo 4, o aumento da concentração de peptídeo leva ao aumento da banda de absorção do Trp e do espalhamento da dispersão lipídica. A Figura 5.3 mostra alguns exemplos dos espectros de absorção Trp para $T=25^{\circ} \mathrm{C}$ com o aumento da razão $\operatorname{molar}[\mathrm{P}] /[\mathrm{L}]$.

Novamente, para monitorar os valores da absorbância do Trp em $\lambda=280 \mathrm{~nm}$, subtraímos uma linha de base, conforme o exemplo da Figura 5.3, curva vermelha. Nesta linha de base estão incluídos o espalhamento de luz e bandas de absorção de maior energia.

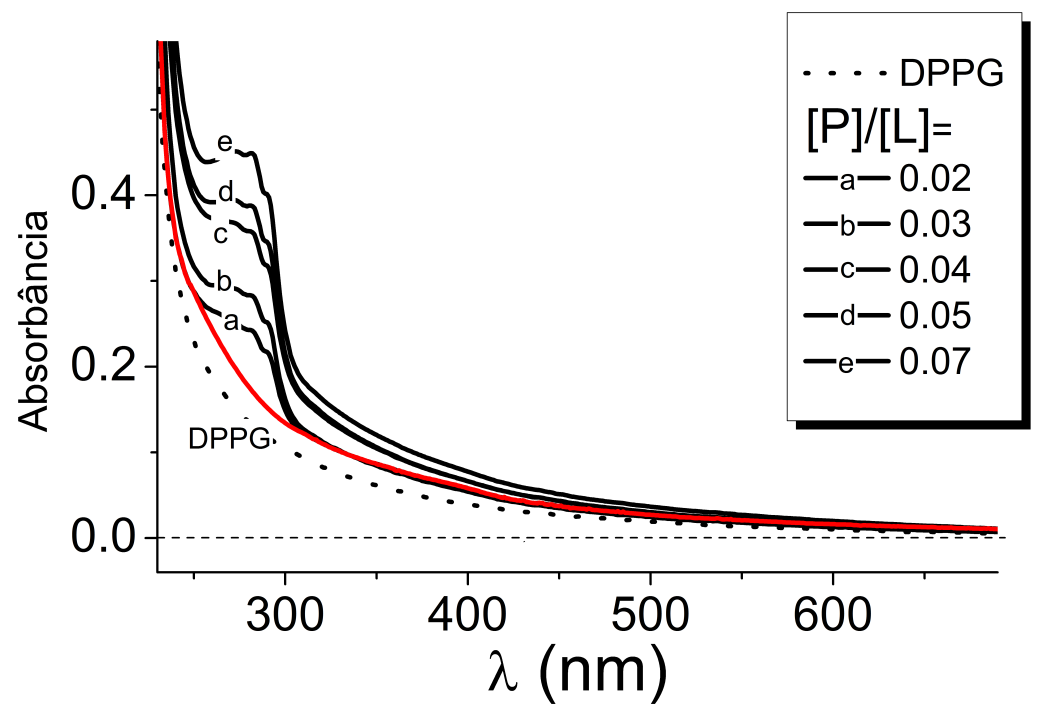

Figura 5.3: Espectro de absorção do Trp, para $T=25^{\circ} C$, com o aumento da concentração de peptídeo. A curva pontilhada representa o DPPG na ausência de peptídeo.

Visto que, a adição do peptídeo leva ao aumento dos valores da absorbância, especialmente no intervalo 270-350 nm, então a fluorescência do Trp e do Laurdan foram corrigidas pelo efeito de filtro interno ("Inner filter effect") (Tucker et al., 1992). Embora o efeito de filtro interno seja menor nos espectros de emissão do Laurdan, estes também foram corregidos. Para maiores informações sobre a metodologia aplicada, rever capítulo 4, seção 4.2.7.

\subsubsection{Fluorescência estática do Trp e do Laurdan}

Espectros de emissão fluorescente do $\operatorname{Trp}\left(\lambda_{\text {exc }}=280 \mathrm{~nm}\right)$ e do Laurdan $\left(\lambda_{\text {exc }}=340 \mathrm{~nm}\right)$ foram obtidos no espectrofotômetro de fluorescência (Varian Cary Eclipse, Santa Clara, CA). Amostras contendo $500 \mu L$ de dispersão lipídica são colocadas em cubetas de quartzo (0.2 x $1.0 \mathrm{~cm}$ ) e o porta-amostra contém um controlador de temperatura do tipo (Carry Peltier thermostatted). Alíquotas de peptídeo são adicionadas à dispersão lipídica para aumentar as 
razões molares de peptídeo $[\mathrm{P}] /[\mathrm{L}]$, conforme descrito na seção 5.2.4. A coleta de dados foi realizada em aproximadamente 25 minutos após a adição de peptídeo. Os espectros de emissão fluorescente foram corrigidos devido aos efeitos de filtros internos (Inner filter efects).

A equação (5.1) retoma a correção de filtro interno previamente apresentada no capítulo 4, seção 4.2 .8

$$
F=F_{0} \cdot 10^{\left(A_{e x} \cdot x\right)} \cdot 10^{\left(A_{e m} \cdot x^{\prime}\right)}
$$

onde $F_{0}$ e $F$ são a intensidade de fluorescência medida e corrigida, respectivamente, e, o caminho óptico na excitação e emissão correspondem a $(\mathrm{x}=0.1 \mathrm{~cm})$ e $\left(\mathrm{x}^{\prime}=0.5 \mathrm{~cm}\right)$. Para maiores informações sobre a correção de filtro interno, rever 4, seção 4.2.8.

\subsubsection{Análise do espectro de emissão do Laurdan}

O espectro do Laurdan foi tratado de duas maneiras diferentes conforme as análises mais reportadas na literatura (Sanchez, Tricerri, e Gratton, 2012; Sanchez, Tricerri, Gunther, e Gratton, 2007; Lúcio, Vequi-Suplicy, Fernandez, e Lamy, 2010; De Vequi-Suplicy, Benatti, e Lamy, 2006; Koehorst, Spruijt, e Hemminga, 2008; Vequi-Suplicy, Coutinho, e Lamy, 2014). O Laurdan em bicamadas lipídicas exibe um espectro assimétrico, onde a forma do espectro pode ser alterada conforme a hidratação e o empacotamento do ambiente em que se encontra a sonda (próxima a cabeça polar dos lipídios). A Figura 5.4 mostra o espectro do Laurdan obtido na fase gel, $T=25^{\circ} \mathrm{C}$ e fluida, $T=50^{\circ} \mathrm{C}$ em membranas de DPPG. Na fase gel do DPPG, a intensidade máxima é observada em $\lambda=440 \mathrm{~nm}$ e na fase fluida em $\lambda=490 \mathrm{~nm}$.

A assimetria do espectro pode ser atribuída a composição de diferentes bandas fluorescentes. Uma maneira simples de avaliar o balanço destas bandas é descrita na equação (5.2), como o parâmetro GP ("generalized polarization") (Sanchez et al., 2012, 2007; Parasassi, De Stasio, Ravagnan, Rusch, e Gratton, 1991).

$$
G P=\frac{I_{440}-I_{490}}{I_{440}+I_{490}}
$$

Mais recentemente, como sugerido por Vequi e colaboradores (De Vequi-Suplicy et al., 2006; Lúcio et al., 2010), uma análise cuidadosa da emissão do Laurdan pode ser realizada com a decomposição do espectro em duas bandas fluorescentes. A decomposição em bandas espectrais deve ser realizada nos espectros em função de frequência ou energia (Lakowicz, 2006). Os espectros são convertidos para energia, por exemplo, com o uso da expressão $E=h \nu$, e 


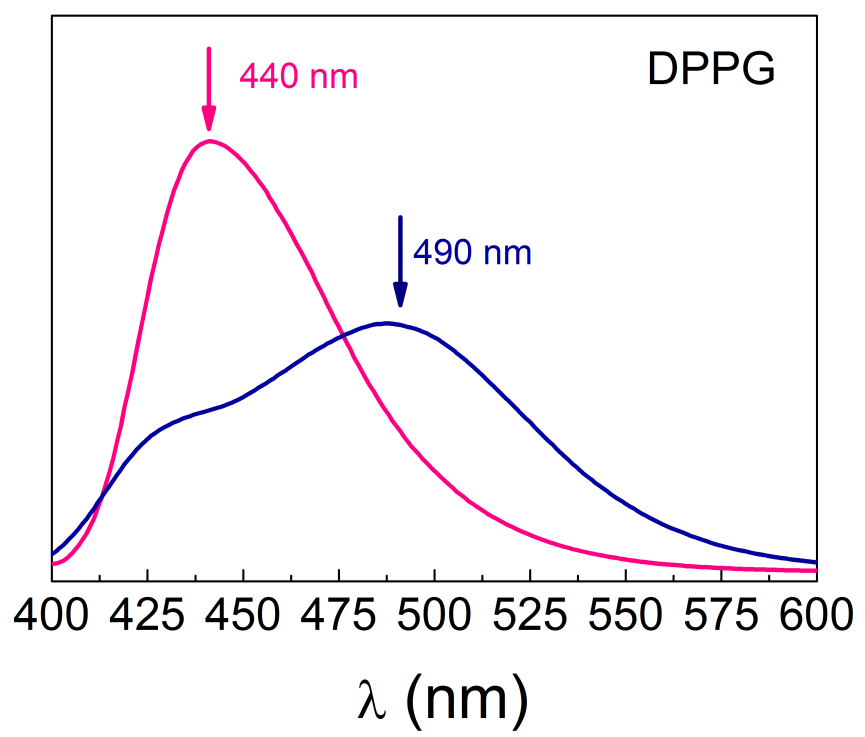

Figura 5.4: Exemplo do espectro de emissão do Laurdan $\lambda_{\text {exc }}=340 \mathrm{~nm}$, para $T=25^{\circ} \mathrm{C}$ com emissão máxima em $\lambda=440 \mathrm{~nm}$ e para $T=50^{\circ} \mathrm{C}$ com emissão em $\lambda=490 \mathrm{~nm}$.

$\nu=c / \lambda$, temos que $E=h c / \lambda$, onde $h=$ (constante de Plank), $\nu$ a frequência e $c$ a velocidade da luz. Contudo uma correção deve ser aplicada a essa transformação (Lakowicz, 2006).

A medida experimental é registrada em intervalos de comprimento de onda constantes, chamados de "bandpass", $\Delta \lambda$, mas a relação entre o intervalo de comprimento de onda e o intervalo de frequência não é linear, conforme indica a equação (5.3),

$$
\begin{aligned}
\Delta \nu=\nu_{1}-\nu_{2} & \alpha\left(\frac{1}{\lambda_{1}}-\frac{1}{\lambda_{2}}\right)=\frac{\Delta \lambda}{\lambda_{1} \cdot \lambda_{2}} \\
\lim _{\Delta \nu \rightarrow 0} & \rightarrow \lambda_{1} \approx \lambda_{2} \\
\Delta \nu & \alpha \frac{\Delta \lambda}{\lambda^{2}}
\end{aligned}
$$

Deste modo, o espectro de emissão em função da frequência, ou energia, deve ser multiplicado pelo fator $\lambda^{2}$ (Lakowicz, 2006), conforme a equação (5.4)

$$
\begin{array}{rcc}
I(\lambda) . \Delta \lambda & \alpha & I(\nu) \cdot \Delta \nu \\
I(\nu) & \alpha & \frac{I(\lambda)}{\Delta \nu} \cdot \Delta \lambda \\
I(\nu) & \alpha & I(\lambda) \cdot \lambda^{2} .
\end{array}
$$

Uma vez que os espectros são representados em função da energia, esses podem então ser decompostos em duas gaussianas, conforme ilustra a Figura 5.22. Por fim, analisamos a 
contribuição e a posição de cada banda espectral, Figuras 5.21 e 5.23.

\subsubsection{Cálculo do rendimento quântico para o Trp}

O rendimento quântico do Trp do peptídeo KHya1 foi calculado de acordo com a equação $(5.5)$

$$
Q=Q_{r} \frac{I}{I_{r}} \cdot \frac{A b s_{r}}{A b s} \cdot \frac{n^{2}}{n_{r}^{2}},
$$

onde $Q_{r}$ equivale ao rendimento quântico de uma substância padrão (referência). Utilizamos como padrão o aminoácido Trp em água excitado em $280 \mathrm{~nm}$, que apresenta $Q=0.13(0.01)$ (Chen, 1967; Lakowicz, 2006). $I_{r}$ e $A b s_{r}$ correspondem à intensidade de fluorescência integrada e à absorbância da referência, e de modo análogo $I$ e Abs para o Trp no peptídeo KHya1. Como mencionado na seção 2.3.1, o rendimento quântico esta associado à relação entre a energia absorvida e emitida na forma radioativa. Neste cálculo do rendimento quântico é realizado de modo comparativo a uma molécula da qual já se conhece o rendimento quântico. O fator $n^{2} / n_{r}^{2}$ vem de uma evidencia experimental que uma fonte de luz em um meio de índice de refração $n_{r}$ coletada por um detector em um meio de índice de refração $n_{0}$, deve ser corrigida pelo fator $n^{2} / n_{0}^{2}$ (Crosby e Demas, 1971).

Por fim, o índice de refração da solução referência e da solução com peptídeo foi medido em um refratômetro de Abe com precisão até a quarta casa decimal.

\subsubsection{Anisotropia do Trp}

A anisotropia de fluorescência do Trp foi medida em um fluorimetro (Varian Cary Eclipse, Santa Clara, CA) com controlador de temperatura do tipo (Carry Peltier thermostatted). Amostras contendo $500 \mathrm{uL}$ de dispersão lipídica são colocadas em cubetas de quartzo (0.2 x $1.0 \mathrm{~cm}$ ) e para controle do espalhamento de luz foi utilizado concentração lipídica $1.0 \mathrm{mM}$ de DPPG. Alíquotas de peptídeo são adicionadas a dispersão lipídica para aumentar as razões $[\mathrm{P}] /[\mathrm{L}]$, conforme descrito na seção 5.6.

$$
r=\frac{I_{/ /}-G I_{\perp}}{I_{/ /}+2 G I_{\perp}}
$$

A anisotropia do Trp do peptídeo KHya1 foi medida utilizando $\lambda_{e x c}=280 \mathrm{~nm}$ e $\lambda_{e m}=330$ $n m$. Experimentos controles também foram realizados com o amino ácido L-TRP $(60 \mu M)$ solubilizado no tampão HEPES (descrito na seção 5.2.2). Diferentes soluções contendo o amino 
ácido L-TRP $(60 \mu M)$ foram preparadas individualmente contendo diferentes concentrações de nano esferas de poliestireno $(0,12.5,25,37.5,50$ e $75 \mathrm{~g} / L)$, de tamanho padrão $(92 \pm 3.7$ nm) (Thermo Fisher Sicentific, USA). A anisotropia do Trp foi então monitorada juntamente com a turbidez das amostras. A anisotropia do amino ácido Trp em solução aquosa foi medida utilizando $\lambda_{\text {exc }}=280 \mathrm{~nm}$ e $\lambda_{e m}=350 \mathrm{~nm}$.

\subsubsection{Fluorescência temporal do Trp e do Laurdan}

Os decaimentos fluorescentes resolvidos no tempo para o Trp e o Laurdan foram medidos em um fluorimetro temporal utilizando o método de contagem de um único fóton. A excitação no fluorimetro temporal é realizada por um laser de titânio-safira (Tsunami 3950, SpectraPhysics), bombeado por um laser de estado sólido (Millenia Pro - J80, Spectra Physics), com o uso de um selecionador de pulsos (3980-25, SpectraPhysics), onde a taxa de repetição foi ajustada em $80 \mathrm{MHz}$. O comprimento de excitação utilizado para o Trp e o Laurdan foram $\lambda_{\text {exc }}=280 \mathrm{~nm}$ e $\lambda_{\text {exc }}=340 \mathrm{~nm}$, respectivamente. Tais comprimentos de onda correspondem ao terceiro harmônico do pulso de excitação. O laser foi ajustado para sair do modulo Tsunami 3950 com comprimento de onda de $990 \mathrm{~nm}$, e, com o uso de um cristal ( $G W N$-23PL, SpectraPhysics) selecionamos o harmônico desejado. A emissão fluorescente foi detectada em um ângulo de $90^{\circ}$ com relação à direção da excitação. Os comprimentos de onda da emissão fluorescente são selecionados por um monocromador. Os fótons emitidos são detectados por uma fotomultiplicadora (Hamamatsu R3809U), a qual é mantida refrigerada. Os decaimentos fluorescentes foram coletados em diferentes comprimentos de onda: (i) para o Trp em solução aquosa entre $\lambda_{e m}=315-435 \mathrm{~nm}$, (ii) para o Trp em dispersão lipídica $\lambda_{e m}=315-335 \mathrm{~nm}$ e (iii) para o Laurdan em dispersão lipídica entre $\lambda_{e m}=420-500 \mathrm{~nm}$. Além disso, as medidas foram realizadas em diferentes temperaturas: $T=25,30,35,40,45$ e $50^{\circ} \mathrm{C}$. As temperaturas das amostras foram estabilizadas com o auxílio de um banho térmico (Julabo HP 25).

\subsubsection{Análise dos decaimentos fluorescentes: Análise global}

Os decaimentos fluorescentes foram analisados utilizando o programa fornecido pela Edinburgh Instruments. Portanto, com esse, realizamos a deconvolução da lâmpada, conforme descrito na seção 2.5, bem como os ajustes dos tempos de vida. Os decaimentos foram coletados próximos ao máximo de emissão fluorescente, conforme previamente observado no espectro 
de emissão, e ajustados com o uso da equação (5.7) (análise global)

$$
I(t)=I_{0} \sum_{i} a_{i} \exp \left(-t / \tau_{i}\right)
$$

onde $I_{0}$ corresponde à intensidade no tempo $t=0$ e $I(t)$ à intensidade emitida pela sonda, em função do tempo; o índice i designa o número de monoexponencias ajustadas, que discriminam diferentes tempos de vida em decaimentos multiexponencias. O tempo de vida é dado por $\tau_{i}$, e $a_{i}$ corresponde ao fator pré-exponcial.

A análise global foi realizada a partir de 3 a 5 decaimentos. A Figura 5.5 ilustra o decaimento fluorescente do Trp em dispersão lipídica de DPPG, onde o máximo da emissão fluorescente é observado em $\lambda_{e m}=325 \mathrm{~nm}$. Para o ajuste dos tempos de vida do Trp, por exemplo, como ilustra a Figura 5.5, as 3 curvas foram ajustadas com os mesmos tempos de vida, onde a fração de cada tempo varia de acordo com o comprimento de onda de emissão.

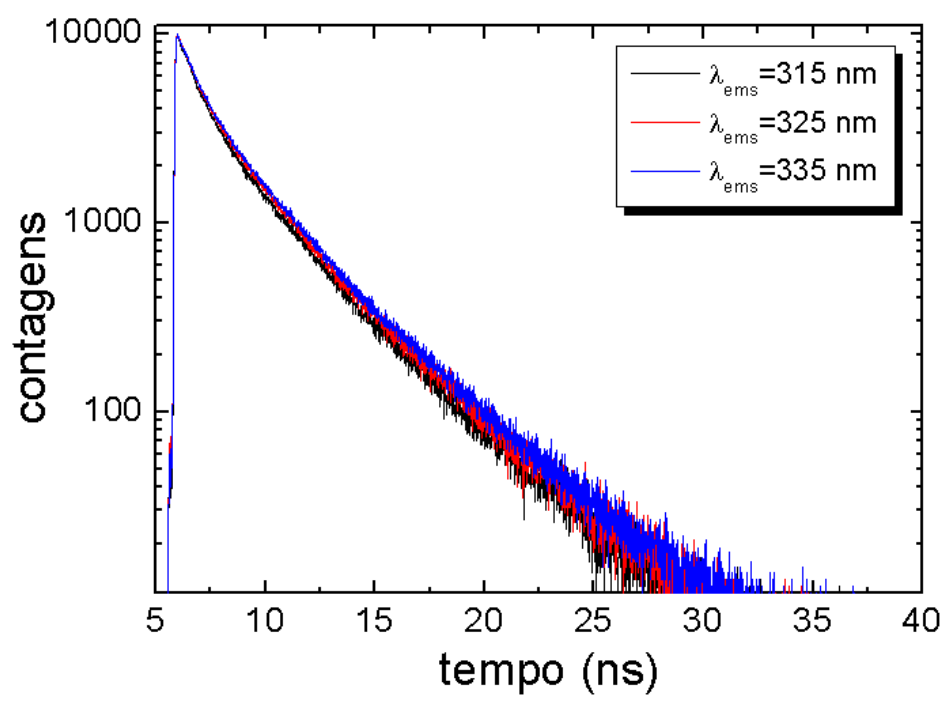

Figura 5.5: Exemplo dos decaimentos fluorescentes do Trp obtidos para $\lambda_{\text {exc }}=280 \mathrm{~nm}, \lambda_{\text {em }}=315$, 325 e $335 \mathrm{~nm}, \mathrm{~T}=50^{\circ} \mathrm{C}$.

\subsubsection{Espectros de emissão associados aos decaimentos (DAS)}

Os tempos de vida associados ao espectro de emissão (DAS) foram obtidos a partir dos decaimentos fluorescentes e do espectro de emissão, para o Trp do peptídeo KHya1 em solução aquosa e em dispersão lipídica, para as temperaturas $T=50^{\circ} \mathrm{C}$, assim como para o Laurdan incorporado à membrana. Para o peptídeo em solução aquosa, os decaimentos fluorescentes 
foram medidos nos comprimentos de onda $\lambda_{\text {em }}=315,325,335,345,355,365,375,385,395$, 405, 425 e $435 \mathrm{~nm}$; e para o peptídeo membranas lipídicas em $\lambda_{e m}=315,325,335,345$ e 355

$n m$. Para o Laurdan os decaimentos fluorescentes foram obtidos em $\lambda_{e m}=420,430,440,450$, 460, 470, 480, 490 e $500 \mathrm{~nm}$.

Os tempos de vida de cada sonda, em seus respectivos ambientes, foram obtidos com a análise global de todos os decaimentos, conforme descrito na seção 5.2.12.

O DAS é então construído pelo produto da intensidade do espectro de emissão, para um dado $\lambda$ fixo, pela contribuição fracional de cada tempo, conforme descrito pela equação (5.8)

$$
I_{i}(\lambda)=\underbrace{\frac{\alpha_{i}(\lambda) \tau_{i}}{\sum_{i} \alpha_{i}(\lambda) \tau_{i}}}_{f_{i}} I(\lambda)
$$

onde $f_{i}$ é a contrição fracional de cada tempo,

$$
f_{i}=\frac{\alpha_{i}(\lambda) \tau_{i}}{\sum_{i} \alpha_{i}(\lambda) \tau_{i}}
$$

\subsubsection{Transferência de energia (FRET)}

A transferência de energia foi identificada pela sobreposição dos espectros de absorção e emissão, conforme ilustra a Figura 5.26, assim como pela mudança dos tempos de vida do doador na presença do aceitador.

A sobreposição entre as bandas espectrais do par doador-aceitador, $J$, representa a intensidade de ressonância entre o estado excitado do doador e o estado fundamental do aceitador. Essa grandeza pode ser descrita pela equação (5.10)

$$
J=\int_{0}^{\infty} F_{d}(\lambda) \epsilon_{a}(\lambda) \lambda^{4} d \lambda
$$

onde $F_{d}(\lambda)$ é o espectro de emissão do doador normalizado, e $\epsilon_{a}(\lambda)$ é a absorbância/ $(x c)$, com $(x=0.1 \mathrm{~cm})$ e $c$ corresponde a concentração em mol/L, conforme apresentado no capítulo 2, seção 2.7 .

\subsubsection{Cálculo da distância de Förster}

A distância de Förster foi obtida com o uso da equação (5.11)

$$
R_{0}^{6}=8.810^{-25}\left(\kappa^{2} n^{-4} \phi_{d} J\right)
$$


onde $\kappa^{2}$ corresponde ao fator orientacional, e refere-se à dependência das orientações dos momentos de dipolo do doador e aceitador (ver capítulo 2). Neste trabalho adotamos $\kappa^{2}=2 / 3$, conforme previamente reportado por (Wang, Martin, Cimino, Omann, e Glaser, 1988; Lakowicz, 2006) ${ }^{3}$. É importante observar que para o uso desta equação $J$ deve ter unidades de $M . \mathrm{cm}^{-3}$.

\subsubsection{Cálculo da eficiência do FRET entre Trp e Laurdan}

A eficiência do FRET entre o Trp e o Laurdan foi calculada de acordo com a equação (5.12) (Lakowicz, 2006)

$$
E=1-\frac{I_{d a}}{I_{d}}
$$

onde $I_{d a}$ e $I_{d}$ correspondem às intensidades de emissão fluorescente integradas sob os espectros, ou seja, as áreas sob as curvas, do Trp (doador) na presença $\left(I_{d a}\right)$ e ausência do aceitador $\left(I_{d}\right)$, Laurdan. Para maiores detalhes sobre a dedução da equação (5.12) ver capítulo 2, seção 2.7. A Figura 5.6 mostra um exemplo dos espectros de emissão do Trp quando em presença e ausência do aceitador.

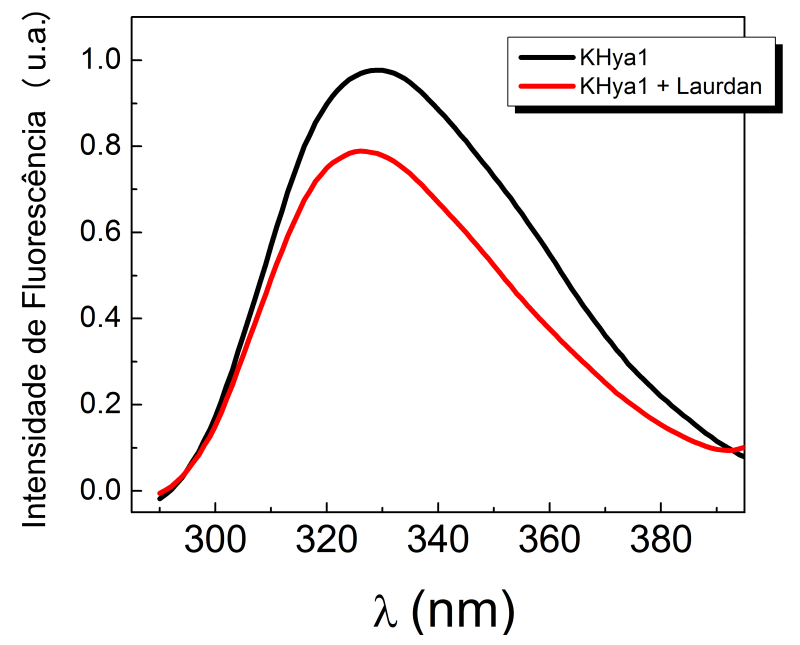

Figura 5.6: Emissão fluorescente do Trp (doador), resíduo 7 do peptídeo KHya1, em ausência de Laurdan (aceitador) curva preta e em presença de aceitador, curva vermelha. A eficiência do FRET foi calculada de acordo com as áreas dos espectros, segundo a equação (5.12) (ver também Lakowicz, 2006).

\footnotetext{
${ }^{3}$ Utilizamos $\kappa^{2}=2 / 3$ assim como previamente reportado por Wang et.al 1998, embora esse valor seja obtido do cálculo para rotações livres em 3 dimensões
} 


\subsubsection{Reprodutibilidade dos resultados}

Todas as medidas discutidas neste trabalho foram realizadas em duplicatas de amostras ou reproduzidas mais de 2 vezes. Em resultados, apresentamos os valores médios, onde o erro experimental foi estimado de acordo com o desvio padrão das amostras réplicas.

\subsection{Resultados e discussões}

\subsubsection{Calorimetria diferencial de varredura (DSC)}

A interação do peptídeo antimicrobiano KHya1 com membranas modelo negativamente carregadas apresenta um interessante fenômeno. Resultados de calorimetria diferencial de varredura, DSC, mostram que o peptídeo KHya1 interage com membranas modelo compostas por DPPG de um modo peculiar, onde é possível identificar dois microambientes na bicamada, como discutido no capítulo 4.

A Figura 5.7 retoma os resultados da calorimetria diferencial de varredura (DSC) de vesículas aniônicas compostas por DPPG (preto) e ao longo do aumento da razão molar peptídeo/lipídio, $[\mathrm{P}] /[\mathrm{L}]=0.02$ (vermelho), 0.03 (verde), 0.04 (azul), 0.05 (azul claro) e 0.07 (marrom).

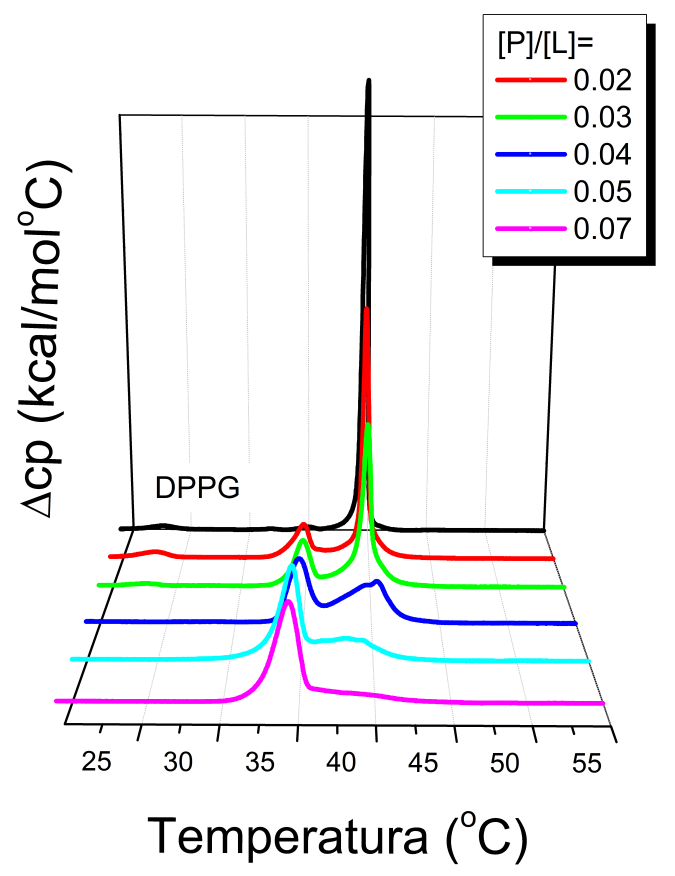

Figura 5.7: Perfis de calorimetria diferencial de varredura (DSC) para lipossomos compostos por DPPG (preto) e com o aumento da concentração de peptídeo. Resultado semelhante foi apresentado no capítulo 4 . 
Para baixas concentrações de peptídeo, $[\mathrm{P}] /[\mathrm{L}]=0.02$, 0.03, os termogramas mostram a coexistência de um evento térmico que surge em $T=34^{\circ} \mathrm{C}$ e a transição de fase principal do lipídio, $T_{m}=39.5^{\circ} \mathrm{C}$. Esse resultado sugere um microambiente perturbado pelo efeito do peptídeo e outro isento de sua ação. O aumento da concentração de peptídeo, $[\mathrm{P}] /[\mathrm{L}]=0.04,0.05$ e 0.07, leva ao aumento gradual desse evento térmico, e, consequentemente, ao decréscimo do pico calorimétrico referente a $T_{m}$.

Os resultados de DSC para o DPPG já foram previamente apresentados no capítulo 4, seção 4.3.1, e foram reapresentados nesta seção para facilitar a comparação com os demais experimentos.

\subsubsection{Absorção óptica}

A absorção do Trp em $\lambda=280 \mathrm{~nm}$ foi monitorada em função do aumento da concentração de peptídeo em bicamada lipídica, após a subtração da linha de base, conforme descrito na seção 5.2.6. Análises similares foram apresentadas no capítulo 4, seção 4.3.2. Neste trabalho, apresentamos diferentes amostras que foram preparadas com maior concentração lipídica, e as análises foram estendidas para diferentes temperaturas.

Na Figura 5.8, mostramos os valores de absorbância em $\lambda=280 \mathrm{~nm}$ em função da concentração de peptídeo e para as temperaturas $T=25,30,35,40,45$ e $50^{\circ} \mathrm{C}$. O comportamento linear da absorção com a concentração de peptídeo em vesículas de DPPG sugere que não há agregação lateral do peptídeo (contato Trp-Trp), de modo a mudar suas propriedades ópticas, para as concentrações aqui estudadas, e nas diversas temperaturas. Portanto, mesmo em amostras que apresentam maiores valores de absorbância, incluindo o espalhamento da dispersão, observamos o mesmo resultado como antes reportado no capítulo4, (ver item 4.3.2).

\subsubsection{Fluorescência estática do Trp}

A Figura 5.9 mostra os espectros de emissão fluorescente (A), e os espectros normalizados (B), do peptídeo KHya1 em solução aquosa para diferentes temperaturas: $T=25,30,35,40$, 45 e $50^{\circ} \mathrm{C}$. A intensidade da emissão fluorescente do peptídeo em solução aquosa diminui com o aumento da temperatura. Essa diminuição da intensidade fluorescente pode ser explicada pelo aumento das taxas não radioativas, e consequentemente com a diminuição do rendimento quântico com a temperatura. 

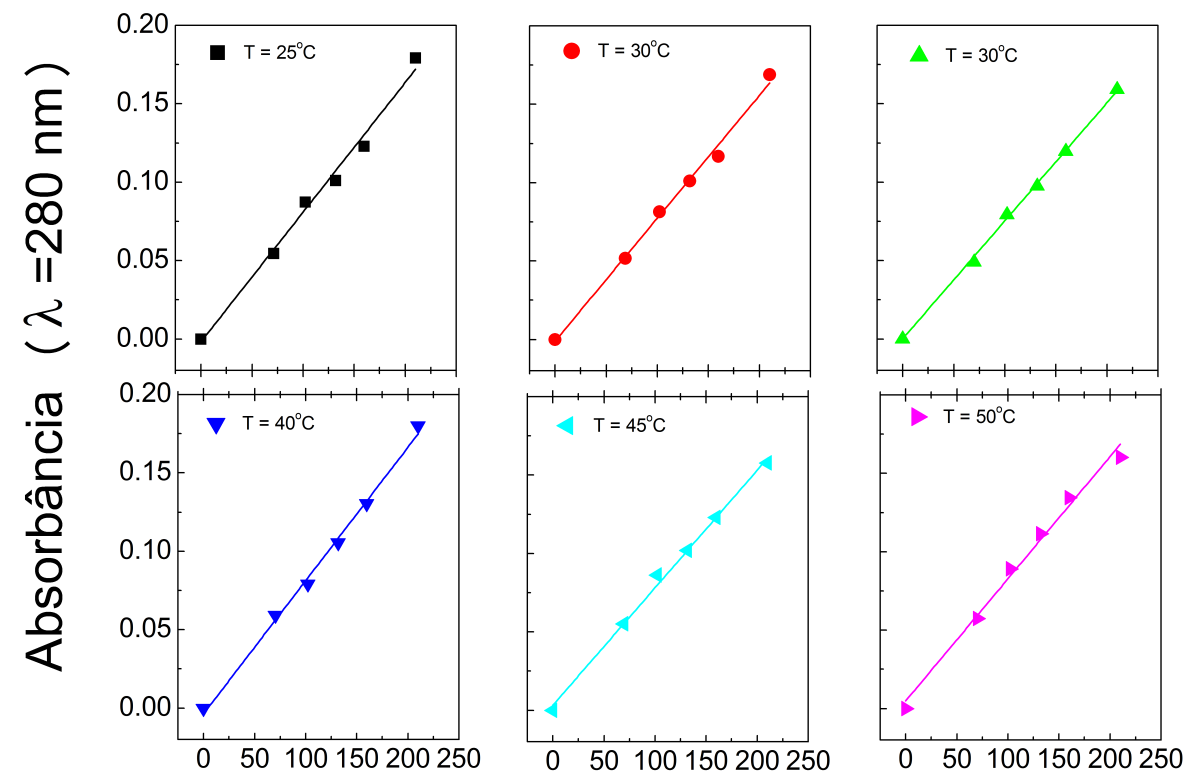

[KHya1] $(\mu \mathrm{M})$

Figura 5.8: Valores da absorbância medidos em $\lambda=280 \mathrm{~nm}$, após subtração da linha de base conforme descrito na seção 5.2.6 e em função da concentração de peptídeo, e para as temperaturas $T=25,30$, $35,40,45$ e $50^{\circ} \mathrm{C}$.
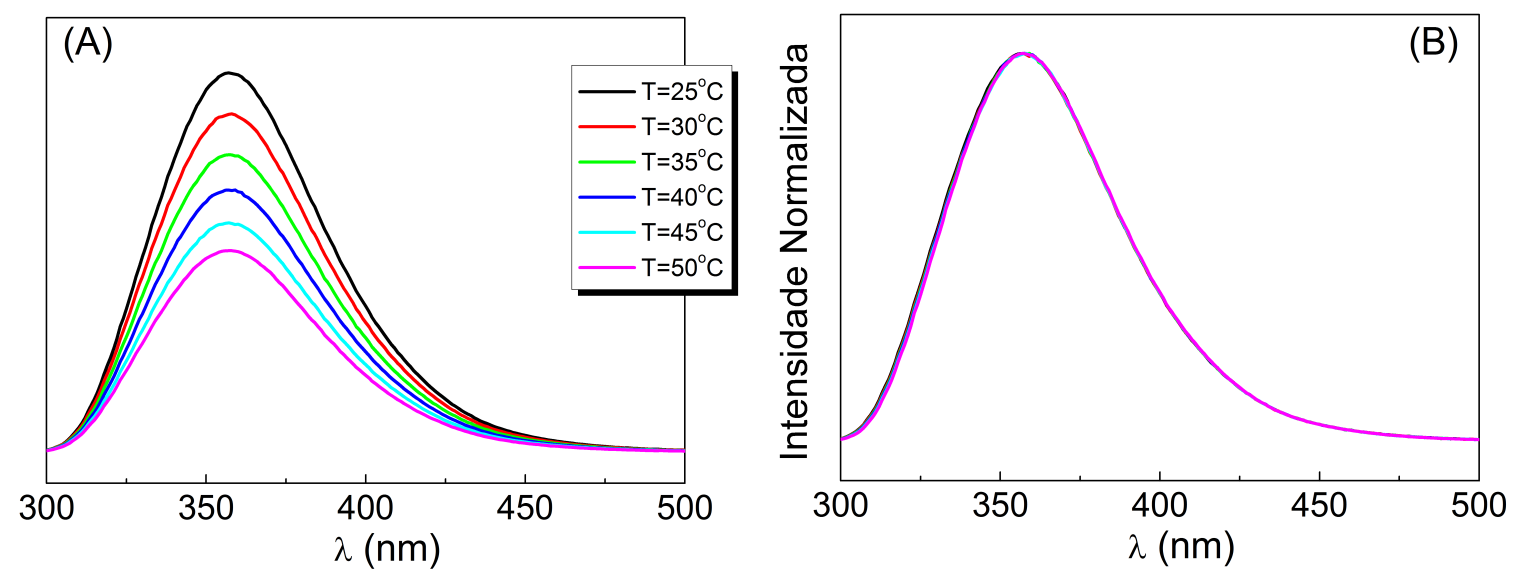

Figura 5.9: Espectros da emissão fluorescente do Trp, resíduo 7 do peptídeo KHya1 (70 $\mu M)$, em solução aquosa, tampão HEPES . (A) Emissão do Trp em diferentes temperaturas $T=25,30,35,40$, 45 e $50^{\circ} \mathrm{C}$. (B) Os espectros do painel (A) foram normalizados pela intensidade máxima.

O rendimento quântico pode ser descrito pela equação (5.13)

$$
Q=\frac{\Gamma}{\Gamma+k_{n r}},
$$

onde $\Gamma$ representa as taxas radioativas e $k_{n r}$ as taxas não radioativas (ver capítulo 2, seção 
$2.3 .1)$.

Substâncias com alto rendimento quântico, como por exemplo, a rodamina $Q=0.94$ (etanol) (Karstens e Kobs, 1980; Lakowicz, 2006), apresentam altas intensidades na emissão fluorescente, pois a maior parte da energia absorvida é emitida na forma de radiação. Entretanto, o aumento do decaimento não radioativo, por exemplo, pode levar à diminuição do rendimento quântico. Szabo e colaboradores (Szabo e Rayner, 1980) citam e observam alguns estudos com o grupo indol do Trp variando a temperatura. Os autores mostraram que em solventes polares há, pelo menos, dois processos não radioativos do Trp, e um deles é dependente da temperatura.

O espectro de emissão normalizado do peptídeo em solução aquosa, Figura 5.9(B), mostra que não há variação na posição espectral com o aumento da temperatura, e sugere que o Trp está sempre envolto pelo mesmo microambiente. Crusca e colaboradores (Crusca et al., 2011) reportam que o peptídeo em solução aquosa não apresenta estrutura secundária ("random coil"). Portanto, os resultados indicam que no intervalo de temperatura estudado não há enovelamento ou degradação do peptídeo como um efeito causado pela temperatura.

A Figura 5.10 mostra os espectros de emissão fluorescente do peptídeo KHya1 em dispersões lipídicas de DPPG, e com aumento da razão molar $[\mathrm{P}] /[\mathrm{L}]$, nas temperaturas $T=25,30^{\circ} \mathrm{C}$ (fase gel do DPPG); 35 e $40^{\circ} \mathrm{C}$ (eventos térmicos e/ou transições de fase) e 45 e $50^{\circ} \mathrm{C}$ (fase fluida do DPPG). Os espectros de emissão foram corrigidos por efeitos de filtro interno, conforme retomado na seção 5.2 .7 (em detalhes, capítulo 4, seção 4.2.8).

Podemos observar que o comportamento da intensidade fluorescente do Trp em bicamada lipídica para as diferentes temperaturas não decresce de modo análogo ao comportamento observado para o peptídeo em solução aquosa (tampão HEPES), Figura 5.9. Para quantificar essa variação, que está relacionada ao rendimento quântico, comparamos $A_{T} / A_{\left(T=25^{\circ} C\right)}$, onde $A_{T}$ corresponde à área sob o espectro para a temperatura $T$, e $A_{\left(T=25^{\circ} \mathrm{C}\right)}$ à área sob o espectro para $T=25^{\circ} C$. Portanto, essa razão indica a diminuição do rendimento quântico em relação a $T=25^{\circ} \mathrm{C}$, Figura 5.11 .

A Figura 5.11 ilustra a diminuição gradual da intensidade de fluorescência do Trp com o aumento da temperatura em uma relação aproximadamente linear, quando o peptídeo está em solução aquosa. Em presença da membrana lipídica podemos observar que a razão molar $[\mathrm{P}] /[\mathrm{L}]=0.02$ apresenta dois regimes, os quais se diferenciam na temperatura de transição do $\mathrm{DPPG}, 40^{\circ} \mathrm{C}$. Então, na fase gel, há um regime para variação da intensidade de fluorescência do Trp com a temperatura, que difere do regime observado na fase fluida. As demais razões molares também estão diretamente relacionadas aos termogramas ilustrados na Figura 5.7. Portanto, 

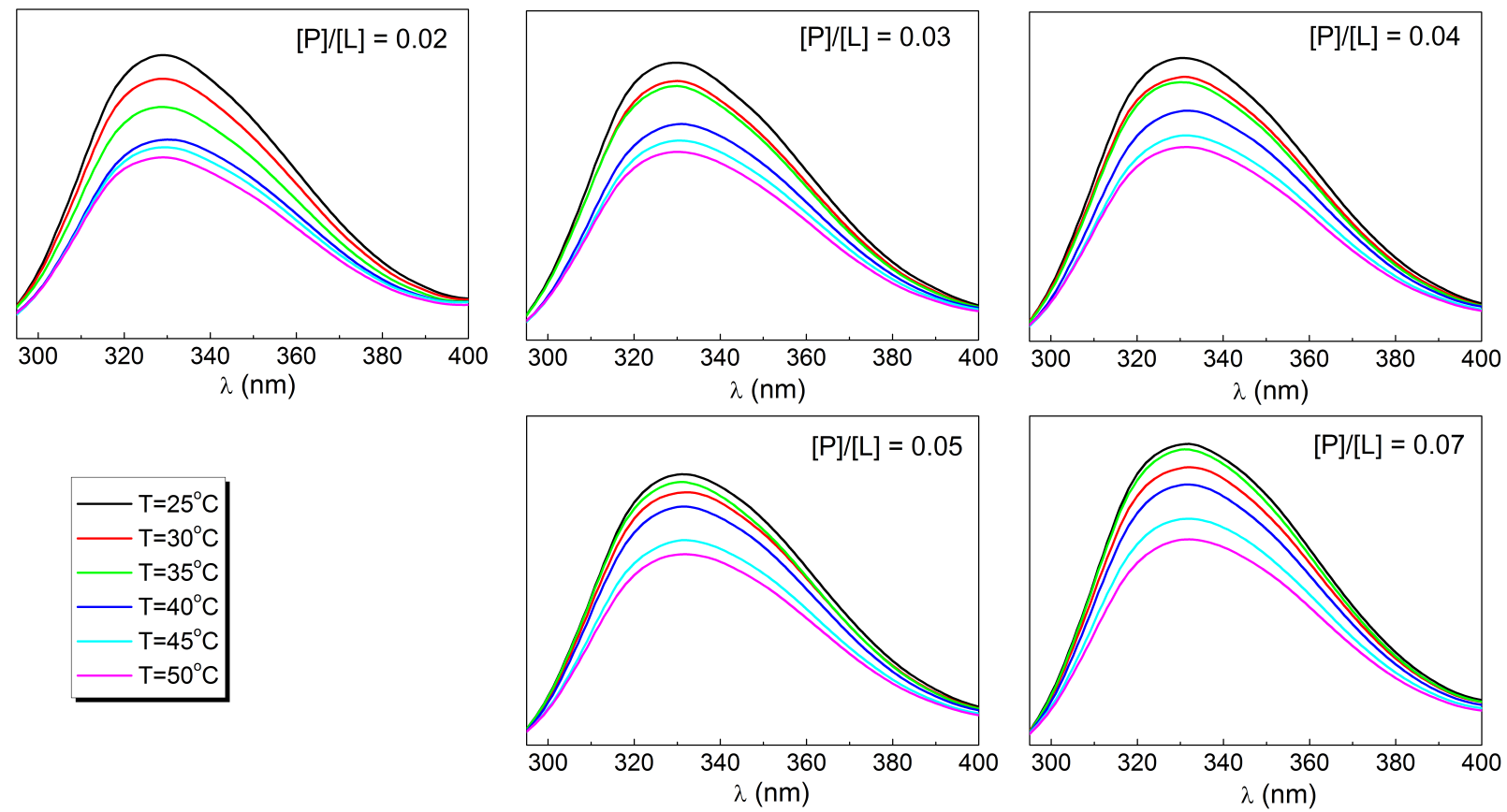

Figura 5.10: Espectros da emissão fluorescente do Trp, resíduo 7 do peptídeo KHya1, em membranas lipídicas de DPPG em diferentes temperaturas $T=25,30,35,40,45$ e $50^{\circ} \mathrm{C}$ e para diferentes razões molares $[\mathrm{P}] /[\mathrm{L}]$ conforme indicado nos painéis.

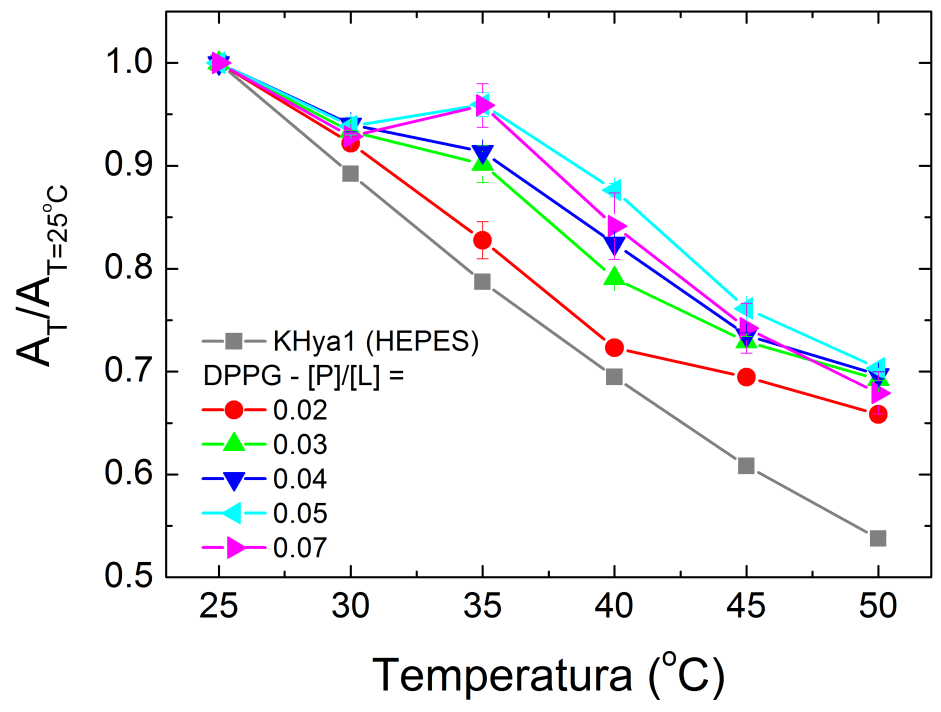

Figura 5.11: Razões entre as áreas dos espectros $A_{T} / A_{\left(T=25^{\circ} \mathrm{C}\right)}$, onde $T=25,30,35,40,45$ e $50^{\circ} \mathrm{C}$ para o peptídeo em solução aquosa, e em diferentes concentrações na bicamada lipídica, $[\mathrm{P}] /[\mathrm{L}]=0.02$, $0.03,0.04,0.05$ e 0.07 .

uma vez que a intensidade de fluorescência também está relacionada ao rendimento quântico, então as taxas de emissão radioativas e não radioativas podem ser sensíveis à estrutura da 
bicamada, e/ou o Trp encontra-se em um ambiente ligeiramente mais protegido do solvente nas temperaturas que se iniciam o primeiro evento térmico da transição de fase da bicamada (ver Figura 5.7).

Os espectros de emissão do peptídeo em dispersão lipídica foram normalizados pela intensidade máxima, conforme ilustra a Figura 5.12. As intensidades normalizadas mostram que a forma e a posição do espectro não variam com o aumento da temperatura ou com o aumento da concentração de peptídeo, como discutido no capítulo 4.
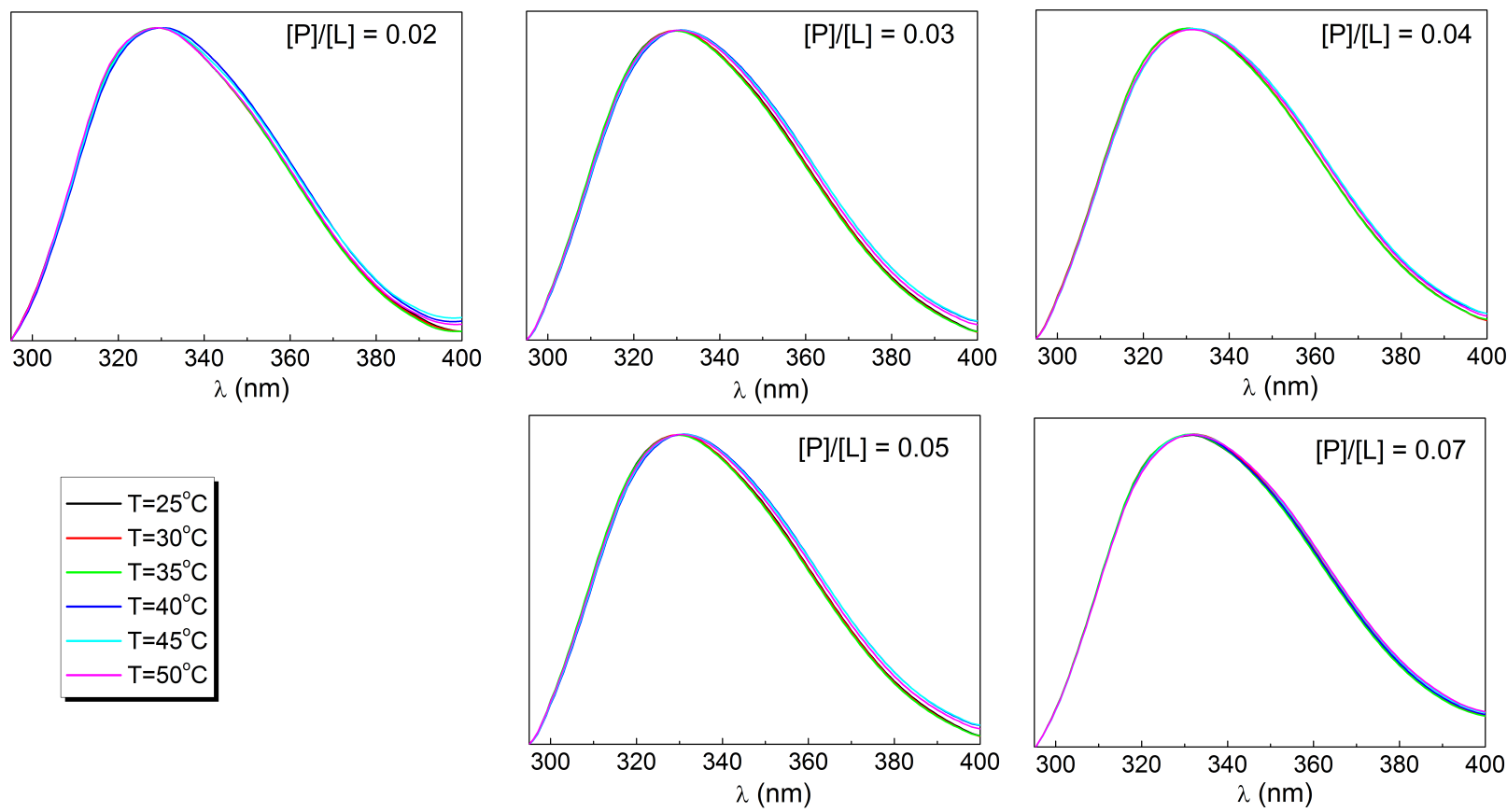

Figura 5.12: Espectros da emissão fluorescente do Trp da Figura 5.10 normalizados pela intensidade máxima.

Deste modo, podemos comparar o deslocamento espectral entre o peptídeo em solução aquosa (Figura 5.9(B)) e em membrana (Figura 5.10), utilizando um espectro característico para representar a posição de cada espectro. A Figura 5.13 ilustra os espectros de emissão fluorescente normalizados do peptídeo KHya1 em solução tampão (HEPES) e em membranas lipídicas de DPPG. Como já mencionado no capítulo 4, observamos um deslocamento espectral de $27 \mathrm{~nm}$ em direção a baixos comprimentos de onda, partindo do espectro em solução aquosa para o espectro em dispersão lipídica.

A não variação da posição espectral em bicamada lipídica com o aumento da concentração de peptídeo, nos leva a supor que o peptídeo está totalmente ligado à membrana. Portanto, a posição do espectro de emissão está diretamente relacionada à sua posição na membrana. Como discutido anteriormente, capítulo 4, essa posição espectral é comparável a posição do 


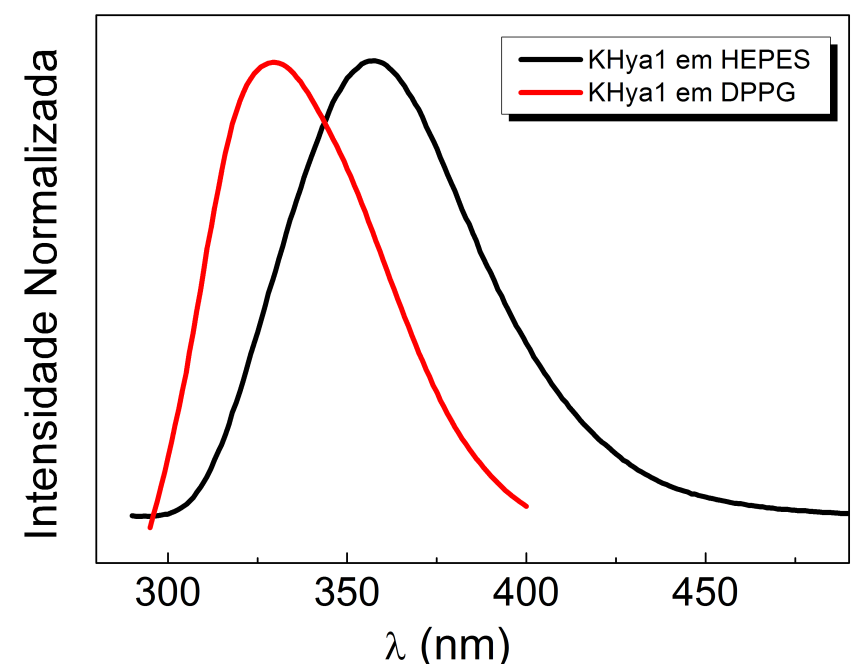

Figura 5.13: Comparação entre a posição espectral do peptídeo em solução aquosa (preto) e o peptídeo em bicamada lipídica de DPPG (vermelho).

espectros de peptídeos conhecidamente transmembranares (Gleason et al., 2012; De Planque et al., 2002; Vostrikov et al., 2010).

Além disso, o fato do peptídeo estar totalmente ligado à bicamada confere ao sistema uma vantagem para ser estudado por fluorescência resolvida no tempo, pois os tempos de vida ajustados do decaimento fluorescente correspondem apenas aos tempos de vida do Trp em um único ambiente, a bicamada lipídica.

A intensidade da fluorescência também pode ser analisada para uma temperatura fixa e variando a concentração de peptídeo. A Figura 5.14 mostra a intensidade integrada (área sob o espectro de emissão) em função da concentração de peptídeo, [P]. A reta de maior coeficiente angular (preta) corresponde às intensidades obtidas a partir dos espectros de emissão em dispersão lipídica para $T=25^{\circ} \mathrm{C}$, onde o Trp apresenta os maiores rendimentos quânticos. As demais retas, com menor inclinação representam as temperaturas $T=30,35,40,45$ e $50^{\circ} \mathrm{C}$.

Como já discutido no capítulo 4, a relação linear entre a intensidade de fluorescência e a concentração de peptídeo até $[\mathrm{P}] /[\mathrm{L}]=0.05$ sugere que não há agregação lateral do peptídeo de modo a alterar as propriedades ópticas do Trp (contato Trp-Trp), conforme observado pela absorção óptica, Figura 5.8 .

Como os espectros de emissão fluorescente foram corrigidos pelo efeito de filtro interno (seção 5.2.7), e o peptídeo causa o aumento da turbidez (espalhamento) da dispersão lipídica, é possível que pequenos desvios da linearidade do gráfico da Figura 5.14, observados para $[\mathrm{P}] /[\mathrm{L}]=0.07$, sejam apenas consequência do espalhamento da dispersão onde a correção de 


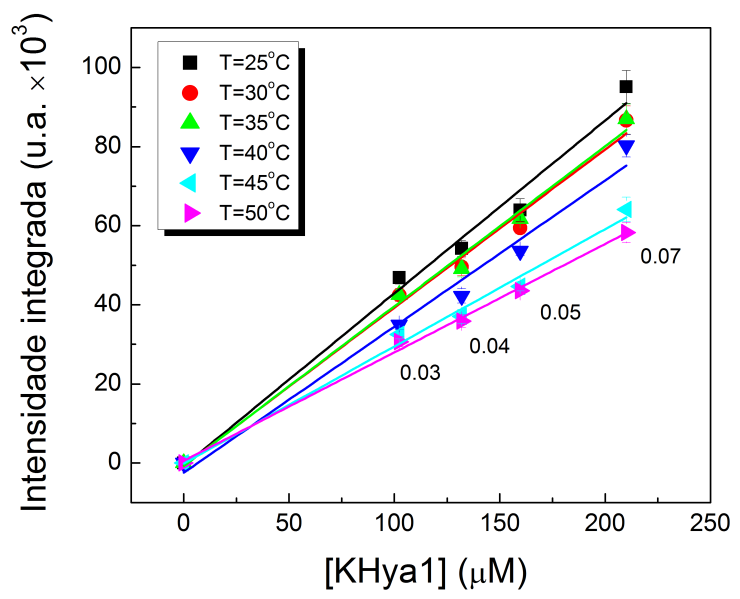

Figura 5.14: Intensidade integrada ou área sob o espectro de emissão em função da concentração de peptídeo. As diferentes retas representam as diferentes temperaturas conforme legenda. Os números indicados no gráfico representam a razão molar, $[\mathrm{P}] /[\mathrm{L}]$.

filtro interno tenha atingido seu limite de funcionalidade.

Experimentos similares foram reproduzidos para uma concentração lipídica menor e utilizando as mesmas razões molares $[\mathrm{P}] /[\mathrm{L}]$ aqui estudadas, em $T=25$ e $50^{\circ} \mathrm{C}$, e também foi observado uma relação linear entre a intensidade de fluorescência e a concentração de peptídeo, Figura 4.7 capítulo 4. No presente trabalho utilizamos uma concentração lipídica maior e em acordo com a concentração utilizada nos experimentos de DSC (ver seção 5.2.2), pois o foco principal deste trabalho está no estudo da fluorescência resolvida no tempo e nos tempos de vida do Trp, seções 5.3.5 e 5.3.9.

\subsubsection{Cálculo do Rendimento quântico do Trp}

A Tabela 5.1 mostra o rendimento quântico, $Q$, calculado para o peptídeo em bicamada lipídica segundo a equação (5.5), apresentada na seção 5.2.9. Como esperado, o rendimento quântico do Trp diminui com o aumento da temperatura.

O rendimento quântico é necessário para o cálculo de $R_{0}$, o qual será apresentado a seguir, na seção 5.3.9. Observamos um erro de cerca de 30\% no cálculo do rendimento quântico do Trp do peptídeo KHya1. Esse erro pode ser também atribuído à dificuldade de trabalhar com os espectros de absorção e fluorescência das amostras em dispersões lipídicas, devido ao espalhamento da dispersão. A banda de absorção do Trp foi obtida após a subtração de uma linha de base, e, os espectros de fluorescência passaram por um tratamento de correção de 
Rendimento quântico do Trp no peptídeo KHya1 (\%)

\begin{tabular}{cccccc}
\hline$T\left({ }^{\circ} \mathrm{C}\right) /[P] /[L]$ & 0.02 & 0.03 & 0.04 & 0.05 & 0.07 \\
\hline \hline 25 & $7 \pm 3$ & $7 \pm 3$ & $7 \pm 3$ & $7 \pm 2$ & $7 \pm 3$ \\
30 & $7 \pm 2$ & $6.5 \pm 2.4$ & $6.2 \pm 2.5$ & $6 \pm 2$ & $6.1 \pm 2.4$ \\
35 & $6 \pm 2$ & $6.6 \pm 2.2$ & $6.1 \pm 2.4$ & $7 \pm 2$ & $6.1 \pm 2.5$ \\
40 & $6 \pm 2$ & $5 \pm 2$ & $5.2 \pm 2.1$ & $6 \pm 2$ & $5.7 \pm 2.0$ \\
45 & $6 \pm 2$ & $5 \pm 2$ & $4.6 \pm 2.0$ & $4.7 \pm 1.5$ & $4.5 \pm 2.0$ \\
50 & $5.0 \pm 1.5$ & $5 \pm 2$ & $4 \pm 2$ & $4.6 \pm 1.3$ & $4 \pm 2$ \\
\hline \hline
\end{tabular}

Tabela 5.1: Rendimento quântico do Trp no peptídeo KHya1. O rendimento quântico do peptídeo foi calculado de acordo com a equação (5.5).

filtro interno. Esse processamento de dados pode aumentar os erros do cálculo do rendimento quântico. Entretanto tal erro em $Q$ leva a um erro de aproximadamente $7 \%$ no cálculo de $R_{0}$, seção 5.3.9.

\subsubsection{Fluorescência temporal do Trp}

Os decaimentos do Trp foram ajustados com 3 tempos de vida, conforme reportado por diversos estudos com peptídeos e proteínas (Beechem e Brand, 1985; Albani, 2014; Tanaka, Tamai, Mataga, Tonomura, e Hiromi, 1994; Lakowicz, 2006). A Figura 5.15 mostra os tempos de vida do Trp para o peptídeo em solução aquosa e na dispersão lipídica de DPPG em função da temperatura e para as diferentes razões molares $[\mathrm{P}] /[\mathrm{L}]$. Os tempos de vida foram obtidos a partir de uma análise global de vários decaimentos conforme descrito em na seção 5.2.12. Da Figura 5.15 podemos observar que os tempos de vida do Trp diminuem com o aumento da temperatura. A diminuição do rendimento quântico com a temperatura conforme mostrado na Tabela 5.11 está diretamente relacionada à diminuição dos tempos de vida do Trp com a temperatura. Os tempos de vida correspondem ao inverso da soma das taxas radiotivas e não radiotivas, conforme equação, 5.14. Logo, o rendimento quântico, equação 5.13, pode ser escrito na forma $Q=\Gamma \tau$

$$
\tau=\frac{1}{\Gamma+k_{n r}} .
$$

Considerando agora a temperatura fixa, podemos analisar a varriação dos tempos de vida do Trp em função da concentração de peptídeo. A Figura 5.16 mostra os tempos de vida do 

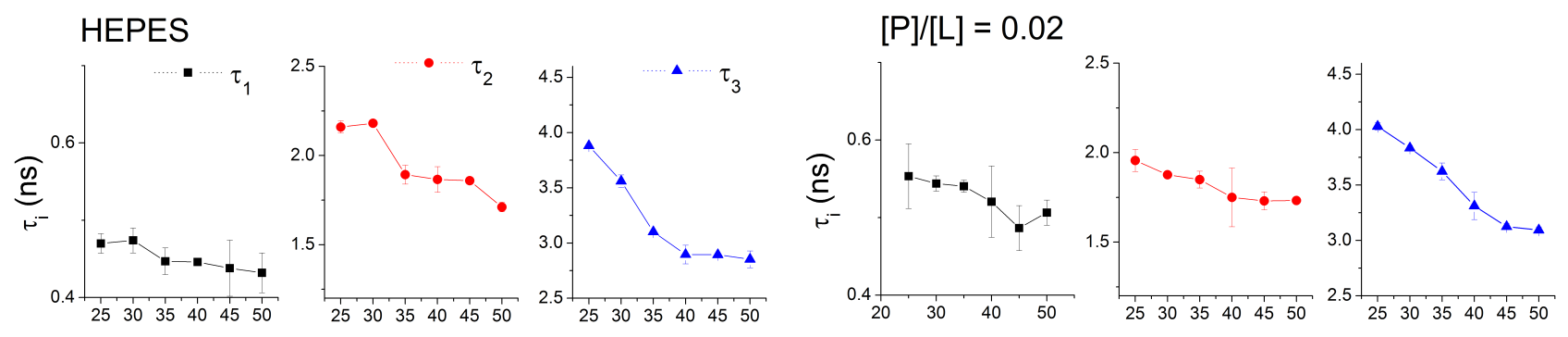

$[\mathrm{P}][\mathrm{L}]=0.03$
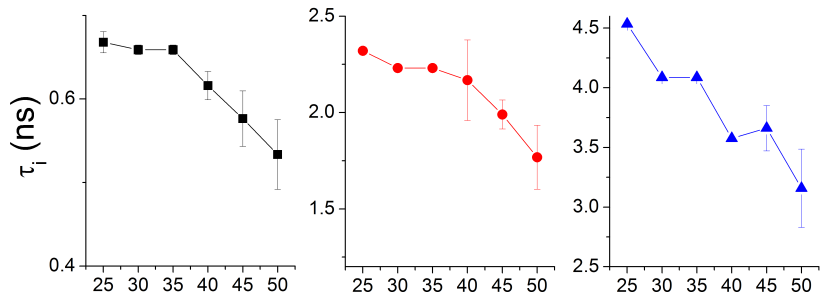

$[P] /[L]=0.04$

$[\mathrm{P}] /[\mathrm{L}]=0.05$
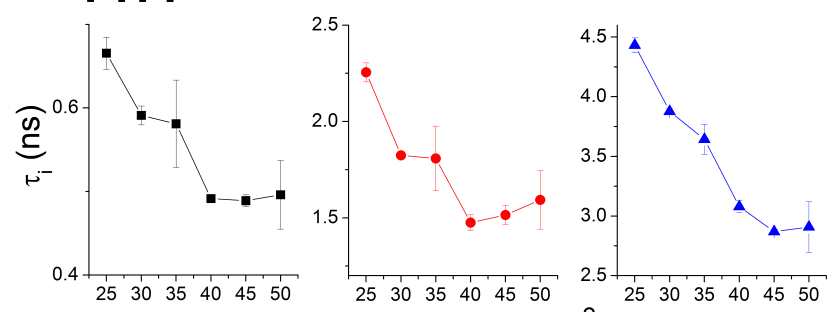

Temperatura $\left({ }^{\circ} \mathrm{C}\right)$

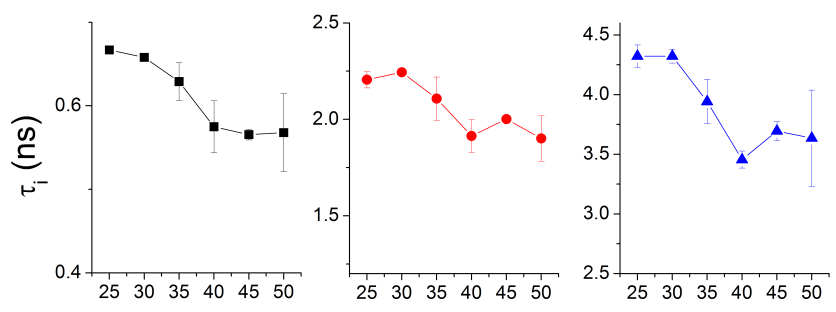

$[\mathrm{P}] /[\mathrm{L}]=0.07$
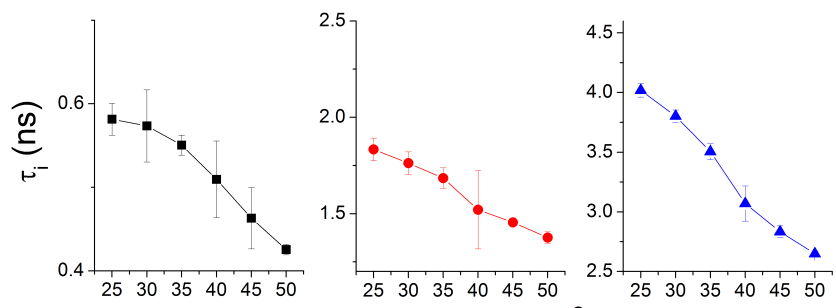

Temperatura $\left({ }^{\circ} \mathrm{C}\right)$

Figura 5.15: Tempos de vida do Trp em solução aquosa e em bicamadas lipídicas de DPPG em função da temperatura, mostrando a diminuição dos tempos de vida com o aumento da temperatura, $\lambda_{\text {exc }}=$ $280 \mathrm{~nm}$, análise global $\lambda_{e m}=315,325$ e $335 \mathrm{~nm}$.

Trp para o peptídeo em dispersões lipídicas de DPPG em função do aumento da concentração de peptídeo, $[\mathrm{P}] /[\mathrm{L}]=0.02,0.03,0.04,0.05$ e 0.07 , e para as temperaturas $T=25,30^{\circ} \mathrm{C}$ (fase gel do DPPG); 35 e $40^{\circ} \mathrm{C}$ (eventos térmicos e/ou transições de fase) e 45 e $50^{\circ} \mathrm{C}$ (fase fluida do DPPG). As linhas tracejadas na horizontal indicam os tempos de vida do Trp, para o peptídeo em água.

Os tempos de vida do Trp em bicamada lipídica, em geral são maiores que os tempos de vida do peptídeo em solução aquosa, indicando que o Trp encontra-se protegido do solvente quando o peptídeo está ligado na membrana. Entretanto, para $\tau_{2}$, principalmente, podemos observar que alguns tempos de vida diminuem com o aumento da concentração de peptídeo, assumindo valores menores que os encontrados em solução aquosa. Essa diminuição do tempo de vida não poderia estar associada a uma mudança de ambiente do peptídeo, pois como mostrado na Figura 5.13 não foi evidenciado deslocamento espectral em função do aumento da concentração de peptídeo. Além disso, a absorção óptica e a intensidade de fluorescência, não mostram a 

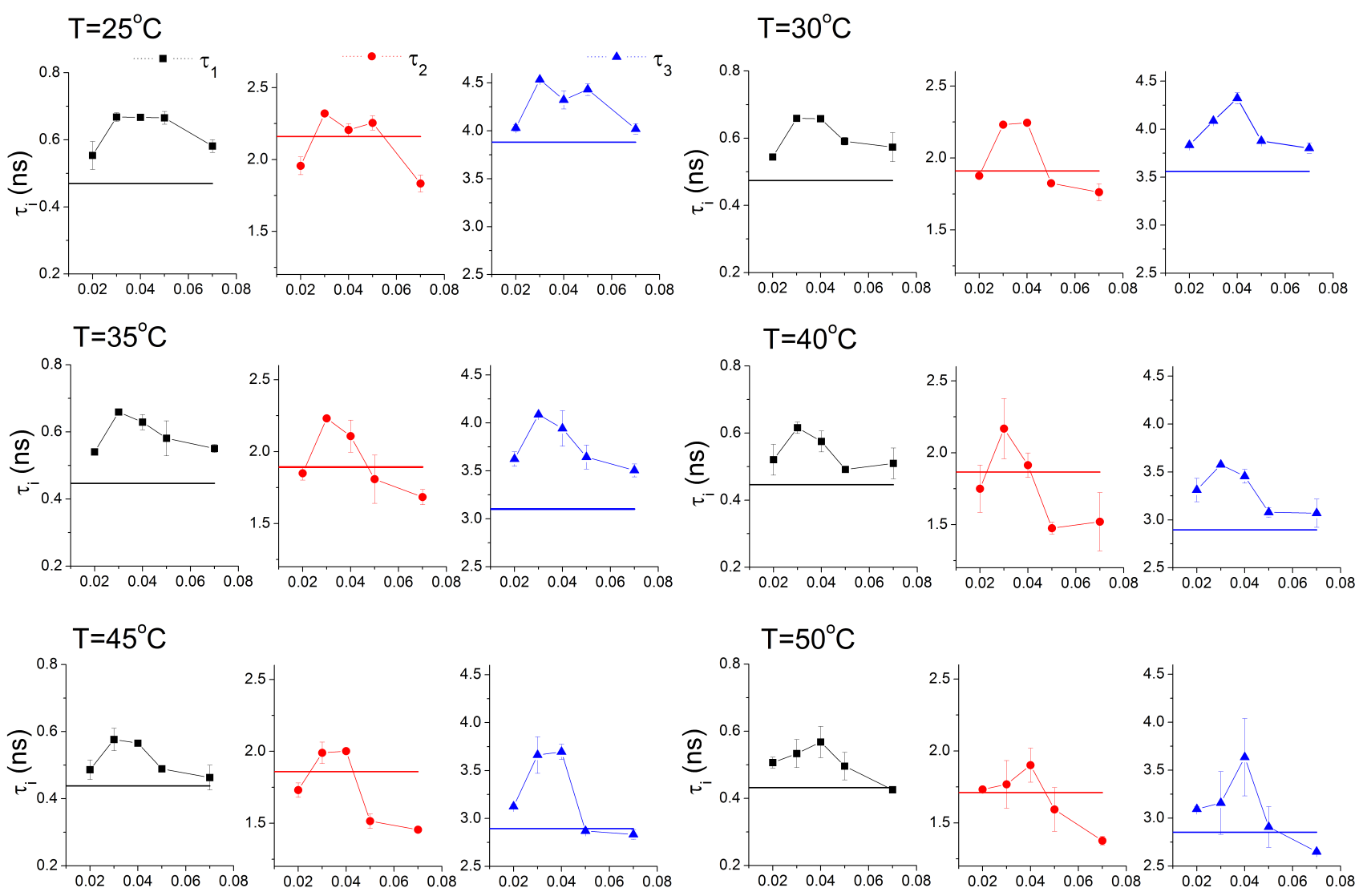

$[\mathrm{P}] /[\mathrm{L}]$
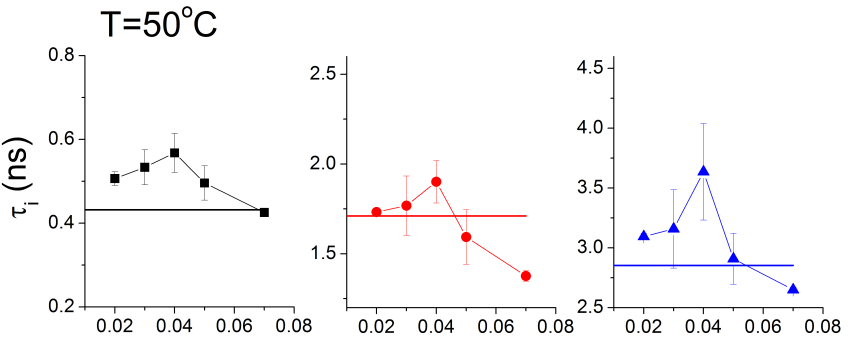

$[\mathrm{P}] /[\mathrm{L}]$

Figura 5.16: Tempos de vida do Trp em solução aquosa (linhas contínuas) e em bicamadas lipídicas de DPPG em função da concentração de peptídeo, para cada temperatura estudada $T=25,30,35$, $40,45,50^{\circ} \mathrm{C}, \lambda_{\text {exc }}=280 \mathrm{~nm}$, análise global $\lambda_{e m}=315,325$ e $335 \mathrm{~nm}$.

agregação lateral do peptídeo.

Para melhor entender o quão relevante é a diminuição do tempo de vida $\tau_{2}$ com o aumento da concentração de peptídeo, calculamos o tempo de vida médio, $\langle\tau\rangle$, segundo equação (5.15)

$$
\langle\tau\rangle=\sum_{i} \alpha_{i} \tau_{i}
$$

A Figura 5.17 mostra os tempos de vida médios em função da concentração de peptídeo em membranas de DPPG, e para as temperaturas $T=25,30,35,40,45$ e $50^{\circ} \mathrm{C}$. Para uma dada concentração de peptídeo constante, podemos observar que os tempos médios diminuem com a temperatura, como esperado, pois todos os 3 tempos de vida diminuem com o aumento da temperatura, como ilustra a Figura 5.16. Entretanto, o tempo de vida médio não se altera com o aumento da concentração de peptídeo, possivelmente indicando que a diminuição de $\tau_{2}$, em função de $[\mathrm{P}] /[\mathrm{L}]$, Figura 5.16, não leva a grandes mudanças nos decaimentos. 


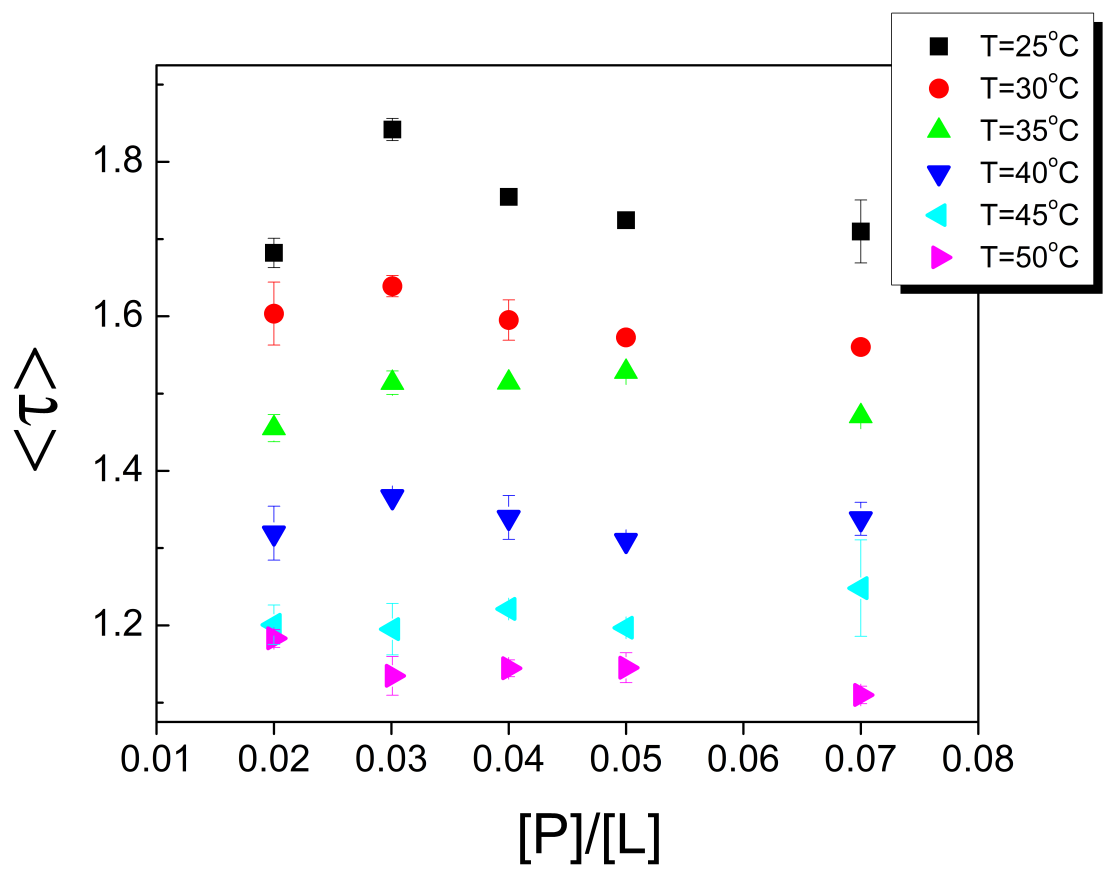

Figura 5.17: Tempos de vida médios em função da concentração de peptídeo em membranas de DPPG, e para as temperaturas , $T=25,30,35,40,45$ e $50^{\circ} C, \lambda=280 \mathrm{~nm}$ e $\lambda=325 \mathrm{~nm}$.

Portanto, considerando a dificuldade de atribuição e analise dos três tempos de vida do Trp, que pode ser devido a 3 diferentes rotâmetros (Fleming et al., 1978; Petrich, Chang, McDonald, e Fleming, 1983), é prudente olharmos para o cálculo de $\langle\tau\rangle$, que indica invariância com a concentração de peptídeo, assim como observado para a posição do espectro de emissão.

Visto que $\langle\tau\rangle$ não varia com a concentração de peptídeo, a diminuição de $\tau_{2}$, em função de $[\mathrm{P}] /[\mathrm{L}]$ deve ser compensada por outro fator, como por exemplo por meio da diminuição da contribuição desse tempo.

A Figura 5.18 mostra as contribuições fracionais de cada tempo de vida com o aumento da concentração de peptídeo, e para as temperaturas $T=25,30,35,40,45$ e $50^{\circ} \mathrm{C}$. Em bicamadas lipídicas, $\tau_{2}$ corresponde à contribuição fracional predominante, mas esta diminui gradualmente com o aumento da concentração de peptídeo, enquanto a contribuição de $\tau_{3}$ aumenta. A contribuição de $\tau_{1}$ também diminui com o aumento da concentração de peptídeo atingindo valores de $10-20 \%$.

Também podemos observar que a maior contribuição no decaimento do Trp do peptídeo em solução aquosa provém de dois tempos de vidas, $\tau_{3}$ o qual é predominante nas temperaturas $T=25,30$ e $35^{\circ} \mathrm{C}$ e $\tau_{2}$ predominante em $T=45$ e $50^{\circ} \mathrm{C}$. Em $T=40^{\circ} \mathrm{C}$ as contribuições de ambos os tempos são semelhantes. E o menor dos tempos, $\tau_{1}$ tem uma contribuição minoritária ao longo das temperaturas. É importante ressaltar que o peptídeo em solução aquosa não 


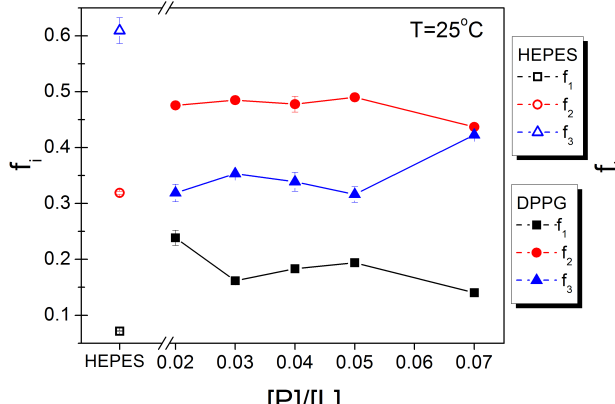

$[\mathrm{P}] /[\mathrm{L}]$

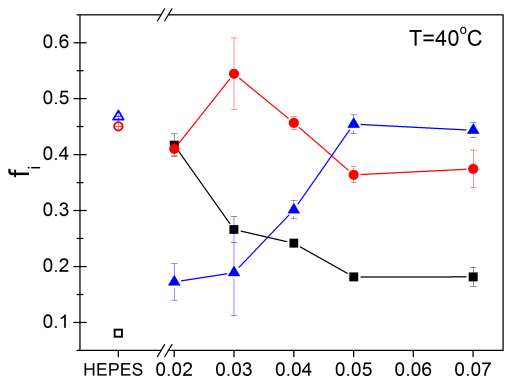

$[\mathrm{P}] /[\mathrm{L}]$

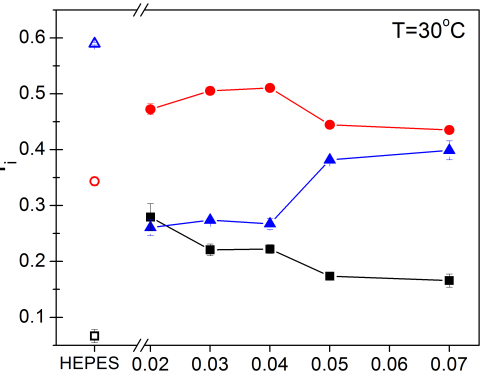

$[\mathrm{P}] /[\mathrm{L}]$

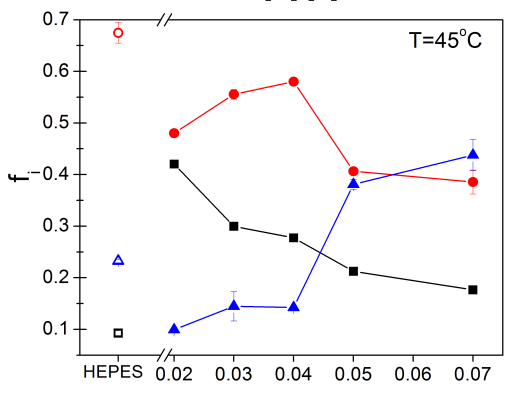

$[\mathrm{P}] /[\mathrm{L}]$

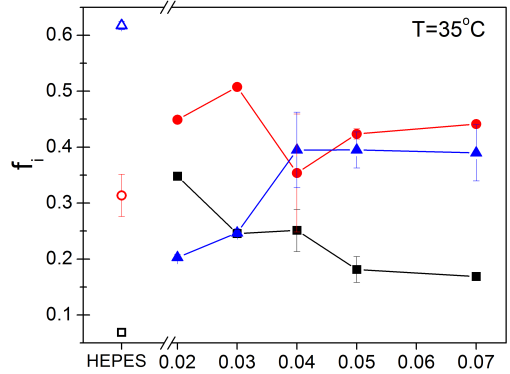

$[\mathrm{P}] /[\mathrm{L}]$

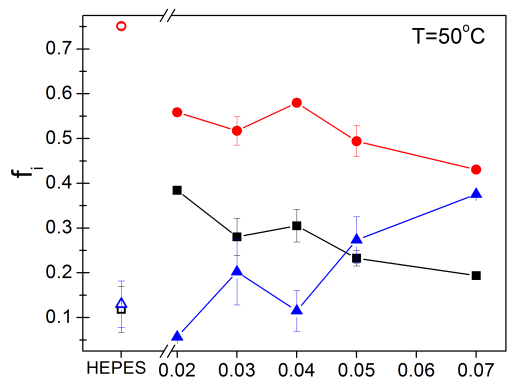

$[\mathrm{P}][\mathrm{L}]$

Figura 5.18: Contribuições fracionais dos tempos de vida com o aumento da concentração de peptídeo e para as temperaturas, $T=25,30,35,40,45$ e $50^{\circ} \mathrm{C}, \lambda_{\text {exc }}=280 \mathrm{~nm}$, análise global $\lambda_{\text {em }}=315,325$ e $335 \mathrm{~nm}$.

apresenta uma estrutura secundária definida (Crusca et al., 2011), portanto essa inversão da contribuição fracional não pode ser relacionada à desnaturação do peptídeo. Além disso, a desnaturação/degradação de peptídeos ou proteínas, ou mudanças em suas estruturas secundarias, em geral, são acompanhadas de um significativo deslocamento espectral (Lakowicz, 2006), o que não ocorre para o peptídeo KHya1 em solução aquosa, ou na bicamada lipídica.

\subsubsection{Espectros associados aos decaimentos (DAS) para o Trp}

Adicionalmente calculamos os tempos de vida associados ao espectro de emissão (Decay Associated Spectra: DAS) para o peptídeo em solução aquosa, HEPES, e em dispersão lipídica de DPPG, na razão molar $[\mathrm{P}] /[\mathrm{L}]=0.02$, para $T=25$ e $50^{\circ} \mathrm{C}$. Os tempos de vida e a contribuição de cada tempo foram ajustados a partir de uma análise global de vários decaimentos medidos em diferentes comprimentos onda, $\lambda_{e m}$, no intervalo da emissão fluorescente (ver seção 5.2.13).

O DAS mostra que os três tempos de vida do Trp contribuem ao longo de uma única banda de emissão do Trp, mas a contribuição de cada tempo pode mudar de acordo com o ambiente do peptídeo ou a temperatura. Ito e colaboradores observaram resultado similar, DAS, para os tempos de vida do Trp no peptídeo $\alpha$-MSH em vesículas de POPS (Ito et al., 1993), onde 

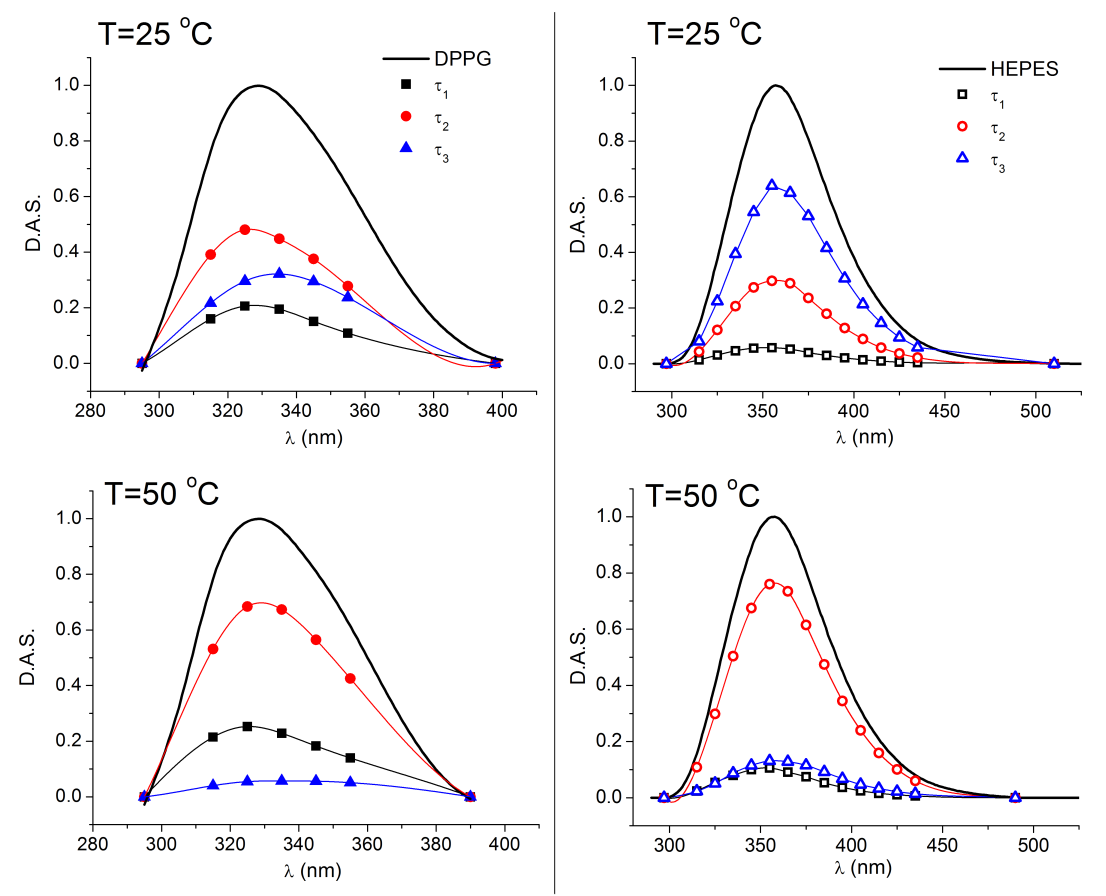

Figura 5.19: Tempos de vida do Trp associados ao seu espectro de emissão (DAS), $\lambda_{\text {exc }}=280 \mathrm{~nm}$, para $T=50^{\circ} \mathrm{C}$ e $[\mathrm{P}] /[\mathrm{L}]=0.02$.

os três tempos de vida do Trp também estão presentes ao longo de sua banda de emissão, mas com diferentes contribuições das observadas neste trabalho.

Em solução aquosa, a maior contribuição do decaimento deve-se a $\tau_{3}$ em $\mathrm{T}=25^{\circ} \mathrm{C}$, e a $\tau_{2}$ em $\mathrm{T}=50^{\circ} \mathrm{C}$, como previamente apontado na Figura 5.18. Comparando as contribuições dos tempos de vida para $\mathrm{T}=25$ e $50^{\circ} \mathrm{C}$ que correspondem as fases gel e fluida da membrana, respectivamente, é interessante notar que $\tau_{3}$ tem contribuição maior que $\tau_{1}$ na fase gel, enquanto que na fase fluida essa relação se inverte, a contribuição de $\tau_{1}$ passa a ser maior que a contribuição de $\tau_{3}$. Podemos, então, supor que a contribuição de $\tau_{3}$ trona-se mais relevante na fase gel, onde o sistema encontra-se com maior grau de empacotamento. Também poderíamos dizer que quando a contribuição de $\tau_{3}$ torna-se maior que a contribuição de $\tau_{1}$ o sistema se assemelha mais à fase gel, ou há um maior empacotamento da membrana.

Deste modo, o aumento da contribuição fracional observada para $\tau_{3}$ em função da concentração de peptídeo, Figura 5.18, pode sugerir que o Trp é sensível ao maior grau de empacotamento da membrana com o aumento da concentração de peptídeo, tanto na fase gel quanto na fase fluida. Na fase fluida, é evidente que a contribuição de $\tau_{3}$ supera a contribuição de $\tau_{1} \operatorname{com} o$ aumento da concentração de peptídeo. Essa discussão será retomada na seção 5.3.7. 


\subsubsection{Fluorescência estática do Laurdan}

O Laurdan é uma sonda fluorescente de membranas lipídicas que foi sintetizada por Weber e Farris (Weber e Farris, 1979). O Laurdan possui um momento de dipolo devido à separação parcial de cargas entre o grupo 2-dimetilamino e os hidrocarbonetos de sua cauda hidrofóbica (Sanchez et al., 2012). Os trabalhos (Sanchez et al., 2012, 2007; Parasassi et al., 1991), por exemplo, sugerem que a relaxação do solvente com o momento de dipolo do estado excitado pode ser sensível à maior ou à menor hidratação da bicamada, e, uma vez que a penetração de água na superfície da bicamada, região a qual se encontra o Laurdan, está correlacionada ao empacotamento dos lipídios e fluidez da membrana, o Laurdan pode ser utilizado para identificar tais modificações.

O espectro de fluorescência do Laurdan em bicamada lipídica é assimétrico, e foi constatado fenomenologicamente que a forma do espectro pode mudar com a fase da bicamada lipídica. Segundo os autores (Sanchez et al., 2012, 2007; Parasassi et al., 1991)(Vequi-Suplicy2015), a banda de menor comprimento de onda representa um estado de menor relaxação com o meio, e essa, portanto, indica um ambiente menos polar. Por outro lado, a banda de maior comprimento de onda refere-se ao estado com maior relaxação com o meio, sugerindo um ambiente mais polar.

Nesse trabalho, utilizamos o Laurdan para monitorar o grau de empacotamento da membrana lipídica de DPPG na ausência e presença do peptídeo antimicrobiano KHya1, e em função da temperatura.

A Figura 5.20 mostra os espectros de emissão fluorescente do Laurdan em membranas lipídicas de DPPG puras e com o aumento da concentração do peptídeo KHya1, $[\mathrm{P}] /[\mathrm{L}]=0$, 0.02, 0.03, 0.04, 0.05 e 0.07, e para diferentes temperaturas. Os espectros de emissão do Laurdan para o DPPG puro mostram dois tipos de espectros característicos da fase gel e fluida, e um espectro intermediário, indicando a transição de fase do lipídio, em $\mathrm{T}=40^{\circ} \mathrm{C}$, primeiro painel da Figura 5.20. Com o aumento da concentração de peptídeo, observamos que o número de espectros intermediários, entre os espectros característicos da fase gel e fluida aumenta, indicando que a região de transição entre $\left(35-43^{\circ} C\right)$ vai se tornando cada mais evidente para o Laurdan.

Os autores (Parasassi et al., 1991; Sanchez et al., 2012, 2007) sugerem o parâmetro GP ("generalized polarization") para acessar as mudanças espectrais, conforme descrito na equação (5.2). Portanto, a Figura 5.21 mostra os valores obtidos para o GP, para as dispersões lipídicas de DPPG, com o aumento da concentração de peptídeo $[\mathrm{P}] /[\mathrm{L}]=0,0.02,0.03,0.04,0.05$ e 0.07 , 

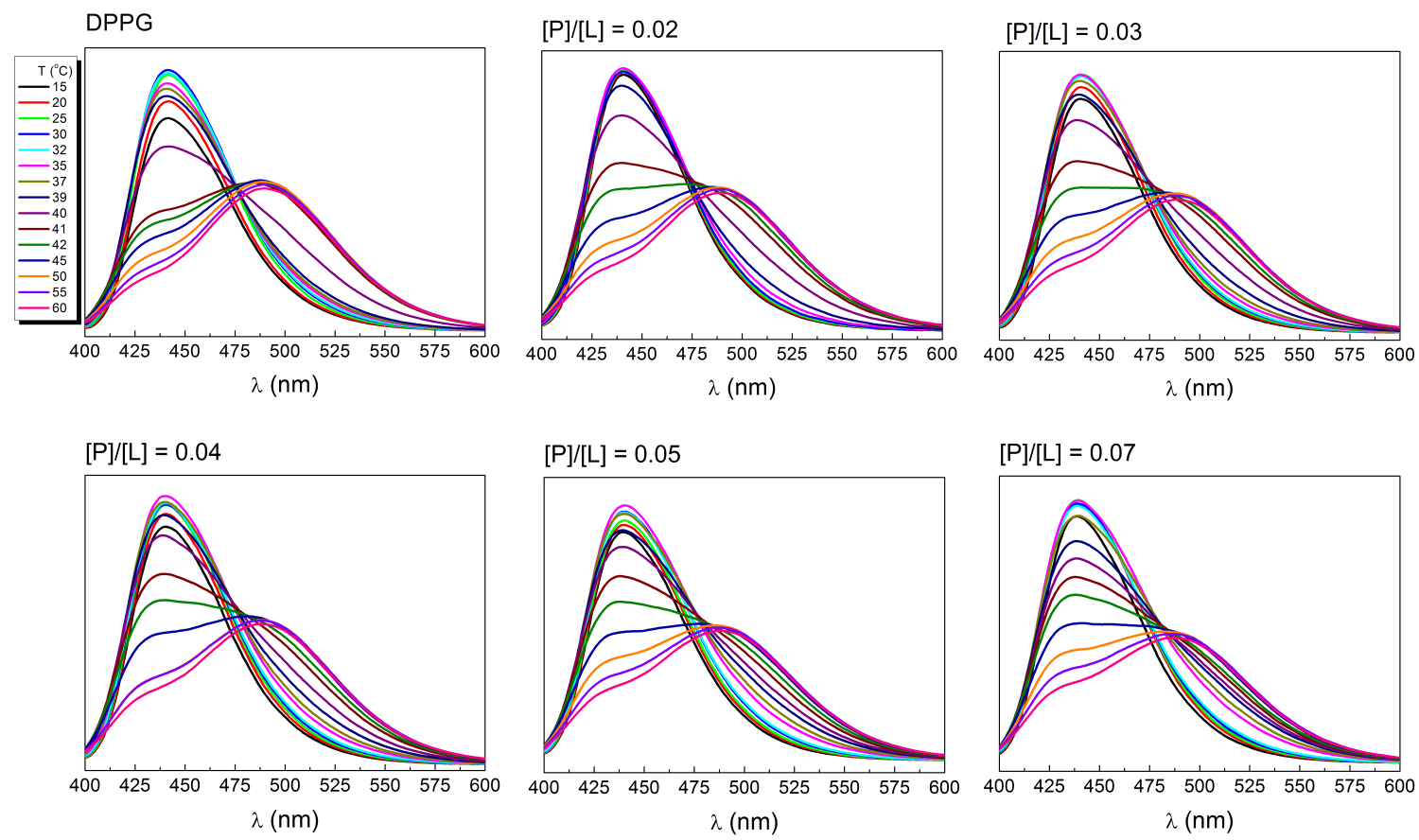

Figura 5.20: Espectros de emissão fluorescente do Laurdan $\lambda_{e x c}=340 \mathrm{~nm}$ em membranas de DPPG em ausência de peptídeo e com o aumento da concentração de peptídeo, $[\mathrm{P}] /[\mathrm{L}]=0.02,0.03,0.04,0.05$ e 0.07 .

e para diferentes temperaturas.

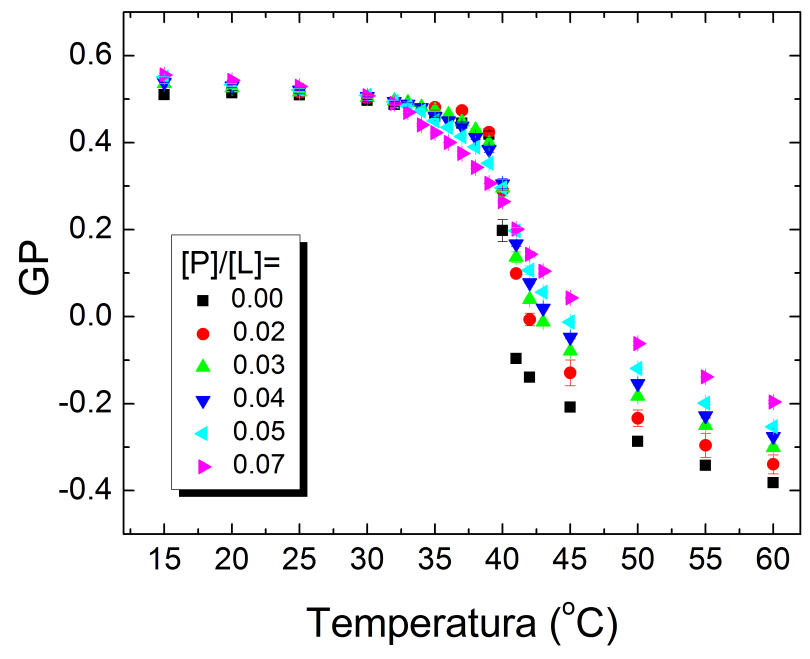

Figura 5.21: Parâmetro GP calculado para os espectros da Figura 5.20 de acordo com a equação (5.2).

Os valores de GP para o DPPG puro são compatíveis com os valores encontrados para o DPPC, conforme reportado por (Parasassi et al., 1991). Além disso, o aumento da concentração de peptídeo leva ao aumento gradual do valor de GP. Esse aumento está presente na fase gel e fluida da membrana, sendo mais significativo na fase fluida. Os resultados indicam que a 
população do estado excitado da banda menos relaxada com o solvente é cada vez maior à medida que a concentração de peptídeo aumenta.

Como sugerido por (De Vequi-Suplicy et al., 2006; Sanchez et al., 2012), o aumento dessa banda de menor comprimento de onda, indica que a sonda está exposta a um ambiente menos polar, ou em um ambiente de menor mobilidade. Esse resultado pode ser interpretado como o peptídeo aumentando o grau de empacotamento da bicamada, tanto na fase gel quanto na fase fluida do lipídio.

Vequi e colaboradores (De Vequi-Suplicy et al., 2006; Lúcio et al., 2010; Vequi-Suplicy, Coutinho, e Teresa Lamy, 2013; Vequi-Suplicy et al., 2014)(Vequi-Suplicy2015) mostram que a decomposição do espectro de emissão do Laurdan em duas bandas fluorescentes pode ser mais sensível a mudanças estruturais na bicamada do que o parâmetro GP, além de trazer informações adicionais.

A Figura 5.22 mostra alguns exemplos da decomposição do espectro em duas bandas de emissão. A decomposição espectral deve ser calculada a partir dos espectros em função da energia, conforme descrito na seção 5.2.8. Nomeamos a banda de menor comprimento de onda, ou maiores energias, com índice 1, enquanto a banda de maior comprimento de onda recebe o índice 2, Figura 5.22.

Das análises realizadas para o DPPG na ausência de peptídeo, observamos que a fração relativa da banda 1, curva preta da Figura 5.22, corresponde a menos de $50 \%$ do espectro, na fase gel, esta fração diminui gradualmente à medida que a bicamada vai se tornando mais fluida. Enquanto que a banda 2 tem fração relativa sempre predominante e aumenta com a fluidez da membrana.

As frações relativas das bandas de emissão podem ser comparadas em termos do cálculo das áreas relativas. A Figura 5.23 mostra a área relativa da banda $1, A_{1} / A_{T}$, com o aumento da temperatura e variando a concentração de peptídeo. O aumento gradual de $A_{1} / A_{T}$ com o aumento da razão molar peptídeo/lipídio, indica que a contribuição da banda 1 aumenta. O aumento da contribuição desta banda de maior energia, e menor comprimento de onda, pode ser associado ao acesso da sonda a um ambiente cada vez menos polar. Portanto, o aumento gradual desta banda pode ser interpretado como o aumento do grau de empacotamento da bicamada, de modo análogo ao descrito pelo parâmetro GP, Figura 5.21. Curiosamente, essa razão indica que na região de transição de fase do lipídio na presença, ou ausência de peptídeo, há um nítido aumento da banda 1, e essa informação somente pode ser acessada com a decomposição espectral. 

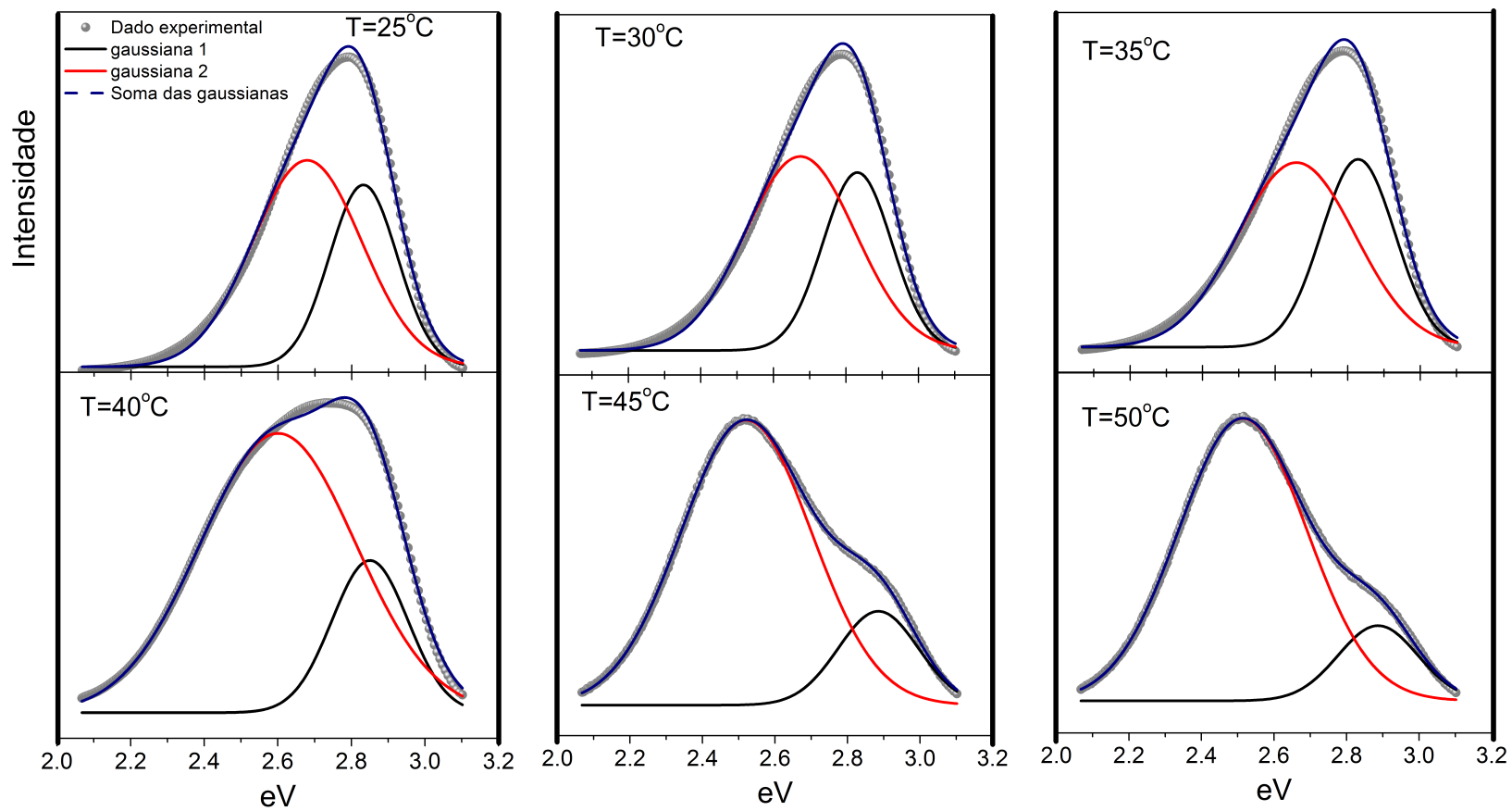

Figura 5.22: Exemplos da decomposição do espectro de emissão do Laurdan em bicamadas de DPPG para diferentes temperaturas, e diferentes fases da membrana.

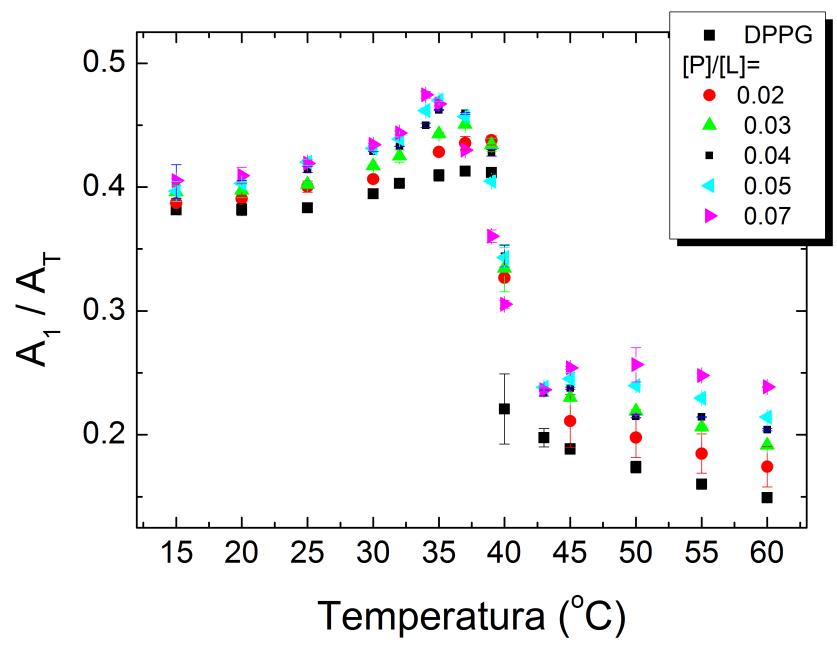

Figura 5.23: Comparação das bandas de emissão do Laurdan utilizando a razão entre a área da banda 1 e o espectro de emissão total, $A_{1} / A_{T}$, em função da temperatura, e para as diferentes concentrações de peptídeo, $[\mathrm{P}] /[\mathrm{L}]=0.00,0.02,0.03,0.04,0.05$ e 0.07 .

A decomposição dos espectros em duas bandas fluorescentes também permite analisar a posição de cada banda. A Figura 5.24 ilustra como varia a posição espectral das bandas $A_{1}$ e $A_{2}$ em função da temperatura, e para as diferentes concentrações de peptídeo. Para auxiliar a 
compreensão do gráfico da Figura 5.24, a decomposição de um espectro característico da fase gel é representada em baixas temperaturas, e, de modo análogo, para a fase fluida em altas temperaturas.

A posição de cada banda espectral (1- preta) e (2- vermelha) depende da fase lipídica. Podemos observar que a banda 1 (maior energia, menor $\lambda$ ) na fase fluida encontra-se deslocada para altas energias comparada a sua posição na fase gel. Por outro lado, a banda 2, na fase fluida, encontra-se deslocada para baixas energias comparada a sua posição na fase gel. Esse comportamento complexo foi e tem sido objeto do grupo de biofísica e não será abordado aqui (ver por exemplo, tese de doutorado de Vequi-Suplicy, 2010) (Vequi-Suplicy2015).

Comparando a posição das bandas espectrais em ausência e presença de peptídeo podemos observamos que a banda 2 (menor energia, maior $\lambda$ ) apresenta gradual deslocamento para maiores energias, ou seja, em direção ao azul (menores $\lambda$ ), indicando que essa banda é sensível a um ambiente cada vez menos polar. Novamente, esse resultado pode sugerir uma bicamada com maior grau de empacotamento, onde as cabeças polares, região onde se encontra o Laurdan, estão menos hidratadas e/ou tem menor mobilidade. Similar efeito pode ser observado para a banda 1 na fase gel, enquanto que, na fase fluida, a posição desta banda não varia ou o efeito muito inferior ao observado pela banda 2 é observado na direção oposta.

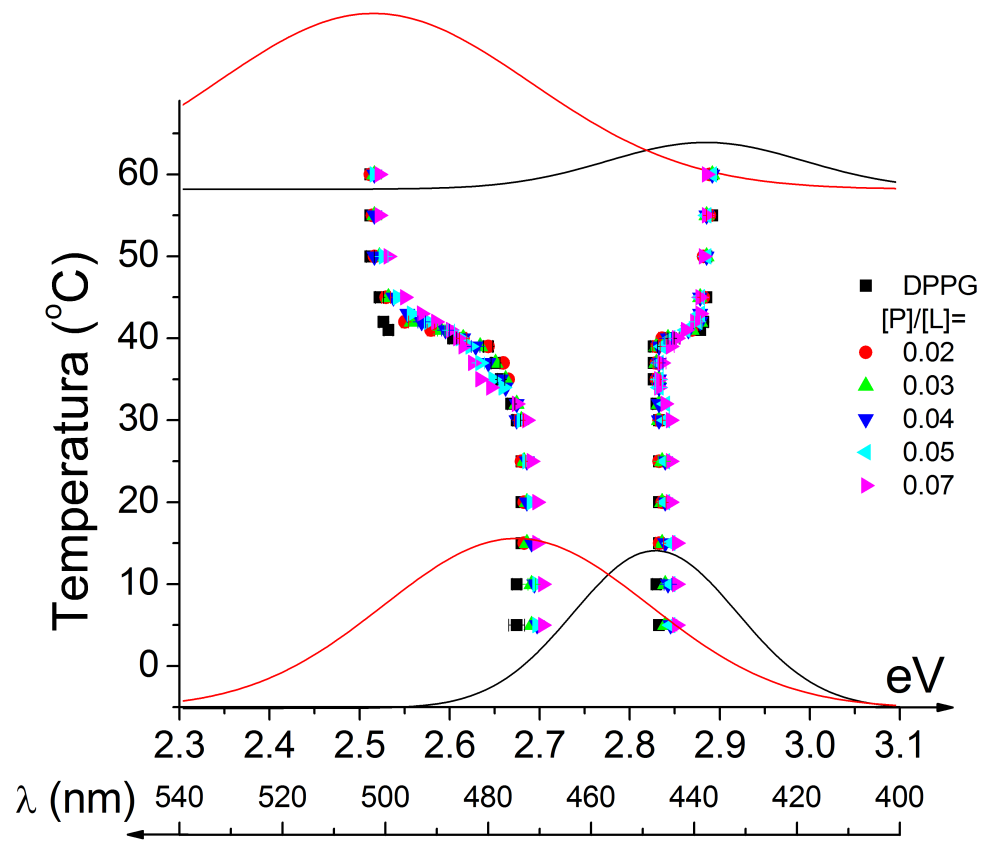

Figura 5.24: Posição espectral das bandas de emissão fluorescente obtidas a partir da decomposição espectral. O perfil das bandas na fase gel dos lipídios é representado em baixas temperaturas, assim como um perfil da fase fluida é representado em altas temperaturas, para facilitar a compreensão. 
Portanto, o estudo da emissão fluorescente do Laurdan sugere que o peptídeo KHya1 causa o aumento do grau de empacotamento da membrana, tanto na fase gel quanto na fase fluida da bicamada lipídica.

Retomando os resultados discutidos anteriormente, seção 5.3.5, para os tempos de vida do Trp e as frações de cada tempo, Figura 5.18, em função da concentração de peptídeo, observamos que o aumento da contribuição fracional, $f_{3}$, do tempo de vida $\tau_{3}$ também pode ser um indicativo que o Trp é sensível a um ambiente com maior grau de empacotamento. O DAS mostrado na Figura 5.19, por exemplo, para $\mathrm{T}=25$ e $50^{\circ} \mathrm{C}$ indica que $f_{3}$ é maior na fase gel, e como mencionado anteriormente, o aumento da concentração de peptídeo leva ao aumento de $f_{3}$ sugerindo o aumento do grau de empacotamento da membrana Figura 5.18.

Portanto, tanto a fluorescência estática do Laurdan quanto os tempos de vida do Trp indicam o aumento do grau de empacotamento da membrana. É interessante notar que o peptídeo modifica a membrana, aumentando seu empacotamento (como mostrou o Laurdan), mas ao mesmo tempo o peptídeo é afetado pelas modificações que causou (como sugerem as frações dos tempos de vida).

\subsubsection{Espectros associados aos decaimentos (DAS) para Laurdan}

Adicionalmente, calculamos os tempos de vida associados ao espectro de emissão ("Decay Associated Spectra": DAS) para o Laurdan em bicamada lipídica de DPPG. Os tempos de vida e a contribuição de cada tempo foram ajustados a partir de uma análise global de vários decaimentos medidos em diferentes comprimentos onda, $\lambda_{\text {exc }}=340 \mathrm{~nm}$ (ver seção 5.2 .13 ). A Figura 5.25 mostra o DAS com o espectro do Laurdan em energia (esquerda), onde foi calculada a decomposição das bandas espectrais, e a partir deste, retomamos o espectro em função do comprimento de onda, Figura 5.25 (direita).

O DAS mostra um balanço de dois tempos de vida, que concorda com a decomposição espectral em duas bandas fluorescentes, para $T=50^{\circ} \mathrm{C}$. Diferente do observado com o DAS do Trp, Figura 5.19, há um balanço dos tempos de vida de Laurdan ao longo de seu espectro de emissão. A contribuição de cada tempo de vida do Laurdan concorda com a decomposição do espectro em duas bandas espectrais, para $\mathrm{T}=50^{\circ} \mathrm{C}$. 

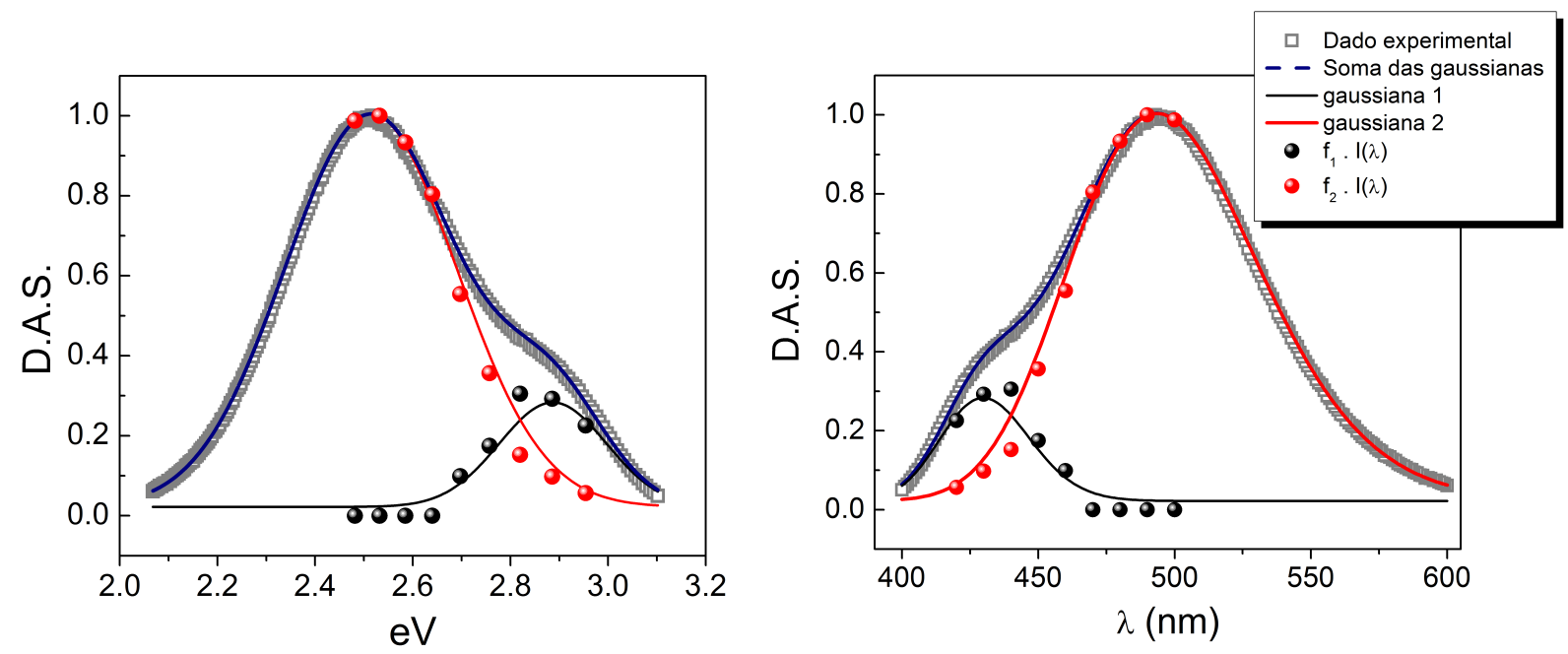

Figura 5.25: Tempos de vida do Laurdan associados ao seu espectro de emissão (DAS), $\lambda_{\text {exc }}=340 \mathrm{~nm}$, para $T=50^{\circ} \mathrm{C}$.

\subsubsection{Transferência de Energia}

Nesta seção, caracterizamos a transferência de energia entre o Trp (doador) e o Laurdan (aceitador), e entre resíduos de Trp (homo-FRET).

\section{FRET entre o Trp e o Laurdan}

O Trp é uma sonda fluorescente natural e está presente em muitos peptídeos e proteínas. A fluorescência do Trp é largamente utilizada para monitorar o ambiente da molécula de interesse. Por outro lado, o Laurdan é uma sonda fluorescente muito utilizada em membranas lipídicas, especialmente por sua habilidade em distinguir o grau de empacotamento da bicamada. Neste trabalho, além do estudo das sondas individualmente, também caracterizamos o par Trp-Laurdan como um par doador-aceitador no processo de transferência de energia.

A Figura 5.26 mostra a região de intersecção do espectro de absorção do Laurdan (aceitador) e o espectro de emissão fluorescente do Trp (doador). A distância de Förster, $R_{0}$, foi calculada conforme descrito na seção 5.2.14, equação (5.11) e encontramos $R_{0}=23 \pm 3 \AA$.

Também medimos os tempos de vida do Trp na presença de Laurdan. Devido à transferência de energia entre o Trp e o Laurdan, os tempos de vida do Trp (doador) são menores que os tempos vida do Trp na ausência de aceitador indicando que há transferência de energia. Os tempos de vida do Trp na ausência de aceitador foram apresentados na Figura 5.16. Para comparar os tempos de vida do Trp em presença e ausência de Laurdan (aceitador) utilizamos a relação $\tau_{d a} / \tau_{d}$, onde $\tau_{d a}$ representa o tempo de vida da espécie $i$ do doador em presença do 


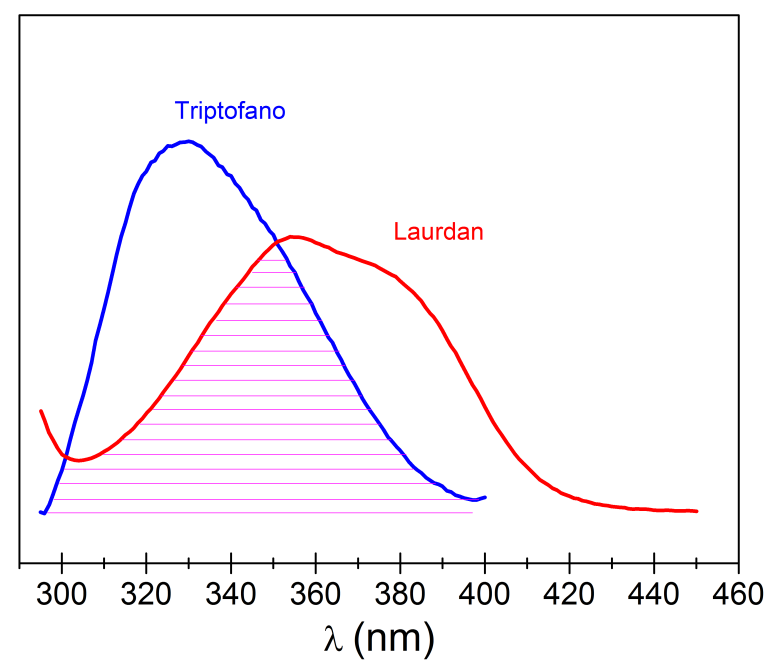

Figura 5.26: Sobreposição dos espectros de absorção do Laurdan e de emissão do Trp, onde a área de intersecção representa $J$, é utilizada para o cálculo de $R_{0}$ (Trp - Laurdan).

aceitador e $t_{d}$ o tempo de vida do doador na ausência de aceitador. Portanto, para $\tau_{d a} / \tau_{d}<1$, temos que $\tau_{d a}<\tau_{d}$. A Figura 5.27 mostra a razão $\tau_{d a} / \tau_{d}$ para as temperaturas: $T=25,30,35$, 40,45 e $50^{\circ} \mathrm{C}$.
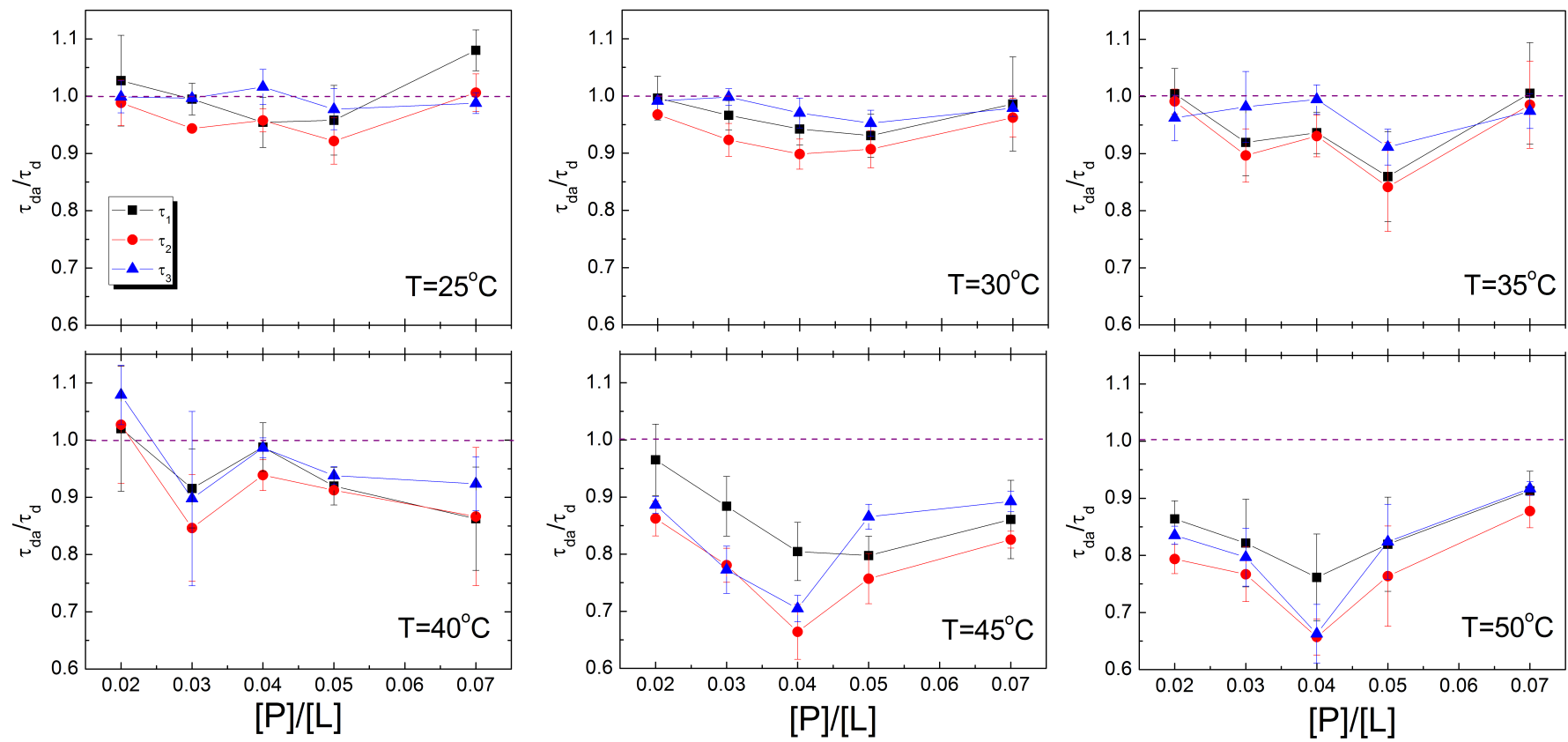

Figura 5.27: Razões entre os tempos de vida do Trp na presença do aceitador, $\tau_{d a}$, e ausência do aceitador, $\tau_{d}$.

Para $T=25^{\circ} C$, observamos que alguns decaimentos não participam do FRET, e para $T=35$ e $40^{\circ} \mathrm{C}$ que são temperaturas na região de transição de fase, há uma incerteza sobre o tempo 
de vida $\tau_{3}$. Para $T=30^{\circ} \mathrm{C}$ fase gel do DPPG e $T=45$ e $50^{\circ} \mathrm{C}$, observamos que os tempos de vida do doador na presença do aceitador diminuem até $[\mathrm{P}] /[\mathrm{L}]=0.04$, e passam a aumentar para $[\mathrm{P}] /[\mathrm{L}]=0.05$ e 0.07 . Esses resultados indicam que a eficiência do FRET passa a diminuir a partir de $[\mathrm{P}] /[\mathrm{L}]=0.04$, com o aumento da concentração de peptídeo.

A Figura 5.28 mostra a eficiência da transferência de energia, a qual foi calculada dos espectros de emissão em ausência e presença do aceitador, Figura 5.6, e conforme descrito na seção 5.2.16. Observamos que a razão molar $[\mathrm{P}] /[\mathrm{L}]=0.02$ exibe baixa eficiência no processo de transferência de energia. Por sua vez, a eficiência do FRET entre Trp e Laurdan aumenta para $[\mathrm{P}] /[\mathrm{L}]=0.03$ e 0.04 , mas volta a diminuir para $[\mathrm{P}] /[\mathrm{L}]=0.05$ e 0.07 . A baixa eficiência do FRET para $[\mathrm{P}] /[\mathrm{L}]=0.02$ pode ser justificada apenas pelo fato do doador e o aceitador estarem distantes comparados à distância de Förster $R_{0}$ (Trp - Laurdan). Entretanto, o aumento da concentração de peptídeo implica na diminuição da distância entre doador e aceitador, uma vez que não foi detectado razoável aumento do peptídeo para a solução aquosa, Figura 5.13. Deste modo, convém supor que o aumento da razão molar peptídeo-lipídio leve ao aumento da eficiência do FRET. De fato, para $[\mathrm{P}] /[\mathrm{L}]=0.03$ e 0.04 há aumento da eficiência. Contudo, a diminuição da eficiência observada para $[\mathrm{P}] /[\mathrm{L}]=0.05$ e 0.07 pode indicar que a distância média entre Trp e o Laurdan aumentou em vez de diminuir como o esperado.

O aumento da distância entre o par doador (Trp) e aceitador (Laurdan) pode sugerir o aumento área superficial do lipossomo, levando ao aumento da distância média entre pares doador-aceitador, Trp-Laurdan. Esse resultado pode indicar a formação de poros ou o aumento do tamanho dos poros. Resultados de Microscopia óptica, Figura 4.14, mostram que o peptídeo KHya1 pode causar o aumento da área superficial dos lipossomos compostos por lipídios negativamente carregados, sugerindo a abertura de grandes poros.

Além disso, também devemos observar que na fase gel a eficiência do FRET é menor que na fase fluida. Deste modo, a diminuição da eficiência do FRET para $[\mathrm{P}] /[\mathrm{L}]=0.05$ e 0.07 também pode ser devido ao aumento do grau de empacotamento da membrana causado pelo peptídeo, como discutido nos resultados anteriores.

Também realizamos um estudo da distribuição de distâncias entre Trp e Laurdan, ajustando os decaimentos com a equação 2.41 e através da transformada de Laplace inversa calculamos uma distribuição de distância entre pares, apêndice A. 


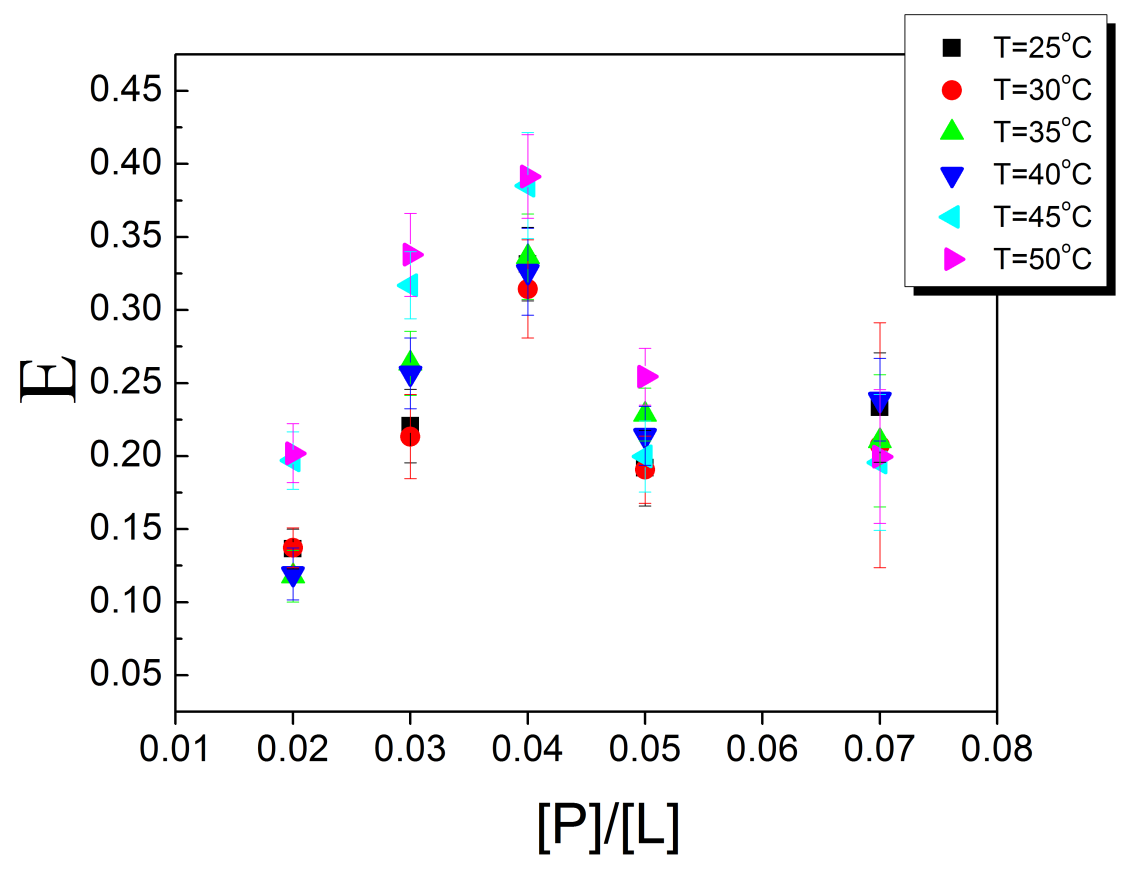

Figura 5.28: Eficiência da transferência de energia entre Trp e Laurdan. A eficiência do FRET foi calculada de acordo com a equação 5.12 .

\section{Homo-FRET entre resíduos de Trp}

Visto que o Trp do peptídeo na bicamada encontra-se em uma região bastante hidrofóbica, seu espectro de emissão apresenta pequena sobreposição a seu espectro de absorção, Figura 5.29. A sobreposição dos espectros de absorção e emissão fluorescente pode indicar a transferência de energia entre resíduos de Trp. Calculamos a distância de Forster para o homo-FRET entre Trps e obtemos o valor $R_{0}=9 \pm 1 \AA$. O valor encontrado para $R_{0}$ está de acordo com o intervalo de distâncias de Forster para o Trp segundo a literatura, $R_{0}=5-16 \AA$ (Kayser, Chennamsetty, Voynov, Helk, e Trout, 2011). As pequenas distâncias de Foster para o Trp são devido ao baixo rendimento quântico do Trp (Weber, 1960; Kayser et al., 2011; Lakowicz, 2006) e referências desse artigo.

É importante observar que o ambiente do Trp, e, portanto, o ambiente do peptídeo, cria a possibilidade da transferência de energia entre Trp. O peptídeo em solução aquosa, por exemplo, exibe espectro de emissão fluorescente centrado em $355 \mathrm{~nm}$, o qual não apresenta sobreposição com o espectro de absorção do Trp.

Além disso, para ocorrer FRET entre resíduos de Trp, é necessário que os Trp se encontrem a uma distância, $r$, da ordem de $2 R_{0}$. A distância de Forster, $R_{0}$, corresponde a distância onde há eficiência de $50 \%$ no processo de transferência de energia e, em $2 R_{0}$ há uma baixa eficiência 


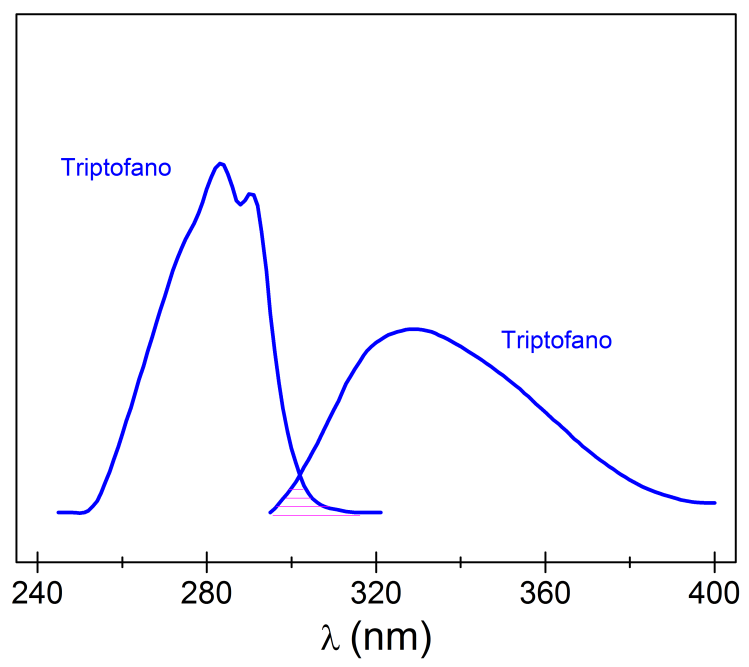

Figura 5.29: Sobreposição dos espectros de absorção do Trp e de emissão do Trp, onde a área de intersecção representa, $J$, e é utilizada para o cálculo de $R_{0}$ (Trp - Trp).

do FRET (Lakowicz, 2006), (ver Figura 2.14, capítulo 2).

No entanto, no homo-FRET não há mudanças no tempo de vida do estado excitado assim como não é observado supressão da emissão fluorescente (Valeur e Berberan-Santos, 2012). Deste modo, para verificar a transferência de energia entre resíduos de Trp se faz necessário medir a anisotropia do Trp.

A transferência de energia envolve a interação dos momentos de dipolo do doador e do aceitador. A taxa de transferência de energia depende da orientação dos momentos de dipolos transientes e da distância de entre pares. Deste modo, quando ocorre a transferência de energia há também uma larga distribuição de momentos de dipolos, a qual leva a despolarização da luz incidente, inicialmente polarizada. Portanto, medimos a anisotropia do Trp para investigar a possibilidade de homo-FRET.

\subsubsection{Anisotropia do Trp}

A Figura 5.30 mostra a anisotropia do Trp com o aumento da concentração de peptídeo, para as temperaturas $T=25,30,35,40,45$ e $50^{\circ} \mathrm{C}$. Observamos que o aumento da concentração de peptídeo leva a diminuição gradual da anisotropia do Trp, até a razão molar $[\mathrm{P}] /[\mathrm{L}]=0.05$, e a partir desta, a anisotropia se mantém constante ou passa a apresentar pequeno aumento.

Observamos com o estudo do Laurdan (Figuras 5.21 e 5.23) e com as contribuições dos tempos de vida do Trp (Figuras 5.18 e 5.19) que o aumento da concentração de peptídeo leva ao aumento do empacotamento da bicamada. O aumento do empacotamento da bicamada 


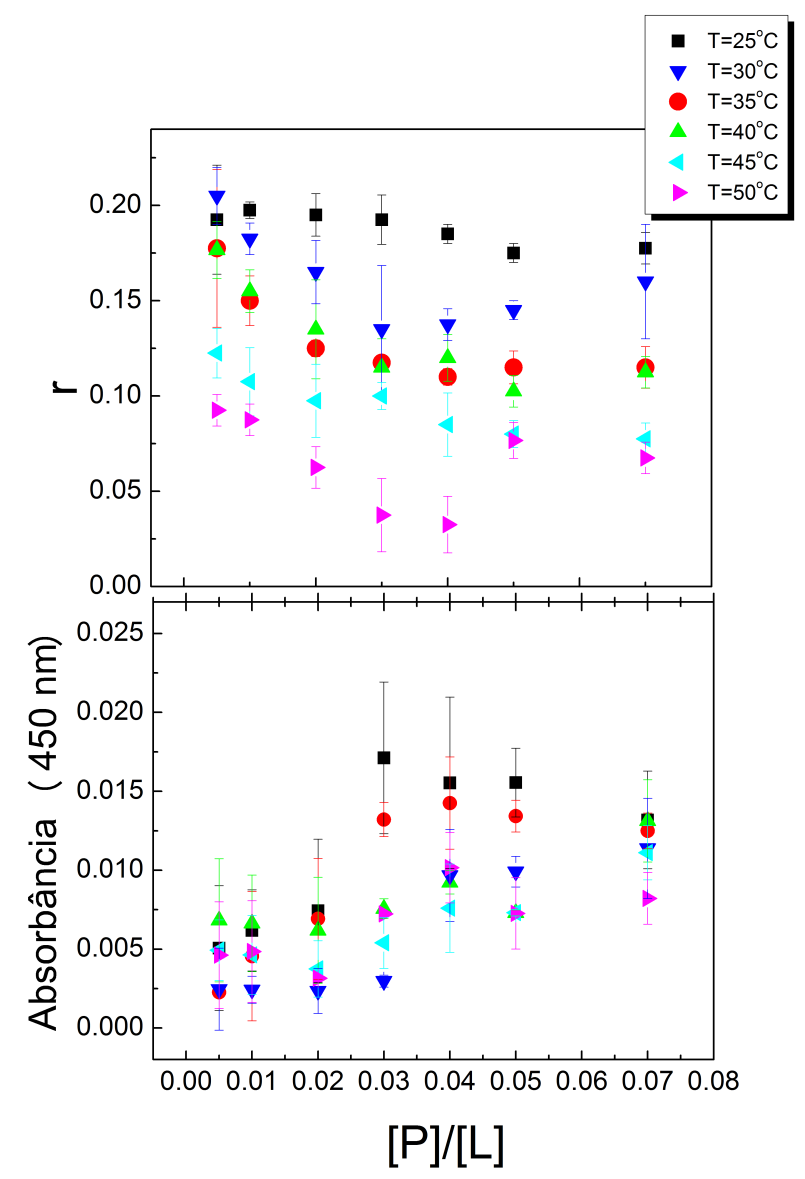

Figura 5.30: Anisotropia de fluorescência do Trp do peptídeo KHya1 em bicamadas de DDPG com o aumento da concentração de peptídeo e para as temperaturas $\mathrm{T}=25,30,35,40,45$ e $50^{\circ} \mathrm{C}$. As medidas de anisotropia foram realizadas utilizando $\lambda_{e x c}=280 \mathrm{~nm}$ e $\lambda_{e m}=330 \mathrm{~nm}$ (gráfico superior). Valores da absorbância das amostras medidos em $\lambda=450 \mathrm{~nm}$, para monitoramento do espalhamento da dispersão (gráfico inferior).

poderia levar ao aumento da anisotropia do Trp, com o aumento de $[\mathrm{P}] /[\mathrm{L}]$, mas observamos oposto. Também devemos notar que o aumento da turbidez da dispersão pode influenciar as medidas de anisotropia. Todavia, a luz espalhada tem igual polarização a luz incidente, o que também levaria ao aumento da anisotropia (ver equação 5.6). O efeito do aumento da turbidez na anisotropia será discutido a seguir com o uso de um experimento para controle.

A Figura 5.31 mostra a anisotropia do amino ácido L-Trp em solução aquosa, tampão HEPES, e com o aumento da concentração de nano esferas de poliestireno (92 nm). As nano esferas são pouco interagentes e causam grande aumento da turbidez das amostras.

A Figura 5.31 mostra que o aumento do espalhamento causa pequeno aumento na anisotropia do Trp, o qual encontra-se exposto ao solvente (Figura 5.32). Entretanto, para valores de absorbância acima de 0.1 (medidos em $\lambda=450 \mathrm{~nm}$ ) os valores da anisotropia começam a 


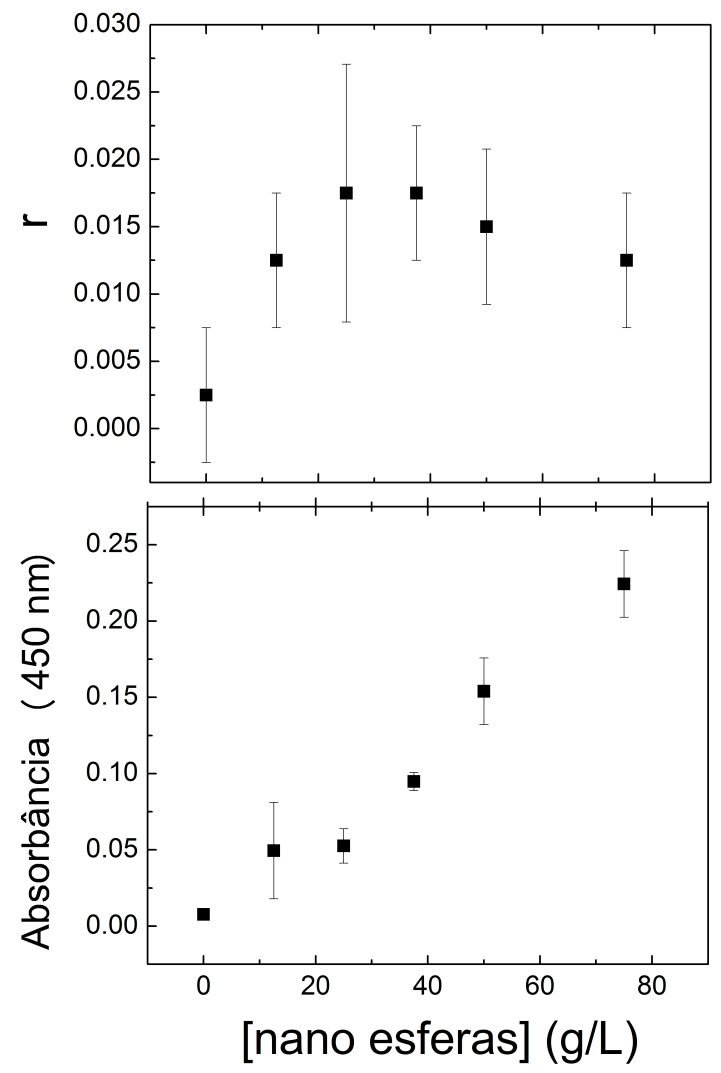

Figura 5.31: Anisotropia de fluorescência do amino ácido Trp em solução aquosa com o aumento da concentração de nano esferas de poliestireno em $\mathrm{T}=25^{\circ} \mathrm{C}$. As medidas de anisotropia foram realizadas utilizando $\lambda_{e x c}=280 \mathrm{~nm}$ e $\lambda_{e m}=350 \mathrm{~nm}$ (gráfico superior). Valores da absorbância das amostras medidos em $\lambda=450 \mathrm{~nm}$, para monitoramento do espalhamento da solução (gráfico inferior).

diminuir. Altos valores de turbidez, ou espalhamento, podem causar grande atenuação da intensidade da luz espalhada, refletindo agora na diminuição da anisotropia.

Também é importante observar que o amino ácido Trp livre em solução aquosa tem anisotropia média equivalente a 0.0025, onde a posição da intensidade máxima do espectro de emissão fluorescente é observada em $\lambda=358.5 \mathrm{~nm}$ (após a correção de filtro interno), Figura 5.32 (símbolos vermelhos). Além disso, a Figura 5.32 também mostra que a posição do espectro se mantém em $\lambda=358 \mathrm{~nm}$, até a concentração $50 \mathrm{~g} / \mathrm{L}$, sugerindo que o Trp continua exposto ao solvente, sem interagir com as nano esferas de poliestireno. A Figura 5.32 também compara a posição dos espectros de emissão sem a correção de filtro interno (ver seção 5.2.7), onde na ausência da correção (símbolos pretos), os espectros deslocam-se para maiores comprimentos de onda (red shift). Esse deslocamento pode ser explicado pelo efeito de filtro interno secundário, pois em menores comprimentos de onda o espalhamento e atenuação da emissão são maiores. Para 
a maior concentração de nano esferas de poliestireno aqui utilizada, $75 \mathrm{~g} / \mathrm{L}$, o espalhamento torna-se muito grande, e a correção de filtro interno parece não ser apropriada.

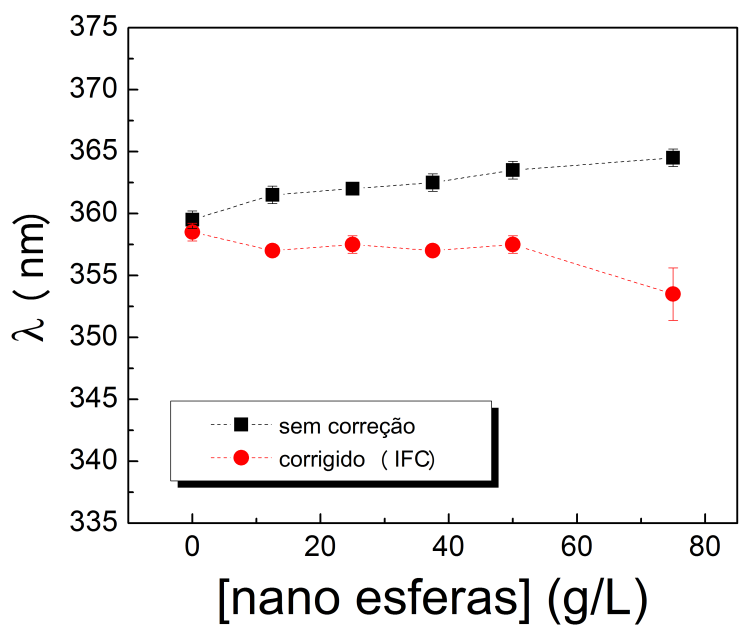

Figura 5.32: Posição da intensidade máxima do espectro de emissão fluorescente do amino ácido Trp em função do aumento da concentração de nano esferas de poliestireno. Os símbolos pretos mostram os valores da posição espectral sem a correção de filtro interno e em vermelho após a correção.

Deste modo, a anisotropia deve ser analisada juntamente com a turbidez da amostra. Na Figura 5.30 são mostrados a anisotropia do Trp do peptídeo KHya1 em bicamada lipídica e os valores da absorbância (medida em $\lambda=450 \mathrm{~nm}$ ). Como mencionado anteriormente o aumento da concentração de peptídeo leva a diminuição da anisotropia, mas este também é acompanhado do aumento da turbidez. Entretanto, esse aumento da turbidez não excede ao valor de absorbância equivalente a 0.05 (medida em $\lambda=450 \mathrm{~nm}$ ). Comparando os valores de absorbâncias medidos na Figura 5.30 e 5.31 observamos que nesse regime de espalhamento era esperado o aumento da anisotropia, mas os resultados da Figura 5.30 mostram o oposto.

Logo, convém supor que a diminuição da anisotropia seja devido a transferência de energia entre resíduos de Trp, homo-FRET. Também é importante observar que embora os valores de anisotropia diminuem com o aumento da concentração de peptídeo, a posição do espectro de emissão não se altera, conforme discutido anteriormente e mostrado na Figura 5.13.

Além disso, é curioso que para $[\mathrm{P}] /[\mathrm{L}]=0.05$ e 0.07 os valores da anisotropia deixam de diminuir e para algumas temperaturas mostram um nítido aumento. Similar efeito foi observado para $\tau_{d a} / \tau_{d}$ na Figura 5.27. Esse último indica a diminuição da eficiência do FRET entre Trp e Laurdan para as maiores concentrações de peptídeo, sugerindo um aumento das distâncias médias entre pares de Trp e Laurdan, que poderia ser interpretado como formação ou aumento 
do número e/ou tamanhos de poros. De modo análogo, a eficiência do FRET entre Trps pode deixar de aumentar ou passar a diminuir devido ao aumento das distâncias médias entre peptídeos, causados por exemplo pelo aumento do tamanho dos poros.

A caracterização do homo-FRET entre peptídeos traz uma importante informação sobre a distribuição de peptídeos em membranas aniônicas. Visto que a distância de Forster para a interação entre resíduos de Trp do peptídeo KHya1 equivale a $R_{0}=9 \pm 1 \AA$, então podemos supor que existem pares de peptídeos que estão dentro do alcance da interação que caracteriza o homo-FRET, que neste caso corresponde a $2 R_{0}=18 \pm 2 \AA$.

Para estimar a distância entre resíduos de Trp podemos propor um cálculo simplificado, considerando a princípio uma distribuição homogênea de peptídeos pela membrana. A razão $[\mathrm{P}] /[\mathrm{L}]=0.01$, por exemplo, equivale a 100 lipídios para 1 peptídeo. Considerando que o peptídeo que o peptídeo atravessa a membrana, conforme proposto no capítulo 45 então 1 peptídeo encontra-se cercado por 50 lipídios na camada externa e 50 lipídios na camada interna. Logo, a distância entre peptídeos equivale à aproximadamente a distância unilateral de $\sqrt{50}$ lipídios. Visto que, a área por cabeça polar de DPPG é $a=61 \AA\left(l^{2}\right)$, a distância entre peptídeos será de aproximadamente $\sqrt{50} \sqrt{61} \AA(l) .{ }^{4}$ De modo análogo, aumentando a concentração de peptídeo, por exemplo, $[\mathrm{P}] /[\mathrm{L}]=0.02$ temos 1 lipídio para cada 25 lipídios (com acesso a camada externa) e assim sucessivamente. A Tabela 5.2 mostra o cálculo dessas distâncias para cada razão [P]/[L].

Além disso, para comparação e completeza do cálculo, também podemos considerar o peptídeo na superfície da membrana e ocupando ambas as camadas interna e externa da membrana. Neste caso, para $[\mathrm{P}] /[\mathrm{L}]=0.01$ cada peptídeo na camada externa se encontraria cercado por 100 lipídios na camada externa e igualmente para a camada interna. Então, esse cálculo levaria a distâncias maiores as distancias calculadas anteriormente, Tabela 5.2.

Dos valores obtidos por esses cálculos simples observamos que as distâncias médias entre resíduos de Trp, considerando uma distribuição homogênea de peptídeos na membrana, são superiores ou da ordem de $2 R_{0}$, indicando que a transferência de energia entre Trps seria pouco provável ou de eficiência muito baixa para esse arranjo.

Portanto, a caracterização do homo-FRET, como o aumento da concentração de peptídeo, sugere regiões de diferentes densidades de peptídeo na membrana, caracterizando uma distribuição não homogênea de peptídeos. Os resultados de SAXS apresentados no capítulo 6, por exemplo, mostram que o peptídeo causa grande perturbação na membrana, logo, convém supor que a ligação de novos peptídeos na membrana torna-se mais favorável em regiões já

\footnotetext{
${ }^{4}$ desprezando o volume excluído do peptídeo.
} 
Distância estimada entre Trp para distribuição homogênea

\begin{tabular}{c|ccc|ccc}
\hline \multirow{2}{*}[\mathrm{P}]{$/[\mathrm{L}]$} & \multicolumn{3}{|c}{ (A) Trp:lipídio $(1: 50)$} & \multicolumn{3}{r}{ (B) Trp:lipídio $(1: 100)$} \\
& \multicolumn{3}{|c}{ distância unilateral em número de lipídios ou em $(\AA)$} \\
& $\begin{array}{r}\text { número de } \\
\text { lipídios }\end{array}$ & $\mathrm{d}(\AA)$ & $\mathrm{d}(\AA)$ & lipídios & $\mathrm{d}(\AA)$ & $\mathrm{d}(\AA)$ \\
\hline \hline 0.01 & 7.07 & 55.23 & 56.57 & 10.00 & 78.10 & 80.00 \\
0.02 & 5.00 & 39.1 & 40.00 & 7.07 & 55.2 & 56.57 \\
0.03 & 4.08 & 31.9 & 32.66 & 5.77 & 45.1 & 46.19 \\
0.04 & 3.54 & 27.6 & 28.28 & 5.00 & 39.1 & 40.00 \\
0.05 & 3.16 & 24.7 & 25.30 & 4.47 & 34.93 & 35.78 \\
0.06 & 2.89 & 22.54 & 23.09 & 4.08 & 31.9 & 32.66 \\
0.07 & 2.67 & 20.87 & 21.38 & 3.78 & 29.5 & 30.24 \\
\hline \hline
\end{tabular}

Parâmetros utilizados nos cálculos

DPPG fase gel DPPG fase fluida

\begin{tabular}{ccc} 
area por lipídio $\left(\AA^{2}\right)$ & 61 & 64 \\
$l$ distância lateral de um lipídio $(\AA)$ & 7.8 & 8 \\
\hline \hline
\end{tabular}

Tabela 5.2: Distância estimada entre peptídeos considerando uma distribuição homogênea de peptídeos pela membrana.

perturbadas, criando, portanto, domínios ricos em peptídeos.

Esse resultado também está de acordo com a distribuição de distâncias entre Trp e Laurdan apresentada no apêndice A, Figura A.1, que sugere uma rica região de peptídeos.

\subsection{Conclusão}

A fluorescência estática do Laurdan mostrou que o peptídeo KHya1 causa o aumento do grau de empacotamento da bicamada de DPPG, nas fases gel e fluida da bicamada. O estudo dos tempos de vida do Trp em ausência de aceitador, também sugerem que o peptídeo é sensível a um ambiente de maior ordem e/ou menor mobilidade e hidratação. O Laurdan encontra-se próximo à superfície, na região das cabeças polares, enquanto o Trp do peptídeo pode estar inserido mais próximo às cadeias hidrocarbônicas, de acordo com sua posição espectral. Deste modo, a fluorescência estática do Laurdan e temporal do Trp podem sugerir que ambas regiões apresentam maior empacotamento com o aumento da concentração de peptídeo. 
Além disso, estudos da transferência de energia entre o doador (Trp) e o aceitador (Laurdan) sugerem que para altas concentrações de peptídeo $[\mathrm{P}] /[\mathrm{L}]=0.05$ e 0.07 há uma diminuição da transferência de energia que pode indicar maior empacotamento da bicamada, como discutido acima e/ou o aumento da área dos lipossomos possivelmente devido à formação de poros, ou ao aumento do tamanho dos poros.

A anisotropia de fluorescência do Trp, sugere a interação entre resíduos de Trp, homo-FRET, indicando que pode haver pares de peptídeos próximos entre si, dentro de uma distância de aproximadamente 20 A. Esse resultado sugere uma distribuição não homogênea de peptídeos na membrana de DPPG. 



\section{Capítulo 6}

\section{Posições diferentes do peptídeo}

\section{antimicrobiano KHya1 em membranas}

neutras e aniônicas são a causa de efeitos

\section{distintos nas membranas}

\subsection{Motivação}

Neste trabalho investigamos a interação do peptídeo antimicrobiano KHya1 com membranas modelo compostas por DPPC, DPPG e a mistura DPPC:DPPG (1:1) por Ressonância Paramagnética Eletrônica (ESR- Electron Spin Ressonance) de marcadores de spin incorporados à membrana e por Espalhamento de raios-X a baixo ângulo (SAXS - Small angle X-ray Scattering).

Com o uso da técnica ESR podemos estudar a perturbação que o peptídeo causa na membrana em sítios específicos: próximos à região do carbono 5 e próximos à região do carbono 16 das cadeias hidrocarbônicas. Por sua vez, a técnica SAXS investiga as modificações estruturais que o peptídeo causa em membranas lipídicas. Esse trabalho contribui com as discussões dos capítulos anteriores e os resultados aqui apresentados corroboram os modelos apresentados. ${ }^{1}$

\footnotetext{
${ }^{1}$ Entretanto, ainda estamos trabalhando nas análises dos dados para a finalização deste trabalho.
} 


\subsection{Materiais e Métodos}

\subsubsection{Reagentes}

Reagentes da seção 4.2.1. Neste trabalho, utilizamos a mais as sondas paramagnéticas incorporadas na membrana. Marcador paramagnético: 1-palmitoil-2-stearoyl- (5-doxyl) -sn-glicero3-fosfocolina (5PCSL), 1-palmitoil-2-stearoyl- (16-doxyl) -sn-glicero-3-fosfocolina (16PCSL), Figura 6.1.
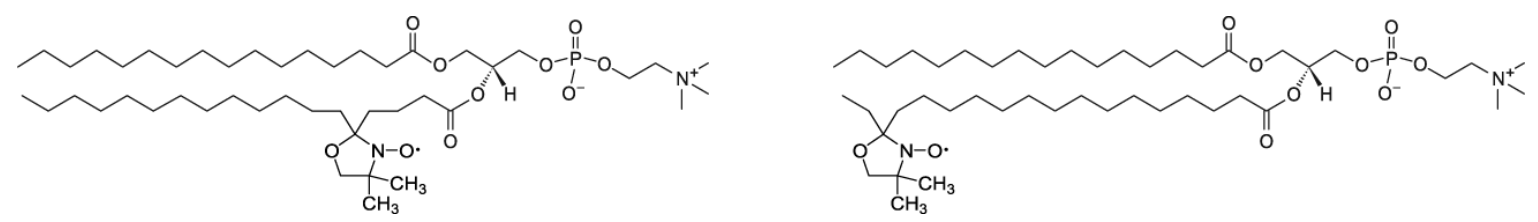

Figura 6.1: Estrutura química das moléculas 5PCSL e 16PCSL.

\subsubsection{Preparações das dispersões lipídicas}

Para preparação de lipossomos, os lipídios são diluídos em clorofórmio e depois submetidos a um fluxo de nitrogênio, $N_{2}$, levando à formação de um filme na parede do tudo de ensaio. Para as medidas de ESR foi acrescentado $0.04 \mathrm{~mol} \%$ do marcador paramagnético 16PCSL ou 5PCSL. A fração de marcador de spin foi previamente estudada, conforme descrito no capítulo 3. Então, o filme foi submetido à baixa pressão por três horas para remover resquícios do solvente orgânico. As dispersões lipídicas são suspendidas com a adição de tampão HEPES 10 mM em pH=7.4 com $1.0 \mathrm{mM}$ de EDTA e $3.0 \mathrm{mM}$ de $\mathrm{NaCl}$ aos filmes lipídicos e sob agitação (vórtex) durante aproximadamente 2 minutos, na temperatura $T=45^{\circ} \mathrm{C}$.

\subsubsection{Vesículas não extrusadas}

Neste trabalho também mostraremos alguns resultados de vesículas não extrusadas, seção 6.4.3. As vesículas não extrusadas foram suspendidas com o tampão descrito no item 6.2.2, e contendo peptídeo na concentração desejada. Deste modo o peptídeo pode interagir com as monocamadas externa e interna da membrana. 


\subsubsection{Vesículas extrusadas}

Após a suspensão da dispersão lipídica com o tampão descrito no item 5.2.2, as vesículas foram extrusadas conforme reportado na seção 4.2.3.

\subsubsection{Razão molar do peptídeo}

Conforme reportado anteriormente, seção 4.2.5, a razão molar peptídeo/lipídio, [P]/[L], corresponde à razão entre a concentração de peptídeo [P] e a concentração de lipídio [L], onde L pode ser DPPC, DPPG ou a mistura DPPC:DPPG (1:1). Neste trabalho cada razão molar foi preparada individualmente.

As amostras de ESR são preparadas em pequenos volumes, cerca de $50 \mu L$. Deste modo, o volume de peptídeo acrescentado também é bem pequeno, e um bom controle deste volume é necessário para minimizar os erros da preparação. Para isso utilizamos, acoplado à seringa, uma ferramenta que auxilia em dispensar volume de $0.5 \mu L$ precisamente ("repeting dispenser", Hamilton), conforme ilustra a Figura 6.2.

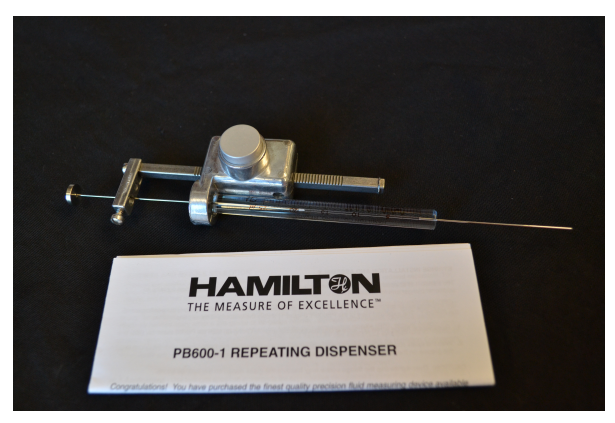

Figura 6.2: Fotografia do "repeating dispenser" da Hamilton.

\subsubsection{Ressonância Paramagnética Eletrônica (ESR)}

As medidas de ESR foram realizadas no espectrofotômetro EMX da Bruker com amplitude de modulação $1.0 \mathrm{G}$ e potência de micro-onda de $10 \mathrm{~mW}$. O controle de temperatura foi realizado com o uso do modulo BVT-2000 da Bruker (Eurothem). A temperatura ajustada na interface de aquisição difere da temperatura na amostra. Com o uso de uma curva de calibração, previamente obtida, determinamos a temperatura real na amostra, conforme descrito no capítulo 3, Modelo e Controles, seção 3.2.7.

Cerca de $50 \mu L$ da amostra são colocados em capilares de quartzo, e os terminais do capilar são selados com o auxílio da chama de um bico de Bunsen. Esses capilares são então coloca- 
dos em um segundo tubo de quartzo que apresenta perfeito encaixe com o porta-amostra do controlador de temperatura. A cavidade ressonante é otimizada para a medida (tune) a cada temperatura, e então inicia-se a coleta de dados.

\subsubsection{Análises dos espectros de ESR}

Ao total foram coletados 747 espectros, o que torna a análise laboriosa e delicada. Para os diferentes sistemas lipídicos, DPPC, DPPG e DPPC:DPPG, e variando a concentração de peptídeo, foram coletadas medidas em diferentes temperaturas, que caracterizam a fase gel, fluida e uma região de transição de fase, conforme indica os termogramas da Figura 4.3, capítulo 4 .

Além disso, utilizamos dois diferentes marcadores paramagnéticos, que estão localizados em diferentes regiões da bicamada lipídica. O marcador 5PCSL encontra-se ligado ao carbono 5 da cadeia carbônica, enquanto o marcador 16PCSL encontra-se ligado ao carbono 16. Em resultados, optamos em mostrar alguns espectros característicos. Os espectros aqui apresentados foram normalizados pelo máximo e alinhados pela posição central.

Os espectros foram analisados com parâmetros medidos diretamente do sinal paramagnético. Devido à complexidade e variedade dos sinais, diferentes sondas (5 e 16PCSL) e diferentes fases da bicamada, gel e fluida $\left(\mathrm{T}=15-65^{\circ} \mathrm{C}\right)$, as análises não podem ser descritas com um único parâmetro ao longo da variação da temperatura, e para as diferentes sondas.

Deste modo, na fase gel dos lipídios (DPPC, DPPG e DPPC:DPPG) utilizamos o parâmetro $2 A_{\max }$, para monitorar o grau de empacotamento da bicamada em baixas temperaturas, para ambos marcadores 5 e 16 PCSL (ver Figura 2.24, capítulo 2).

Na fase fluida dos lipídios, para o marcador 16PCSL, utilizamos a razão entre as alturas $h_{-1} / h_{0}$ (ver Figura 2.21, capítulo 2), e para o marcador 5PCSL, calculamos o parâmetro de ordem efetivo, $S_{e f}$, de acordo com a equação 6.1

$$
S_{e f}=\frac{A_{/ /}-A_{\perp}}{A_{z z}-(1 / 2)\left(A_{x x}+A_{y y}\right)} \cdot \frac{A_{0}^{\prime}}{A_{0}}
$$

onde

$$
\begin{aligned}
& A_{0}^{\prime}=\frac{1}{3}\left(A_{x x}+A_{y y}+A_{z z}\right) \\
& A_{0}=\frac{1}{3}\left(A_{/ /}+A_{-} \perp\right)
\end{aligned}
$$

e $A_{x x}=5.9, A_{y y}=5.4, A_{z z}=32.9$ (Griffth e Jost, 1976). 
O valor de $A_{/ /}$equivale ao desdobramento hiperfino máximo, $A_{/ /} \approx A_{\max }$ e $A_{\perp}$ é calculado a partir da equação 6.3 (McConnell and Hubbell 1971),

$$
A_{\perp}=A_{\min }+1.4\left[1-\frac{A_{\max }-A_{\min }}{A_{z z}-(1 / 2)\left(A_{x x}+A_{y y}\right)}\right]
$$

A Figura 6.3 mostra como medir $A_{\min }$ e $A_{\max }$ diretamente dos espectros. Esta figura foi previamente apresentada no capítulo 2, Figura 2.23.

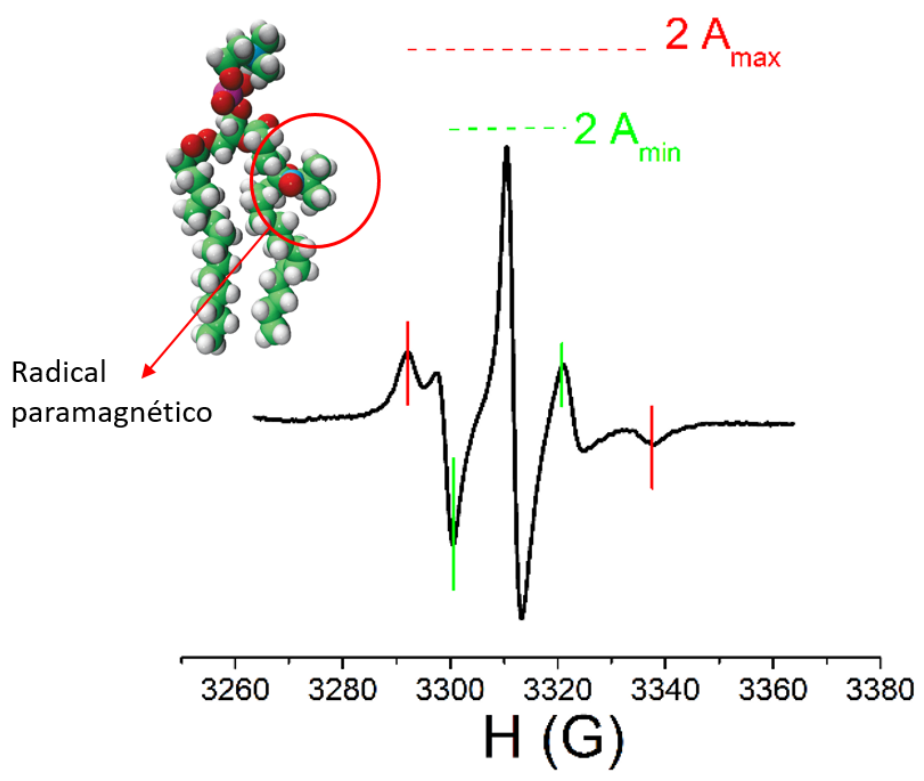

Figura 6.3: Exemplo de como medir os parâmetros $2 A_{\max }$ e $A_{\min }$ diretamente do sinal de ESR, para o marcador 5PCSL, na fase fluida do lipídio

Para maiores detalhes dos parâmetros medidos dos sinais paramagnético, ver capítulo 2, seção 2.10.2.

\subsubsection{Espalhamento de Raio-X a baixo ângulo (SAXS)}

As medidas de SAXS foram realizadas no Laboratório Nacional Luz Sincrotron (LNLS), na linha SAXS $1^{2}$, com distância entre a amostra e o detector de $1000 \mathrm{~mm}$. A linha por onde passa o feixe é mantida a baixa pressão ao longo das medidas. As amostras são colocadas em um porta-amostra, o qual é previamente montado com laminas de mica, na região em que o feixe atravessa a amostra. A temperatura foi controlada com o auxílio de um banho térmico acoplado à linha e monitorada por um termopar conectado ao porta-amostra.

\footnotetext{
${ }^{2}$ em colaboração com o Prof. Dr. Leandro Barbosa (IF-USP)
} 
Para cada curva experimental aqui analisada foi subtraído o espectro o espectro do tampão HEPES, e este dado foi corrigido pela atenuação da amostra. Esse pré-tratamento das curvas foi realizado com o uso de um programa utilizado no LNLS baseado na rotina fit2D-ESRF.

\subsubsection{Analise das curvas de SAXS}

Algumas curvas de SAXS descritas apenas por um fator de forma foram analisadas com o programa GIFT (Generalized Indirect Fourier Transform) desenvolvido por Otto Glatter (Glatter, 1977).

A intensidade da radiação espalhada em função do modulo do vetor de espalhamento $q$ é dada por

$$
I(q) \sim P(q) . S(q)
$$

onde $P(q)$ e $S(q)$ são os fatores de forma e estrutura, respectivamente. Aqui, como o uso do programa GIFT, calculamos uma função $p(r)$ definida como a transformada de Fourier da intensidade medida $I(q)$, em ausência do fator de interferência, $S(q)$ (ver capítulo 2). Através da deconvolução da função $p(r)$ podemos obter a função de densidade eletrônica. Aqui utilizamos o programa DECON para realizar tal deconvolução. Para sistemas lipídicos a função de densidade eletrônica pode trazer informações sobre a espessura da bicamada. A Figura 6.4 ilustra um exemplo do resultado, onde a distância entre os picos corresponde a distância entre as cabeças polares, $d_{h h}$.

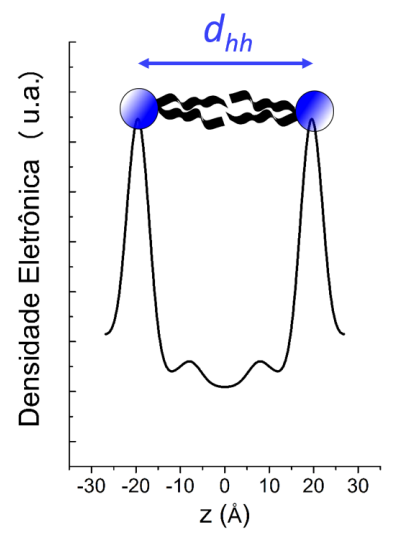

Figura 6.4: Exemplo do perfil de densidade eletrônica obtido para bicamadas lipídicas. 


\subsection{Resultados e discussões}

Separamos os resultados experimentais em seções para facilitar suas apresentações. Os resultados de ESR, por exemplo, foram divididos segundo a fase da bicamada lipídica, gel e fluida, e de acordo com o marcador utilizado. Enquanto os resultados de SAXS foram divididos pela abordagem experimental com vesículas extrusadas, e não extrusadas e pela composição lipídica.

\subsubsection{Fase gel}

\section{Marcador de spin 16PCSL}

A Figura 6.5 mostra alguns resultados de ESR para o DPPC na ausência e com o aumento da concentração de peptídeo, na fase gel do lipídio. Podemos observar, que as curvas são caraterizadas por um único sinal de ESR típico da fase gel. Além disso, os resultados mostram pequenas variações dos perfis com relação ao parâmetro $2 A_{\max }$ (ver Figura 2.24), em maior detalhe na Figura 6.8.

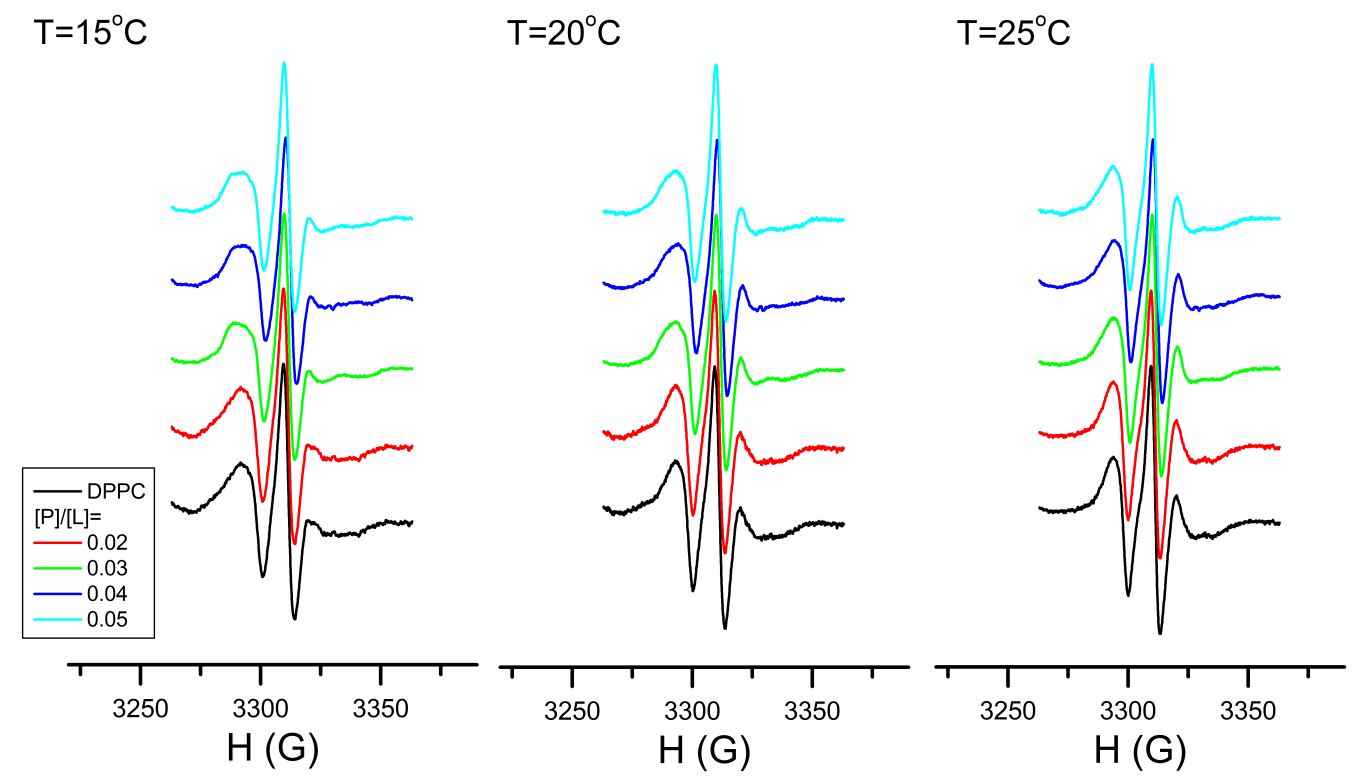

Figura 6.5: Sinais paramagnéticos da sonda 16PCSL incorporada em membranas de DPPC na ausência e com o aumento da concentração de peptídeo, $[\mathrm{P}] /[\mathrm{L}]=0.00,0.02,0.03,0.04$ e 0.05, nas temperaturas $T=15,20$ e $25^{\circ} C$, fase gel do lipídio.

De modo análogo na Figura 6.6, podemos observar algumas curvas na fase gel do DPPG, na ausência e com o aumento de $[\mathrm{P}] /[\mathrm{L}]$. Novamente, os perfis são perfis característicos da fase 


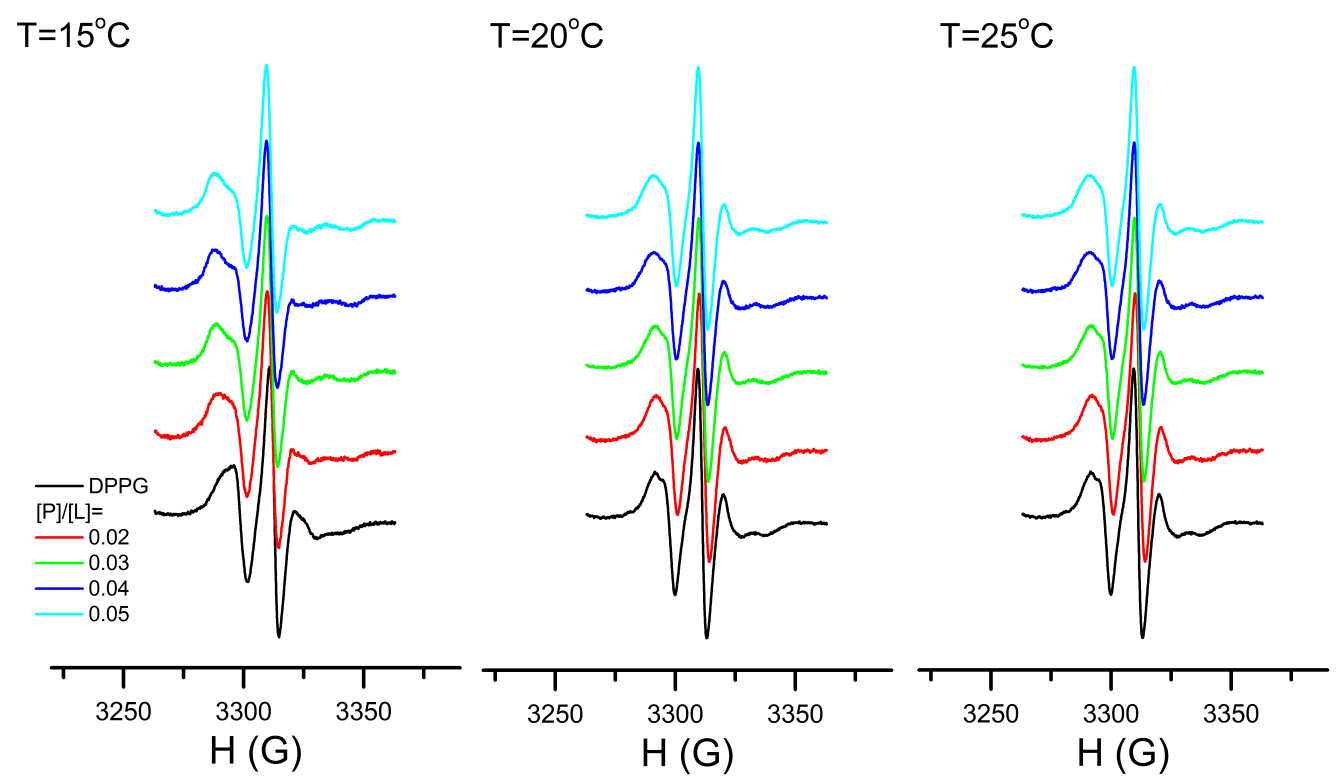

Figura 6.6: Sinais paramagnéticos da sonda 16PCSL incorporada em membranas de DPPG na ausência e com o aumento da concentração de peptídeo, $[\mathrm{P}] /[\mathrm{L}]=0.00,0.02,0.03,0.04$ e 0.05, nas temperaturas $T=15,20$ e $25^{\circ} C$, fase gel do lipídio.

gel. O parâmetro $2 A_{\max }$ já se mostra claramente maior com o aumento da concentração de peptídeo.

Os resultado para a fase gel da mistura DPPC:DPPG, Figura 6.7, são similares ao observado para o DPPG. Os perfis característicos da fase gel mostram que o ambiente da sonda paramagnética apresenta maior empacotamento com o aumento da concentração de peptídeo.

Os parâmetros $2 A_{\max }$ para os sistemas lipídicos DPPC, DPPG e DPPC:DPPG na ausência e presença de peptídeo são resumidos na Figura 6.8, onde no painel inferior foram calculados o aumento (ou diminuição) de $2 A_{\max }$ com relação ao observado para os lipídios em ausência de peptídeo $\left(2 A_{\max }^{[P] /[L]} / 2 A_{\max }^{L}\right)$.

O aumento do parâmetro $2 A_{\max }$ está relacionado ao grau de empacotamento do sítio em que se encontra a sonda paramagnética, e este incorpora ordem e mobilidade. Portanto, esse resultado sugere que o peptídeo aumenta o empacotamento das bicamadas aniônicas, na fase gel, pois, em geral, há um aumento igual ou superior a $5 \%$ de $2 A_{\max }$ na presença de peptídeo.

Para vesículas neutras, concentrações baixas de peptídeo $[\mathrm{P}] /[\mathrm{L}]=0.02$ e 0.03 mostraram uma pequena diminuição deste parâmetro, depois seguido de pequeno aumento para $[\mathrm{P}] /[\mathrm{L}]=0.04$ e 0.05. Entretanto, a variação do comportamento desse parâmetro pode estar associada ao erro experimental, refletindo a dificuldade de medir o parâmetro $2 A_{\max }$ na fase gel dos lipídios, com o marcador 16PCSL. 


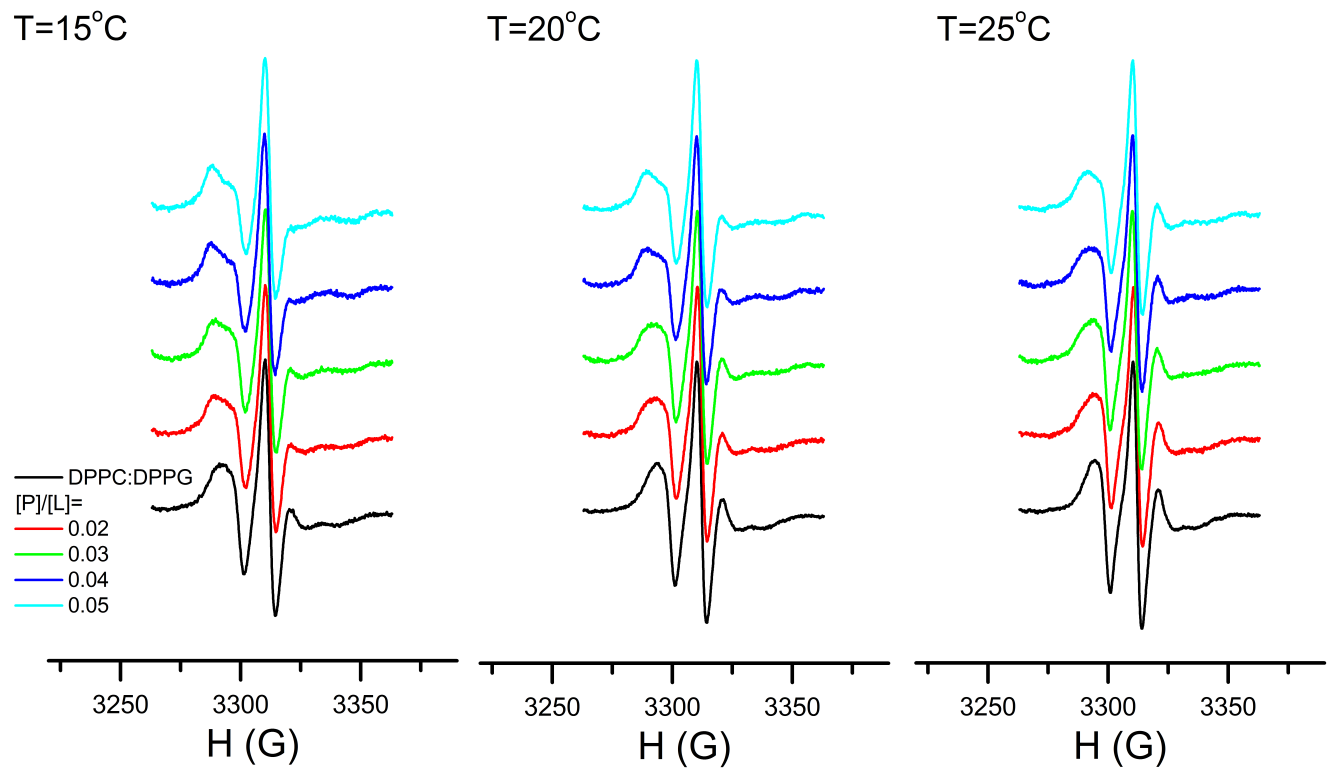

Figura 6.7: Sinais paramagnéticos da sonda 16PCSL incorporada em membranas de DPPC:DPPG na ausência e com o aumento da concentração de peptídeo, $[\mathrm{P}] /[\mathrm{L}]=0.00,0.02,0.03,0.04$ e 0.05, nas temperaturas $T=15,20$ e $25^{\circ} C$, fase gel da mistura.
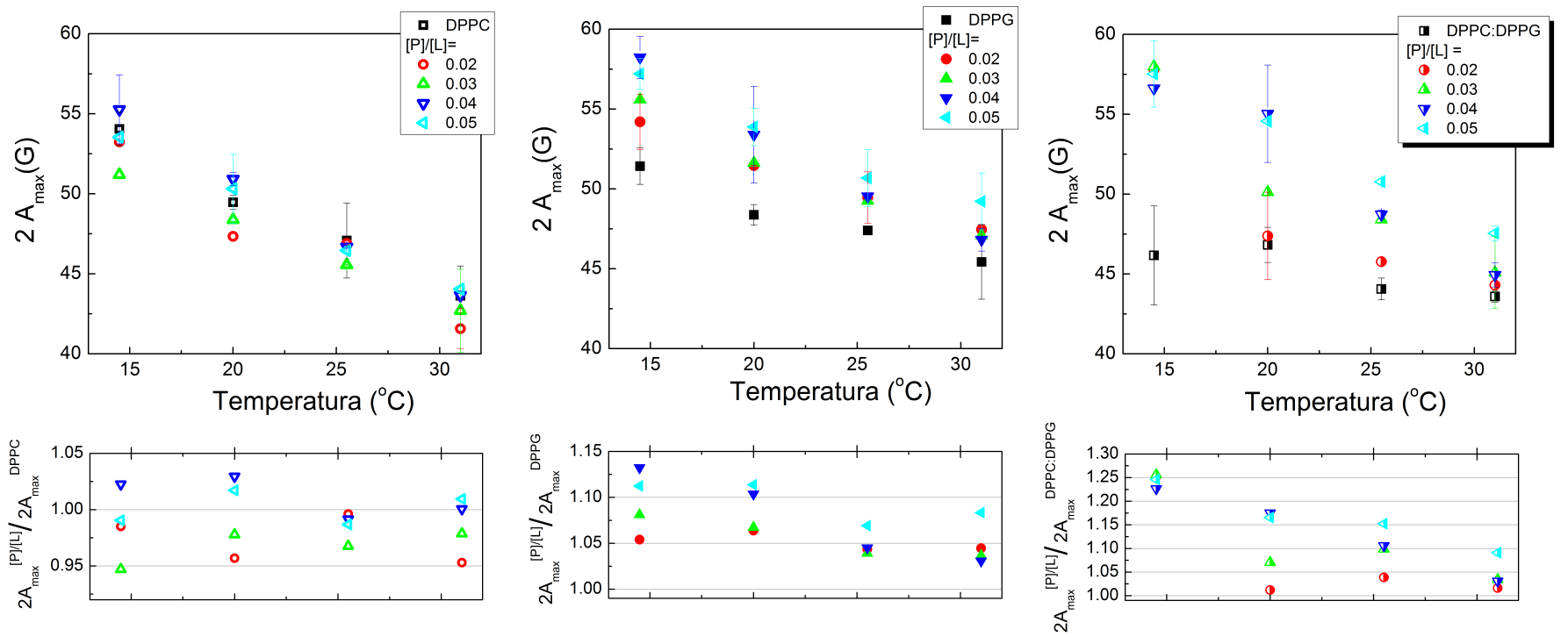

Figura 6.8: Resumo dos valores medidos para $2 A_{\max }$, com o marcador 16PCSL, para as dispersões lipídicas (DPPC, DPPG e DPPC:DPPG), na ausência e com o aumento da concentração de peptídeo, na fase gel dos lipídios e para diferentes temperaturas. Os painéis inferiores mostram as relações de aumento/diminuição dos parâmetros $2 A_{\max }$ em função da concentração de peptídeo, comparados aos obtidos em dispersões lipídicas em ausência de peptídeo.

Deste modo, conhecida a dificuldade de medir o parâmetro $2 A_{\max }$ na fase gel para o marcador 16PCSL, também medimos o parâmetro $\Delta H_{0}$ (ver Figura 2.24). Esse parâmetro está 
associado à largura de linha do pico central e à medida que os sistema se torna mais fluido, os espectros tende a diminuir o valor de $\Delta H_{0}$.

A Figura 6.9 mostra os valores de $\Delta H_{0}$ para DPPC, DPPG e DPPC:DPPG na presença e ausência de peptídeo. Podemos observar que para o DPPC em presença de peptídeo, os valores de $\Delta H_{0}$ variam em torno do valor obtido pelo DPPC na ausência de peptídeo. Por outro lado, para as vesículas aniônicas DPPG e DPPC:DPPG observamos um aumento em torno de 10$20 \%$ desse parâmetro, indicando que o aumento da concentração de peptídeo leva ao aumento do empacotamento da membrana, em acordo com o observado para $2 A_{\max }$.
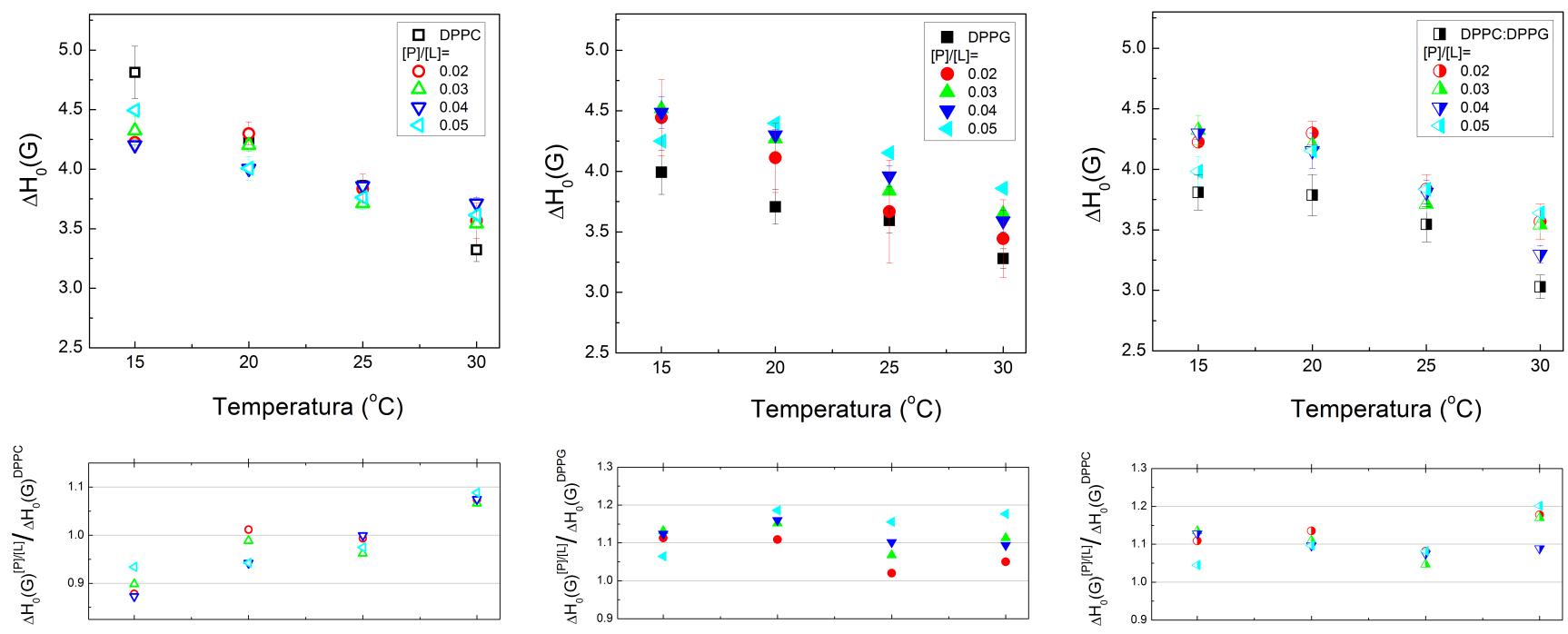

Figura 6.9: Resumo dos valores medidos para $\Delta H_{0}$, com o marcador 16PCSL, para as dispersões lipídicas (DPPC, DPPG e DPPC:DPPG), na ausência e com o aumento da concentração de peptídeo, na fase gel dos lipídios e para diferentes temperaturas. Os painéis inferiores mostram as relações de aumento/diminuição dos parâmetros $\Delta H_{0}$ em função da concentração de peptídeo, comparados aos obtidos em dispersões lipídicas em ausência de peptídeo.

Portanto, os parâmetros $2 A_{\max }$ e $\Delta H_{0}$ sugerem que para o DPPC o peptídeo causa pequenas perturbações na região do carbono 16 na fase gel do lipídio. Entretanto, tais parâmetros $\left(2 A_{\max }\right.$ e $\left.\Delta H_{0}\right)$ mostraram que para vesículas aniônicas o peptídeo aumenta o grau de empacotamento da membrana, nesta região para a fase gel dos lipídios DPPG e DPPC:DPPG.

\section{Marcador de spin 5PCSL}

As Figuras 6.10, 6.11 e 6.12 mostram alguns exemplos dos perfis obtidos para a fase gel dos lipídios DPPC, DPPG e DPPC:DPPG na ausência e presença de peptídeo, agora, com o uso 
do marcador paramagnético 5PCSL.

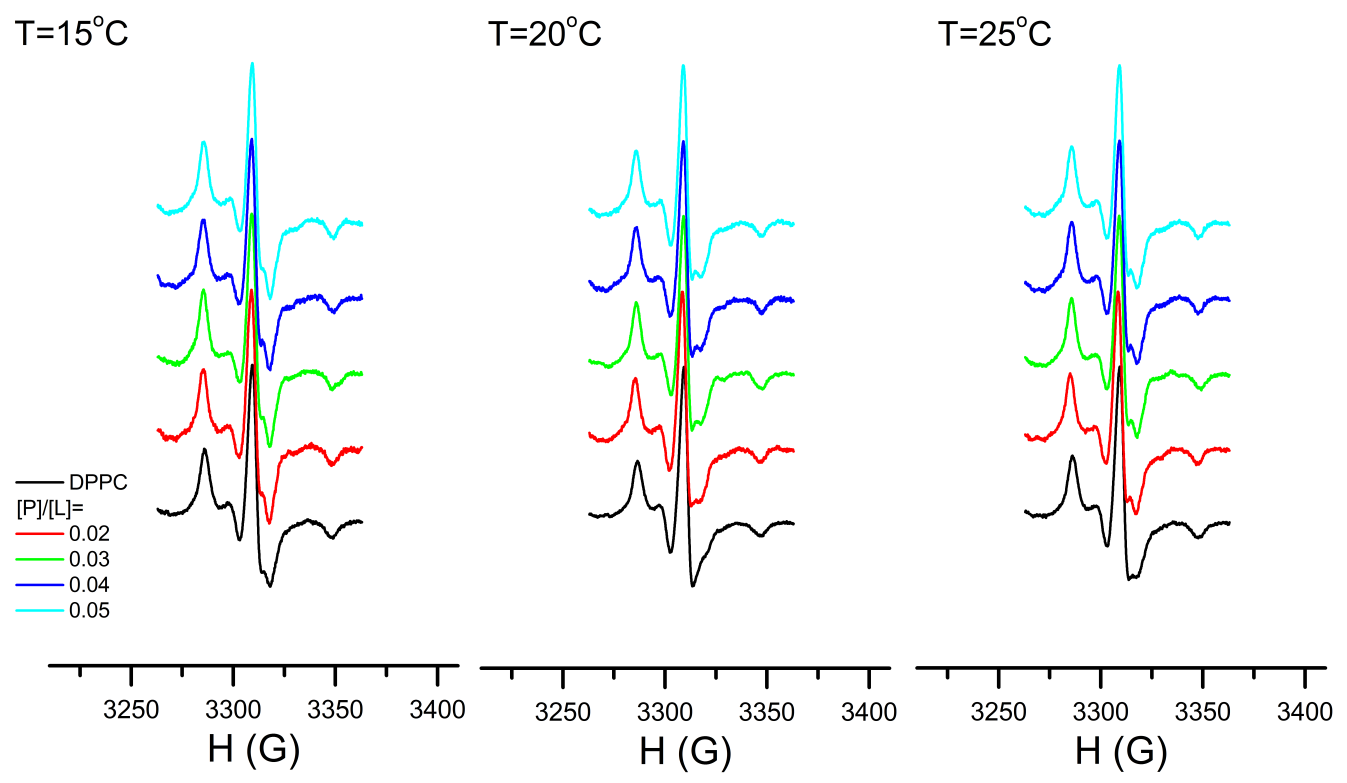

Figura 6.10: Sinais paramagnéticos da sonda 5PCSL incorporada em membranas de DPPC na ausência e com o aumento da concentração de peptídeo, $[\mathrm{P}] /[\mathrm{L}]=0.00,0.02,0.03,0.04$ e 0.05, nas temperaturas $T=15,20$ e $25^{\circ} \mathrm{C}$, fase gel do lipídio.

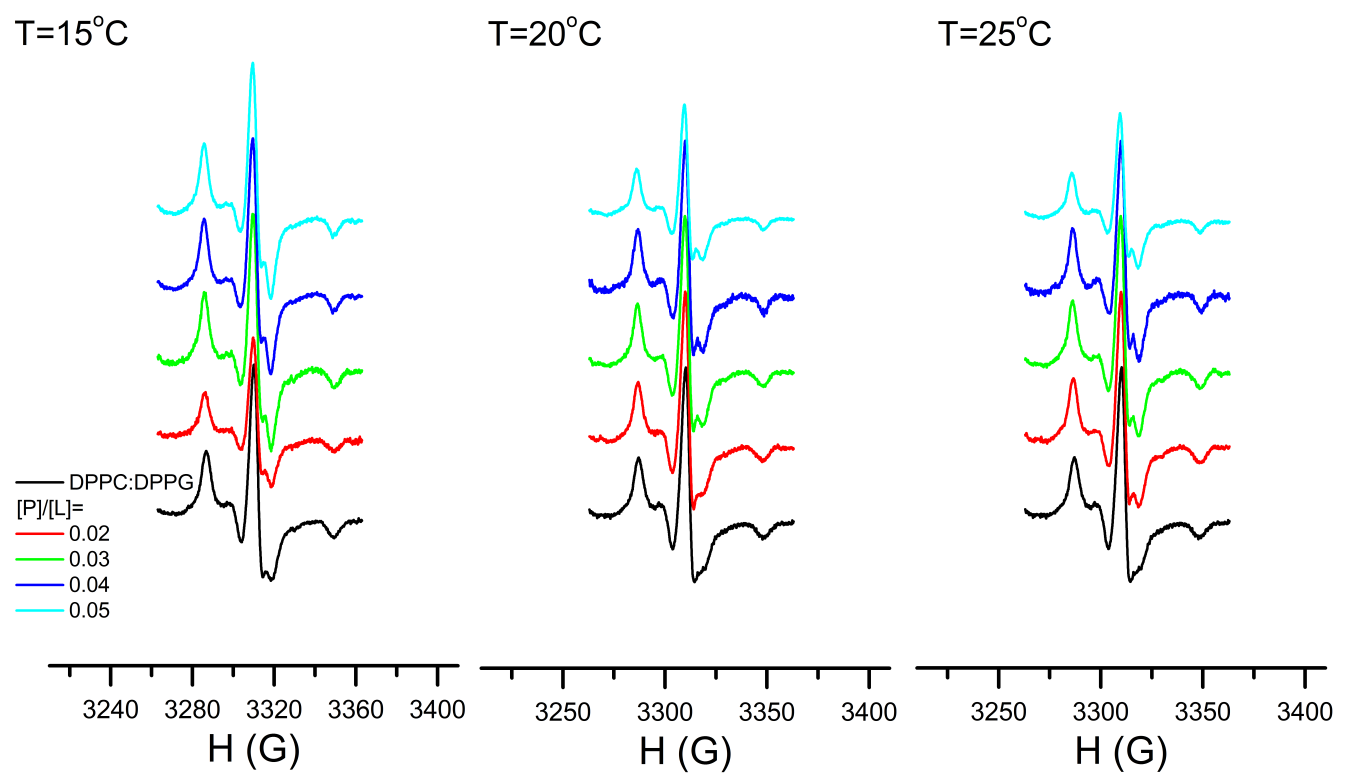

Figura 6.11: Sinais paramagnéticos da sonda 5PCSL incorporada em membranas de DPPG na ausência e com o aumento da concentração de peptídeo, $[\mathrm{P}] /[\mathrm{L}]=0.00,0.02,0.03,0.04$ e 0.05, nas temperaturas $T=15,20$ e $25^{\circ} C$, fase gel do lipídio.

Para facilitar a comparação das diferentes composições lipídicas, os valores de $2 A_{\max }$ (ver Figura 2.24) são resumidos na Figura 6.13. Em geral, para todos os sistemas lipídicos há um 


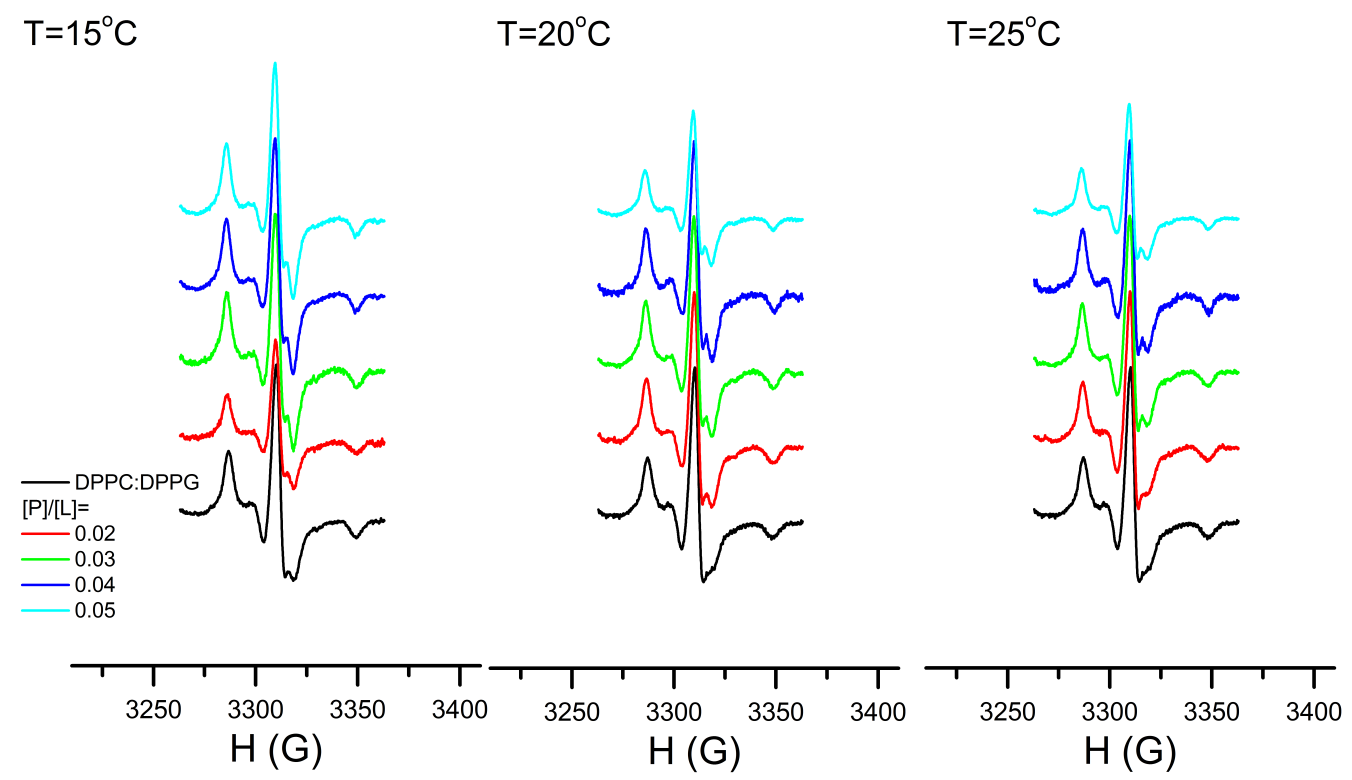

Figura 6.12: Sinais paramagnéticos da sonda 5PCSL incorporada em membranas de DPPC:DPPG na presença e com o aumento da concentração de peptídeo, $[\mathrm{P}] /[\mathrm{L}]=0.00,0.02,0.03,0.04$ e 0.05, nas temperaturas $T=15,20$ e $25^{\circ} C$, fase gel da mistura.

aumento do parâmetro $2 A_{\max }$, e, curiosamente, o aumento observado para DPPC é similar ao aumento observado para as demais composições aniônicas.

Esses resultados indicam que o peptídeo aumenta a ordem e/ou diminui a mobilidade dos lipídios (DPPC, DPPG e DPPC:DPPG) na fase gel, próximo à região do carbono 5.

\subsubsection{Fase fluida}

\section{Marcador de spin 16PCSL}

A Figura 6.14 mostra alguns perfis de ESR para os sistemas lipídicos DPPC, DPPG e DPPC:DPPG, na fase fluida do lipídio, em ausência e com o aumento da concentração de peptídeo.

A Figura 6.15 compara as alturas relativas $h_{-1} / h_{0}$ (ver Figura 2.21) para os três sistemas lipídicos, onde é evidente a grande diferença entre vesículas neutras e aniônicas. Para vesículas aniônicas, esta relação diminui gradativamente com o aumento da concentração de peptídeo, onde é observado maior efeito em lipossomos compostos apenas por PG. É interessante notar que para o DPPG há uma diminuição de cerca 30 a $40 \%$ deste parâmetro para $[\mathrm{P}] /[\mathrm{L}]=0.05$ e em torno de 30\% para o DPPC:DPPG. Esse resultado sugere que o peptídeo causa grande perturbação na região do carbono 16, na fase fluida de bicamadas aniônicas, aumentando o 

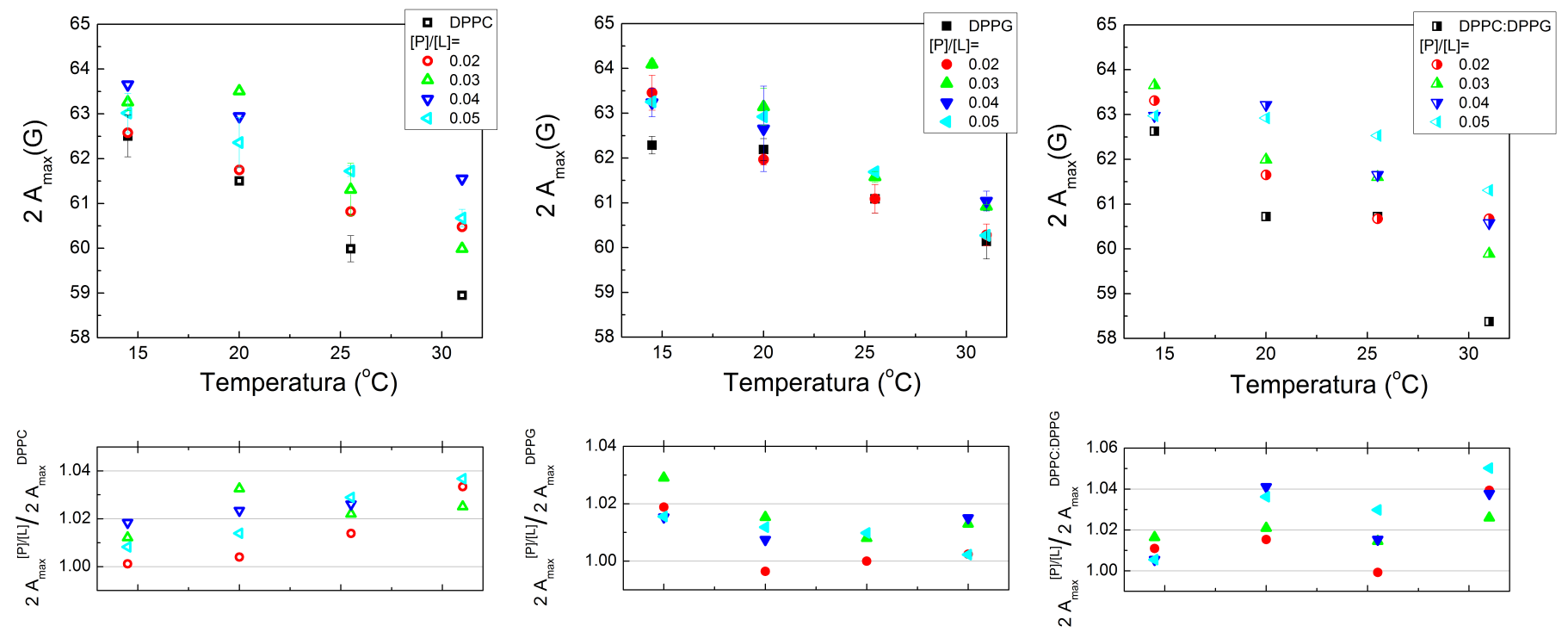

Figura 6.13: Resumo dos valores medidos para $2 A_{\max }$, com o marcador 5PCSL, para as dispersões lipídicas (DPPC, DPPG e DPPC:DPPG), na ausência e com o aumento da concentração de peptídeo, na fase gel dos lipídios e para diferentes temperaturas. Os painéis inferiores mostram as relações de aumento/diminuição dos parâmetros $2 A_{\max }$ em função da concentração de peptídeo, comparados aos obtidos em dispersões lipídicas em ausência de peptídeo.
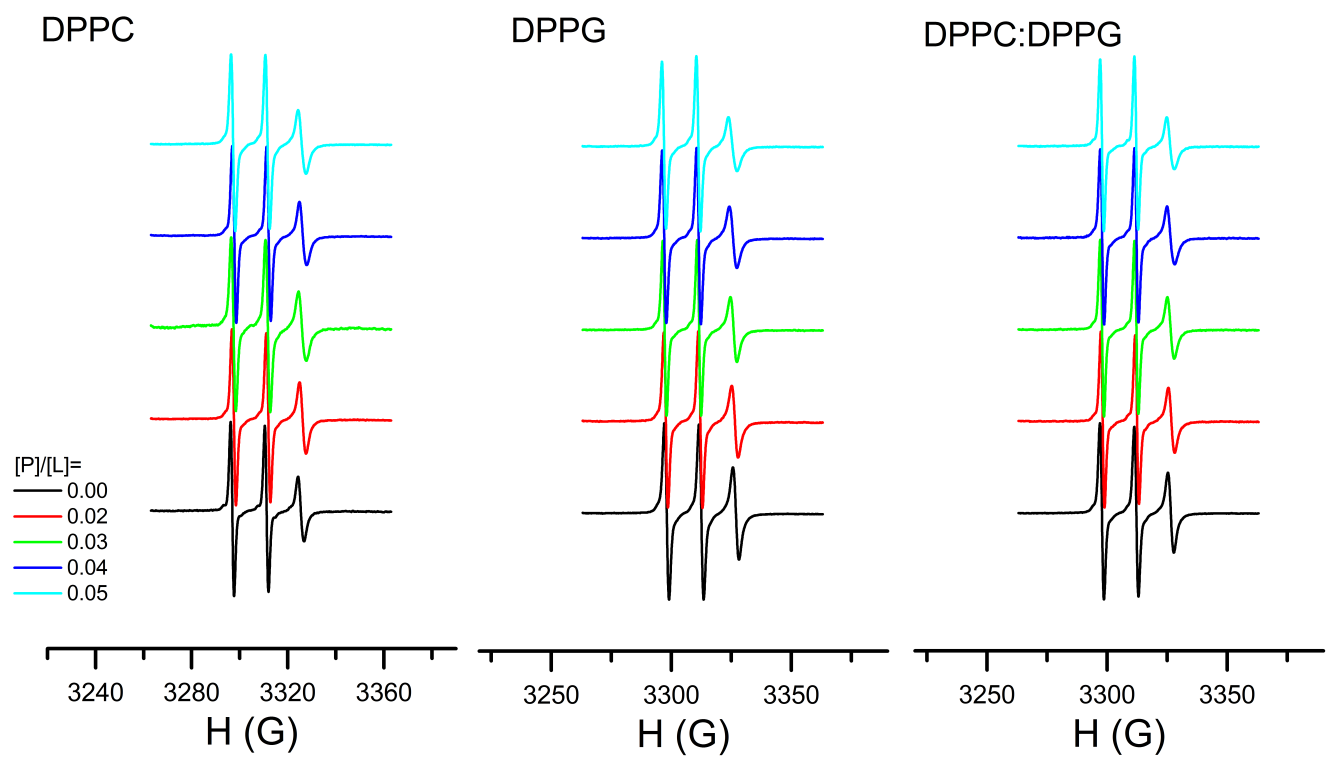

Figura 6.14: Sinais paramagnéticos da sonda 16PCSL incorporada em membranas de DPPC, DPPG, e DPPC:DPPG na ausência e com o aumento da concentração de peptídeo, $[\mathrm{P}] /[\mathrm{L}]=0.00,0.02,0.03$, 0.04 e 0.05 , exemplo obtido na temperatura $T=50^{\circ} C$, fase gel do lipídio.

empacotamento da bicamada nesta região.

Para vesículas neutras, há um pequeno aumento da relação $h_{-1} / h_{0}$, para $[\mathrm{P}] /[\mathrm{L}]=0.02$ e 

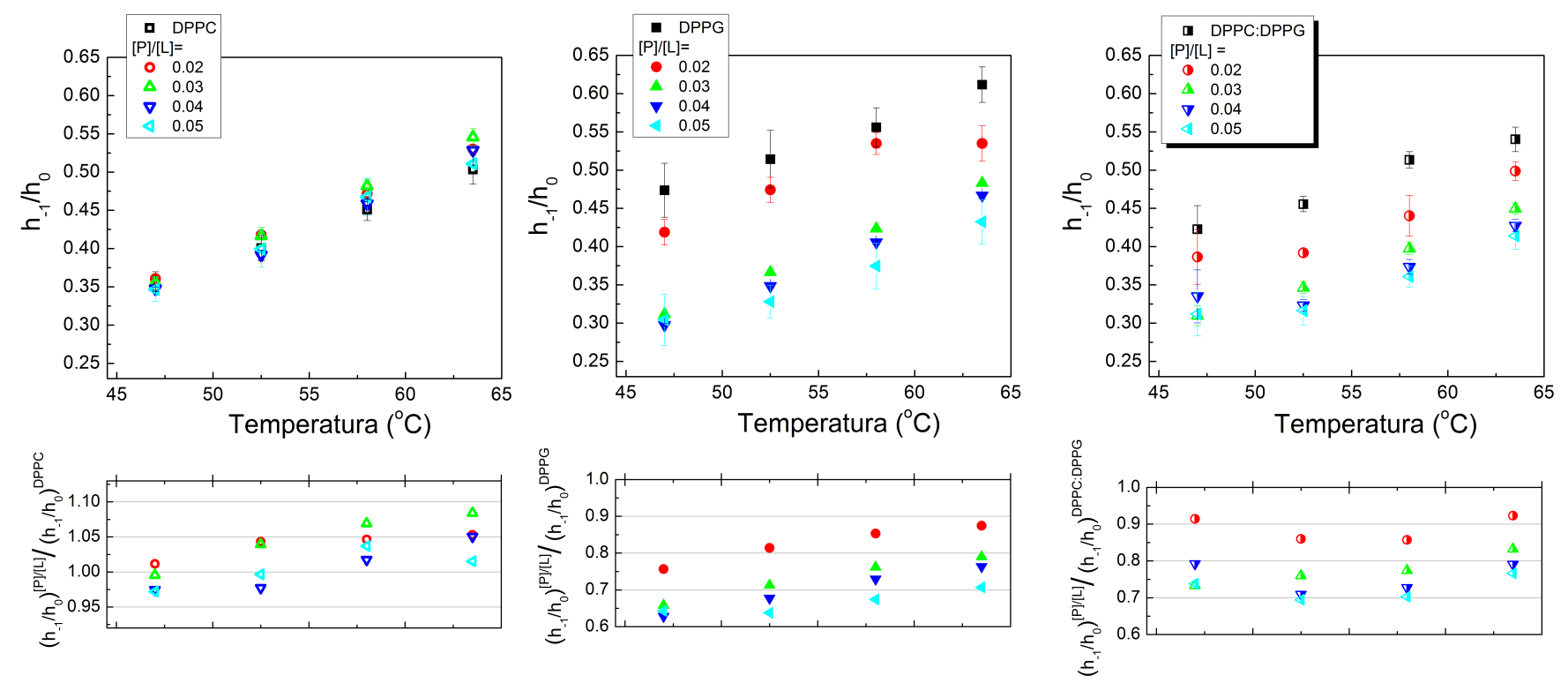

Figura 6.15: Resumo dos valores medidos para $h_{-1} / h_{0}$, com o marcador 16PCSL, para as dispersões lipídicas (DPPC, DPPG e DPPC:DPPG) na ausência e com o aumento da concentração de peptídeo, na fase fluida dos lipídios e para diferentes temperaturas. Os painéis inferiores mostram as relações de aumento/diminuição dos parâmetros $h_{-1} / h_{0}$ em função da concentração de peptídeo, comparado às dispersões lipídicas em ausência de peptídeo.

0.03, seguido de uma pequena diminuição para $[\mathrm{P}] /[\mathrm{L}]=0.04$ e 0.05 , contudo, em geral os valores de $h_{-1} / h_{0}$ são moires que os observados em DPPC na ausência de peptídeo. A diminuição de $h_{-1} / h_{0}$ em presença de peptídeo, comparada com os valores em ausência de peptídeo pode indicar que peptídeo fluidifica a membrana na região monitorada pelo 16PCSL. Em geral, moléculas que aderem à superfície da membrana podem aumentar o empacotamento da bicamada próximo a superfície e fluidificar a região central da bicamada.

Além disso, para as mais altas temperaturas foram observados aumento do parâmetro $h_{-1} / h_{0}$, onde as maiores variações são da ordem de $7 \%$. Comparados aos valores observados em membranas compostas por lipídios aniônicos, com diminuições de 30 a 40\%, as variações de $h_{-1} / h_{0}$ em DPPC são muito pequenas.

\section{Marcador de spin 5PCSL}

A Figura 6.16 mostra alguns exemplos do sinal paramagnético da sonda 5PCSL para a fase fluida das dispersões lipídicas DPPC, DPPG e DPPC:DPPG.

Com o uso da equação (6.1) foi calculado o parâmetro de ordem efetivo, $S_{e f}$. Deste modo, a Figura 6.17 compara como o peptídeo modifica o parâmetro de ordem efetivo na região do 


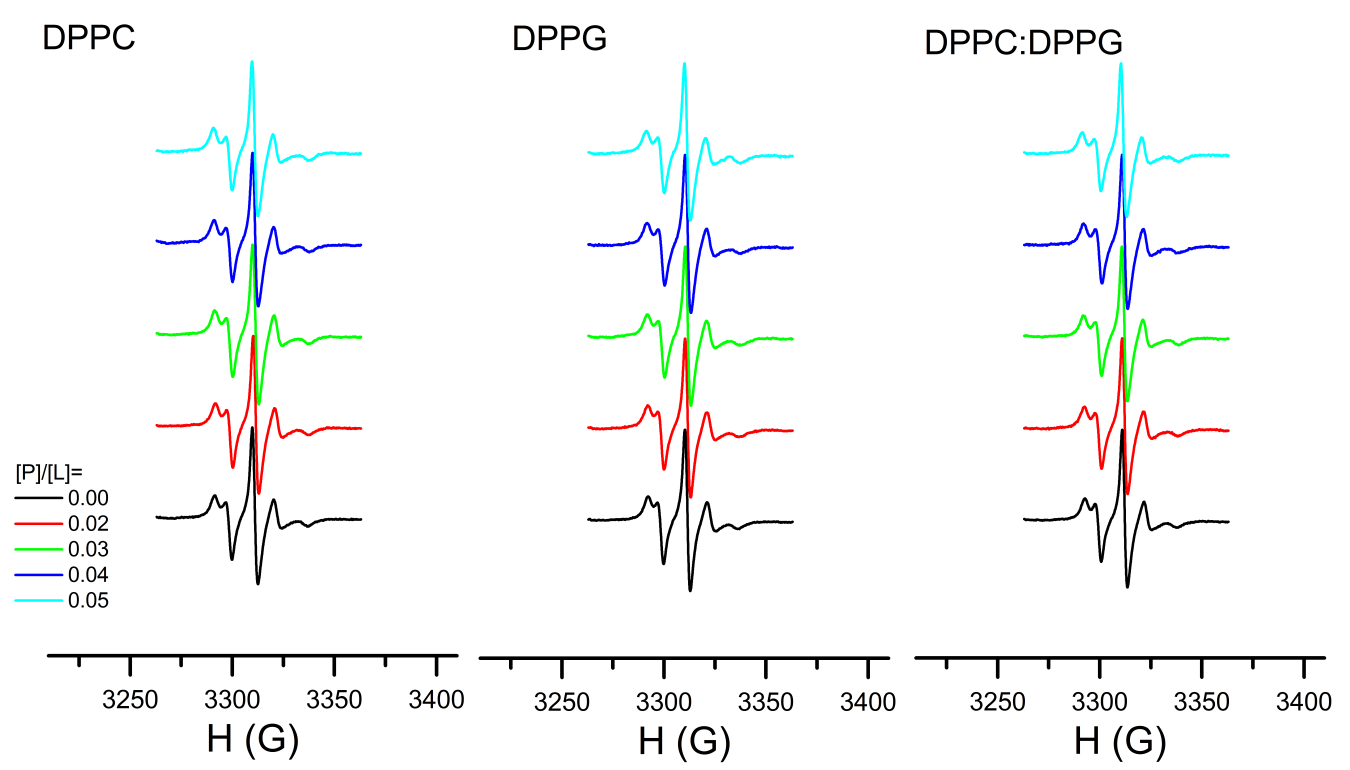

Figura 6.16: Sinais paramagnéticos da sonda 5PCSL incorporada em membranas de DPPC, DPPG, e DPPC:DPPG na ausência e com o aumento da concentração de peptídeo, $[\mathrm{P}] /[\mathrm{L}]=0.00,0.02,0.03$, 0.04 e 0.05 , exemplo obtido na temperatura $T=50^{\circ} C$, fase gel do lipídio.

carbono 5 nas membranas de diferentes composições lipídicas.
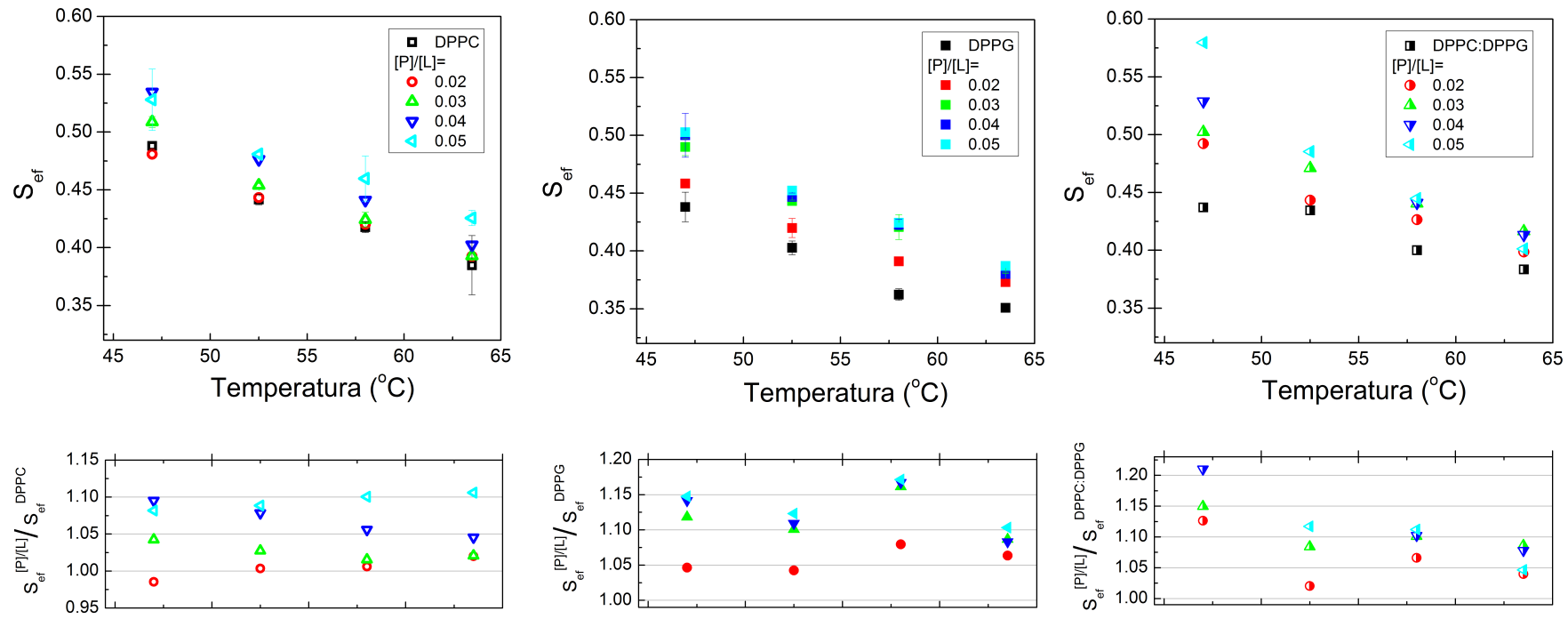

Figura 6.17: Resumo dos valores calculados para $S_{\text {ef }}$, com o marcador 5PCSL na fase fluida dos lipídios, para as dispersões lipídicas (DPPC, DPPG e DPPC:DPPG) na ausência e com o aumento da concentração de peptídeo. Os painéis inferiores mostram as relações de aumento/diminuição dos parâmetros $S_{\text {ef }}$ em função da concentração de peptídeo, comparado às dispersões lipídicas em ausência de peptídeo. 
Em geral, observamos um aumento de até 10 -15\% do parâmetro de ordem para membranas compostas por DPPC e com o aumento da concentração de peptídeo, e de até 15\% ou pouco maior que 15\%, para o DPPG e DPPC:DPPG. Esse resultado indica que o peptídeo aumenta a ordem da bicamada, na região do carbono 5 e na fase fluida de todos os lipídios aqui analisados.

Podemos resumir os resultados de ESR de acordo com os itens listados a seguir:

DPPC

- Na fase gel, e na região do carbono 16, o peptídeo causa pouca perturbação nesta região da bicamada. Os parâmetros $2 A_{\max }$ e $\Delta H_{0}$ em presença de peptídeo variam em torno dos parâmetros observados na ausência de peptídeo.

- Na fase gel, e na região do carbono 5, o aumento da concentração de peptídeo leva ao aumento gradual do empacotamento da bicamada.

- Na fase fluida, e na região do carbono 16, pequenas variações são observadas, onde para baixas concentrações de peptídeo, $[\mathrm{P}] /[\mathrm{L}]=0.02$ e 0.03 , foram observados pequena diminuição do grau de empacotamento da membrana, e para $[\mathrm{P}] /[\mathrm{L}]=0.04$ e 0.05 o oposto.

- Na fase fluida, e na região do carbono 5, foi observado aumento do parâmetro de ordem efetivo com o aumento da concentração de peptídeo.

\section{DPPG e DPPC:DPPG}

- Na fase gel, na região do carbono 16 e na região do carbono 5, o aumento da concentração de peptídeo leva ao aumento gradual do empacotamento da bicamada.

- Na fase fluida, e na região do carbono 16, o aumento da concentração de peptídeo leva ao aumento gradual do empacotamento da bicamada.

- Na fase fluida, e na região do carbono 5, foi observado aumento do parâmetro de ordem efetivo com o aumento da concentração de peptídeo.

Portanto, os resultados de ESR sugerem que o peptídeo KHya1, em DPPC, localiza-se próximo à superfície da membrana, por perturbar mais a região do carbono 5 e afetar pouco a região do carbono 16. A pequena fluidificação causada pelo peptídeo em DPPC pode ser devido à sua penetração na região da interface, afastando as cadeias no centro da bicamada.

Por outro lado, em presença de lipídios negativamente carregados, PG, o peptídeo perturba tanto a região do carbono 5 quanto a região do carbono 16 da bicamada, sugerindo que o peptídeo encontra-se em uma posição transmenbranar. 
É razoável supor que o peptídeo na posição transversal aumente o grau de empacotamento da bicamada, tanto na região próxima à superfície quanto na região central da membrana, como foi observado com os resultados experimentais.

\subsection{SAXS}

Nos resultados de SAXS, primeiramente vamos introduzir uma breve comparação de vesículas não extrusadas e extrusadas. Essa primeira análise com vesícula não extrusadas auxilia na compreensão do fator de estrutura observado na organização multilamelar.

Embora a maior parte dos resultados apresentados ao longo dos capítulos 4 e 5 foram realizados com vesículas extrusadas, neste trabalho também foram realizados alguns experimentos com vesículas não extrusadas, para investigação dos fatores de estrutura.

\subsubsection{Sistemas multilamelares e unilamelares em ausência de peptídeo}

A Figura 6.18 mostra as curvas de SAXS obtidas para lipossomos compostos por DPPC na ausência de peptídeo, para as fases gel e fluida do lipídio. Nos painéis (A) e (B) mostramos dispersões lipídicas de DPPC não extrusadas, em $T=30$ e $45^{\circ} C$, respectivamente, e em (C) e (D) as dispersões extrusadas.

As vesículas de DPPC não extrusadas organizam-se em estruturas multilamelares, onde os picos observados na Figura 6.18 (A-B) correspondem aos picos de Bragg dado pelo empilhamento das multicamadas. Na fase gel observamos quatro picos de difração correspondentes as distâncias entre multilamelas, enquanto na fase fluida podemos observar claramente apenas dois picos.

Há diferentes razões para que os picos de maior ordem se tornem menos evidentes nas curvas de espalhamento. Dentre essas razões, temos, as flutuações térmicas das bicamadas, defeitos no empilhamento das bicamadas (a distância entre algumas bicamadas pode ser diferente das demais) e a membrana pode apresentar diferentes amplitudes de flutuações perturbando a ordem a longo alcance das multicamadas (Pabst, 2003). Esse último está relacionado à constante de curvatura da membrana, $\kappa$, ("bending modulus"); e sabe-se que $\kappa$ da fase fluida é cerca de 10 vezes menor que da fase gel (Dimova, Pouligny, and Dietrich 2000). Deste modo, dado o aumento das flutuações térmicas e as diferenças nas constantes de curvatura, naturalmente espera-se que a ordem ao longo alcance das multicamadas seja reduzida na fase fluida. 

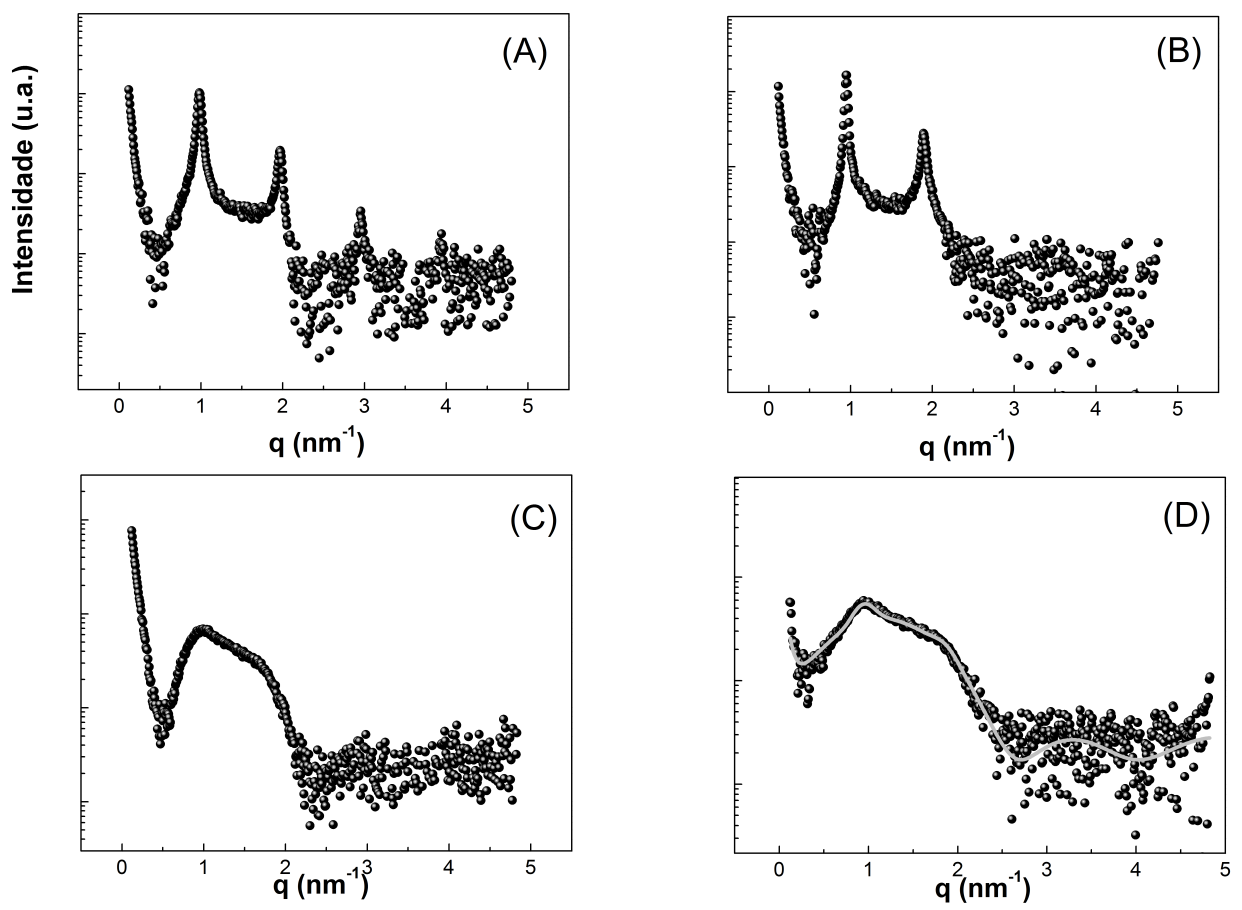

Figura 6.18: Curvas de SAXS obtidas para dispersões lipídicas de DPPC. Dispersões não extrusadas formando vesícula multilamelares, MLVs: (A) fase gel do lipídio, $T=30^{\circ} \mathrm{C}$. (B) fase fluida, $T=50^{\circ} \mathrm{C}$. Dispersões extrusadas formando majoritariamente vesículas unilamelares, LUVs: (C) fase gel do lipídio, $T=30^{\circ} \mathrm{C}$. (D) fase fluida, $T=50^{\circ} \mathrm{C}$. Em (D) mostramos um ajuste obtido com $20 \%$ de MLVs e $80 \%$ de LUVs.

Para os sistemas não extrusados, observamos que os picos do fator de interferência ocorrem nas posições, na fase gel $q=0.944$ (primeira ordem) e $q=1.892$ (segunda ordem). Para a fase fluida esses valores são vistos em $q=0.982$ (primeira ordem) e $q=1.969$ (segunda ordem). Deste modo, a posição dos picos leva a uma distância de repetição de 6.4 e $6.7 \mathrm{~nm}$ para a fase gel e fluida, respectivamente. Essa distância de repetição refere-se a espessura da bicamada e a espessura da camada de água entre bicamadas consecutivas. Esses resultados estão em acordo com a literatura, com por exemplo reportado por (Guler et al. 2009 e Heftberger et al. 2014).

Para o DPPC extrusado, tanto na fase gel quanto na fase fluida, Figura 6.18 (C e D), observamos um perfil de espalhamento que contém pequena contribuição de um fator de estrutura. A curva representada na Figura 6.18 (D) foi ajustada considerando uma fração de $80 \%$ de vesículas unilamelares (LUVs) e 20\% de vesículas multilamelares (MLVs) com baixa ordem de repetição, 3 camadas. ${ }^{3}$ De modo análogo ao mencionado acima, as distâncias de repetição

\footnotetext{
${ }^{3}$ Esse ajuste foi realizado pelo Prof. Leandro Barbosa, colaborador desse trabalho, e foi realizado com uso do programa Genfit. Não vamos fazer grandes descrições deste programa aqui. Esse dado foi utilizado apenas
} 
dessa organização multilamenlar de baixa ordem também são equivalente a 6.4 e $6.7 \mathrm{~nm}$.

Então, esse resultado sugere que mesmo após o processo de extrusão (61 vezes) ainda restam algumas poucas estruturas multilamelares com baixa ordem de repetição, aproximadamente 3 lamelas. As vesículas multilamelares restantes e com baixa ordem de repetição podem possuir diâmetro inferior ao tamanho do poro utilizado na extrusão (100 nm). Deste modo, tais vesículas podem atravessar a membrana do extrusor sem se organizarem em vesículas unilamelares, LUVs.

Para as vesículas aniônicas de DPPG, e a mistura de DPPC:DPPG, podemos observar exemplos das curvas de espalhamento das dispersões lipídicas extrusadas e não extrusadas, e nas fases gel e fluida, conforme ilustra a Figura 6.19. Nos painéis (A) e (B) estão representadas as curvas das vesículas não extrusadas, e em (C) e (D) das dispersões extrusadas.
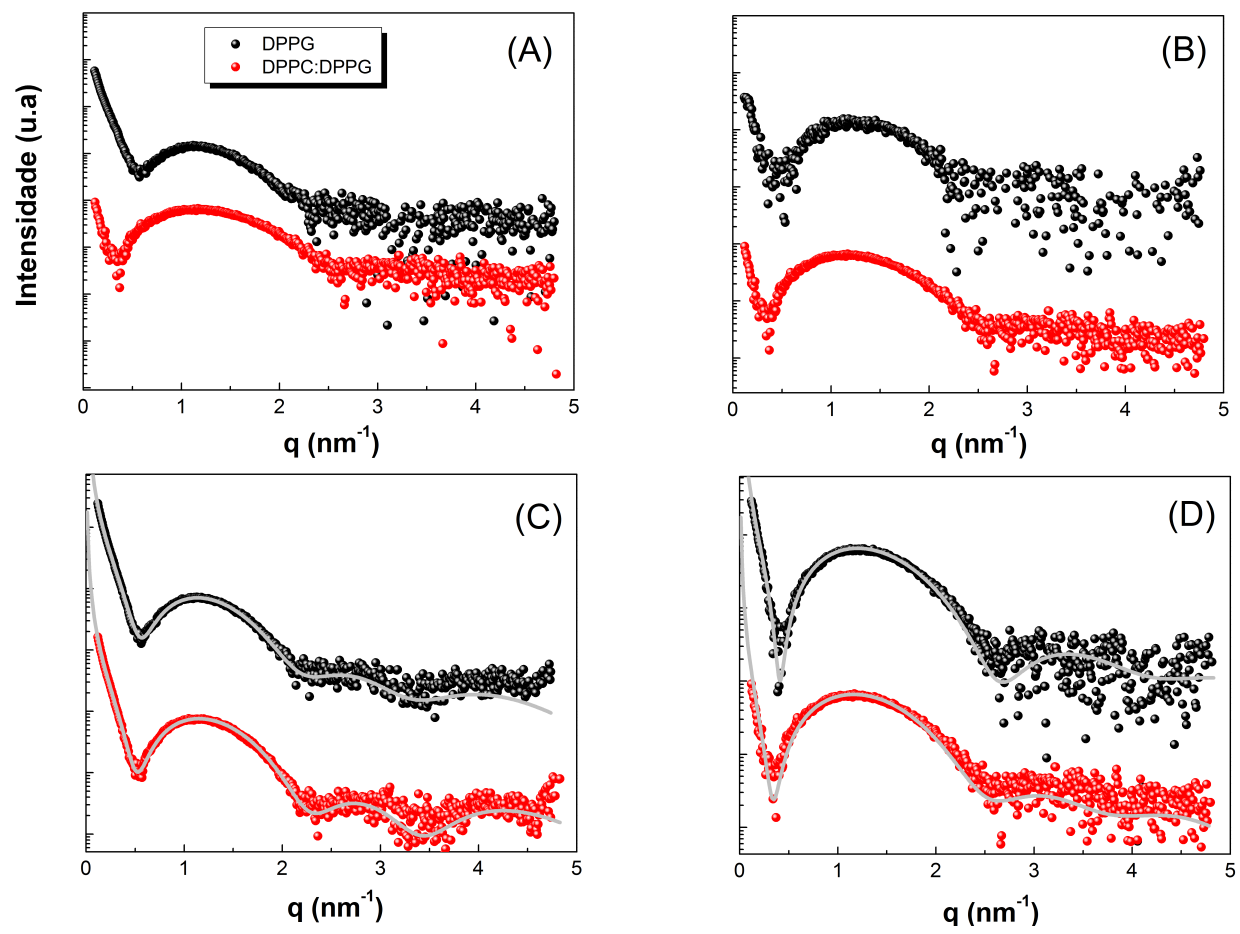

Figura 6.19: Curvas de SAXS obtidas para dispersões lipídicas de DPPG (preto) e DPPC:DPPG (vermelho). Dispersões não extrusadas formando vesículas unilamelares, LUVs: (A) fase gel do lipídio, $T=30^{\circ} \mathrm{C}$. (B) fase fluida, $T=50^{\circ} \mathrm{C}$. Dispersões extrusadas formando vesículas unilamelares, LUVs: (C) fase gel do lipídio, $T=30^{\circ} \mathrm{C}$. (D) fase fluida, $T=50^{\circ} \mathrm{C}$

Os lipossomos compostos por lipídios negativamente carregados, em geral, tendem a se organizar em LUVs, em baixa força iônica, pois a densidade de carga e a interação repulsiva desfavorece a formação de MLVs. Os dados da Figura 6.19, (C) e (D) foram ajustados com o

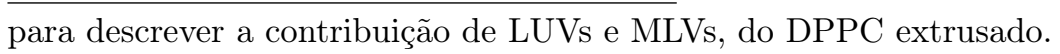


programa GIFT (Glatter, 1977) (ver capítulo 2), e alguns parâmetros do ajuste estão resumidos na Tabela 6.1.

\subsubsection{Vesículas extrusadas em presença de peptídeo}

A Figura 6.20 mostra as curvas de SAXS obtidas para vesículas neutras compostas por DPPC na ausência de peptídeo (curvas pretas), e aumentando a concentração de peptídeo, para as temperaturas $T=25,30,36,40,45$ e $50^{\circ} \mathrm{C}$. As curvas estão deslocadas na direção vertical para facilitar a visualização.

A linha tracejada desenhada nos gráficos auxilia a comparação dos deslocamentos das curvas em relação a $q$, esta linha marca o primeiro mínimo do fator de forma das vesículas em ausência de peptídeo (curva preta).
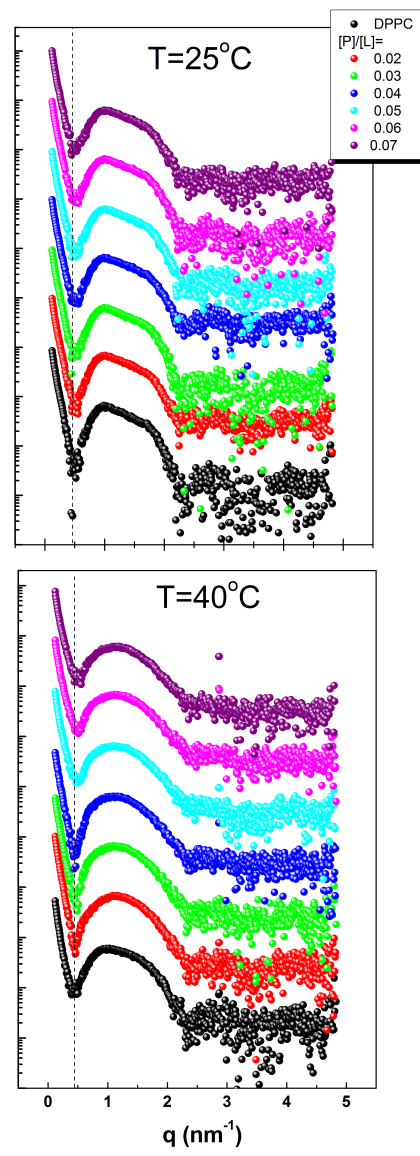
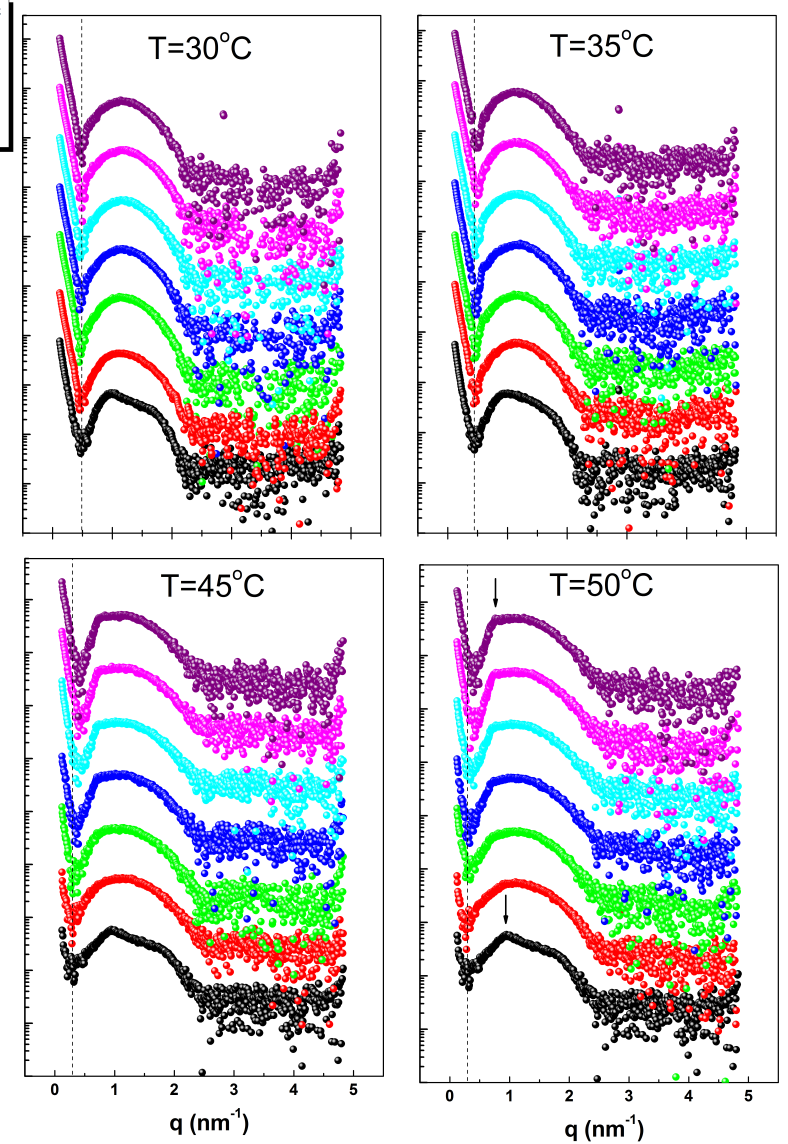

Figura 6.20: Curvas de SAXS obtidas para dispersões lipídicas extrusadas de DPPC em ausência e com o aumento da concentração de peptídeo, $[\mathrm{P}] /[\mathrm{L}]=0.00,0.02,0.03,0.04,0.05,0.06$ e 0.07 , e para diferentes temperaturas, $T=25,30,35,40,45$ e $50^{\circ} \mathrm{C}$.

O efeito do peptídeo em membranas de DPPC depende da temperatura, ou seja, da fase 
da bicamada lipídica. Para $T=25^{\circ} C$, fase gel do $\mathrm{DPPC}$, pequena alteração é observada. A dispersão lipídica composta por uma pequena fração de MLVs continua a apresentar certa fração de MLVs mesmo para as mais altas concentrações de peptídeo.

O aumento da temperatura favorece a interação do peptídeo antimicrobiano com a membrana neutra. Para $\mathrm{T}=30^{\circ} \mathrm{C}$ desde a mais baixa até a mais alta concentração de peptídeo são observadas vesículas unilamelares. Esse resultado indica que o peptídeo destrói a organização em multicamadas das MLVs. O mesmo efeito é observado para $\mathrm{T}=35$ e $40^{\circ} \mathrm{C}$.

Na fase fluida, a Figura 6.20 mostra que para baixas concentrações de peptídeo $[\mathrm{P}] /[\mathrm{L}]=0.02$ e 0.03, os perfis de espalhamento são característicos de vesículas unilamelares. Entretanto, para concentrações maiores de peptídeo, surge um pico de interferência diferente do previamente observado em DPPC na ausência de peptídeo. Comparando o pico de interferência observado no DPPC em ausência (curva preta) e em alta concentração de peptídeo, podemos observar que em presença de peptídeo, este se encontra deslocado para baixos valores de $q$, conforme indica as setas no ultimo painel, $\mathrm{T}=50^{\circ} \mathrm{C}$.

No capítulo 4 os resultados da fluorescência estática para o DPPC mostraram que a posição do espectro de emissão do Trp apresenta menor deslocamento em direção a baixos comprimentos de onda (relativo ao espectro em solução aquosa) na fase gel, do que o observado para a fase fluida, sugerindo que a interação do peptídeo com membranas neutras depende da fase da membrana, e, portanto da interação lipídio-lipídio. Deste modo, os resultados de SAXS corroboram os dados de fluorescência previamente apresentados.

A Figura 6.21 mostra as curvas de SAXS obtidas para vesículas compostas por DPPG na ausência de peptídeo (curvas pretas), e aumentando a concentração de peptídeo, para as temperaturas $T=25,30,36,40,45$ e $50^{\circ} \mathrm{C}$.

Diferente do estudo com o DPPC, não foi observado fator de estrutura para as concentrações de peptídeo aqui estudadas para o DPPG, o que torna as análises do DPPG mais simples. Deste modo, a análise das curvas obtidas para o DPPG podem ser tratadas apenas com um fator de forma, conforme mostram as análise da seção 6.4.4.

Também podemos observar que com o aumento da concentração de peptídeo há um deslocamento gradual das curvas em direções a maiores valores de $q$. Esse deslocamento, para o DPPG, é mais evidente na fase gel, embora também ocorra na fase fluida. Para o DPPC, podemos observar pequeno deslocamento das curvas compostas apenas por um fator de forma, por exemplo $T=30^{\circ} \mathrm{C}$ ao longo do aumento da concentração de peptídeo, Figura 6.20.

De modo análogo, a Figura 6.22 mostra as curvas de SAXS obtidas para vesículas compostas 

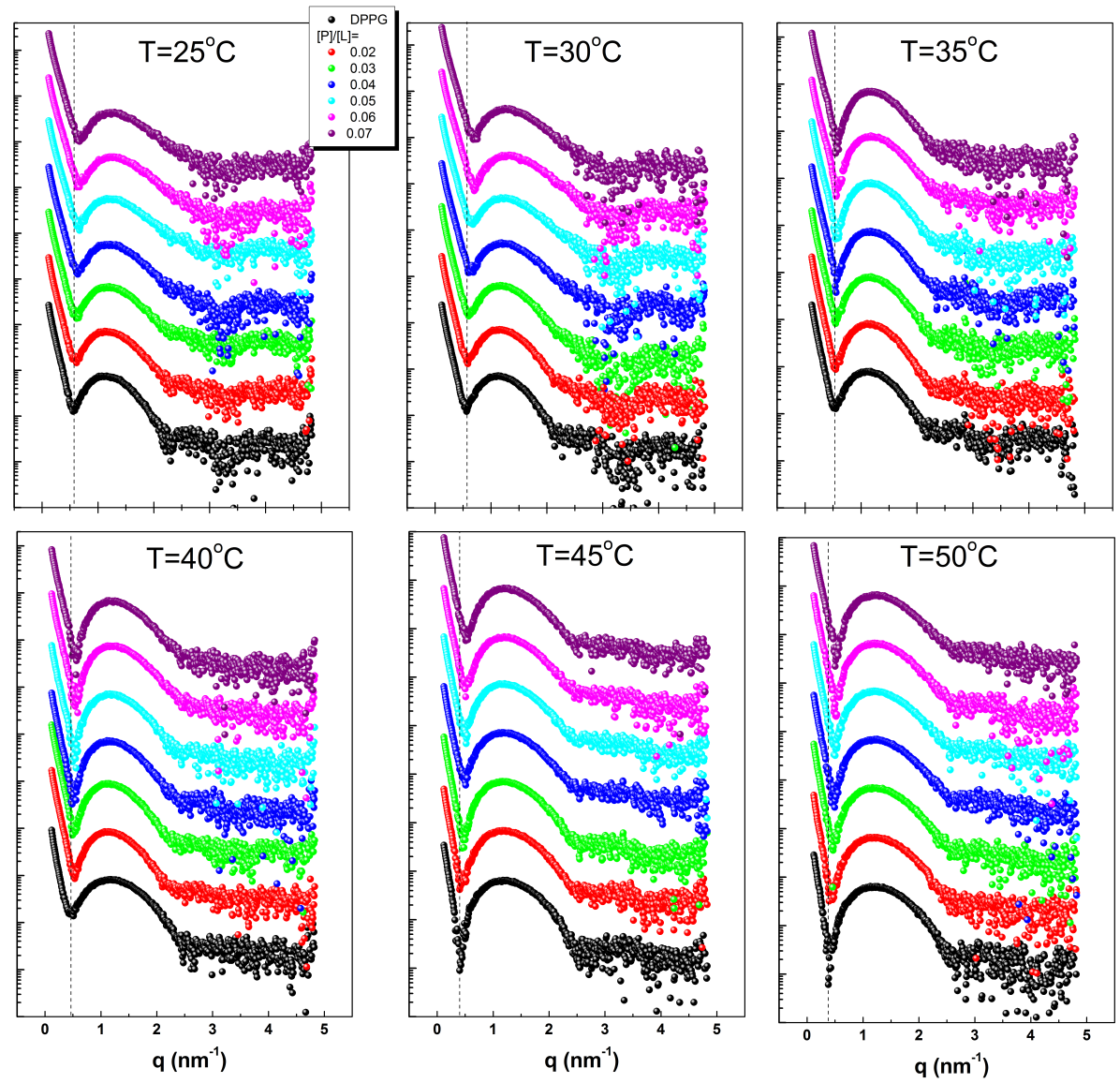

Figura 6.21: Curvas de SAXS obtidas para dispersões lipídicas extrusadas de DPPG em ausência e com o aumento da concentração de peptídeo, $[\mathrm{P}] /[\mathrm{L}]=0.00,0.02,0.03,0.04,0.05,0.06$ e 0.07 , e para diferentes temperaturas, $T=25,30,35,40,45$ e $50^{\circ} \mathrm{C}$.

por DPPC:DPPG na ausência de peptídeo (curvas pretas), e aumentando a concentração de peptídeo para as temperaturas $T=25,30,35,40,45$ e $50^{\circ} \mathrm{C}$.

Para a mistura, DPPC:DPPG, em ausência de peptídeo, as curvas de espalhamento são curvas características de LUVs. Para as temperaturas $\mathrm{T}=25,30$ (fase gel), 35 e $40^{\circ} \mathrm{C}$ (evento térmicos e transição de fase), observamos que as curvas de SAXS em presença de peptídeo que também são curvas características de LUVs, ou seja, compostas apenas por um fator de forma.

Para a fase fluida da mistura, e baixas concentrações de peptídeo $[\mathrm{P}] /[\mathrm{L}]=0.02$ e 0.03 , novamente observamos LUVs, enquanto que para $[\mathrm{P}] /[\mathrm{L}]=0.04,0.05,0.06$ e 0.07 observamos um pico de interferência como previamente reportado para o DPPC. A seta ilustrada no último painel indica a posição do pico relacionado a um fator de estrutura.

Em presença de peptídeo as curvas de espalhamento (fator de forma) também se deslocam gradativamente com o aumento da concentração de peptídeo para maiores valores de $q$, e tais deslocamentos são comparativamente maiores dos observados em DPPG. 

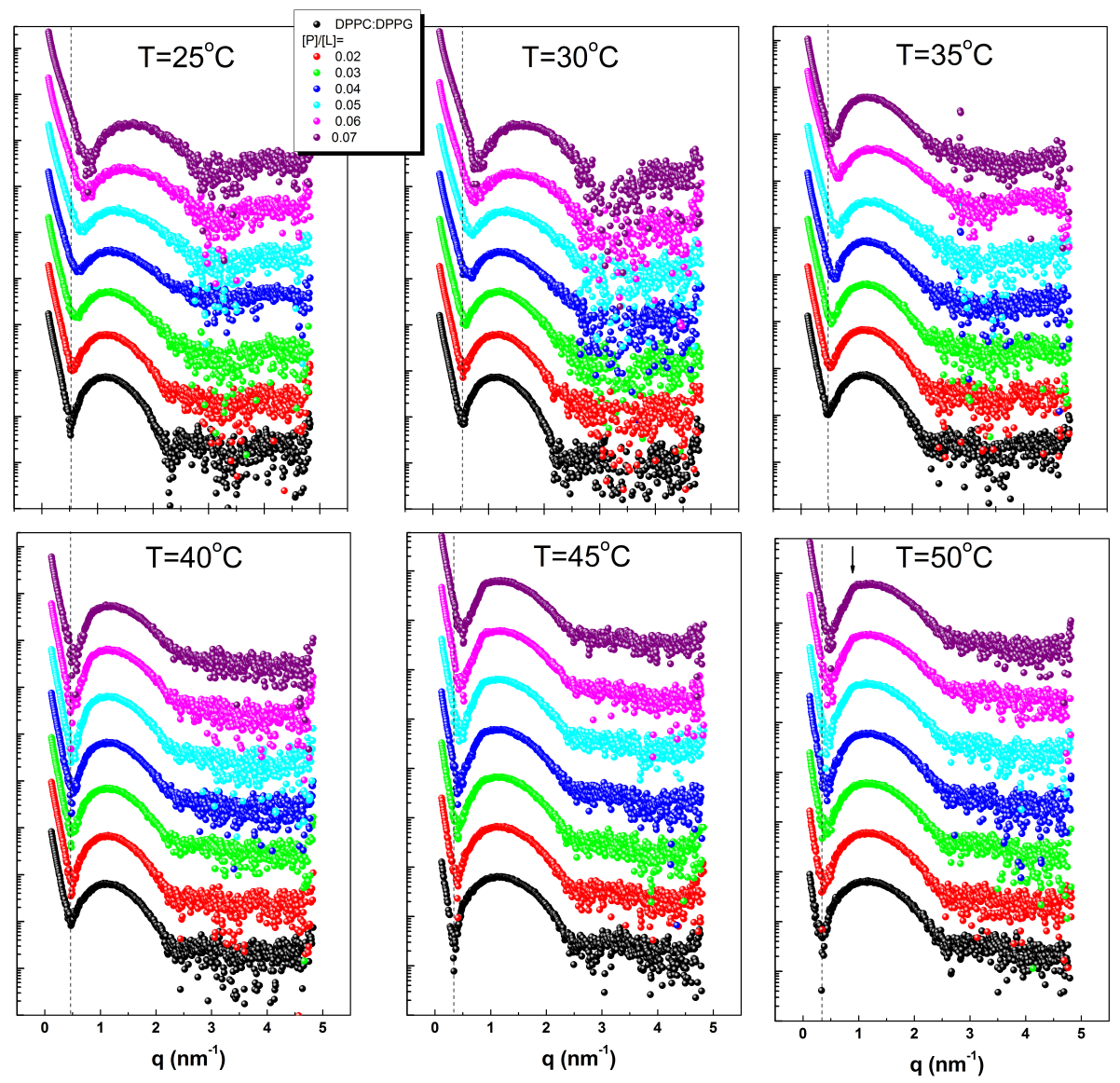

Figura 6.22: Curvas de SAXS obtidas para dispersões lipídicas extrusadas de DPPC:DPPG em ausência e com o aumento da concentração de peptídeo, $[\mathrm{P}] /[\mathrm{L}]=0.00,0.02,0.03,0.04,0.05,0.06$ e 0.07, e para diferentes temperaturas, $T=25,30,35,40,45$ e $50^{\circ} \mathrm{C}$.

A Figura 6.23 mostra um exemplo comparando os deslocamentos das curvas de espalhamento para as vesículas de DPPC, DPPG e DPPC:DPPG em $\mathrm{T}=30^{\circ} \mathrm{C}$. Nesta figura, mostramos uma ampliação da região próxima ao mínimo do fator de forma (indicado pela linha vertical das figuras anteriores). Comparando as curvas de espalhamento para lipossomos compostos por lipídios aniônicos na ausência e presença de peptídeo, podemos observar um gradual deslocamento das curvas de SAXS para maiores valores de $q$ com o aumento da concentração de peptídeo. Para vesículas neutras, DPPC, os efeitos de deslocamento são menores o que torna a analise visual da curva difícil de ser interpretada.

Os deslocamentos para a mistura DPPC:DPPG em presença de peptídeo são maiores que os observados para nas dispersões de DPPG, como mencionado anteriormente, e o mesmo efeito também é observado na fase fluida desses lipídios. Contudo, tais deslocamentos, na fase fluida, são menores que seus respectivos deslocamentos na fase gel. De modo análogo ao DPPC na fase gel, os deslocamentos observados na fase fluida do DPPC e em presença de peptídeo são 

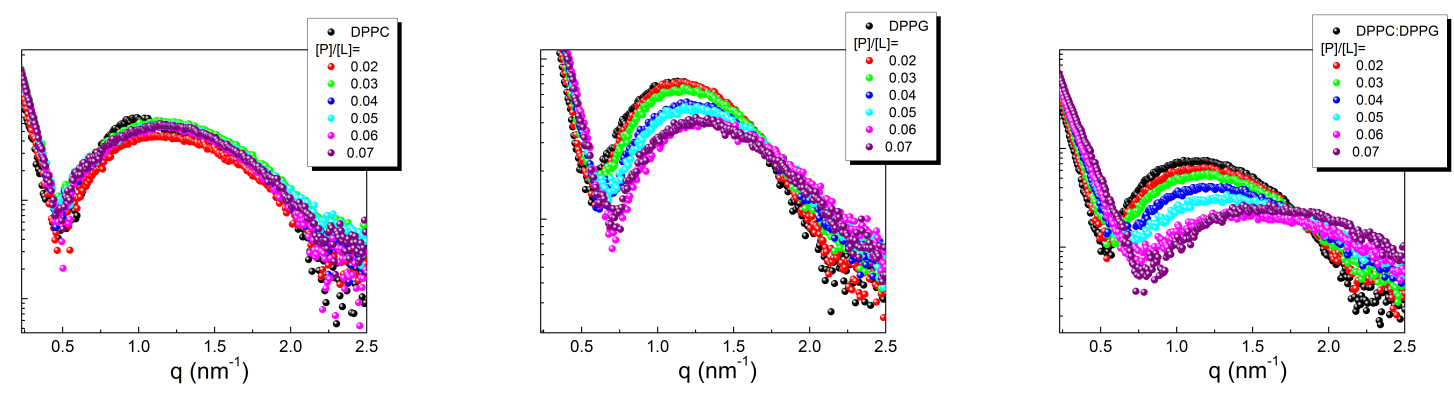

Figura 6.23: Curvas de espalhamento para as vesículas de DPPC, DPPG e DPPC:DPPG em T $=30^{\circ} C$, mostrando uma ampliação da região próxima ao mínimo do fator de forma (indicado pela linha vertical das figuras anteriores).

menores e difícil de serem detectados apenas por esta análise visual.

O fator de interferência que surge nas curvas de espalhamento dos lipossomos neutros, DPPC, na fase fluida e razões molares $[\mathrm{P}] /[\mathrm{L}]=0.04-0.07$, deve ser proveniente de uma organização que apresenta uma estrutura de repetição. De modo análogo, podemos supor o mesmo para a mistura na fase fluida e para razões molares $[\mathrm{P}] /[\mathrm{L}]=0.05-0.07$.

A Figura 6.24 mostra o exemplo de uma curva de espalhamento para vesículas unilamellares, obtido para o DPPG em ausência de peptídeo, a qual é comparada com curvas obtidas para DPPC na razão molar $[\mathrm{P}] /[\mathrm{L}]=0.07, \mathrm{~T}=50^{\circ} \mathrm{C}$. A Figura 6.24 está representada na escala logarítmica $(\log / \log )$, onde torna-se mais evidente a diferença entre as curvas, podendo esta diferença ser devido a uma nova estrutura de repetição, conforme indicam as setas na figura.

Além disso, podemos supor que a curva de espalhamento de DPPC razão molar $[\mathrm{P}] /[\mathrm{L}]=$ 0.02 pode ser aproximada a contribuição do fator de forma para dispersões lipídicas neutras em presença de peptídeo. Visto que a intensidade de espalhamento é dada pela equação 6.4. Podemos, então, estimar a contribuição do fator de estrutura, segundo a relação.

$$
S(q) \sim I(q) / P(q)
$$

Considerando, por exemplo, a curva de espalhamento de DPPC com razão molar $[\mathrm{P}] /[\mathrm{L}]=0.04$ $\left(\mathrm{T}=50^{\circ} \mathrm{C}\right)$, a qual apresenta a contribuição dos fatores de forma e estrutura, podemos então, dividi-la pelo fator de forma (aqui aproximado à curva de DPPC com $[\mathrm{P}] /[\mathrm{L}]=0.02$ ), para obter a contribuição do fator de estrutura.

A Figura 6.25 mostra o resultado desta divisão, onde podemos observar picos de interferência em q=0.704 (primeira ordem) e q=1.398 (segunda ordem). Isso leva a uma distância de repetição equivalente a $\mathrm{d}=9 \mathrm{~nm}$. A distância de repetição d, para sistemas multilamelares, é dada pela soma da espessura da bicamada e a espessura de camadas de água que separam as 


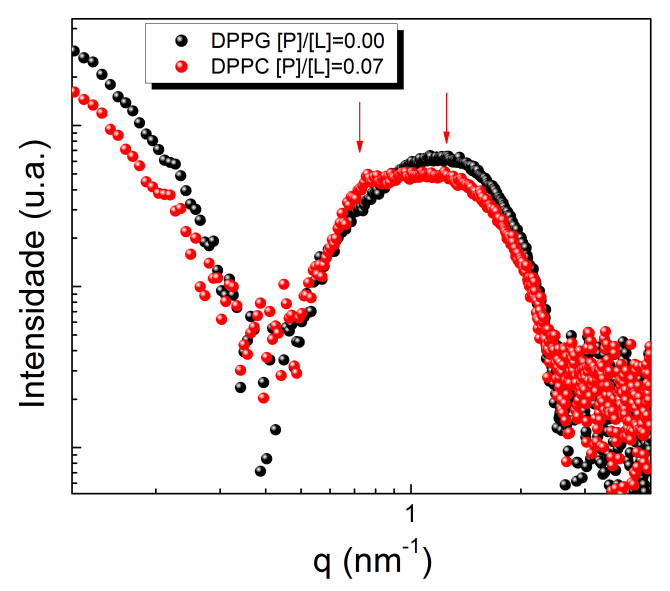

Figura 6.24: Comparação entre a curva de SAXS obtida para o DPPG em ausência de peptídeo exibindo um perfil de vesículas unilamelares e a curva obtida para o DPPC com razão molar $[\mathrm{P}] /[\mathrm{L}]=0.07$. As curvas são representadas em escala log-log e as setas apontam possível evidencia de uma estrutura de repetição.

multilamelas. Comparando a distância de repetição encontrada na ausência de peptídeo, DPPC na fase fluida, $\mathrm{d}=6.7 \mathrm{~nm}$ (Figura 6.18), e em presença de peptídeo $\mathrm{d}=9 \mathrm{~nm}$, podemos observar uma distância de repetição maior para vesículas em presença de peptídeo. Esse aumento da distância de repetição entre lamelas, em presença de peptídeo, pode sugerir que o peptídeo encontra-se na superfície da membrana aumentando a distância de separação entre bicamadas.

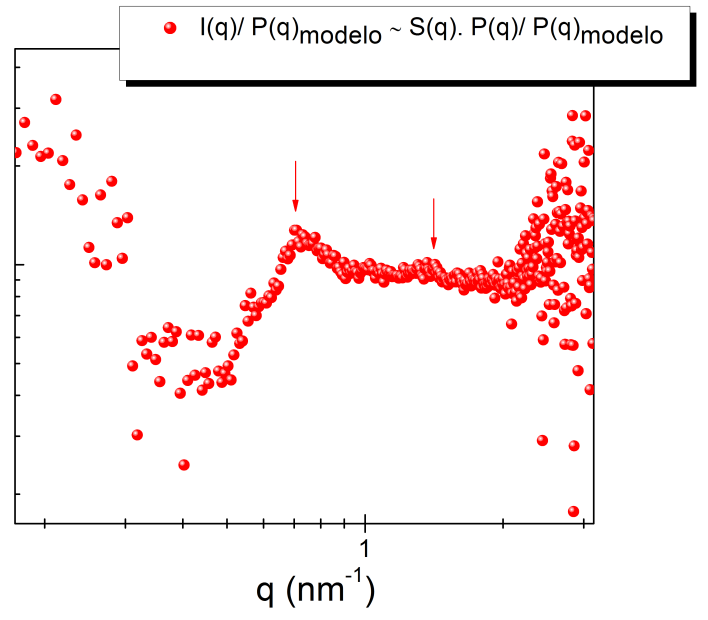

Figura 6.25: Intensidade de espalhamento dividida pelo fator de forma (curva aproximada à curva de DPPC com $[\mathrm{P}] /[\mathrm{L}]=0.02)$.

Curiosamente, similar fator de interferência também ocorre em vesículas de DPPC:DPPG, 
para altas concentrações de peptídeo, $[\mathrm{P}] /[\mathrm{L}]=0.05-0.07$. Novamente, a distância de repetição observada em presença de peptídeo é maior que a esperada em ausência de peptídeo (comparado ao DPPC na fase fluida). Esse resultado pode sugerir que para altas concentrações de peptídeo, o peptídeo também pode ser encontrado na superfície da membrana.

\subsubsection{Vesículas não extrusadas em presença de peptídeo}

Para melhor investigar o fator de estrutura observado no DPPC e na mistura, também preparamos dispersões lipídicas não extrusadas. Os filmes lipídicos foram preparados como descrito na seção 6.2.3, onde o tampão utilizado para suspender o filme lipídico já continha a quantidade desejada de peptídeo. Deste modo, nesta preparação, o peptídeo tem acesso tanto a camada externa, quanto a camada interna dos lipossomos, diferente da preparação com vesículas extrusadas onde o peptídeo é adicionado após a formação dos lipossomos.

A Figura 6.26 mostra as curvas de espalhamento para vesículas não extrusadas em ausência (controle), e presença de peptídeo. Nesses experimentos coletamos apenas duas razões molares, $[\mathrm{P}] /[\mathrm{L}]=0.02$ e 0.05 e duas temperaturas, $T=30^{\circ} \mathrm{C}$ e $\mathrm{T}=45^{\circ} \mathrm{C}$, fase gel e fluida dos lipídios.

Observamos que em presença de peptídeo não há formação de estruturas MLVs com alta ordem de repetição como observado, por exemplo, para o DPPC na ausência de peptídeo (curva preta primeiro painel).

De modo análogo ao observado nos resultados com vesículas extrusadas, para o DPPC, e baixa concentração de peptídeo $[\mathrm{P}] /[\mathrm{L}]=0.02$, observamos curvas de espalhamento características de LUVs, para a fase gel e fluida, assim como para $[\mathrm{P}] /[\mathrm{L}]=0.05$ na fase gel. Novamente, para $[\mathrm{P}] /[\mathrm{L}]=0.05$, na fase fluida observamos a contribuição de um fator de estrutura que pode sugerir uma estrutura de repetição de baixa ordem, como discutido na seção anterior.

Para as dispersões aniônicas de DPPG observamos curvas de espalhamento de vesículas unilamelares em ausência e presença de peptídeo, e semelhante ao discutido para vesículas extrusadas, as curvas são deslocadas para maiores valores de $q$ com o aumento da concentração de peptídeo. Novamente, esse efeito é maior na fase gel do que na fase fluida.

Para a mistura, na fase gel também foi observado efeito semelhante ao DPPG na fase gel e também análogo as dispersões lipídicas mistas e extrusadas como discutido anteriormente. Embora menos evidente, para a fase fluida da mistura $[\mathrm{P}] /[\mathrm{L}]=0.05$ também é observado um pico possivelmente proveniente de um fator de estrutura, como observado para o DPPC não extrusado em presença de peptídeo $[\mathrm{P}] /[\mathrm{L}]=0.05$, e como antes discutido para a mistura extru- 

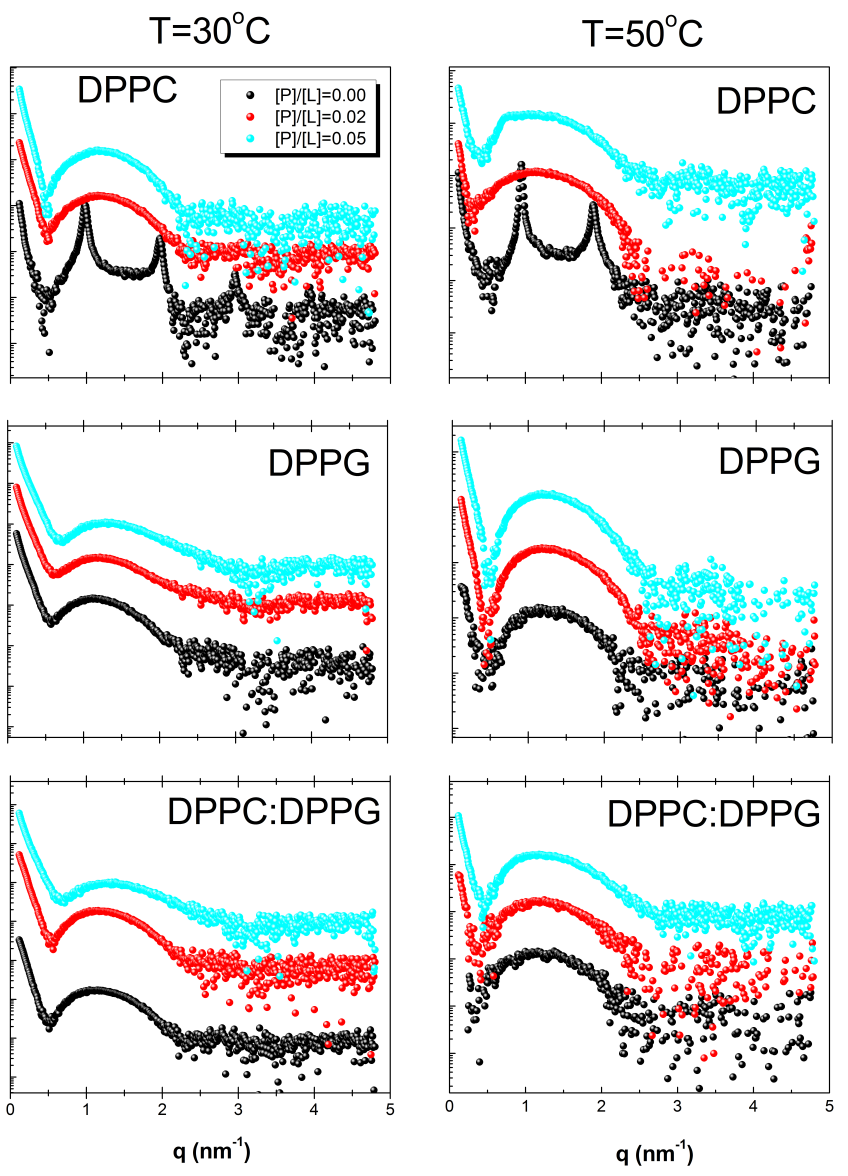

Figura 6.26: Curvas de SAXS obtidas para dispersões lipídicas não extrusadas de DPPC, DPPG, e DPPC:DPPG em ausência e com o aumento da concentração de peptídeo, $[\mathrm{P}] /[\mathrm{L}]=0.00,0.02$ e 0.05, e para diferentes temperaturas, $T=30$ e $50^{\circ} \mathrm{C}$.

sadas.

Em resumo, realizamos de duas preparações diferentes: (i) vesículas extrusadas com adição do peptídeo externamente aos lipossomos, e (ii) vesículas não extrusadas com peptídeos no meio interno e externo dos lipossomos. Para ambas preparações obtivemos resultados semelhantes. Logo, podemos sugerir que no primeiro caso, (i) os peptídeos podem atravessar a membrana e também interagir com a camada interna da membrana, conforme ocorre no segundo caso (ii).

Os resultados de microscopia óptica apresentados no capítulo 4, seção 4.3.6 também mostram que o peptídeo pode atravessar a membrana. A Figura 4.14 (A) (capítulo 4) mostra uma vesícula gigante dentro de outra, onde nos primeiros segundos de contato com o peptídeo a GUVs externa perde o contraste, e após poucos segundos a vesículas contida no interior da primeira também perde o contraste.

Os autores (Yandek et al., 2007) discutem que a ligação do peptídeo na membrana pode provocar grande mudança na curvatura da camada externa, comparada a camada interna, e tal 
deformação acaba facilitando a travessia do peptídeo para a monocamada interna.

Visto que as curvas apresentadas nas seções 6.4 .2 e 6.4 .3 são semelhantes, focaremos nossas análises nas curvas obtidas para vesículas extrusadas, em acordo com os resultados de DSC, seção 4.3.1, capítulo 4 .

\subsubsection{Análises preliminares das curvas de SAXS}

A seguir mostramos algumas análises preliminares obtidas dos dados de SAXS, para vesículas extrusadas. Aqui, utilizamos o programa GIFT para ajustar as curvas de espalhamento, obtendo a função $\mathrm{p}(\mathrm{r})$ e com o uso do programa DECON, a $p(r)$ a é deconvoluida na função de densidade eletrônica, conforme ilustra a Figura 6.31 (ver capítulo 2, seção 2.11). As curvas de espalhamento que contém contribuições de um fator de forma e um fator de estrutura ainda não foram analisadas.

\section{DPPC}

A Figura 6.27 mostra os ajustes obtidos para as curvas das dispersões lipídicas de DPPC em ausência de peptídeo e com o aumento da concentração de peptídeo, $[\mathrm{P}] /[\mathrm{L}]=0.02,0.03$, 0.04, 0.05 e 0.07 , na fase gel, $T=30^{\circ} \mathrm{C}$.
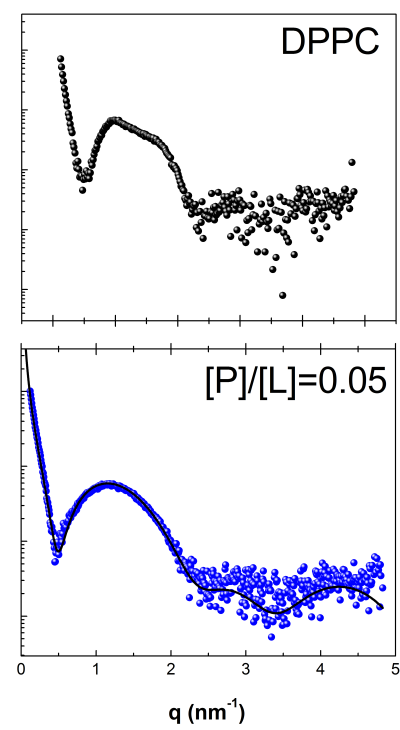
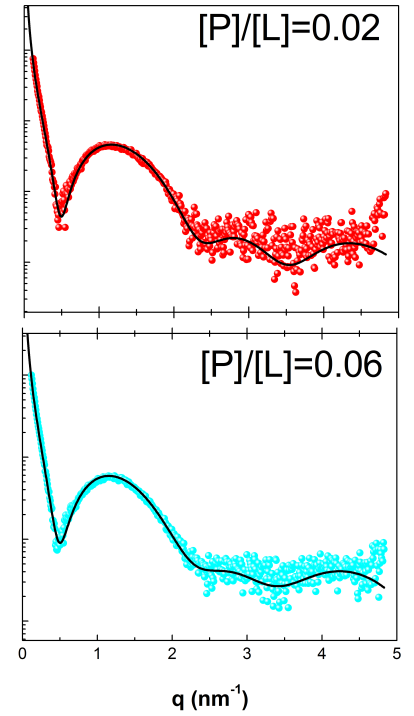
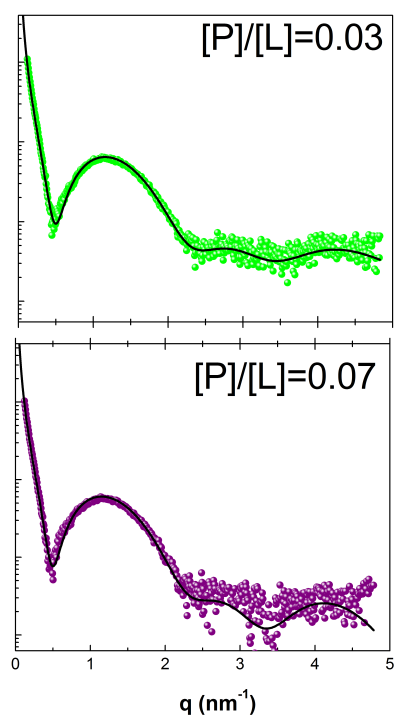

Figura 6.27: Exemplos dos ajustes para as curvas de SAXS obtidas para o DPPC em presença de peptídeo, nas razões molares $[\mathrm{P}] /[\mathrm{L}]=0.02,0.03,0.05,0.06$ e 0.07 para $\mathrm{T}=30^{\circ} C$, fase gel do lipídio. $\mathrm{O}$ primeiro painel ilustra a curva de espalhamento do DPPC em ausência de peptídeo, que além do fator de forma apresenta também um fator de estrutura. 
Para a fase fluida, a Figura 6.28 mostra as curvas de espalhamento para o DPPC em ausência de peptídeo e para as concentrações $[\mathrm{P}] /[\mathrm{L}]=0.02$ e 0.03 pois o fator de estrutura que surge em altas concentrações de peptídeo ainda não modelado.
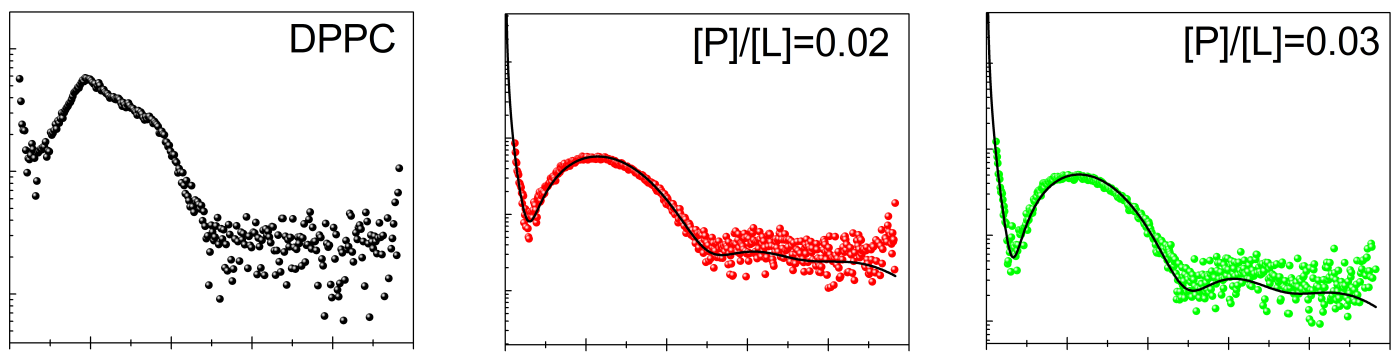

Figura 6.28: Exemplos dos ajustes para as curvas de SAXS obtidas para o DPPC em presença de peptídeo, nas razões molares $[\mathrm{P}] /[\mathrm{L}]=0.02$ e 0.03 para $\mathrm{T}=45^{\circ} C$, fase gel do lipídio. O primeiro painel ilustra a curva de espalhamento do DPPC em ausência de peptídeo, que além do fator de forma apresenta fator de estrutura. O ajuste dessa curva foi previamente apresentado na Figura 6.20 (D). 


\section{DPPG}

As Figuras 6.29 e 6.30 mostram os ajustes obtidos para as curvas das dispersões lipídicas de DPPG, com o aumento da concentração de peptídeo, $[\mathrm{P}] /[\mathrm{L}]=0,0.02,0.03,0.04,0.05,0.06$ e 0.07, e para as temperaturas, $\mathrm{T}=30$ e $45^{\circ} C$, fases gel e fluida do lipídio.
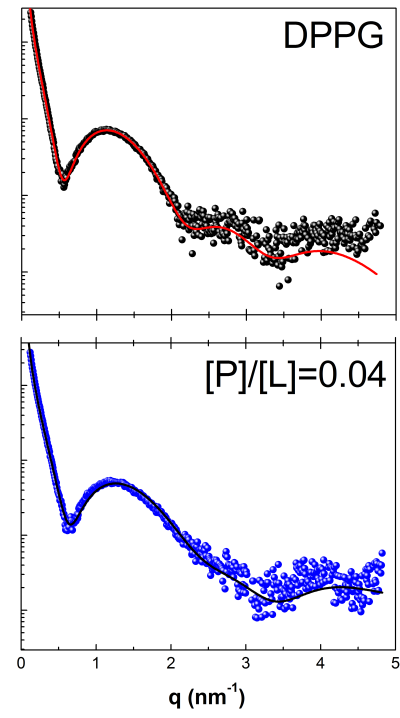
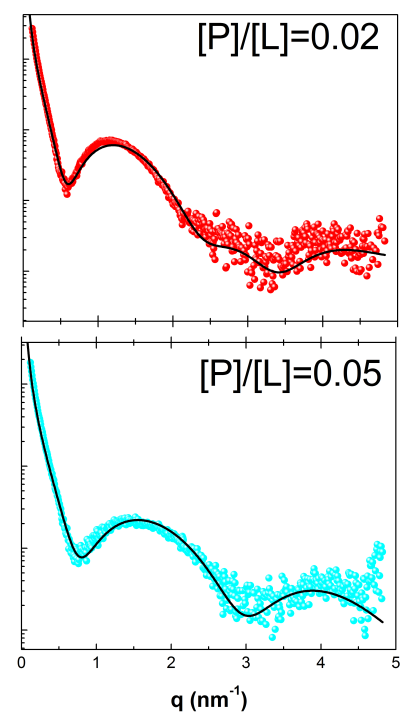
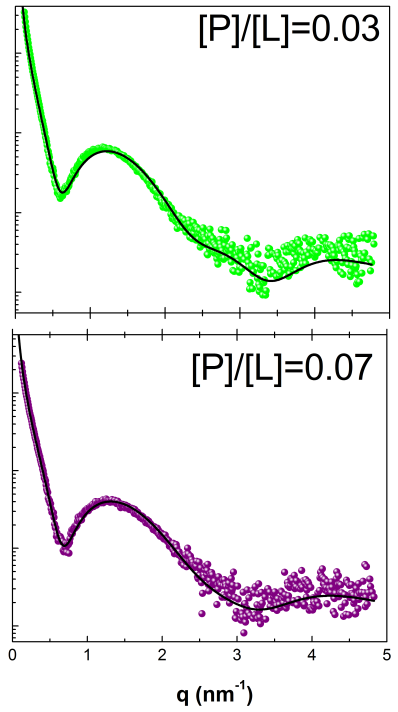

Figura 6.29: Exemplos dos ajustes para as curvas de SAXS obtidas para o DPPG em ausência e presença de peptídeo, nas razões molares $[\mathrm{P}] /[\mathrm{L}]=0.02,0.03,0.04,0.05$ e 0.07 para $\mathrm{T}=30^{\circ} C$, fase gel do lipídio.

Embora temos analisado algumas curvas de DPPC:DPPG, observamos que os resultados analisados ainda precisam ser melhor trabalhados, pois os modelos simplórios que estamos utilizando não são suficiente para a complexidade da mistura.

A Figura 6.31 mostra o perfil de densidade eletrônica para as curvas que foram ajustadas apenas com o fator de forma, utilizando os programas GIFT e DECON. No perfil de densidade eletrônica temos que o grupo fosfato apresenta densidade eletrônica maior que os hidrocarbonetos $\left(-\mathrm{CH}_{2}\right)$, enquanto o grupo $\mathrm{CH}_{3}$ apresenta densidade eletrônica ligeiramente menor que o $\mathrm{CH}_{2}$.

A Tabela 6.1 resume os valores encontrados para a espessura da bicamada, distância entre as cabeças polares, $d_{h h}$, de acordo com os ajustes obtidos para o DPPC, DPPG e DPPC:DPPG. Os dados foram obtidos a partir da função de densidade eletrônica, distância entre os picos. ${ }^{4}$

Os resultados mostrados na Tabela 6.1 para o DPPC na ausência de peptídeo foram obtidos da literatura (Tristram-Nagle e Nagle, 2004; Leekumjorn e Sum, 2007; Heftberger et al., 2014).

\footnotetext{
${ }^{4}$ Os ajustes das demais curvas apresentadas na seção 6.4 .2 ainda estão em andamento.
} 

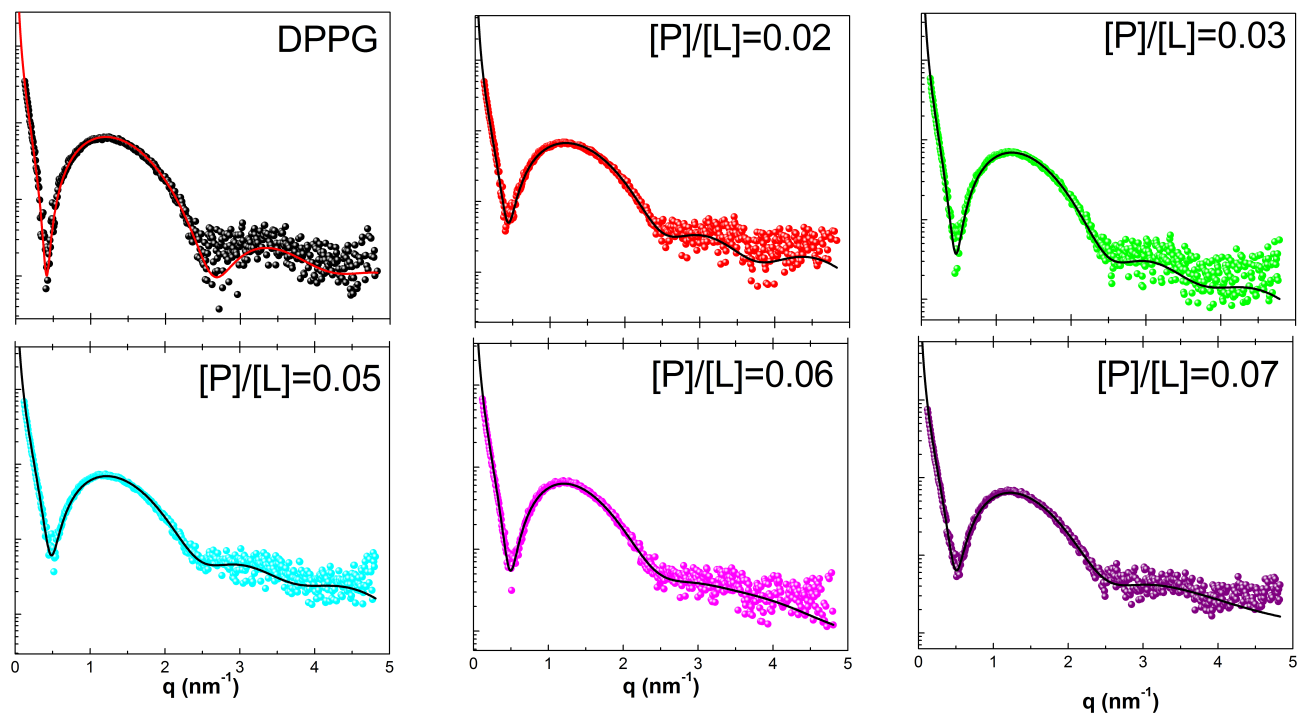

Figura 6.30: Exemplos dos ajustes para as curvas de SAXS obtidas para o DPPG em ausência e presença de peptídeo, nas razões molares $[\mathrm{P}] /[\mathrm{L}]=0.02,0.03,0.05,0.06$ e 0.07 para $\mathrm{T}=45^{\circ} C$, fase fluida do lipídio.
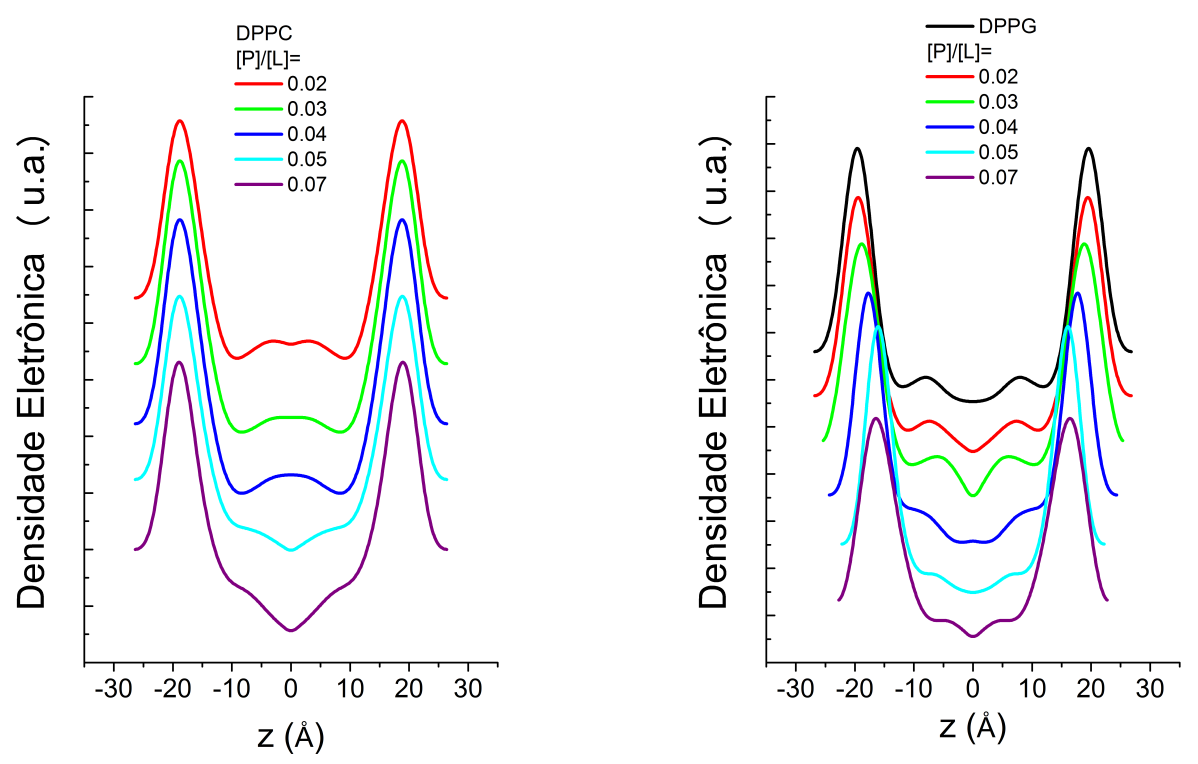

Figura 6.31: Exemplos dos perfis de densidade eletrônica obtidos a partir dos ajustes mostrados na Figura, para o DPPC e DPPG em ausência e presença de peptídeo, para $\mathrm{T}=30^{\circ} \mathrm{C}$, fase gel do lipídio.

Visto que o DPPG tem mesmo número de carbonos que o DPPC, podemos comparar os valores ajustados para $d_{h h}$ de ambos os lipídios e da mistura. Os valores de $d_{h h}$ obtidos dos cálculos, para o DPPG (seção 6.4.4) em ausência de peptídeo estão em acordo com valores da literatura para o DPPC, na fase gel e fluida. 
Espessura das bicamadas

\begin{tabular}{ccccc}
\hline & \multicolumn{2}{c}{$\mathrm{DPPC}$} & \multicolumn{2}{c}{$\mathrm{DPPG}$} \\
\hline$[\mathrm{P}] /[\mathrm{L}]$ & $\mathrm{T}=30^{\circ} C$ & $\mathrm{~T}=50^{\circ} C$ & $\mathrm{~T}=30^{\circ} C$ & $\mathrm{~T}=50^{\circ} C$ \\
& $d_{h h}(\AA)$ & $d_{h h}(\AA)$ & $d_{h h}(\AA)$ & $d_{h h}(\AA)$ \\
0 & $40^{a}$ & $37.9^{b}-38.4^{a}$ & 42.7 & 39.1 \\
0.02 & 37.9 & 38.5 & 38.8 & 37.6 \\
0.03 & 37.6 & 38 & 37 & 37 \\
0.04 & 37.7 & - & 35 & 34 \\
0.05 & 37.6 & - & 32.2 & - \\
0.06 & - & - & - & 33.3 \\
0.07 & 37.9 & - & 32.9 & 33.3 \\
\hline \hline
\end{tabular}

Tabela 6.1: Espessura das bicamadas em presença e com o aumento da concentração de peptídeo KHya1, para $\mathrm{T}=30^{\circ} C$ e $\mathrm{T}=50^{\circ} C$. Valores obtidos da literatura ( ${ }^{a}$ Nagle e Nalge, 2003, Leekumjorn e Sum 2007) e ( ${ }^{b}$ Heftberger et al. 2014)

Para facilitar a comparação dos dados, os valores resumidos na Tabela 6.1 foram graficados na Figura 6.32, onde separamos os resultados de acordo com a fase da bicamada e calculamos a fração relativa de diminuição da espessura da bicamada, comparada a espessura da membrana em ausência de peptídeo. Deste modo, a Figura 6.32 mostra $d_{h h}^{[P] /[L]}$ obtido dos ajustes para diferentes concentrações de peptídeo, dividido por $d_{h h}^{L}$, onde $\mathrm{L}=\mathrm{DPPC}, \mathrm{DPPG}$.
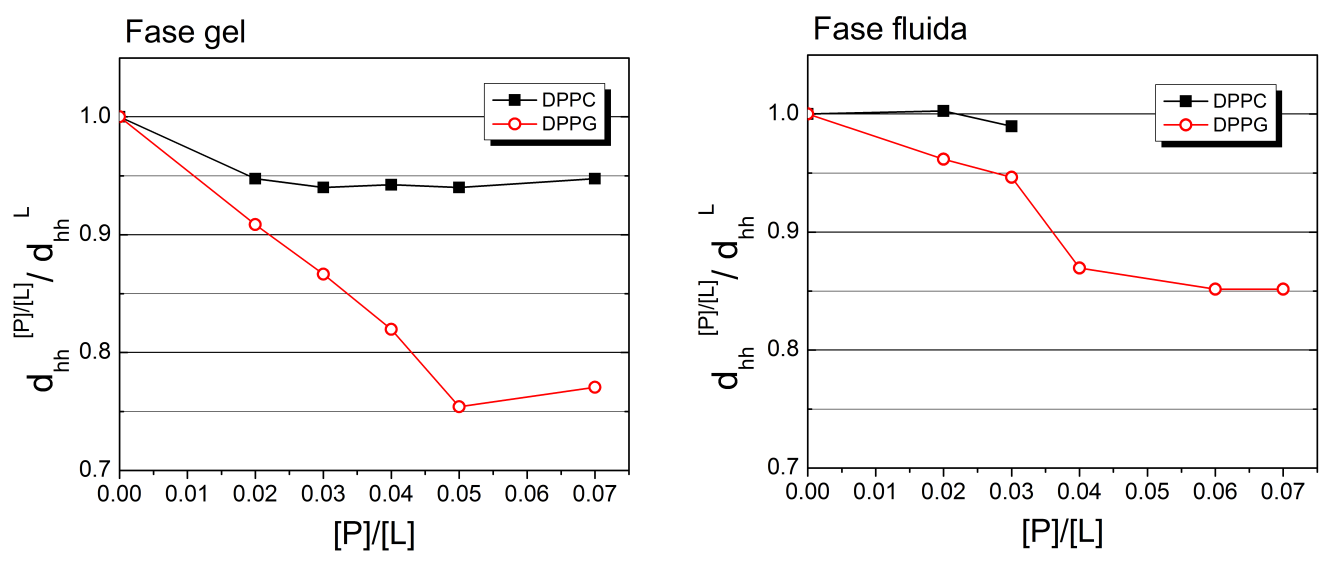

Figura 6.32: Diminuição da espessura da bicamada em presença de peptídeo.

Em geral a diminuição da espessura da bicamada observada em membranas aniônicas (DPPG), com o aumento da concentração de peptídeo, é maior na fase gel do que na fase 
fluida.

Para a mistura DPPC:DPPG, ainda estamos trabalhando nas análises dos dados. ${ }^{5}$ Visto que o peptídeo KHya1 interage preferencialmente com o PG, como mostraram os resultados de DSC, fluorescência do Trp e ESR convém supor que seu efeito na membrana mista também seja semelhante ao DPPG.

Pabst e colaboradores (Pabst et al., 2008) sugerem que o estreitamento da bicamada não está necessariamente relacionado a formação de poros. Neste trabalho, os autores mostram um exemplo de peptídeo antimicrobiano, $\mathrm{PGLa}^{6}$, que forma poros e causa aumento da espessura da bicamada (fase fluida). Neste trabalho, os autores estudaram a interação do PGLa em membrana aniônicas de DMPG, DPPG e DSPG. Os autores reportam resultados por calorimetria diferencial de varredura (DSC) onde tal peptídeo também causa a coexistência de dois picos calorimétricos nos termogramas desses lipídios. Entretanto, o pico calorimétrico que surge da interação do peptídeo com tais membranas ocorre em temperaturas superiores à da transição de fase do lipídio puro, $T_{m}$. Portanto, os autores concluem que tal estiramento da bicamada, observado na fase fluida dos lipídios, depende da relação entre o comprimento do peptídeo e a extensão das cadeias carbônicas.

Em nosso trabalho também observamos a coexistência de dois picos calorimétricos nas curvas de DSC. Entretanto, nossos resultados de DSC mostram que o peptídeo KHya1 causa um evento térmico que ocorre em temperaturas inferiores a temperatura de transição dos lipídios em ausência de peptídeo, $T_{m}$ e afinamento da espessura da bicamada. Logo, os resultados aqui observados são complementares aos observados por Pabst e colaboradores (Pabst et al., 2008), pois o peptídeo KHya1 diminui a espessura da bicamada (SAXS) e causa um evento térmico em temperaturas menores da $T_{m}$ (DSC), e o peptídeo PGLa amenta a espessura da bicamada (SAXS) e causa um evento térmico em temperaturas maiores da $T_{m}$ (DSC).

Semelhante ao proposto por (Pabst et al., 2008), sugerimos que a diminuição da espessura da bicamada causada pelo peptídeo KHya1 também pode depender de seu comprimento, ou ao comprimento dos resíduos que estão em contato com as cadeias carbônicas, comparado ao comprimento das cadeias.

Então, visto que a fase gel é naturalmente mais espessa que a fase fluida, a diferença entre a extensão do peptídeo comparada a espessura da bicamada pode ser maior na fase gel. Deste

\footnotetext{
${ }^{5}$ Os resultados de SAXS são relativamente recentes, foram coletados no LNLS em Junho de 2015

${ }^{6}$ PGLa: GMASKAGAIAGKIAKVLKL- $\mathrm{NH}_{2}$, peptídeo da família da magainina a qual foi originalmente isolado da pele do sapo africano, Xenopus laevis
} 
modo, o peptídeo causa maior estreitamento da fase gel para casar sua extensão com a espessura da membrana, o que torna esse efeito menor na fase fluida.

Além disso, o estreitamento da espessura da bicamada causado pelo peptídeo KHya1 pode levar a membrana se romper causando poros, como visto e sugerido por outras técnicas experimentais, capítulo 4 e 5 .

Também podemos observar que na fase gel do DPPC também há estreitamento da bicamada, mas esse não depende da concentração de peptídeo, ou seja, o aumento da concentração de peptídeo não altera mais espessura da bicamada.

\subsection{Considerações gerais}

Como discutido anteriormente, os resultados apresentados no capítulo 4 sugerem que o peptídeo KHya1 pode ser localizado em posições diferentes em membrana neutra e aniônicas/ mistas. Em membranas neutras o peptídeo pode ser encontrado preferencialmente na superfície da bicamada, enquanto em membranas compostas por lipídios negativos, o peptídeo pode estar atravessando a membrana e em contato com as cadeias carbônicas.

Os resultados de ESR aqui apresentados confirmam que o peptídeo antimicrobiano KHya1 encontra-se próximo à superfície da membrana neutra, DPPC, enquanto em vesículas aniônicas (DPPG), o peptídeo está inserido na posição transversal da bicamada.

Adicionalmente, podemos retomar uma discussão apresentada no capítulo 4 que pode estar relacionada ao estreitamento da espessura da bicamada. Como sugerido no modelo apresentado no capítulo 4, as cargas positivas dos resíduos nas extremidades do peptídeo podem interagir com os grupos PG, estabilizado o peptídeo na vertical. Além disso, o peptídeo pode ser ancorado pelos resíduos Trp na posição 7 e um resíduo carregado, Lys, na posição, 15 (ou pelos resíduos Phe na posição 3 e a Lys15). Entretanto, esta Lys na posição 15 e localizada próxima a interface polar e apolar tende buscar a superfície e causar o estreitamento da membrana, conforme ilustra o esquema da Figura 6.33 (previamente apresentada no capítulo 4).

Para o DPPC também foi observado estreitamento da membrana (principalmente na fase gel), e este também pode sugerir o peptídeo em uma posição transversal como discutido acima. Entretanto, os resultados de DSC e ESR sugerem que o peptídeo encontra-se preferencialmente próximo a superfície de membranas neutras. Neste caso, é possível que uma pequena fração de peptídeo procure atravessar a membrana de modo análogo ao proposto em vesículas aniônicas, mas essa posição do peptídeo em DPPC pode não ser tão estável, quanto o é em presença de 


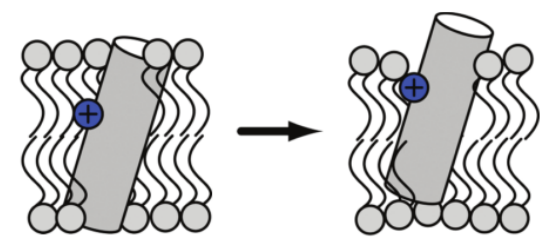

Figura 6.33: Figura esquemática e obtida da referência Vostrikov et. al. 2010 (adaptada) para ilustrar que o peptídeo pode causar o estreitamento da bicamada na tentativa de seu resíduo positivo buscar a superfície ("snorkeling").

PG. Conforme sugerido no capítulo 4, a exposição das cargas positivas do peptídeo ao solvente pode desestabiliza-lo na posição transversal, sendo mais favorável que ele ocupe a superfície das membranas neutras.

Também é importante observar que os sinais paramagnético da sonda 5PCSL e 16PCSL são diferentes na fase gel, para os lipídios DPPC, DPPG e DPPC:DPPG. Esse resultado indica que o estreitamento da bicamada observado por SAXS não pode ser atribuído a interdigitação das cadeias.

\subsection{Conclusões}

Os resultados de ESR, para vesículas compostas por lipídios aniônicos, mostraram que o aumento da concentração do peptídeo leva ao aumento do grau de empacotamento da membrana, tanto na região do carbono 5 quanto na região do carbono 16, e para as fases gel e fluida da membrana. Esse resultado comprova que o peptídeo está localizado na posição transversal da membrana aumentando o empacotamento lateral da bicamada.

Por outro lado, os resultados de ESR, para vesículas neutras, mostraram que o peptídeo causa o aumento do empacotamento ou da ordem da membrana na região do carbono 5, e causa pequenas perturbações na região do carbono 16, para as fases gel e fluida. Esse resultado sugere que o peptídeo pode estar localizado próximo à superfície.

Os resultados de SAXS mostram que o peptídeo causa o estreitamento das vesículas compostas por lipídios aniônicos (DPPG). Esses efeitos são maiores na fase gel que na fase fluida porque a diferença entre a extensão do peptídeo e a espessura da bicamada é maior na fase gel. Embora também foi observado pequeno estreitamento para o DPPC na fase gel este não aumenta com a concentração de peptídeo. Na fase fluida do DPPC em presença de peptídeo $[\mathrm{P}] /[\mathrm{L}]=0.04-0.07$, assim como para a mistura na fase fluida e $[\mathrm{P}] /[\mathrm{L}]=0.05-0.07$, foram ob- 
servados um fator de interferência possivelmente causado por uma nova ordem de repetição fracamente correlacionada. Esse resultado sugere que o peptídeo pode induzir a formação de MLVs, com distância de repetição entre lamelas maiores das observadas na ausência de peptídeo, sugerindo que o peptídeo pode ocupar a superfície da membrana. Curiosamente, efeito semelhante também é observado em vesículas de DPPC:DPPG, fase fluida e $[\mathrm{P}] /[\mathrm{L}]=0.05-0.07$, o que pode indicar que o peptídeo também poderia ser encontrado na superfície da membrana para as mais altas concentrações de peptídeo.

Os resultados aqui apresentados corroboram os resultados do capítulos 4, reforçando o modelo que o peptídeo KHya1, encontra-se na posição transversal em membranas aniônicas e preferencialmente na superfície de membranas neutras. Na mistura, o peptídeo interage preferencialmente com o grupo PG, mas para altas concentrações de peptídeo, pode haver um aumento da partição do peptídeo em PC. Os diferentes efeitos que o peptídeo antimicrobiano KHyal causa em membranas neutras ou aniônicas pode ser uma consequência direta de sua posição na membrana. 


\section{Capítulo 7}

\section{Conclusões}

Esse trabalho mostra diferentes interações do peptídeo antimicrobiano KHya1 com membranas neutras, e membranas negativamente carregadas. As diferenças na interação do peptídeo com membranas modelo foram mostradas por diversas técnicas experimentais: calorimetria diferencial de varredura (DSC), fluorescência estática e temporal, utilizando a sonda natural do peptídeo (Trp) e sonda extrínseca de bicamada (Laurdan), por vazamento de sonda fluorescente encapsulada, espalhamento de luz dinâmico, microscopia óptica, ressonância paramagnética eletrônica (ESR) e espalhamento de raios-X a baixo ângulo (SAXS). A seguir resumimos as principais diferenças observadas de acordo com a composição lipídica.

\section{DPPC}

Observamos que em membranas neutras o peptídeo KHya1 causa uma perturbação média na membrana, diminuindo a cooperatividade dos lipídios ao longo da transição de fase (DSC), de modo a sugerir que o peptídeo pode se difundir na membrana, estando pouco ancorado à superfície da mesma, possivelmente, ocupando uma posição mais próxima à superfície.

A fluorescência estática do Trp em membranas neutras mostrou que a interação do peptídeo com a membrana depende da temperatura, e, portanto, da fase da bicamada, sendo que na fase fluida pode haver mais peptídeos ligados à membrana e/ou os peptídeos podem inserir-se em regiões mais apolares da bicamada.

Experimentos de vazamento de sonda fluorescente encapsulada por lipossomos mostram que o peptídeo também causa vazamento em membranas neutras, mas, a partir de $[\mathrm{P}] /[\mathrm{L}]=0.04$, a porcentagem de vazamento final cresce muito lentamente com a concentração de peptídeo. As cinéticas de vazamento também mostraram uma resposta de vazamento mais lenta, comparada 
ao observado em vesículas aniônicas. A microscopia óptica também observou perda de contraste de GUVs, e, diferentemente do observado em vesículas aniônicas, não foi visto formação de grandes poros e destruição dos lipossomos. Deste modo, o vazamento em membranas neutras pode ser devido à inserção/ difusão do peptídeo próximo à superfície, causando defeitos na bicamada e aumentando a permeabilidade da membrana.

Os resultados de ESR mostraram que o peptídeo causa o aumento do empacotamento da membrana na região do carbono 5, e causa pequenas perturbações na região do carbono 16 , para as fases gel e fluida, corroborando a hipótese do peptídeo localizar-se na superfície da membrana.

Os resultados de SAXS também mostraram que a interação do peptídeo com a membrana neutra depende da temperatura, ou fase de bicamada, em acordo com a fluorescência estática do Trp. Além disso, o peptídeo causa pequeno estreitamento na membrana (fase gel principalmente), mas esse efeito não cresce com o aumento da concentração de peptídeo. Na fase gel e altas concentrações de peptídeo, foi observado um fator de estrutura que pode estar relacionado à formação de $\mathrm{MLVs}^{1}$

Portanto, reunindo os resultados aqui apresentados, podemos sugerir que o peptídeo pode estar localizado próximo à superfície, conforme ilustra a Figura 7.1.

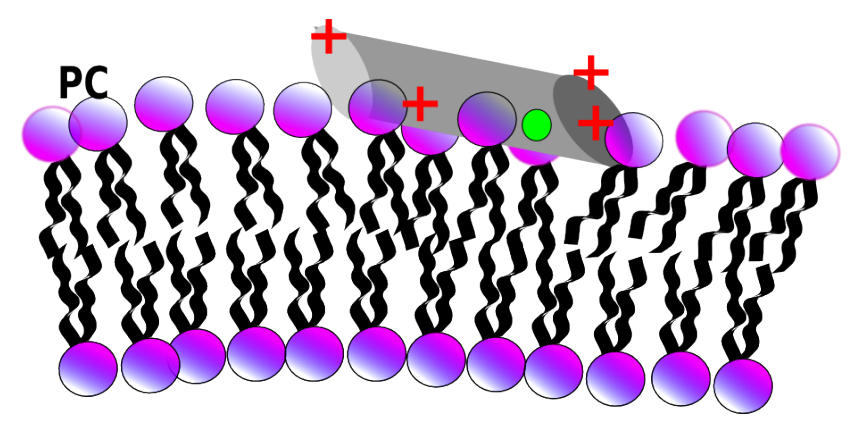

Figura 7.1: Modelo para interação do peptídeo antimicrobiano com membranas neutras de DPPC.

\section{DPPG e DPPC:DPPG}

Em membranas compostas por lipídios aniônicos, os resultados de DSC sugerem que a bicamada pode ser composta por duas regiões distintas, uma perturbada pelo peptídeo e outra isenta de sua ação (bulk bilayer). A difusão lenta do peptídeo, de modo a preservar as duas

\footnotetext{
${ }^{1}$ Esses resultados ainda estão sob investigação.
} 
regiões distintas na membrana, sugere que o peptídeo deve estar fortemente ancorado na bicamada.

Neste caso, o peptídeo pode estar, por exemplo, em uma posição transmembranar, onde o Trp (resíduo na posição 7) encontra-se em um ambiente bastante apolar, de acordo com a fluorescência estática do Trp.

As cinéticas de vazamento mostram um abrupto vazamento da sonda encapsulada pelos lipossomos nos primeiros instantes da interação do peptídeo com membranas aniônicas. Para a mistura, as cinéticas de vazamento podem assumir um comportamento híbrido do aqui mencionado e do observado para vesículas neutras. Além disso, o vazamento causado pelo peptídeo é maior na mistura. Esse efeito pode ser consequência da maior razão molar peptídeo-PG, e/ou o peptídeo pode causar a segregação de lipídios aniônicos modificando a permeabilidade da membrana.

A microscopia óptica mostrou que o peptídeo KHya1 pode fazer grandes poros em membranas mistas (PC:PG). A formação de poros também concorda com os resultados de DSC.

Para vesículas aniônicas (apenas DPPG neste caso), a fluorescência estática do Laurdan mostrou que o peptídeo causa o aumento do grau de empacotamento da bicamada. Além disso, estudos de FRET entre o peptídeo e o Laurdan também podem sugerir a formação de poros em vesículas aniônicas.

Os resultados de ESR, para vesículas compostas por lipídios aniônicos, mostraram que o aumento da concentração do peptídeo leva ao aumento do grau de empacotamento da membrana, tanto na região do carbono 5 quanto na região do carbono 16, e para as fases gel e fluida da membrana. Esse resultado sugere fortemente que o peptídeo está localizado transversalmente na membrana, aumentando o empacotamento lateral da bicamada.

Apesar de estarem em processo de análise, os resultados de SAXS sugerem que o peptídeo causa o estreitamento das vesículas compostas por lipídios aniônicos (DPPG). Esses efeitos são maiores na fase gel do que que na fase fluida, provavelmente porque a diferença entre a extensão do peptídeo e a espessura da bicamada é maior na fase gel. Entretanto, na fase fluida da mistura fase fluida e $[\mathrm{P}] /[\mathrm{L}]=0.05-0.07$, foram observados um fator de interferência possivelmente causado por uma nova estrutura de repetição, mas fracamente correlacionada, semelhante ao observado para o DPPC (discutido acima).

Portanto, reunindo os resultados para vesículas aniônicas, sugerimos que o peptídeo pode estar na posição transversal, conforme mostra a Figura 7.2.

Para a mistura, foi observado que o peptídeo interage preferencialmente com o PG, mas 


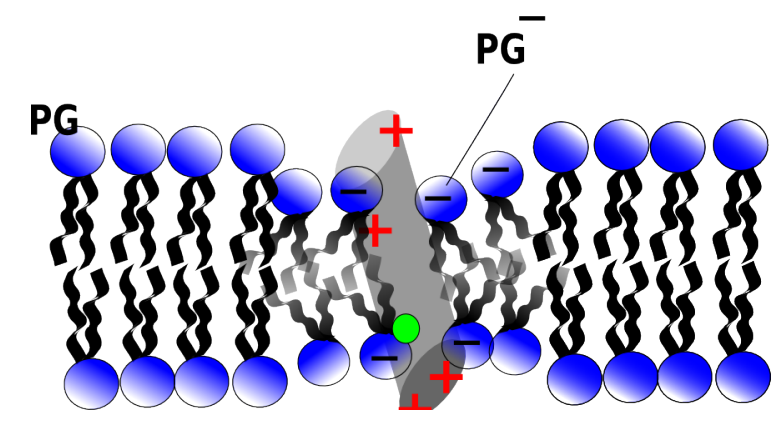

Figura 7.2: Modelo para interação do peptídeo antimicrobiano com membranas neutras de DPPG.

também é possível que ambos os efeitos aqui discutidos para vesículas neutras e aniônicas coexistam na mistura, atuando em sinergia, e também por isso, o efeito do peptídeo na mistura seja maior.

A distinção e seleção que peptídeos antimicrobianos fazem por membranas neutras de membranas aniônicas, é um ponto relevante para sua possível aplicação como um substituto de antibióticos convencionais. Neste trabalho, mostramos que o peptídeo KHya1 pode ter diferentes mecanismos de ação em membranas neutras e aniônicas devido a diferentes posições que o peptídeo pode ocupar na membrana. 


\section{Apêndice A}

\section{Distribuição de distâncias entre Trp e Laurdan}

\section{A.1 Distâncias entre Trp e Laurdan}

Para os decaimentos fluorescentes obtidos com razão molar $[\mathrm{P}] /[\mathrm{L}]=0.03$ e 0.04 e em presença de Laurdan, calculamos uma distribuição de distância entre o par doador e aceitador, para $T=30$ e $45^{\circ} \mathrm{C}$, fase gel e fluida do DPPG.

Uma vez que o decaimento fluorescente pode ser escrito em termos da distância entre pares e de $R_{0}$, equação (2.42), podemos calcular uma função de distribuição de distâncias, obtendo a transformada inversa de Laplace da equação (2.44). Para isso utilizamos um algoritmo chamado Contin, conforme descrito no capítulo 2.

A Figura A.1 mostra a distribuição de distâncias entre doador e aceitador obtidas a partir dos decaimentos fluorescentes com razão molar de peptídeo $[\mathrm{P}] /[\mathrm{L}]=0.03$ e 0.04 e para as temperaturas $T=30$ e $45^{\circ} \mathrm{C}$, as quais caracterizam a fase gel e fluida da bicamada lipídica de $\mathrm{DPPG}$, respectivamente.

Observamos que as funções de distribuição de distância obtidas da análise apresentam um perfil característico de uma função de distribuição radial, $g(r)$, com distância de repetição entre doador (Trp) e aceitador (L) equivalente a um múltiplo de $15 \AA$.

A interação entre o doador e o aceitador é limitada à distância de Forster, $R_{0}$, onde a uma distância equivalente a $2 R_{0}$, já não há interação entre pares. Deste modo, é surpreendente que dentro da curta distância de resolução do FRET possamos identificar 3 distâncias de repetição médias. 

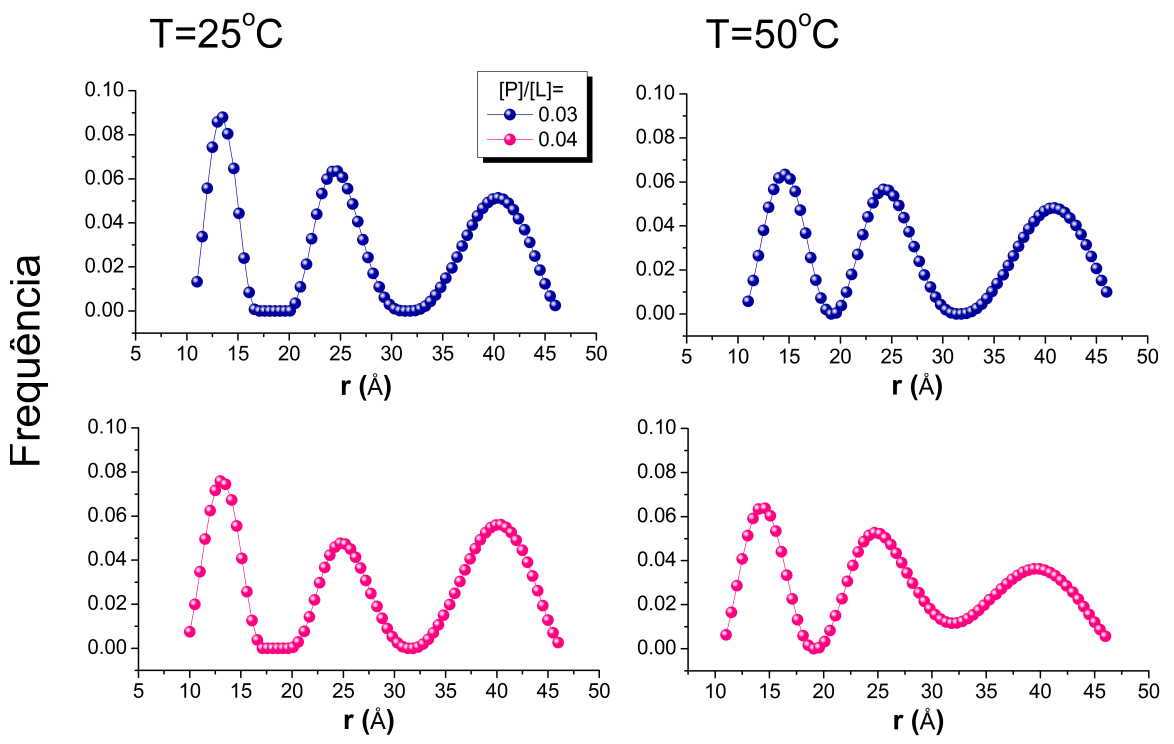

Figura A.1: Distribuição de distâncias entre doador e aceitador obtidas a partir dos decaimentos fluorescentes para peptídeo $[\mathrm{P}] /[\mathrm{L}]=0.03$ e 0.04 e para as temperaturas $T=30$ e $45^{\circ} C$, caracterizando a fase gel e fluida dos lipídios, respectivamente.

Esse resultado indica que há regiões que o Laurdan está cercado por uma rica região de peptídeo. Deste modo, é surpreendente que dentro da curta distância de resolução do FRET possamos identificar 3 picos caracterizando distâncias de repetição similares a camadas de solvatação como observado no fator de estrutura de líquidos. Caso a distribuição do peptídeo na membrana fosse uniforme, poderíamos encontrar distancias descritas por uma gaussiana (um pico), pois as distancias de ordens maiores não seriam acessadas devido a limitação de $2 R_{0}$ (ver Tabela 5.2).

A análise da distribuição de distancias assim como o FRET considerando múltiplas transições entre doares e aceitadores envolvem cálculos complicados que ainda estão em andamento. Podemos propor um cálculo simplificado para estimar a distância entre resíduos de Trp, considerando uma distribuição homogênea de peptídeos pela membrana. A razão $[\mathrm{P}] /[\mathrm{L}]=0.01$, por exemplo, equivale a 100 lipídios para 1 peptídeo. Considerando que o peptídeo que o peptídeo atravessa a membrana, conforme proposto no capítulo 4, então 1 peptídeo encontra-se cercado por 50 lipídios na camada externa e 50 lipídios na camada interna. Logo, a distância entre peptídeos equivale à aproximadamente a distância unilateral de $\sqrt{50}$ lipídios. Visto que, a área por cabeça polar de DPPG é $a=61 \AA\left(l^{2}\right)$, a distância entre peptídeos será de aproximadamente $\sqrt{50} \sqrt{61} \AA(l) .{ }^{1}$ De modo análogo, aumentando a concentração de peptídeo, por

\footnotetext{
${ }^{1}$ desprezando o volume excluído do peptídeo.
} 
exemplo, $[\mathrm{P}] /[\mathrm{L}]=0.02$ temos 1 lipídio para cada 25 lipídios (com acesso a camada externa) e assim sucessivamente. A Tabela 5.2 mostra o cálculo dessas distâncias para cada razão [P]/[L].

Além disso, para comparação e completeza do cálculo, também podemos considerar o peptídeo na superfície da membrana e ocupando ambas as camadas interna e externa da membrana. Neste caso, para $[\mathrm{P}] /[\mathrm{L}]=0.01$ cada peptídeo na camada externa se encontraria cercado por 100 lipídios na camada externa, e igualmente para a camada interna. Então, esse cálculo levaria a distâncias maiores as distâncias calculadas anteriormente, Tabela 5.2. 



\section{Apêndice B}

\section{Partição do peptídeo transmembranar}

GWALP23 entre as fases liquido ordenada

(Lo) e liquido desordenada (Ld) para

\section{sistemas com macro e nano-domínios.}

\section{B.1 Introdução}

A morfologia dos domínios lipídicos, quando há a coexistência de fases liquidas: Liquido ordenado (Lo) e Liquido desordenado (Ld), pode afetar o comportamento da membrana das células (Lingwood e Simons, 2010). Algumas evidencias experimentais mostram a participação de pequenos domínios em processos realizados pela membrana celular, tais como: o arranjo de proteínas nas membranas, a entrada por vírus e outros processos de sinalização (Lingwood e Simons, 2010).

Em modelos de membrana plasmática, a coexistência de fase liquida pode ocorrer em duas escalas diferentes, reportadas na literatura como macro e nano escalas (Konyakhina, Wu J., A., e Feigenson, 2013; Petruzielo, Heberle, Drazba, Katsaras, e Feigenson, 2013; Heberle et al., 2013, 2012). Basicamente, a diferença dessas escalas é caracterizada pela composição lipídica, a qual define como ocorre as interações entre lipídios. É sabido que os sistemas DSPC/DOPC/Chol e bBS/DOPC/Chol apresentam macro domínios, com escalas micrométricas, enquanto os sistemas DSPC/POPC/Chol e bBS/POPC/Chol apresentam nano domínios, de tamanhos aquém da resolução óptica. 
Esse trabalho tem como objetivo o estudo da partição de um peptídeo transmembranar (GWALP23) nas fases Lo ou Ld, para os sistemas mencionados a cima. O peptídeo mimetiza a parte de uma proteína de membrana a qual está emersa na bicamada, portanto, o coeficiente de partição investigado pode vir a ser utilizado como um primeiro modelo da partição de proteínas em modelos com coexistência de fases liquidas. Além disso, esse estudo permite comparar diretamente os sistemas com macro e nano domínios, a fim de avaliar se ambos os modelos poderiam mimetizar membranas reais no quesito: a partição das proteínas.

A família de peptídeos WALP tem se mostrado um bom modelo para proteínas de membrana e no estudo da interação peptídeo-lipídio (Gleason, et at., 2012). Esses peptídeos apresentam uma estrutura em hélice hidrofóbica, com Leu e Ala alternadas, além de um amino ácido polar ou aromático para ancorar o peptídeo em uma posição especifica da bicamada (Gleason et al., 2012). Em particular, o peptídeo GWALP23 apresenta 23 resíduos de amino ácidos com uma Phe na posição 4 e 5, e um Trp na posição 19.

\section{B.1.1 Diagramas de fase}

Os diagramas de fase das misturas ternarias DSPC ou bSM/DOPC/Chol e DSPC ou bBS/POPC/Chol foram previamente determinados (Konyakhina et al., 2013; Petruzielo et al., 2013). A Figura B.1 mostra os diagramas DSPC/DOPC/Chol e DSPC/POPC/Chol, como exemplos.
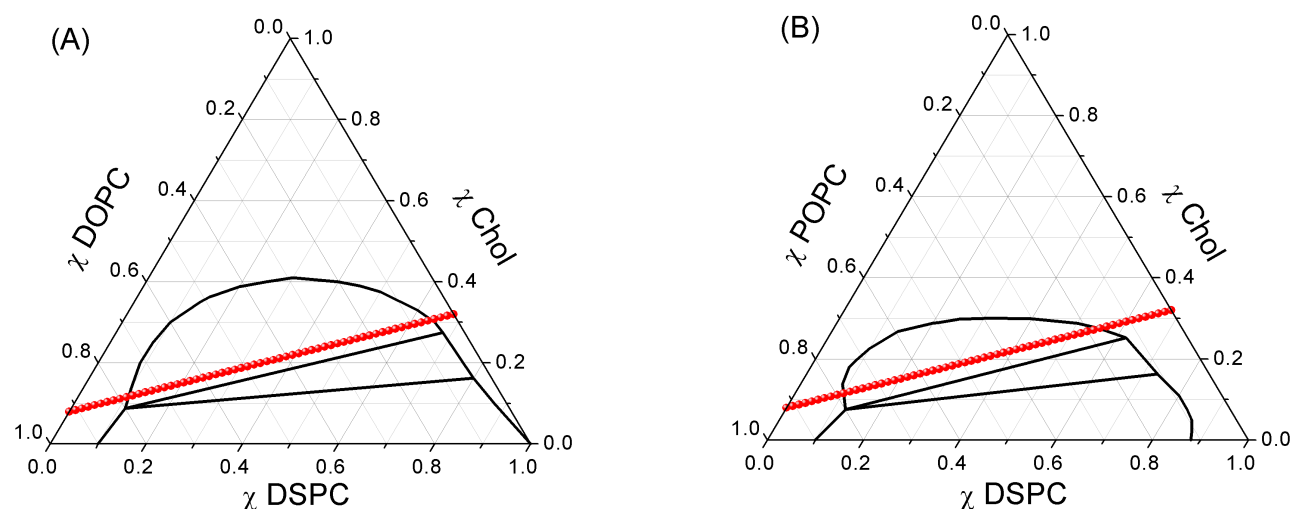

Figura B.1: Diagramas de fases para os sistemas DSPC/DOPC/Chol (A), and DSPC/POPC/Chol (B), Konyakhina et al., 2013. Trajetória ao longo da linha de coexistência de fases em vermelho.

Em resumo, uma grande quantidade amostras, com pequenos incrementos na composição lipídica, são preparadas com diferentes pares de sondas fluorescentes para a determinação desses diagramas de fases. As sondas utilizadas são pares doador/aceitador no processo de transferên- 
cia de energia (FRET), onde suas propriedades fluorescentes e físico-químicas são conhecidas. Também podemos substituir uma das sondas do par de FRET por uma sonda ou molécula de interesse para investigar algumas de suas propriedades, como por exemplo seu coeficiente de partição.

Deste modo, na região de coexistência de fase, a eficiência do FRET pode ser realçada ou reduzida, dependendo da partição das sondas fluorescente utilizadas. Esse fenômeno pode ser explicado por simples conceitos físicos. A eficiência do FRET depende da distância de separação entre o doador e o aceitador. Portanto, quando o par doador/aceitador apresenta coeficientes de partição favoráveis a mesma fase, a eficiência do FRET aumenta. Por outro lado, se os coeficientes de partição são favoráveis a fases diferentes a eficiência do FRET diminui. Note que os dois comportamentos descritos a cima, o aumento do sinal de FRET ou a sua diminuição, referem-se a dois experimentos diferentes, pois exigem diferentes pares de FRET. Logo, ambos os experimentos podem ser utilizados em conjunto para determinar precisamente as linhas de transição de fase, assim como as propriedades de partição da molécula investigada.

\section{B.2 Apresentação da parte teórica}

O sinal de FRET devidamente corrigido pelo espalhamento, ou pela emissão fluorescente não proveniente da transferência de energia (Buboltz, 2007) pode ser analisado de acordo com a equação (B.1), para sistemas com macro domínios.

$$
F R E T=\frac{F L d+\chi L o\left(F L o K_{p}^{1} K_{p}^{2}-F L d\right)}{\left[1+\left(K_{p}^{1}-1\right) \chi L o\right]\left[1+\left(K_{p}^{2}-1\right) \chi L o\right]}
$$

onde $\chi L o$ é a fração da fase ordenada, FLd e FLo são os sinais de FRET nas fases puras, Ld e Lo, respectivamente e $K_{p}^{1}$ e $K_{p}^{2}$ são os coeficientes de partição das sondas fluorescentes. Definimos $K_{p}>0$ favorável a fase ordenada, e consequentemente $K_{p}<0$ favorável a fase desordenada.

Logo, o ajuste dos dados experimentais com o uso da equação (B.1), para sistemas com macro domínios, permite a investigação do coeficiente de partição de uma ou ambas as sondas. Nesse apêndice, resumiremos o coeficiente de partição do peptídeo GWALP23, o qual possui um resíduo Trp e atua como doador no processo de transferência de energia para as sondas DHE e Bodipy (ver materiais e métodos).

A Figura B.2 ilustra simulações da equação (B.1) para diferentes valores de K1 e K2, onde exemplificamos diferentes condições experimentais. Na Figura B.2(A-B) as duas sondas 
particionam na mesma fase, dado que em A ambas preferem a fase Ld e em B a fase Lo. Em $\mathrm{C}$ e D as sondas particionam em diferentes fases onde o sinal de FRET das fases puras, FLd e FLo, possuem valores diferentes, e esses podem modificar o formato da curva.
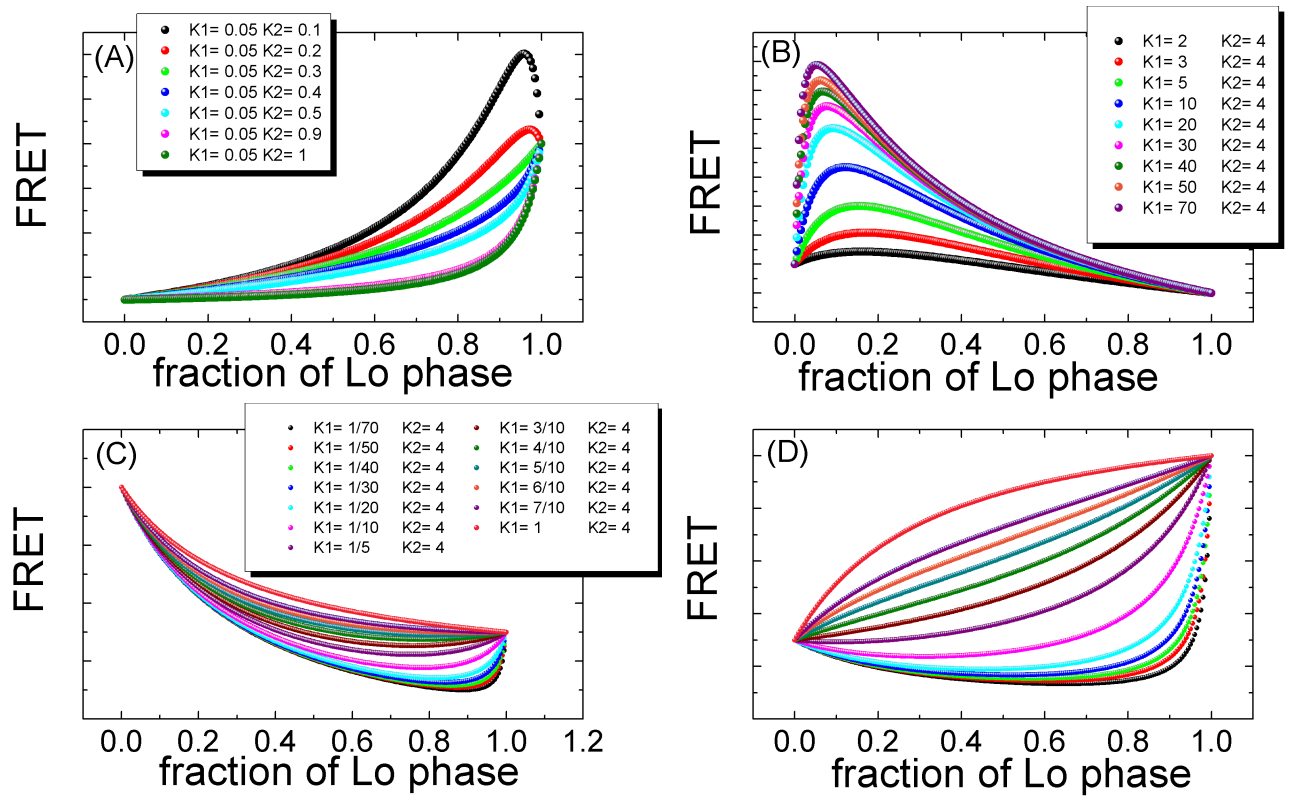

Figura B.2: Sinal de FRET de acordo com a Eq. (1). Sondas particionando na mesma fase, Ld (A), Sondas particionando na mesma fase, Lo (B). Sondas particionando em diferentes fases, FLd > FLo (C), e FLd < FLo (D).

Entretanto, os sistemas que apresentam nano domínios não podem ser analisados da mesma maneira, pois quando a dimensão do domínio torna-se comparável a distância de Forster, $R_{0} \mathrm{o}$ tamanho do domínio deve ser considerado. De maneira simplificada, se a dimensão relevante para o FRET, $\sim 2 R_{0}$, for da ordem ou inferior ao tamanho do domínio, então, por exemplo, caso as sondas particionam em diferentes fases, o sinal de FRET não consegue resolver a separação das sondas. Embora a região de coexistência de fases seja clara para o FRET, a modelagem do coeficiente de partição não pode ser realizada com o uso da equação (B.1). Deste modo, Fred Herbele desenvolveu um código que considera a distribuição das sondas em diferentes fases utilizando o algoritmo de Metropolis e a partir da distribuição de distância entre pares doador e aceitador, a rotina calcula a eficiência de FRET e o sinal de FRET aqui estudado (medida experimental) ao longo da trajetória de amostras. Essa rotina esta implementada no programa Mathematica e exige a simulação paralela dos dados, o qual foi realizada no cluster do laboratório do Prof. Feigenson (lipid.cac.cornell.edu). Aqui não descreveremos detalhes do código. ${ }^{1}$

\footnotetext{
${ }^{1}$ Herbele desenvolveu o código e me ensinou a usá-lo, e eu desenvolvi as análises e ajustes.
} 
Deste modo, para sistemas com nano domínios além da análise do coeficiente de partição, também podemos estudar o tamanho dos domínios. A simulação das curvas de FRET foram testadas com os dados experimentais, no caso de macro domínios e apresentam concordância com a solução analítica (B.1). A Figura B.3 mostra um exemplo obtido com o uso da solução analítica e com o uso da solução numérica.

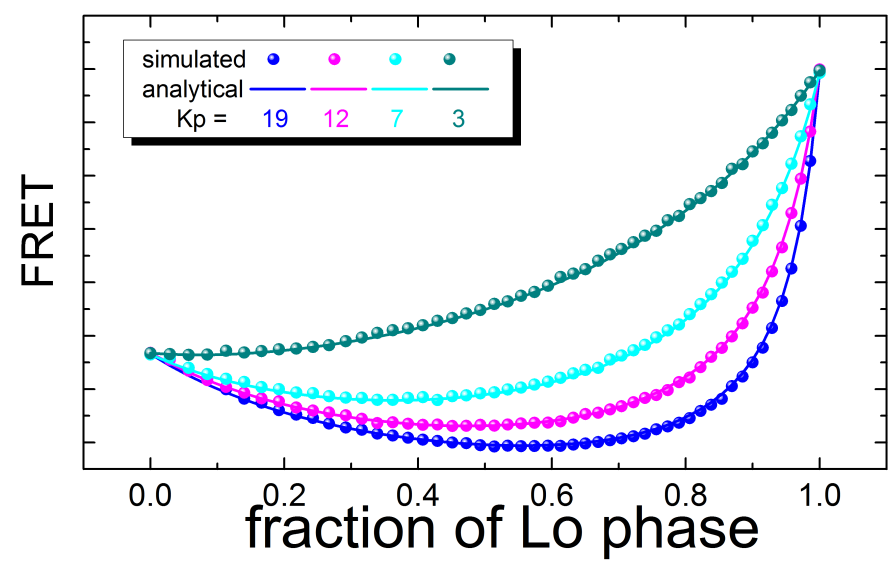

Figura B.3: Comparação da solução teórica, equação (B.1) e simulação numérica, no regime macroscopico.

Os experimentos de FRET são laboriosos pois é necessário o preparo de um grande número de amostras. Neste trabalho, para cada trajetória apresentada a seguir, na seção B.5, foram preparadas cerca de 75 amostras e mais cerca 10 a 15 controles. Aqui, neste apêndice são mostrados apenas alguns exemplos.

\section{B.3 Materiais e Métodos}

DOPC, POPC, bSM foram obtidos da Avanti Polar Lipids (Alabaster, AL, USA), e Chol da $\mathrm{Nu}$ Chek Prep (Elysian, MN, USA). PIPES, KCl, EDTA foram obtidos da Sigma Aldrich (St Louis, MO, USA). A concentração dos lipídios foi determinada por dosagem de fosfato, conforme descrito em (Kingsley and Feigenson, 1979). As concentrações lipídicas encontradas sempre apresentam um erro menor que 1\% para as 10 replicatas medidas. Foram utilizados lipídios com pureza superior a 99\%, dado confirmado por Thin Layer Chromatography (TLC). As sondas fluorescentes: DHE da Sigma Aldrich, Bodipy and C12:0 DiI da Invitrogen (Carlsbad, CA), e TRPOE (tryptophan oleoyl ester) sintetizado em laboratório, são preparadas em clorofórmio. A concentração das sondas fluorescentes é determinada por absorção espectroscópica usando metanol. 


\section{B.4 Preparação das amostras para FRET - trajetórias de FRET}

Aqui, as amostras com diferentes composições lipídicas são preparadas ao longo da linha representa no diagrama de fase, Figura B.1. Esse conjunto de amostras será referido como, trajetória de FRET, ou trajetória de amostra. A quantia certa para cada fração molar de fosfolipídio, Chol e sondas fluorescentes são adicionadas aos tubos (tubos com tampas) com a ajuda de uma ferramenta que dispensa alíquotas precisas, da Hamilton, Figura 6.2. Então, a solução tampão (0.5 mL of PIPES 5 mM, KCl 200 mM, EDTA 1mM, pH = 7.0) é adicionada a mistura de lipídios, que encontra diluída em clorofórmio. O clorofórmio é removido por um processo conhecido como Rapid Solvent Exchange (RSE), esse procedimento pode ser encontrado em, por exemplo, (Buboltz e Feigenson, 1999). Por fim, as amostras são seladas com um fluxo de Argônio e colocadas em um banho térmico a $50^{\circ} \mathrm{C}$, e lentamente são esfriadas a $23^{\circ} \mathrm{C}$ usando uma taxa de aproximadamente $4^{\circ} C / h$.

As frações molares das sondas fluorescentes, ou de peptídeo foram: DHE (1.0 mol\%), Bodipy (0.07 mol\%), Trp-oe (1.0 mol\% ou $0.5 \mathrm{~mol} \%)$ e GWALP $(1.0 \mathrm{~mol} \%)$

Os dados de FRET são coletados em um fluorimetro Hitachi F7000 FL (Hitachi High Technologies America, Inc., Schaumburg, IL) em temperatura ambiente $23^{\circ} \mathrm{C}$, onde a intensidade de fluorescência foi registrada nos seguintes canais ( $\lambda$ excitação / $\lambda$ emissão $(\mathrm{nm})$ ) Fluorescência do Trp (284/335), Emissão estimulada do aceitador DHE, (284/393) - (doador: Trp), Fluorescência do DHE (327/393), Emissão estimulada do aceitador Bodipy, (327/517) - (doador: DHE), ou Emissão estimulada do aceitador Bodipy, (280/517) - (doador: Trp), Fluorescência do Bodipy (509/517), Espalhamento dos lipossomos (420/420).

\section{B.5 Resultados e Discussões}

A Figura B.4 mostra o sinal de FRET obtido para trajetória de FRET ilustrada na Figura B.1(A) com diferentes pares de sondas fluorescente (doador/aceitador). Em A e B observamos o FRET entre o Trp (doador)/ DHE (aceitador), e entre DHE (doador)/ Bodipy (aceitador), respectivamente. Como o ergosterol DHE é uma molécula muito similar ao Chol, é sabido que ele apresenta partição favorável a fase Lo. As trajetórias da Figura B.4 mostram a redução do sinal de FRET na região de coexistência de fases, indicando que o peptídeo GWALP23, as sondas Trp-oe e Bodipy apresentam partição favorável a fase Ld. Além disso, as figuras também 
comparam o Trp de diferentes moléculas (GWALP23 e Trp-oe). Em preto podemos observar o Trp-oe e em azul o Trp na posição 19 do peptídeo GWALP23.

\section{$\chi$ DSPC}

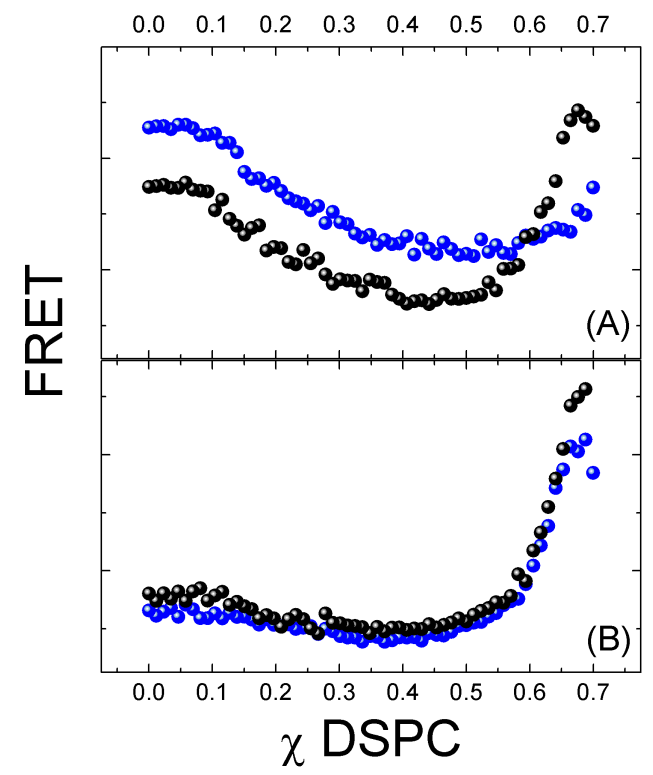

Figura B.4: Sinal de FRET usando os pares Trp-oe (doador) e DHE (aceitador), em preto, e Trp -GWALP23 (doador) e DHE (aceitador), em azul (A). Sinal de FRET usando os pares DHE (doador) e Bodipy (aceitador) (em preto, em presença de Trp-oe) e (em azul, em presença de GWALP23) (B). Sistema macroscópico DSPC/DOPC/Chol.

Observamos que embora diferentes, as moléculas GWALP23 e Trp-oe não influenciam na partição das outras sondas, DHE e Bodipy, como mostra a Figura B.4(B).

Para obter os coeficientes de partição das sondas ou do peptídeo é necessário conhecer as linhas de transição de fase, e se a presença do peptídeo modifica ou não o digrama de fase (região de coexistência). Esse dado é importante pois os parâmetros experimentais FLd e FLo são requeridos na equação (B.1). Em geral, o ponto referente ao contorno de fase é obtido pelo intercepto das retas traçadas na fase pura com a região de coexistência de fases, como ilustra a Figura B.5. Em A e C definimos o contorno de fase entre Ld e Ld+Lo, e em B e D entre Ld + Lo e Lo. O exemplo ilustrado foi realizado sobre os dados da Figura B.4. Observamos que para baixas frações molares de peptídeo, até $2 \mathrm{~mol} \%$, não foi observado grandes mudanças no diagrama de fases.

Também realizamos experimentos similares para sistemas nanoscopicos, como por exemplo DSPC/POPC/Chol, onde seu diagrama de fases pode ser encontrado na Figura B.1(B). A Figura B.6 mostra a trajetória de FRET realizada ao longo da linha de coexistência de fases 

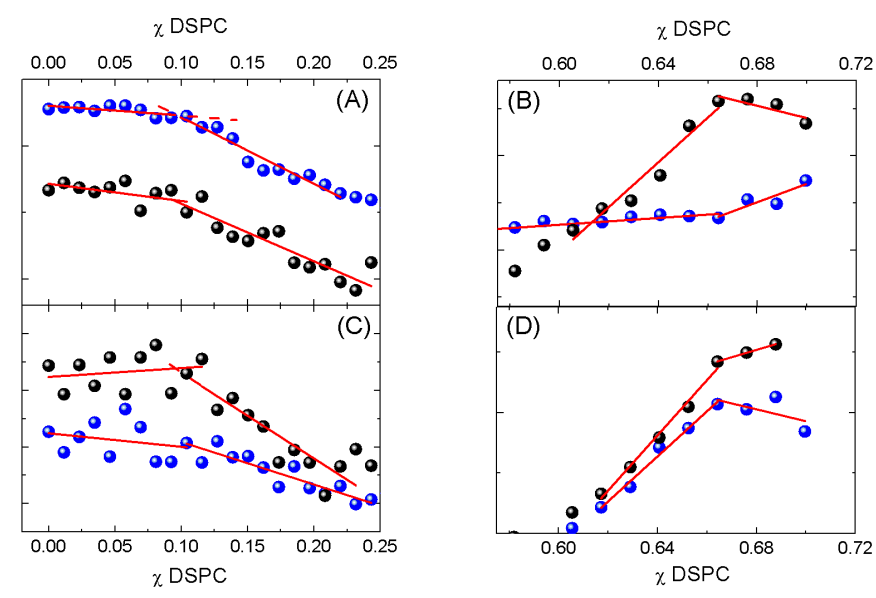

Figura B.5: Contornos de fase para DSPC/DOPC/Chol + GWALP23 são determinados pelo encontro das retas traçadas em (Ld ou Lo) e a região de coexistência $(\mathrm{Lo}+\mathrm{Ld})$. Os gráficos tem a mesma legenda do anterior.

ilustrada na Figura B.1(B), para DSPC/POPC/Chol.

\section{$\chi$ DSPC}

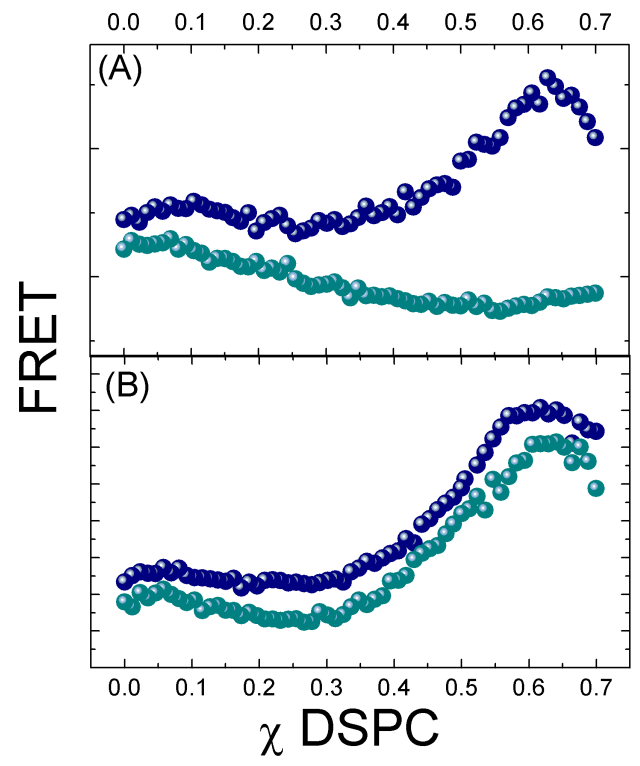

Figura B.6: Sinal de FRET usando os pares Trp-oe (doador) e DHE (aceitador), em azul, e TrpGWALP23 (doador) e DHE (aceitador), em verde (A). Sinal de FRET usando os pares DHE (doador) e Bodipy (aceitador) (em azul, em presença de Trp-oe) e (em verde, em presença de GWALP23) (B). Sistema macroscópico DSPC/POPC/Chol. 


\section{B.6 Modelagem do coeficiente de partição}

A modelagem do coeficiente de partição foi realizada com o teste de diversos parâmetros, onde com uma análise global, ou seja, para todas as curvas medidas, obtivemos o melhor conjunto de dados que melhor ajusta as curvas experimentais.

\section{B.6.1 macro domínios}

A Figura B.7 ilustra a variação de parâmetros estudados para o ajuste das curva experimentais referente a mistura DSPC/DOPC/Chol. Deste modo, melhor conjunto de parâmetros para esse sistema é dado por $K_{p}^{G W A L P 23}=11 \pm 2$ e $K_{p}^{\text {Bodipy }}=7 \pm 1$.

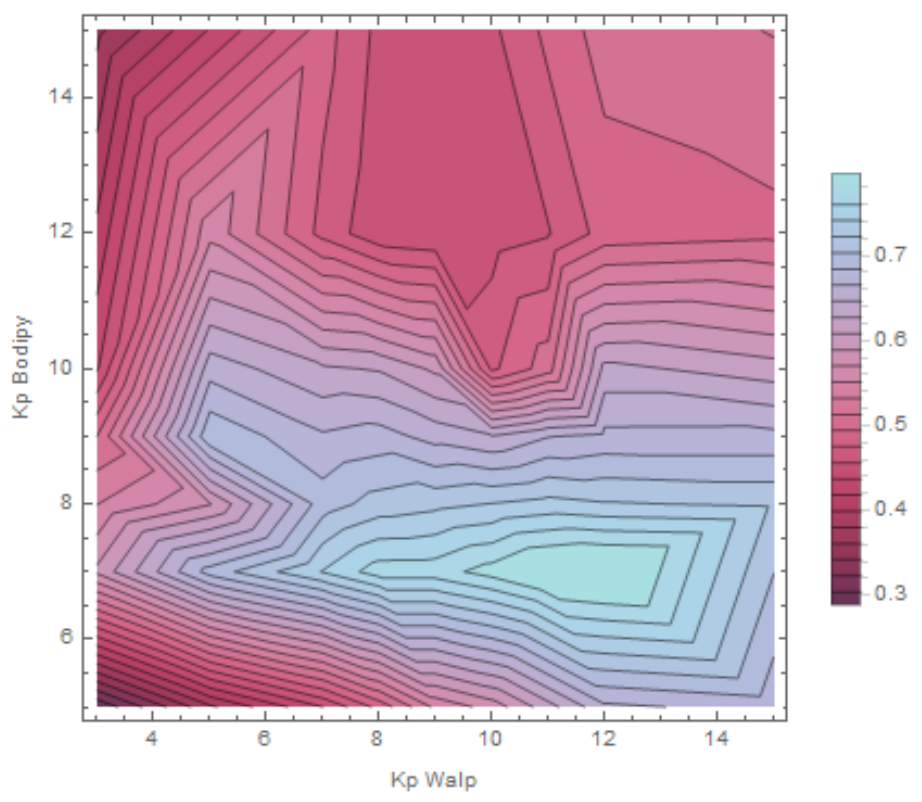

Figura B.7: Mapeamento dos coeficientes de partição do peptídeo GWALP23 e da sonda Boidipy em DSPC/DOPC/Chol.

Os ajustes referentes aos parâmetros mencionados a cima, para o DSPC/DOPC/Chol, podem ser vistos na Figura B.10. 

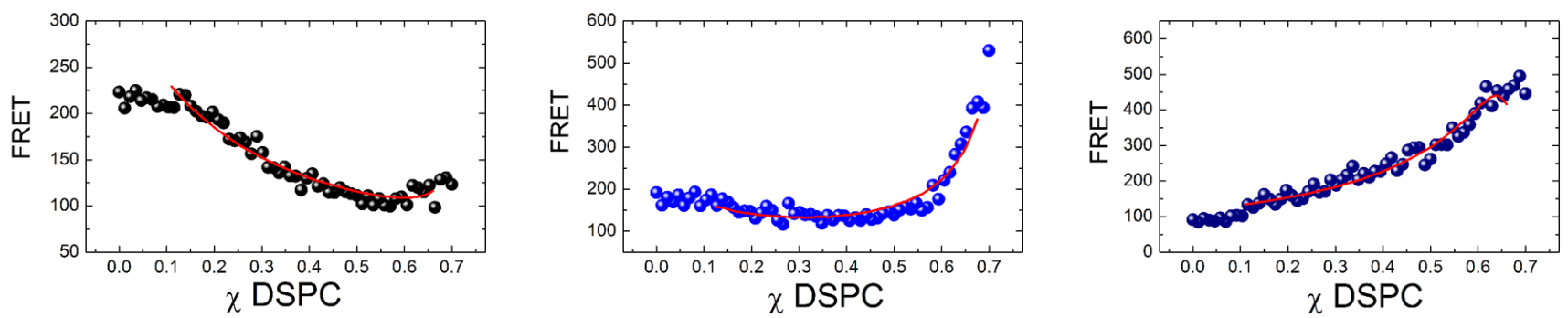

Figura B.8: Ajustes obtidos das análises para o sistema DSPC/DOPC/Chol, para diferentes pares de FRET, GWALP23-DHE, DHE-Bodipy e GWALP23-Bodipy.

\section{B.6.2 nano domínios}

Para sistemas que apresentam não domínios, esta análise também depende do tamanho do domínio, aqui os domínios são aproximados a domínios esférico de raio, $R_{d}$. A Figura B.9 ilustra a variação de parâmetros estudados para o ajuste das curva experimentais referente a mistura DSPC/POP/Chol.

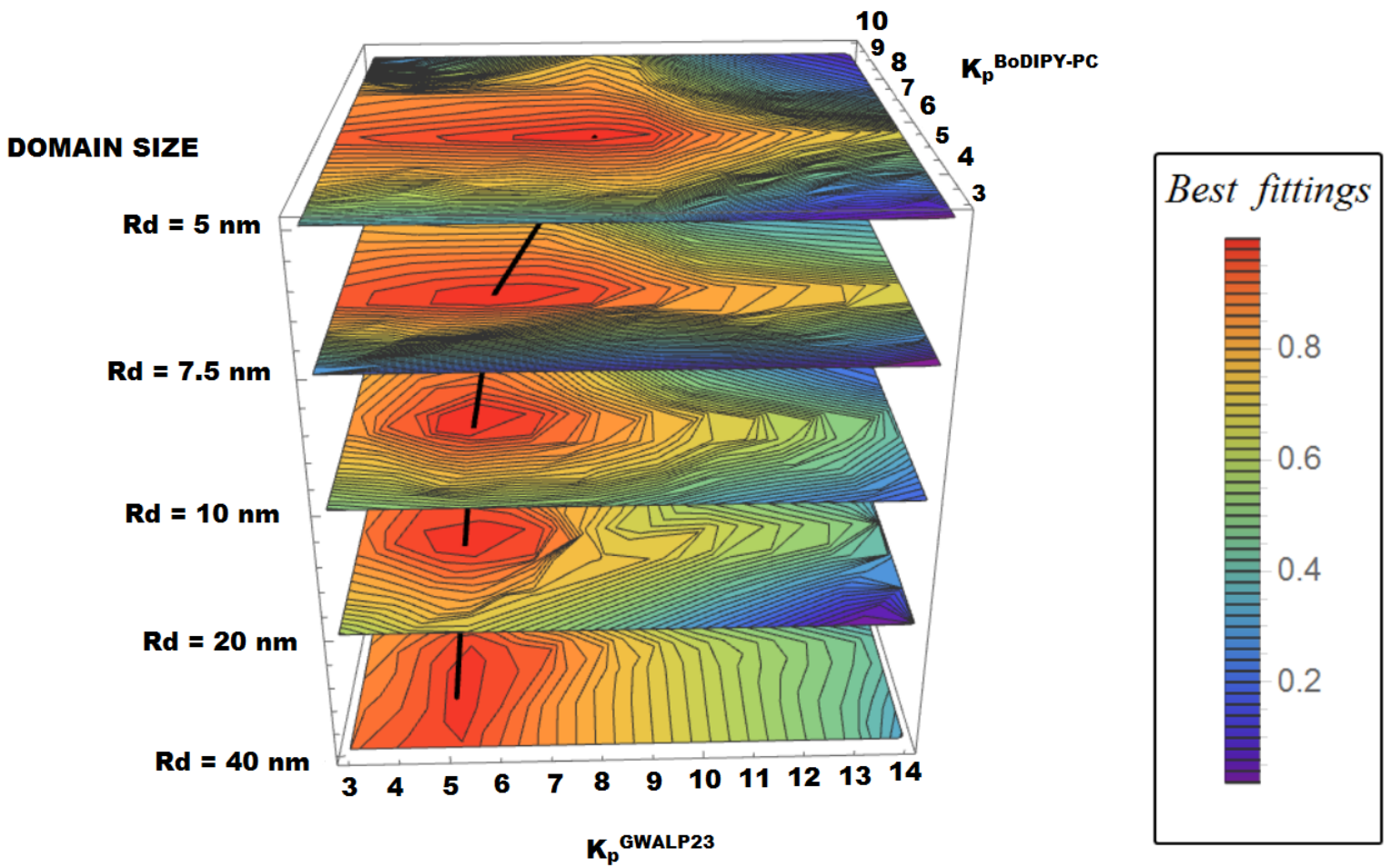

Figura B.9: Mapeamento dos coeficientes de partição do peptídeo GWALP23 e da sonda Boidipy, e do tamanho dos dominios, em DSPC/POPC/Chol.

Dado o conjunto de parâmetros livres que estamos trabalhando, $K_{p}$ e $R_{d}$ torna-se difícil avaliar o coeficiente de partição ou o tamanho do domínio. Experimentos independes estão sendo realizados para diminuir para a estimativa de $K_{p}$. 
Os ajustes obtidos para, por exemplo, domínios $R_{d}=50 \AA, K_{p}^{G W A L P 23}=8 \pm 1$ e $K_{p}^{\text {Bodipy }}=$ $6.0 \pm 0.5$, para o DSPC/DOPC/Chol, podem ser vistos na Figura ??.
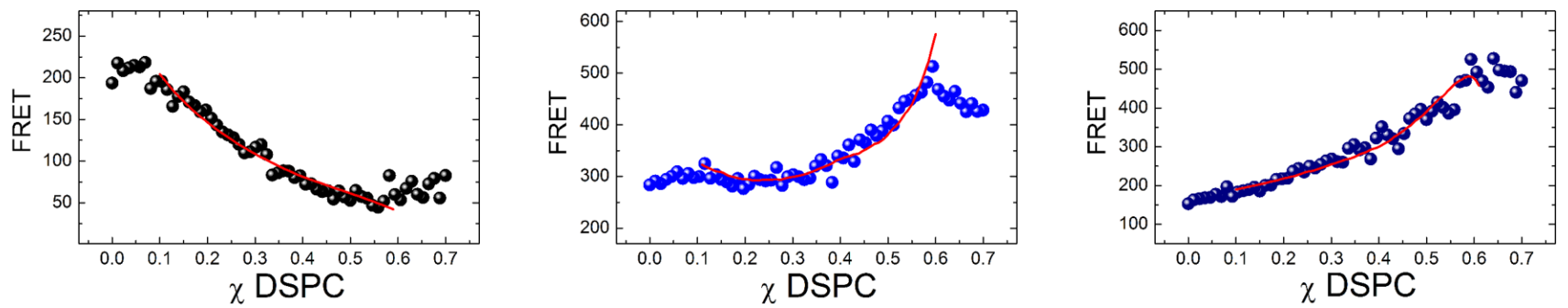

Figura B.10: Ajustes obtidos das análises para o sistema DSPC/POPC/Chol, para diferentes pares de FRET, GWALP23-DHE, DHE-Bodipy e GWALP23-Bodipy.

Analises semelhantes também foram realizadas para os sistemas lipídicos bSM/DOPC/Chol e bSM/POPC/Chol, e também para outras sondas fluorescentes. 



\section{Apêndice C}

\section{Estudo de vesículas assimétricas em sistemas ternários: bSM ou DSPC / DOPC / Chol.}

\section{C.1 Introdução}

Membranas celulares apresentam diferentes composições lipídicas na camada interna e externa. A membrana exoplasmatica de eucariotos, por exemplo, é rica em fosfatidilcolina (PC) e esfingomielina (SM). Por outro lado, a monocamada do citoplasma é composta principalmente por fosfatidiletanolamina (PE) e fosfatidilserina (PS) (Kiessling, Wan, e Tamm, 2009; Chiantia, Schwille, Klymchenko, e E., 2011). Além disso, as células procariotas também apresentam diferentes composições lipídicas em suas camadas interna e externa, onde a membrana externa é rica principalmente em PG e PE (Yeaman e Yount, 2003).

Recentemente, um grande esforço tem sido realizado no desenvolvimento de um protocolo para preparar vesículas assimétricas, assim como no estudo da correlação entre as camadas interna e externa da bicamada. Este apêndice apresenta brevemente alguns resultados obtidos no estudo de modelos de membranas assimétricas. Neste trabalho, preparamos vesículas gigantes (Giant Unilamellar Vesicles - GUVs) compostas por bSM/DOPC/Chol ou DSPC/DOPC/Chol, sistemas que apresentam domínios macroscópicos, quando visualizados no microscópio. Nesses sistemas substituímos os lipídios da camada externa por DOPC sem alterar a concentração de Chol. Deste modo, a camada externa tende a ser composta predominantemente por DOPC/Chol, enquanto que a camada interna é mantida na composição ternaria inicial. 
Dos resultados, obtivemos diferentes comportamentos entre o acoplamento e as fases das monocamadas lipídicas, dados por: (1) monocamadas uniformes, (2) uma das monocamadas uniforme, enquanto a outra apresentava separação de fase, (3) ambas monocamadas com separação de fase, e perfeito alinhamento entre as camadas interna e externa, e (4) ambas com separação de fase e anti-alinhadas. Ainda não sabemos explicar por completo a origem dos diferentes comportamentos encontrados experimentalmente. Entretanto, supomos que eles estão relacionados a porcentagem de lipídios substituídos na camada externa.

\section{C.2 Materiais e métodos}

As vesículas gigantes são preparadas de acordo com o procedimento (Angelova e Dimitrov, 1986) e as vesículas assimétricas de acordo com o protocolo (Chiantia et al., 2011).

\section{C.3 Resultados}

Mostramos aqui alguns dos experimentos realizados com a mistura ternaria bSM/DOPC/Chol. A Figura C.1 mostra uma vesícula gigante com composição lipídica inicial bSM/DOPC/Chol=0.3/0.3/0.4, nessas frações molares de lipídios a GUV apresenta coexistência das fases Ld e Lo (veja também o diagrama de fases da Figura C.2). As GUVs são preparadas apenas com a sonda fluorescente C12:0DiI, a qual apresenta uma partição preferencial a fase Ld e possui emissão fluorescente no vermelho.

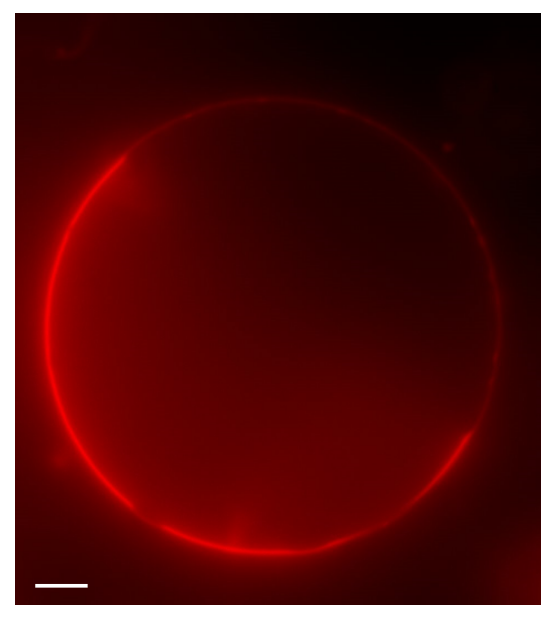

Figura C.1: GUV simétricas com coexitência de fase líquida, Ld+Lo,bSM/DOPC/ Chol=0.3/0.3/0.4. GUVs com sondas vermelhas C12:0 DiI. Barra de escala $10 \mu \mathrm{m}$.

Então, as vesículas gigantes descritas a cima, entram em contato com uma solução doadora 
de lipídios, a qual irá substituir os lipídios de suas camadas externa. Nessa solução doadora há o lipídio que será substituído na camada externa da memebra, DOPC, e contém pequena fração de sonda fluorescente que emite no verde, Bodipy, onde ambos estão complexados com $\alpha$ ciclodextrin. Ciclodextrin são oligossacarídeos cíclicos que apresentam uma cavidade hidrofóbica enquanto seu exterior é hidrofílico. É sabido que esses açúcares podem formar complexos com lipídios e podem promover a troca de lipídios da camada externa de membranas. Chiantia e colaboradores (Chiantia et al., 2011) propõem um estudo para a formação de vesículas assimétricas, aqui, utilizamos um protocolo semelhante, mas com algumas modificações. O mecanismo de troca do $\alpha$ ciclodextrin ainda não é completamente compreendido.

Em particular, o $\alpha$ ciclodextrin apresenta um anel pequeno, e o Chol não se ajusta em sua cavidade de modo que essa molécula não pode se complexar com o Chol. Logo, o Chol não é removido ou substituído da camada externa da bicamada. Portanto, à medida que o DOPC (lipídio doador) substitui os lipídios da camada externa sem alterar a concentração de Chol, a fração de bSM diminui enquanto que a fração de DOPC aumenta e a composição lipídica da camada externa varia no sentido da flecha descrita na Figura C.2.

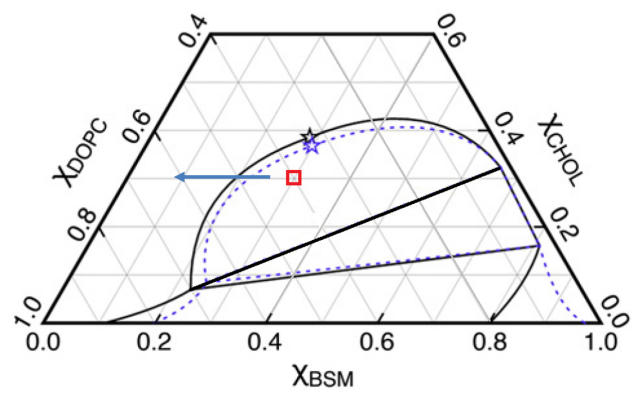

Figura C.2: Diagrama de fases bSM/DOPC/Chol adaptado de Petruzielo et al., 2013. O diagrama de fase mostra a composição inicial das GUVs (quadrado). Assim que a camada externa é substituída por DOPC, e a fração de Chol não muda, a composição da monocamada externa se altera na direção da seta.

Nos exemplos mostrados nas Figuras C.3 e C.4 podemos identificar diferentes comportamentos do acoplamento das camadas interna e externa das vesículas gigantes, agora assimétricas. Note que, após a formação de vesículas assimétricas, o sinal de fluorescência verde marca apenas a monocamada externa (a qual foi substituída) e sinal de fluorescência vermelho marca principalmente a monocamada interna. De fato, pode haver algum sinal de fluorescência da sonda vermelha na monocamada externa, mas esse sinal é diluído e muito inferior ao sinal da sonda verde, pois obtivemos mais de $70 \%$ de substituição da camada externa. 


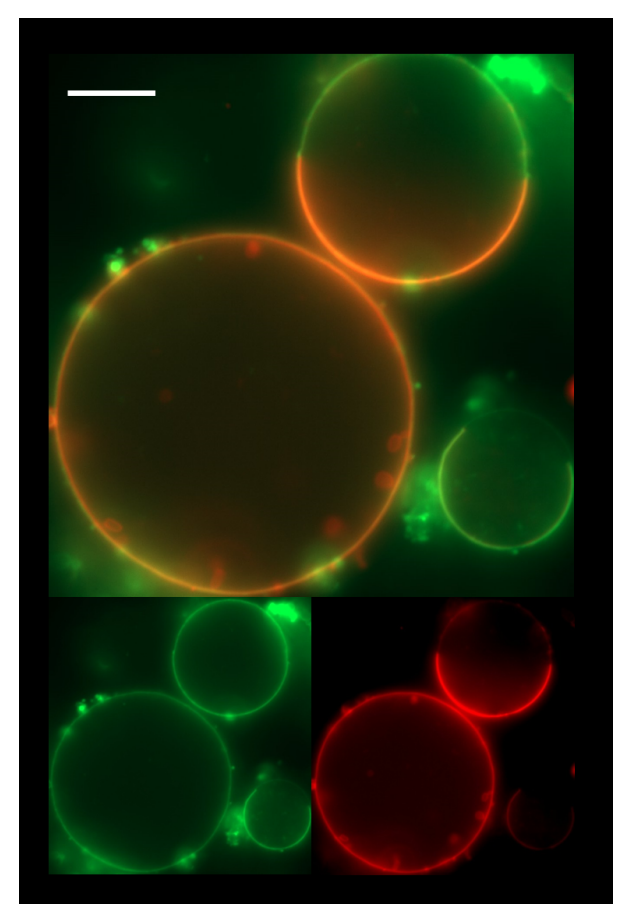

Figura C.3: GUVS assimétricas. A sonda verde marca os lipídios que foram substituídos na camada externa, e a sonda vermelha marca principalmente a camada interna. (A) Canais vermelho e verde do microcópio combinados. (B) Canal verde. (C) Canal vermelho. Barra de escala $20 \mu \mathrm{m}$.

Como já discutido anteriormente, ambas as sondas C12:0DiI (vermelha) e Bodipy (verde) apresentam partição favorável a mesma fase Ld, portanto se os domínios da camada interna e externa estão alinhados as duas sondas devem marcar a mesma região.

A Figura C.3 mostra a combinação dos canais vermelho e verde em (A), apenas o canal verde em (B) e apenas o canal vermelho em (C). Observamos que a GUV indicada pelo número 1 apresenta ambas as bicamadas uniformes, enquanto que a vesícula indicada por 2 apresenta a monocamada interna com separação de fases e a monocamada externa uniforme, por fim a vesícula 3 apresenta ambas as camadas com separação de fase, onde os domínios estão alinhados. Em particular na vesícula 3 foi observado uma alta porcentagem de substituição, havendo portanto uma grande diluição da sonda vermelha que tem sua fluorescência diminuída.

A Figura C.4 ilustra outro exemplo de GUV assimétrica, e esse foi o mais curioso efeito observado, onde a monocamada interna apresenta separação de fases, assim com a monocamada externa. Entretanto, a fase Ld da camada interna (vermelho) esta acoplada a fase Lo da camada externa (sinal fluorescente verde de menor intensidade), e vice e versa. Estudos por simulações computacionais reportados em (Perlmutter e Sachs, 2011), mostraram similar resultado, onde foi identificado teoricamente o não alinhamento de domínios Lo e Ld ao longo da seção transversal de bicamada. Os autores justificam esse efeito com uma tentativa de mini- 


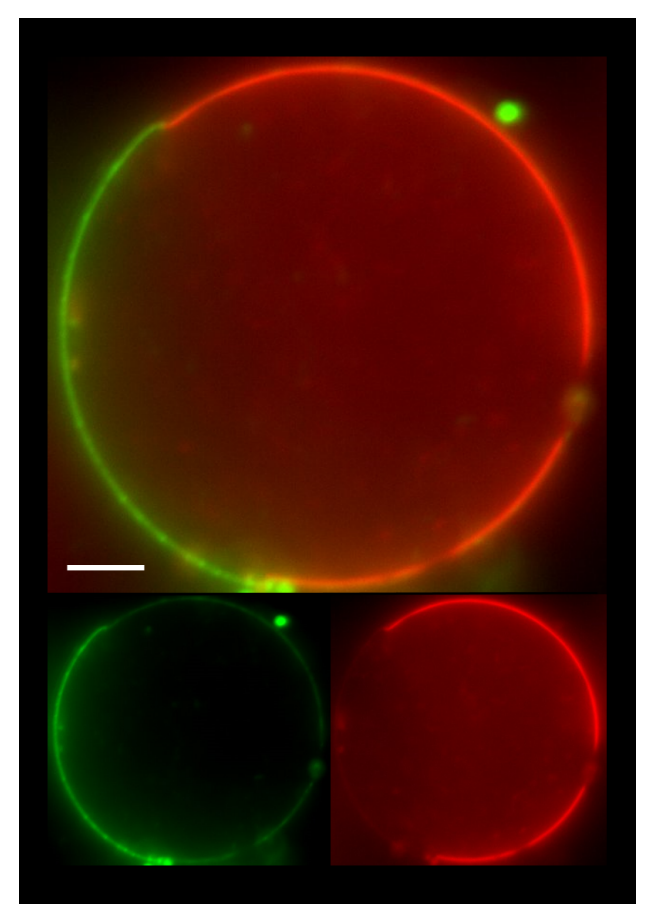

Figura C.4: GUVS assimétricas. A sonda verde marca os lipídios que foram substituídos na camada externa, e a sonda vermelha marca principalmente a camada interna. (A) Canais vermelho e verde do microcópio combinados. (B) Canal verde. (C) Canal vermelho. Barra de escala $10 \mu \mathrm{m}$.

mizar o custo energético associado com a exposição da parte hidrofóbica dos domínios lipídicos Lo, causado na interface entre os domínios Ld e Lo.

Esse projeto além de ser muito interessante, busca o avanço dos modelos de membranas, que mimetizariam a assimetria das membranas reais (procarióticas ou eucarioticas). 



\title{
Apêndice D
}

\section{Partição do peptídeo antimicrobiano}

\section{KHya1 entre as fases liquido ordenada}

\author{
(Lo) e liquido desordenada (Ld) para
}

\section{sistemas com macro e nano-domínios.}

\section{D.1 Introdução}

Neste trabalho aplicamos as técnicas aprendidas e desenvolvidas no laboratório de Prof. Feigenson com o peptídeo antimicrobiano KHya1. Similarmente ao discutido no apêndice B, obtivemos o coeficiente de partição desse peptídeo entre as fases Liquido desordenada, Ld e Liquido ordenada, Lo, para os sistemas macro e nanoscopico (DSPC/DOPC/Chol) e (DSPC/POPC/Chol), respectivamente. Além disso, observamos por microscopia de fluorescência em vesículas gigantes que as fases moduladas são evidenciadas em valores menores de $\rho$, onde a magnitude $\rho$ refere-se o quão próximo o sistema se encontra do regime macroscópico (e distante do regime nanoscopico). Esse resultado sugere que o peptídeo evita a interface entre os domínios. Ainda utilizando microscopia de fluorescência, observamos o efeito do peptídeo antimicrobiano ao longo da linha de coexistência de fase do regime macroscópico e notamos que o peptídeo leva a protuberância da menor fase. 


\section{D.2 Materiais e métodos}

Ver anexo B, seção B.3 para experimentos realizados com FRET e anexo C, seção C.2 para experimentos com microscopia de fluorescência.

\section{D.3 Resultados e Discussões}

A Figura D.1 mostra as trajetórias de FRET realizadas ao longo das linhas de coexistência de fases ilustrada na Figura B.1 (A) DSPC/DOPC/Chol e (B) DSPC/POPC/Chol na presença do peptídeo antimicrobiano KHya1. As setas indicam as linhas de transições de fases (ou contornos de fases), as quais se assemelham aos contornos de fase dos conhecidos diagramas ternários, mostrando portanto, que não houve grande variação da região de coexistência de fases.
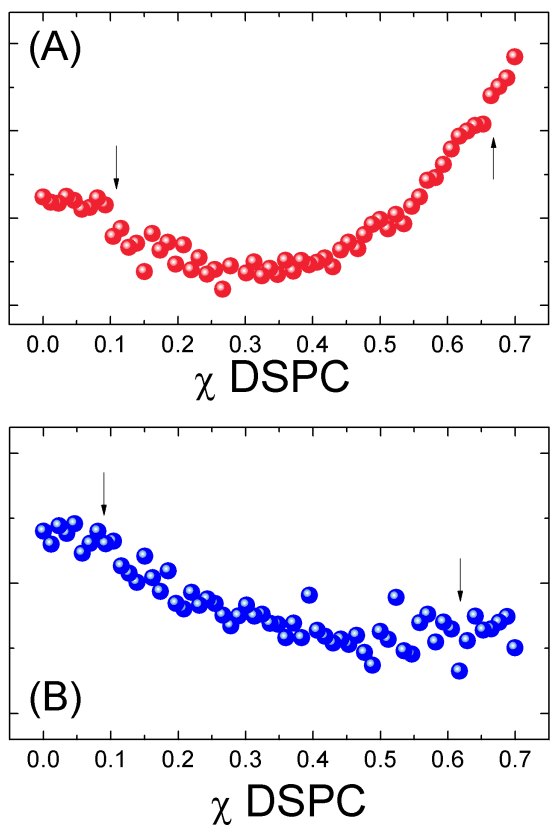

Figura D.1: Sinal de FRET usando os pares TRP-KHya1 (doador) e DHE (aceitador), DSPC/DOPC/Chol + KHya1 (A) e DSPC/POPC/Chol + KHya1 (B). As setas indicam os contornos de fases.

Obtivemos os coeficientes de partição para o caso macroscópico, através de um ajuste simples com o uso da equação (B.1), $K_{p}=10 \pm 2$. Para sistemas que apresentam nano domínios as análises são mais complicadas e exigem uma investigação ampla dos parâmetros $K_{p}$ e $R_{d}$, como apresentado no apêndice B

Também poderíamos questionar a afinidade do peptídeo pela interface entre domínios. Essa 
questão foi cuidadosamente respondia neste e no caso anterior (GWALP). Para melhor entendimento dessa questão faz-se necessário a introdução de alguns novos conceitos.

Brevemente, foi observado em diagramas de fases quaternários (Konyakhina et al., 2013; Heberle et al., 2013, 2012), que ao longo da transição de macro domínios para nano domínios há a existência de uma fase chamada de fase modulada, onde os domínios lipídicos deixam de ser caracterizados por domínios esféricos ou arredondados passando para formas padrões, Figura D.2.
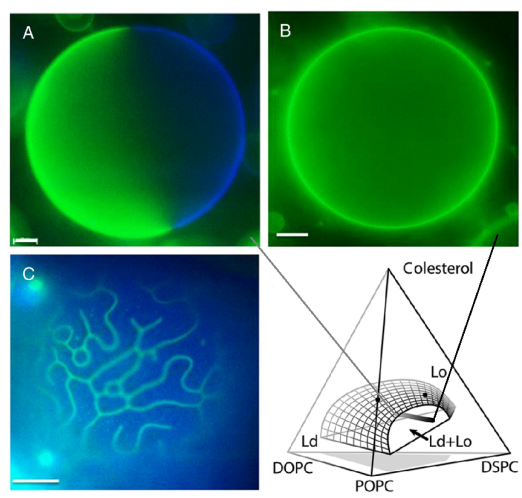

Figura D.2: Esquema ilustrando a transição entre sistemas macorscópicos para nanoscópicos passando por fases moduladas.

Esses padrões podem ser explicados basicamente pela competição de dois parâmetros energéticos: a tensão linear entre domínios e a curvatura ou propriedades elásticas da bicamada ("bending energy"). O esquema da Figura D.3 ilustra de maneira bem simplificada o acoplamento das interações descritas a cima em função da fração da fase macroscópica, $\rho$, onde $\rho=0$ implica no sistema nanoscopico e $\rho=1$ no sistema macroscópico.
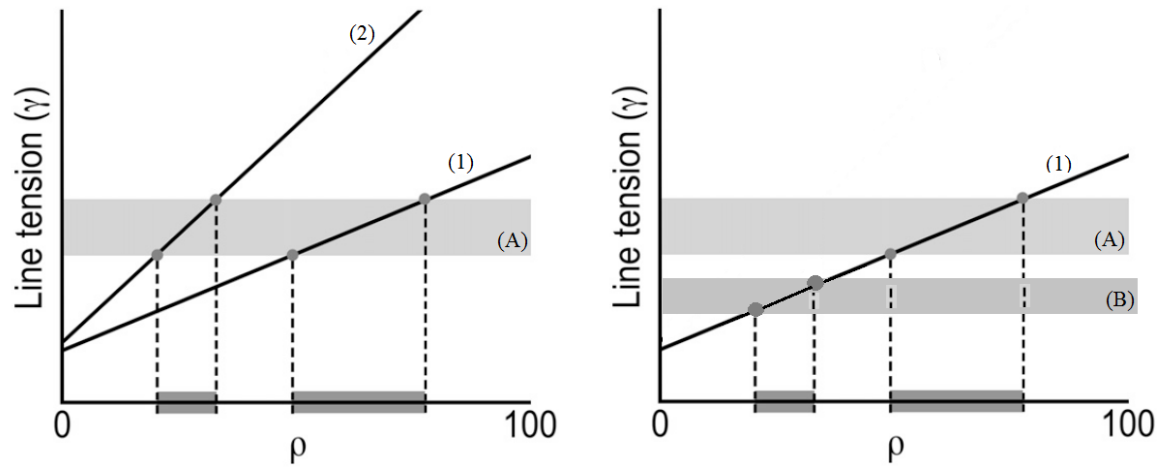

Figura D.3: Esquema ilustrando a conexão entre tensão linear e tensão de curvatura, adaptado de Amazon et. al. 2014.

As fases moduladas ocorrem em um intervalo de valores específicos da tensão linear e energia 
de curvatura, onde na Figura D.3 estão demarcados por uma janela de $\rho$ (" $\rho$ window"), onde corresponde a $\rho=\chi D O P C /(\chi D O P C+\chi P O P C)$. O deslocamento das fases moduladas para valores menores de $\rho$, pode implicar em duas condições: (i) o aumento da tensão linear Figura D.3-esquerda, (ii) a mudança da energia de curvatura, a qual muda o intervalo onde são observadas as fases moduladas (B), Figura D.3-direita.

É sabido que a tensão linear é proporcional ao perímetro do contorno de fase (Amazon e Feigenson, 86), e além disso, a interface é minimizada quando a razão área por perímetro é maximizada, ou seja, para macrodominios. Deste modo, o aumento da tensão linear, como no exemplo da Figura D.3, sugere a tendência do sistema para macro escalas, e consequentemente diminuindo a interface entre domínios. Por outro lado, a mudança da tensão de curvatura também pode influenciar nesses resultados, sendo necessário medir experimentalmente esses valores na ausência e presença do peptídeo.

A Figura D.4 mostra um resumo dos resultados experimentais obtidos com GUVs, onde foi observado que o peptídeo leva ao deslocamento de fases moduladas para valores menores de $\rho$. Se o peptídeo particionasse preferencialmente na interface, seria esperado a diminuição da tensão linear, e, portanto, o oposto do observado. Há fortes evidencias que a tensão linear entre domínios diminui, todavia, a tensão de curvatura deve ser diretamente medida.

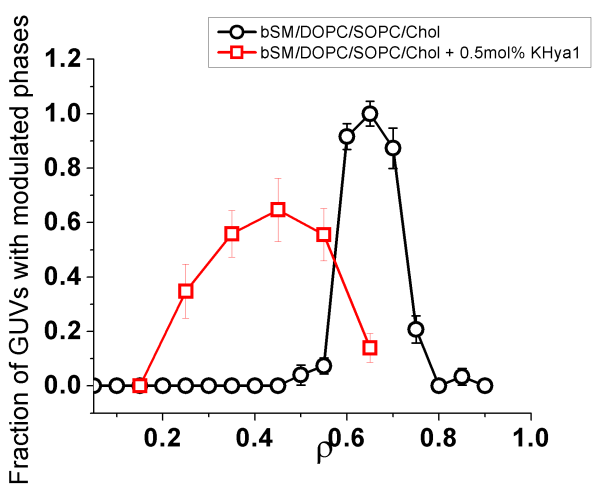

Figura D.4: Janela onde ocorre as fases moduladas muda em presença de KHya1 0.5mol\% bSM/ $(\mathrm{DOPC}+\mathrm{SOPC}) / \mathrm{Chol}=0.39 / 0.39 / 0.22$.

Por fim, podemos observar na Figura D.5, GUVs com macro-domínios ao longo da linha de coexistência de fases (A, B, C, D, E e F) e as mesmas composições lipídicas na presença de peptideo (A', B', C', D', E' e F’). Notamos que na presença do peptídeo, há formação de uma protuberância da fase minoritária, esse fenômeno pode ser atribuído em mudanças significativas na tensão linear ou energia de curvatura. Entretanto, são necessárias maiores investigações.

Tendo visto que o peptídeo KHya1 é solúvel em agua, sua partição em agua e bicamada 


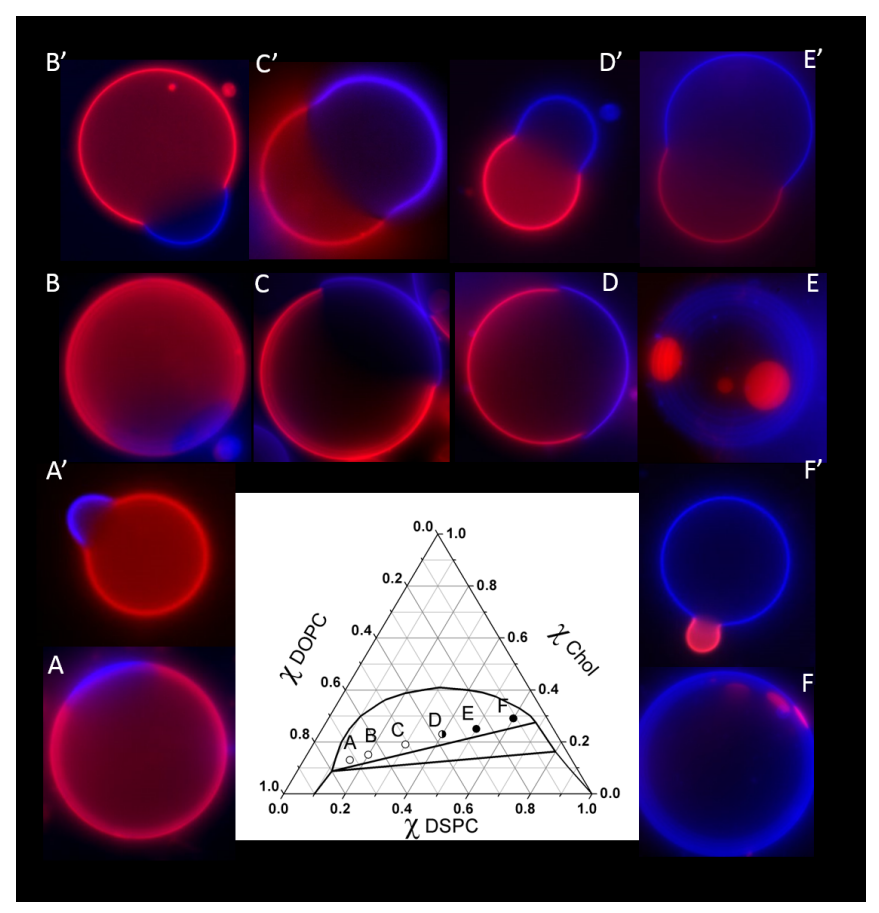

Figura D.5: Morfologia dos domínios ao longo da linha de coexistência de fase para DSPC/DOPC/Chol. Em ausência de peptídeo (A, B, C, D, E, e F). Em presença de 0.5 mol\% de KHya1 (A', B', C', D', E', and F').

pode ser diferente ao longo da linha de coexistência de fases, ou de modo simplório para as composições ilustradas em A, B, C, D, E, e F. Se isso ocorrer, o seu coeficiente de partição medido entre Lo e Ld não será um número realístico. 



\section{Referências Bibliográficas}

Albani, J. R. (2014). "Origin of Tryptophan Fluorescence Lifetimes Part 1 . Fluorescence Lifetimes Origin of Tryptophan Free in Solution". 93-104.

Amazon, J., e Feigenson, G. (86). Phys. Rev. E, 022702.

Angelova, M. I., e Dimitrov, D. S. (1986). "Liposome electroformation". Faraday Discussions of the Chemical Society, 81, 303.

Beechem, J. M., e Brand, L. (1985). "Time-resolved fluorescence of proteins.". Annual review of biochemistry, 54, 43-71.

Beer. (1852). "Determination of the absorption of red light in colored liquids". In J. C. Poggendorff (Ed.), Annalen der physik und chemie (pp. 78-88). J.A. Barth.

Berne, R., B.J. anda Pecora. (2000). Dynamic light scattering. Dover.

Brogden, K. a. (2005). "Antimicrobial peptides: pore formers or metabolic inhibitors in bacteria?". Nature reviews. Microbiology, 3(3), 238-50.

Brown, W. (1993). Dynamic light scattering, the methods and some aplications. Carendon Press.

Buboltz, J. T. (2007). Phys. Rev. E, 76, 021903.

Buboltz, J. T., e Feigenson, G. W. (1999). Biochim. Biophys. Acta., 232, 1417.

Cabrera, M. P. d. S., Alvares, D. S., Leite, N. B., Souza, B. M. de, Palma, M. S., Riske, K. A., e Neto, J. a. R. (2011). "New insight into the mechanism of action of wasp mastoparan peptides: lytic activity and clustering observed with giant vesicles.". Langmuir : the ACS journal of surfaces and colloids, 27(17), 10805-13. 
Castro, M. S., Ferreira, T. C. G., Cilli, E. M., Crusca, E., Mendes-Giannini, M. J. S., Sebben, A., Ricart, C. A. O., Sousa, M. V., e Fontes, W. (2009). "Hylin a1, the first cytolytic peptide isolated from the arboreal South American frog Hypsiboas albopunctatus ("spotted treefrog" ).". Peptides, 30(2), 291-6.

Chen, R. F. (1967). "Fluorescence Quantum Yields of Tryptophan and Tyrosine". Analytical Letters, 1(1), 35-42.

Chiantia, S., Schwille, P., Klymchenko, A. S., e E., L. (2011). Biophysical J., L01-L03.

Contreras, L. M., Almeida, R. F. de, Villalaín, J., Fedorov, A., e Prieto, M. (2001). "Interaction of alpha-melanocyte stimulating hormone with binary phospholipid membranes: structural changes and relevance of phase behavior.". Biophysical journal, 80(5), 2273-83.

Crosby, G. A., e Demas, J. N. (1971). "Measurement of photoluminescence quantum yields. Review". The Journal of Physical Chemistry, 75(8), 991-1024.

Crusca, E., Rezende, A. a., Marchetto, R., Mendes-Giannini, M. J. S., Fontes, W., Castro, M. S., e Cilli, E. M. (2011). "Influence of N-terminus modifications on the biological activity, membrane interaction, and secondary structure of the antimicrobial peptide hylin-a1.". Biopolymers, 96(1), 41-8.

De Planque, M. R. R., Boots, J. W. P., Rijkers, D. T. S., Liskamp, R. M. J., Greathouse, D. V., e Killian, J. A. (2002). "The effects of hydrophobic mismatch between phosphatidylcholine bilayers and transmembrane ??-helical peptides depend on the nature of interfacially exposed aromatic and charged residues". Biochemistry, 41(26), 8396-8404.

De Vequi-Suplicy, C. C., Benatti, C. R., e Lamy, M. T. (2006). "Laurdan in fluid bilayers: Position and structural sensitivity". Journal of Fluorescence, 16(3), 431-439.

Disalvo, E. (1991). "Optical properties of lipid dispersions induced by permeant molecules". Chemistry and Physics of Lipids, 59(3), 199-206.

Domingues, T. M., Riske, K. A., e Miranda, A. (2010). "Revealing the lytic mechanism of the antimicrobial peptide gomesin by observing giant unilamellar vesicles.". Langmuir : the ACS journal of surfaces and colloids, 26(13), 11077-84. 
Enoki, T. A., Henriques, V. B., e Lamy, M. T. (2012). "Light scattering on the structural characterization of DMPG vesicles along the bilayer anomalous phase transition.". Chemistry and physics of lipids, 165(8), 826-37.

Epand, R. F., Schmitt, M. A., Gellman, S. H., e Epand, R. (1999). Biochim.Biophys. Acta, 1758, 1343-1350.

Epand, R. M., e Epand, R. F. (2009a). "Domains in bacterial membranes and the action of antimicrobial agents.". Molecular bioSystems, 5(6), 580-7.

Epand, R. M., e Epand, R. F. (2009b). "Lipid domains in bacterial membranes and the action of antimicrobial agents.". Biochimica et biophysica acta, 1788(1), 289-94.

Fleming, G. R., Morris, J. M., Robbins, R. J., Woolfe, G. J., Thistlethwaite, P. J., e Robinson, G. W. (1978). "Nonexponential fluorescence decay of aqueous tryptophan and two related peptides by picosecond spectroscopy.". Proceedings of the National Academy of Sciences of the United States of America, 75(10), 4652-6.

Glatter, O. (1977). "A new method for the evaluation of small-angle scattering data". Journal of Applied Crystallography, 10(5), 415-421.

Gleason, N. J., Vostrikov, V. V., Greathouse, D. V., Grant, C. V., Opella, S. J., e Koeppe, R. E. (2012). "Tyrosine replacing tryptophan as an anchor in GWALP peptides.". Biochemistry, 51(10), 2044-53.

Griffith, O. H., e Jost, P. C. (1976). Spin Labeling. Elsevier.

Guo, L., Smith-Dupont, K. B., e Gai, F. (2011). "Diffusion as a probe of peptide-induced membrane domain formation.". Biochemistry, 50(12), 2291-7.

Heberle, F. A., Doktorova, M., Goh, S. L., Standaert, R. F., Katsaras, J., e Feigenson, G. W. (2013). J. Am. Chem. Soc, 135, 14932.

Heberle, F. A., Petruzielo, R. S., Pan, J., Drazba, P., Kucerka, N., Standaert, R., Feigenson, G. W., e Katsaras, J. (2012). J. Am. Chem. Soc., 135, 6853.

Heftberger, P., Kollmitzer, B., Heberle, F. a., Pan, J., Rappolt, M., Amenitsch, H., Kučerka, N., Katsaras, J., e Pabst, G. (2014). "Global small-angle X-ray scattering data analysis 
for multilamellar vesicles: the evolution of the scattering density profile model". Journal of Applied Crystallography, 47(1), 173-180.

Ito, a. S., Castrucci, a. M., Hruby, V. J., Hadley, M. E., Krajcarski, D. T., e Szabo, a. G. (1993). "Structure-activity correlations of melanotropin peptides in model lipids by tryptophan fluorescence studies.". Biochemistry, 32(45), 12264-72.

Jong, D. H. de, Lopez, C. A., e Marrink, S. J. (2013). "Molecular view on protein sorting into liquid-ordered membrane domains mediated by gangliosides and lipid anchors". Faraday Discuss., 161, 347-363.

Karstens, T., e Kobs, K. (1980). "Rhodamine B and rhodamine 101 as reference substances for fluorescence quantum yield measurements". The Journal of Physical Chemistry, 84(14), $1871-1872$.

Kayser, V., Chennamsetty, N., Voynov, V., Helk, B., e Trout, B. L. (2011). "Tryptophantryptophan energy transfer and classification of tryptophan residues in proteins using a therapeutic monoclonal antibody as a model.". Journal of fluorescence, 21(1), 275-88.

Kiessling, V., Wan, C., e Tamm, L. K. (2009). Biochim. Biophys. Acta, 1788, 64.

Killian, J. (2003). "Synthetic peptides as models for intrinsic membrane proteins". FEBS Letters, 555(1), 134-138.

Kim, T., Lee, K. I., Morris, P., Pastor, R. W., Andersen, O. S., e Im, W. (2012). "Influence of hydrophobic mismatch on structures and dynamics of gramicidin a and lipid bilayers.". Biophysical journal, 102(7), 1551-60.

Koehorst, R. B. M., Spruijt, R. B., e Hemminga, M. a. (2008). "Site-directed fluorescence labeling of a membrane protein with BADAN: probing protein topology and local environment.". Biophysical journal, 94(10), 3945-3955.

Koller, D., e Lohner, K. (2014). "The role of spontaneous lipid curvature in the interaction of interfacially active peptides with membranes.". Biochimica et biophysica acta, 1838(9), $2250-9$.

Konyakhina, T., Wu J., J. D., Mastroianni, A., H. F., e Feigenson, G. W. (2013). Biochim. Biophys. Acta., 1828, 2204. 
Koppel, D. E. (1972). "Analysis of Macromolecular Polydispersity in Intensity Correlation Spectroscopy: The Method of Cumulants". The Journal of Chemical Physics, 57(11), 4814 .

Lakowicz, J. R. (2006). Principles of Fluorescence Spectroscopy Principles of Fluorescence Spectroscopy.

Leekumjorn, S., e Sum, A. K. (2007). "Molecular studies of the gel to liquid-crystalline phase transition for fully hydrated DPPC and DPPE bilayers.". Biochimica et biophysica acta, 1768(2), 354-65.

Lingwood, D., e Simons, K. (2010). Science, 327, 46.

Lúcio, A. D., Vequi-Suplicy, C. C., Fernandez, R. M., e Lamy, M. T. (2010). "Laurdan spectrum decomposition as a tool for the analysis of surface bilayer structure and polarity: a study with DMPG, peptides and cholesterol.". Journal of fluorescence, 20(2), 473-82.

Manzini, M. C., Perez, K. R., Riske, K. A., Bozelli, J. C., Santos, T. L., Silva, M. A. da, Saraiva, G. K. V., Politi, M. J., Valente, A. P., Almeida, F. C. L., Chaimovich, H., Rodrigues, M. A., Bemquerer, M. P., Schreier, S., e Cuccovia, I. M. (2014). "Peptide:lipid ratio and membrane surface charge determine the mechanism of action of the antimicrobial peptide BP100. Conformational and functional studies.". Biochimica et biophysica acta, 1838(7), 1985-99.

Marsh, D. (1981). Membrane spectroscopy. Springer Verlag.

Marsh, D., Watts, A., Pates, R. D., Uhl, R., Knowles, P. F., e Esmann, M. (1982). "ESR spinlabel studies of lipid-protein interactions in membranes.". Biophysical journal, 37(1), $265-74$.

McConnell, H. M., e Hubbell, W. L. (1971). "Molecular motion in spin-labeled phospholipids and membranes". Journal of the American Chemical Society, 93(2), 314-326.

Mendonça, A., Rocha, A. C., Duarte, A. C., e Santos, E. B. H. (2013). "The inner filter effects and their correction in fluorescence spectra of salt marsh humic matter.". Analytica chimica acta, 788, 99-107. 
Oliveira, T. de. (2008). Caracterização estrutural de agregados formados pelo antifúngico anfotericina b e lipídios catiônicos: uma possivel formulação farmacológica. disertação de mestrado.

Pabst, G., Grage, S. L., Danner-Pongratz, S., Jing, W., Ulrich, A. S., Watts, A., Lohner, K., e Hickel, A. (2008). "Membrane thickening by the antimicrobial peptide PGLa.". Biophysical journal, 95(12), 5779-5788.

Parasassi, T., De Stasio, G., Ravagnan, G., Rusch, R. M., e Gratton, E. (1991). "Quantitation of lipid phases in phospholipid vesicles by the generalized polarization of Laurdan fluorescence.". Biophysical journal, 60(1), 179-89.

Park, S.-C., Park, Y., e Hahm, K.-S. (2011). "The role of antimicrobial peptides in preventing multidrug-resistant bacterial infections and biofilm formation.". International journal of molecular sciences, 12(9), 5971-92.

Perlmutter, J. D., e Sachs, J. N. (2011). J. Am. Chem. Soc., 133, 6563.

Petrich, J. W., Chang, M. C., McDonald, D. B., e Fleming, G. R. (1983). "Nonexponential fluorescence decay of tryptophan, tryptophylglycine, and glycyltryptophan". Journal of the American Chemical Society, 105(12), 3819-3824.

Petruzielo, R. S., Heberle, F. A., Drazba, P., Katsaras, J., e Feigenson, G. W. (2013). Biochim. Biophys. Acta, 1828, 1302.

Power, J. P. S., e Hancock, R. E. W. (2003). Peptides, 24, 1681-1691.

Riske, K. A. (2001). Comportamento térmico peculiar de dispersões aquosas do fosfolipídeo aniônico dmpg. tese de doutorado.

Riske, K. d. A. (2012). Peculiar thermal behavior of aqueous dispersions of the anionic phospholipid DMPG. Unpublished doctoral dissertation.

Rodembusch, F. (2001). Espalhamento de luz estático e dinâmico em polímeros do tipo polimetilmetacrilato fluorescentes por transferência protônica intramolecular no estado eletrônico excitado (tpiee). Disertção de mestrado.

Sanchez, S. a., Tricerri, M. a., e Gratton, E. (2012). "Laurdan generalized polarization fluctuations measures membrane packing micro-heterogeneity in vivo". Proceedings of the National Academy of Sciences, 109(19), 7314-7319. 
Sanchez, S. a., Tricerri, M. a., Gunther, G., e Gratton, E. (2007). "Laurdan Generalized Polarization: from cuvette to microscope". Modern research and educational topics in microscopy: applications in physical/chemical sciences. Formatex Research Center, Badajoz, Spain, 1007-1014.

Sato, H., e B.Feix, J. (2006). Biochim. Biophys. Acta., 1758, 1245-1256.

Silva, B. R. da, Freitas, V. A. a. A. de, Carneiro, V. A., Arruda, F. V. S., Lorenzón, E. N., Aguiar, A. S. W. de, Cilli, E. M., Cavada, B. S., e Teixeira, E. H. (2013). "Antimicrobial activity of the synthetic peptide Lys-a1 against oral streptococci.". Peptides, 42, 78-83.

Souza, E. S. de, Hirata, I. Y., Juliano, L., e Ito, A. S. (2000). "End-to-end distance distribution in bradykinin observed by Förster resonance energy transfer". Biochimica et Biophysica Acta (BBA) - General Subjects, 1474(2), 251-261.

Szabo, a. G., e Rayner, D. M. (1980). "Fluorescence decay of tryptophan conformers in aqueous solution". Journal of the American Chemical Society, 102(2), 554-563.

Tanaka, F., Tamai, N., Mataga, N., Tonomura, B., e Hiromi, K. (1994). "Analysis of internal motion of single tryptophan in Streptomyces subtilisin inhibitor from its picosecond timeresolved fluorescence.". Biophysical journal, 67(2), 874-80.

Tristram-Nagle, S., e Nagle, J. F. (2004). "Lipid bilayers: thermodynamics, structure, fluctuations, and interactions". Chemistry and Physics of Lipids, 127(1), 3-14.

Tucker, S. A., Amszi, V. L., e Acree, W. E. (1992). "Primary and secondary inner filtering. Effect of $\mathrm{K} 2 \mathrm{Cr} 2 \mathrm{O} 7$ on fluorescence emission intensities of quinine sulfate". Journal of Chemical Education, 69(1), A8.

Valeur, B., e Berberan-Santos, M. N. (2012). Molecular Fluorescence: Principles and Applications (2. Edition ed.). Weinheim: Wiley-VCH.

Vequi-Suplicy, C. C., Coutinho, K., e Lamy, M. T. (2014). "Electric dipole moments of the fluorescent probes Prodan and Laurdan: experimental and theoretical evaluations". Biophysical Reviews, 6(1), 63-74.

Vequi-Suplicy, C. C., Coutinho, K., e Teresa Lamy, M. (2013). "Optical characterization of Prodan aggregates in water medium.”. Physical chemistry chemical physics : PCCP, 15(28), 11800-7. 
Viera, L., Senisterra, G., e Disalvo, E. (1996). "Changes in the optical properties of liposome dispersions in relation to the interlamellar distance and solute interaction". Chemistry and Physics of Lipids, 81(1), 45-54.

Vostrikov, V. V., Hall, B. a., Greathouse, D. V., Koeppe, R. E., e Sansom, M. S. P. (2010). "Changes in transmembrane helix alignment by arginine residues revealed by solid-state NMR experiments and coarse-grained MD simulations". Journal of the American Chemical Society, 132(16), 5803-5811.

Wang, S., Martin, E., Cimino, J., Omann, G., e Glaser, M. (1988). "Distribution of phospholipids around gramicidin and D-.beta.-hydroxybutyrate dehydrogenase as measured by resonance energy transfer". Biochemistry, 27(6), 2033-2039.

Weber, G. (1960). "Fluorescence-polarization spectrum and electronic-energy transfer in proteins.". The Biochemical journal, 75, 345-52.

Weber, G., e Farris, F. J. (1979). "Synthesis and spectral properties of a hydrophobic fluorescent probe: 6-propionyl-2-(dimethylamino)naphthalene". Biochemistry, 18(14), 3075-3078.

Yandek, L. E., Pokorny, A., Florén, A., Knoelke, K., Langel, U., e Almeida, P. F. F. (2007). "Mechanism of the cell-penetrating peptide transportan 10 permeation of lipid bilayers.". Biophysical journal, 92(7), 2434-2444.

Yeaman, M. R., e Yount, N. Y. (2003). "Mechanisms of antimicrobial peptide action and resistance.". Pharmacological reviews, 55(1), 27-55.

Yolcu, C., Haussman, R. C., e Deserno, M. (2014). "The Effective Field Theory approach towards membrane-mediated interactions between particles". Advances in Colloid and Interface Science, 208, 89-109.

Zasloff, M. (2002). "Antimicrobial peptides of multicellular organisms". Nature, 415(January), 389-395. 


\title{
Agradecimentos
}

\author{
Acknowledgment
}

Agências de fomento
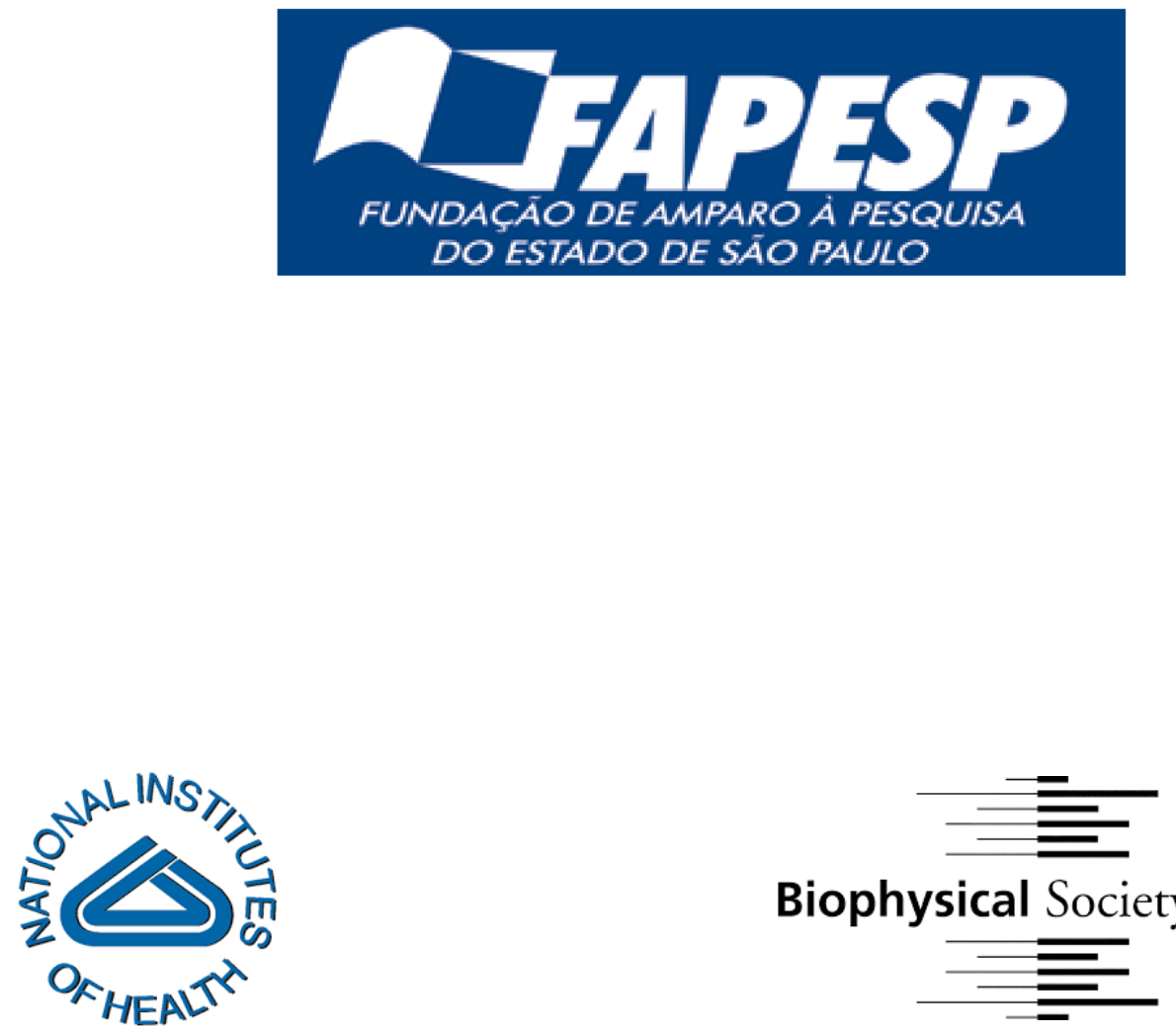

Biophysical Society

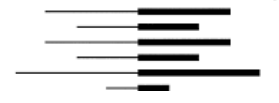




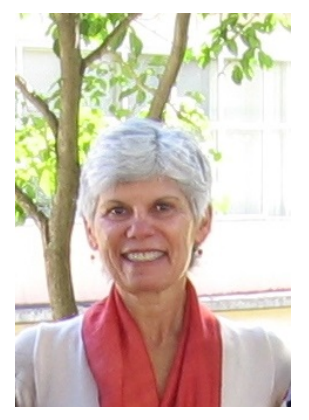

Profa. Dra. Maria Teresa Lamy

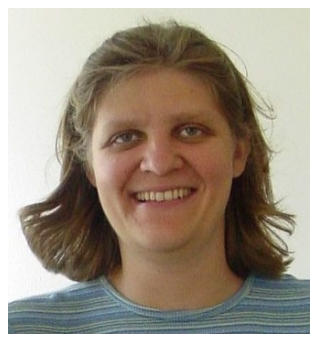

Profa. Dra. Karin A. Riske

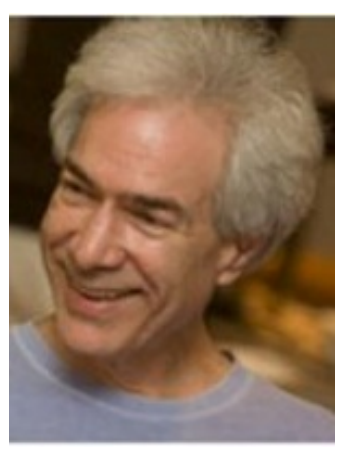

Prof. Dr. Gerald W. Feigenson

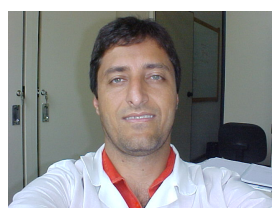

Prof. Dr. Eduardo Cilli

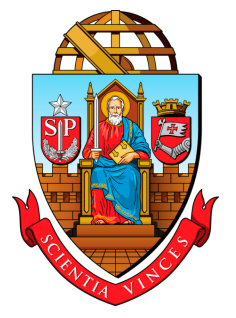

Universidade de São Paulo

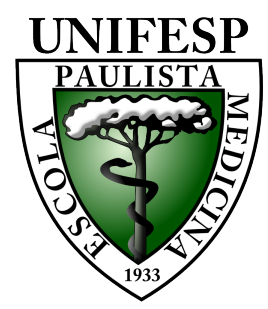

Universidade Federal

de São Paulo

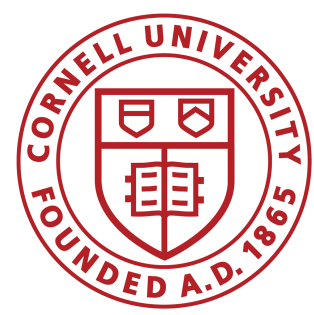

Cornell University

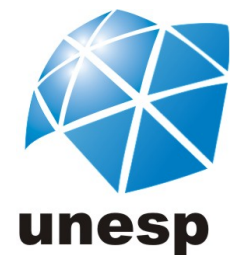

Universidade Estadual

Paulista 
Grupo de pesquisa e colaboradores

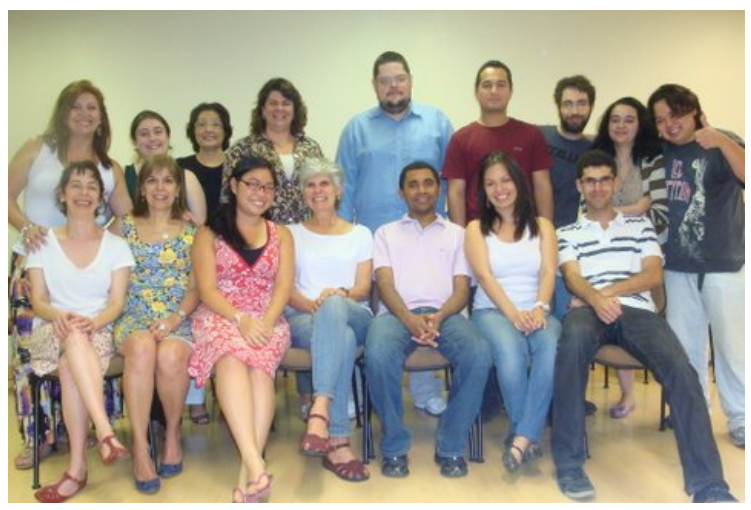

Carla, Fátima, Daniela, Teresa, Antônio, Evanildo, Silvana, Cíntia, Dirce, Kaline, Leandro, Marcus, Diogo, Catharina e Daniel.

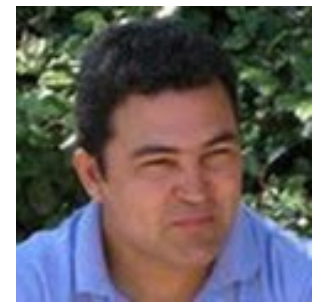

Prof. Dr. Eduardo

Souza

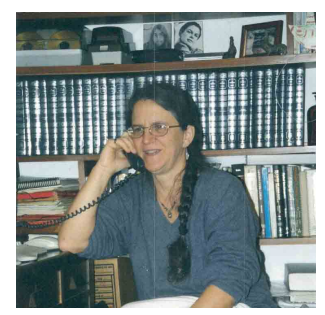

Profa. Dra. Vera B.

Henriques

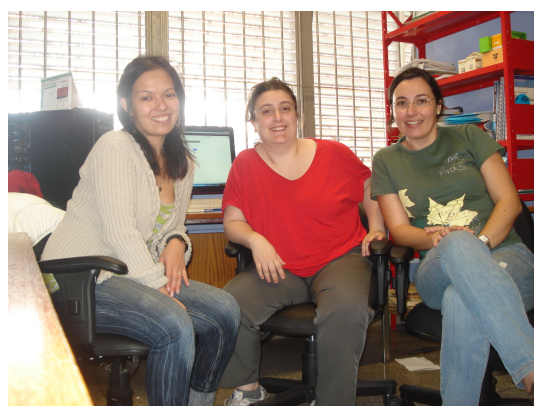

Dra. Cintia C. Vequi-Suplicy Profa. Dra. Cassia Maquezin
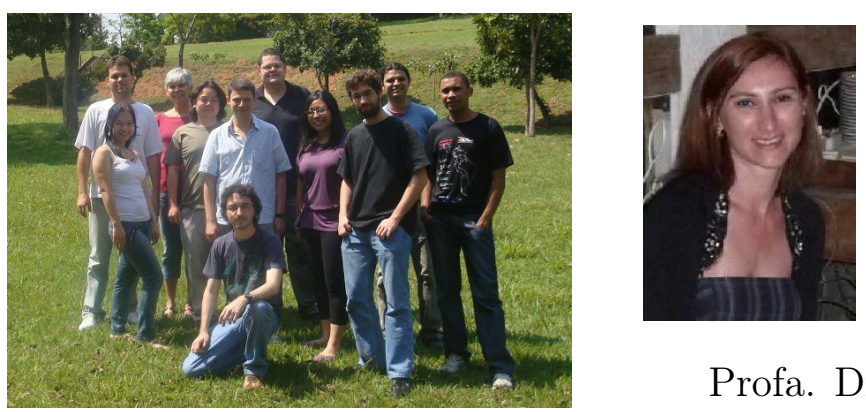

Profa. Dra. Katia Perez 


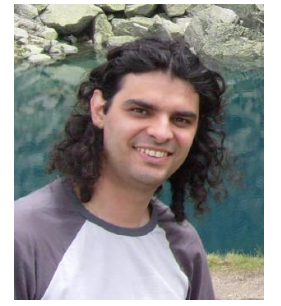

Dr. Evandro Duarte

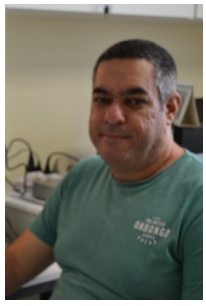

Marcelo E. Frade

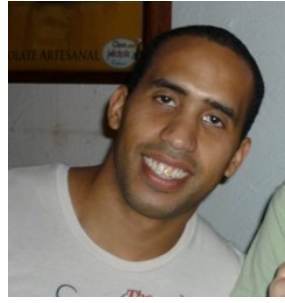

Prof. Dr. Tiago Oliveira

Agradeço também ao comitê examinador.

Grupo de pesquisa - Cornell University

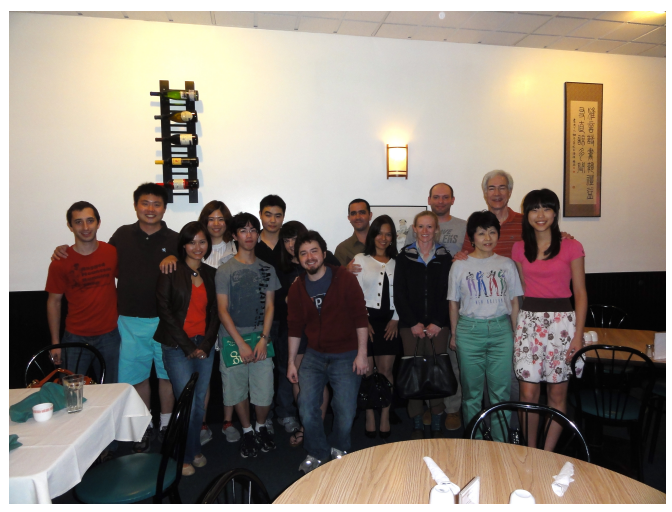

David, Lynda, Mary, Thomas, Shu, Jonh, Danilo, Rob, Jerry, (esposa) e Sarah.

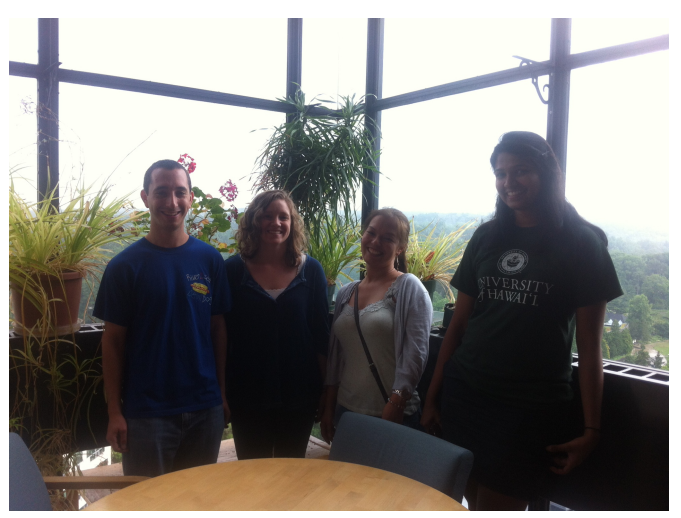

David, Rebecca e Sanju. 
Amigos, colegas e funcionarios

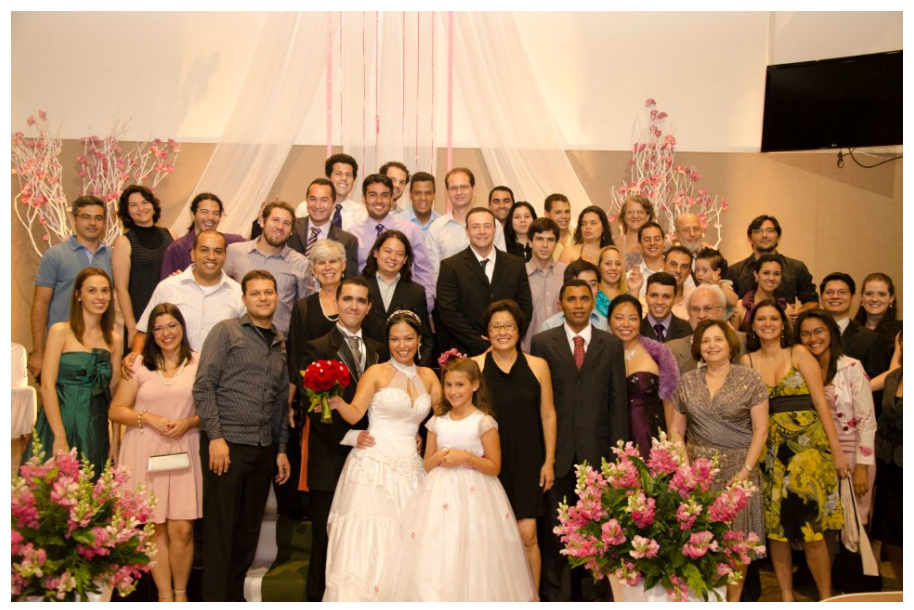

Paula, Jozismar, Lenilson, Teresa, Daniel, Alexei, Pedro (nono), Dirce, Antônio, Dani, Diego, Masayuki, Prof. Salina, (esposa), Sales, Lilian, Jorgivan, Éber, Hélio, Vera, Tiago, Paula, Yoelvis, Helder, Maycon, Felipe D, Pedro (da Paula), Antônio Mário, Marcus, Felipe, Lucas e Rone.

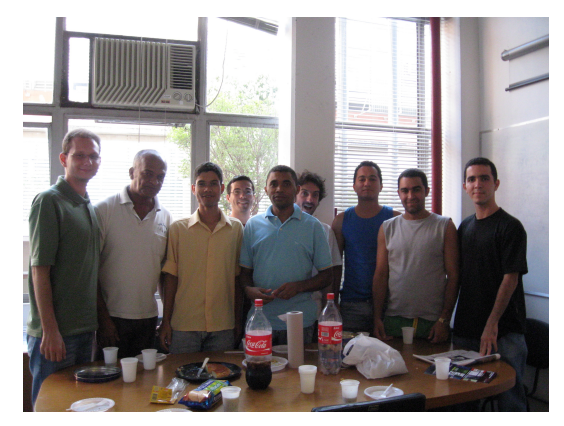

Helder, Seu Roberto, David, Lucas,

Antônio, Marcelo, Marcus, Yoelvis e Danilo.

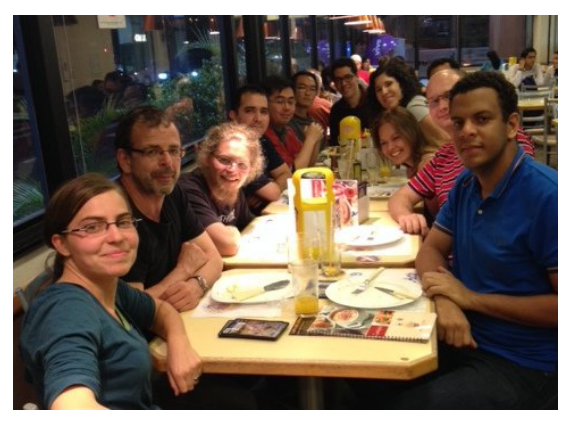

Uli, Felix, Danilo, Masayuki, Alexander, Pedro, Carol, Helder e Maycon.

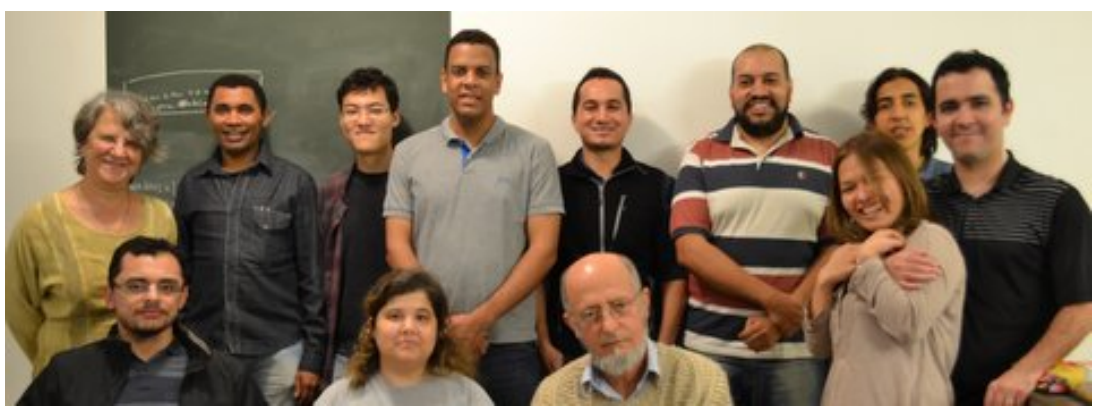

Eduardo, Tati, Hélio, Danilo, Oscar, Jozismar, Marcus, Maycon,

Fernando, Antônio e Vera. 


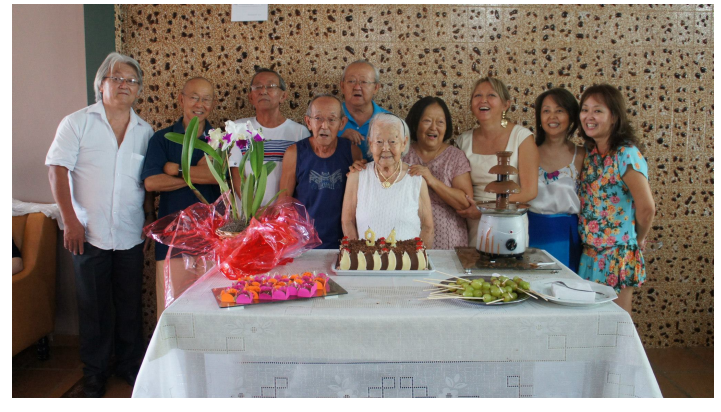

Tosio, João, Massa, Caju, Akira, Tokie,

Helena, Hujico, Kasue e Regina.

Homenagem à Tokie Enoki

(Jan 1919 - Jan 2016)

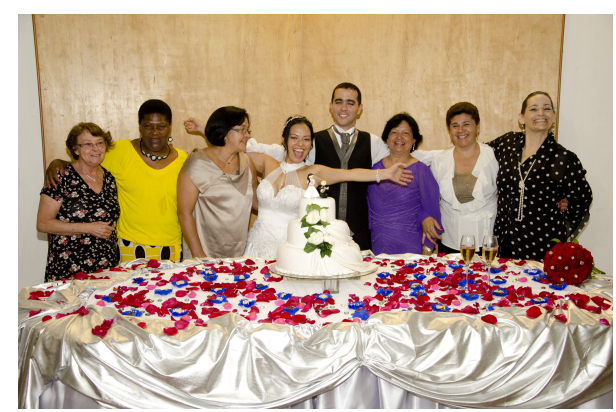

Geralda, Joana, Cida, Danilo,

Maria José, Matilde e Rosangela (representando IQMD).

\section{Agradecimentos especiais}

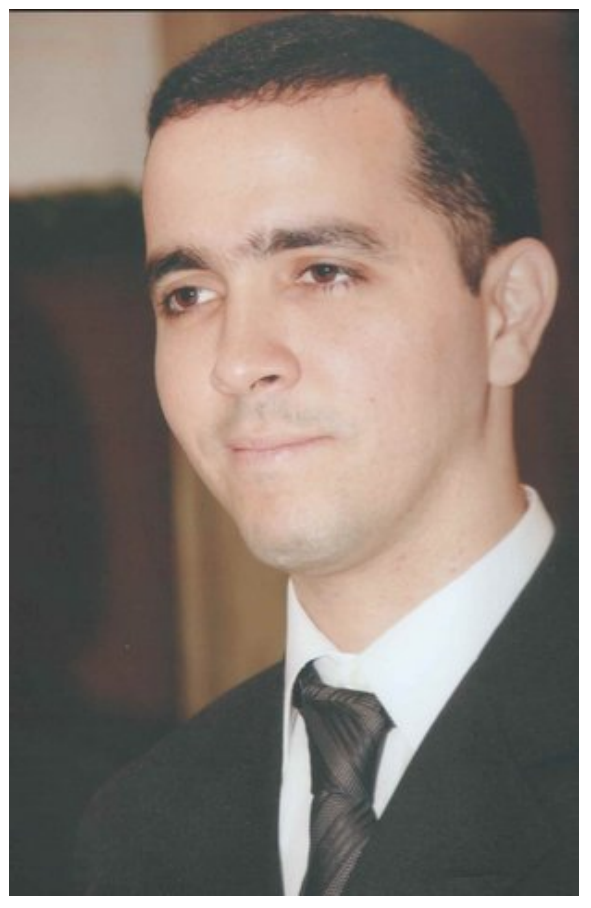

Danilo Barbosa Liarte

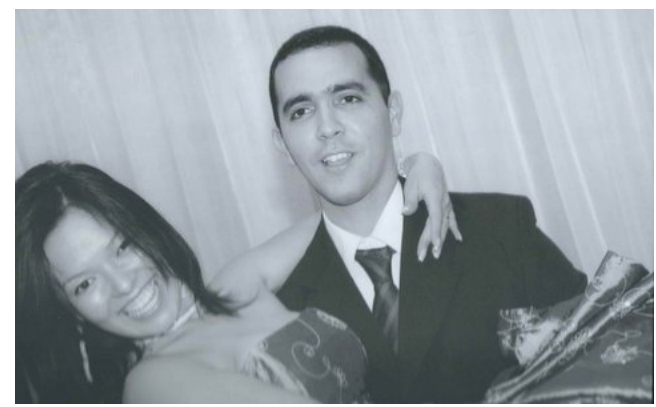




\section{Agradecimentos especiais}

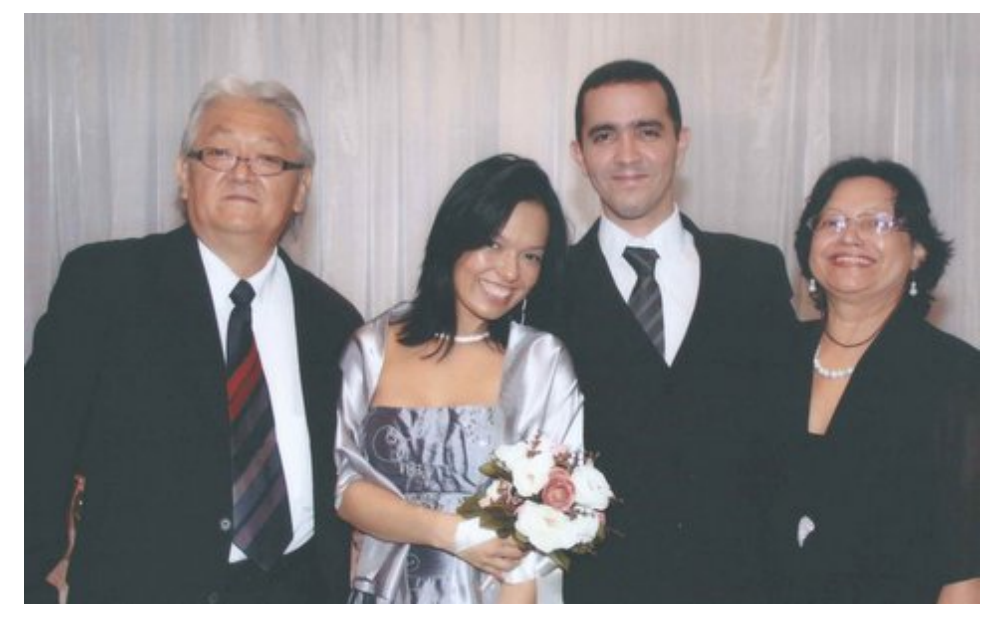

Tosio Enoki, Danilo B.Liarte e Maria José A. Enoki.

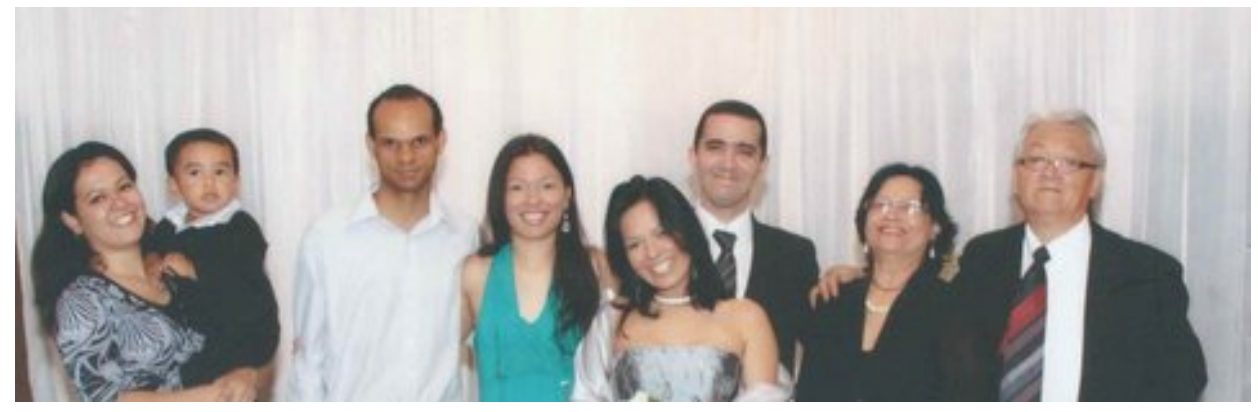

Priscilla A. Enoki, Lucas Enoki, Roberto, Natacha A. Enoki, Danilo B. Liarte, Maria José A. Enoki e Tosio Enoki.

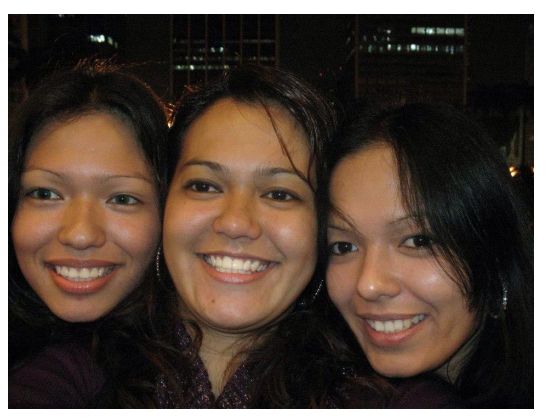

Natacha A. Enoki, Priscilla A. Enoki

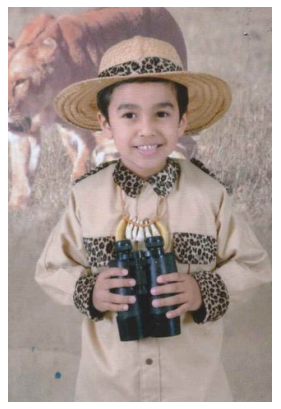

Lucas Enoki de Oliveira

Agradeço ao meu Deus, o Deus do impossível.

Thank you God for everything. 